\title{
VIDAS ITINERANTES EN UN ESPACIO LABORAL TRANSNACIONAL MIGRACIÓN Y FAMILIAS ENTRE PUEBLA-TLAXCALA Y NUEVA
YORK
}

TESIS PARA OPTAR POR EL GRADO DE DOCTOR EN CIENCIAS ANTROPOLOGICAS

\section{FERNANDO FRANCISCO HERRERA LIMA}

ASESOR INTERNO:

ASESORES EXTERNOS:
DR. LUDGER PRIES

DRA. VANIA SALLES

DR. AGUSTÍN ESCOBAR LATAPÍ

DEPARTAMENTO DE ANTROPOLOGIA

UAM-I

JULIO DE 2002

EL AUTOR AGRADECE AL CONACYT LA BECA QUE LE FUE OTORGADA PARA LA REALIZACIÓN DE SUS AESTUDIOS DE DOCTORADO 


\section{INDICE}

\section{INTRODUCCION}

I. IMAGENES, INDICIOS

II. PLANTEAMIENTO GENERAL Y OBJETIVOS GENERALES DE LA TESIS

\section{PRIMERA PARTE}

\section{CAPITULO PRIMERO: LOS ORIGENES DEL PROYECTO}

I. LA CONSTITUCION DEL EQUIPO DE INVESTIGACION

II. LA ELECCION DEL UNIVERSO EMPIRICO: LA MIGRACION ENTRE EL ESTADO DE PUEBLA Y LA ZONA METROPOLITANA DE LA CIUDAD DE NUEVA YORK.

CAPITULO SEGUNDO: EL ESTUDIO DE LAS MIGRACIONES Y DEL MERCADO DE TRABAJO

I. PRESENTACION

II. LA DISCUSION ACTUAL SOBRE EL ESTUDIO DE LAS MIGRACION

III. LA DISCUSION ACTUAL SOBRE EL MERCADO DE TRABAJO: ¿ENTRE EL DETERMINISMO ESTRUCTURALISTA Y LA PLENA ELECCION RACIONAL?

IV. LAS INSTITUCIONES ESTRUCTURANTES DE LOS MERCADOS DE TRABAJO

V. LAS DISTINTAS APROXIMACIONES AL ESTUDIO DEL MERCADO DE TRABAJO, SUS SUPUESTOS Y SUS PROPUESTAS

VI. LOS PROYECTOS BIOGRAFICOS LABORALES Y LAS REDES DE RELACIONES SOCIALES

VII. CONCLUSIONES PARCIALES 


\section{CAPITULO TERCERO: EL ANALISIS DE LAS TRAYECTORIAS}

\section{LABORALES}

I. LAS TRAYECTORIAS LABORALES, LAS INSTITUCIONES SOCIALES Y EL MERCADO DE TRABAJO

II. OPERACIONALIZACIÓN DE LAS INSTITUCIONES SOCIALES

III. CARACTERISTICAS METODOLOGICAS GENERALES DEL PROYECTO

\section{SEGUNDA PARTE}

\section{CAPITULO CUARTO: EL CONFINAMIENTO SECTORIAL DEL TRABAJO DE LOS MIGRANTES}

I. INTRODUCCION

II. PRIMERA APROXIMACIÓN GENERAL

III. CARACTERISTICAS PRINCIPALES DE LOS TRABAJOS

IV. SUDANDO EN LOS TALLERES, SUDANDO EN LAS COCINAS: LOS PROCESOS DE TRABAJO MAS IMPORTANTES

V. EL DESPLIEGUE DE LAS TRAYECTORIAS LABORALES

VI. CONTINUIDADES Y DISCONTINUIDADES OCUPACIONALES EN LAS TRAYECTORIAS LABORALES, EN MÉXICO Y LOS ESTADOS UNIDOS

VII. CONCLUSIONES PARCIALES

\section{CAPITULO QUINTO: UN MERCADO DE TRABAJO PARA MIGRANTES RECIENTES}


I. LA CONSTRUCCION HISTORICA DE LA SEGREGACION LABORAL

1. Introducción

2. La nueva ola migratoria en Nueva York

2. La reestructuración económica en los EUA y en Nueva York

3.

II. EL ENCLAUSTRAMIENTO DEL TRABAJO MEXICANO

1. Los nichos de mercado de los inmigrantes en Nueva York

2. No todas las puertas están abiertas para los migrantes: nichos de trabajo etiquetados

3. Trayectorias laborales dentro de los nichos etiquetados: movilidad acotada y restringida

4. Algunas conclusiones preliminares

\section{CAPITULO SEXTO: LA ESTRUCTURACION SOCIAL DE LAS TRAYECTORIAS LABORALES}

I. INTRODUCCION

II ¿CÓMO ME VOY Y A DÓNDE LLEGO?; O NO ES LO MISMO LLEGAR SOLO QUE SÓLO TENER QUE LLEGAR

1. Una mano para irme...

2. ...y otra para alojarme

II. CADA VEZ NECESITO QUE ME AYUDEN MENOS, PERO CADA VEZ AYUDO MÁS: RECIPROCANDO, PERO SIEMPRE RECIBIENDO

III. DISPERSOS, PERO UNIDOS: LA VIVIENDA DE LA GENTE DE MÉXICO EN NUEVA YORK Y SUS ALREDEDORES

IV. A LA CHAMBA ¿AQUÍ DÓNDE SE PREGUNTA?

1. Lo primero es empezar: el primer trabajo

2. En los siguientes trabajos: informo y me informan; recomiendo y me recomiendan

V. LOS MIGRADÓLARES, ALGO MÁS QUE DINERO 
1. ¿Se envía dinero desde que se llega?

2. ¿Se sigue enviando después?: la permanencia de los envíos de dinero (y del mantenimiento de los vínculos y la pertenencia)

VI. ¿DEJO EL TRABAJO PORQUE PUEDO, PORQUE QUIERO O PORQUE NO ME QUEDA DE OTRA (O POR ALGO MÁS)?: HACIA EL NORTE JALA MÁS EL DINERO, HACIA EL SUR LOS AFECTOS

VII. CONCLUSIONES PARCIALES

\section{CAPITULO SEPTIMO: UNA FAMILIA TRANSNACIONAL}

I. INTRODUCCIÓN

II. LA FAMILIA TRANSNACIONAL DE DOÑA ROSA

III. PRIMERA IMAGEN EN MOVIMIENTO: LA PLURILOCALIZACIÓN DE LOS MIEMBROS DE LA FAMILIA

1. Las múltiples actividades

2. Acercamiento a los campos de futbol de Nueva York

3. Corte al pueblo de origen

IV. SEGUNDA IMAGEN EN MOVIMIENTO: LA FAMILIA EN LA FIESTA PATRONAL DEL PUEBLO DE ORIGEN

V. TERCERA IMAGEN EN MOVIMIENTO: LOS ORIGENES

VI. LA HISTORIA QUE UNE ESAS IMÁGENES

VII. COMENTARIOS FINALES

\section{CONCLUSIONES}




\section{INTRODUCCION}

\section{IMAGENES, INDICIOS}

Dentro de la ciudad de Nueva York ha aparecido en los últimos años una nueva especie vegetal. Se trata del árbol que en México se llama "Guaje". Este árbol produce una vaina alargada que contiene las semillas con las que se reproduce la especie. Esas semillas sirven también para otro uso fundamental; sólo que a muchos, muchos, kilómetros de la ciudad de Nueva York. En la zona sur del estado de Puebla, en la Mixteca poblana, ellas son la base fundamental del sabor de los principales platillos regionales: los huasmoles o huashimullis; los que, sobre todo durante las fiestas de los muertos, en el mes de noviembre de cada año, son indispensables en la dieta mixteca. Sirven también para preparar una salsa con la que se acompañan varios platillos regionales. Los poblanos de la Mixteca que llevaron y sembraron esas semillas, pueden ahora guizar sus platillos con guajes frescos. Las tortillas para acompañarlos no son un problema, porque muchos poblanos las producen allá, "en el norte".

En Acatlán de Osorio, ciudad considerada como la capital de la Mixteca poblana así como Huajuapan de Léon lo es de la oaxaqueña y Tlapa de la guerrerense-, han empezado a aparecer en los últimos años fenómenos y comportamientos novedosos. Por ejemplo, no es infrecuente ver en alguna de las calles que rodean el parque central a jóvenes agrupados para beber cerveza alrededor de algún automóvil convertible blanco, de modelo atrasado, pero arreglado como si acabara de salir de la agencia de ventas. Estos jóvenes se presentan con el pelo cortado casi al rape, pero con una larga coleta trenzada o simplemente anudada en la parte posterior de la cabeza, vestidos con pantalones muy holgados, de mezclilla o manta, con chalecos de colores, zapatos tenis ornamentados y adornos dorados o plateados en los cuellos y las muñecas. Esas prácticas son comunes; sólo que a muchos, muchos kilómetros de la ciudad de Acatlán de Osorio: en algunos barrios de la ciudad de Nueva York. Allá las aprendieron los jóvenes hijos de migrantes que están ahora de visita en el pueblo de sus padres, para la celebración de la fiesta patronal y, tal vez, para asistir a la fiesta de quince años de alguna prima, igualmente nacida en Nueva York. 
Los presidentes municipales de zonas contiguas y vinculadas productiva o comercialmente acostumbran reunirse para tratar asuntos comunes de diverso tipo. No es por ello extraño que se reúnan los alcaldes de Piaxtla, Chinantla y Tulcingo de Valle, ciudades unidas por la carretera que va de la desviación de Las Palomas a la ciudad de Tlapa, Guerrero, y vinculadas entre sí por una tradición que las diferencia de las localidades que se ubican en la carretera que va de Izucar de Matamoros a Huajuapan de León, Oaxaca. Tampoco es extraño que el motivo de sus reuniones sea la discusión de temas como las inversiones productivas en sus municipios, la obtención de descuentos en los pasajes de transporte de los habitantes de sus comunidades o la instrumentación de programas alimenticios para los hijos menores de sus pueblos. Sí resulta extraño que esas reuniones se realicen en la ciudad de Nueva York $^{1}$ y que a ellas asistan los representantes no sólo gubernamentales -como por ejemplo el viceconsul de México-, sino también de organismos de mexicanos -o de ex-mexicanos, o de hijos norteamericanos de mexicanos- que cuentan con personalidad jurídica en los EUA y que han conquistado con serias dificultades (Smith, 1995) ser reconocidos como miembros de la comunidad política de sus lugares de origen. Es interesante, por lo demás, observar que los proyectos productivos que discuten son, al menos en parte, financiados por las asociaciones de migrantes en Nueva York; así como que los descuentos en el transporte que se negocian, son con las compañías aéreas internacionales que tienen vuelos entre México y Nueva York; y que los programas de alimentación están dirigidos a los hijos de los migrantes en Nueva York ${ }^{2}$

No tiene por qué causar extrañeza el hecho de que la tienda de un matrimonio piaxtleco, esto es, originario de Piaxtla, en el sur mixteco del estado de Puebla, esté provista de toda clase de chiles secos, de harinas para preparar tamales y tortillas, de pastas para hacer mole, de refrescos mexicanos populares como los jarritos, de cervezas como la corona o la sol, de videos de los rodeos recientes de los pueblos de la mixteca poblana, de vegetales como el guaje y, en fin, de todos los múltiples ingredientes y condimentos que se

$1 \quad$ En el mes de julio de 1996, nuestra compañera Marcia Campillo tuvo la oprtunidad de estar presente en algunas de las actividades que en Nueva York realizaron estos alcaldes con los migrantes originarios de sus localidades. En agosto, Saúl Macías y Fernando Herrera tuvimos al respecto una larga e interesante plática con el alcalde de Chinantla, quien por cierto había recibido momentos antes más de 2 mil fotografías de ese viaje a Nueva York y no tuvo retiscencia en mostrarnos una buena parte de ellas.

2 "para que no coman pura chatarra", nos dice a Saúl Macías y a mi el Presidente municipal de Chinantla, médico por cierto, en esa misma plática. 
utilizan en la cocina mixteca. Tampoco parece extraño que el mismo matrimonio posea, en el local adjunto al de su tienda, una panadería en la que se hornea y expende un estilo de pan típicamente mixteco. Lo que sí puede llamar la atención es que esos negocios estén situados en el corazón de El Barrio, en el East Harlem de Manhattan, zona de Nueva York que tradicionalmente ha estado poblada por italianos, primero, y por puertorriqueños, más adelante. También puede sucitar extrañeza que ese matrimonio tenga la nacionalidad norteamericana y que mantenga la práctica de turnarse para viajar a México una vez al mes, para surtirse de todos los productos mexicanos que más se venden en su tienda, a una clientela, por cierto, conformada no sólo por mexicanos, sino también por puertorriqueños, dominicanos, colombianos, afroamericanos y anglosajones.

Precisamente, el propietario de un próspero negocio de productos mexicanos de todo tipo, recuerda en una plática con parte de nuestro equipo de investigación desarrollada en el interior de la propia tienda, en 1997, que en el primer desfile de la hispanidad llevado a cabo en la ciudad de Nueva York, en el año de 1981, desfilaron sólo cinco mexicanos. En contraste, en 1998, pudimos constatar que en el ahora tradicional desfile de la hispanidad, no sólo la delegación mexicana era de proporciones considerables, sino que de una manera activa participaba acompañando a quienes desfilaban oficialmente, una enorme cantidad de mexicanos y mexicanas que corrían en los costados del desfile, a lo largo de la Quinta Avenida, a la altura del Central Park, portando banderas mexicanas de muy diversos tamaños. Encabezando la delegación, por cierto, se encontraba el personal del consulado de México, incluido el muy activo consul José Antonio Lagunas, encargado en NY precisamente del programa de atención a las comunidades mexicanas en el extranjero, así como los presidentes de las muy numerosas ligas de futbol (más de 60 equipos en la de Manhattan, para tener una idea) y de varios de los no tan infrecuentes empresarios poblanos y sus familias, que iniciaron su estancia en Nueva York como trabajadores ilegales, tal vez allá por los inicios de los años setenta, desempeñándose como lavaplatos, como repartidores callejeros de diversos alimentos o como vendedores de fruta; o bien ubicados en el trabajo agotador, precario e insalubre de los famosos sweatshop, o en las distintas actividades vinculadas a los servicios domésticos. Ocupaciones, por cierto, que absorben en la actualidad a la mayoría de los mexicanos, documentados e indocumentados (la mayoría), exitosos o no (estos últimos, la mayoría) y poblanos (la inmensa mayoría), tlaxcaltecas (la 
primera minoría) o de cualquier otra procedencia mexicana (sobre todo del norte de Oaxaca, de Morelos y de Guerrero y de ciudad Nezahualcóyotl, vecina de la ciudad de México) (Pries, Herrera y Macías, 1998).

Aparte de muchísimas tiendas y panaderías similares a las referidas, dispersas por todas las zonas de la ciudad de Nueva York y sus alrededores (sobre todo en ciudades de Nueva Jersey, como Passeic y Paterson), no es nada extraño toparse al caminar por el Bronx, Queens, Brooklin, Manhattan, Yonkers o Staten Island, con bares y restaurantes especializados en comida mexicana (o bien, cuasimexicana, como los burritos) y que ofrecen tequila y cervezas mexicanas. $\mathrm{O}$ bien con tortillerías o sus camionetas repartidoras que indican orgullosamente en sus costados su razón social: Tortillería Piaxtla, por ejemplo.

Ya Robert Smith, profesor de la Universidad de Columbia y pionero en el estudio de la migración de los poblanos a la zona metropolitana de Nueva York, había presentado evidencias de una presencia mexicana creciente en la zona. Tanto en su tesis de doctorado (Smith, 1994) como en un programa de televisión, que muy significativamente se denominó “La Mixteca en Nueva York”, y que en México transmitieron los canales 11 y 13 en 1995 y 1996, este académico había empezado a dar cuenta de las tortillerías, de los empleados mexicanos de los restaurantes y de cómo la vida neoyorkina empezaba a integrar en su inmensamente amplio mosaico cultural este nuevo ingrediente. Más adelante, Luz María Valdez acuñaría incluso un término ingenioso para reflejar el fenómeno: la Gran Manhattitlán (Valdez, 1996) denominó a ese continumm social que se desarrolla entre el estado de Puebla y la ciudad de Nueva York. Robert Smith lo definiría como una comunidad transnacional (1994). Más adelante, se propondrá en esta tesis el concepto de espacio social transnacional (desarrollado, entre otros, por Pries); mismo que ha estado presente de manera cada vez más generalizada -junto con otros como transmigrantes, transmigración, enfoque transnacional (Glick Shiller, et al), localidad transnacional (Goldrging) circuitos migratorios transnacionales (Rouse) y sistemas migratorios transnacionales(Smith y )- en las discusiones recientes que se interesan en la caracterización de lo que está sucediendo actualmente con las migraciones internacionales.

Cabe precisar que la creciente presencia mexicana en Nueva York, es un fenómeno tal vez menor -incluso muy menor- si se le ve en términos cuantitativos frente a la 
población neoyorkina y a otras migraciones; pero de enormes proporciones si se le ve, cuantitativa y sobre todo cualitativamente, desde las comunidades de origen, en el sur del estado de Puebla.

Pero resulta que no sólo la Mixteca empieza a "estar en Nueva York" y Nueva York a "estar en la Mixteca". En un proceso que arrancó sobre todo desde los años ochenta, también Atlixco -vieja ciudad textilera, cuyo ciclo industrial está en su fase terminal y que está ubicada en el centro del estado y muy cerca de la ciudad capital- empieza a "estar en Nueva York" y Nueva York a "estar en Atlixco"; sobre todo en las zonas rurales del municipio, situadas al noreste de la zona urbana. Nuevamente, para Nueva York, el número de migrantes atlixquences se pierde fácilmente en cualquier cuantificación, no solamente de la población total, sino incluso de la fuerza de trabajo ubicada en los nichos de mercado que han recibido de manera preferente a los migrantes poblanos. Pero para localidades como Nexatengo, Juán Uvera, Santa Lucía Cosamaploapan o San Isidro Huilotepec, dentro del municipio de Atlixco, que en promedio no rebasan los 2 mil habitantes, resulta un hito en su vida el hecho de que un porcentaje sumamente elevado de su población económicamente activa $^{3}$-hombre y mujeres- haya decidido "irse para el norte" a buscar trabajo. En estas pequeñas localidades son claros los signos que hablan, por ejemplo, de las remesas de dólares que llegan de Nueva York: en los pueblos, muchas casas de palma y adobe han sido cambiadas por construcciones de tabique y cemento; en las fiestas, el gasto se ha incrementado de manera considerable 4 por efecto de los dólares que envían los familiares desde Nueva York; en las calles, todas ellas sin pavimentar, circulan muchas "trocas" y camionetas de tipo "Van", con placas de Nueva York o Nueva Jersey...; en fin, Nueva York "llegó" también al municipio de Atlixco.

3 Aunque no sería serio arriesgar por lo pronto alguna cuantificación, cabe mencionar que sólo en la población de Santa Lucía Cosamaloapan, a lo largo de tres meses de aplicación de nuestra encuesta, básicamente entre migrantes que han venido de visita a su pueblo con motiva de su fiesta patronal, hemos podido aplicar más de cincuenta cuestionarios, sin repetir unidades domésticas.

$4 \quad$ La mayor parte de la información que se maneja aquí proviene de pláticas amsitosas -más que "informales"- con la trabajadora social Elia Morales, de Nexatengo, y sus familiares y amigos en las distintas localidades. Cabe señalar que esta región es tradicionalmente "fiestera". Como un ejemplo, valga decir que hay al menos una fiesta importante, de las que reunen a todas las localidades de la zona, por cada mes del año; además de muchísimas otras fiestas más locales o particulares. Personas que habitan desde hace digamos 20 o 30 años en la región coinciden en señalar que el gasto en estas fiestas ha crecido muy considerablemente en los últimos 10 o 15 años; y que eso es debido precisamente a las remesas de los que "están en el norte". 
Pero la historia no termina ahí; sino que esta presencia a distancia sigue surgiendo y desarrollándose. A lo largo de la investigación, quienes conformábamos el equipo pudimos irnos enterando de que las redes migratorias que se habían originado en la Mixteca poblana, no habían llegado solamente a la zona de Atlixco; sino que habían seguido extendiendo sus ramales hacia el norte del estado de Puebla, pasando por Cholula y la misma capital del estado, para después seguir extendiéndose hacia el del estado de Tlaxcala, para llegar después hasta la sierra norte del estado de Puebla y conectarse con las comunidades totonacas del centro del estado de Veracrúz. Por otro lado, hacia el occidente de Izucar de Matamoros, su influencia se había expandido a varios lugares del estado de Morelos. El caso es que a lo largo de los últimos diez o quince años, se ha presentado un enorme crecimiento de los lugares que envían personas a la zona metropolitana de la ciudad de Nueva York; esto es, de comunidades que empiezan a "estar en Nueva York", al tiempo en que "Nueva York está" en ellas.

Varios elementos comparten todos esos procesos migratorios y varios parecen diferenciarlos. Uno, que los unifica, llama poderosamente la atención: su destino, en Nueva York y sus alrededores (en donde los destinos también se están diversificando aceleradamente); y su ocupación, en labores preferentemente urbanas, ubicadas en nichos específicos de mercado. A diferencia, significativamente, de la migración que se origina en la Mixteca oaxaqueña y que se dirige sobre todo al estado de California y se ocupa mayoritariamente en labores agrícolas (Velazco, 1995). El regreso frecuente para visitar a las familias y para gozar de las fiestas patronales, los constantes envíos de dinero y la muy frecuente comunicación que se mantiene entre "los que se van" y "los que se quedan", así como la alternancia de trabajos en los lugares de origen y Nueva York, son otros elementos comunes importantes.

Otras semejanzas, así como las diferencias, serán presentadas como parte de los resultados que aquí se ofrecen. Pero quiere destacarse, para terminar esta introducción, la importancia que tienen estos procesos, como se espera que se constate a lo largo de la tesis, en la constitución de lo que más arriba se ha denominado como espacios sociales transnacionales. Esto es, no sólo se trata de que una sociedad que está alejada de otra por miles de kilómetros "tenga presencia" en ésta. Se trata de algo que cualitativamente va mucho más allá. Se trata de que entre dos espacios sociales antes separados, se desarrolla a 
través de la migración y los migrantes, con sus redes de relaciones sociales y su ir y venir entre uno y otro espacio o territorio, un tipo de vínculo que integra a ambos en una nueva realidad social, unificada en varios sentidos (infraestructurales, intersubjetivos, institucionales) y plurilocalizada.

\section{PLANTEAMIENTO Y OBJETIVOS GENERALES DE LA TESIS}

El objetivo general de la tesis consiste en demostrar un planteamiento central y dos más que se interrelacionan con el primero y también entre sí; los tres inmersos en importantes debates actuales. El planteamiento central se refiere a la importancia actual del surgimiento y consolidación de un tipo de espacio social, de carácter transnacional, ligado al desarrollo de un nuevo tipo de procesos migratorios internacionales. Por su parte, los planteamientos complementarios consisten en proponer, el primero, la centralidad del trabajo en la estructuración de las trayectorias laborales de los migrantes; mientras que el segundo, la importancia que tienen como fuerzas estructurantes las diversas instituciones sociales que intervienen en el mercado de trabajo, para complementar, reorientar o resignificar la acción del mercado propiamente dicho.

En cuanto al planteamiento central, lo que se quiere afirmar es que:

primero: en los procesos migratorios internacionales del presente existe un tipo de migración que es pendular, recurrente y de final indeterminado, que se suma a las formas que han sido más estudiadas tradicionalmente - estacionales o definitivas- y en las que participa un nuevo tipo de migrante, el transmigrante, que se suma a los migrantes tradicionales, como lo son los migrantes definitivos (emigrantes/inmigrantes), los exmigrantes y los migrantes de las diásporas. Este tipo de migración y de migrante, si bien ya existía en el pasado de manera marginal o excepcional, está cobrando una importancia creciente en los flujos migratorios contemporáneos;

y, segundo: ese tipo de migración, cuya importancia es creciente, tiene como característica destacada su capacidad de ser producto-productor de espacios sociales de tipo transnacional y plurilocalizados, dadas sus características oscilatorias o pendulares, así como su capacidad para desarrollar formaciones sociales reticulares densas, en las que se desarrollan elementos infraestructurales, institucionales y 
simbólicos propios; mismos que no son ni la mera reproducción de lo preexistente en las sociedades a las que vinculan estos procesos migratorios, ni tampoco creaciones ex-nihilo; sino que se trata de procesos de apropiación, recreación e innovación sumamente creativos.

Cabe una precisión al respecto de este primer planteamiento. No se trata de afirmar que estos espacios sociales transnacionales sean o tengan que llegar a ser una realidad dominante a nivel mundial o regional; ni que sean algo totalmente nuevo o exclusivo de los procesos migratorios; ni tampoco que todo proceso migratorio internacional tenga que desembocar necesariamente en el surgimiento de este tipo de espacios. En cuanto a lo primero, es obvio que, pese a los muy poderosos procesos de globalización, los estados y la sociedades nacionales siguen siendo la presencia dominante en la organización social mundial. En cuanto a lo segundo, realidades como la iglesia católica, algunos procesos migratorios antiguos, como el de chinos a los Estados Unidos, o bien las compañías transnacionales, sirven para ilustrar que este tipo de espacio social de carácter transnacional tiene importantes antecedentes. En lo tocante al tercer punto, resulta claro en la investigación acumulada que muchos procesos migratorios siguen presentando características propias de las migraciones tradicionales, como lo es la ruptura o el alejamiento sustancial con los lugares de origen.

De esta forma, con mayor precisión, el planteamiento central de este trabajo postula la existencia de ESPACIOS SOCIALES TRANSNACIONALES (EST) creados por el proceso migratorio desarrollado entre varias comunidades de los estados de Puebla y Tlaxcala, en México, y la zona metropolitana de Nueva York y sus alrededores, en los Estados Unidos. Espacios Sociales Transnacionales que existen a la vez en cada uno de estos extremos -localidades de origen y de destino de la migración-, pero también entre ambos lugares, en la forma de un continuum social (Massey, et al, 1991), sustentado en (Pries, et al, 1998b):

a) elementos objetivos, como una base infraestructural, que sirve para el intercambio y traslado de personas, mercancías y una amplia gama de bienes materiales y simbólicos; 
b) elementos intersubjetivos, ligados a formas culturales y representaciones colectivas de los actores involucrados, tanto directa como indirectamente, en el proceso migratorio;

c) un conjunto de instituciones, tanto de tipo formal como social, que intervienen activamente en los procesos de estructuración de estos espacios sociales.

Ahora bien, se plantea que hacia el interior de estos EST se ha desarrollado un conjunto de redes de relaciones sociales que le dan continuidad y estructuración tanto a los aspectos infraestructurales e institucionales, como a los que tienen que ver con la dimensión de la cultura, la identidad y las representaciones en el imaginario colectivo. Insistiendo: no es un espacio que resulte de la suma de dos subespacios relacionados entre sí (las comunidades de origen y las de destino), sino que es un nuevo espacio social que existe, por un lado, tanto en las comunidades de origen en los estados de Puebla y Tlaxcala, como en Nueva York y sus alrededores, pero también entre ambos lugares; y que existe también, al menos parcialmente, al margen de México y los Estados Unidos, en tanto que estados nacionales formal y culturalmente diferenciados. Tentativamente, puede plantearse que tal vez para los actores de este EST sea más relevante para fines prácticos e identitarios la frontera que los separa del resto de México y los Estados Unidos, que la que separa internamente su propio espacio social entre una parte asentada en México y otra en los Estados Unidos 5 .

Junto a este planteamiento central, como ya se ha dicho, se presentan otros dos que refiren al campo conceptual y empírico en el que se quiere corroborar la propuesta central. El primero se refiere a la centralidad del trabajo - entendido éste en un sentido amplio e incluyente y como articulador de espacios y prácticas- en la organización o estructuración de las historias personales de quienes se convierten en migrantes. Como lo ha comprobado la investigación acumulada sobre la migración de México a los Estados Unidos, la razón fundamental que la produce está en el terreno laboral y no en otros campos, como la política o la religión. No se trata aquí de reivindicar las viejas posiciones que sostuvieron muy diversos tipos de marxismo (y aun fuera de él, como en el caso de Touraine), en el

\footnotetext{
5 Más adelante, esta propuesta será puesta a discusión con otras con las que tiene tanto puntos de divergencia como de convergencia.
} 
sentido de considerar al proletariado como un sujeto histórico predeterminado y privilegiado, para la constitución de sujetos históricos cargados de misiones y destinos. Sí se trata de explorar en el campo acotado de este estudio la posibilidad de que, para grupos significativos en las sociedades actuales, el trabajo siga siendo el eje articulador de historias y dimensiones, no sólo personales, sino también colectivas; al tiempo que también existan posibilidades de que el mundo del trabajo siga siendo un campo de interacción social en torno al cual pueden seguirse constituyendo sujetos sociales -ni únicos, ni predeterminado, ni cargados de taréas históricas-, con capacidad de intervenir creativamente en los procesos sociales y de generar, por tanto, nuevas realidades sociales, como lo son precisamente los referidos espacios sociales transnacionales.

Precisando para los fines de este trabajo, se trata aquí de analizar cómo el mundo del trabajo, al tiempo que estructura centralmente la historia y los mundos de vida de quienes migran, colabora de manera fundamental para la estructuración también de los propios espacios sociales transnacionales; a través de procesos en los que la vida laboral se transnacionaliza. Que sin embargo el trabajo no es de ninguna manera el agente único de estos procesos, se intenta probar aquí a través del análisis de las instituciones sociales que a su vez estructuran las trayectorias y biografías laborales de quienes migran, transmigran y dejan de migrar en estos procesos oscilatorios y pendulares, creadores de espacios sociales transnacionales y plurilocalizados.

El anterior es precisamente el terreno en el que se ubica segundo planteamiento complementario de este trabajo. Este, en síntesis, consiste en proponer que el mundo del trabajo, y en especial la estructuración de los mercados de trabajo, se ve ampliamente influido o condicionado por la acción de diversas fuerzas institucionales de la sociedad, que complementan, reorientan o resignifican la acción de las fuerzas propiamente del mercado. De tal manera que instituciones sociales como la organización de la empresa, la organización de las profesiones o los oficios, las redes de relaciones sociales y, sin ánimos de exahustividad, los múltiples esquemas de segregación social y el propio mercado, resultan ser las grandes fuerzas estructuradoras de los procesos de movilidad, ubicación y remuneración de la fuerza de trabajo, efectivamente aplicada o potencial, a través de todo el abanico de puestos de trabajo disponibles en la sociedad y a través de toda la división social del trabajo; que es por cierto como Escobar (1997) define al propio mercado de trabajo. 
Más específicamente para los fines de este trabajo, se propone que si bien el trabajo es el espacio central para la estructuración de las historias, personales y colectivas del grupo migrante seleccionado; las historias ocupacionales de las personas involucradas, a su vez, están estructuradas por una multiplicidad de fuerzas institucionales. Pero, en el caso particular que se estudia, es posible detectar cómo la segregación y las redes de relaciones sociales, especialmente las vinculadas a la familia -que son ambas instituciones que provienen de los espacios o mundos de vida aparentemente menos económicos de los involucrados-, son las que mayor fuerza estructurante muestran en relación a las trayectoria laborales.

Se dijo aparentemente menos económicos, para referirse a este tipo de espacios o mundos de vida, y debe reiterarse. Aunque obedezcan, al menos parcialmente, a lógicas distintas a la de la maximización de la ganancia y del cálculo preciso y objetivo; son también espacios de actividades económicas, o bien de trascendencia económica, fundamentales; como lo son las que se relacionan con la (re)producción cotidiana de la propia fuerza de trabajo; así como con decisiones fundamentales sobre la actividad económica. Son, incluso, los espacios privilegiadosen donde se filtran, regeneran y reprocesan, en la interacción social reiterada, los procesos de legitimación de las prácticas relacionadas con el trabajo, los proyectos de vida y las decisiones sobre permanecer o no en el lugar de origen; o bien regresar a él o no hacerlo; o incluso, de mantenerse permanentemente transitando entre los diversos territorios del espacio social transnacional. 


\section{PRIMERA PARTE}

\section{CAPITULO PRIMERO: LOS ORIGENES DEL PROYECTO}

\section{I.LA CONSTITUCION DEL EQUIPO DE INVESTIGACION}

Considero que conocer, al menos someramente, el origen y el desarrollo del proyecto de investigación en el que se ubica mi proyecto particular puede ser de utilidad. Por ello, antes de proceder a presentar con destalle mi propio trabajo, expongo a continuación una breve síntesis al respecto.

Este proyecto se originó cuando un grupo de investigadores decidió, en septiembre de 1994, ingresar al Doctorado en Ciencias Antropológicas del Departamento de Antropología Social de la UAM-I. Para ello, pensamos originalmente en la investigación de algunos mercados de trabajo regionales que tuvieran como característica común la de tener una fuerte presencia de la industria automotriz 6 . Desde el inicio, también, tomamos la decisión metodológica de trabajar con la reconstrucción de Trayectorias y de Biografías Laborales. Al respecto, conocíamos sobre todo los trabajos realizados por Agustín Escobar (1984, 1993 a y b) sobre la ciudad de Guadalajara, de Ludger Pries (1939, 1994 y sf, a y b), sobre la ciudad de Puebla, y los ya clásicos de Balán, Browning y Jelin (1974), sobre la ciudad de Monterrey; y de Muñóz, Oliveira y Stern, sobre la ciudad de México (1977). Sabíamos igualmente que en el COLEF investigadores como Ma. Eugenia de la O (1993) y Oscar Contreras (1993) estaban realizando, desde esa perspectiva, investigaciones sobre los trabajadores y las trabajadoras de la maquiladoras de la frontera. Sin embargo, nuestro conocimiento tanto del estudio de los mercados de trabajo, como de la metodología biográfica, era incipiente y algo imprecisa. Por otro lado, no quedaba claro cómo podíamos resolver el problema de la necesaria vinculación interdisciplinaria entre la Sociología del Trabajo y la Antropología Social

6. La razón era que tanto Patricia García como Fernando Herrera se había especializado en el estudio de esta industria. 
A esa conclusión llegamos cuando fuimos finalmente admitidos como alumnos en el Doctorado. Antes de que esto sucediera, se tuvieron que conjuntar varios elementos afortunados para nosotros los aspirantes. El principal de ellos fue la buena disposición y la apertura a lo interdisciplinario que asumieron Roberto Varela, Coordinador del programa de Doctorado, Ludger Pries, sociólogo de profesión, que fue invitado para asesorarnos y aceptó hacerlo (más adelante se habría de integrar también como investigador al proyecto); y Enrique de la Garza, que a nombre de la Maestría en Sociología del Trabajo de la UAM-I intervino para recomendarnos y, más allá de eso, para facilitar que Pries fuera "prestado" por la Maestría -coordinada por Javier Melgoza, quien también sumó su buena disposiciónpara que fungiera como nuestro asesor. Lo anterior se hizo necesario debido a que el Doctorado en Antropología, interesado en los temas del trabajo, no contaba sin embargo por el momento con alguna persona especializada que pudiera hacerse cargo de nuestro proyecto.

Lo primero que hizo Pries fue comunicarnos su opinión crítica sobre el proyecto que habíamos presentado y con el cual habíamos sido aceptados. El proyecto era impreciso, tenía confusiones conceptuales importantes, carecía de un escenario empírico bien definido para desarrollarse, la propuesta metodológica era vaga $\mathrm{y}$, tal vez lo más grave, la investigación parecía prácticamente irrealizable dentro de los plazos que resultan razonables para elaborar una tesis de Doctorado. En pocas palabras: nada fuera de lo normal al iniciar una investigación de este tipo. Al Dr. Pries le pareció interesante y aceptable que el problema central girara en torno a los mecanismos que estructuran la ocupación -el estudio de lo que habitualmente se conoce como Mercados de Trabajo- y que la metodología fuera una que permitiera ver los procesos de manera longitudinal y dinámica, con la utilización privilegiada de técnicas como las Trayectorias y las Biografías Laborales. Ese fue el punto de partida. El siguiente paso tenía que ser la definición precisa del problema que investigaríamos. Todavía no sabíamos que estudiaríamos la migración transnacional.

Este tema y su ubicación específica en el flujo que se ha generado desde los años 40 entre el estado de Puebla, en México, y la zona de la ciudad de Nueva York, en los EUA, surgió de manera un tanto azarosa y fue producto colectivo. Ludger Pries compartía con Saúl Macías y con Fernando Herrera un conocimiento mas bien amplio del estado y de la 
ciudad de Puebla, en la que los tres habían vivido y trabajado durante varios años. Ninguno de los tres podía precisar cuándo había empezado a oir versiones acerca de la migración de los poblanos a Nueva York; sin embargo, los tres habían empezado a sentir curiosidad al respecto desde tal vez finales de los años 80; ya fuera porque habían tenido alumnos de licenciatura que habían migrado en esa dirección, ya fuera porque habían leido algo en algún periódico de la región o porque habían captado información en algún noticiero radiofónico poblano; o bien, porque en Puebla "se sabía" desde los años 80 que el fenómeno estaba ocurriendo. Más precisamente, los tres tenían conocimiento reciente de los testimonios de migrantes poblanos en Nueva York que habían recogido en esa ciudad una extensionista cultural de la UAP -Enriqueta Silva-, un músico roquero rupestre-Carlos Arellano- y un escritor y periodista -"El Gallo" Oscar López-. Estos testimonios habían sido dramatizados -obviamente el trabajo no era de antropólogos ni tenía fines científicos- y transmitidos por una estación radiofónica local. Carlos Arellano, por su parte, había incluso compuesto algunas canciones sobre estos migrantes poblano-neoyorkinos.

En el equipo se planteó entonces (inicios de 1995): ¿y si elegimos ese proceso como problema de investigación? No hubo objeciones y sí mucho entusiasmo: era un tema actual que permitía una investigación con las características que habíamos acordado; tenía un fuerte contenido laboral; era original (aunque muy pronto sabríamos que no era absolutamente original, puesto que al menos Robert Smith, Thoric Cederström y Luz María Valdéz habían iniciado su estudio); evidentemente no se limitaba a los procesos de trabajo y a los espacios urbanos; abría espacios para un ejercicio interdisciplinario, entre la Antropología y la Sociología del Trabajo; se prestaba claramente para un ejercicio de reconstrucción de Trayectorias y Biografías Laborales (ahora para nosotros MigratorioLaborales); y posibilitaba acercarse a la pregunta de cómo los mercados laborales articulan y estructuran a la sociedad a partir de las prácticas sociales cotidianas. Además, era un tema de gran actualidad tanto por la renovación del discurso y las prácticas anti-inmigratorias y xenofobas en los EUA, como por su relación con los procesos de globalizaciónregionalización presentes en la sociedad y la economía mundiales de los años 90. No obstante lo anterior, se presentaba un problema de ninguna manera menor: salvo Ludger Pries, nadie del equipo sabía sobre la migración más de lo que cualquier persona más o menos atenta a lo que sucede en el país y el mundo puede saber. 
Antes de pasar a describir cómo fuimos adentrándonos en el tema, tanto teórica como empíricamente, y cómo fuimos definiendo nuestro problema de investigación, primero en términos de un planteamiento general y más adelante en la forma de proyectos particulares interrelacionados, cabe señalar que el equipo que trabaja en este proyecto ha sufrido cambios en el trayecto. Este proyecto lo iniciamos originalmente Patricia García que participó sólo en el inicio del trabajo de campo-, Fernando Herrera y Saúl Macías. Un año después de iniciado, el proyecto se enriqueció con la llegada de Marcia Campillo y de Saúl Moreno, quien colaboró efímeramente y quien lamentablemente tuvo que cambiar su proyecto de investigación por exigencias de la institución que financiaría su Doctorado. Más adelante, después de haber realizado una parte del trabajo de campo tanto en México como en Nueva York, en el mes de mayo de 1996, Marcia Campillo se retiró a finales de ese mismo año, por cuestiones personales que la llevaron a cambiar su residencia a su lugar de origen, en Mexicali, BC.

Desde el inicio, el director del proyecto ha sido Ludger Pries; quien fue además el responsable del Proyecto ante el Conacyt y el asesor interno ante el Doctorado en Ciencias Antropológicas de la UAM; y quien se integró al trabajo como otro investigador más. Nuestros asesores externos han sido, desde 1995, Vania Salles, de El Colegio de México, y Agustín Escobar, de CIESAS de Occidente.

Una mención especial debe hacerse de las dos personas que trabajaron como ayudantes de investigación en el proyecto y que, de hecho, fueron mucho más que eso. Primero se integró al equipo el pasante de Antropología de la UAP Gustavo López Angel, quien ya había trabajado con Ludger Pries como ayudante en una investigación sobre el mercado de trabajo en la ciudad de Puebla y que estaba realizando su tesis de licenciatura, bajo la dirección de Thoric Cëdestrom, en la comunidad de El Rosario Micaltepec, municipio de Petlalcingo, en la Mixteca poblana. Su aportación fue invaluable para contactarnos con una gran cantidad de redes sociales que nos permitieron realizar el trabajo de campo, ya que es un profundo conocedor de la Mixteca poblana, gracias a un muy profesional trabajo dentro de la Dirección de Culturas Populares de la SEP, a partir de principios de los años noventa. Fue precisamente por su intervención que hemos sido recibidos con facilidad y cordialidad en varias comunidades a las que era muy improbable 
acceder como desconocidos. El estuvo en el proyecto hasta principios de 1997, cuando su vida personal lo llevó por otros rumbos.

Después se integró como ayudante María Luisa Cortés, pasante de la carrera de historia en la UAM-I y quien contaba con su propia y extensa red social entre los migrantes de una zona industrial y urbana del sur de Tlaxcala, colindante con la zona urbanaindustrial de la ciudad de Puebla. Gracias a ella, incluimos en nuestro proyecto una región más que, como Atlixco, tampoco estaba prevista inicialmente y sobre cuya migración a la zona de Nueva York ni siquiera habíamos oido hablar. María Luisa se integró al equipo cuando nos fuimos a realizar el trabajo de campo a Nueva York, en el mes de agosto de 1997 (por cierto, cabe mencionar como anécdota que para los administradores del presupuesto en la UAM-I, resultaba casi inadmisible que se pudiera realizar trabajo de campo en la ciudad de Nueva York, y fue sólo gracias a la lucidez y buena disposición de Alejandro Zamorano que pudimos ejercer nuestro presupuesto del Conacyt sin mayores problemas). Desde entonces ha permanecido en el proyecto y su ayuda ha sido fundamental tanto en el trabajo de campo, como en la codificación, captura y procesamiento de la información. De hecho, ha sido una investigadora más en el equipo.

Aparte de ese nucleo central del proyecto, hubo un sinnúmero de personas que desarrollaron trabajos invaluables para nuestra investigación. En particular, tres de ellas se convirtieron en verdaderas coordinadoras regionales de nuestro trabajo de campo, después de poner a nuestra disposición su capital social o relacional. En Atlixco (Nexatengo), la trabajadora social Elia Ramírez. En Acatlán (Amatitlán), el ingeniero agrícola Cuahutemoc ¿? . Finalmente, en Tlaxcala (San Miguel del Milagro), el tesista de la carrera en Trabajo Social Orlando Ramírez.

Un elemento importante para comprender algunas de las características y, sobre todo, algunos de los problemas a los que nos hemos enfrentado en esta investigación, consiste en que quienes hemos participado hasta ahora en este proyecto tenemos formaciones y trayectorias más o menos heterogéneas y, sobre todo, ubicadas fuera de la Antropología Social. En términos generales, lo que nos unifica es la experiencia común en torno a la Maestría en Sociología del Trabajo de la UAM-I7, ya sea como egresados de ella

$7 \quad$ Experiencia que arrancó desde que esta Maestría era sólo un proyecto y que tuvo como algunos de sus momentos más importantes los cursos de Formación de Profesores en Sociología del Trabajo (en México, DF, en 1983; en Puebla, Pue., en 1985; y en 
-Marcia Campillo, Fernando Herrera, Saúl Macías y Saúl Moreno-, ya sea como profesores de la misma -Ludger Pries y Fernando Herrera-, ya sea como participantes en uno o más de los proyectos de investigación y extensión impulsados desde ese espacio académico por Enrique de la Garza. Nos unifica también un interés sostenido en la investigación en torno a los trabajadores industriales y urbanos (automotrices, en el caso de Patricia García, Ludger Pries y Fernando Herrera; universitarios, en el de Saúl Macías; telefonistas y telegrafistas, en el de Marcia Campillo; petroleros, finalmente, en el de Saúl Moreno). Sin embargo, nuestros antecedentes son más diversificados: Marcia Campillo es Socióloga, egresada de la UABC; Patricia García es Economista, egresada de la UNAM y con Maestría en la Universidad de París; Fernando Herrera cursó una licenciatrura en Relaciones Internacionales, en El Colegio de México; Saúl Macías es Licenciado en Historia por la UAP; y Saúl Moreno es Sociólogo por la UV. Gustavo López estudió Antropología en la UAP y María Luisa Cortés Historia, en la UAM-I.

Un elemento de gran importancia que nos hizo confluir en esta investigación fue la decisión común de buscar un campo que permitiera dar salida a varias inquietudes que compartíamos desde el inicio y que se han ido precisando como problemas conceptuales y como propuestas metodológicas. Básicamente, tales preocupaciones giran en torno a los siguientes temas: a) la necesidad de ir en la investigación más allá de los límites determinados por los espacios laborales, pero sin dejar de pensar al trabajo y a los trabajadores como centro de nuestras preocupaciones 8 ; b) un acuerdo de que el mercado de trabajo podía ser el campo privilegiado para el estudio, como lo propone Escobar (1993b), de la articulación de los espacios en los que se realiza el trabajo cotidianamente- el espacio de los procesos de trabajo diversos-, con los espacios en los que se intercambian las diversas mercancías, y muy especialmente con aquellos espacios en los que la sociedad asigna a los trabajadores a las diversas ocupaciones y con aquellos otros en los que los trabajadores se reproducen cotidianamente; c) otro acuerdo más giraba en torno a la necesidad de ver los procesos sociales de manera longitudinal y dinámica -a diferencia de

Tlaxcala, Tlax., en 1987) y los Coloquios de Xalapa, de 1986, 1989 y 1992), eventos todos impulsados sobre todo por el Dr. Enrique de la Garza.

8. Como puede constatarse en el primer número de la Revista Latinoamericana de Estudios del Trabajo (1995), esta preocupación es ampliamente compartida en la actualidad por los principales centros en los que se estudia el trabajo en América Latina y, si hacemos caso a JJ Castillo (1995), prácticamente en todo el mundo. 
transversalmente y de manera estática o como cortes de tiempo-, de tal manera que los procesos de estructuración de la sociedad pudieran captarse a través de los instrumentos que buscan reconstruir las trayectorias de los actores a través del tiempo y del espacio; aproximación que permite observar (Escobar, 1993b) no sólo los resultados de los procesos sociales en un momento determinado, sino sobre todo los procesos de estructuración de la sociedad.

\section{LA ELECCION DEL UNIVERSO EMPIRICO: LA MIGRACION ENTRE EL ESTADO DE PUEBLA Y LA ZONA DE LA CIUDAD DE NUEVA YORK.}

Una vez que decidimos que nuestro objeto de estudio sería la migración de poblanos hacia Nueva York, empezamos a intentar precisar lo que sería nuestro universo empírico específico. Un primer descubrimiento importante consistió en constatar que ya existían -y de muy buena calidad- trabajos pioneros en el estudio del fenómeno migratorio correspondiente a esta migración. En particular, encontramos que Robert Smith (1994 y 1993, a y b) no sólo había realizado un profundo estudio en la comunidad de Chinantla (y, marginalmente, Piaxtla), sino que también había iniciado una importante discusión teórica en torno al carácter transnacional de estas comunidades, como producto de la migración a Nueva York. Encontramos también que Thoric Cedeström (sf) había investigado el efecto de las remesas de los migrantes en la comunidad de El Rosario Micaltepec, Mpio. de Petlalcingo. Por otro lado, tuvimos acceso al trabajo que realizó Luz Ma. Valdez (1994) en la $\mathrm{Cd}$. de Nueva York con los migrantes poblanos, en ese espacio que ella ha denominado recientemento como "La Gran Mannhatitlan" (1996) y en el que avanza de manera importante en un intento de cuantificación y de ubicación laboral de los migrantes.

Al inicio, todo parecía indicar que esta migración tenía su origen, básicamente, en la zona sur del estado de Puebla, en la región conocida como la Mixteca poblana 9 . No fue

9 La Mixteca Poblana es una porción del territorio del estado de Puebla que está situado en el extremo sur, en la parte en que Puebla tiene límites con los estados de Oaxaca y Guerrero. Está insertada en dos de las regiones económico-administrativas del estado: la VI de Izúcar de Matamoros y la VII de Tehuacán. Está integrada de 34 municipios, 26 de la Región de Izúcar de Matamoros y 8 de la Región de Tehuacán.

De la Región de Izúcar de Matamoros está integrada de los siguientes municipios: Acatlán, Ahuehuetitla, Albino Zertuche, Cohetzala, Cuayuca, Chiautla de Tapia, Chigmecatitlán, Chila de las Flores, Chila de la Sal, Chinantla, Guadalupe, Ixcamilpa de Guerrero, Petlalcingo, Piaxtla, San Jerónimo Xayacatlán, San Miguel Ixitlán, San Pablo Anicano, San Pedro Yeloixtlahuaca, Santa Catarina Tlaltempa, Tecomatlán, Tehuitzingo, Totoltepec de Guerrero, Tulcingo del Valle, Xayacatlán de Bravo, Xicotlán, Zacapala. De 
difícil constatar que un gran número de localidades de esa región se habían convertido en fuertes expulsores de migrantes desde, al menos, los años 80 (incipientemente, desde mucho antes, tal vez desde los años 40), y que la mayor parte de quienes migraban desde esos lugares lo hacía hacia la zona de la ciudad de Nueva York. Chinantla y Piaxtla, tal vez desde los años 40; Acatlán y Tehuitzingo, tal vez desde los 60; Xayacatlán de Bravo, El Rosario Micaltepec y Tepejillo, quizas desde los 80, eran comunidades que enviaban migrantes y que parecían inicialmente indicar que era posible encontrar diferencias subregionales en esta migración de mixtecos poblanos (mejor dicho: de poblanos originarios de la región Mixteca del estado de Puebla; porque también encontrararíamos que las poblaciones que pueden definirse étnicamente como mixtecas son actualmente una minoría dentro de esa región).

Una cosa muy importante, sin embargo, que parecían compartir como elemento común y que nos llamó ampliamente la atención desde el inicio, era que estos migrantes no parecían pertenecer ni al tipo de los que se van y nunca regresan -o bien, sólo lo hacen aquellos que no pueden quedarse-, ni tampoco al de los que se van sólo estacionalmente, de manera más o menos regular, cada año o cada seis meses, por ejemplo. A diferencia de ellos, estos migrantes parecían tener un comportamiento migratorio, por así decirlo oscilatorio o pendular, en el que resultaban normales los continuos desplazamientos de ida y vuelta, entre las comunidades de origen y la Cd. de Nueva York; ya fuera por la vía larga del paso "indocumentado", por Tijuana y San Diego, o bien por Nogales y Tucson; ya fuera por la vía directa y aérea, "semidocumentada" (con visa de turista) o incluso ya "documentada" (con licencia para trabajar o residencia legal).

Dentro de estos comportamientos, resaltaba también el mantenimiento constante de comunicación entre los migrantes y, por supuesto, sus familias; pero de la misma manera se mantenían abiertos y ocupados los canales de diverso tipo (teléfono, videograbación) que permitían conexiones importantes, por ejemplo, entre organizaciones de migrantes en

\footnotetext{
la Región de Tehuacán está integrada de: Caltepec, Coyotepec, Ixcaquixtla, Tepexi de Rodríguez, San José Miahuatlán, San Martín Atexcal, Santa Inés Ahuatempan, Zapotitlán Salinas.

La Mixteca Poblana está integrada por un territorio que abarca una extensión de $77711.12 \mathrm{kms}{ }^{2}$, que representan el $23.02 \%$ del territorio total del estado de Puebla.

En esta región pueden encontrarse, según los datos del censo de población de 1990, 192318 habitantes, 144066 habitantes pertenecen a la Región de Izúcar de Matamoros y 48252 pertenecen a la Región de Tehuacán, que representan el 4.66\% de la población del estado. Su densidad de población es variada; sin embargo, aparecen algunos municipios que destacan por una elevada densidad: por ejemplo, Petlalcingo, Piaxtla y San Pablo Anicano se encuentran por arriba de los 4 habitantes por kilómetro cuadrado (4.82, 4.73, y 4.55 respectivamente); Guadalupe está por arriba de los 5 habitantes; Chigmecatitlán por arriba de los 6; y Acatlán e Ixcaquixtla por arriba de los 7 habitantes por kilómetro cuadrado (7.05 y 7.08 respectivamente) (Cf. Macías, 1996).
} 
Nueva York y las autoridades municipales o eclesiásticas de la Mixteca (al menos en las comunidades estudiadas por Robert Smith (1994 y 1995); para tratar temas tan relevantes como la forma de financiar y organizar tanto las fiestas religiosas, como la construcción de obras públicas o el remodelamiento o la mejora de templos; y aun las formas posibles de participación política de los migrantes en sus pueblos de la Mixteca.

En los meses de noviembre (por los días de muertos) a febrero o marzo del año siguiente, era evidente para cualquier persona que llegara a esa región la presencia, física y simbólica, de los "paisanos que están en el norte", para atender a las fiestas principales del año, para convivir con sus familiares y vecinos, para celebrar complementariamente algunas fiestas familiares (cumpleaños, bodas, quince años, bautisos); así como algunos duelos familiares (de alto contenido simbólico resulta el hecho de que los cadáveres de las las personas que fallecen en Nueva York sean enviados a los lugares de origen para los ritos de despedida). Con menor intensidad, era posible ver que en cada pueblo se vivía una situación similar en la fecha correspondiente a la fiesta del Santo Patrón, aun cuando ésta no coincidía con el fin de año, como es el caso de Piaxtla, cuya fiesta patronal es en el mes de agosto.

En fin, con matices seguramente y con particularidades que parecía más que sugerente investigar, las conclusiones de Robert Smith sobre Chinantla y Piaxtla, acerca del surgimiento de algo nuevo y distinto a lo preexistente, en las comunidades mixtecas afectadas por fuertes flujos migratorios hacia Nueva York -que él caracterizó como el surgimiento de Comunidades Transnacionales y al que nosotros preferimos referirnos como Espacios Sociales Transnacionales-, parecía a primera vista extensible a una gran cantidad de localidades de la región llamada Mixteca.

Ahora bien, en el equipo nos preguntamos: ¿qué conclusiones podrían ser accesibles si, en lugar de estudiar una sola comunidad, intentáramos el estudio comparativo de varias de ellas, a partir de una selección basada en criterios de contrastación, por ejemplo, entre la antigüedad del origen del proceso migratiorio, del carácter étnico mixteco o mestizo de la comunidad, del tamaño relativo de la misma, de sus características más o menos urbanas y, en fin, del tipo de tierra a disposición? Sabíamos de entrada que sería imposible plantearse un estudio en el que pudiera conseguirse una representatividad estadística, debido a que, 
como Cortés (199 ), Smith (1993 a y b) y Valdéz (1994) lo han aclarado, resulta prácticamente imposible conocer el universo total de la migración. Sabíamos también que nuestra investigación no podía plantearse responder a todas las preguntas relevantes que se pueden proponer desde la teoría al proceso migratorio. Teníamos que fijar entonces con claridad los objetivos y los límites de nuestro trabajo.

Decidimos así que, en lugar de tratar de formular conclusiones válidamente generalizables para el conjunto de los habitantes de las comunidades de origen 10 , o bien para el conjunto de los migrantes originarios de la mixteca poblana, nosotros buscaríamos indagar sobre las características de esa nueva realidad social que parecía emerger a partir del proceso migratorio desarrollado entre la Mixteca poblana y Nueva York y que Smith había denominado comunidad transnacional (así como Goldring (1992) lo había hecho para las comunidades de Zacatecas que había investigado). Aunque la sustentación conceptual de esta propuesta se desarrolla más adelante, cabe aquí adelantar que, en síntesis, nos proponíamos investigar ese proceso para buscar demostrar que ahí estaban surgiendo Espacios Sociales Transnacionales, que tenían como elementos constitutivos tanto una parte objetiva o material, compuesta por una infraestructura propia, como de una parte intersubjetiva, referida al mundo de la cultura, las identidades y las representaciones colectivas; así como un conjunto de instituciones sociales que estructuraban internamente dichos espacios. Complementariamente, pero en el mismo nivel de importancia, nos interesaba investigar si ese fenómeno, el surgimiento de Espacios Sociales Transnacionales, era sólo una realidad efímera, propia de una fase o etapa de la migración, o bien si era posible descubrir tendencias que hablaran de su posibilidad de permanencia en el tiempo, de una manera digamos transgeneracional.

Como se trataba, desde nuestro punto de vista, de indagar una realidad en vías de constitución o de estructuración, más que algo que pudiera verse como una realidad ya plenamente constituida, nos pareció que el enfoque dinámico y de corte longitudinal que habíamos elegido, resultaba ampliamente justificado. Nos interesaba comparar no sólo la situación actual de las diversas comunidades, sino también comparar el cambio de la

\footnotetext{
10 Por ejemplo, sabemos que en las comunidades de la Mixteca poblana, muy claramente en Tehuitzingo, pero también en otras, existen otros flujos migratorios, tanto internos (por ejemplo, estacionales a Chihuahua y Sonora; o más definitivos, a Baja California y el DF), como internacionales (por ejemplo, a Chicago y Texas)
} 
situación a través del tiempo, en las distintas cohortes y generaciones que habían participado en el proceso migratorio.

Para acabar de definir nuestro universo seguía faltando sin embargo un buen punto de contraste. En nuestras discusiones llegamos a la conclusión de que sería muy interesante que pudieramos comparar el proceso migratorio originado en la Mixteca, con algún otro que tuviera también como destino Nueva York y que se ubicara, de preferencia, también en el estado de Puebla. Afortunadamente, esa realidad empírica existía y se ubicaba muy cerca de la ciudad de Puebla, en la antigua zona textilera de Atlixco y precisamente dentro de los límites de este municipio. Nuevamente gracias a Gustavo López, pudimos entrar en contacto con la sociologa canadiense Kerry Presbisch, quien realizaba en esa zona su trabajo de campo para la obtención de su grado de Maestría en la Universidad de Vancouver. Y gracias a Kerry, pudimos conocer a la trabajadora social Elia Morales, quien se ha convertido en una pieza fundamental para nuestra investigación en la zona que abarcan las comunidades rurales del municipio de Atlixco que envían más migrantes a la Cd. de Nueva York y sus alrededores (Nexatengo, Almazán, Santa Lucía Cosamaloapan, San Isidro Huilotepec, San Félix y Juan Uvera).

De esta forma, nuestro universo empírico había quedado definido y era posible iniciar el trabajo de campo. Para ello, habíamos también llevado de manera paralela una discusión de tipo conceptual y metodológica acerca del estudio de la migración, en particular internacional, y habíamos generado nuestros instrumentos principales de trabajo: un cuestionario para la reconstrucción de las Trayectorias Laborales y una Guía de Entrevista, para reconstruir la Biografías Laborales (ver anexo).

No obstante lo anterior, nuestro universo habría todavía de expandirse, para incliur el estado de Tlaxcala. Tal y como nos sucedería más adelante con algunas zonas del estado de Veracrúz (Papantla y la región de Córdova, Orizaba, Fortín y Huatusco) y de la ciudad de México (ciudad Nezahualcoyotl y la delgación Iztapalapa), a lo largo del proceso mismo de investigación nos enteramos que desde el sur del estado de Tlaxcala, en una zona que combina la actividad industrial con la agrícola, se generaba un importante flujo migratorio hacia la zona de la ciudad de Nueva York. La decisión en favor de incluir esta nueva región en nuestro estudio, a principios de 1997, se vió fuertemente influenciada por el hecho de que una nueva integrante de nuestro equipo, la ayudante de investigación María Luisa 
Cortés, tenía una densa y sólida red de contactos familiares y cuasi familiares con dos familias interelacionadas que tenían una muy elevada composición de migrantes a Nueva York y su zona metropolitana. En mayo de 1997, los miembros de esas familias nos darían uno de los apoyos más importantes para el trabajo de campo en Nueva York, gracias tanto a su muy buena disposición, como a su dispersión habitacional y ocupacional (Brooklin, el alto Manhattan, Staten Island, y diversas localidades de Nueva Jersey, por un lado; restaurantes, tintorerías, venta de flores, trabajo municipal, por el otro).

A lo largo del proceso anterior, una preocupación constante en el equipo fue, lógicamente, la del financiamiento de un proyecto que implicaría para su realización de viajes tanto al estado de Puebla -numerosos-, como a la ciudad de Nueva York y sus alrededores -al menos uno para cada integrante del equipo-. Una pequeña ayuda la obtendríamos de nuestros respectivos centros de trabajo (la UAM y la BUAP); pero requeríamos de más. Decidimos entonces someter nuestro proyecto a la convocatoria del Conacyt. La respuesta favorable a nuestra solicitud, a finales de 1995, nos hizo pensar que el proyecto realmente arrancaba. 


\section{CAPITULO SEGUNDO: EL ESTUDIO DEL MERCADO DE TRABAJO Y LAS MIGRACIONES}

\section{PRESENTACION}

En este capítulo se busca sentar las bases teórico-metodológicas que guiarán la reflexión de la tesis; misma que busca ser un ejercicio ubicado dentro de una aproximación al estudio de las migraciones, desde los territorios limítrofes de la sociología del trabajo y la antropología social. Las fuentes y las discusiones que lo nutren son diversas, pero pueden enmarcarse dentro de dos conjuntos diferenciados, que se articulan de distintas formas, en las propuestas que se retoman.

En primer lugar, se encuentra la línea que lleva de los estudios clásicos sobre migración al surgimiento del enfoque transnacionalista de los flujos migratorios; y en la que se ubica una gran cantidad de desarrollos y discusiones particulares (sobre tipos y causas de la migración, por ejemplo), que a su vez se relacionan tanto con algunas discusiones más generales del campo de la teoría social (como las que se refieren a conceptos tales como espacio social y sociedad, estructura y acción, por ejemplo), como a discusiones ubicadas en el campo de los estudios sociológicos y antropológicos más particulares (como las referidas a la relación entre espacio, territorio, sociedad, nación y Estado; o a nacionalidad y transnacionalidad; o bien a trabajo, familia, comunidad y ciudadanía o pertenencia, por ejemplo).

En segundo lugar, se ubica la línea que ha llevado a la conformación de una propuesta de estudio sociológico y antropológico de los mercados de trabajo, como la que en México han desarrollado Escobar (1997) y Pries (2000), y que pone el énfasis en los procesos de estructuración social de dichos mercados de trabajo, a través del análisis de las instituciones sociales que intervienen como elementos producto-productores en tales procesos. Esta línea parte del reconocimiento de los aportes que han producido los diversos enfoques que se han desarrollado para el estudio de los mercados de trabajo; así como de las muy fuertes críticas y discusiones que se han generado entre las diversas perspectivas, tanto económicas (sobre todo la neoclásica y la institucionalista), como socioeconómicas (como la sociología económica) y de tipo sociológico y antropológico; como las que hacen 
referencia central a los procesos de producción y reproducción -a través de la acción de las personas en su vida social- de los procesos de creación, recreación y transformación de todo el conjunto de actores, procesos, mecanismos, prácticas y reglas, mediante los cuales la sociedad produce al mercado de trabajo, con todo y sus mecanismos de inclusión y exclusión (como la segregación por género, por ejemplo); pero también a través de los cuales el propio funcionamiento del mercado de trabajo produce a la sociedad misma.

Metodológicamente, tanto en el estudio de las migraciones como en el de los mercados de trabajo, se han desarrollado propuestas de investigación que parten de establecer visiones dinámicas, de tipo longitudinal, que permitan aproximarse a los procesos más que sólo a sus resultados; de tal manera que sea posible poner en el primer plano de la atención la acción de los sujetos, insertos por supuesto en marcos institucionales, pero capaces de intervenir activamente en los procesos sociales de estructuración, de la sociedad en general, pero también de sus propias historia laborales en particular. Una importante traducción metodológica de lo anterior, por la que se ha optado en esta investigación, está en la reconstrucción de las trayectorias y las biografías laborales de las personas involucradas en estos procesos.

\section{LA DISCUSION ACTUAL SOBRE EL ESTUDIO DE LAS MIGRACIONES}

Los estudios sobre la migración muestran a nivel mundial un importante reavivamiento en los años recientes. Nuevas características presentes en los flujos migratorios dominantes (Castles y Miller, 1993 y Peña, 1995; Pries, 199 ), así como una revisión crítica de los enfoques que habían sido prevalecientes, acompañada de muy importantes aportes novedosos, son elementos que parecen estar dando lugar a un nuevo mainstream en el estudio de los fenómenos migratorios (Massey, et al, 1993 y Gledhill, 1997).

El complejo fenómeno migratorio -"la movilidad espacial de los hombres" (Tönnies, 1926, citado por: Pries, 1994)-, ha presentado históricamente características cambiantes y ello ha dado lugar al surgimiento casi constante de nuevos problemas de investigación y de amplias discusiones sobre las posibilidades y limitaciones de los enfoques teóricos, los conceptos y las opciones metodológicas que se han desarrollado para dar cuenta de la migración. En los últimos años, esta situación ha cobrado características particulares y 
sumamente prometedoras; especialmente alrededor del llamado enfoque transnacionalista, que en sus mejores propuestas recoge los desarrollos más relevantes de la sociología de la inmigración y de la sociología económica.

Hacia finales de los años ochenta y principios de la década actual, el panorama aparecía menos claro ${ }^{11}$. De hecho, aparecían importantes avances en la crítica a las limitaciones que era posible encontrar en los enfoques dominantes, pero no había aparecido todavía alguna nueva propuesta integradora, capaz de constituirse en una alternativa satisfactoria.

Al respecto, decía Simmons (1991:7) que en el último siglo habían sido tres los caminos que había seguido la investigación sobre la migración. En el primero, los investigadores "volvieron la mirada hacia el pasado, a los periodos históricos anteriores a la industrialización". Más adelante, extendieron sus alcances a "las naciones menos desarrolladas y a los países con tradiciones culturales diferentes a las de Europa y las naciones de ultramar colonizadas por los europeos. El tercer camino seguido consistió en aproximarse a las "tendencias surgidas recientemente, tales como la reversión urbana y la "circulación""'.

Ahora bien, observaba que:

Durante este proceso, los observadores han percibido nuevos fenómenos $e$ interpretado los antiguos de manera novedosa. Los nuevos fenómenos en algunos casos pueden serlo en realidad (surgen de un contexto cambiante), o tratarse simplemente de patrones que existían con anterioridad pero que se han hecho evidentes ahora a la luz de nuevas preocupaciones y conceptos. (...) Cada "nuevo" proceso de migración y su aproximación conceptual ofrecen y plantean desafios a los modelos y enfoques anteriores, lo cual dificulta simultáneamente la integración de perspectivas y conclusiones. (Simmons, 1991, p. 7-8).

Simmons (1991:27-28) adelantaba una observación que sintetiza muy adecuadamente el sentido del cambio en los estudios sobre la migración. El proponía que incluso las metáforas con las que se buscaba expresar las características del fenómeno migratorio se habían trasformado:

\footnotetext{
11 Esto puede constatarse en los principales "estados del arte" elaborados en esos años, como los de Boyd, 1989; Cadwallader 1992; Portes y Börökz, 1989; y Simmons, 1991.
} 
Los cambios recientes en los enfoques dominantes en el estudio de la migración se han asociado con un cambio global en la terminología y en las imágenes de la naturaleza de la migración. Las antiguas metáforas concebían a los migrantes como partes mecánicas (empujados de un lugar, atraídos por otro) que se reacomodaban permanentemente dentro de una gran maquinaria industrial. Las imágenes recientes son más cibernéticas y consideran a los migrantes como partículas flotantes que se mueven hacia atrás y hacia adelante, circulan de un lugar a otro y ayudan a integrar, sostener y cambiar un sistema socioeconómico más fuerte en el que frecuentemente cuentan con escaso poder directo. (Simmons, 1991, p.27-28).

En el contexto de la revisión crítica mencionada líneas arriba, uno de los enfoques que fue más atacado desde el inicio, es el que centraba su atención en los llamados factores de expulsión (push) y de atracción (pull) que las comunidades de origen y de destino de los migrantes presentaban para los actores del proceso (Boyd, 1989; Portes y Börökz, 1989). Como señalaba Mónica Boyd (1989), desde los últimos años de la década pasada, los trabajos sobre migración internacional empezaban con una referencia crítica de rigor a ese tipo de aproximaciones. Se cuestionaba en ellas que la migración era vista como un evento que se presentaba aisladamente, por única vez en el tiempo, mientras que tenía un punto de partida (origen) y un punto final de llegada (destino) claramente ubicables y era realizado por individuos (generalmente de género masculino) que decidían migrar después de haber realizado una evaluación racional acerca de los costos y los beneficios que les proporcionaba dicha decisión.

En consecuencia, los temas principales de las investigaciones sobre migración, se centraban en las condiciones estructurales que habían generado la decisión de migrar (generalmente las asociadas a la pobreza y a la falta de oportunidades de empleo de las zonas rurales de los países atrasados) y en los factores que condicionaban la elección de los lugares de destino de los migrantes (generalmente asociadas a las oportunidades de empleo y a los mejores salarios existentes en las localidades de destino). El otro gran tema de investigación era el que centraba su atención en las modalidades de integración socialización o aculturación- o de no integración -conformación de etnias o de guetos- de los migrantes en las sociedades huéspedes (Portes, 1995).

No se negaba en la crítica, por supuesto, la necesidad de atender a dichos factores y temas. Se cuestionaba tanto el hecho de considerar que la migración era una acción meramente individual y racional (en el sentido neoclásico), como la concepción misma de 
del hecho migratorio como unidireccional, con fechas claras de inicio y de fin, y económicamente monocausado. La evidencia empírica parecía indicar comportamientos diversos y en las investigaciones, por ejemplo sobre los migrantes turcos a Alemania o sobre los caribeños y mexicanos a los EUA, aparecían elementos explicativos de corte más sociológico, que obligaban a relativizar tanto el carácter individual, sólo económicamente causado y plenamente racional de las migraciones, como la posibilidad de delimitar con claridad los momentos de inicio y, sobre todo, del final de las migraciones.

Una propuesta de análisis con profundas raíces tanto en la sociología como en la antropología, reapareció en los intentos de dar cuenta de procesos migratorios en los que era necesario explicar por qué las personas de una misma comunidad, algunas de ellas incluso con posibilidades no tan limitadas de subsistencia, decidían migrar a un mismo lugar y en periodos de tiempo que quedaban aparentemente abiertos hacia el futuro. La elección del momento de iniciar la migración, del lugar de destino (y aun del lugar específico de habitación) y del lugar y tipo de trabajo, no parecían explicarse correctamente si no se tomaba en cuenta el contexto específico de relaciones cotidianas, cara a cara, de los individuos en el seno de las familias, las vecindades y las comunidades.

Las redes de relaciones sociales aparecieron entonces como un elemento fundamental para explicar la existencia de cadenas y aun de sistemas migratorios, en donde las familias, los grupos de amigos y de vecinos y, en fin, los habitantes de una misma comunidad o localidad, decidían cuándo, cómo, con quiénes y a dónde migrar; no a partir de una amplia y exhaustiva información sobre los mercados de trabajo y las oportunidades alternas de ocupación, sino a partir de la información directa, particular e incluso parcial, de las personas conocidas y confiables que ya habían migrado y que eran capaces de ofrecer no sólo información, sino incluso apoyo en el traslado y la subsistencia inicial en los lugares de destino. De esta manera, las redes sociales aparecían como realidades sumamente útiles para explicar aspectos fundamentales del proceso migratorio, tales como su dinámica autorreproductiva (ligada a los procesos de causación acumulativa), su relativa autonomía frente a los elementos de tipo económico que pueden haber estado presentes de manera importante en su origen, y aun su forma particular de generar espacios sociales que estructuran hacia su interior canales de comunicación y de intercambios (Boyd, 1989; Faist, 1995b; Fawcett, 1994; y Portes y Börökz, 1989). 
Tanta importancia conceden algunos autores al papel desempeñado por este tipo de redes, que Portes y Börökz (1989: 614) proponen que:

Más que como un movimiento de un lugar a otro, la migración laboral debe ser conceptualizada como un proceso de construcción progresiva de redes. Las redes conectan a los individuos y los grupos, distribuidos a través de diferentes lugares, y maximizan las oportunidades económicas, por medio de desplazamientos múltiples. La migración laboral es así un recurso a través del cual los trabajadores individuales $y$ sus familiares se adaptan a las oportunidades desigualmente distribuidas en el espacio.

En una apretada síntesis, puede decirse que las relaciones propias de las redes de relaciones sociales cumplen con las siguientes funciones:

1) proporcionan información acerca de las posibilidades de empleo, de las modalidades de traslado, de las formas de sobrevivencia cotidiana, de las particularidades de la vida en el lugar de destino y, en fin, acerca del propio funcionamiento de las redes;

2) ayudan a resistir el costo del proceso (desempleo, traslado, subsistencia, mantenimiento de la familia, instalación);

3) proporcionan contactos con posibles empleadores;

4) ayudan a hacer tolerable "subjetivamente" el choque cultural con un medio desconocido y presumiblemente hostil;

5) ayudan a la construcción del imaginario o la representación colectiva capaz de intervenir en el diseño de estrategias, individuales y colectivas, que ubican la migración como una alternativa viable dentro de las alternativas ocupacionales; y,.

6) por tanto, se constituyen en un elemento de primera importancia para la definición, transformación o adecuación de los proyectos biográfico-laborales- de las personas.

No han faltado críticas, sobre todo en los últimos años, en relación a lo que se ha considerado como una visión exesivamente optimista de las redes de relaciones sociales (p.e.: De la Rocha, 1999; Della Giusta, 2000). Por un lado, se ha señalado que su funcionamiento no es necesariamente armónico, igualitario y cooperativo; sino que puede contener fuertes elementos de conflictividad, jerarquización y competencia. Ya los estudios sobre uno de los componentes centrales de estas redes - esto es, las familias- han apuntado también en esta dirección (p.e.: Salles y Tuirán, 199 ). Por otro lado, desde trabajos clásicos 
como el de Grannoveter (19 ), o más recientes como el de Sässen (1994), se ha señalado también que la pertenencia a cierto tipo de redes puede resultar más bien contraproducente, especialmente en relación al mercado de trabajo, cuando las redes se aislan en relación al resto de la sociedad (prevalecen los lazos fuertes por sobre los débiles) y las personas quedan inmersas en nichos precarios del mercado. En fin, las redes pueden tener también capitales culturales muy pobres (Fernández Kelly, 1994), que dificultan el acceso de sus integrantes a oportunidades sociales deseables. Los señalamientos críticos como los anteriores no hacen, por supuesto, sino enriquecer la perspectiva de análisis.

En su recuento crítico de la producción realizada en el campo de la migración internacional hacia finales de los años ochenta, Mónica Boyd (1989) señala precisamente que las tendencias dominantes indicaban claramente que la investigación en la década de los noventa estaría marcada por la importancia de dos presencias: la que tiene que ver con la dimensión del género y la que tiene que ver con la creciente importancia del análisis de las redes de relaciones sociales. En ambos aspectos le ha concedido la razón el desarrollo de la investigación que se ha hecho en los años noventa.

De hecho, en la actualidad ya nadie discute la importancia de este tipo de redes para la comprensión de los procesos migratorios. En realidad, lo que ahora se discute tiene más que ver con las formas como estas redes sirven como base de estructuración para la conformación de un nuevo tipo de realidades sociales, creadas por la propia migración -por la acción cotidiana de los migrantes- y que se ha coincidido en denominar como transnacionales.

Pero antes de pasar a revisar este nuevo enfoque, actualmente dominante, cabe señalar que existe un muy importante estudio que ejemplifica de manera muy elocuente este nuevo estilo de investigación sobre la migración internacional, que recoge los elementos hasta aquí señalados y que de hecho establece un puente hacia la forma en que el llamado enfoque transnacionalista va a recuperar esos aportes. Se trata del que realizaron Massey, Alarcón, Durand y González (1991), en los años ochenta y que tiene por subtítulo una síntesis de lo que constituye el eje de estos nuevos estudios: "el proceso social de la migración internacional". Su universo se ubica entre algunas localidades del estado de Jalisco, en México, y otras del estado de California, en los EE.UU. En este trabajo se llega a importantes conclusiones teórico-metodológicas con relación a la importancia de las redes 
de relaciones sociales en el proceso de migración internacional. Es interesante también señalar que, aunque no se menciona aún explícitamente el concepto de transnacionalidad, están presentes los principales elementos que caracterizarán a los trabajos que se han realizado después con este enfoque; sobre todo por su énfasis en el carácter indeterminado de la finalización de las migraciones, en el mantenimiento constante de lazos de vinculación (materiales y simbólicos) entre los lugares de origen y los de destino y en el papel estructurante de nuevas realidades sociales desempeñado por las redes de relaciones sociales, que pasan de ser meros elementos posibilitadores de nuevas migraciones a ser verdaderos entramados sociales que, de manera permanente, posibilitan prácticas que dan cohesión a los espacios sociales transnacionalizados.

De hecho, todas las fases que se identifican en el proceso migratorio en esta investigación, son explicadas de manera relevante por el desarrollo del tipo de redes mencionadas. En efecto, se concluye que una vez que la migración ha sido originada históricamente en los cambios de la estructura socioeconómica de las sociedades de origen $y$ destino, se inicia un proceso en el cual las redes de relaciones sociales sirven para apoyar e incrementar el flujo migratorio; de tal manera que el

...proceso social de la migración (...) desarrolla una infraestrucutura social que le permite convertir el movimiento inicial en un fenómeno permanente y masivo. Con el tiempo, los lazos sociales entre las comunidades de origen y las de destino crecen hasta formar verdaderas redes de relaciones que a la larga reducen los costos de la migración internacional. La gente de una misma comunidad queda entrampada en una red de obligaciones recíprocas por las cuales los nuevos migrantes son atraidos y encuentran trabajo en los lugares de destino. El alcance de la red crece a medida que ingresan nuevos migrantes, lo que a su vez consolida el proceso hasta convertir a la migración internacional en un fenómeno masivo. (Ibid., p.13)

Masividad del proceso que tiene directamente que ver con el hecho de que las redes sociales hacen cada vez más accesible la migración internacional y el empleo en otro país, de tal forma que las propias unidades familiares pueden hacer que se convierta en parte de sus estrategias de sobrevivencia:

una vez que las redes sociales se han desarrollado hasta el punto de que un empleo en el extranjero está dentro del alcance inmediato, la migración internacional se convierte en la opción más conveniente para que las familias pobres puedan aliviar las presiones económicas 
causadas por tener un mayor número de dependientes que de trabajadores (p.14)

En este camino, la migración tiende a convertirse en un proceso autosuficiente, en tanto afecta a las comunidades de origen, desde los niveles individuales hasta los que tienen que ver con las estructuras más generales, pasando por las estrategias familiares, en tanto es incorporada la posibilidad de migrar como un elemento factible y activo en el proceso de toma decisiones.

Para apuntalar la mencionada autosuficiencia o autodinamismo del proceso migratorio, intervienen también dos fenómenos complementarios, en los que la existencia de las redes sociales resulta fundamental. Por un lado, en el estudio se constata que (...) aun entre los emigrantes temporales hay un proceso inevitable de establecimiento en el extranjero; y, por el otro, que (...) entre los emigrantes establecidos existe un proceso de migración de retorno (Ibid., p.15). Así, los autores concluyen que:

... no importa que tan temporal puede parecer un flujo de migración; el establecimiento de algunos migrantes dentro de la sociedad que los acoje es inevitable (...). Estos colonos forman comunidades con gran cohesión en la sociedad receptora, lo cual fortalece los lazos con las comunidades de origen, al ofrecer una base firme para el sistema de redes de relaciones sociales y crear un contexto seguro dentro del cual los emigrantes pueden llegar, adaptarse $e$ integrarse(...). (Complementariamente), las redes sociales se mantienen mediante el mismo proceso de emigración y retorno, en el que los emigrantes recurrentes vuelven con regularidad a casa y los emigrantes establecidos regresan habitualmente a sus comunidades de origen. (p. 14-15)

Pero ese proceso de creciente estructuración de las relaciones sociales propias del proceso migratorio, es precisamente el que llevó a plantear a diversos estudiosos que con las nuevas migraciones no sólo se generaban redes sociales capaces de pervivir durante largos periodos, como sustento de una migración autoreproductiva y acumulativamente causada; sino que a partir de dichas redes y de las prácticas sociales desarrolladas regularmente en ellas, se estaban empezando a crear unos espacios sociales de carácter transnacional, dotados de infraestructrura e instituciones propias, en donde los transmigrantes $^{12}$ tenían la posibilidad de mantener unidos de manera constante los lugares

12 Cf. Glick Shiller, et al, 1992. En su ya clásica definición, estas autoras proponen que los transmigrantes son aquellos migrantes que con sus prácticas dan vida a campos sociales que integran sus lugares de origen y destino, pese a la no contigüidad geográfica: "...a new kind of migrating peopulation...composed of those whose networks, activities and patterns of life encompass both their host and 
de origen y destino y de desarrollar en ellos sus proyectos biográfico-laborales ${ }^{13}$; todo ello en el contexto de marcos administrativo-legales propios de Estados nacionales diferenciados e inmersos en profundos procesos de reestructuración ${ }^{14}$.

Una pregunta fundamental que se plantean quienes están trabajando con estos procesos parte de la observación de que estos espacios sociales transnacionales muestran tendencias de convertirse en un fenómeno de carácter no transitorio, sino capaz de trascender en el tiempo y convertirse en una realidad permanente o, al menos, muy duradera.

El enfoque transnacionalista se ha desarrollado principalmente a partir del estudio de las migraciones del Caribe y México, hacia los EUA; pero también ha recibido aportes con base en estudios sobre la migración de turcos hacia Alemania (los sistemas migratorios transnacionales de Faist, p.e.). El inicio de esta aproximación tal vez pueda encontrarse en Rouse (1987 y 1991), quien a partir de sus estudios sobre la migración de oaxaqueños a California, empezó a hablar de "circuitos migratorios transnacionales", para dar cuenta de la existencia de mecanismos permanentes de intercambio de bienes, servicios, personas e información, entre los migrantes, sus lugares de origen y los de destino.

Más adelante, el equipo de investigación de Nina Glick Shiller, Linda Basch y Cristina Stanton Blanc (1992), a partir de sus trabajos sobre la migración del Caribe a los EUA, fueron más allá, al proponer que podía desarrollarse todo un nuevo enfoque o aproximación -transnacionalista- para el estudio de estos fenómenos. Por otro lado, para el estudio de la migración de mexicanos de diversas procedencias a los EUA, la aproximación transnacionalista empezó a convertirse en el eje conceptual. Así, Luin Goldring (1992 y 1997 a y b) lo ha desarrollado con gran creatividad, para migraciones de Zacatgecas a

home societies. Their lives cut across national boundaries and bring two societies into a single social field...Transmigrants take actions, make decitions, and feel concerns whitin social networks that connect them to two or more societies simultaneously" (p1-2)

13 Pries (1995) propone este concepto para dar cuenta de "todas las ideas de 'normalidad' y las prácticas y los planes que tengan que ver con el trabajo y el empleo”. Más adelente se desarrollará esta propuesta con mayor de tenimiento.

14 Esta síntesis de los elementos que componen los espacios sociales transnacionales ha sido propuesta por Pries (1997), en el marco de un proyecto colectivo, en el que participan también Fernando Herrera y Saúl Macías, que estudia la transmigración entre los estados de Puebla y Tlaxcala, en México, y los de Nueva York y Nueva Jersey, en los EEUU. 
California y Robert Smith (1994 y 1997) para la de Puebla a Nueva York. Una propuesta transnacionalista ubicada dentro de la Sociología del Trabajo para el estudio de la migración es la de Pries (1997) y su equipo (Macías y Herrera, 1997), para estudiar la migración de los estados de Puebla y Tlaxcala a la zona metropolitana de la ciudad de Nueva York. En este proyecto, se trata de estudiar las trayectorias y las biografías migratorio-laborales de los migrantes, dentro de los espacios sociales transnacionales que esta migración ha generado, teniendo como guía el análisis de la estructuración institucional de la ocupación (Pries, 2000).

¿Qué caracteriza al enfoque transnacionalista?. En primer lugar, el reconocimiento de que existe un tipo de migración y de migrantes que, si bien pudo haber existido marginalmente en el pasado, se está convirtiendo en dominante en la actualidad. Esta nueva migración, fuertemente asentada en la existencia y consolidación de sólidas redes sociales, tiene un carácter recurrente y oscilatorio y mantiene de manera constante fuertes vínculos, materiales y simbólicos, entre los lugares de origen y las sociedades huéspedes y, más allá de eso, desarrolla infraestructuras, instituciones y formas culturales propias, en el marco de regulaciones y acciones administrativo-legales cambiantes de los Estados involucrados.

En segundo lugar, esta aproximación o enfoque, si bien surgió a partir de evidencias empíricas dispersas y no de una construcción teórica previa, ha evolucionado hasta proponerse en la actualidad como un marco general o un enfoque global para el estudio de las migraciones contemporáneas.

En tercer lugar, los conceptos propios, o apropiados, que ha generado para dar cuenta de los procesos que ha abordado y que informan del sentido del enfoque, pero también de los importantes puntos de debate que se están desarrollando hacia su interior: transnacionalismo, transmigración, transmigrantes, comunidades transnacionales, localidades transnacionales, espacios sociales transnacionales, circuitos migratorios transnacionales, sistemas migratorios transnacionales, familias transnacionales, son algunos de los más importantes.

En cuarto lugar, puede mencionarse un fenómeno que habla de la gran vitalidad y creatividad de este enfoque y que consiste en que está produciendo una buena cantidad de sustanciosos debates propios, entre los que destacan los siguientes: 
a) esas nuevas realidades sociales creadas por los transmigrantes y la transmigración: ¿son comunidades transnacionales, como lo han propuesto Goldring (199 , 1995 y 1997) o Smith (199 , 199 y 199 )? ¿son localidades transnacionales, como más descriptivamente se ha propuesto en otros trabajos (Massey y Goldring)? ¿o bien son espacios sociales transnacionales, como lo han propuesto Pries y asociados (Pries, 1997; Herrera y Macías, 1997)?. La discusión va más allá de las palabras. Quienes proponen el concepto de espacios sociales transnacionales, cuestionan la utilidad y pertinencia del concepto de comunidad, tanto en el sentido de "comunidad imaginaria" de Benedict (199), como en el que más tradicionalmente le ha dado la sociología (por ejemplo, en la distinción entre "comunidad" y "sociedad" de Tonies), para referirse a marcos de relaciones sociales directas, cara a cara y claramente acotadas espacialmente. Goldring (1997), por el contrario, defiende el análisis basado en "comunidades que se transnacionalizan" y que son sólo una de las realidades posibles, dentro de las diversas formas de espacios sociales transnacionales generadas por la transmigración. Pero, en todo caso, argumenta sobre la pertinencia de realizar los estudios a partir de las comunidades de origen y no de países o etnias de manera global. En todo caso, las distintas propuestas se enfrentan a la realidad de la existencia de campos de relaciones sociales unificados, que se desarrollan en espacios sociales que no presentan contigüidad geográfica, sino que sus partes integrantes pueden estar situados a grandes distancias unos de otros (plurilocalizdos).

b) las unidades de análisis más adecuados para el estudio de estos fenómenos se constituye como un debate por sí mismo y parte del reconocimiento de que, en el surgimiento del enfoque, ha habido básicamente dos formas de operar, que plantean niveles de análisis distintos, y tal vez incompatibles, como lo ha observado Goldring (1997). Por un lado, está la forma de trabajo del equipo de Bash, Glick Shiller y Blac Stanton, quienes en sus estudios sobre la migración de países caribeños a los EUA han tomado como universos a países y a etnias completas -e, incluso, a la región caribeña como un todo-, y con esa base han llegado a sus conclusiones sobre el transnacionalismo. Por el otro, está la que se ha desarrollado en los estudios de diversos procesos migratorios de mexicanos a los EUA (Buitrago y Villalón, Goldring, Massey, Smith, Pries y asociados), y que ubican universos acotados por las localidades en donde se origina en México el proceso migratorio, les llamen "comunidades" o no. La primera aproximación ha llegado más rápido a 
conclusiones generales sobre la transnacionalidad; mientras que la segunda ha mostrado una cautela mayor y sólo se permite conclusiones limitadas a los universos específicos a los que se ha abocado; si bien ha intentado establecer comparaciones de los resultados de los trabajos parciales entre sí.

c) otro debate importante tiene que ver con las soberanías estatales, frente a estos procesos que obviamente cuestionan los límites de los estados nacionales y complican el accionar de las autoridades, debido a la itinerancia de los transmigrantes, a sus instituciones transnacionales, al funcionamiento transnacional de su infraestructura y a su crítica relación con las legislaciones y reglamentaciones de los estados involucrados. Aquí el debate se ubica con relación a los límites de la merma de las soberanías estatales sobre los transmigrantes: ¿son estas nuevas realidades sociales transnacionales algo que esté ya siendo, o bien tenga posibilidades de ser, totalmente "desterritorializado" y sustraido a los poderes estatales, como se desprende de la propuesta de Glick, et al? ¿o bien se trata de un nuevo tipo de relación, que aún se está construyendo en procesos de negociación entre los estados y los transmigrantes; en donde estos últimos desarrollan ciudadanías y pertenencias múltiples, o al menos dobles, y una vinculación ambigua en relación a los estados involucrados, sus legislaciones y sus formas de definir precisamente las ciudadanías, nacionalidades, criterios de inclusión y exclusión y ámbitos y sujetos de ejercicio del derecho; pero en procesos en los que los estados realizan esfuerzos que no parecen estar condenados al fracaso para mantener su soberanía, en las nuevas condiciones, sobre los ciudadanos que se han convertido en transmigrantes? Luin Goldring y Robert Smith han insistido, con evidencias muy convincentes, sobre esta segunda opción. Por supuesto, más investigaciones puntuales en este terreno lindante con la sociología política podrán arrojar mejos luz para saldar el debate sobre una realidad que, debe insistirse, está por definir sus características futuras, a partir de la acción tanto de los transmigrantes y sus instituciones propias, como de los estados involucrados y aun de otros actores, como los empleadores y tal vez algunas agencias internacionales.

d) finalmente, y sin pretender que este recuento sea exhaustivo, es preciso señalar la observación que hace Gledhill (1997) acerca del peligro que representa considerar como algo absolutamente nuevo las realidades sociales transnacionales creadas por la migración. Este autor recurre al ejemplo de las migraciones chinas al continente americano -muy 
especialmente, a los EUA-, para argumentar que su existencia puede rastrearse hasta al siglo pasado. En todo caso, parece que el enfoque transnacionalista tendrá que realizar también investigaciones dentro de la sociología histórica para acercarse a una respuesta satisfactoria.

Para finalizar este apartado, resulta pertinente regresar a la propuesta que se hacía más arriba, en el sentido de que los elementos principales del enfoque transnacionalista, abren posibilidades muy interesantes para realizar estudios que integren la migración internacional con la que ocurre dentro de las fronteras nacionales de los diversos países involucrados. Lo anterior, a partir de que es posible pensar en la existencia de espacios sociales interegionales, en los que las redes de relaciones sociales han ido estructurando ese continum social que permite, precisamente, vincular no sólo a través de los medios de comunicación y transporte, sino también a través de territorios intermedios, a los espacios sociales transnacionales que no están vinculados por la contigüidad geográfica.

Puede para esto tomarse el ejemplo de un proceso migratorio muy estudiado, el de los mixtecos oaxaqueños al estado de California; o bien el menos estudiado de los salvadoreños y los guatemaltecos con el mismo destino. En estos casos, puede detectarse que estos espacios interegionales existen, en el primer caso, entre las comunidades de origen del estado de Oaxaca, Ciudad Nezahualcoyotl (junto al Distrito Federal) y Tijuana, Baja California. Y, en el segundo, aunque con un carácter de hipótesis creible, por lo pronto, entre los pueblos de El Salvador y Guatemala, como origen, y diversas comunidades del estado de Chiapas, primero, y los puntos que conectan entre sí los espacios interegionales de los migrantes oaxaqueños, más adelante. Para, en ambos casos, presentarse una integración de dichos espacios sociales interegionales en el espacio social de carácter transnacional generado por la migración. Visto así, puede verse a los espacios interegionales como una dimensión analítica de los espacios transnacionales. 


\section{LA DISCUSION ACTUAL SOBRE EL ESTUDIO DEL MERCADO DE TRABAJO: ¿ENTRE EL DETERMINISMO ESTRUCTURALISTA Y LA PLENA ELECCION RACIONAL?}

En México, como ha sucedido en la mayoría de los paises, para el estudio de los mercados

de trabajo 15 ha existido, sobre todo hasta los años setenta, un monopolio de la economía (un verdadero imperialismo económico), que ha situado en el centro de la atención, en primer lugar, en el análisis de las macro estructuras y, complementariamente, se ha detenido en análisis micro basados en supuestos indivudualistas extremos.

Por un lado, el interés se ha fijado en el comportamiento de las grandes estructuras económicas -y, como interferencia ilegítima, políticas (Misses)-, relacionadas con el empleo, los salarios, la tecnología y, en el centro de todo, el mercado. Por el otro, sobre todo al estudiar los momentos de encuentro entre la oferta y la demanda de trabajo, el interés se ha centrado en el comportamiento racional de los actores individuales; los cuales, dice el planteamiento neoclásico, buscan siempre y en todo lugar y momento la maximización de sus beneficios, a partir de una situación que garantiza la libre movilidad entre empleos y proporciona a los actores información pertinente y confiable acerca de las oportunidades alternas de ocupación.

En esas perspectivas están presentes, como supuesto, dos tipos de actores. En las más individualistas, está el sujeto plenamente racional, que siempre maximiza su utilidad y que sólo se relaciona en forma diádica con individuos igualmente racionales y maximizadores, con quienes no se supone que tenga relación social alguna. Por el contrario, en los enfoques más estructuralistas, el sujeto es visto como totalmente determinado por las estructuras y es, por tanto, incapaz de actuar estratégicamente. Como lo ha hecho ver Granovetter, tanto en la primera de esta visiones, a la que él denomina como infrasocializada, como en la segunda, a la que llama como sobresocializada, el actor en realidad es irrelevante para el análisis, puesto que lo que determina su acción está previamente resuelto por los supuestos del enfoque. En el primero de los casos, se está ante actores que reaccionan de manera automática y siempre racional ante los estímulos que les envía el mercado. En el segundo, ya sea por un proceso de introyección de valores, ya sea

15 Carrillo, De la Garza y Zapata, 1993; Granovetter, 1983; Toharia, 1983 
por tener la conciencia que corresponde a su ubicación en la estructura de clases, el actor tampoco es capaz de tomar decisiones entre múltiples cursos de acción alternativos y excluyentes, dentro de marcos acotados de posibilidades de acción.

Sólo recientemente, en diversos medios académicos 16 , y a partir de diversas orientaciones teóricas, se ha venido perfilando el surgimiento de una aproximación -o, más bien, una serie de aproximaciones- de corte sociológico y antropológico al campo de los mercados de trabajo. En estas aproximaciones, las preguntas centrales dejan de ser aquellas referidas al funcionamiento macro de las grandes estructuras ${ }^{17}$ : empleo, salarios, composición por edad, género y calificación (nacionalidad en muchos casos, sobre todo europeos y norteamericanos); y de cómo estas grandes estructuras se relacionan con los ciclos económicos, las políticas económicas estatales, las estructuras tecnológicas, el comercio internacional, las estructuras sindicales e, incluso, el sistema político.

Ahora, en las nuevas aproximaciones, las preguntas más relevantes giran en torno a los procesos sociales -que preceden y siguen al momento del intercambio (Sassen, 1995)- a través de los cuales se conforman los sujetos, individuales y colectivos, que intervienen, tanto por el lado de la oferta como por el de la demanda, en el funcionamiento de los mercados de trabajo; así como a los procesos sociales mediante los cuales se generan, reproducen y transforman las reglas, normas y prácticas que estructuran dicho mercado. Se trata en estas aproximaciones de ubicar sujetos, prácticas, espacios y momentos de los procesos constitutivos y reconstitutivos de las principales dimensiones de los mercados de trabajo. Y se trata también, lo cual es de suma importancia, de dar cuenta de las formas cambiantes a través de las cuales el mercado de trabajo actúa como un espacio multidimensionado de articulación de diversos procesos centrales para la reproducción y la transformación simultáneas de la propia sociedad como sociedad de clases (Escobar, 19 \}.

En esas propuestas queda claro que no basta con atender exclusivamente a las partes más formalizadas y mercantilizadas de las relaciones laborales, en donde la forma casi exclusiva que asume la ocupación es aquella que está mediada por un contrato formal entre un empleador establecido y un conjunto de trabajadores aslariados. Por el contrario, es

\footnotetext{
16 Pries (2000) hace un amplilo recuento de estos desarrollos y discusiones; Tohaira (19 ) realizó un muy interesante y temprano esfuerzo por presentar las diversas posiciones en disputa.

${ }^{17}$ Eestructura aquí entendida como patrón de funcionamiento, externalidad frente a los sujetos, etc. ; tal como (iddens (1984) señala que lo ha propuesto tradicionalmente el funcionalismo
} 
necesario partir de una noción ampliada del mercado de trabajo y atender también a todas aquellas formas a través de las cuales las personas obtienen los ingresos necesarios para su mantenimiento, mediante la realización de las más diversas actividades y en el marco de una gran heterogeneidad y de formas marcadas por la inestabilidad, la informalidad y la aleatoriedad; ya sea en sus formas posmodernas (por cierto, sumamente difíciles de encontrar en México), ya sea en las múltiples formas tan conocidas y difundidas de precarización del trabajo. Esto implica que el autoempleo, el trabajo familiar, el trabajo a domicilio, el trabajo doméstico, el trabajo a tiempo parcial y el multichambismo, por ejemplo, son tan importantes para el análisis, como los empleos asalariados, dependientes, formales, estables, de tiempo completo, normalizados y reglamentados. No porque en un sentido estricto (Rendón y Salas, 2000) todas estas actividades formen parte del mercado de trabajo; sino porque con su existencia se ven directa e indirectamente afectadas las condiciones de existencia y el funcionamiento del mismo.

De la misma forma, resulta necesario atender a las múltiples formas en que las personas resuelven el problema de la reproducción, personal y familiar; y de cómo éstas se articulan con las diversas formas de ocupación de individuos ubicados en contextos familiares; tal y como lo han propuesto Orlandina de Oliveira y Vania Salles (2000). Esto es, en el estudio del mercado de trabajo, una dimensión de gran importancia es el de la articulación entre el espacio de la producción de mercancías y el de la reproducción de las propias personas que realizan el trabajo, y de las condiciones materiales, sociales y simbólicas en las que dicha reproducción se realiza; dimensión en la cual las unidades familiares y las redes de relaciones sociales resultan ser actores fundamentales.

En estas propuestas, las redes de relaciones sociales 18 en el acceso, promoción, permanencia y salida del empleo, junto con la noción de "calificación social", muy cercana, por cierto, a la idea de conciencia práctica de Giddens (1987), a diferencia de la calificación técnica o profesional, más formalizada, o formalizable, y procesada, o procesable discursivamente, se convierte en un rico y sugerente campo de estudio, en el que debe partirse de lo más micro y cotidiano (los campos de la conducta estratégica: interacción cotidiana en los procesos productivos y reproductivos, dentro y fuera de los lugares de

18 Cf.: Bott, 1990; Granovetter, 1983; Heuz,, 1990; Outin, 1990; Rees, 1966; Requena, 1989 y 1991; Speck y Atteneave, 1974; Boyd, Portes y Börokz; Escobar, Pries. 
trabajo y de los hogares); para intentar articularlo con los elementos más macro (el campo de los marcos institucionales: características del periodo -políticas, económicas, culturales-, forma de los mercados -internos o abiertos, composiciones sociales -genéricas, por edades, etc.-, reglamentaciones legales, acuerdos corporativos, etc.).

Por otro lado, complementariamente, se empieza a desarrollar una metodología de estudio que tiene en la reconstrucción de las trayectorias y las biografías laborales un asidero fundamental. Esta metodología, por cierto, plantea retos importantes; muchos de ellos comunes a las aproximaciones cualitativas e interpretativas: representatividad, necesidad de una doble hermenéutica, por ejemplo.

De hecho, puede hablarse de un verdadero y significativo cambio en los "estilos de investigación" sobre los mercados de trabajo; si por esta noción entendemos, como lo propone De la Garza (1993), una combinación de técnicas y métodos, enfoques teóricos y objetos privilegiados.

\section{LAS INSTITUCIONES ESTRUCTURANTES DE LOS MERCADOS DE TRABAJO}

Para poder escapar de la dicotomía que en muchos momentos se ha tendido a establecer entre la pura determinación estructural y la plena elección racional de los individuos, en la definición de las trayectorias laborales de las personas, se ha recurrido a la creación de conceptos y categorías que buscan dar cuenta tanto de la presencia de elementos estructurales e institucionales, como de espacios en los que la acción de los sujetos tiene posibilidades reales de modificar el curso de la realidad, dentro de márgenes cambiantes en el tiempo y en el espacio.

Se trata sobre todo de reconstruir procesos sociales, a partir de la acción de las personas en el campo de los mercados de trabajo. Personas ubicadas en contextos inmediatos de interacción social y en marcos institucionales generales; y procesos sociales a través de los cuales se conforman los sujetos individuales y colectivos que intervienen, tanto por el lado de la oferta como por el de la demanda, en el funcionamiento de los mercados de trabajo; así como a los procesos sociales mediante los cuales se generan, reproducen y transforman las reglas, normas y prácticas que estructuran dicho mercado. Se trata en estas aproximaciones de ubicar sujetos, prácticas, espacios y momentos de los 
procesos constitutivos y reconstitutivos de las principales dimensiones de los mercados de trabajo.

La importancia del mercado de trabajo como campo de estudio radica en que constituye un espacio privilegiado de articulación de los procesos sociales fundamentales para la producción de la sociedad (Escobar, 199 ). Esto es, de procesos tales como los de producción y reproducción (material, cultural, biológica) de los individuos y los grupos sociales; así como los de producción y circulación de los bienes y servicios como mercancías, y de los géneros, de las generaciones; pero también, lo que es fundamental, de las estructuras de desigualdad de oportunidades, posibilidades y opciones, para las personas y los grupos sociales (desde las unidades familiares hasta los constitutivos de sujetos sociales, pasando por las redes de relaciones sociales y las organizaciones).

Metodológicamente, en la reconstrucción de las historias laborales de las personas, se trata de realizar dos tipos de operación de construcción de sentido: uno que está referido al nivel institucional y otro que lo está al nivel actoral. El primero se refiere, entonces, a las instituciones estructurantes de los mercados de trabajo. Aquí se trata de un sentido atribuido por el investigador, quien interpreta una reconstrucción de eventos objetivos, tales como los que pueden ser captados a partir de la reconstrucción de las trayectorias laborales de los personas (por trayectorias laborales debe entenderse las secuencias objetivas y claramente medibles de personas a través de posiciones ocupacionales). Operación que permite, por ejemplo, observar las formas en que cambian a través del tiempo (de los periodos, de las cohortes) los patrones de movilidad y de inserción de la fuerza de trabajo en la estructura de ocupaciones de la sociedad; y permite observar igualmente, las formas en que las propias instituciones estructurantes de los mercados de trabajo son modificadas debido a esos cambios en los patrones de comportamiento de las trayectorias laborales.

En el segundo, se trata de realizar un análisis de las conductas estratégicas de los actores; esto es, se trata de un sentido atribuido por el investigador a la interpretación que el actor hace en relación a su experiencia en el mercado de trabajo, a lo largo de toda su vida; a partir por ejemplo de las narraciones que pueden obtenerse mediante la reconstrucción de las biografías laborales de las personas (si por biografías laborales se entiende la reconstrucción subjetiva que desarrollan las personas acerca de su pasado, presente y futuro ocupacionales). En esta búsqueda del sentido actoral se intenta crear las condiciones para 
que el actor transite de la conciencia práctica a la conciencia discursiva; en tanto se está suponiendo que los actores son autoreflexivos, capaces de conocer, de interpretar y de decidir, por ejemplo en relación a sus destinos laborales o, más ampliamente, frente a sus posibles proyectos biográfico laborales (Pries,1994). Aunque, por cierto, las consecuencias no prevista de la acción (Giddens, 1984) puedan actuar fuertemente para llevar a los actores hacia situaciones no sólo no deseadas, sino abiertamente rechazadas.

Con relación a los instituciones estructurantes de los mercados de trabajo, deben hacerse algunos señalamientos. Por un lado, es preciso hacer referencia a la existencia de un consenso creciente acerca de la importancia de las instituciones sociales en la estructuración de los mercados de trabajo y de las carreras ocupacionales de las personas (Pries, 2000). Por otro, debe mencionarse la existencia de otro consenso en el terreno más específico en el que se busca identificar cuáles son las instituciones sociales más influyentes en este campo.

En primer lugar está propiamente el mercado: las fuerzas de la oferta y la demanda y su interacción. Ni siquera los críticos más radicales de los enfoques económicos de tipo neoclásico pensarían en negar la importancia del mercado como tal en la estructuración del mundo de la ocupación. Más bien, lo que se busca es ver las diversas formas y grados en que las fuerzas del mercado interactuan con otras fuerzas institucionales en la estructuración de los mercados de trabajo.

A partir de las críticas de los autores segmentalistas y radicales a los enfoques neoclásicos, y a partir también de sus descubrimientos empíricos acerca de la importancia y difusión de los mercados internos de trabajo y de la segmentación múltiple de los mercados, es comunmente aceptado que tanto la empresa y su organización, como la profesión (en algunos casos el oficio) y sus formas de organización, son dos instituciones básicas para la explicación del funcionamiento de los mercados de trabajo.

Por otro lado, a partir de los desarrollos de la nueva sociología económica, y muy especialmente a partir de los trabajos pioneros de Granovetter (p.e., 1973 y 1985), las redes de relaciones sociales aparecen como otra de las instituciones sociales cuya acción resulta de primera importancia, no sólo para entender la estructuración de los mercados de trabajo, sino también para establecer lo que algunas propuestas denominan como los lazos messo (Faist, 199 ), para poder vincular analíticamente el análisis microsocial con el de los marcos 
institucionales más macro, a través de procesos como los de regionalización y rutinización (Giddens, 1984).

Finalmente, en un recuento no exhaustivo, otra institución social que en algunos casos puede ser incluso la más relevante en la estructuración de algunos mercados de trabajo, es la que ha sido resaltada por los estudios sobre la segregación ocupacional (por género, por etnia, por nacionalidad).

Una precisión puede ser necesaria. Con la enumeración anterior no se busca establecer un marco institucional cerrado (o un modelo de análisis institucional cerrado), en el que de manera excluyente estén consideradas todas las instituciones sociales suceptibles de ser consideradas en un análisis de este tipo. Se trata más bien de ilustrar o ejemplificar, con las instituciones sociales más frecuentemente consideradas en los estudios más conocidos, el tipo de institución social que puede ser pertinente en la explicación de los mercados de trabajo.

Ahora bien, para un análisis de las instituciones que intervienen en la estructuración de los mercados de trabajo y las historias laborales de las personas, resulta últil establecer una diferenciación en niveles de análisis, tal que permita referirse, por un lado, a los elementos más abstractos ${ }^{19}$ y permanentes de las instituciones; aquellos que permiten identificar como una misma institución a conjuntos de prácticas sociales, difundidas y persistentes, aunque que puedan mostrar una gran diversidad de formas particulares; pero que cuentan con tipos identificables de reglas y recursos que permiten diferenciarlas de otras instituciones y de prácticas sociales que no pueden ser consideradas como instituciones sociales, debido a su insuficiente difusión y persistencia. Esto es, este nivel se refiere a los elementos que permiten ubicar formas institucionales típicas en los capitales (económico, social, simbólico, cultural, organizacional, por ejemplo), formas de comunicación, de intercambio (por ejemplo, de valores o de información), de simbolización y de interacción.

El otro nivel de análisis que puede ser útil, es el que se refiere precisamente a los elementos cambiantes de las instituciones, en lo que corresponde a sus niveles y formas de influencia (en el tiempo, en el espacio, en la estructura social u ocupacional), a su fuerza, a

\footnotetext{
19 Más abstractos en tanto pueden ser observados analíticamente sin considerar el conjunto de determinaciones que intervienen cuando se analizan situaciones históricas específicas (De la Garza, 198 )
} 
su difusión y a su persistencia, en contextos sociales acotados y en periodos definidos de tiempo.

En el estudio de los mercados de trabajo, lo anterior puede ayudar a pasar del reconocimiento e identificación de las instituciones estructurantes (tales como el mercado, la organización de la empresa, la organización de la profesión o el oficio, las redes de relaciones sociales y la segregación, por ejemplo), a su medición dinámica en universos acotados espacial y temporalmente.

Con relación a los instituciones estructurantes de los mercados de trabajo, deben hacerse algunos señalamientos más. Por una parte, es preciso hacer referencia a la existencia de un consenso creciente acerca de la importancia de las instituciones sociales en la estructuración de los mercados de trabajo y de las carreras ocupacionales de las personas (Pries, 2000). Por la otra, debe mencionarse la existencia de consenso adicional en el terreno más específico en el que se busca identificar cuáles son las instituciones sociales más influyentes en este campo.

En cuanto a este segundo aspecto, en primer lugar está propiamente el mercado: las fuerzas de la oferta y la demanda y su interacción. Ni siquera los críticos más radicales de los enfoques económicos de tipo neoclásico pensarían en negar la importancia de los mecanismos de mercado como tales en la estructuración del mundo de la ocupación. Más bien, lo que se busca es ver las diversas formas y grados en que las fuerzas del mercado interactuan con otras fuerzas institucionales en la estructuración de los mercados de trabajo.

A partir de las críticas de los autores segmentalistas y radicales a los enfoques neoclásicos, y a partir también de sus descubrimientos empíricos acerca de la importancia y difusión de los mercados internos de trabajo y de la segmentación múltiple de los mercados (o bien de las discusiones acerca del llamado sector informal en América Latina), es comunmente aceptado que tanto la empresa y su organización, como la profesión (en algunos casos el oficio) y sus formas de organización, son dos instituciones básicas para la explicación del funcionamiento de los mercados de trabajo.

Por otro lado, a partir de los desarrollos de la nueva sociología económica, y muy especialmente a partir de los trabajos pioneros de Granovetter (o, más lejanamente en el tiempo, de Polanyi), las redes de relaciones sociales aparecen como otra de las instituciones sociales cuya acción resulta de primera importancia no sólo para entender la estructuración 
de los mercados de trabajo, sino también para establecer lo que algunas propuestas denominan como los lazos messo (Faist, 199 ), para poder vincular analíticamente el análisis microsocial con el de los marcos institucionales más macro, a través de procesos como los de regionalización y rutinización (Giddens, 1994).

Finalmente, en un recuento no exhaustivo, otra institución social que en algunos casos puede ser incluso la más relevante en la estructuración de algunos mercados de trabajo, es la que ha sido resaltada por los estudios sobre la segregación ocupacional (por género, por etnia, por nacionalidad).

Una precisión puede ser necesaria. Con la enumeración anterior no se busca establecer un marco institucional cerrado (o un modelo de análisis institucional cerrado), en el que de manera excluyente estén consideradas todas las institucionaes sociales suceptibles de ser consideradas en un análisis de este tipo. Se trata más bien de ilustrar o ejemplificar, con las instituciones sociales más frecuentemente consideradas en los estudios más conocidos, el tipo de institución social que puede ser pertinente en la explicación de los mercados de trabajo.

A partir de lo que se ha visto hasta aquí, resulta coveniente realizar ahora una breve revisión de algunos planteaminetos relevantes de las distintas corrientes que estudian el mercado de trabajo.

\section{LAS DISTINTAS APROXIMACIONES AL ESTUDIO DEL MERCADO DE TRABAJO, SUS SUPUESTOS Y SUS PROPUESTAS}

La historia más o menos reciente del estudio de los mercados de trabajo ha sido, entonces, testigo de una serie de procesos de gran interés para quien se interesa en ellos desde un punto de vista no sólo económico, sino también sociológico y antropológico. A lo largo de estos procesos, han aparecido nuevas preguntas, nuevos supuestos, nuevos conceptos, nuevas formas de aproximación metodológica y nuevas técnicas de investigación. De la misma forma, se ha recurrido creativamente a la integración de propuestas teóricas provenientes de diversos campos afines, tales como la sociología del trabajo, la antropología industrial, los estudios culturales, los estudios organizacionales y los estudios de género. 
En términos generales, puede decirse que ha habido una inclusión progresiva de sujetos o actores con posibilidades reales de acción, de instituciones sociales estructurantes, de tiempo -en un sentido histórico- y de espacio, tanto en el sentido social como en el territorial. Por otro lado, se ha pasado de una visión estática, ocupada en los cortes transversales; a otra de tipo dinámico, que pone su atención en los cortes longitudinales, sin perder de vista la profundidad de los niveles y las dimensiones que intervienen en los procesos.

En un camino que parte de los aportes neoclásicos y de su crítica, los institucionalistas, los radicales, la sociología económica, la sociología del trabajo, la antropología indiustrial y el feminismo, entre otras contribuciones, han generado la base para una síntesis que, además de lo ya mencionado, busca romper con la visión de lo micro y lo macro como niveles de análisis mutuamente excluyentes, para intentar una visión articulada por vínculos messo sociales, en los que las familias y las redes de relaciones sociales juegan un papel central. Como señala Pries (2000), no puede decirse aún que dicha síntesis esté concluida. Sí puede afirmarse, sin embargo, que los elementos que ha aportado esta trayectoria de discusiones teóricas y de trabajo empírico, resultan sumamente estimulantes para emprender investigaciones basadas en sus hallazgos y propuestas.

Lo que se presenta a continuación es un intento de comparación de los distintos enfoque involucrados en dichas discusiones sobre el estudios del mercado de trabajo, a partir del análisis de sus preguntas principales, del tipo de sujeto o actor que involucran, del tipo de capital o capitales que consideran pertinentes para observar los intercambios, de las instituciones sociales que consideran relevantes, así como de las nociones de tiempo y espacio a las que recurren. Todo ello con el fin de elaborar una propuesta de análisis de las trayectorias laborales de quienes conforman la transmigración que se da entre Puebla y Tlaxcala y Nueva York y Nueva Jersey.

\section{El enfoque neoclásico}

Las preguntas centrales de los neoclásicos al estudiar el mercado de trabajo, tienen que ver sobre todo con problemas tales como el crecimiento económico, el equilibrio, los niveles de empleo y los salarios, y la articulación de este mercado particular con el resto de los mercados de la economía. Ante la aparición de problemas o anomalías, algunas de sus 
preguntas han desembocado en algunas de las propuestas más ricas de este enfoque. Por un lado, son las que se relacionan con las posibilidades diferenciadas que tienen los individuos para obtener mejores salarios y mejores posiciones laborales (preguntas a las que se intenta responder con la teoría del capital humano). Por otro, las que tienen que ver con la existencia de ciertas barreras o incomunicaciones dentro de los mercados nacionales (preguntas a las que se busca dar respuesta con la teoría de los mercados locales),

El actor o sujeto que supone la teoría neoclásica es un actor subsocializado, en términos de Granovetter (19 ). Esto es, un actor que no lo es en sentido estricto, puesto que sólo puede actuar reactivamente y en un único sentido: el de la racionalidad plena, que siempre orienta su acción por la maximación de los beneficios: ¿por cuál tasa salarial es deseable sacrificar el ocio?, sería la pregunta rectora de la negociación en el mercado de trabajo.

Cabe precisar, para este y para los demás items, que la teoría neoclásica de los mercados de trabajo (De la Garza, 2000) es prescriptiva o normativa, y no descriptiva en un sentido empírico. Para no intentar críticas sólo externas a esta teoría, es preciso tener esto en cuenta y comprender que plantea que sólo a partir de sus supuestos se cumplen sus predicciones.

El sujeto considerado, por lo demás, es atomístico y establece únicamente relaciones diádicas con otros sujetos a los que no conoce previamente y a quienes no va a tratar después (o bien, si eso sucede debe ser irrelevante para la transacción). Es por otro lado un actor que no puede influir en el precio de la mercancía que vende (que es trabajo, no fuerza de trabajo como para los marxistas), porque éste está determinado, de acuerdo con la teoría marginal, por la productividad de la última persona empleada (y en función de los diferenciales de capital humano de cada persona); pero es también un actor cabalmente informado de los distintos salarios de la economía y de todas las oportunidades alternas de empleo

El tiempo que toman en consideración los neoclásicos es un tiempo no histórico ni estructurante de lo social. Es el tiempo micro de las ecuaciones diferenciales. En relación al espacio se presenta una situación particular. Esta noción es introducida al análisis, a partir de la constatación de la existencia empírica de espacios de interacción económica diferenciados entre sí -los mercados locales- al interior de una misma economía nacional. 
Sin embargo, esta diferenciación espacial de los mercados no conlleva ningún supuesto de particularidad en el funcionamiento de cada uno de ellos. Por el contrario, el supuesto rector consiste en que todos y cada uno de los mercados locales funcionan hacia su interior de manera exactamente igual que el resto.

De gran interés resulta el planteamiento acerca del capital humano, suceptible de ser intercambiado por el capital propiamente económico. Las personas, dice esta propuesta, tienen posibilidades diferenciadas de acceder a mejores salarios y posiciones de trabajo, en función de las cantidades de dinero y tiempo que han invertido en su propia formación, a lo largo de sus vidas, tanto dentro como fuera de los sistemas escolarizados formales, y aun dentro de sus propias labores productivas.

Todo lo que se oponga al funcionamiento del mercado de trabajo bajo los supuestos anteriores (Estado, sindicatos, monopolios, monopsomios), son elementos extraeconómicos que deben ser evitados.

\section{El enfoque segmentalista y su derivación radical}

Los aportes segmentalistas (también denominados neo-institucionalistas) al estudio de los mercados de trabajo parten de una crítica al modelo neoclásico, a partir de la constatación de hechos empíricos cuya explicación neoclásica no se considera satisfactoria. En especial, la existencia de elementos de segmentación de los mercados, relacionada con la influencia de las formas de organización de las empresas, lleva a los institucionalistas a introducir elementos de análisis sociológico en el estudio de los mercados de trabajo.

Las empresas generan, dice este enfoque, mecanismos administrativos internos que sustituyen en condiciones específicas a los mecanismos propiamente de mercado, en los procesos de reclutamiento y de asignación de las personas a los puestos de trabajo. Esto es, se conforma una suerte de mercados internos de trabajo, cuyo ámbito de acción es sustraido a la libre competencia. Como consecuencia, en la economía se forma un mercado dual o segmentado, que ofrece un sector primario (externamente no competitivo, tecnológicamente avanzado, y caracterizado por altos niveles relativos de remuneración, prestaciones, estabilidad y posibilidades de desarrollo) y uno secundario (abierto a la libre competencia y en donde prevalecen tecnologías atrasadas, bajos salarios relativos, una 
ausencia de prestaciones, la precariedad y el estancamiento laboral), que no está dinámicamente conectado con el primario.

Un tercer sector puede estar presente hacia el interior de las empresas; lo que establece un nivel más de segmentación. Es el sector compuesto por profesionales y técnicos de alto nivel, al que los trabajadores de cuello azul no tienen posibilidades de acceder y cuya estructuración incluye la acción de otra institución social con posibilidades estructurantes: la organización de las profesiones y, en ciertas condicones, de los oficios.

Las preguntas de los institucionalistas, entonces, están enfocadas hacia el campo de las imperfecciones del mercado; y, especialmente, hacia su segmentación (doble o triple) y hacia la conformación y formas de funcionamiento de los mercados internos de trabajo. Una pregunta importante que se plantean los institucionalistas, en debate con los neoclásicos, es sobre la relevancia de la categoría de capital humano como categoría explicativa fundamental.

El sujeto que suponen los institucionalistas (Piore, 19 ), aunque difiere en mucho del sujeto neoclásico, está lejos de ser un actor en sentido estricto. Por su pertenencia de clase -media o baja-, está cargado de valores que ha introyectado y que determinan su acción en la mejor tradición parsoniana. En términos de Granovetter, se trata de un sujeto sobresocializado que, por lo demás, también busca la maximación del benefico económico. De hecho, los grandes actores en esta perspectiva son, por supuesto y la igual que en la perspectiva neoclásica, las fuerzas del mercado; pero ahora complementadas (corregidas, desviadas, reorienteadas) por las organizaciones o instituciones (empresas, profesiones), que pueden influir realmente en el funcionamiento de los mercados de trabajo.

Tanto el tiempo como el espacio son abordados en esta perspectiva con un mayor contenido social que en la visión neoclásica. Por un lado, hay una diferenciación de diversos espacios sociales de acción, que son los correspondientes a los distintos segmentos de los mercados de trabajo (los espacios internos de la empresa, los del entorno competitivo). Pero, por otro, se presenta el supuesto de un funcionamiento homogéneos de estos espacios hacia su interior, independientemente de los cambios por ejemplo regionales.

En cuanto se refiere al tiempo, puede observarse su relevancia, más allá de su intervención como variable en la medición de la velocidad de los procesos, al menos en dos campos. Uno, macro, es el de la evolución de la tecnología (fundamental en el 
planteamiento neo-institucionalista para explicar la segmentación; elemento exógeno para el enfoque neoclásico). Otro, micro, se presenta en relación a las trayectorias laborales individuales y a las cadenas de ascenso de los trabajadores, dentro de los mercados internos de trabajo. Elemento este último que puede referir a una noción de tiempo organizacional, no desligado de la de capital organizacional, que resulta de gran utilidad para comprender el contenido de los intercambios dentro de un mercado de trabajo regido por normas administrativas y no solamente de mercado.

Los conocimientos específicos acerca del funcionamiento, formal e informal, de las empresas y las profesiones, el tiempo transcurrido dentro de la empresa o grupo profesional y la posición alcanzada dentro de los escalafones del mercado interno de trabajo, serían algunos de los elementos a considerar como componentes centrales de este capital organizacional, suceptible de ser intercambiado por otro tipo de capitales en el mercado de trabajo.

Cabe señalar que, pese a que los segmentalistas desarrollan buena parte de sus argumentos en debate contra la propuesta neoclásica del capital humano, los componentes señalados muestran la importancia que este enfoque brinda a los conocimientos adquiridos por los trabajadores, tanto formal como informalmente; si bien estos son mayormente especificados e incluyen conocimientos que se adquieren y utilizan no sólo en relación directa con el trabajo, sino también en el ambiente sociocultural de la empresa y el medio profesional. No parece exesivo ligar esta noción a la de capital cultural de Bourdieu, con su parte dura u objetivada, ligada a la educación formal, y su parte más suave, relacionada con la que se obtiene de la vida en sociedad (habitus).

Una variante de la propuesta neo-institucionalista es la que formulan los autores autodenominados radicales, como Edwrds, Gordon y Reich ${ }^{20}$. A diferencia de Piore, que ubica su análisis de la segmentación en los espacios micro de las empresas y que ubica a la tecnología como el factor determinante, los radicales centran su atención en los espacios macrosociales de la lucha de clases y consideran que la segmentación de los mercados de trabajo es una estrategia del capital para dividir a los trabajadores y debilitar sus posibilidades de acción. Así, introducen como actores a las organizaciones de clase, como

\footnotetext{
20 Varios modelos de segmentación del mercado de trabajo se han realizado a partir de esta propuesta. Llamas destaca los siguientes:
} 
los sindicatos y, en su perspectiva, el Estado, junto con las fuerzas del mercado y las empresas (vistas más como parte del capital que como actores individuales). Nuevamente, se está ante un actor sobresocializado, en este caso por su pertenencia de clase, determinado estructuralmente y, por tanto, sin posibilidades de actuar con algún margen de libertad.

Las preguntas en esta variante neo-institucionalista se dirigen también al terreno de las imperfecciones de un mercado segmentado y cuyo funcionamiento puede ser influido por la acción de los macroactores sociales. Esto es, se trata de un mercado intervenido política y organizacionalmente, que debe ser estudiado en función de los efectos que la lucha clases tiene sobren su estructura.

Esta propuesta establece, en cuanto al espacio, una diferenciación de espacios sociales de acción. Al tiempo organizacional de la primera propuesta institucionalista, agrega una noción de tiempo histórico, estructurante de lo social, relativa a las largas duraciones de la lucha de clases. En cuanto a los capitales que entran en juego, implícitamente conceden una importancia central a lo que puede denominarse como capital político, y que es puesto en juego por actores tales como los sindicatos, los empresarios y el Estado.

En América Latina, las propuestas ligadas al enfoque segmentalista se han referido básicamente a las discusiones sobre el llamado sector informal de la economía, que se ha asimilado a la noción de mercado secundario; aunque, como afirman Rendón y Salas (2000), la expresión “sector informal” constituya más bien un concepto sin teoría.

\section{La sociología económica.}

Esta aproximación al estudio de los mercados de trabajo plantea de entrada que sólo para fines analíticos puede presentarse lo económico como desligado de lo social. A partir de la categoría de embededness, propone que toda acción económica está necesariamente contenida o entremada en interacciones sociales 21 . En este sentido, representa una verdadera sociologización del análisis de los mercados de trabajo; que pone el funcionamiento de las redes de relaciones sociales en el centro de la estructuración de los intercambios involucrados en los procesos de reclutamiento, remuneración, asignación a

\footnotetext{
21 Aunque, como señala el trabajo clásico de Polanyi ( ), en la sociedad de mercado, aparecca que lo económico enguye a lo social.
} 
puestos y movilidad de la fuerza de trabajo en el mundo de la ocupación. No se trata por supuesto de que se niegue la presencia de las fuerzas propiamente de mercado, ni tampoco la acción de las fuerzas organizacionales que enfatizan los institucionalistas; de lo que sí se trata es de incluir todos los elementos que intervienen en el funcionamiento de los mercados de trabajo en un marco analítico que reconozca el carácter social de los intercambios económicos; lo cual supone partir de una noción distinta del sujeto, del tiempo y del espacio.

El sujeto en este caso sigue siendo racional, pero no en el sentido neoclásico estricto, porque puede ver influida su acción por elementos no económicos, como los de carácter afectivo o los que tienden a cumplir con los compromisos sociales que están en la base del capital social (lealtades, reciprocidades). En este sentido, puede ser un sujeto maximizador, pero no en relación a una ganancia necesariamente económica, sino que ésta puede ser también social o simbólica. Por otra parte, es un sujeto que no está totalmente determinado por las estructuras, sino que es capaz de actuar dentro de ciertos margenes de libertad y constreñimiento. En términos de Granovetter, no es un sujeto ni infra ni sobresocializado.

Otra característica distintiva importante de este sujeto, es que no actúa de manera atomística ni establece únicamente relaciones diádicas; sino que por el contrario, existe socialmente en un campo de interacciones múltiples y recurrentes, que suponen no sólo el conocimiento cercano de los individuos con quienes realiza los intercambios, sino también el conocimiento de las reglas sociales de funcionamiento de los espacios sociales acotados en los que se desenvuelve. De hecho, el actor en esta perspectiva es tanto individual como colectivo. Son individuos inmersos en redes múltiples de relaciones sociales quienes realmente intervienen en los mercados de trabajo. Con la posibilidad, además, de influir efectivamente en el funcionamiento de los mismos.

De tal manera que la pertenencia a estas redes de relaciones sociales resulta determinante para el desempeño de las personas en los mercados de trabajo; ya sea en un sentido positivo -redes con múltiples conexiones débiles, con capitales culturales de buena calidad-, ya lo sea en uno negativo -redes enclustradas, con pobres capitales culturales-. La información acerca de los empleos posibles, las recomendaciones para ingresar al trabajo, las posibilidades de ascenso, las protecciones contra el despido, el acceso a la capacitación 
y la movilidad ascendente, son algunos de los principales elementos que en esta propuesta están estructurados -aunque no de manera exclusiva, porque las fuerzas del mercado, de la organización y de las profesiones, por ejemplo, siguen actuando- por el funcionamiento de las redes de relaciones sociales.

El tiempo cobra una importancia central dentro de esta aproximación al estudio de los mercados de trabajo; tanto en un sentido macro, como elemento estructurador de lo social en una perspectiva histórica; como también en un sentido messo y micro social, en tanto que el énfasis está puesto en los procesos sociales involucrados en las relaciones que se desarrollan en el mundo del empleo y que, como señala Sassen (1995), anteceden y siguen al momento del intercambio de la oferta y la demanda .

El espacio es igualmente de gran relevancia para esta propuesta. Las redes de relaciones sociales son espacios sociales diferenciados que, si bien tienen elementos en común, están fuertemente determinados por sus características particulares, relacionadas por ejemplo con la clase social, la ubicación geográfica o el contenido nacional o étnico. De hecho, la extensión social y territorial de la redes tiene fuertes implicaciones para el desempeño de sus integrantes en los mercados de trabajo (en el caso de las migraciones esto es de primordial importancia).

El capital relacional o social es la principal posesión que pueden tener las personas en esta perspectiva. El número, la cantidad y la calidad de contactos sociales, son la base de un capital que, aunque puede intercambiarse por los elementos típicos de intercambio de otros capitales -dinero, posición social, certificados o credenciales, reconocimiento social, ubicación dentro de algún escalafón, por ejemplo-, depende para su sobrevivencia y acrecentamiento, del cumplimiento de rituales y de mecanismos de tipo informal, basados en la costumbre, la lealtad, la reciprocidad y el acatamiento de las normas que son consideradas como legítimas hacia el interior de las propias redes de relaciones sociales. Lo cual, como ha señalado González de la Rocha (1999), implica también un elevado costo, que llega a imperdir, en determinadas condiciones, que la posesión de contactos sociales pueda convertirse efectivamente en capital social.

Como consecuencia lógica de lo anterior, el mercado de trabajo no es visto por la sociología económica como un ente que se autorrgule automáticamente, sino como una compleja institución social, cuyo funcionamiento depende de la acción de las personas y 
sus mundos de interacción, tanto como del funcionamiento de las instituciones sociales, como el mercado o el Estado, por ejemplo. La información sobre el mercado de trabajo no está a la libre disposición de todas las personas de manera igualitaria, sino que, en gran medida, es patrimonio de los grupos sociales; esto es, forma parte del capital social de las redes de relaciones sociales, tanto en los mercados competitivos, como en los mercados internos de trabajo.

Una importante aportación particular que se ha realizado desde la sociología económica, es la reformulación que ha hecho Sassen (1995) en relación a los mercados locales de trabajo, en debate con las propustas neoclásicas, como la de Borjas ( ), sobre los mercados locales de trabajo a los que tienen acceso los trabajadores migrantes en los Estados Unidos. En la propuesta de Sassen, los mercados locales pueden ser incluso transterritoriales (transnacionales también) y no presentar una contigüidad territorial entre las múltiples localizaciones territoriales en las que se asientan. Por otro lado, en ellos no son las diferencias en la calidad del capital humano de los trabajadores lo que explica su ubicación en determinados mercados locales de trabajo, sino más bien su pertenencia a redes de relaciones sociales.

\section{La perspectiva segregacionista.}

La evidencia empírica acerca de la existencia de situaciones claramente diferenciadas para distintos grupos sociales, en función del sexo, la nacionalidad, la étnia, la preferencia sexual, la religión e, incluso, la edad, llevó a la formulación de fuertes críticas hacia las distintas explicaciones existentes sobre el funcionamiento de los mercados de trabajo. En relación más o menos directa con la emergencia de movimientos sociales, ligados a diversos grupos sociales que se reconocían como víctimas de diversos procesos de discriminación, surgió la propuesta de analizar dichos mercados teniendo en cuenta no sólo la presencia de las fuerzas del mercado, de las formas organizacionales de las empresas, de los mecanismos organizativos de las profesiones y los oficios y de las redes de relaciones sociales; sino considerando también la existencia de múltiples estructuras sociales de segregación. A la segmentación, había que agregar la segregación. A las redes de relaciones sociales, y muy especialmente a las de tipo familar, debía dejar de vérseles como sólo armónicas e igualitarias, para reconocérseles como ámbitos de interacción social abiertos 
también al conflicto y a la jerarquización; y como instituciones que actuan de manera importante en la reproduccción de las estructuras de dominación y exclusión de la sociedad, en general, y en el mundo del trabajo, en particular.

En las aproximaciones al estudio de los mercados de trabajo que consideran la segregación, se está ante las formas más sociologizadas de análisis. El tipo de actor que se supone, es tanto indivudual como colectivo; se concibe a las personas inmersas en contextos familiares, que a su vez lo están en contextos sociales (redes, grupos de pares, organizaciones voluntarias). Si existe alguna forma de determinismo, éste está lejos de ser de tipo económico. Como lo han señalado varias apreciaciones críticas, el sesgo determinista aparece en estas visiones como determinismo cultural, en relación con las estructuras que preservan las reglas de inclusión y de exclusión social. La racionalidad, por otra parte, está presente en los actores, pero no es la racionalidad puramente instrumental de los actores económicos del modelo neoclásico; sino que es una racionalidad que puede obedecer a distintas lógicas, ya sea de tipo trascendental, ya sea de tipo comunicativo. Lejos de ser la información un bien distribuido igualitariamente entre las distintas personas involucradas en los mercados de trabajo, y más allá de ser una parte del capital organizacional, en las empresas, o bien del capital social, en el mundo de las redes de relciones sociales; se convierte en estos enfoques en un bien acotado por las estructuras de segregación social.

Directamente vinculado a los procesos de reconocimiento y valoración sociales, el capital cultural es el más relevante en los mercados de trabajo. La jerarquización social de las posiciones, conforme al sexo, la edad, la nacionalidad, la etnia, la prefrencia sexual o la religión, explican mejor que los haberes educacionales, por ejemplo, las posibilidades de acceso al trabajo y a los mejores sitios en la estructura de remuneraciones. La calidad del capital social y la cuantía del económico pueden, sin embargo, atenuar la fuerza de las presiones discriminadoras o excluyentes.

El tiempo cobra una posición central en estos enfoques, en tanto su énfasis, al igual que en los de la sociología económica, se centra en los procesos sociales y no sólo en sus resultados. De hecho, sus planteamientos requieren de una diferenciación entre distintos tipos de tiempo, por ejemplo, entre uno individual (en donde el tiempo es el de la edad y de las trayectoria de trabajo de las personas), otro relativo al ciclo familiar (en los procesos de 
socialización y de reproducción de los estereotipos de género y generación) y otro más referido a las largas duraciones de los ciclos sociohistóricos (en donde pueden incubarse las grandes transformaciones sobre dichos estereotipos y sobre las estructuras de discriminación y exclusión).

El espacio también resulta fundamental para los análisis que enfatizan la segregación para el estudio de los mercados de trabajo, tanto en un sentido social, como en uno geográfico o territorial. En el primer sentido, cobra importancia el análisis de los espacios sociales diferenciados en donde se producen, reproducen y transforman los ya referidos estereotipos culturales relativos al género, la etnia, la religión, la edad, la preferencia sexual y la nacionalidad. En el segundo, resalta la importancia de las diferencias, a veces sumamente importantes, que se presentan al comparar entre sí las muy diversas estructuras, nacionales o regionales, de discriminación y exclusión social.

Se está en estos enfoques, entonces, ante una noción de mercado sumamente distinta a la del punto de partida neoclásico. Aquí no hay automatismo alguno que regule armónicamente su funcionamiento; sino que son más bien los conflictos, los consensos y las negociaciones de los actores, a muy distintos niveles de agregación, los que van determinando con su acción las características de este espacio social de lucha y acuerdo, entre quienes ejercen la segregación o se benefician de ella, y quienes ven limitadas sus posibilidades de acción y desarrollo, precisamente por su existencia..

\section{La importancia de la noción de capital: un elemento compartido por lod distintos enfoques}

Como puede verse en la exposición anterior, un elemento fundamental para entender el funcionamiento de las distintas insituciones sociales estructurantes de los mercados de trabajo, radica en la noción de capital, que se convierte en un instrumento básico de expresión para los elementos propios de cada una de las mencionadas instituciones.

La utilización del concepto de capital, en este contexto, hace claramente referencia en varios sentidos a la noción marxista de capital; si bien de una manera heterodoxa y, en algunos caos, casi metafórica. Como en la noción marxista de capital, lo importante es ver a los diversos tipos de recursos con los que cuentan las personas como elementos objetivos que potencialmente puden convertirse en capital; pero que no lo son por sí mismos. Así 
como en la propuesta marxista el dinero no es por sí mismo capital, sino que sólo deviene en éste cuando se destina a la adquisición de medios de producción y fuerza de trabajo que serán utilizados en el proceso productivo, en estas propuestas sucede otro tanto; sobre todo en los desarrollos realizados a partir del concepto de capital social (Bordieau, Coleman), en donde se enfatiza el carácter virtual de los contactos sociales de las personas, como base objetiva que sólo en su actualización en las relaciones sociales puede convertirse en capital.

Así, los capitales son básicamente formas de relacion social, como en el marxismo, y no meras posesiones de bienes materiales, relacionales, posicionales o simbólicos. Además, y también como en la propuesta marxista, estos capitales pueden ser valorizados (haciendo que como valor produzcan más valor; si bien la categoría de plusvalía resultaría sumemente problemática en este contexto), a través de su puesta en práctica; o sea de su actualizacion en relaciones de producción de diversos productos sociales, por ejemplo en el mercado de trabajo. Pueden igualmente ser intercambiados por las formas de materialización de los demás capitales (dinero, como recurso del capital económico, por conocimiento, como recurso del capital humano, por ejemplo); y pueden ser acumulados por las personas, tal como lo propone Bordieu, mediante diversas composiciones de capital, que varían a través del tiempo y de las acciones y las relaciones sociales.

Entre los diversos capitales que resultan pertinentes para el estudio de los mercados de trabajo,en esta perspectiva, destacan los siguientes:

a) el capital económico, que se materializa básicamente en el dinero y sus múltiples equivalentes (posesiones materiales, productivas o improductivas); y que se relaciona sobre todo con el mercado como institución social;

b) al capital humano, que se expresa a través del conjunto de conocimientos adquiridos por las personas, tanto en los sistemas escolares formales, como en la práctica laboral misma; y que se relaciona también de manera destacada con el mercado como instiución social;

c) el capital organizacional, que se manifiesta en la posición que las personas tienen dentro de los dispositivos organizacionales de las empresas y en el conocimiento que esas personas poseen acerca de los mecanismos (formales e informales) de funcionamiento de las mismas; y que se relaciona 
fundamentalmente con la organización de la empresa como institución social estructurante;

d) el capital político; que se materializa en el poder relativo que las personas tienen dentro de determinadas situaciones de correlación de fuerzas (por ejemplo, en las negociaciones en los mercados de trabajo, entre empresarios y sindicatos); y que se relaciona también con la organización de la empresa como institución estructurante; pero igualmente con la posible acción del Estado (sobre todo, cuando existen pactos corporativos en la sociedad; o bien formas autoritarias de gobierno);

e) el capital social, que se condensa en los contactos y relaciones sociales de las personas (familiares, amistosas, vecinales, etc.), en la forma de lazos sociales, tanto fuertes como débiles, tanto enclaustrados como abiertos, refiere al campo de las relaciones que las personas establecen con los demás a partir de su interacción cotidiana, reiterada, cara a cara, con base en vínculos de solidaridad, lealtad y reciprocidad (sin que esto excluya posibles conflictos y enfrentamientos); y que es base objetiva de la institución social relativa a las redes de relaciones sociales o clanes;

f) el capital cultural, que tiene, de acuerdo a Bordieu, tanto una parte objetivada (muy similar al capital humano, por cierto), que refiere a la educación y a la capacitación recibida por las personas, como uno no objetivada (habitus), relativa al aprendizaje informal que las personas reciben a través de sus procesos de socialización y que está muy marcada por el origen y la trayectoria social de las personas; y que, como el capital simbólico, se relaciona prácticamente con todas las instituciones estructurantes de los mercados de trabajo; pero que tiene su principal relación con las instituciones sociales que intervienen en los esquemas de discriminación o segregación, basados en el género, la etnia, la nacionalidad o la edad, por ejemplo.

g) el capital simbólico, finalmente, refiere a las formas en las que las personas son valoradas o apreciadas por el resto de las personas en una sociedad determinada; esto es, a las formas en que se manifiesta el prestigio social acumulado por alguien y que refiere, a su vez, a los procesos sociales de generación de 
legitimidades como formas colectivas de estructuración de juicios de valor. Por su naturaleza, este tipo de capital no se relaciona de manera preferencial con ninguna institución social particular; sino que está presente en el funcionamiento de todas ellas

\section{LOS PROYECTOS BIOGRAFICOS LABORALES Y LAS REDES DE RELACIONES SOCIALES.}

Para abordar el estudio de lo que se plantea, este trabajo propone algunas reflexiones a partir del concepto de proyecto biográfico laboral que ha propuesto Ludger Pries (1994), para el estudio sociológico de los mercados de trabajo. Este concepto tiene la virtud de reconocer tanto los elementos de racionalidad, como los no meramente racionales de la acción social, y es un intento por establecer vínculos metodológicos entre los niveles micro y los macro en los procesos de estructuración ligados al mundo del trabajo. Por un lado, por

proyecto biográfico, Pries entiende "las ideas y nociones de normalidad de la secuencia temporal y material de las diferentes fases de vida...y las prácticas y los planes de vida correspondientes de los actores", de tal forma que la propuesta busca "integrar cosas muy diferentes en dos dimensiones: en el eje del tiempo combina lo pasado, lo presente y lo futuro y, en el eje de la relación actor-sociedad, integra la estructura social histórica, tal y como es percibida e interpretada por el actor, como base y constreñimiento de sus planes y acciones individuales". En un nivel de mayor especificidad, entonces el proyecto biográfico laboral refiere a "todas las ideas y nociones de normalidad y las prácticas y los planes que tienen que ver con el trabajo y el empleo".

Paralelamente a lo anterior, se ofrecen algunas reflexiones sobre las posibilidades del análisis de redes de relaciones sociales, como posibilidad metodológica útil dentro de la propuesta anterior. Ello, a partir de un énfasis en la noción de legitimidad, entendida ésta como un proceso social de estructuración colectiva de juicios de valor, dentro de una propuesta de análisis de lo cultural como conjunto de procesos de estructuración colectiva de significaciones, de constitución también social de contextos de significados o redes de significaciones, y de formas colectivamente legítimas (e ilegítimas) de atribución de sentido; todo ello ubicado en el tiempo (necesariamente transgeneracional) y en el espacio (en este caso, no necesariamente en territorios contiguos, sino en espacios vinculados entre 
sí de manera simbólica o imaginaria, aparte de su vinculación mediante intercambios materiales).

Ya se ha dicho que dentro de estos nuevos estilos para la investigación sobre los mercados de trabajo, tanto nacionales como transnacionales, se han elaborado propuestas que buscan romper tanto con el determinismo estructuralista que niega al sujeto, como con el individualismo metodológico que niega la relevancia o la existencia de las estructuras. Una de estas propuestas ubica la noción de proyectos biográfico laborales como base de un estilo de investigación que, en lugar de dar por sentada alguna hipótesis fuerte acerca de los que los sujetos deben hacer, se pregunta por las formas de constitución de los sujetos, en condiciones históricas específicas. Esto es, se pregunta por los espacios, las prácticas y los momentos en los que se van constituyendo identidades y subjetividades colectivas, capaces de dar lugar a proyectos y capaces también de constituir formas comunitarias para la realización de tales proyectos.

Así, puede pensarse, como una especie de guía heurística, en la presencia de una "ruta crítica" en la elaboración de tales proyectos. Ahora bien, dentro de tal "ruta crítica" pueden ubicarse los siguientes puntos analíticos y secuencias construidas analíticamente, para intentar dar cuenta de un proceso constantemente reiniciado y con elementos en constante interacción y mutua retroalimentación; a través de los cuales no se pretende proponer hipótesis acerca de qué es lo que se espera encontrar, sino con los que se busca formular preguntas abiertas para intentar la reconstrucción de los procesos. No se trata, y esto es muy importante, de suponer que las personas tengan una elaboración previa altamente codificada y lista para ser transmitida al investigador; sino que se trata de encontrar los mecanismos y los momentos adecuados para facilitar que el proceso de elaboración pase de un estado, por así decirlo: latente, a otro en el que se construya una expresión discursiva que permita la mutua comprensión:

-un primer momento o punto analítico tiene que ver con el reconocimiento, individual y colectivo (sobre todo en las unidades familiares y en las redes sociales en las que se está inmerso), de las necesidades (tanto materiales como afectivas), aspiraciones y preferencias que se tienen; así como de la jerarquizaciones que de éstas realizan las personas; 
-junto con lo anterior, el siguiente punto refiere al reconocimiento, también, de los medios y de los recursos (humanos, materiales, simbólicos, relacionales) con los que se cuenta -o bien los que habría que adquirir- para la consecución de los bienes y servicios que se han reconocido como deseables, y a las formas que se consideran como viables para su consecusión;

-otro punto analítico se refiere al proceso de asimilación de dos tipos básicos de experiencia (ya sea la experiencia propia o bien la de las personas más cercanas): la que se vive en las relaciones cotidianas, acotadas, cercanas y más o menos permanentes, y la experiencia vivida en otros mundos de vida, tales como el de la ocupación (incluyendo, por supuesto, la dimensión migratoria cuando esta se hace presente), el mercado, la religión, el deporte y las diversas formas de participación en actividades colectivas, sean o no de contenido directa o abiertamente político;

-el punto siguiente propone que existe un proceso de elaboración, a partir de las experiencias referidas en el punto anterior, de representaciones, tanto individuales como colectivas, acerca del mundo de la ocupación (incluida la migración), del mundo del mercado y, en general, de los demás mundos de vida y del mundo de las relaciones sociales, incluidas aquí, y de manera muy importante aquellas que se desarrollan en las redes de pertenencia de las personas;

-por separado, dada su importancia, es preciso señalar que los procesos de elaboración señalados en los puntos anteriores, no se pretende que se refieran solamente a reconocimientos, asimilaciones de experiencias y formulación de conclusiones de tipo, por así decirlo, objetivistas, sino que suponen, y de manera sumamente relevante, procesos colectivos de elaboración o estructuración de juicios de valor acerca de lo que es posible, permisible, deseable, o bien descartable, eludible o incluso condenable. Esto es, refieren a procesos sociales de estructuración de legitimidades; 
-por ello, el siguiente punto tiene que ver con la construcción en el imaginario, individual y colectivo, de una noción de futuro deseable, posible y socialmente legítimo (aunque, sobre todo en casos en los que ese futuro o ese proyecto biográfico laboral que se proyecta hacia el futuro tiene que ver con las migraciones internacionales, esa legitimidad social conferida a las prácticas reconocidas como necesarias para su consecusión, choque abiertamente con las legalidades vigentes en los estados nacionales involucrados); $\mathrm{y}$, finalmente;

-analíticamente ubicable como el punto final de cada ciclo, puede situarse el complejo proceso de toma de decisiones, individuales y colectivas, en relación a los contenidos específicos del proyecto biográfico laboral elegido, a sus momentos, a sus formas para la obtención y utilización de los recursos, a las renuncias necesarias frente a proyectos que se pueden haber apreciado como alternativos (por ejemplo, en el caso de los migrantes, la renuncia a su espacio tradicional o a la cercanía de algunos afectos importantes).

Cabe aquí destacar la importancia fundamental que tienen las redes de relaciones sociales, como el espacio privilegiado en donde se encuentran desde los aspectos más micro, referidos a las actuaciones individuales de las personas, con formas de pertenencia colectiva que conectan con algunas formas estructurales más macro. Esto es, es posible ver a estas redes de relaciones sociales como una especie de "vínculo messo", en donde se desarrollan importantes procesos de estructuración. Vistas estas redes como espacios de interacción social directa, cara a cara, reiterativa y prolongada en el tiempo, aunque acotada en el espacio (así sea este no contiguo, sino plurilocalizado, pero con fuertes interconexiones, como en el caso de los espacios sociales transnacionales de la migración), en su interior y a lo largo de su existencia es posibles prever la presencia no sólo de lazos cooperativos y solidarios, y de relaciones armoniosas y consensuales, aspectos que han sido los más destacados en su análisis; sino que también es válido suponer en ellas el surgimiento de antagonismos, de intercambios utilitarios, de conflictos y de disensos. 


\section{CONCLUSIONES PARCIALES}

Se ha hecho aquí referencia a la propuesta que hace Pries de los Proyectos Biográfico Laborales, que pretende tender puentes entre los condicionantes estructurales y las decisiones y acciones de los sujetos; más con una idea de estructuración y de institucionalización -esto es, de procesos en los que la acción de los sujetos transforma y reproduce la realidad social, al mismo tiempo y con las mismas acciones-, que con una noción "dura" de estructura. Y más con una idea de acción individual acotada por la presencia de elementos estructurantes y de racionalidad limitada, que con los supuestos "duros" del individualismo metodológico propio, por ejemplo, del rational choice.

En una visión sintética, puede decirse que, para la elaboración de los proyectos biográfico-migratorio-laborales, intervienen tanto factores institucionales -mercado, organización de la empresa y de la profesión, estructuras de discriminación y relaciones sociales consideradas informales, pero repetitivas y localizadas-, como factores temporales -edad, periodo y cohorte-, y factores de tipo personal, tanto de adscripción como de adquisición. Ahora bien, la influencia de cada uno de esos niveles en los diversos casos particulares no puede pensarse que se mantiene invariable, sino que, por el contrario, es precisamente tarea de la investigación indagar las configuraciones precisas que se presentan en distintos momentos históricos. De hecho, el proceso tal vez pueda representarse imaginando un vector que atravieza un campo de fuerzas (las instituciones estructurantes), cuyos componentes intervienen de manera diferenciada (en cada momento) y cambiante ( a lo largo del tiempo) en el comportamiento del vector; pero que a su vez son afectadas, tanto internamente como en relación con el resto de las fuerzas, por la acción del propio vector que las atravieza.

Ahora bien, se ha dicho igualmente que para el estudio de los mercados de trabajo es necesario tanto partir de una noción ampliada de dichos mercados, como de un énfasis en el reconocimiento del lugar estratégico que juegan en la articulación de algunos de los más importantes procesos de producción y reproducción de la sociedad misma. Complementariamente, se ha insistido en la necesidad de abordar este estudio de los mercados de trabajo con una visión o aproximación de tipo longitudinal y dinámica, que se interese, como dice Escobar, más la reconstrucción de los procesos que llevan a resultados, 
que en los resultados mismos. Para ello, se han propuesto como herramientas básicas la reconstrucción de las trayectorias y de las biografías laborales de las personas. 


\section{CAPITULO TERCERO: EL ANALISIS DE LAS TRAYECTORIAS LABORALES}

\section{LAS TRAYECTORIAS LABORALES, LAS INSTITUCIONES SOCIALES Y EL MERCADO DE TRABAJO}

El análisis de las trayectorias laborales, como una forma de visión longitudinal de la vida laboral de las personas, permite ver tanto las continuidades como las rupturas del itinerario vital de las personas en el mundo del trabajo; y permite ver el efecto acumulado de las historias personales en su ubicación en el mercado de trabajo; así como el efecto que el tiempo social tiene sobre ellas. Pero, sobre todo, permite observar e incluso medir la forma en que esas trayectorias laborales son estructuradas por las diversas instituciones sociales que intervienen en el funcionamiento de los mercados de trabajo (Dombois, Pries). Para el estudio de las migraciones internacionales y los procesos de creación de espacios sociales transnacionales, eso es particularmente útil. Como muchos trabajos sobre las migraciones lo han encontrado, la inserción de las personas en este tipo de procesos tiene efectos de gran significación en la movilidad social que, como apunta Escobar ( ), no debe verse como separada de la espacial, salvo para fines analíticos.

En el caso de las migraciones internacionales, lo anterior resulta ser de una importancia enorme, dado que el motivo explícito de gran parte de quienes migran consiste precisamente en ir al norte a conseguir unos ingresos que les permitan regresar a sus lugares de origen a tener una vida mejor, para ellas y ellos y para sus familias. Esto es, se va a conseguir un capital económico que les permita precisamente su reubicación hacia arriba en la estructura social (consiguen, además, no sólo intercambiar por éste el capital social que llevan, sino también en muchas ocasiones incrementarlo y diversificarlo). En el proceso se presentan, aunque ese no haya sido un objetivo explícito cuando de tomó la decisión de migrar, también importantes cambios en la composición de capital (Bourdieau) de las personas. Por ejemplo, su el capital cultural puede modificarse y acrecentarse de manera considerable y se puede adquierir un importante capital simbólico en el momento del regreso al lugar de origen; sea este regreso temporal o definitivo. 
Por supuesto que el mismo proceso hace que muchas veces las decisiones y las expectativas originales cambien y se adecuen a las condiciones que se encuentran en los dos polos y en los diversos puntos intermedios del proceso migratorio; polos que a veces no son sino nuevos puntos de partida hacia nuevos destinos, tanto laborales como espaciales y sociales.

Para el proceso migratorio que se estudia en este trabajo, uno de esos elementos que transforman los proyectos biográfico laborales de las personas, consiste en que de repente se encuentran en una situación en la que la migración deja de tener principio y fin, para convertirse en una parte constitutiva permanente de la existencia; al tiempo que los polos distantes del proceso migratorio empiezan a convertirse más bien en dos localizaciones de un mismo espacio social, que traspasa y trasvasa las fronteras; espacio entonces transnacional que las mismas personas migrantes construyen con su constante ir y venir, ya sea físico o simbólico, ya sea de manera personal o a través de alguien más.

A continuación, se presenta una descripción analítica de estas trayectorias laborales transnacionalizadas. Inicialmente, se verán las trayectorias previas a la migración internacional y después el proceso de integración al mercado de trabajos de los EUA. Después de ello, se ofrecerá un panorama general de las trayectorias laborales (TL), tanto en México, como en los EUA, una vez que se ha iniciado la migración y hasta el momento en el que la encuesta fue levantada.

El objetivo central consiste en ver cómo son estructuradas socialmente las TL en el espacio transnacional, por configuraciones cambiantes en el tiempo y en el espacio de las distintas instituciones sociales que intervienen en los mercados de trabajo; a la vez que las propias TL actúan como fuerzas estructuradoras de los EST22. Especialmente, el énfasis estará en ver el papel de las familias, transnacionales o no, en estos procesos.

De acuerdo con los resultados, se trata de demostrar que las familias y las redes de relaciones sociales juegan un papel fundamental en la estructuración de las trayectorias laborales en los espacios transnacionales en los que se desarrolla este proceso migratorio; pero también que este papel es diferenciado y cambiante, ya sea si se le ve a lo largo de las trayectorias y a lo largo de las cohortes; ya sea si se le ve en relación con el género o el país

\footnotetext{
22 Esta segunda parte se menciona aquí solamente como una opción teórica, que no se desarrollará propiamente en el análisis de los datos empíricos, que se concentrará en la primera parte de la propuesta.
} 
en el que tienen lugar los eventos. No se quiere afirmar que la anterior sea la única institución estructuradora de las trayectorias laborales; puesto que, como se verá más adelante, y en concordancia con hallazgos previos (Pries, 2000), se presentan siempre formas combinadas para la actuación del conjunto de las instituciones que estructuran los mercados de trabajo. Paralelamente, se busca demostrar también que estas acciones en el mundo del trabajo son fundamentales para la constitución y la estructuración de los EST.

Como se verá a continuación, aquí se plantea en el capítulo que es posible realizar un ejercicio de operacionalización, que permita contar con herramientas que posibiliten la medición dinámica de la forma en que las diversas instituciones involucradas en los mercados de trabajo intervienen para estructurar las trayectorias laborales de las personas. ¿Cómo obtuvieron la información sobre el trabajo?; ¿cómo consiguieron ser reclutadas?; ¿cómo consiguen permanecer e incluso ascender dentro del trabajo?; ¿quién se ha hecho cargo del costo de su preparación para el trabajo?; ¿qué criterios toman en cuenta para permanecer en un trabajo, o bien para abandonarlo, sobre todo si eso implica un cambio de país?; ¿qué comparten con las personas con las que trabajan?: ¿nacionalidad? ¿etnia? ¿condición migratoria? ¿sexo? ¿profesión u oficio?; ¿qué comparten con la personas que las emplea o en qué se diferencian de ella?; ¿qué recursos o tipos de capital movilizan para desempeñarse dentro del mercado de trabajo?; cuando han tenido que dejar de trabajar por algún périodo: ¿cómo han subsistido?; en fin, ¿su trabajo les ha permitido ascender laboral (en el salario o en la posición en el trabajo) o socialmente?. 


\section{OPERACIONALIZACIÓN DE LAS INSTITUCIONES SOCIALES}

Ahora bien, ¿es posible obtener algún tipo de medición de los efectos que el funcionamiento de cada una de estas instituciones tiene sobre la estructuración de las trayectorias laborales?. Aquí se plantea que la respuesta es afirmativa. Lo que a continuación se presenta es un intento de operacionalización de cada una, a partir de la construcción de indicadores relacionados con aspectos relevantes del funcionamiento de los mercados de trabajo, tales como los son:

a) los canales para la obtención de la información acerca de los trabajos disponibles;

b) los procedimientos y criterios de reclutamiento utilizados por los empleadores;

c) los criterios que los trabajadores emplean para tomar sus decisiones acerca del empleo (buscar el ingreso; buscar la permanencia; o bien buscar el cambio de empleo);

d) el tiempo de permanencia en el empleo;

e) los cambios de categoría del trabajador, dentro de una misma empresa;

f) la permanencia del trabajador en empleos similares, a lo largo de su trayectoria laboral;

g) las formas en que es cubierto el costo de la búsqueda del empleo; lo cual incluye el tiempo de espera (alimentación, alojamiento), el traslado al lugar en el que se encuentra el puesto de trabajo (sobre todo si el proceso implica migración) y, en ocasiones, la manutención de la familia;

h) el tipo de capital que es movilizado como recurso principal por quien busca empleo y el que es demandado por el empleador (mismos que no necesariamente coinciden);

i) la composición (por sexo, por etnia, por profesión u oficio, por nacionalidad, por edad, etc.) de los compañeros de trabajo;

j) el tipo de relación existente entre el trabajador y su empleador;

k) las posibilidades de ascenso social a partir del trabajo;

1) y, en un orden más general, el tipo de mercado de trabajo (interno/externo; competitivo/cerrado, etc.) en el que se inserta el trabajador. 
Cada uno de estos indicadores puede moverse desde los niveles más universalistas (impersonalidad, generalidad de criterio, racionalidad pura) hasta las más particularistas (relaciones personales, criterios cauísticos, afectividad). En otro sentido, pueden referirse tanto a situaciones en las que las personas no tengan que cambiar su lugar de residencia, como a otras en las que sí tengan que hacerlo, dentro de sus propios regiones de origen, dentro de su propio territorio nacional, o bien más allá de las fronteras de su país. Por otro lado, cada uno de estos ejercicios de operacionalización tiene como refrente algún modelo típico ideal, que no existe de forma pura en la realidad; sino que corresponde a un intento por diferenciar y medir los efectos que cada una de las instituciones sociales puede tener sobre la estructuración de las trayectorias laborales.

En el mundo empírico, lo que va a encontrarse son distintas combinaciones de la acción de los diversos elementos involucrados en el funcionamiento de cada una de las instituciones consideradas. El esfuerzo, entonces, estará en la utilización de estas operacionalizaciones para medir, en un momento dado, la influencia diferencial que cada institución tiene sobre las trayectorias laborales; pero también, y esto es de primera importancia, las formas en que estas influencias diferenciales cambian a lo largo del tiempo y del espacio para estructurar el comportamiento de dichas trayectorias laborales

Para realizar el análisis propuesta, se ha considerado útil establecer una tipología en la que se destacan los elementos comparables que definirían el funcionamiento del mercado de trabajo si fuera sólo alguna de las instituciones sociales estructurantes la que ejerciera de manera exclusiva la acción estructurante. Los tipos así construidos para el análisis se presentan a continuación en forma esquemática:

\section{A. SI LA INSTITUCION QUE ESTRUCTURA ES EL MERCADO.}

1. La información sobre los trabajos disponibles se obtiene a través de medios públicos e impersonales.

2. El acceso al trabajo es mediado por mecanismos de aplicación general e impersonal.

3. Los criterios para tomar las decisiones dependerán de las diferencias salariales relativas y de los costos de la búsqueda del empleo, tanto en el nivel local, como en el nacional y en el transnacional. 
4. Los compañeros de trabajo pueden ser de cualquier origen nacional o étnico (o bien, la composición de la fuerza de trabajo deberá reflejar la de la sociedad local).

5. Habrá un nivel significativo de rotación laboral externa.

6. El capital humano del trabajador será el elemento determinante para definir sus posibilidades de empleo, su nivel de ingresos y su posición en el trabajo.

7. Sus haberes de capital social, organizacional o cultural, serán en todo caso complementos subordinados, que buscará convertir en capital humano.

8. En los periodos de inactividad laboral, el trabajador subsistirá con sus ahorros o a través del endeudamiento en el sistema bancario o comercial.

9. Esta posible inactividad laboral estará siempre determinada por las decisiones estratégicas del trabajador (desempleo voluntario).

10. Para trasladarse y alojarse, el trabajador deberá aprovechar sus propios recursos (como ahorros o la venta de propiedades), sus posibilidades de endeudamiento bancario o comercial y las ofertas del mercado.

11. El efecto de la migración laboral en los mercados de trabajo de las sociedades huéspedes, tanto en los niveles salariales como en los de empleo, tiende a homogeneizar las condiciones en nuevos niveles de equilibrio (efecto de "clearing").

12. El nivel de las instituciones determinantes es nacional/local; esto es, la ocupación de los migrantes, (p.e. en NY), se estructurará por las particularidades locales del mercado de trabajo nacional de los EUA.

\section{B. SI LA INSTITUCION QUE ESTRUCTURA ES LA EMPRESA.}

1. En los MIT, la información sobre las alternativas de empleo es interna y fluye a través de los mecanismos administrativos de las empresas (en los sectores competitivos o mercados externos rigen los mecanismos de mercado).

2. El acceso al trabajo a los MIT, desde afuera, es sólo a los puertos más bajos del escalafón, y a través de mecanismos públicos e impersonales.

3. El cambio de posición ocupacional dentro de las empresas se da a través de mecanismos administrativos públicos, impersonales y formalizados. 
4. Las decisiones acerca del cambio ocupacional estarán en función de cálculos racionales que tomen en cuenta tanto las oportunidades internas de ascenso, como las que puedan brindar las empresas competidoras.

5. Los compañeros de trabajo pueden ser de cualquier origen nacional o étnico, como producto de las decisiones de la empresa.

6. La rotación externa deberá ser muy baja o nula con relación a la movilidad interna, que será sobre todo ascendente.

7. El principal recurso de los trabajadores será su capital organizacional (ubicación estructural en el organigrama, antigüedad, conocimiento del funcionamiento, la reglamentación y las normas internas de la empresa, calificación específica para las necesidades de la empresa).

8. Los periodos de inactividad laboral serán financiados por las propias empresas, conforme a sus normas, previsiones y procedimientos internos; o bien por las compensaciones previstas administrativamente para los casos de suspensión definitiva del empleo (recortes de personal, desaparición de la empresa, jubilación).

9. Si el cambio de posición ocupacional implica translados, los gastos que se deriven, así como los del alojamiento en las nuevas locaciones, serán las empresas las encargadas de cubrirlos.

10. El nivel de las instituciones estructurantes -local, nacional, transnacionaldependerán en este caso básicamente del carácter de la propia empresa (local, nacional o transanacional).

11. A partir de esta pauta de funcionamiento, se constituirán mercados de trabajo con situaciones altamente diferenciadas; pero sólo en algunos casos se tratará de verdaderas segmentaciones del mercado (imposibilidad de que las personas se desplacen de una situación a otra).

\section{SI LA INSTITUCION QUE ESTRUCTURA ES LA PROFESION, EL OFICIO O EL GREMIO.}

1. La información acerca de las posibilidades de empleo fluirá sobre todo a través de las asociaciones profesionales o gremiales y a través de los círculos de interacción social de quienes pertenecen a las profesiones o los gremios (redes sociales específicas); aunque también podrá obtenerse en los medios públicos e impersonales propios del mercado profesional o gremial.

2. El acceso al trabajo estará restringido (de manera formal o por la práctica) a quienes acrediten la pertenencia a la profesión o el gremio; pero puede ser necesaria la pertenencia a las organizaciones típicas de cada una ellos (Colegios, Asociaciones, Cofradías, etc.). 
3. Los compañeros de trabajo reflejarán en su composición las restricciones nacionales, étnicas o de otro tipo que sean peculiares de la profesión o el gremio. Adicionalmente, habrá altas correlaciones con las trayectorias y lugares de educación y formación.

4. Se podrán presentar diversos grados de rotación externa e interna; pero deberá presentarse una marcada continuidad en el tipo de trabajo que se realiza.

5. El capital cultural -saber hacer específico del gremio o la profesión y socialmente reconocido- o educacional -en el caso de las profesiones- será el principal recurso que podrán movilizar los trabajadores; aunque también podrá serlo el llamado credencalismo.

6. En los periodos de inactividad laboral, el trabajador susbsistirá de sus propios ahorros y del endeudamiento comercial o bancario; pero puede darse el caso de que existan mecanismos de ayuda mutua, profesionales o gremiales.

7. Los translados y realojamientos que resulten de cambios de empleo deberán ser financiados por el propio trabajador, a menos que existan formas mutuales de ayuda profesional o gremial.

8. La presencia de trabajadores migrantes en mercados de trabajo de este tipo, afectará los niveles de empleo y salario ("clearing"); pero no es de esperarse que los migrantes se ubiquen en posiciones desfavorables frente a sus colegas de la sociedad huesped.

9. En este tipo de mercados de trabajo, las instituciones estructurantes tendrán una fuerte influencia nacional/local (regulaciones nacionales sobre las profesiones y los gremios, matizadas por costumbres y normas locales).

\section{SI LA INSTITUCION QUE ESTRUCTURA ES LA FORMADA POR LAS REDES DE RELACIONES SOCIALES O LOS CLANES.}

1. La información sobre los trabajos se obtendrá básicamente a través de contactos personales (parientes, paisanos, amigos, compadres; así como los contactos de estos contactos); que pueden ser tanto muy cercanos ("lazos fuertes"), como más o menos lejanos ("lazos débiles" o "puentes").

2. El acceso al trabajo estará mediado por la recomendación de este tipo de contactos personales.

3. Los criterios de decisión para permanecer en un mismo empleo, para cambiarlo, para migrar o no hacerlo, o bien para regresar al lugar de origen después de haber migrado, estarán fuertemente marcados por cuestiones ajenas a la lógica de la obtención del máximo 
beneficio económico y propias de las relaciones familiares y amistosas, como por ejemplo los lazos afectivos.

4. Los (as) compañeros (as) de trabajo serán mayoritariamente del mismo origen nacional, regional o étnico; aunque pueda haber personas de otros orígenes igualmente diferenciados nacional, regional o étincamente (que pueden, p.e., haber sido admitidos dentro de redes o clanes que no sean los de su adscripción original).

5. Quienes se muevan en este tipo de mercados de trabajo podrán permanecer o no por mucho tiempo en un mismo trabajo, o bien rotar o no con frecuencia.

6. El capital social del trabajador será el principal recurso en el mercado de trabajo: tener los contactos adecuados y suficientes, así como saber activarlos y conocer y respetar las reglas, implícitas por lo general, de funcionamiento de las redes o clanes (reciprocidad, respeto de valores y tradiciones comunes, p.e.). El capital humano que un migrante, por ejemplo, lleva consigo desde su comunidad de origen, por el contrario, será muy poco relevante para definir sus posibilidades de empleo.

7. Las posibilidades de movilidad ascendente en el mercado laboral estarán en relación directa con la cantidad y diversificación de los lazos débiles, y en relación inversa con la cantidad y la concentración de los lazos fuertes, de que disponga la persona.

8. En los periodos de inactividad laboral, los contactos personales brindan el apoyo básico para subsistir.

9. El costo de los translados y el alojamiento en los nuevos lugares de trabajo serán absorbidos (como préstamo, como adelanto e incluso como regalo) por los parientes, amigos, paisanos y compadres; ya sea porque éstos lo hagan por compromisos de lealtad, confianza y reciprocidad, o bien que lo hagan como parte de su ocupación ("polleros" o "coyotes"), que depende en gran medida de la existencia de lazos de confianza mutuos. (En este punto es necesario establecer una diferencia entre aquellas personas que pueden ser válidamente consideradas como traficantes de trabajadores migrantes (generalmente desconocidos, dispuestos a engañar a, y abusar de, quienes compran sus servicios, por ejemplo, en la zona roja de Tijuana) y aquellas otras que, si bien obtienen sus ingresos principales del translado de migrantes indocumentados, son personas conocidas en las comunidades de origen, se mantienen en permanente contacto con ellas e incluso pueden repartir su tiempo entre trabajos temporales en Nueva York, trabajos temporales en sus pueblos y su labor como "polleros").

10. La inactividad y la movilidad laborales estarán fuertemente influidas por cuestiones propias de las relaciones familiares, comunitarias o amistosas.

11. El nivel de las instituciones que estructuran este tipo de mercados de trabajo, en el caso de la migración internacional, será local o comunitario/transnacional.

12. Estos mercados de trabajo tendrán, en el caso de los migrantes transnacionales o transmigrantes (Sassen, 1995), las características de enclaustramiento, desterritorialización 
parcial (o falta de contigüidad geográfica) y de escasas posibilidades de mejoría para quienes participan de ellos, que Sassen (1995) descubre en algunos mercados locales que no afectan a, ni son afectados por, los niveles de empleo y salarios de los mercados de trabajo abiertos de las sociedades huéspedes (no hay efecto de "clearing" por el mercado).

\section{F. SI LA INSTITUCION QUE ESTRUCTURA ES LA SEGREGACION (POR GENERO, ETNIA, NACIONALIDAD, ETC.)}

1. La información sobre los trabajos que efectivamente pueden ser ocupados por las personas que forman parte de algún grupo discriminado (o beneficiado por la discriminación), correrá a través de las propias redes sociales del grupo involucrado; al igual que la información acerca de cuáles trabajos son inaccesibles (trabajos "etiquetados") o indeseables.

2. Los mecanismos de acceso a los trabajos pueden explícitamente incluir o excluir a los grupos discriminados o beneficiados (legislaciones, reglamentaciones, cuotas); pero en general contendrán fuertes componentes de valoración personal por parte de quienes se encarguen directamente del reclutamiento.

3. Las personas compartirán empleos y posiciones de trabajo preferentemente con otras personas que compartan con ellas la pertenencia a determinado grupo o categoría social o culturalmente construida (mujeres u hombres, jóvenes o viejas, indias o no indias, migrantes o no migrantes, negras o blancas, homosexuales o heterosexuales, etc.).

4. Las decisiones acerca de seguir en un trabajo o de abandonarlo, estarán muy influidas por elementos involuntarios (climas de trabajo insoportables; en las crisis, "los migrantes salen primero"; o bien los jóvenes, o las mujeres, o los negros).

5. La rotación puede ser muy baja si las personas aceptan el enclaustramiento en nichos específicos; pero también muy elevada si las personas intentan salir del enclaustramiento.

6. En aspectos como la supervivencia en periodos de desempleo; o bien de costos de la búsqueda de trabajo (traslado, alojamiento, p.e.), los grupos discriminados pueden actuar de manera muy similar a como lo hacen las redes sociales en general (como redes sociales específicas: de migrantes, de mujeres, de homosexuales, etc.).

7. El capital cultural es la forma de capital dominante (incluso con la presencia de fuertes componentes culturales compartidos entre quienes se benefician de la segregación y quienes son perjudicados por ella) cuando hay segregación; aunque tanto el capital político (para ejercer la segregación como para combatirla), como el social (como en el caso de las redes de relaciones) pueden jugar papeles importantes. 
8. En estos mercados de trabajo se constituirán verdaderos nichos étnicos, o de migrantes, o de género, o de nacionalidad, que tenderán a estar efectivamente segmentados (no sólo diferenciados) del resto del mercado de trabajo.

Como ya se ha dicho, en la realidad se presenta de manera combinada la acción estructurante de las instituciones, lo cual introduce una gran complejidad. Para captar esa complejidad en su dinamismo, se hará un triple seguimiento. Por un lado, se analizarán las trayectorias evento por evento (agrupando el conjunto de primeros, segundos, terceros, hasta " $n$ " eventos), tanto agregadamente, como por país y sexo. Por otro, se analizarán los eventos agrupándolos en cohortes y también por país y sexo. Eso permitirá ver tanto los cambios a lo largo de las trayectorias individuales agregadas, como los cambios con relación a periodos de tiempo más amplios. Pero, además de ello, se hará un análisis más particular de los eventos que inmediatamente preceden a los cambios laborales de país en uno y otro sentido, entre México y los EUA. El objetivo de este análisis consiste, como se ha dicho, en observar la forma en que las diversas instituciones sociales intervienen para estructurar las trayectorias laborales.

La separación por sexo, obedece a que sí se presentan evidencias de que existe una marcada diversificación de las TL de mujeres y hombres. Esto es, sí existe una "construcción social de una diferencia en el mercado de trabajo, a partir de la diferencia sexual" o construcción de género; o bien una transnacionalización o reproducción en el espacio social transnacional, de la diferencia de género en el mercado de trabajo.

La idea de separar por país las trayectorias, obedece a que ha aparecido suficiente evidencia de que se presentan fuertes y claras rupturas o discontinuidades, en aspectos fundamentales de las TL, si se comparan los eventos realizados en los EUA con los que tienen lugar en México.

Las características de las TL se analizarán conforme a la información que se tiene captada en tres tipos de variables:

a) características de los trabajos: ubicación, sector y rama, días y horas de trabajo y duración del evento. En esta parte, descriptiva, se trata de ver qué tipo de trabajo es y en qué tipo de proceso y de relaciones laborales se inscribe, qué requisitos de formación y capacitación requiere y, en fin, qué tan precario o no es. Además de la información del cuestionario, aquí será de gran utilidad la información 
captada en las entrevistas, en la observación directa y en los trabajos acerca del mercado de trabajo en NY y México.

b) Características del funcionamiento del sector o nicho del mercado de trabajo en el que se ubican los trabajos. Para ello, se verán, por un lado, cosas como las relaciones previas que puedan haber existido con el patrón, así como el origen étnico-nacional del empleador y de los compañeros de trabajo. Nuevamente, la información del cuestionario deberá complementarse. Aquí serán de gran utilidad los trabajos escritos sobre NY, en torno a la nueva ola migratoria y sus efectos sobre la conformación de nichos de mercado de (en ocasiones) y para los nuevos inmigrantes, tanto en la confección como en los servicios.

c) En la tercera parte, se trata de analizar las variables que refieren más directamente a los mecanismo de estructuración de las trayectorias laborales por las instituciones sociales; y, muy especialmente, a las características del funcionamiento de las redes sociales familiares, y más generales, en todo el proceso de migración, transmigración y, en su caso, fin de la migración. Para esto último, los indicadores están en las fuentes de información y de recomendación acerca del empleo. Los indicadores serán los apoyos para los traslados y para el alojamiento, y su contraparte en las remesas, y su intervención en los mecanismos de la toma decisiones al respecto. Otra vez, las entrevistas y la observación directa serán en esta parte de gran utilidad.

Como ya se ha señalado, una parte importante del análisis se realizará a partir de la confección de cohortes, que permitan observar posibles cambios y tendencias dentro de las TL. Al respecto, es necesaria una precisición; acerca de los criterios que se tomaron en cuenta para construir las cohortes que sirvieron de base para el análisis. Estas cohortes o conjunto de eventos que fueron vividos o experienciados por conjuntos de personas en un mismo periodo de tiempo, se elaboraron particularmente para cada forma distinta de agrupar el conjunto total de eventos considerados en la base de datos que se confeccionó a partir del cuestionario de trayectorias laborales. Así, se elaboraron las siguientes cohortes: una se refiere al total de eventos de la base; una segunda, al total de eventos que se realizaron en México; una tercera, a los que se realizaron en los Estados Unidos; una 
cuarta, al subconjunto de primeros eventos desarrollados en México; finalmente, una quinta, a los eventos que significaron la integración de las personas consideradas en el mercado de trabajo norteamericano. Como el objetivo era observar los cambios ocurridos en el tiempo para cada subconjunto de eventos; éstos se distrubuyeron de tal forma que en cada subagrupamiento temporal dentro de las cohortes, quedara un número suficiente de casos como para realizar diversos cruces de variables.

Un comentario adicional se hace necesario. En la encuesta se captó únicamente el trabajo principal de las personas (por el ingreso y por número de horas y días de trabajo). Por los testimonios recabados en las entrevistas, se sabe que en los Estados Unidos una enorme cantidad de migrantes trabaja, además de hacerlo en su trabajo principal, en una gran cantidad de actividades complementarias, como lo son: la venta domiciliaria de productos mexicanos (las rutas, que más adelante merecerán un tratamiento particular), la venta callejera de flores y frutas, la elaboración casera de alimentos para la venta, la elaboración casera de partes para la industria de la confección y, en los fines de semana, el arreglo de casas y jardines. Estacionalmente, en el tiempo de las cosechas, es también frecuente que durante los fines de semana se realice trabajo agrícola en campos cercanos a la ciudad de Nueva York, ya sea en el mismo estado, o bien en Nueva Jersey. También de manera estacional, se sabe que un cierto número de mexicanos trabaja en los hipódromos de la costa este - como jinetes y como cuidadores de los caballos y las instalacionessiguiendo la ruta que impone el cambio climático, de sur a norte y a la inversa.

El caso de Aurora (Piaxtla) es elocuente al respecto. Ella refiere que la patrona con la que trabajó como servidora doméstica alrededor de diez años, le ayudaba a conseguir trabajos adicionales, en fiestas y reuniones de gente conocida:

...entonces no eran 100 dólares lo que yo ganaba, en los trabajos; por 2, 3 horas, me daban 40, 45 dólares. Entonces, cuando se presentaba alguna fiesta, me decía: señora, ¿usted quiere ir a hacer este... hacer ese trabajo, dos, tres horas; le van a dar 60, 70 dólares?. Y yo decía: sí. Yo nunca dije no, porque yo a lo que fui, a trabajar, a hacer dinero. Y me daba... me daban esos trabajos. (Aurora)

También le conseguía trabajos temporales en el campo: 
...Los fines de semana, cuando se llegaba el día del campo, que empieza (en) marzo, abril, mayo, junio; me decía: "señora, ¿usted quiere ir a... a trabajar al campo, se va a ganar 60 dólares por el domingo, y las comidas de su hija y usted?”. Sí, todo el tiempo dije sí.(Ibid.)

Por otro lado, obtenía ingresos adicionales, vendiendo comida en los bailes que organizaban sus hermanos

... yo salía los viernes a las 5 de la tarde (del trabajo con la señora), llegaba yo a la casa de mi mamá, descansaba yo, al otro día, este...íbamos a hacer la compra, y empecé a vender tacos con ellos. Depende como ellos les fuera en el baile, ellos me daban 400, 500 dólares en la noche, pero era toda la noche, hasta las 6 de la mañana.(Ibid.)

Pese a la desvelada, nunca dejó de cumplir con su trabajo normal:

...(después de los bailes) ya nada más llegaba a la casa de mi mamá, me bañaba, tomaba café y me iba al trabajo, porque al trabajo tenía que entrar a las 6 de la... a las 7 de la mañana. Nunca fui inrresponsable (sic), nunca me enfermé en ese lugar, yo quería este...siempre conservar mi trabajo, siempre, no ser una persona inrresponsable (sic), que decir: bueno, hoy gané buen dinero, hoy no voy a trabajar con ella.(Ibid.).

Tal vez por la razón mencionada, en los reportajes y artículos periodísticos en los que se habla de la gente de México en la ciudad de Nueva York, normalmente se hace referencia a la venta callejera de flores y frutas, al arreglo de jardines y a la construcción ${ }^{23}$, que en realidad no son las actividades más importantes. Son, sin embargo, las más públicas. Los trabajos en las cocinas de los restaurantes y en los sweatshop son, por el contrario, invisibles; lo cual es intencionalmente utilizado por las y los mexicanos que trabajan en esos lugares. Mientras menos me vean, mejor, parece ser la idea que guía una gran parte de sus actividades cotidianas.

\footnotetext{
23 En Staten Island sí hay una cantidad importante de mexicanos, y ocasionalmente mexicanas, trabajando; pero en su mayoría son de los estados de Michoacán y Oaxaca.
} 
Complementariamente, cabe señalar que, en México, una gran cantidad de personas considera como no trabajo, actividades que sí lo son en un sentido estricto. Cooperar en el lugar de origen con las labores agropecuarias regulares de la familia (siembra, cuidado de los cultivos, cosecha, cuidado de los animales, ordeña, etc.), participar en trabajos de construcción, ampliación o remozamiento de la vivienda familar, encargarse del cuidado de los niños o de los ancianos de la familia, por ejemplo, son algunas de las actividades que generalmente son asimiladas a la vida cotidiana y consideradas como parte de las vacaciones o de la inactividad: ...entonces no hacía nada, no trabajaba, sólo me dedicaba a ver que engordaran los cochinos y a construir mi casa (Aurora, Chinantla); o bien: ...aquí no estoy trabajando; lo que sí, le ayudo a mi tía, voy al monte por leña en las mañanas, desmontamos para sembrar, sembramos... (Jorge, Piaxtla).

\section{CARACTERISTICAS METODOLOGICAS GENERALES DEL PROYECTO}

Como han demostrado los intentos de cuantificación del proceso migratorio que se ha desarrollado entre Puebla, Tlaxcala y otras zonas del centro de México, y la zona metropolitana de la ciudad de Nueva York ${ }^{24}$, el universo total de la población migrante resulta muy difícil de cuantificar y, por tanto, es prácticamente imposible realizar una encuesta estadísticamente representativa. Por esa razón, en esta investigación se optó por una metodología que puede considerarse intermedia entre el estudio de caso (conjunto de estudios de caso) y la muestra representativa. Una de sus principales características es que combina una aproximación de tipo cuantitativo (cuestionario cerrado para la reconstrucción de trayectorias laborales, aunque con una muestra no representativa estadísticamente), con aproximaciones de tipo cualitativo (entrevistas narrativas a profundidad para la reconstrucción de biografías laborales; así como observación directa y participante). En cualquier caso, esta investigación no puede dejar de considerarse como inicial y aproximatoria; aunque se mantiene la confianza en que sus resultados arrojan importantes pistas y hallazgos para la investigación futura.

\footnotetext{
${ }^{24}$ Por ejemplo, en México: Cortés, 1998, 1999 y 2000; y Herrera y Macías, 1996) y en Nueva York: Valdés, 1996; Smith, 2000.
} 
Para la realización de la investigación, se eligieron cinco regiones en las que se detectaron importantes flujos migratorios hacia la zona de la ciudad de Nueva York. Estas regiones de origen fueron seleccionadas en función de algunas características importantes que resultan contrastantes entre ellas, tales como la antigüedad relativa de la migración, el carácter predominentemente rural o urbano, el tamaño y el grado de marginación. Una característica de gran importancia que se previó incluir, la étnica, fue finalmente desechada, debido a que las comunidades que pueden ser definidas como étnicamente mixtecas (en los municipios de Xayacatlán de Bravo, San Jerónimo Xayacatlán y Petlalcingo, básicamente), no presentan una migración de proporciones significativas hacia los EUA, sino que su población migra preferentemente hacia otras localidades de México (sobre todo el D.F. y los estados de Morelos y Puebla) (López Angel, 1999). Las regiones así seleccionadas son:

a) la de Chinantla-Piaxtla-Tecomatlán, ubicada en la Mixteca poblana, que representa la migración relativamente más antigua y constituye un área rural de comunidades muy pequeñas y de elevada marginación; si bien los efectos de las remesas y de las inversiones de los migrantes han elevado en los últimos años las tendencias hacia la urbanización y disminuido los índices de marginación (mejores comunicaciones, pavimento, drenajes, agua potable, construcciones de materiales duraderos) (Herrera y Macías, 1996; Smith, 1996 y 2000). Las tierras, por otro lado, son sumamente áridas y su propiedad está muy concentrada;

b) la de Acatlán-Petlalcingo-Tehuitzingo, ubicada también en la zona mixteca poblana; pero con una migración de antigüedad intermedia, cuyas comunidades combinan áreas urbanas y rurales de tamaño medio y presentan menores grados relativos de marginación; ello en buena parte debido a que se ubican en la vía tradicional de comunicación entre el centro del país y la ciudad de Oaxaca (la carretera Panamericana) y eso les permite contar con fuentes de trabajo ligadas al comercio y los servicios; además de las tradicionales labores agrícolas, que se realizan en tierras muy áridas y mal distribuidas;

c) la de los barrios del municipio de Atlixco, ubicada fuera de la zona mixteca, en el centro del estado de Puebla, en lo que fue hasta los años cincuenta una de las principales zonas textileras del país. La migración de esta región es muy reciente, a 
partir de comunidades (los barrios) rurales de elevada marginación, agravada por un lado por la crisis de los precios de su producción hortícola y por la elevada concentración de las mejores tierras (productoras de flores); pero atenuada parcialmente por el efecto reciente de las remesas, lo que se está traduciendo en mejoras a la comunicación y en un cambio notorio del estilo de construcción (del adobe y la palmilla, al tabique y al cemento). Las tierras son de alta calidad y se dispone de agua en abundancia; pero la concentración de la propiedad es muy elevada (Prebich, 1996);

d) la de la ciudad de Atlixco y su periferia, de migración también muy reciente, y de características urbanas y suburbanas, de un tamaño medio, con muy bajos índices de marginación y fuentes de trabajo ligadas a la producción de leche y sus derivados, al comercio (su mercado semanal es muy importante regionalmente) y los servicios en general. Esta región urbana fue precisamente la más afectada por la crisis de la industria textil tradicional; muy recientemente, se han asentado en la ciudad algunos talleres maquiladores de la industria de la confección, de capital coreano; muy similiares, por cierto, a los sweatshop neoyorquinos.

e) finalmente, está la región del sur de Tlaxcala, integrada funcionalmente con la zona norte de la ciudad de Puebla y sus corredores industriales. Esta región presenta la migración relativamente más reciente, de entre las consideradas. Aunque combina características urbanas con rurales, en términos generales es una zona de asentamiento de industrias modernas y de servicios que, a diferencia de Atlixco, está en proceso de crecimiento y expansión, y no de crisis. Sus comunidades son relativamente pequeñas, pero están altamente conurbadas (a diferencia de los barrios de la región rural de Atlixco y de la Mixteca en general); y sus índices de marginación son intermedios.

f) como región de destino, que es lo que unifica en esta investigación a las comunidades de origen seleccionadas, está exclusivamente la amplia zona metropolitana de la ciudad de Nueva York (incluidas zonas de Nueva Jersey)

El trabajo con el cuestionario cerrado, elaborado para la reconstrucción de los eventos laborales de las personas y de las características generales de su trayectoria migratorio laboral, fue aplicado solamente a:

a) personas mayores de 18 años; 
b) originarias de alguna de las regiones consideradas (incluida la ciudad de Nueva York, como excepción, en dos casos de personas hijas de migrantes de la ciudad de Piaxtla, que vivieron en esta localidad desde muy temprana edad y más adelante han estado repartiendo su vida entre Nueva York y el estado de Puebla);

c) que hubieran estado al menos una vez en la zona de destino, trabajando o buscando trabajo por un periodo no menor a tres meses; $y$

d) que no pertenecieran al mismo hogar de otra persona ya incluida en la muestra;

Ante los ya mencionados problemas de cuantificación de la magnitud precisa de la migración, los entrevistados fueron seleccionados por ayudantes de investigación reclutados en las mismas comunidades (sobre todo, estudiantes y profesores), bajo la lógica del azar y de la "bola de nieve". Con ello se buscó, en las comunidades, que quienes colaboraban en el levantamiento de la encuesta, pertenecieran a distintos núcleos familiares y diversas redes sociales, para aumentar así la posible cobertura de situaciones diferenciadas.

El cuestionario aplicado tiene las siguientes carácterísticas: se divide en dos secciones:

1.- preguntas en relación a la persona, su familia y su historia (150 variables, que incluyen los eventos migratorios propios y los de sus padres, sus hermanos y sus hijos, los estudios propios y de los familiares mencionados, la estructura del hogar a lo largo de su trayectoria vital, los lugares de residencia, etc.);

2.- preguntas en relación a los eventos laborales, con 24 variables para cada evento laboral: inicio y fin del trabajo, ubicación, actividad específica en el trabajo, rama de actividad económica, nacionalidad u origen del empleador y de los compañeros de trabajo, jornada diaria y semanal, formas de obtención de información y recomendación para el trabajo, destino de las remesas, ingresos en comparación con el anterior, razones para abandoner cada trabajo, etc.

En total, se aplicaron en total cerca de 800 cuestionarios; pero sólo se consideraron válidos 648. A partir de la información recabada, se integró una base en dos archivos del programa SPSS (uno para la parte orientada a las personas y otro para la parte orientada a los eventos). Como resultado, se pudo trabajar con una muestra con las siguientes carácterísticas: 
a) 200 mujeres y 448 hombres;

b) la edad promedio es de 32.3 años;

c) la distribución por regiones quedó así:

-Mixteca de migración más antigua: 39 mujeres y 75 hombres

-Mixteca de migración intermedia: 31 mujeres y 99 hombres

-Atlixco urbano: 152 mujeres y 77 hombres

-Atlixco rural: 50 mujeres y 107 hombres

-16 mujeres y 89 hombres

d) se incluyen 3060 eventos válidos;

e) el promedio de eventos por persona es de 4.7;

f) el promedio de duración de los eventos fue de 3.6 años;

g) el promedio de cambios laborales de país por persona, de 2.4 (126 personas cambiaron cuatro o más veces de país);

La segunda parte de la investigación consistió en la grabación magetofónica de entrevistas a profundidad de distinto tipo; mismas que después fueron transcritas con el procesador de palabras Word, en varias de sus distintas versiones y después uniformadas con la más reciente. Para la presentación de esta tesis, el tratamiento de las narraciones así obtenidas se hizo a través de procesamiento sucesivos, agrupando los bloque temáticos definidos por el investigador (migración, trabajo, familia, etc.); pero en esta fase no se tuvo acceso a ningún paquete especializado. Actualmente, se están reprocesando estos materiales con el paquete Nuddist. Las entrevistas realizadas pueden agruparse en tres bloques:

a) primero están las entrevistas semiestructuradas que se hicieron a personas que fueron consideradas como informantes privilegiados. A esta categoría pertenecen, por ejemplo, las narraciones de personas como el consul mexicano en Nueva York para la atención de las comunidades mexicanas en el extranjero; como organizadores sindicales del Centro de Justicia del indicato UNITE; como los sacerdotes de algunas comunidades de origen; o como los dirigentes de las ligas deportivas mexicanas en Nueva York;

b) en segundo lugar, están las que se orientaron hacia los empresarios mexicanos de distintos ramos y rangos, que tienen en común el que sus negocios estén ubicados en Nueva York y el haber iniciado su carrera migrante básicamente 
como lavaplatos de restaurante (este bloque prácticamente no aparece más que anecdóticamente en esta tesis);

c) finalmente, en tercer lugar, están las que se dirigieron específicamente a la reconstrucción de las historias de las familias transnacionales. En estos casos, se buscó incluir a miembros del mayor número posible de generaciones, a partir de narraciones libres, en las que el papel del entrevistador se limitó al máximo. Cabe aclarar que este paquete de entrevistas no fue propiamente previsto o planeado desde el inicio de la investigación; sino que fue un resultado que apareció con el avance mismo del trabajo de campo, cuando el involucramiento personal en las redes sociales de los migrantes permitió detectar la posible importancia de este tipo de familias. La reconstrucción de la historia de dos de estas familias resulta de primordial importancia en particular para esta tesis; una de ellas es de la región mixteca de mayor antugüedad en la migración; la otra es de la región de Tlaxcala. La primera ha permitido desarrollar de manera amplia la dinámica familiar transnacional. La segunda, reconstruir muchos aspectos fundamentales de la forma de vida y trabajo de los mexicanos y mexicanas en Nueva York.

La otra parte del trabajo de campo consistió en la observación y la participación directa en algunos de los espacios y momentos que se fueron revelando como claves para la vida en el espacio social transnacional. A partir del involucramiento personal con la vida dentro de las redes sociales de los migrantes, fue posible agregar a los dos primeros tipos de trabajo señalados anteriormente, importantes periodos de convivencia y de intercambio, por ejemplo con los miembros de las dos familias con las que se realizó un trabajo más extenso y más a profundidad; incluso con aquellas personas que no estuvieron dispuestas a aceptar una entrevista grabada, pero que con toda generosidad sostuvieron con el equipo de investigación largas e instructivas pláticas.

Lo anterior sucedió de distintas maneras en México y en los EUA. De hecho, gracias a que se había desarrollado en las comunidades de origen un amplio proceso de contactación y comunicación, fue posible aprovechar de una manera eficiente el poco tiempo que los recursos permitieron para las estancias en Nueva York. En México, fueron sobre todo las fiestas, religiosas, civiles y familiares, las que permitieron abrir los canales 
de comunicación y permitieron también observar de manera directa la existancia e importancia de las redes de relaciones sociales. Pero también la vida cotidiana, en ese tiempo que parece que no transcurre, cuando no hay fiesta y cuando la mayoría de los migrantes están en los EUA, genera espacios en los que el trato entre los actores del proceso -que fueron y regresaron y están por irse de nueva cuenta- y quien realiza la investigación adquiere características de amistad y contenidos afectivos, que permiten el acceso a comentarios, informaciones, valoraciones, expectativas y formas de ver la vida que, sin ser representativas estadísticamente, brindan una enorme riqueza al trabajo de investigación. En Nueva York, la convivencia en los campos de futbol, en los restaurantes y bares en los que trabaja la gente de México, así como en muchas de las casas en las que vive, fue la ocasión propicia para ahondar en preguntas e inquietudes que iban surgiendo del proceso mismo de la investigación. 


\section{SEGUNDA PARTE}

\section{CAPITULO CUARTO: EL CONFINAMIENTO SECTORIAL DEL TRABAJO DE LOS MIGRANTES}

\section{INTRODUCCION}

En esta parte se busca ubicar cuáles han sido las principales ocupaciones de la gente migrante de México a la zona metropolitana de Nueva York y sus alrededores, para después poder analizar las trayectorias laborales a la luz de las principales interrogantes de este trabajo, que son las que se refieren a la estructuración de dichas trayectoria por las instituciones sociales que intervienen en los mercados de trabajo.

Para ello, primero se hará un análisis general de las características que asumió la integración de estas personas al mercado de trabajo norteamericano; para después realizar un seguimiento de sus trayectorias laborales, tanto en México, como en los Estados Unidos. En un primer momento se hará una descripción general del conjunto de los casos, para después observar si existe algún efecto ocasionado por las cohortes de integración al mismo. En todos los casos se realizará una comparación entre sexos. Más adelante, se realizará un seguimiento longitudinal de cada una de las variables más relevantes, a lo largo de la sucesión de eventos de las trayectorias laborales. Cabe señalar que esta parte es básicamente descriptiva, pero se hace necesaria para poder después pasar a analizar, primero, la ubicación de la gente de México en nichos étnicos específicos de los mercados de trabajo locales de Nueva York; y, después, la forma y la intensidad con la que intervienen las instituciones sociales en la estructuración de las trayectorias laborales. También se hará en este capítulo una aproximación de tipo etnográfico a los principales procesos de trabajo en los que se inserta la migración mexicana.

Cabe, sin embargo, hacer de entrada la observación de que desde el inicio de las TL en los Estados Unidos, éstas adquieren características peculiares que, más adelante, habrán de mantenerse en lo general; sobre todo en lo que se refiere a su ubicación en sectores determinados del mercado de trabajo de la zona de Nueva York. Mujeres y hombres provenientes de México, de manera diferenciada para cada grupo, ingresan a través de, y se 
mantienen en, trabajos que no pertenecen a los sectores abiertos, libremente concurrenciales, del mercado de trabajo. Por el contrario, se ubican en sólo una determinada gama de trabajos, en general etiquetados socialmente no sólo como trabajos para migrantes; sino, más específicamente, como trabajos para migrantes recientes. Más adelante, se analizarán las características históricas y estructurales de estos nichos de mercado en los que se inserta la migración mexicana.

\section{PRIMERA APROXIMACIÓN GENERAL}

Un primer dato que llama la atención, consiste en que los migrantes de la región de Puebla y Tlaxcala que migran a la zona de la ciudad de Nueva York y su área circundante, tienen como puertos de entrada al mercado de trabajo norteamericano empleos ubicados básicamente en los sectores secundario y terciario de la economía. Sin embargo, como puede verse en la tabla 1, de inmediato salta a la vista que se presenta una situación diferenciada entre hombres y mujeres; elemento que habrá que tener muy en cuenta en los análisis subsecuentes. De inicio, esto hace pensar en que para estas personas migrantes sí existe un importante componente de género -construcción de una diferencia social a partir de la diferencia de sexo- con relación al mercado de trabajo. Para los propósitos específicos de este trabajo, habrá que observar las causas y las consecuencias que tiene esta situación diferenciada, con relación a la forma en que las instituciones sociales -como la familia y las redes de relaciones, el mercado, la organización de las empresas y las profesiones y oficios, y los esquemas de discriminación- intervienen para la estructuración de las trayectorias laborales de mujeres y hombres migrantes.

TABLA 1

\begin{tabular}{|c|c|c|c|c|}
\hline Sector de ingreso al mercado de trabajo norteamericano & \multicolumn{2}{c|}{ Hombres } \\
\hline & \multicolumn{2}{|c|}{ mujeres } & absoluto & $\%$ \\
\hline & absoluto & $\%$ & 41 & 9.4 \\
\hline Sector primario & 5 & 2.6 & 152 & 34.9 \\
\hline Sector secundario & 93 & 48.2 & 243 & 55.7 \\
\hline Sector terciario & 95 & 49.2 & 436 & $100 \%$ \\
\hline Total & 200 & $100 \%$ & & \\
\hline
\end{tabular}


En efecto, mientras que el $48.2 \%$ de las 200 mujeres consideradas en la muestra ingresó por primera vez a un empleo en los Estados Unidos a través del sector secundario, y 49.2\% lo hizo a través del terciario; las cifras correspondientes a los hombres $(n=436)$ alcanzan un $34.9 \%$, en el primer caso, y un 55.7\%, en el segundo. En el sector primario, destino privilegiado de las migraciones tradicionales de México a los Estados Unidos, sólo se ubicaron en su primer trabajo el $2.6 \%$ de las mujeres y el $9.4 \%$ de los hombres. Adicionalmente, debe señalarse que la mayoría (64.7\%) de quienes ingresaron a través de este sector lo hizo en lugares de la Unión Americana distintos a la zona Nueva York-Nueva Jersey, sobre todo en al estado de California (32.5\%).

Si este primer ingreso es observado a través de las distintas cohortes ${ }^{25}$, puede verse también una situación diferenciada. Mientras que en el caso de los hombres se presenta un perfil relativamente estable y con cambios poco significativos a lo largo de las cohortes (un comportamiento oscilatorio en el primario y una disminución constante de la importancia relativa del secundario), en el que destaca claramente la mayor importancia relativa del sector terciario; en el caso de las mujeres sí se presentan cambios importantes. Por un lado, la presencia en el sector terciario crece constantemente hasta llegar a convertirse, en la última cohorte, en el principal puerto de entrada; en tanto que el sector secundario pierde peso relativo y pasa a ocupar el segundo lugar. Por el otro, resulta interesante ver que el perfil de la distribución de las mujeres en la cohorte más reciente, tiende a asemejarse considerablemente al que muestra la de los hombres en todas las demás.

La diferencia señalada queda más claramente ilustrada si se ubica la ocupación específica a la cual ingresaron las personas migrantes en su primer evento laboral en los Estados Unidos. Mientras que para las mujeres destaca como el principal puerto de entrada el subsector de la industria de la confección (con un 42.5\%), esto es: los sweatshop, que históricamente han sido la fuente de trabajo fundamental para las mujeres de las sucesivas olas migratorias que han llegado a Nueva York, y en segundo lugar se ubica el servicio

\footnotetext{
25 Las cohortes a partir de las cuales se hará el análisis de la integración al mercado de trabajo norteamericano son las siguientes: 1=hasta 1983 (14 mujeres y 63 hombres), 2=de 1984 a 1988 (24 mujeres y 70 hombres), 3=de 1989 a 1993 (112 mujeres y 215 hombres), y 4=de 1994 en adelante (33 mujeres y 83 hombres).
} 
doméstico (22.3\%); para los hombres el punto de acceso se sitúa sobre todo en los restaurantes (con un 33\%, contra sólo un 15\% de las mujeres), y después, muy lejanamente, en la propia industria de la confección $(16.3 \%)^{26}$, en el comercio (13.5\%) y en la construcción (12.8\%). Debe recordarse que también los restaurantes han sido tradicionalmente un nicho de mercado fundamental para las sucesivas inmigraciones a esta zona.

Para las mujeres (cuadro y gráfica \# 1 y tabla 2), la importancia central que la confección reviste como puerto de ingreso se mantiene a lo largo del tiempo; aunque en la cohorte más reciente cede el primer lugar frente al trabajo doméstico, que desde la segunda cohorte crece constantemente en peso relativo. Entonces, la terciarización de los primeros eventos laborales de las mujeres, obedece sobre todo a esta importancia ascendente de labores privadas en hogares norteamericanos, aunque no sea despreciable el trabajo en restaurantes y en el comercio (la importancia de las demás actividades es sólo marginal y la construcción está completamente excluida).

Para los hombres (cuadro y gráfica \# 2 y tabla 2), los restaurantes son claramente el principal puerto de entrada. Aunque su importancia relativa disminuye constantemente a lo largo de las cohortes, en la más reciente aún duplica la importancia de cualquier otra actividad. Con relación al resto de las actividades, la agricultura y la construcción, que fueron los segundos puertos de entrada en la cohorte más antigua, tienden a perder importancia relativa; en tanto que la confección y el comercio tienden a aumentarla (el peso de las demás actividades es marginal).

\footnotetext{
${ }^{26}$ Aunque debe señalarse que en esta industria, el número absoluto de hombres que ingresó por su conducto al mercado de trabajo norteamericano prácticamente iguala al de las mujeres
} 
TABLA \# 2

\begin{tabular}{|c|c|c|}
\hline \multicolumn{3}{|c|}{$\begin{array}{c}\text { DISTRIBUCIÓN PORCENTUAL DE HOMBRES Y MUJERES, POR COHORTE, EN LAS SUBRAMAS } \\
\text { DE ACTIVIDAD (1er trabajo en los EUA) }\end{array}$} \\
\hline $\begin{array}{l}\text { Cohorte de ingreso al mercado de } \\
\text { trabajo en EUA }\end{array}$ & $\begin{array}{l}\text { Mujeres } \\
\% \text { del total por cohorte }\end{array}$ & $\begin{array}{c}\text { Hombres } \\
\% \text { del total por cohorte }\end{array}$ \\
\hline \multicolumn{3}{|c|}{ Confección } \\
\hline Hasta 1983 & 43.8 & 7.6 \\
\hline De 1984 a 1988 & 44.0 & 11.6 \\
\hline De 1989 a 1993 & 47.4 & 21.9 \\
\hline Desde 1994 en adelante & 25.0 & 12.8 \\
\hline \multicolumn{3}{|c|}{ Restaurantes } \\
\hline Hasta 1983 & 18.8 & 40.9 \\
\hline De 1984 a 1988 & 24.0 & 39.1 \\
\hline De 1989 a 1993 & 11.2 & 31.2 \\
\hline Desde 1994 en adelante & 19.4 & 26.7 \\
\hline \multicolumn{3}{|c|}{ Construcción } \\
\hline Hasta 1983 & 0 & 21.2 \\
\hline De 1984 a 1988 & 0 & 21.7 \\
\hline De 1989 a 1993 & 0 & 8.4 \\
\hline Desde 1994 en adelante & 0 & 10.5 \\
\hline \multicolumn{3}{|c|}{ Comercio } \\
\hline Hasta 1983 & 0 & 0 \\
\hline De 1984 a 1988 & 8.0 & 13.0 \\
\hline De 1989 a 1993 & 7.8 & 18.1 \\
\hline Desde 1994 en adelante & 13.9 & 12.8 \\
\hline \multicolumn{3}{|c|}{ Agricultura } \\
\hline Hasta 1983 & 0 & 21.2 \\
\hline De 1984 a 1988 & 0 & 5.8 \\
\hline De 1989 a 1993 & 3.4 & 5.6 \\
\hline Desde 1994 en adelante & 2.8 & 12.8 \\
\hline \multicolumn{3}{|c|}{ Trabajo doméstico } \\
\hline Hasta 1983 & 25.0 & 1.5 \\
\hline De 1984 a 1988 & 16.0 & 2.9 \\
\hline De 1989 a 1993 & 20.7 & 5.1 \\
\hline Desde 1994 en adelante & 30.6 & 10.5 \\
\hline \multicolumn{3}{|c|}{ Otros servicios } \\
\hline Hasta 1983 & 0 & 0 \\
\hline De 1984 a 1988 & 0 & 1.4 \\
\hline De 1989 a 1993 & 4.3 & 5.6 \\
\hline Desde 1994 en adelante & 5.6 & 4.7 \\
\hline \multicolumn{3}{|c|}{ Otras industrias } \\
\hline Hasta 1983 & 12.5 & 7.6 \\
\hline De 1984 a 1988 & 8.0 & 4.3 \\
\hline De 1989 a 1993 & 5.2 & 4.2 \\
\hline Desde 1994 en adelante & 2.8 & 9.3 \\
\hline
\end{tabular}


Además de esa distinta distribución de las actividades dentro del sector de los servicios, entre mujeres y hombres puede ubicarse también como una diferencia importante el hecho de que, en la última cohorte, las mujeres concentren sus eventos iniciales en cuatro actividades principales que muestran diferencias de participación entre ellas (trabajo doméstico, con el 30.6; confección, con el 25\%; restaurantes, con el 19.4\%; y comercio, con el 13.9\%). En esa misma cohorte, mientras tanto, los hombres muestran una mayor diversificación, con un peso relativo similar, en sus puertos de entrada. Aparte de los restaurantes, que representan el 26.7\%, seis actividades muestran pesos relativos significativos y más o menos parejos entre sí (confección, comercio y agricultura, con casi el $13 \%$ cada una; construcción y trabajo doméstico, con el 10.5\% cada una; y otro tipo de industrias, con el 9.3\%).

\section{CARACTERISTICAS PRINCIPALES DE LOS TRABAJOS}

Resulta ahora interesante detenerse en una descripción general de algunas de las características principales de los trabajos que conformaron las trayectorias laborales, tales como el tamaño de los establecimientos, las jornadas de trabajo (diarias y semanales) y la duración de los eventos.

La mayoría de las personas encuestadas, tanto mujeres como hombres, se empleó por primera vez en los Estados Unidos en empresas muy pequeñas, con largas jornadas diarias de trabajo y con una extensa jornada semanal. En cuanto a lo primero, casi el 50\% entró a trabajar en establecimientos de un máximo de 10 trabajadores $(40.5 \%$ de las mujeres y $53.9 \%$ de los hombres) y sólo alrededor de un $16 \%$ lo hizo en establecimientos con más de 35 trabajadores.

En lo que toca a la jornada semanal por días laborados, cerca del $65 \%$ del total trabajaba 6 días a la semana (el $69.2 \%$ de las mujeres y el $62.4 \%$ de los hombres) y otro 16.7\% lo hacía durante 7 días. Sólo marginalmente, tanto hombres como mujeres llegaron a emplearse por menos de cinco días a la semana. En tanto, sus jornadas semanales por horas de trabajo, fueron de más de 60 horas para un $20.4 \%$ (para el 15.7\% de las mujeres y para el $22.4 \%$ de los hombres) y sólo para el $22.4 \%$ eran de 40 horas o menos (para el $20.5 \%$ de las mujeres y para el $22.4 \%$ de los hombres). 
Un dato que tal vez pueda resultar sorprendente es que, en su primer trabajo en los Estados Unidos, las personas que conforman la muestra tuvieron una permanencia importante. Cerca del $45 \%$ permaneció en ese primer empleo por más de dos años (el 3.2\% lo hizo por más de 10 años), sin diferencias importantes entre hombres y mujeres; y sólo el $10.7 \%$ estuvo menos de cuatro meses.

También visto por cohortes (cuadros y gráficas \# 4 y 5 y tabla 3), el tamaño de los establecimientos en los que trabajaron las personas migrantes en su primer evento laboral en los Estados Unidos, es predominantemente pequeño. Con la excepción de las mujeres en la primera cohorte, más de la mitad, tanto de mujeres como de hombres, siempre correspondió a un tamaño máximo de 20 trabajadores. En el caso de los hombres, más de la mitad en las tres últimas cohortes se ubicó en establecimientos de menos de 11 trabajadores; como lo hizo cerca del $63 \%$ de las mujeres de la última. En general, en todas las cohortes, más mujeres que hombres en promedio se situaron en establecimientos mayores a las 21 personas.

Los días semanales laborados (cuadros y gráficas \# 5 y 6 y tabla 4) se concentran marcadamente en seis, en todas las cohortes, para ambos sexos, con la excepción de las mujeres en la primera de ellas, cuando el $43.8 \%$ trabajó cinco días. Cabe hacer resaltar que sólo marginalmente, hombres y mujeres trabajaron de uno a cuatro días semanales y que alrededor de una sexta parte, en ambos casos, laboró sin tener al menos un día semanal de descanso.

En cuanto a las horas semanales de trabajo (cuadros y gráficas \# 7 y 8 y tabla 5), destaca que las jornadas parciales de menos de 40 horas fueron siempre la excepción en estos primeros eventos; salvo en el caso de las mujeres en la primera cohorte (18.8\%), siempre fueron inferiores al $15 \%$ en ambos casos. En el extremo contrario, las jornadas superiores a las 60 horas a la semana fueron, sobre todo entre los hombres, bastante significativas (oscilaron entre poco menos de un quinto y poco más de un cuarto del total); y entre las mujeres fueron de un $13.5 \%$ a un $25 \%$. Sin embargo, el grueso de las jornadas se ubicó entre las 40 y las 60 horas a la semana, con una tendencia marcada a ubicarse arriba de las 50 horas en el caso de las mujeres, en las últimas dos cohortes. 
Pese a las diferencias señaladas, las jornadas de trabajo semanales, tanto en días como en horas, no presentan diferencias significativas para hombres y mujeres, en el conjunto de las cohortes.

Las diferencias entre mujeres y hombres son un poco más pronunciadas, aunque no tajantes, si se compara la duración de estos primeros eventos (cuadros y gráfica \# 9 y 10 y tabla 6). Un primer dato que resulta sorprendente, es que el $17.4 \%$ de los hombres de la cohorte más antigua, permaneció en su empleo por más de diez años; mientras que tanto los hombres de la segunda cohorte y las mujeres de ambas, muestran porcentajes entre el $6 \%$ y el $8 \%$ para este tipo de duración. En el extremo contrario, destaca que, con la excepción de la tercera cohorte, las mujeres tuvieron porcentajes siempre superiores a los de los hombres en los eventos que duraron sólo hasta un tercio del año (el porcentaje fue de casi un 37\% en la cohorte más reciente).

Aunque de manera decreciente a lo largo de las cohortes, los datos muestran una permanencia digna de consideración, tanto para hombres como para mujeres. Al respecto, cabe hacer resaltar que en los estratos de más de dos y hasta cuatro años de duración, y de más de cuatro y hasta diez años (excluyendo la última cohorte, para la que es poco pertinente el cálculo), se concentra aproximadamente la mitad de las mujeres y de los hombres.

No obstante lo anterior, debe señalarse que en la última cohorte, arriba de la mitad de cada uno de ambos sexos se ubicó en trabajos que duró un máximo de un año; y que otra cuarta parte, para las mujeres, o cerca de un tercio, para los hombres, lo hizo en eventos que duraron como máximo dos años.

Con relación al ingreso que tenían antes de este trabajo, como era de esperarse, la inmensa mayoría de hombres y mujeres (el 92.1\%) declaró ganar más que en su antiguo trabajo.

Hasta aquí puede verse que las personas migrantes a Nueva York, originarias de los estados de Puebla y Tlaxcala, se ubicaron en su primer trabajo en los Estados Unidos preferentemente en trabajos de los sectores secundario y terciario (las mujeres sobre todo en la industria de la confección y los hombres en los restaurantes), en establecimientos más bien pequeños, con extensas jornadas de trabajo, pero con una cierta estabilidad y con ingresos superiores a los que tenían previamente en México. 
TABLA \# 3

\begin{tabular}{|c|c|c|}
\hline \multicolumn{3}{|c|}{$\begin{array}{l}\text { DISTRIBUCIÓN PORCENTUAL DE HOMBRES Y MUJERES, POR COHORTE Y POR TAMAÑO DEL } \\
\text { ESTABLECIMIENTO (primer trabajo en EUA) }\end{array}$} \\
\hline $\begin{array}{l}\text { Cohorte de ingreso al mercado de } \\
\text { trabajo en EUA }\end{array}$ & $\begin{array}{c}\text { Mujeres } \\
\% \text { del total por cohorte }\end{array}$ & $\begin{array}{c}\text { Hombres } \\
\% \text { del total por cohorte }\end{array}$ \\
\hline \multicolumn{3}{|l|}{ Hasta 10 trabajadores } \\
\hline Hasta 1983 & 26.7 & 32.3 \\
\hline De 1984 a 1988 & 46.2 & 58.8 \\
\hline De 1989 a 1993 & 33.9 & 57.7 \\
\hline Desde 1994 en adelante & 62.9 & 57.1 \\
\hline \multicolumn{3}{|c|}{ De 11 a 20 trabajadores } \\
\hline Hasta 1983 & 13.3 & 30.8 \\
\hline De 1984 a 1988 & 7.7 & 17.6 \\
\hline De 1989 a 1993 & 20.2 & 23.3 \\
\hline Desde 1994 en adelante & 11.4 & 25.0 \\
\hline \multicolumn{3}{|c|}{ De 21 a 35 trabajadores } \\
\hline Hasta 1983 & 13.3 & 9.2 \\
\hline De 1984 a 1988 & 26.9 & 11.8 \\
\hline De 1989 a 1993 & 21.1 & 8.8 \\
\hline Desde 1994 en adelante & 11.4 & 10.7 \\
\hline \multicolumn{3}{|c|}{ De 36 a 60 trabajadores } \\
\hline Hasta 1983 & 13.3 & 15.4 \\
\hline De 1984 a 1988 & 15.4 & 8.8 \\
\hline De 1989 a 1993 & 21.1 & 8.8 \\
\hline Desde 1994 en adelante & 14.3 & 2.4 \\
\hline \multicolumn{3}{|c|}{ De más de 60 trabajadores } \\
\hline Hasta 1983 & 33.3 & 12.3 \\
\hline De 1984 a 1988 & 3.8 & 2.9 \\
\hline De 1989 a 1993 & 3.7 & 1.4 \\
\hline Desde 1994 en adelante & 0 & 4.8 \\
\hline
\end{tabular}


TABLA \# 4

\begin{tabular}{|c|c|c|}
\hline \multicolumn{3}{|c|}{$\begin{array}{l}\text { DISTRIBUCIÓN PORCENTUAL DE HOMBRES Y MUJERES, POR COHORTE Y POR DIAS } \\
\text { SEMANALES DE TRABAJO (primer trabajo en EUA) }\end{array}$} \\
\hline $\begin{array}{l}\text { Cohorte de ingreso al mercado de } \\
\text { trabajo en EUA }\end{array}$ & $\begin{array}{c}\text { Mujeres } \\
\% \text { del total por cohorte }\end{array}$ & $\begin{array}{c}\text { Hombres } \\
\% \text { del total por cohorte }\end{array}$ \\
\hline \multicolumn{3}{|c|}{1 DIA } \\
\hline Hasta 1983 & 0 & 0 \\
\hline De 1984 a 1988 & 0 & 0 \\
\hline De 1989 a 1993 & 0 & 0.5 \\
\hline Desde 1994 en adelante & 0 & 0 \\
\hline \multicolumn{3}{|c|}{2 DIAS } \\
\hline Hasta 1983 & 0 & 0 \\
\hline De 1984 a 1988 & 0 & 0 \\
\hline De 1989 a 1993 & 0 & 0.5 \\
\hline Desde 1994 en adelante & 0 & 0 \\
\hline \multicolumn{3}{|c|}{3 DIAS } \\
\hline Hasta 1983 & 0 & 0 \\
\hline De 1984 a 1988 & 0 & 0 \\
\hline De 1989 a 1993 & 1.8 & 1.9 \\
\hline Desde 1994 en adelante & 0 & 1.2 \\
\hline \multicolumn{3}{|c|}{4 DIAS } \\
\hline Hasta 1983 & 0 & 1.5 \\
\hline De 1984 a 1988 & 0 & 1.5 \\
\hline De 1989 a 1993 & 1.8 & 0.5 \\
\hline Desde 1994 en adelante & 0 & 3.7 \\
\hline \multicolumn{3}{|c|}{5 DIAS } \\
\hline Hasta 1983 & 43.8 & 20.0 \\
\hline De 1984 a 1988 & 28.0 & 16.9 \\
\hline De 1989 a 1993 & 7.2 & 13.2 \\
\hline Desde 1994 en adelante & 12.1 & 17.1 \\
\hline \multicolumn{3}{|c|}{6 DIAS } \\
\hline Hasta 1983 & 37.5 & 63.1 \\
\hline De 1984 a 1988 & 56.0 & 66.2 \\
\hline De 1989 a 1993 & 74.8 & 61.9 \\
\hline Desde 1994 en adelante & 75.8 & 59.8 \\
\hline \multicolumn{3}{|c|}{7 DIAS } \\
\hline Hasta 1983 & 18.8 & 15.4 \\
\hline De 1984 a 1988 & 16.0 & 15.5 \\
\hline De 1989 a 1993 & 14.4 & 18.6 \\
\hline Desde 1994 en adelante & 12.2 & \\
\hline
\end{tabular}


TABLA \# 5

\begin{tabular}{|c|c|c|}
\hline \multicolumn{3}{|c|}{$\begin{array}{l}\text { DISTRIBUCIÓN PORCENTUAL DE HOMBRES Y MUJERES, POR COHORTE Y POR HORAS } \\
\text { SEMANALES DE TRABAJO (primer trabajo en EUA) }\end{array}$} \\
\hline $\begin{array}{l}\text { Cohorte de ingreso al mercado de } \\
\text { trabajo en EUA }\end{array}$ & $\begin{array}{c}\text { Mujeres } \\
\% \text { del total por cohorte }\end{array}$ & $\begin{array}{l}\text { Hombres } \\
\% \text { del total por cohorte }\end{array}$ \\
\hline \multicolumn{3}{|c|}{ MENOS DE 40 HORAS } \\
\hline Hasta 1983 & 18.8 & 3.1 \\
\hline De 1984 a 1988 & 12.0 & 14.1 \\
\hline De 1989 a 1993 & 13.5 & 14.0 \\
\hline Desde 1994 en adelante & 6.1 & 14.6 \\
\hline \multicolumn{3}{|c|}{ DE 40 A 50 HORAS } \\
\hline Hasta 1983 & 43.8 & 33.8 \\
\hline De 1984 a 1988 & 36.6 & 43.7 \\
\hline De 1989 a 1993 & 25.2 & 36.7 \\
\hline Desde 1994 en adelante & 30.3 & 40.2 \\
\hline \multicolumn{3}{|c|}{ DE 50 A 60 HORAS } \\
\hline Hasta 1983 & 12.5 & 36.9 \\
\hline De 1984 a 1988 & 36.0 & 18.3 \\
\hline De 1989 a 1993 & 47.7 & 30.7 \\
\hline Desde 1994 en adelante & 45.5 & 17.1 \\
\hline \multicolumn{3}{|c|}{ MAS DE 60 HORAS } \\
\hline Hasta 1983 & 25.0 & 26.2 \\
\hline De 1984 a 1988 & 16.0 & 23.9 \\
\hline De 1989 a 1993 & 13.5 & 18.6 \\
\hline Desde 1994 en adelante & 18.2 & 28.0 \\
\hline
\end{tabular}


TABLA \# 6

\begin{tabular}{|c|c|c|}
\hline \multicolumn{3}{|c|}{$\begin{array}{l}\text { DISTRIBUCIÓN PORCENTUAL DE HOMBRES Y MUJERES, POR COHORTE Y POR DURACION } \\
\text { DEL EVENTO LABORAL (primer trabajo en EUA) }\end{array}$} \\
\hline $\begin{array}{l}\text { Cohorte de ingreso al mercado de } \\
\text { trabajo en EUA }\end{array}$ & $\begin{array}{l}\text { Mujeres } \\
\% \text { del total por cohorte }\end{array}$ & $\begin{array}{c}\text { Hombres } \\
\% \text { del total por cohorte }\end{array}$ \\
\hline \multicolumn{3}{|l|}{ HASTA CUATRO MESES } \\
\hline Hasta 1983 & 12.5 & 5.8 \\
\hline De 1984 a 1988 & 17.9 & 10.8 \\
\hline De 1989 a 1993 & 5.1 & 7.8 \\
\hline Desde 1994 en adelante & 36.8 & 22.1 \\
\hline \multicolumn{3}{|c|}{ DE CUATRO MESES A UN AÑO } \\
\hline Hasta 1983 & 18.8 & 26.1 \\
\hline De 1984 a 1988 & 17.9 & 16.2 \\
\hline De 1989 a 1993 & 28.0 & 23.7 \\
\hline Desde 1994 en adelante & 23.7 & 33.7 \\
\hline \multicolumn{3}{|c|}{ DE MAS DE UNO HASTA DOS AÑOS } \\
\hline Hasta 1983 & 12.5 & 15.9 \\
\hline De 1984 a 1988 & 10.7 & 5.4 \\
\hline De 1989 a 1993 & 19.5 & 20.1 \\
\hline Desde 1994 en adelante & 26.3 & 30.2 \\
\hline \multicolumn{3}{|c|}{ DE MAS DE DOS HASTA CUATRO AÑOS } \\
\hline Hasta 1983 & 25.0 & 13.0 \\
\hline De 1984 a 1988 & 25.0 & 36.5 \\
\hline De 1989 a 1993 & 28.8 & 31.5 \\
\hline Desde 1994 en adelante & 13.2 & 14.0 \\
\hline \multicolumn{3}{|c|}{ DE MAS DE CUATRO HASTA DIEZ AÑOS } \\
\hline Hasta 1983 & 25.0 & 21.7 \\
\hline De 1984 a 1988 & 21.4 & 23.0 \\
\hline De 1989 a 1993 & 18.6 & 16.9 \\
\hline Desde 1994 en adelante & 13.2 & 14.0 \\
\hline \multicolumn{3}{|c|}{ MAS DE DIEZ AÑOS } \\
\hline Hasta 1983 & 6.3 & 17.4 \\
\hline De 1984 a 1988 & 7.1 & 8.1 \\
\hline De 1989 a 1993 & 0 & 0 \\
\hline Desde 1994 en adelante & 0 & 0 \\
\hline
\end{tabular}


A continuación se procederá a presentar una descripción analítica de los dos principales trabajos desarrollados por las personas migrantes de México a la zona metropolitana de la ciudad de Nueva York. Más adelante, se verá lo que sucedió a lo largo de las trayectorias laborales de las personas de la muestra.

\section{SUDANDO EN LOS TALLERES, SUDANDO EN LAS COCINAS: LOS PROCESOS DE TRABAJO MAS IMPORTANTES}

Por la importancia evidente de los trabajos en los talleres de confección y en los restaurantes, resulta conveniente proceder a una descripción detenida de las características del trabajo en estos establecimientos, basada en los testimonios recabados, en la observación directa y en algunas fuentes secundarias.

\section{Los sweatshops}

Este tipo de establecimientos, conocidos tradicionalmente como sweatshop, (talleres de confección de ropa y accesorios, sobre todo; o bien, en menor medida, de artículos de plástico o de partes metálicas 27 ), han sido ampliamente estudiadas (Ross y Trachte, 1982; Leichter, Von Nostitz y González, 1981; Foner, 1987; Marshall, 1987; Sassen, 1991; Green, 1997). Por un lado, son establecimientos que operan, en varios sentidos, al margen de las leyes y las reglamentaciones oficiales, pero son tolerados porque, entre otras cosas, ayudan a mantener la competitividad de la industria norteamericana.

La palabra sweatshop fue usada originalmente en el siglo XIX para describir un sistema de subcontratación en el cual el intermediario extraía sus ganancias del margen existente entre la cantidad que recibía del contratista y la cantidad que él pagaba a los trabajadores que subcontrataba. Se decía entonces que el margen era el sudor exprimido a los trabajadores, porque éstos recibían ingresos mínimos a cambio de jornadas exesivas de trabajo realizadas en condiciones insalubres (Sindicato Unite, página webb, octubre de 1999, traducción propia).

No ha cambiado radicalmente esa pauta de funcionamiento. En estos talleres, históricamente, la mayor parte de las personas que trabaja ha sido siempre inmigrante,

\footnotetext{
27.- La información para este apartado proviene tanto de los resultados preliminares de los datos obtenidos a
} través del cuestionario y las entrevistas; pero también de la observación directa (fuimos a muchos de esos 
ahora indocumentada en su mayoría, y particularmente conformada por mujeres jóvenes (actualmente, sobre todo de origen mexicano y ecuatoriano), que son contratadas en forma precaria, a través de acuerdos verbales, con salarios inferiores al mínimo establecido y sin las prestaciones que generalmente están asociadas a los trabajos industriales. A lo largo de las sucesivas olas de inmigrantes a Nueva York, este ha sido un puerto de entrada fundamental al mercado de trabajo. De hecho, quienes han estudiado el tema (Foner, 1987; Green, 1997; Marshall, 1987; Piore, 1990), consideran que estos trabajos no existirían sin los migrantes. Esto es, no se presenta aquí un fenómeno de desplazamiento de la mano de obra local por la inmigrante, sino que las sucesivas olas migratorias se han integrado a este segmento del mercado de trabajo y después lo han abandonado, cuando han tenido la oportunidad de conseguir mejores trabajos y, en general, cuando su situación ha experimentado una mejoría general.

Por el otro lado, la propiedad de muchos de estos establecimientos es también de migrantes, especialmente de judíos, de italianos y, más recientemente, de coreanos 28 . Cabe señalar que resulta relativamente barato instalar un negocio de este tipo. En 1996, de acuerdo a la información del sindicato Unite, 50 mil dólares eran suficientes; mientras que una tienda de abarrotes requería de una inversión inicial de más de 200 mil. De acuerdo también a la información de Unite (página web, noviembre de 1999), en 1994 había en la industria norteamericana del vestido unos 5 mil establecimientos, de los cuales 4,500 eran sweatshop.

Las condiciones de trabajo en los sweatshop combinan jornadas diarias de 10 o 12 horas, con ambientes llenos de ruido, polvo y partículas volantes de los materiales de trabajo. Regularmente, se trabaja con instrumentos manuales y máquinas mecánicas y eléctricas no automatizadas, que realizan operaciones elementales de corte o ensamble; y que dependen en buena medida de las habilidades y destrezas de la fuerza de trabajo. No obstante, para trabajar ahí no es necesario ningún tipo de entrenamiento previo. De hecho, en el propio trabajo se adquiere la capacitación necesaria. Como señala Piore, la industria de la confección y otras similares en Nueva York, gracias a la constante y siempre renovada

talleres a solicitar trabajo) y de la gentil colaboración de Bertha Williams y Juán Carlos, del Centro de Justicia del Sindicato UNITE de Manhattan.

${ }^{28}$ Este tema se desarrollará más ampliamente en un apartado subsecuente. 
disposición de una fuerza de trabajo inmigrante barata, han escapado a las presiones en favor de la introducción de nuevas tecnologías productivas (Piore, 1990).

Por otro lado, el trato a los trabajadores es despótico y, según refieren algunas de las personas entrevistadas por nosotros, se llega incluso al maltrato físico. Al hablar de su experiencia en ellos, Aurora refiere que ella trabajaba en un taller

... de ropa de niña, y ahí mismo en ese piso, había una de tarjetas de navidad. Entonces, de noche trabajaba yo en la de tarjeta de navidad, y en el día, trabajaba yo en la de la ropa... Pero, la gente es muy exigente, para entrar al baño, 5 minutos, y no tantas veces; para comer, 10 o 20 minutos solamente, no más, no tienes que estar hablando con las demás personas, y nada más estaban vigilando...; no, el señor iba y venía, hasta de nervios ponía porque era de caminar y caminar y caminar, ese era el trabajo del señor. El que cuidaba, pues, el encargado... (Aurora, originaria de Piaxtla).

Una buena parte de los propietarios de estas empresas son de origen asiático (especialmente coreano), pero también los hay judíos, italianos y latinoamericanos. Por otro lado, es necesario decir que este tipo de establecimientos está distribuido por todas las zonas de la ciudad de Nueva York. Una buena parte de ellos se ubica en el centro de Manhattan, pero también existen concentraciones importantes en El Bronx, en Queens y en Brooklyn. Según refieren el Sindicato Unite, que desarrolla un importante trabajo de organización y defensa de los trabajadores de estos establecimientos, una práctica frecuente consiste en eludir el pago de los salarios ya devengados por los trabajadores; ya sea mediante el cierre imprevisto del taller en una ubicación, mismo que después se reabre en otra; ya sea mediante la simple negativa directa o el despido injustificado. Se llega incluso, y no de manera infrecuente, a casos en los que el propietario denuncia anónimamente la presencia de indocumentados en el taller, para que la migra realice una redada. Bertha Williams ${ }^{29}$, del Centro de Justicia de Unite nos dice que eso ha llevado a disputas entre el

\footnotetext{
${ }^{29}$ Bertha Williams es una mujer de aproximadamente 40 años de edad, veinte de los cuales los ha pasado en Nueva York. Nacida en Ecuador, trabajó durante mucho tiempo en este tipo de talleres. Actualmente, se dedica de tiempo completo a las tareas de organización sindical y defensa de los derechos de los migrantes. Para esta investigación, su colaboración fue fundamental.
} 
Departamento del Trabajo, sobre todo cuando Sweeney era delegado del trabajo, y las autoridades migratorias; en las que las primera exigen que al menos se cubran los salarios devengados. Con orgullo, afirma Bertha Williams:

Nosotros hemos recuperado, en los 3 últimos años, alrededor de más de un millón de dólares, en salarios atrasados, que sobrepasa la cantidad de salarios atrasados que el Departamento de Trabajo ha recuperado.

En términos generales, la rotación en estos establecimientos es muy alta y las posibilidades de estabilidad o ascenso resultan mínimas. Para ingresar a estos establecimientos no se requiere ni de exámenes, ni de credenciales de ningún tipo. En general, las recomendaciones tampoco son necesarias. Más bien, el reclutamiento se hace a partir de quienes llegan directamente a pedir empleo y a través exclusivamente de la discrecionalidad de los reclutadores, que generalmente son a un tiempo los dueños, los administradores y los capataces del taller ${ }^{30}$.

Gracias a Bertha y Juán Carlos ${ }^{31}$, del Centro de Justicia de Unite, fue posible conocer por dentro esos talleres y los mecanismos de contratación. En la entrevista que concedieron, se les preguntó por las formas de contratación y amablemente las explicaron. Al final, Bertha le pidió a Juan Carlos que organizara una especie de excursión para conocer de directamente a conocer las factories. El consideró que era un buen momento: pues ahora mismo, porque es hora del lunch y mucha gente está entrando y saliendo de los edificios, hay un buen chance para hacerlo. La mayor parte de los sweatshop se encuentran alrededor de 7 a.avenida, entre la calle 42 y la 35 . Junto a la terminal de autobuses y trenes, Porth Authority, empieza una zona muy grande de factories. Es el corazón productivo del distrito de la costura; tal y como lo ubica Green (1997), en el corazón de Manhattan.

El primer taller al que se pudo entrar se encontraba en un gran edificio, poblado exclusivamente por sweatshop, en un promedio de tres o cuatro por piso. En la entrada,

\footnotetext{
30.- Aunque, en algunos casos, el capataz es una persona contratada para el efecto; y, muchas veces, es de la nacionalidad de la mayoría de los trabajadores.

31 Juan Carlos es un jóven (19 o 20 años), originario de la región de Tehuacán, en el estado de Puebla, que entró a trabajar en los sweatshops por orientación de una tía suya que lleva ya varios años en Nueva York. No se limita a trabajar: es además un importante organizador sindical de base.
} 
sentada frente a un escritorio, pero con la vista atenta sobre el taller, se encontraba una mujer coreana. Desde la puerta era posible ver prácticamente todo el establecimiento. Sin divisiones, mal ventilado e iluminado, consistía en un verdadero apilamiento de máquinas mecánicas y eléctricas para cortar, hacer dobladillos y cocer. También había mesas en las que se realizaban operaciones manuales, con instrumentos sencillos, como tijeras y agujas. Los talleres clandestinos que el terremoto de 1985 sacó a la luz en la ciudad de México, en la zona de San antonio Abad, tienen un enorme parecido con los neoyorquinos. ¿El tercer mundo en el primero? ¿la periferia en el corazón del centro? ¿la ciudad global?, como dirían Jean Franco (art de Nexos: Nueva York como ciudad del tercer mundo), Ross y Tratchke (1981), o Sassën (199 ). Por todos lados, de veían amontonamientos de materia prima y productos semiprocesados.

La gran mayoría del personal estaba compuesto por mujeres jóvenes de aspecto indudablemente latinoamericano; pero sobre todo resaltaban las muchachas poblanas: morenas, bajitas de estatura, delgaditas, de pelo oscuro, largo y atado sobre la espalda. Entre los puestos de trabajo, los capataces circulaban constantemente. Todos ellos parecían coreanos y eran más bien fornidos.

El ritmo de trabajo era acelerado y constante, aunque determinado por la habilidad de las trabajadoras (y de los muy pocos trabajadores); pero sobre todo por la presión directa de los capataces. En algunos talleres el pago es por pieza o a destajo y eso se convierte en el principal determinante del ritmo. No en este, en donde el pago era por hora. Lo supieron ese día los visitantes en trabajo de campo, porque a señas se comunicaron con la que aparentemente era la propietaria y ella les indicó con la mano que pagaba cinco dólares la hora, al tiempo que decía algo que se parecía a: “five dolar, five dolar". Fingiendo molestia, se le hizo ver que era muy poco. Entonces ella nos hizo señas con las dos manos para que los solicitantes de empleo se retiraran. La presencia de los capataces los disuadió de intentar una negociación que, de cualquier manera, sería inútil, de acuerdo a la experiencia de Juán Carlos.

La expedición siguió después en varios talleres más; pero las diferencias entre ellos eran mínimas. Un patrón hablaba como colombiano. Otro, que hablaba un muy inglés difícilmente comprensible, seguramente era judío, según el guía. No se identificó a simple vista a ningún italiano y sí a una gran cantidad de gente de Coréa. Juán Carlos aseguró que 
al conocer esos talleres ya se conocían todos los sweatshop de Nueva York; tal vez con la excepción de los del barrio chino, que tienen algunas características propias que los distinguen, aunque no en lo fundamental.

De acuerdo a los testimonios, en este campo laboral, las redes sociales sirven para la gente de México básicamente para informar a los recién llegados acerca de la ubicación y de las características de los talleres. Más adelante, sirven también para intercambiar información sobre los patrones que hacen trampa con el pago de los salarios y asuntos similares. Pero sirven, sobre todo, para poder abandonar estos trabajos, a cambio de otros con mejores condiciones de trabajo y salariales, por ejemplo en los restaurantes.

\section{Los Restaurantes}

Los restaurantes neoyorquinos son la principal fuente de empleo de los mexicanos en Nueva York y están cobrando crecientemente una importancia similar para las mexicanas migrantes. Como se ha visto, la mayor parte de los migrantes de México ingresaron al mercado de trabajo norteamericano a través de los restaurantes y, como se verá después, se mantuvieron después trabajando en ellos, más que en cualquier otro trabajo. Como también se ha visto ya, las mujeres de las cohortes más recientes, por su parte, cada vez ingresan más por este puerto de entrada, en detrimento de los talleres de confección o sweatshop, que eran las principales vías de acceso en las primeras cohortes migratorias. El de los restaurantes es, entonces, un trabajo que resulta muy significativo para las personas que migran de México a Nueva York 32 . No resulta exagerado decir que las cocinas de los restaurantes neoyorquinos están convirtiéndose crecientemente en un espacio de elevado contenido mexicano, tanto por los platillos que en ellos se preparan, como por su personal.

La suerte que han corrido quienes laboran en los restaurantes es, por supuesto, muy variada. Sin embargo, resulta de gran interés hacer resaltar que prácticamente todos los testimonios que hemos podido recoger, tanto directa como indirectamente $(33)$, coinciden en afirmar que las carreras personales más exitosas, las de quienes han llegado a convertirse en

\footnotetext{
32.- Para la información sobre los restaurantes, fueron fundamentales las pláticas con los amigos, tanto empleados como propietarios, que generosamente nos platicaron sus experiencias, nos permitieron observar directamente su trabajo y nos presentaron, en su caso, con sus empleadores, para que éstos complementaran la información.

33. Esto último, sobre todo a través de las entrevistas realizadas por Oscar López y su equipo.
} 
empresarios de diversos giros y dimensiones, iniciaron sus trayectorias laborales en los restaurantes, generalmente como lavaplatos, y sin que hubieran tenido ningún tipo de contacto previo con ese medio laboral, en los trabajos que tuvieron en México antes de migrar.

El trabajo en los restaurantes de la ciudad de Nueva York 34 está claramente dividido en una serie de categorías laborales diferenciadas y jerarquizadas, de tal forma que permite el funcionamiento de una suerte de mercados internos de trabajo, en los que resulta posible desarrollar carreras ascendentes, basadas en la adquisición de oficios tales como el de carnicero, panadero, ensaladero, cocinero, administrador o incluso propietario. La primera gran división en los restaurantes se establece entre la cocina y la atención al público. Un puerto de entrada que puede desembocar en ambas líneas de ascenso la constituye el puesto de lavaplatos; o bien el de repartidor o delivery, actividad que generalmente se combina con las demás, sobre todo en las etapas iniciales. Es interesante anotar que la mayoría de los y las migrantes de México, trabajan dentro de las cocinas; mientras que en la atención al público se puede detectar una presencia cada vez mayor de personas de origen ecuatoriano, particularmente de la región de Cuenca, así como colombiano.

En las cocinas, la categoría más baja, después del lavaplatos, es la del ayudante, quien se encarga de pelar, cortar, picar, limpiar y licuar los ingredientes de los platillos. La siguiente categoría es la del preparador de alimentos. En este puesto no se diseñan ni se deciden los platillos, sino que, bajo la supervisión del cocinero (cheff), se encarga de reunir los elementos y darles la presentación final. El cocinero, por su parte, se encarga de dirigir todas las operaciones, de diseñar los platillos y de llevar el control de las existencias en la cocina. Es decir, su función es tanto culinaria como administrativa. De hecho, los trabajadores de las cocinas lo consideran como su jefe. En grandes restaurantes, puede existir la figura del sub-cheff, que es un ayudante directo del cocinero. En los más sencillos,

\footnotetext{
${ }^{34}$ Fue una suerte para nuestro equipo llegar a Nueva York con un buen número de personas conocidas que trabajaban en restaurantes, ya sea como empleados, ya sea como propietarios. Eso nos permitió observar directamente los procesos de trabajo y las relaciones de los empleados, tanto entre ellos, como con los empleadores y los clientes. Una forma muy agradable de relizar el trabajo de campo, enmedio de charlas amistosas y muy generosas invitaciones a consumir todo lo disponible en los establecimientos. Pláticas por supuesto muy entrecortadas por las realizaciones de las actividades normales, en paréntesis que permitían observar y tomar nota del funcionamiento de este campo de trabajo y de interacción social.
} 
las categorías de ayudante y preparador pueden fundirse en una sola que, incluso, puede llegar a realizar las labores del lavaplatos. En los restaurantes más grandes y complejos, pueden existir categorías sumamente especializadas y calificadas, como la de carnicero, pescadero, ensaladero o panadero.

El reclutamiento para el trabajo en las cocinas no implica exámenes ni certificación de estudios. Quienes han realizado carreras laborales ascendentes en este campo, refieren que el aprendizaje se realiza en la práctica y depende en gran medida de la disposición de cada trabajador para ir aprendiendo las labores del resto de las funciones. Así, un lavaplatos puede ir voluntariamente colaborando con los ayudantes, los preparadores, los cheffs e, incluso, con los especialistas (carniceros, panaderos, etc.); de tal manera que va adquiriendo en la práctica el o los oficios necesarios para, primero permanecer y, después, ascender en el trabajo.

...Yo empecé a trabajar lavando platos, después de lavar platos yo... fuí bien entrón, yo le entraba yo a ayudar al cocinero, le entraba a ayudar al de las ensaladas, le entraba a ayudar al carnicero, dondequiera, dondequiera le entraba yo. Cuando no tenía yo nada qué hacer en los platos me iba yo a ayudar... cuando faltaba alguien... el dueño... o el encargado de ahí me mandaba: mira, ayuda a fulano, ayuda a... ayuda a este... y ahí iba yo a la cocina o a las ensaladas, dondequiera me aventaba yo y gracias a Dios aprendí mucha cocina, sí... (Antonio, originario de Piaxtla).

En el medio de las cocinas, las redes sociales aparecen como básicas para la obtención del trabajo. La recomendación de un Cheff acreditado, en favor de algún familiar o paisano es el mayor capital con el que puede contar cualquier migrante recién llegado a Nueva York. A cambio, el recién llegado queda obligado, implícita o explícitamente, a no hacer quedar mal a quien lo recomendó; quien se convierte en su mentor en un amplio sentido (aval, maestro y autoridad).

Para quienes ya han desarrollado parte de su trayectoria laboral en los restaurantes y han conseguido ampliar sus contactos sociales y adquirir una cualificación específica en la práctica (conocimientos, habilidades, destrezas, gusto culinario), su propio prestigio personal en el medio puede convertirse en la principal arma en el mercado laboral. Los testimonios hablan de verdaderos pirateos de cheffs prestigiados entre empresarios del ramo.

En la atención al público, existen también varias categorías. Una primera consiste en recibir a las personas que acuden al restaurante y acomodarlas en alguna mesa. Una 
segunda, es la que se encarga de llevar los cubiertos, las servilletas, el menú, el pan y el agua a las mesas; así como de retirar los utensilios y los envases desocupados. Las personas que propiamente se denominan meseros o meseras, son quienes toman la orden a los clientes y van llevando hasta las mesas los diferentes platos. Pero además de ello, son responsables de hacer sentir bien a los comensales, mediante comentarios y sugerencias. Por su contenido más aparente, estos trabajos no requieren de conocimientos complejos, ni requieren de largos periodos de entrenamiento o de cursos escolarizados; sin embargo, implican otro tipo de formación previa, más bien de tipo social (habitus).

Como resulta obvio, un requisito fundamental para estas funciones consiste en un manejo solvente del idioma inglés; pero para la selección del personal que cubre este tipo de puestos intervienen también otros elementos, como la apariencia y los modales. Aunque no sea explícito, las personas con las que hemos platicado de esto nos refieren la presencia, a veces sutil, otras no tanto, de elementos de discriminación y racismo. En esta subdivisión del trabajo de los restaurantes, la importancia de las redes sociales, para el ingreso y la permanencia, es tan importante como en la anterior subdivisión.

Las jornadas de trabajo en los restaurantes son muy prolongadas. En su mayoría, se inician aproximadamente a las once o doce de la mañana y se prolongan hasta las dos o tres de la mañana del día siguiente. O bien, se inician a las cuatro o cinco de la mañana, para finalizar a las seis o siete de la tarde. Cabe señalar que, no obstante, es frecuente que quienes laboran en los restaurantes, cubran más de una jornada, ya sea que prolonguen su permanencia en el mismo establecimiento; o bien, que se contraten por jornadas parciales en algún otro.

Como una compensación parcial, un atractivo del trabajo en los restaurantes está en una forma de pago bastante generalizada, que consiste en que sólo una parte se realiza por medio de un cheque y el resto se hace en efectivo. Para efectos impositivos, únicamente es considerada la primera; mientras que la segunda se convierte en ingreso neto para quien trabaja. Adicionalmente, quienes trabajn en los restaurantes tienen generalmente asegurados los alimentos diarios.

\section{EL DESPLIEGUE DE LAS TRAYECTORIAS LABORALES}


Si se analiza la sucesión del total de los eventos laborales registrados en la encuesta (del conjunto de primeros al conjunto de décimos en adelante), resaltan como elementos destacados: una tendencia general hacia el abandono del sector primario, que inicialmente tiene un considerable peso (cae del $45 \%$ a poco más del $20 \%$ ); una notable fuga hacia el terciario (sube de alrededor del 35\% a más del 60\%); y una constante importancia menor del secundario (con altas y bajas, oscila alrededor del 20\%). Esa primera visión puede, sin embargo, resultar parcialmente engañosa o, más bien, insuficiente; en tanto que oculta importantes diferencias en el contenido de dichas trayectorias, en varios sentidos. Uno de ellos es el que se refiere a lo que sucede en uno y otro país; otro, es el que refiere a las muy marcadas diferencias de género.

Efectivamente, si se separan las trayectorias laborales, entre los eventos ocurridos en los Estados Unidos y los que tuvieron lugar en México ${ }^{35}$, se encuentran perfiles claramente diferenciados. Más adelante, esta ruptura o discontinuidad, será ilustrada con mayor precisión, al analizar los trabajos que se abandonan en México, para ir a los Estados Unidos; y, a la inversa, los que se dejan en este último país para regresar al de origen. Por lo pronto, es importante hacer resaltar algunos elementos de los datos que se presentarán a continuación.

Primero, que resulta clara la confirmación de un rasgo atípico de esta migración, frente a la mayoría de las que se dirigen de México hacia los Estados Unidos, consistente en que quienes migran no van a realizar trabajos de tipo agrícola, salvo por excepción, o bien complementariamente, en la primavera y en el verano, en lugares relativamente cercanos a la zona de Nueva York ${ }^{36}$. El grueso de los eventos se concentra en la industria de los servicios, mayoritaria y crecientemente a lo largo del tiempo, y en la industria manufacturera, aunque sea en su sector degradado, y de manera claramente decreciente (y, como se verá más adelante, segregada). Segundo, que en las trayectoria laborales de las personas migrantes se opera un importante cambio en sus regresos a México. Se presenta tanto una descampesinización del trabajo, como un notorio crecimiento de actividades ubicadas en los servicios y en la industria; lo que habla también de fuertes procesos de transformación no sólo de las vidas de los migrantes, sino también de sus lugares de origen,

\footnotetext{
35 Agrupación de los primeros, segundos, hasta los sextos eventos en adelante, en estos casos, de cada una de las personas de la muestra, en cada uno de los países.

36 En la descripción de los trabajos que se realizan en esta ciudad, se presentan testimonios al respecto.
} 
como efecto fundamentalmente de las remesas; pero también de cambios operados en las expectativas y estilos de vida de quienes han migrado. El tercer elemento que se quiere destacar consiste en que estas trayectorias, en un número importante de casos, mezclan hacia su interior varios eventos en uno y otro país; esto es, se trata de trayectorias transnacionalizadas, que expresan una existencia pendular entre los diversos territorios que conforman el espacio transnacional plurilocalizado. De ellas, se presentará más adelante un análisis especial.

En esta parte, se presentan los datos que permiten describir en términos generales las trayectorias laborales, separadas de acuerdo a los eventos realizados sucesivamente en México y en los Estados Unidos, aunque con interrupciones marcadas precisamente por los cambios de país. En los Estados Unidos es el sector terciario siempre el de mayor importancia relativa (va de casi el 54\% a cerca del 80\%), el sector primario ocupa siempre una posición marginal (del 7.3\% al 4.1\%), y el secundario decrece sensiblemente (del 39\% al 16.3\%). En México, el comportamiento es considerablemente distinto; por un lado, la mayor parte de los arranques de las trayectorias se presentan, como ya se vio anteriormente, en el sector primario (casi el 60\% de los casos), para luego descender hasta casi la mitad (alrededor de un 30\%). En el caso del sector secundario, se presenta un importante crecimiento, que triplica su número de casos (del 10\% al 30\%). Con oscilaciones, la importancia del sector terciario va de poco más de un $30 \%$ a poco más de un $40 \%$ del total de casos.

Si los eventos laborales se agrupan por cohortes ${ }^{37}$, los resultados no difieren sustancialmente. Para los que corresponden a los Estados Unidos, el sector terciario mantiene siempre y de manera clara el mayor número de casos (de casi el 52\% a más del $60 \%$ ); el primario ocupa una posición de muy poca importancia (cae de poco más del 10\% a poco más del 9\%), y el secundario se mantiene en un lugar intermedio con un peso significativo, pero decreciente (de más del 38\% a poco más del 30\% del total de casos). Esa diferencia entre lo que sucede en las trayectorias y lo que sucede en las cohortes, ratifica la idea de que existen algunos puertos de entrada (como los sweatshop) que son abandonados

\footnotetext{
37 Para los eventos realizados en los Estados Unidos, las cohortes son: a) hasta 1988 (63 de mujeres y 216 de hombres), b) de 1989 a 1991 (117 y 285, respectivamente), c) de 1992 a 1994 (169 y 331), y d) de 1995 en adelante (66 y 153). Para los de México: a) hasta antes de 1980, b) de 1980 a 1984, c) de 1985 a 1989, d) de 1990 a 1994, y e) de 1995 en adelante.
} 
por las personas en cuanto es posible; pero su lugar es inmediatamente ocupado por otras que inician su trayectoria migratorio laboral.

En México, el sector primario decrece paulatinamente en importancia relativa (cae de más del $52 \%$ a menos del 39\%) y cede la primacía el terciario (crece de más del $31 \%$ a más del $51 \%$ ). El sector secundario, finalmente, a diferencia de lo que sucede con las trayectorias, a través de las cohortes decrece de más del 16\% a poco más del 10\%.

La desagregación por sexos, como ya se analizó para el caso de los puertos de entrada al mercado de trabajo norteamericano y sus cambios a través del tiempo, muestra que las trayectorias laborales están claramente marcadas por el género, tanto en México, como en los Estados Unidos; pero esto se puede ver con más claridad si se pasa del nivel agregado de los sectores al de las ramas de actividad económica.

Para el caso de las mujeres, ya se vio que el principal puerto de entrada es el de los talleres de confección, factorys o sweatshop; aunque a través de las cohortes de ingreso, hayan disminuido su peso. A lo largo de los eventos de las trayectorias laborales (cuadro y gráfica \# 11), puede verse una situación similar; aunque disminuye su importancia de manera considerable (de más del $42 \%$ a poco menos del $28 \%$ ), en general siguen siendo muy importantes como fuentes de empleo. A esta salida de la industria del hilo y la aguja, corresponde un desplazamiento hacia el sector de los servicios, en general, pero especialmente hacia dos actividades: los restaurantes (su importancia va del 15\% a más del $31 \%$ del total de eventos) y los servicios en general (de apenas un 3.6\% a más de un 17\%). Otra actividad que es abandonada por las mujeres es la del servicio doméstico (baja de más del $22 \%$ a poco más del $10 \%)^{38}$. En general, es el sector de los servicios el que se va convirtiendo en el más importante para las mujeres a lo largo de las trayectorias laborales; aunque debe agregarse que con una clara diversificación de ramas. No es inútil recordar que este camino ha sido el tradicional para las mujeres de las sucesivas olas migratorias, como lo ilustran con claridad Green (1997), Foner (1987) o Marshall (1987). La agricultura, por su parte, empieza teniendo una importancia marginal que acaba por desaparecer hacia el final.

Las trayectorias de los hombres (cuadro \# 12), por su lado, muestran un perfil sumamente distinto al anterior. Desde el inicio, se presenta una marcada concentración en el trabajo en 
los restaurantes y una presencia muy reducida en el resto de las ramas. En efecto, en los restaurantes se concentra más del 33\% de los primeros eventos, para después acabar por abarcar a casi el $50 \%$ de ellos. Debe tenerse en cuenta que la sucesión de eventos en los restaurantes, además, generalmente significa un ascenso laboral (de lavaplatos a cocinero o manager, o incluso propietario, en los casos más afortunados); lo que no sucede en ramas como la de la confección, en donde las oportunidades de mejoría son prácticamente nulas y lo más probable es que después de varios eventos, la situación sea la misma que en el momento del primer ingreso.

Al contrario de lo que sucede con las mujeres, los eventos de los hombres en la confección muestran un ligero crecimiento, si bien su importancia es siempre poco significativa (de menos del 6\% a poco más del 10\%). El resto de las actividades, incluida la construcción, que podría suponerse importante como actividad para hombres migrantes en grandes ciudades, tiene un peso muy menor. Cabe hacer resaltar que la actividad en comercios, que puede ir desde la atención al público en los delis o marquetas, hasta la venta de flores y frutas en la entrada de los negocios y por las calles, si bien es una puerta de entrada relativamente importante, acaba por casi desaparecer como fuente de trabajo principal (baja de más del 16\% a menos del 1\%).

En México son también muy diferenciadas las TL de mujeres y hombres. Mientras que la mayoría de las mujeres tuvo su primera ocupación en este país en el servicio doméstico (más del $40 \%$ de los primeros eventos); poco más del $70 \%$ de los hombres lo tuvo en la agricultura. Para las mujeres, el trabajo en los servicios se convierte a lo largo de las TL (cuadro y grráfica \# 13) en el que, con mucho, es el más importante, hasta alcanzar un porcentaje superior al $40 \%$ en los eventos finales. Para los hombres, la agricultura se mantiene hasta el final de las TL en México (cuadro y gráfica \# 14) como la actividad de mayor importancia, si bien su peso disminuye hasta sólo representar poco más del 30\%. En el caso de las primeras, el trabajo doméstico sigue siendo importante hacia el final (poco más del 20\%) y el comercio ocupa poco menos del 15\%. El resto de las actividades, incluido el trabajo industrial, ocupan un lugar muy reducido (menos del 10\%). En el caso de los hombres, los servicios y el trabajo industrial llegan a tener un peso de alrededor del

\footnotetext{
38 Aunque debe recordarse que como puerto de entrada no sólo mantiene, sino que acrecienta su importancia a lo largo de las cohortes.
} 
$20 \%$, y el comercio y los servicios participan con porcentajes entre el $10 \%$ y el $15 \%$. A lo largo de sus TL, el servicio doméstico ocupa siempre un lugar marginal.

En cuanto se refiere a las características de los trabajos, en términos generales y para el conjunto de los eventos, las jornadas de trabajo son más elevadas en los Estados Unidos, tanto para los hombres como para las mujeres. Mientras que la media de horas de trabajo semanales es de 50.48 para el total de los eventos (49.05 para las mujeres y 50.89 para los hombres); para los que tienen lugar en México es de 48.46 (45.06 y 49.0, respectivamene); y en los Estados Unidos asciende a 51.83 (50.37 y 52.39). Estas jornadas son aún mayores en la industria de la confección de Nueva York, en donde la media alcanza las 53.92 (53.76 para las mujeres, que son la mayoría, y 54.11 para los hombres); pero también en los restaurantes, que tienen una media de 52.46 (49.32 y 53.07, respectivamente).

Si se ven los eventos sucesivos de las TL, puede observarse que en los Estados Unidos, tanto mujeres como hombres (cuadros y gráficas \# 15 y 16) tienden a concentrar sus eventos en jornadas entre las cuarenta y las cincuenta horas semanales; aunque una buena cantidad lo hace en los rangos superiores a las cincuenta (alrdedor de un $25 \%$ de las mujeres y más de un $30 \%$ de los hombres trabajan más de sesenta horas a la semana). Por el contrario, los trabajos de tiempo parcial (menos de 40 horas a la semana), son en general de menor importancia, aunque entre los hombres lleguen a alcanzar un peso de casi un 35\% en los eventos intermedios.

En México, la gran mayoría de ambos grupos (cuadros y gráficas \# 17 y 18) concentra claramente sus eventos entre las cuarenta y las cincuenta horas semanales (más del $40 \%$ en ambos casos). Llama la atención, sin embargo, que las mujeres empiezan sus TL en México con altos porcentajes de trabajos de tiempo parcial (casi el 50\% del total de los eventos iniciales); pero éstos van disminuyendo constantemente, hasta representar menos del 20\% de los últimos eventos. Por el contrario, sólo alrededor del 20\% de los eventos de hombres y mujeres se ubica en el rango de más de sesenta horas a la semana.

Dos comentarios pueden desprenderse. Primero que, en general, en los Estados Unidos no parece que sea deseable trabajar menos, sino más horas a la semana. Esto puede tener mucho sentido en particular en los restaurantes, en donde sí son generalmente cubiertos los sobrepagos por trabajar en horas extra; a diferencia de los sweatshop, en 
donde todos los testimonios hablan de que los patrones hacen trampa en este y en otros campos; aunque aquí el precio por no trabajar horas extra puede significar la pérdida del empleo. Segundo, que las diferencias en las jornadas de mujeres y hombres no aparecen como importantes; aunque se trabaja en distintos nichos de mercado, muchas de sus condiciones son similares.

En cuanto a los días semanales de trabajo, tanto mujeres como hombres en los Estados Unidos (cuadros y gráficas \# 19 y 20) laboran seis en su mayoría (en todos los casos más del $50 \%$ del total de los eventos), pero se presenta una ligera disminución a través de los eventos sucesivos, en favor de contar con dos días libres a la semana. Llama la atención que para ambos grupos, un porcentaje que oscila entre el $10 \%$ y el $20 \%$ trabaja los siete días de la semana. En el otro extremo, los trabajos de tiempo parcial, de menos de cinco días semanales, son claramente marginales. Nuevamente, debe recordarse que eso no quiere decir que no se presenten del todo; sino que, cuando son ocupados, lo son de manera complementaria al trabajo princiapl.

En México, la situación presenta diferencia entre mujeres y hombres. En el caso de las primeras (cuadro y gráfica \# 21), aunque la mayoría labora seis días a la semana, el porcentaje mayor sólo llega a alcanzar a poco más del $40 \%$, en los últimos eventos de las trayectorias; mientras que para los segundos, rebasa siempre el 50\% y hacia el final de la TL se ubica alrededor del 65\%. Para las mujeres, se presenta una caída constante del trabajo semanal de cinco días (del 35\% pasa a poco más del 20\%) y una disminución considerable de la semana laboral de siete días (pasa de casi el 28\% a aproximadamente el 17\%). Por el contrario, llama la atención el crecimiento de los eventos en los que se reportan semanas de tres y cuatro días laborables (llegan a representar más del $20 \%$ de los últimos eventos). No es descabellado plantear que esto pueda ser el resultado de la acumulación de recursos a lo largo de trayectorias laborales de gran esfuerzo en los Estados Unidos; ligadas tal vez al hecho de contar ahora con hijos o parientes que envían remesas desde los Estados Unidos.

Los hombres en México (cuadro y gráfica \# 22), se concentran con mucha mayor claridad en semanas laborales de seis días (desde poco más del 55\% al inicio, hasta poco más del $65 \%$ al final). Se presenta también una disminución, aunque marginal, de la de siete días (de poco más a poco menos del 20\%); y de la de cinco (de poco menos de $17 \%$ a 
poco menos del 10\%). El resto de las jornadas semanales, las de tiempo parcial, ocupan siempre un lugar marginal (menos del 5\% cada una). No puede dejarse a un lado el hecho de que, en los últimos eventos, muchos de estos hombres ya no son asalariados, sino propietarios de los establecimientos en los que laboran.

En términos generales, puede extraerse como conclusión parcial que, si bien en los Estados Unidos, mujeres y hombres se ubican en ocupaciones diferenciadas, algunas características importantes de los trabajos que realizan son, sin embargo, muy similares. A fin de cuentas, debe recordarse que, pese a las diferencias, se trata mayoritariamente de trabajos manuales de baja calificación y, como se verá más adelante, ubicados en nichos de mercado éticamente definidos; aunque el trabajo en los restaurantes, -a diferencia del trabajo en los sweatshop, como se verá a continuación-, permita ir superando esa situación, al permitir la adquisición de calificaciones específicas, y al permitir también carreras ascendentes; y por tanto, mejorar las condiciones de trabajo y las salariales.

\section{CONTINUIDADES Y DISCONTINUIDADES OCUPACIONALES EN} LAS TRAYECTORIAS LABORALES, EN MÉXICO Y LOS ESTADOS UNIDOS

Al seguir las trayectorias laborales de este grupo de personas migrantes transnacionales, un aspecto que salta inmediatamente a la vista es que en ellas se presentan claras y fuertes rupturas ocupacionales. Quien va a trabajar a la confección en Nueva York, lo más probable es que en México nunca trabajara previamente en ese ramo. Quien se va a desempeñar en los restaurantes neoyorquinos, lo más seguro es que nunca antes hubiera tenido un trabajo de ese tipo. Y a la inversa, muy pocos cocineros especializados en comida internacional regresan a su pueblo a trabajar en algo similar, y muy pocas mujeres regresan a México a emplearse en talleres de confección. Los panaderos mixtecos que llegaron a establecerse como tales en el noreste norteamericano son realmente pocos.

Una forma interesante de ver estas rupturas ocupacionales, consiste en comparar los trabajos que se dejan en uno y otro país, cuando se migra en uno u otro sentido de la 
frontera $^{39}$. Esto permite analizar varias cosas. Por un lado, permite indagar si la acumulación de conocimientos, destrezas y habilidades propios de la actividad desarrollada, son puestos o no en juego en los nuevos trabajos, al otro lado de la frontera; esto es, si la acumulación de elementos propios del capital cultural objetivado (o, en otra perspectiva, del capital humano), se traduce efectivamente en una posibilidad de inversión en las nuevas condiciones; o bien, si queda como una reserva de capital que sólo podrá ser activada al regreso al lugar en el que se adquirió. La larga y compleja formación que el campesino obtiene cotidianamente en el propio trabajo, por ejemplo, ¿será de alguna utilidad en Nueva York?. O bien, la rica capacitación también cotidiana, y también en el propio proceso de trabajo, que lleva a un lavaplatos a convertirse en un cocinero apto y cotizado en el mercado de trabajo neoyorquino, ¿tendrá alguna aplicación laboral en Nexatengo, Xicotzingo, Piaxtla o Acatlán?.

Como podrá constatarse a continuación, la respuesta es en general negativa. Sin embargo, no debe descartarse la posibilidad de que sean adquiridas en el trayecto algunas otras habilidades, de tipo más general o cultural, que sí resulten de utilidad en el mercado de trabajo; tales como el conocimiento mismo de los mecanismos a través de los cuales actuan las diversas instituciones que estructuran el propio mercado de trabajo. En las trayectorias se aprende a utilizar los contactos familiares y amistosos en la búsqueda y obtención del empleo (los contactos no son por sí mismos capital social (De la Rocha, 1998), sino que pueden convertirse en tal, en ciertas condiciones y con una inversión de tiempo y recursos); se aprende también a ampliar y diversificar las propias redes sociales; igualmente, se aprende a buscar trabajo por iniciativa propia y sin ayuda; de la misma forma, se aprende a adquirir nuevas habilidades, conocimientos y destrezas y a utilizar esos nuevos elementos en el mercado de trabajo; en otro nivel, existe también un aprendizaje acerca de la vida en sociedades distintas, y casi siempre adversas, a la de origen. Por supuesto, existe un proceso de formación de capital económico que posibilita que la situación laboral en el pueblo natal pueda modificarse sustancialmente.

\footnotetext{
39 Más adelante, en otro apartado, se analizarán también las razones para haber tomado la decisión de abandonar un empleo y la posibilidad de que esta decisión haya sido tomada con la intervención de alguien distinto a la persona directamente involucrada.
} 
Para realizar el análisis, los eventos serán agrupados en cohortes ${ }^{40}$, para poder apreciar los cambios a lo largo de los distintos periodos. Como puede apreciarse en las gráficas, de manera agregada resulta claro que los eventos que se abandonan en México para dirigirse a los Estados Unidos, presentan un perfil que se diferencia grandemente de los que, a la inversa, se abandonan en este último país para regresar al de origen. Mientras que en el primer caso predominan ampliamente los eventos ubicados en el sector primario; en el segundo lo hacen los del terciario. Cabe sin embargo señalar que la situación presenta cambios a lo largo del tiempo. En México (cuadro y gráfica \# 23), la importancia del sector primario decrece constantemente: pasa de representar más de un $67 \%$ del total a sólo un $50 \%$ de los casos. El terciario, por el contrario, crece en importancia: de una cuarta parte del total a casi un $40 \%$. El crecimiento del sector secundario es marginal. Esto es, como se vió al analizar el conjunto de los eventos realizados en México, comprueba que este flujo migratorio tiene un origen cada vez menos agropecuario y cada vez más situado en los servicios.

En el caso de los trabajos que se abandonan en los Estados Unidos (cuadro y gráfica \# 24), cabe apreciar que en la cohorte de los eventos anteriores a 1987, antes de la masificación de la migración, el peso de los sectores secundario y primario era considerable (más del 34\% y más del 25\%, respectivamente), si bien los servicios dominaban el panorama. La evolución a lo largo del tiempo hace que el peso del sector terciario crezca constantemente, para acabar representando casi un $60 \%$ del total en la cohorte de los eventos posteriores a 1994. Ese crecimiento lo explica la pérdida acumulada de importancia del sector primario, que termina por incluir a sólo un poco más del 7\% de los eventos; en tanto que el secundario se mantiene sin variaciones significativas.

Tal y como se ha visto con el total de eventos, también en este caso, al desagregar es posible apreciar que las trayectorias laborales son muy diferenciadas para mujeres y para hombres. En el caso de las primeras (cuadro y gráfica \# 25), el servicio doméstico se mantiene en México como un importante puerto de salida, si bien presenta una tendencia decreciente a partir de la segunda cohorte (en la que llegó a representar casi el 42\%), para acabar representando a poco menos de una tercera parte de los eventos en la más reciente; cuando cede la supremacía a los servicios en general (sin restaurantes), cuya importancia

40 En este caso, las cohortes son: a) antes de 1987 ; b) de 1987 a 1991; c) de 1991 a 1994; y d) de 1995 en 
llega a ser, después de altibajos, de casi el 54\% del total. Resulta interesante anotar que en los eventos de 1994 en adelante, la agricultura acaba por desaparecer como puerto de salida de las mujeres de la muestra. El comercio, por su parte, baja de casi un $17 \%$ a menos del 8\%. Muy importante resulta destacar que el trabajo en labores de confección ocupa inicialmente un lugar marginal (5.6\%), para desaparecer absolutamente en las dos últimas cohortes.

Para el caso de los hombres en México (cuadro y gráfica \# 26), el puerto de partida principal a lo largo de todas las cohortes es la agricultura, muy por encima de todas las demás actividades, pese a que su peso desciende marginalmente (pasa de representar las tres cuartas partes a poco menos del $62 \%$ del total de eventos). El resto de las ramas tienen una presencia muy poco significativa, siempre abajo del $12 \%$ del total. Como en el caso de los mujeres, los hombres no parten a Nueva York de trabajos afines a los que desarrollan mayoritariamente allá. En el caso de los restaurantes, sólo el 1\% de los eventos se ubicó en esos establecimientos en la cohorte más antigua, para después desaparecer absolutamente en las demás.

Los trabajos que dejan en Nueva York las mujeres que regresan a México (cuadro y gráfica \# 27), en todas las cohortes, excepto en la segunda, se concentran mayoritaria y crecientemente en la confección (más del $36 \%$ en la primera; $43.5 \%$ en la última). El servicio doméstico presenta a lo largo del tiempo una gráfica en forma de campana invertida en la que, después de crecer desde poco más de un $9 \%$ hasta más de la tercera parte del total de los eventos, regresa muy cerca del punto de partida (menos del 10\%) en la cohorte más reciente. Pese a que los restaurantes, como se ha visto, se convierten en un nicho de mercado de importancia creciente para las mujeres en Nueva York, como puerto de salida hacia México decrecen en su peso relativo, desde representar poco más de una cuarta parte hasta significar sólo un $16.5 \%$.

Por su parte, los hombres presentan una mayor concentración de sus puertos de salida hacia México (cuadro y gráfica \# 28). Claramente, los restaurantes constituyen el principal: su peso aumenta de poco más del 35\%, en los eventos anteriores a 1987, hasta casi el 42\%, en los posteriores a 1994. Dos actividades que en la primera cohorte habían sido importantes en este rubro -la agricultura (más del 29\%) y la construcción (26.5\%)-,

adelante. 
pierden peso relativo de manera considerable (representan poco más del $8 \%$ y poco menos del $5 \%$, respectivamente, en la última cohorte). El comercio (13\%, en la cohorte final), la confección (menos del 11\%), y el resto de la industria manufacturera (poco arriba del 11\%), ganan importancia. Las demás actividades nunca rebasan el 10\%.

\section{CONCLUSIONES PARCIALES}

Como puede claramente observarse, las trayectorias laborales tanto de mujeres como de hombres, muestran discontinuidades o rupturas dignas de ser tomadas en cuenta, si se parte de comparar los eventos realizados en México y los que tienen lugar en los Estados Unidos; pero si se considera cada uno de estos grupos de eventos por separado, hacia su interior puede igualmente percibirse una tendencia mayor a la continuidad laboral, aunque ésta se vea interrumpida precisamente por los cambios de país, sobre todo entre los hombres que se han dedicado al trabajo en los restaurantes neoyorquinos.

En sentido estricto, el capital humano acumulado en México antes de la migración inicial, no parece haber sido de ninguna utilidad para desempeñarse en los primeros trabajos en los Estados Unidos. Más adelante, los conocimientos específicos que se fueron adquiriendo con los trabajos en nueva York, no parecen haber sido aprovechados sino por excepción para los trabajos que se realizaron en México, en los distintos momentos de retorno a los lugares de origen. Ni parece tampoco haber sido el caso en el sentido inverso. Sin embargo, no se trata de que los frecuentes cambios de país - con las discontinuidades laborales que ello ha implicado- no hayan tenido efectos sobre las personas, sus trayectorias laborales y sus distintas y cambiantes composiciones de capital. Por el contrario, estos efectos parecen haber sido considerables y trascendentes.

Aunque las personas regresen a sus lugares de origen a realizar taréas similares a las que realizaban antes de migrar; en la mayoría de los casos lo hacen desde posiciones sociales que se han transformado considerablemente, como efecto de los recursos materiales obtenidos a lo largo de la experiencia migratoria (tierras, casas, comercios, aparatos domésticos, medios de transporte, hábitos y posibilidades de consumo); pero como efecto también de cambios importantes en su capital cultural, que les permite enfrentar la vida en sociedad con recursos acercentados por la experiencia de haber sido capaces de salir airosos, al menos relativamente, en una sociedad más compleja, diversificada, 
diferente a todo lo conocido hasta entonces y considerablemente riesgosa. Lo que combinado se traduce generalmente en un incremento sustancial del capital simbólico de quienes han migrado.

En la zona de Nueva York, por otro lado, la sucesión de eventos marca en muchos casos una continuidad notable, sobre todo en el trabajo en los restaurantes y en el servicio doméstico. Aquí se presenta una notable acumulación de capital humano (conocimientos, habilidades y destrezas desarrolladas en el trabajo mismo), cultural (conocimiento de las reglas de funcionamiento de los mercados laborales y de la sociedad misma), organizacional (posición dentro de las empresas, conocimiento de sus reglas de funcionamiento, derechos por antigüedad), social (ampliación y crecimiento de las redes, creación de lazos débiles, formación de saldos positivos en los intercambios no comerciales de las redes originales), simbólico (prestigio y reconocimiento en función de un desempeño correcto) y, por supuesto, económico.

A continuación, se verá en el siguiente capítulo una síntesis de los orígenes históricos de los nichos de mercado en los que se han insertado quienes han migrado desde Puebla y Tlaxcala a la zona metropolitana de la ciudad de Nueva York; así como algunos de sus rasgos principales, en relación con los patrones y los compañeros de trabajo. Después se pasará, en el capítulo subsecuente, al análisis de la estructuración social de las trayectorias laborales. 


\section{CUADRO Y GRAFICA \# 1 \\ RAMA}

Mujeres (1er. Trabajo en E.U.A.)

\begin{tabular}{|c|r|r|r|r|r|r|r|r|}
\hline Cohorte & \multicolumn{1}{|c|}{$\begin{array}{c}\text { Agricul- } \\
\text { tura }\end{array}$} & $\begin{array}{c}\text { Construc- } \\
\text { ción }\end{array}$ & $\begin{array}{c}\text { Otros } \\
\text { servicios }\end{array}$ & $\begin{array}{c}\text { Confec- } \\
\text { ción }\end{array}$ & $\begin{array}{c}\text { Otras } \\
\text { industrias }\end{array}$ & $\begin{array}{c}\text { Restauran- } \\
\text { tes }\end{array}$ & $\begin{array}{c}\text { Serv. } \\
\text { Doméstico }\end{array}$ & Comercio \\
\hline Hasta 1983 & 0.00 & 0.00 & 0.00 & 43.80 & 12.50 & 18.80 & 25.00 & 0.00 \\
\hline De 1984 a 1988 & 0.00 & 0.00 & 0.00 & 44.00 & 8.00 & 24.00 & 16.00 & 8.00 \\
\hline De 1989 a 1993 & 3.40 & 0.00 & 4.30 & 47.40 & 5.20 & 11.20 & 20.70 & 7.80 \\
\hline $\begin{array}{c}\text { De 1994 en } \\
\text { adelante }\end{array}$ & 2.80 & 0.00 & 5.60 & 25.00 & 2.80 & 19.40 & 30.60 & 13.90 \\
\hline
\end{tabular}

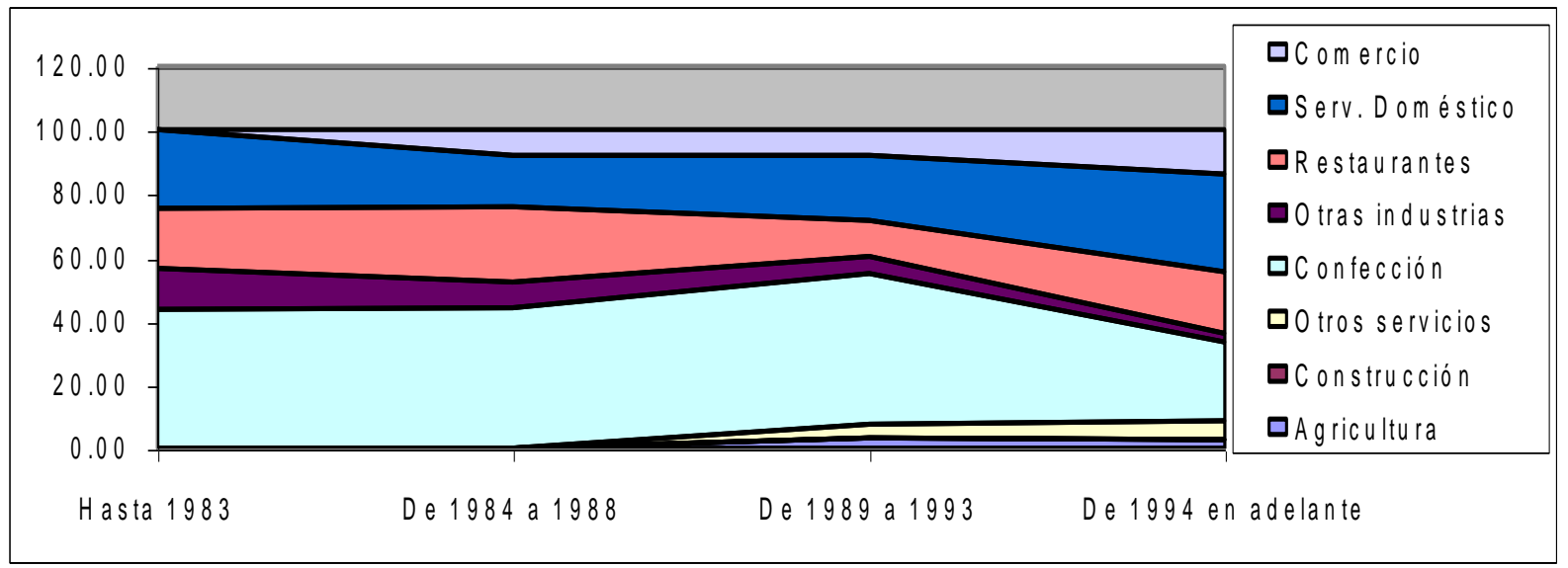

\section{CUADRO Y GRAFICA \# 2}

RAMA

Hombres (1er. Trabajo en E.U.A.)

\begin{tabular}{|c|r|r|r|r|r|r|r|r|}
\hline Cohorte & $\begin{array}{c}\text { Agricul- } \\
\text { tura }\end{array}$ & $\begin{array}{c}\text { Construc- } \\
\text { ción }\end{array}$ & $\begin{array}{c}\text { Otros } \\
\text { servicios }\end{array}$ & $\begin{array}{c}\text { Confec- } \\
\text { ción }\end{array}$ & $\begin{array}{c}\text { Otras } \\
\text { industrias }\end{array}$ & $\begin{array}{c}\text { Restauran- } \\
\text { tes }\end{array}$ & $\begin{array}{c}\text { Serv. } \\
\text { Doméstico }\end{array}$ & Comercio \\
\hline Hasta 1983 & 21.20 & 21.20 & 0.00 & 7.60 & 7.60 & 40.90 & 1.50 & 0.00 \\
\hline De 1984 a 1988 & 5.80 & 21.70 & 1.40 & 11.60 & 4.30 & 39.10 & 2.90 & 13.00 \\
\hline De 1989 a 1993 & 5.60 & 8.40 & 5.60 & 21.90 & 4.20 & 31.20 & 5.10 & 18.10 \\
\hline $\begin{array}{c}\text { De 1994 en } \\
\text { adelante }\end{array}$ & 12.80 & 10.50 & 4.70 & 12.80 & 9.30 & 26.70 & 10.50 & 12.80 \\
\hline
\end{tabular}

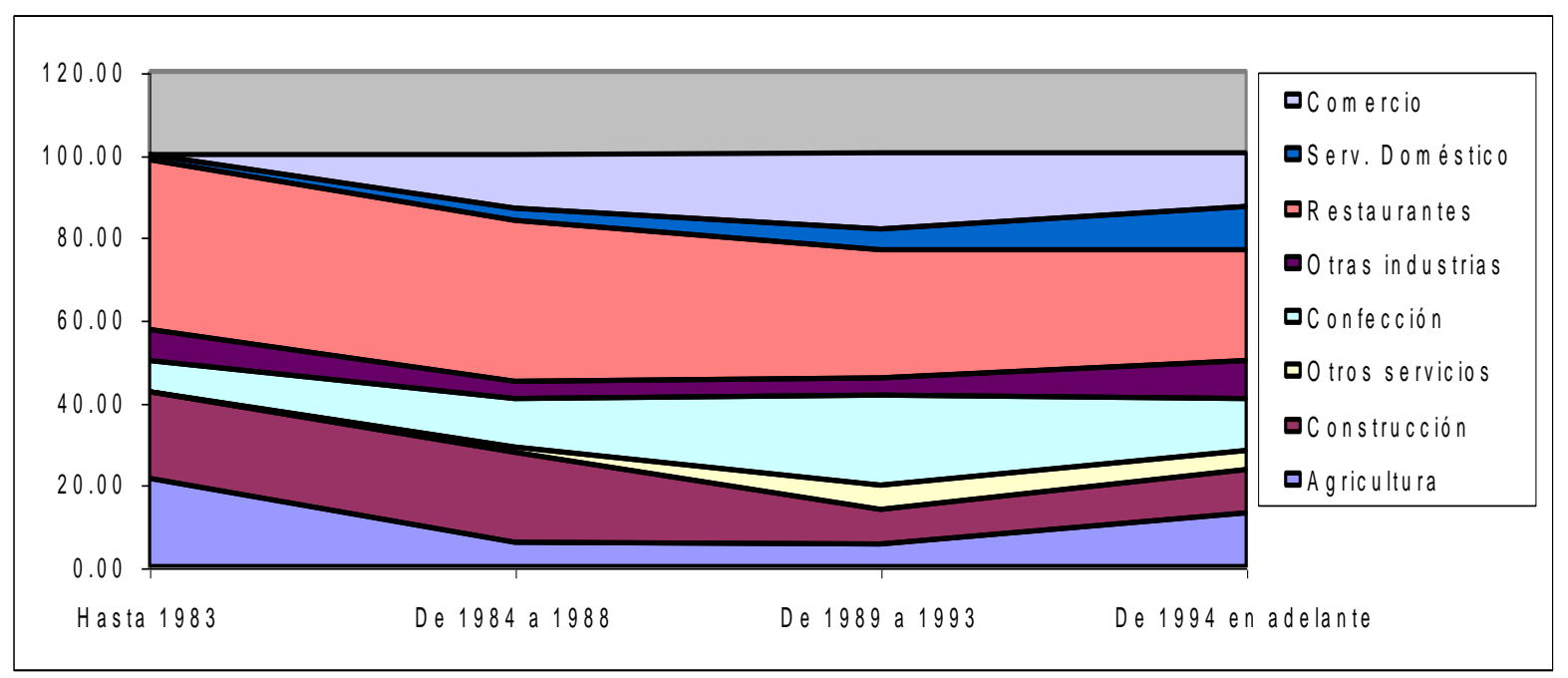


CUADRO Y GRAFICA \# 4

TAMAÑO DEL ESTABLECIMIENTO

Hombres (1er. Trabajo en E.U.A.)

\begin{tabular}{|c|r|r|r|r|r|}
\hline Cohorte & $\begin{array}{c}\text { Hasta 10 } \\
\text { trabajadores }\end{array}$ & $\begin{array}{c}\text { De 11 a 20 } \\
\text { trabajadores }\end{array}$ & $\begin{array}{c}\text { De 21 a 35 } \\
\text { trabajadores }\end{array}$ & $\begin{array}{c}\text { De 36 a 60 } \\
\text { trabajadores }\end{array}$ & $\begin{array}{c}\text { Más de 60 } \\
\text { trabajadores }\end{array}$ \\
\hline Hasta 1983 & 32.30 & 30.80 & 9.20 & 15.40 & 12.30 \\
\hline De 1984 a 1988 & 58.80 & 17.60 & 11.80 & 8.80 & 2.90 \\
\hline De 1989 a 1993 & 57.70 & 23.30 & 8.80 & 8.80 & 1.40 \\
\hline $\begin{array}{c}\text { De 1994 en } \\
\text { adelante }\end{array}$ & 57.10 & 25.00 & 10.70 & 2.40 & 4.80 \\
\hline
\end{tabular}

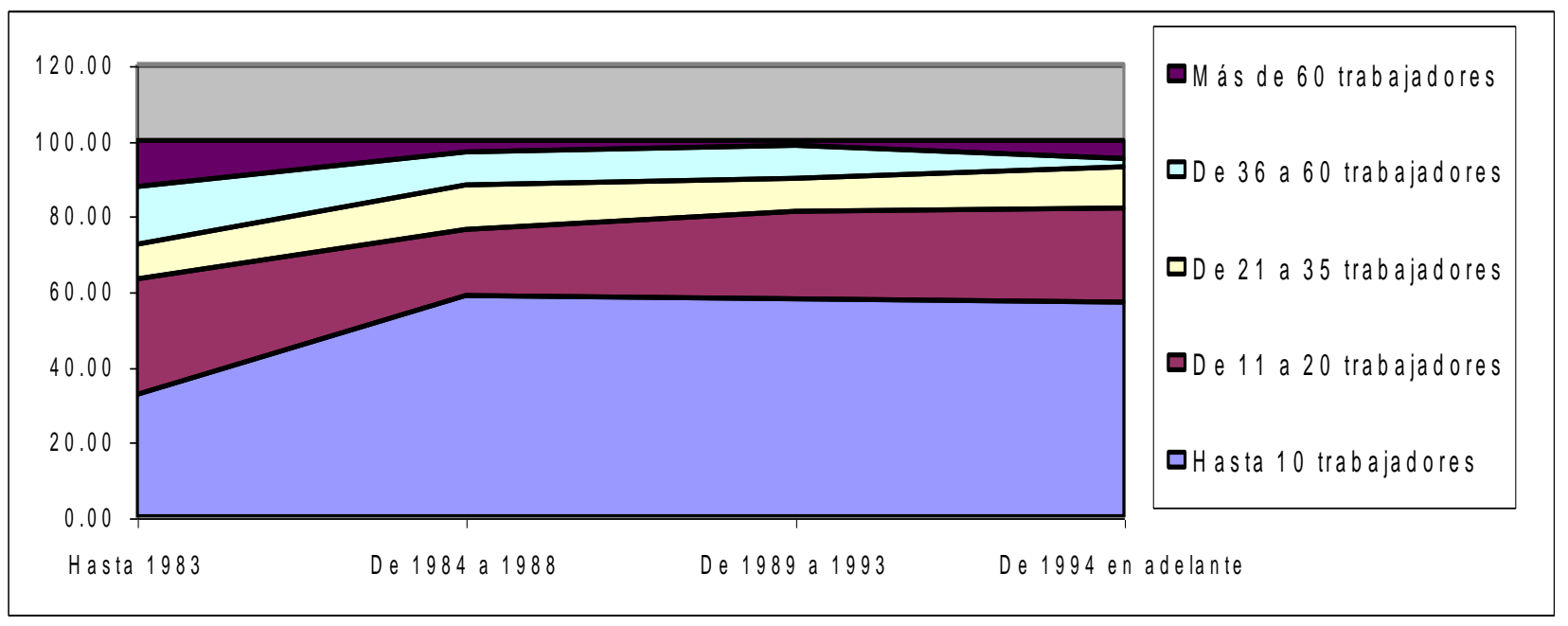

CUADRO Y GRAFICA \# 3

TAMAÑO DEL ESTABLECIMIENTO

Mujeres (1er. Trabajo en E.U.A.)

\begin{tabular}{|c|r|r|r|r|r|}
\hline Cohorte & $\begin{array}{c}\text { Hasta 10 } \\
\text { trabajadores }\end{array}$ & $\begin{array}{c}\text { De 11 a 20 } \\
\text { trabajadores }\end{array}$ & $\begin{array}{c}\text { De 21 a 35 } \\
\text { trabajadores }\end{array}$ & $\begin{array}{c}\text { De 36 a 60 } \\
\text { trabajadores }\end{array}$ & $\begin{array}{c}\text { Más de 60 } \\
\text { trabajadores }\end{array}$ \\
\hline Hasta 1983 & 26.70 & 13.30 & 13.30 & 13.30 & 33.30 \\
\hline De 1984 a 1988 & 46.20 & 7.70 & 26.90 & 15.40 & 3.80 \\
\hline De 1989 a 1993 & 33.90 & 20.20 & 21.10 & 21.10 & 3.70 \\
\hline $\begin{array}{c}\text { De 1994 en } \\
\text { adelante }\end{array}$ & 62.90 & 11.40 & 11.40 & 14.30 & 0.00 \\
\hline
\end{tabular}

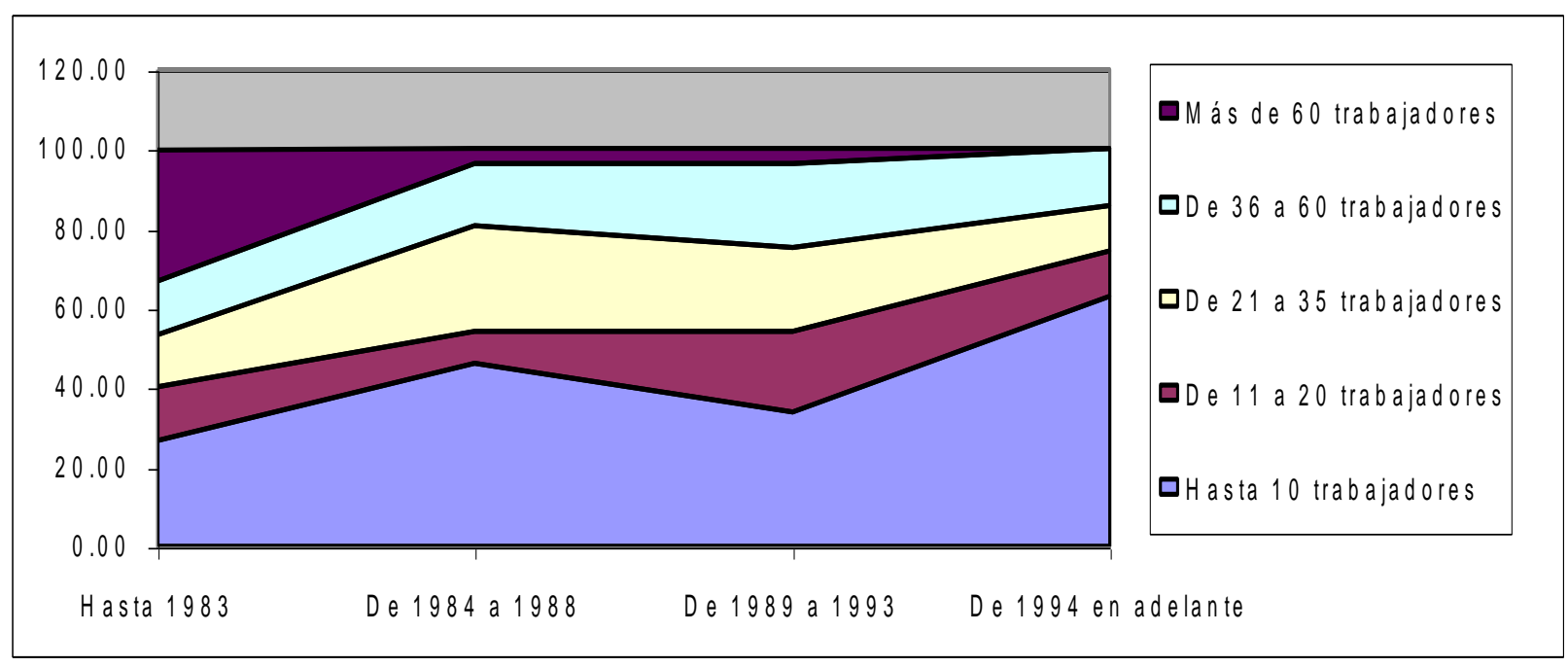


CUADRO Y GRAFICA \# 6

DIAS DE TRABAJO

Hombres (1er. Trabajo en E.U.A.)

\begin{tabular}{|c|r|r|r|r|r|r|r|}
\hline Cohorte & \multicolumn{1}{|c|}{ 1 día } & \multicolumn{1}{c|}{ 2 días } & \multicolumn{1}{c|}{ 3 días } & \multicolumn{1}{c|}{ 4 días } & \multicolumn{1}{c|}{ 5 días } & \multicolumn{1}{c|}{ 6 días } & \multicolumn{1}{c|}{ d días } \\
\hline Hasta 1983 & 0.00 & 0.00 & 0.00 & 1.50 & 20.00 & 63.10 & 15.40 \\
\hline De 1984 a 1988 & 0.00 & 0.00 & 0.00 & 1.50 & 16.90 & 66.20 & 15.50 \\
\hline De 1989 a 1993 & 0.50 & 0.50 & 1.90 & 0.50 & 13.20 & 61.90 & 18.60 \\
\hline De 1994 en adelante & 0.00 & 0.00 & 1.20 & 3.70 & 17.10 & 59.80 & 18.20 \\
\hline
\end{tabular}

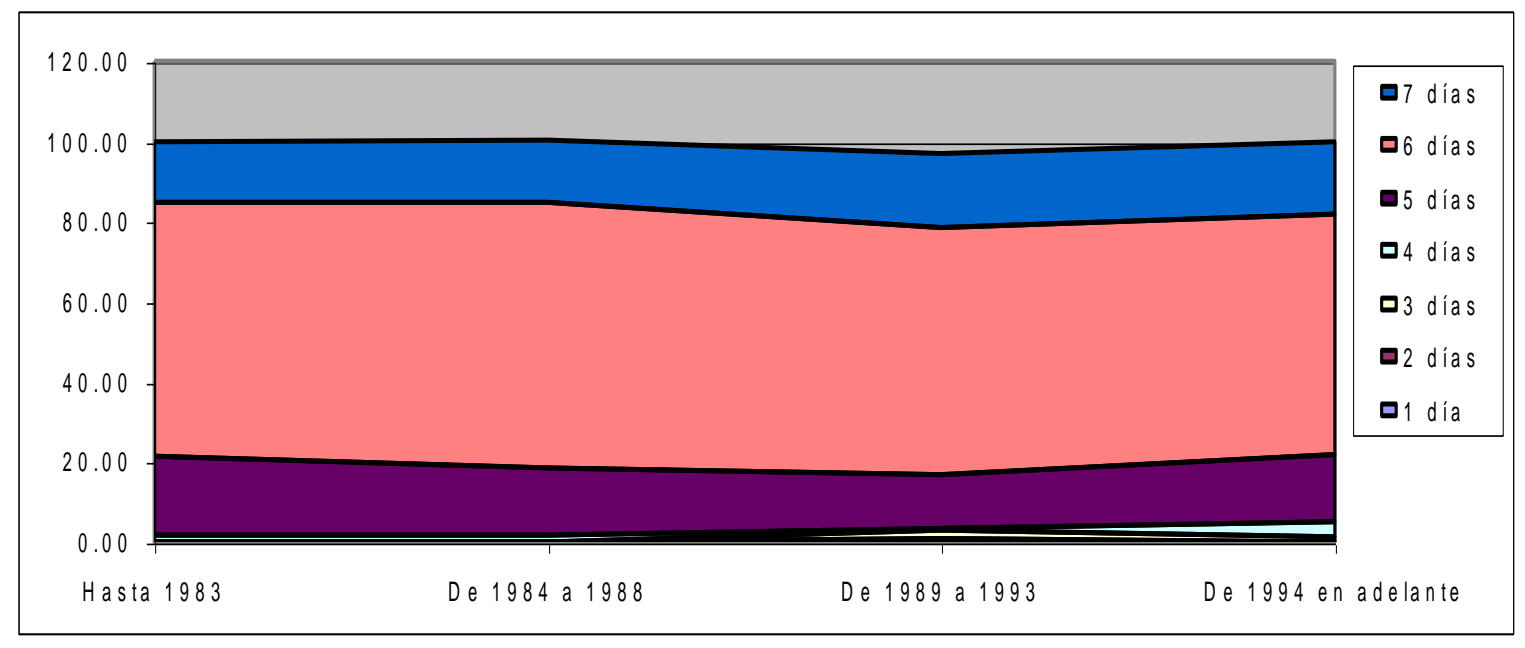

CUADRO Y GRAFICA \# 5

DIAS DE TRABAJO

Mujeres (1er. Trabajo en E.U.A.)

\begin{tabular}{|c|r|r|r|r|r|r|r|}
\hline Cohorte & \multicolumn{1}{|c|}{ 1 día } & \multicolumn{1}{c|}{ 2 días } & \multicolumn{1}{c|}{ 3 días } & 4 días & \multicolumn{1}{c|}{ 5 días } & \multicolumn{1}{c|}{ 6 días } & 7 días \\
\hline Hasta 1983 & 0.00 & 0.00 & 0.00 & 0.00 & 43.80 & 37.50 & 18.80 \\
\hline De 1984 a 1988 & 0.00 & 0.00 & 0.00 & 0.00 & 28.00 & 56.00 & 16.00 \\
\hline De 1989 a 1993 & 0.00 & 0.00 & 1.80 & 1.80 & 7.20 & 74.80 & 14.40 \\
\hline De 1994 en adelante & 0.00 & 0.00 & 0.00 & 0.00 & 12.10 & 75.80 & 12.20 \\
\hline
\end{tabular}

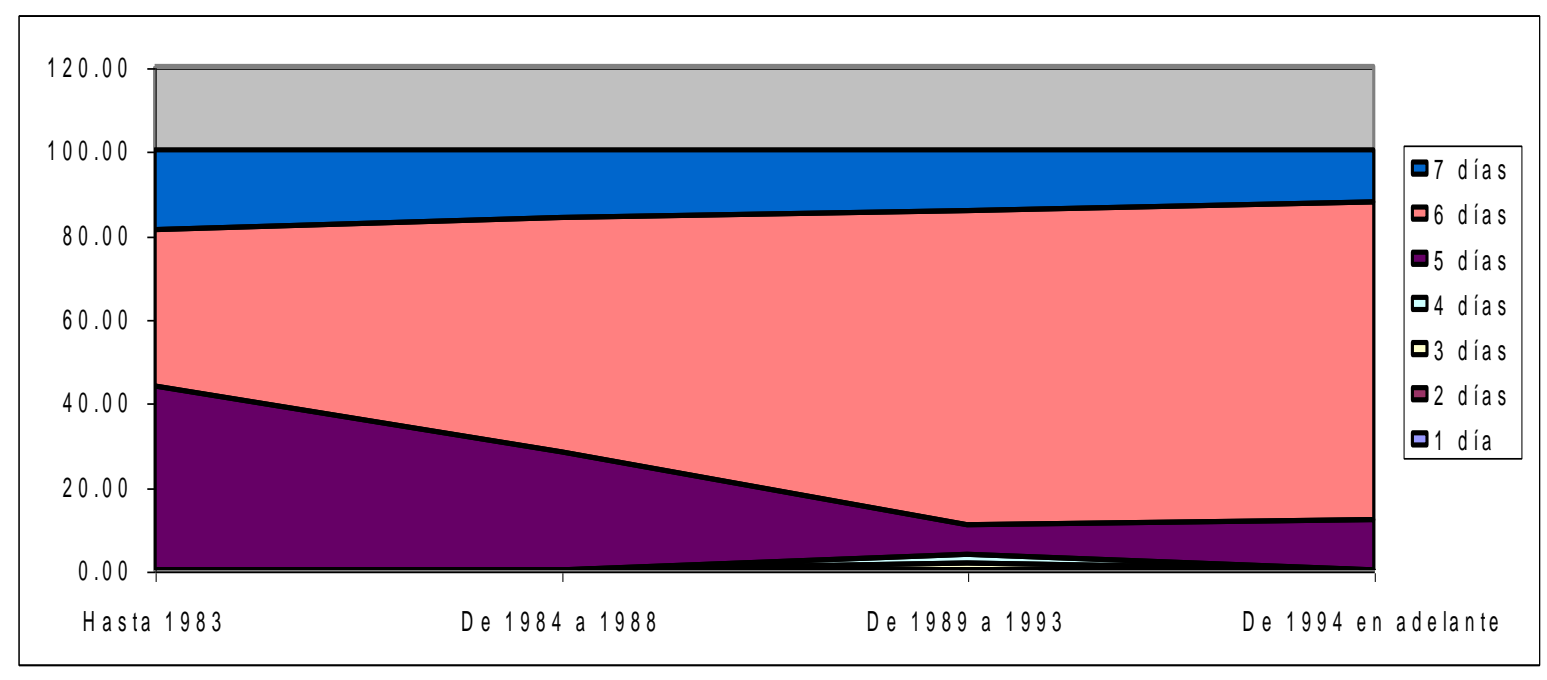




\section{CUADRO Y GRAFICA \# 8}

HORAS POR JORNADA

Hombres (1er Trabajo en E. U. A.)

\begin{tabular}{|c|r|r|r|r|}
\hline Cohorte & $\begin{array}{c}\text { Menos de 40 } \\
\text { hrs. }\end{array}$ & $\begin{array}{c}\text { De 40 a 50 } \\
\text { hrs. }\end{array}$ & $\begin{array}{c}\text { De 50 a 60 } \\
\text { hrs. }\end{array}$ & Más de 60 hrs. \\
\hline Hasta 1983 & 3.10 & 33.80 & 36.90 & 26.20 \\
\hline De 1984 a 1988 & 14.10 & 43.70 & 18.30 & 23.90 \\
\hline De 1989 a 1993 & 14.00 & 36.70 & 30.70 & 18.60 \\
\hline De 1994 en adelante & 14.60 & 40.20 & 17.10 & 28.00 \\
\hline
\end{tabular}

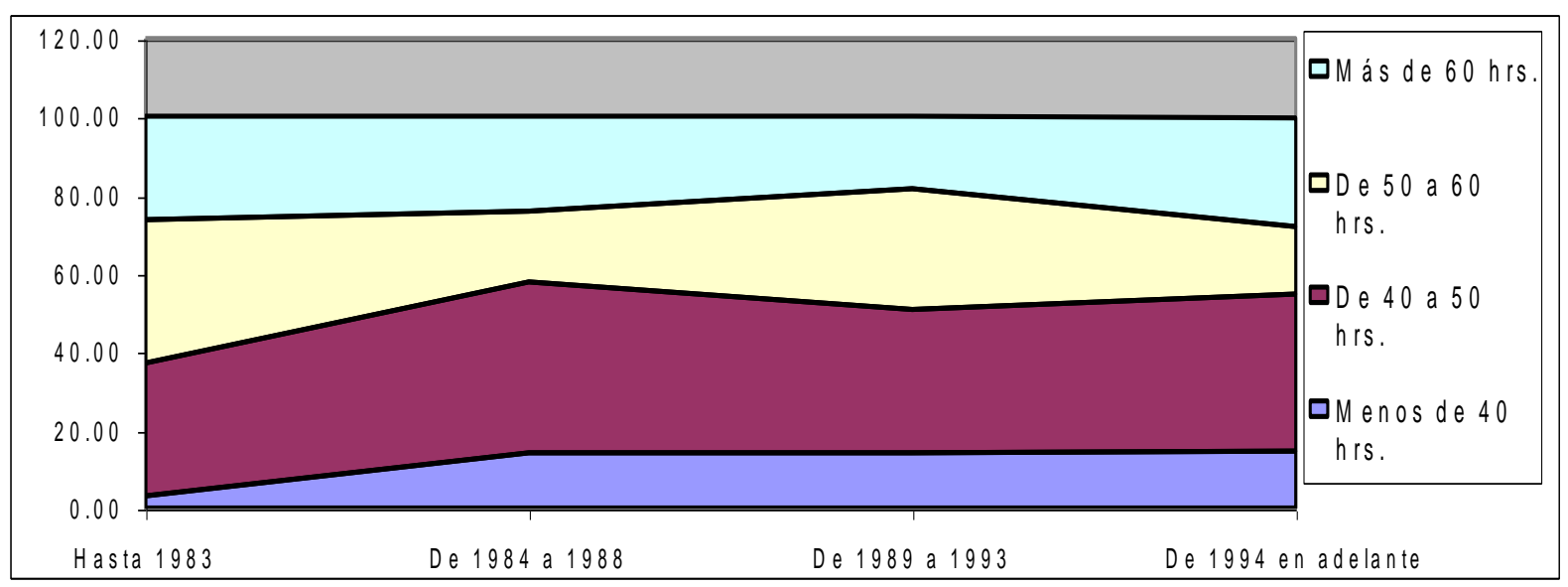

\section{CUADRO Y GRAFICA \# 7 \\ HORAS POR JORNADA}

Mujeres (1er. Trabajo en E. U. A.)

\begin{tabular}{|c|r|r|r|r|}
\hline Cohorte & $\begin{array}{c}\text { Menos de 40 } \\
\text { hrs. }\end{array}$ & $\begin{array}{c}\text { De 40 a } \\
\text { 50 hrs. }\end{array}$ & $\begin{array}{c}\text { De 50 a } \\
\text { 60 hrs. }\end{array}$ & Más de 60 hrs. \\
\hline Hasta 1983 & 18.80 & 43.80 & 12.50 & 25.00 \\
\hline De 1984 a 1988 & 12.00 & 36.60 & 36.00 & 16.00 \\
\hline De 1989 a 1993 & 13.50 & 25.20 & 47.70 & 13.50 \\
\hline De 1994 en adelante & 6.10 & 30.30 & 45.50 & 18.20 \\
\hline
\end{tabular}

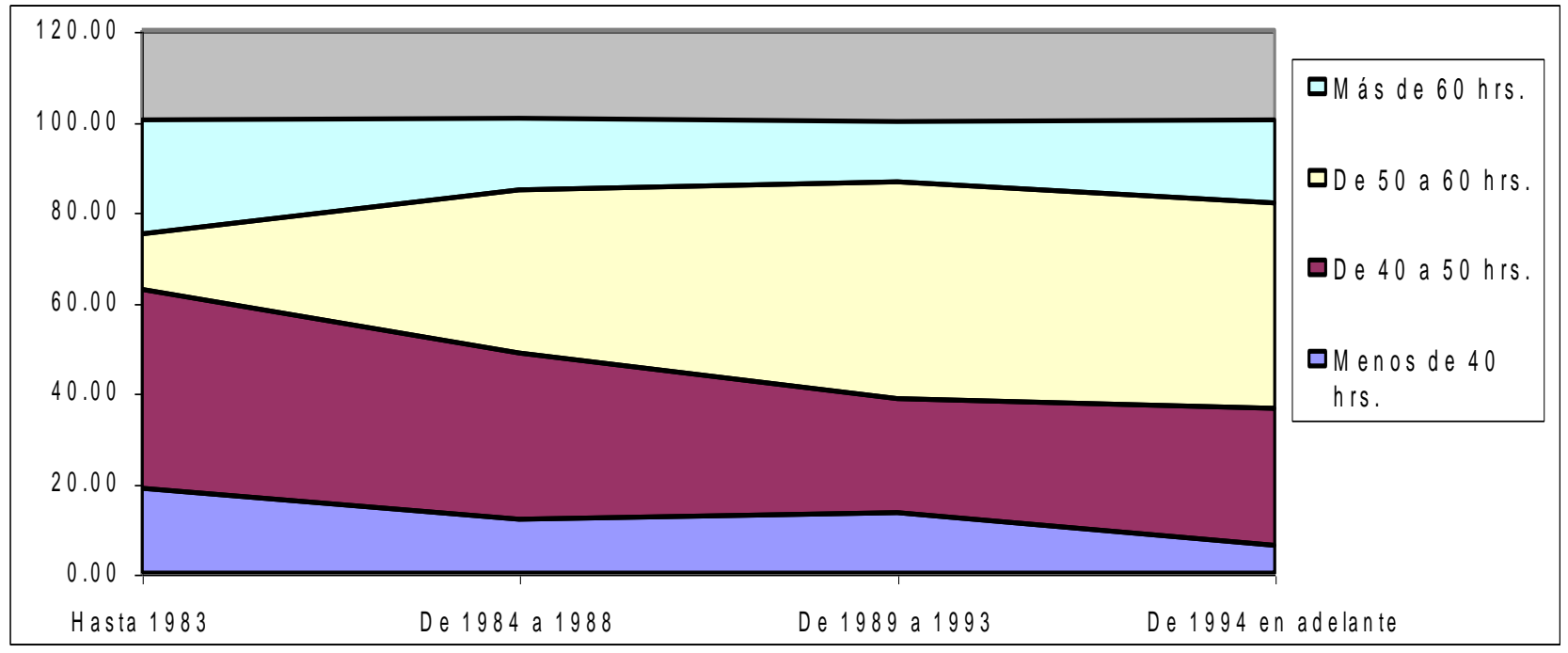


CUADRO Y GRAFICA \# 10

DURACIÓN DEL EVENTO

Hombres (1er. trabajo en E. U. A.)

\begin{tabular}{|c|r|r|r|r|r|r|}
\hline Cohorte & $\begin{array}{c}\text { Hasta 4 } \\
\text { meses }\end{array}$ & $\begin{array}{c}\text { De 4 meses } \\
\text { a 1 año }\end{array}$ & $\begin{array}{c}\text { De más de 1 } \\
\text { a 2 años }\end{array}$ & $\begin{array}{c}\text { De más de 2 } \\
\text { a 4 años }\end{array}$ & $\begin{array}{c}\text { De más de 4 } \\
\text { a 10 años }\end{array}$ & \multicolumn{1}{c|}{$\begin{array}{c}\text { Más de 10 } \\
\text { años }\end{array}$} \\
\hline Hasta 1983 & 5.80 & 26.10 & 15.90 & 13.00 & 21.70 & 17.40 \\
\hline De 1984 a 1988 & 10.80 & 16.20 & 5.40 & 36.50 & 23.00 & 8.10 \\
\hline De 1989 a 1993 & 7.80 & 23.70 & 20.10 & 31.50 & 16.90 & 0.00 \\
\hline De 1994 en adelante & 22.10 & 33.70 & 30.20 & 14.00 & 0.00 & 0.00 \\
\hline
\end{tabular}

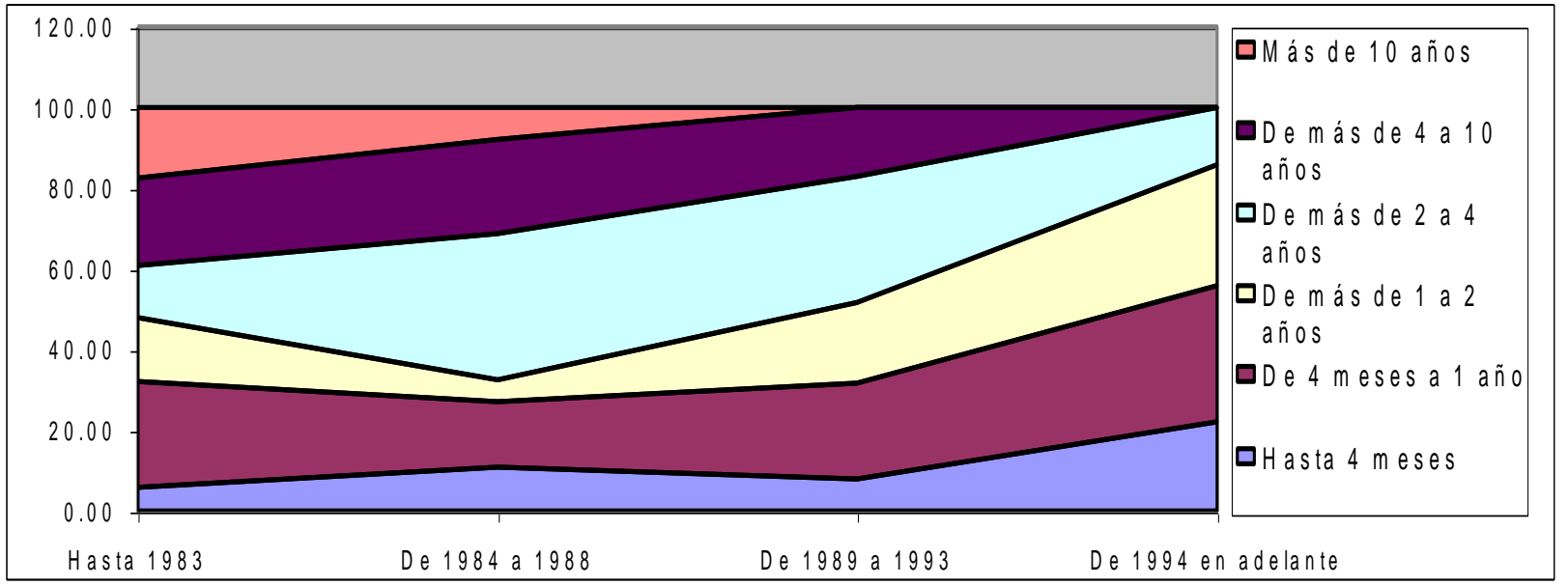

CUADRO Y GRAFICA \# 9

DURACIÓN DEL EVENTO

Mujeres (1er. trabajo en E. U. A.)

\begin{tabular}{|c|r|r|r|r|r|r|}
\hline Cohorte & $\begin{array}{c}\text { Hasta 4 } \\
\text { meses }\end{array}$ & $\begin{array}{c}\text { De 4 meses } \\
\text { a 1 año }\end{array}$ & $\begin{array}{c}\text { De más de 1 } \\
\text { a 2 años }\end{array}$ & $\begin{array}{c}\text { De más de 2 } \\
\text { a 4 años }\end{array}$ & $\begin{array}{c}\text { De más de 4 } \\
\text { a 10 años }\end{array}$ & Más de 10 años \\
\hline Hasta 1983 & 12.50 & 18.80 & 12.50 & 25.00 & 25.00 & 6.30 \\
\hline De 1984 a 1988 & 17.90 & 17.90 & 10.70 & 25.00 & 21.40 & 7.10 \\
\hline De 1989 a 1993 & 5.10 & 28.00 & 19.50 & 28.80 & 18.60 & 0.00 \\
\hline $\begin{array}{c}\text { De 1994 en } \\
\text { adelante }\end{array}$ & 36.80 & 23.70 & 26.30 & 13.20 & 0.00 & 0.00 \\
\hline
\end{tabular}

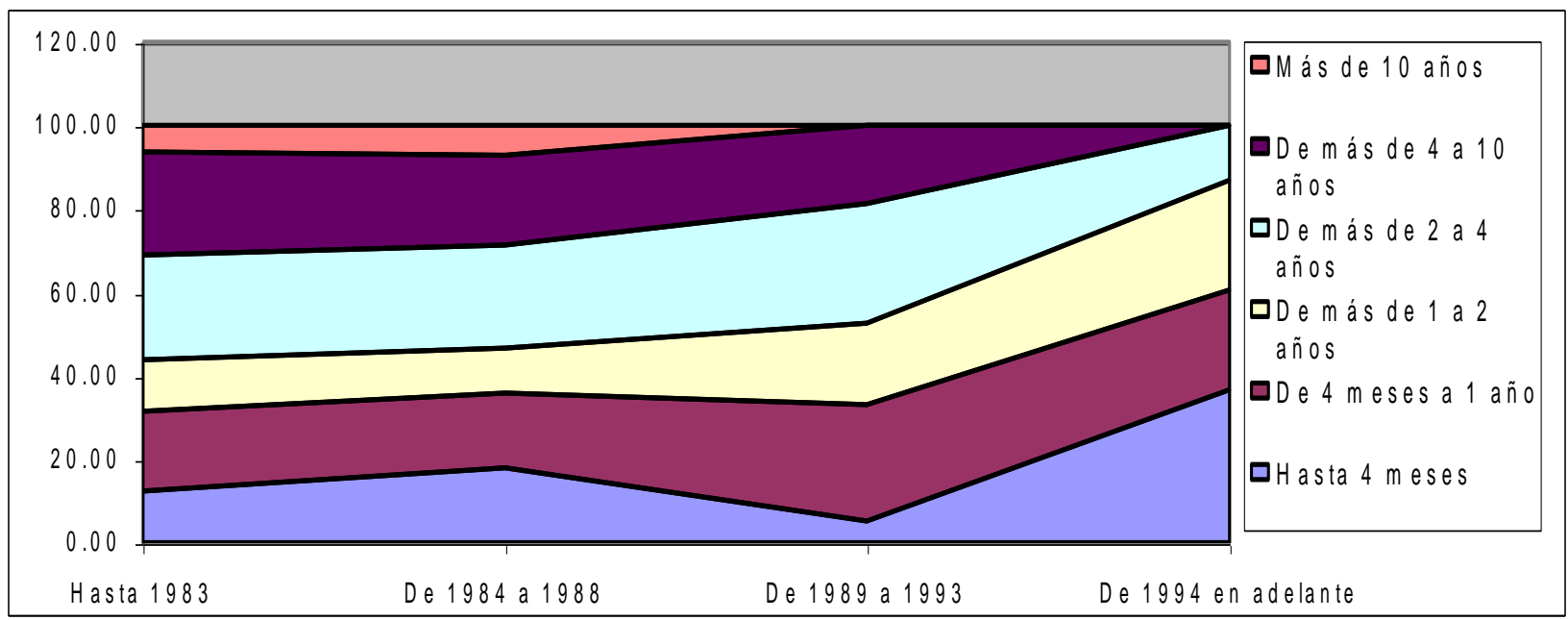


Sector de ubicación de la TL en EUA (hombres) \%:

\begin{tabular}{|c|r|r|r|r|r|}
\hline Sector/Evento & \multicolumn{1}{c|}{$\mathbf{1}^{\mathbf{0}}$} & \multicolumn{1}{c|}{$\mathbf{2}^{\mathbf{0}}$} & \multicolumn{1}{c|}{$\mathbf{3}^{\mathbf{0}}$} & \multicolumn{1}{c|}{$\mathbf{4}^{\mathbf{2}}$} & \multicolumn{1}{|c|}{$\mathbf{5}^{\mathbf{y}+}$} \\
\hline Primario & 9.40 & 6.10 & 2.60 & 4.80 & 5.87 \\
\hline Secundario & 34.90 & 28.50 & 34.20 & 33.30 & 15.93 \\
\hline Terciario & 55.70 & 65.40 & 63.20 & 61.90 & 78.20 \\
\hline Total & 100.00 & 100.00 & 100.00 & 100.00 & 100.00 \\
\hline $\mathbf{N}$ & 448 & 277 & 118 & 68 & 74 \\
\hline
\end{tabular}

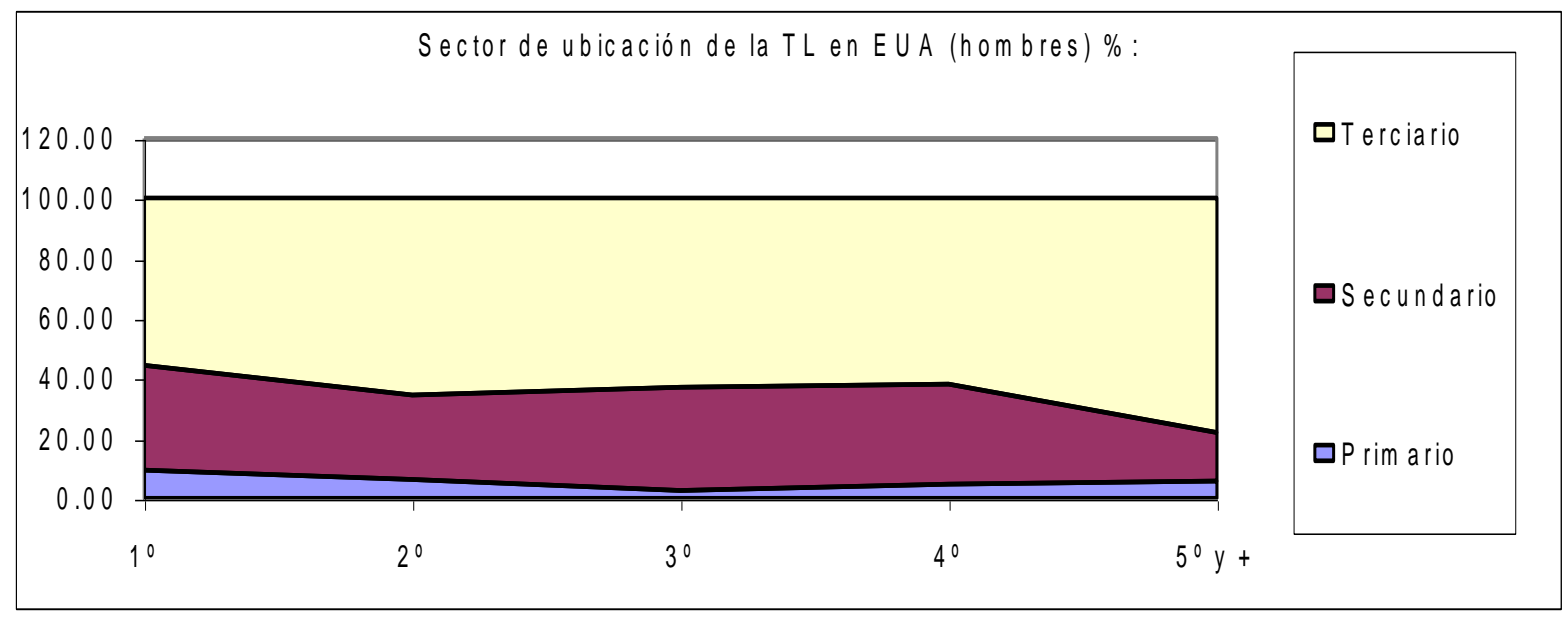

Sector de ubicación de la TL en EUA (mujeres) \%:

\begin{tabular}{|c|r|r|r|r|r|}
\hline Sector/Evento & \multicolumn{1}{|c|}{$\mathbf{1}^{\mathbf{0}}$} & \multicolumn{1}{c|}{$\mathbf{2}^{\mathbf{0}}$} & \multicolumn{1}{c|}{$\mathbf{3}^{\mathbf{0}}$} & \multicolumn{1}{c|}{$\mathbf{4}^{\mathbf{0}}$} & \multicolumn{1}{c|}{$\mathbf{5}^{\mathbf{0}} \mathbf{+}$} \\
\hline Primario & 2.60 & 4.80 & 4.50 & 0.00 & 0.00 \\
\hline Secundario & 48.20 & 41.90 & 40.90 & 38.90 & 31.00 \\
\hline Terciario & 49.20 & 53.30 & 54.60 & 61.10 & 69.00 \\
\hline Total & 100.00 & 100.00 & 100.00 & 100.00 & 100.00 \\
\hline $\mathbf{N}$ & 200 & 116 & 45 & 21 & 33 \\
\hline
\end{tabular}

Sector de ubicación de la TL en EUA (mujeres)\%:

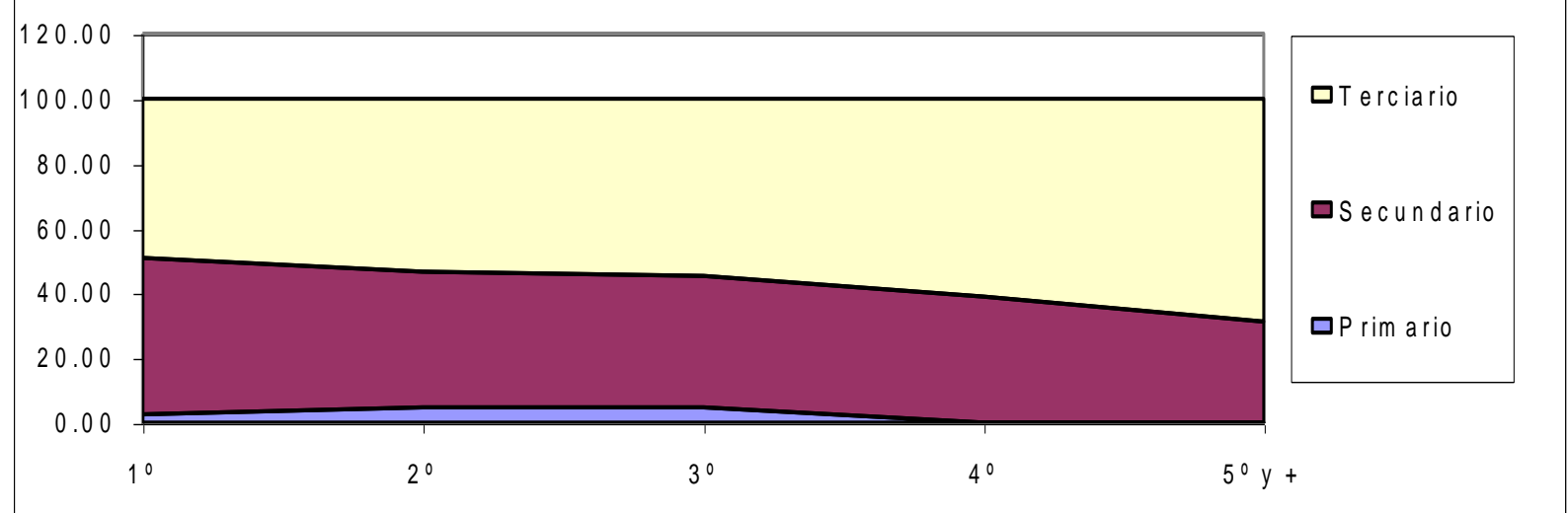


CUADRO Y GRAFICA \# 11

Rama de ubicación de la TL en EUA (mujeres)\%:

\begin{tabular}{|c|r|r|r|r|r|}
\hline Rama/Evento & \multicolumn{1}{|c|}{$\mathbf{1}^{\mathbf{0}}$} & \multicolumn{1}{c|}{$\mathbf{2}^{\mathbf{0}}$} & \multicolumn{1}{|c|}{$\mathbf{3}^{\mathbf{0}}$} & \multicolumn{1}{|c|}{$\mathbf{4}^{\mathbf{0}} \mathbf{\mathbf { + }}$} \\
\hline Agrícola & 2.60 & 4.80 & 4.50 & 0.00 & 0.00 \\
\hline Ind. s/confec. & 5.70 & 6.70 & 4.50 & 22.20 & 3.40 \\
\hline Confección & 42.50 & 35.20 & 34.10 & 16.70 & 27.60 \\
\hline Comercio & 8.30 & 13.30 & 11.40 & 11.10 & 10.30 \\
\hline Servs./rest. & 3.60 & 6.70 & 6.80 & 5.60 & 17.20 \\
\hline Restaurantes & 15.00 & 20.00 & 20.50 & 27.70 & 31.20 \\
\hline Trab. dom. & 22.30 & 13.30 & 15.90 & 16.70 & 10.30 \\
\hline Construcción & 0.00 & 0.00 & 2.30 & 0.00 & 0.00 \\
\hline Total & 100.00 & 100.00 & 100.00 & 100.00 & 100.00 \\
\hline $\mathbf{N}$ & 200 & 116 & 45 & 21 & 33 \\
\hline
\end{tabular}

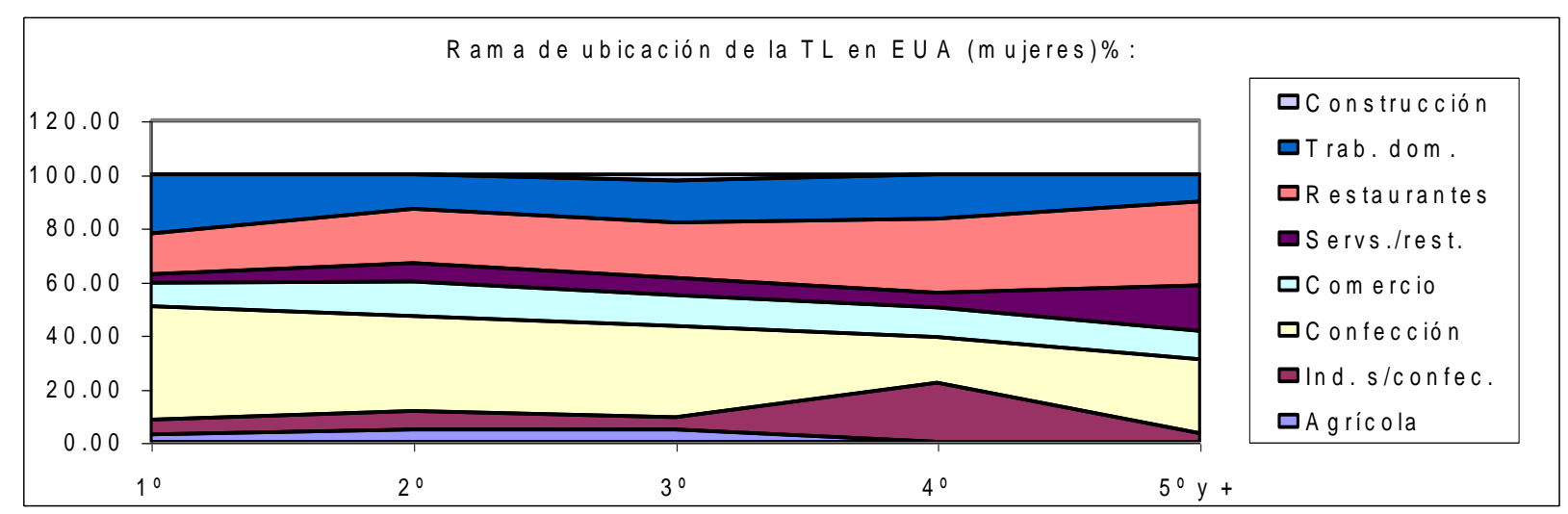

CUADRO Y GRAFICA \# 12

Rama de ubicación de la TL en EUA (hombres)\%:

\begin{tabular}{|c|c|c|c|c|c|}
\hline Rama/Evento & $\mathbf{1}^{\mathbf{o}}$ & $2^{\circ}$ & $\mathbf{3}^{\mathbf{o}}$ & $4^{\circ}$ & $5^{0} y+$ \\
\hline Agrícola & 9.40 & 6.10 & 2.60 & 4.80 & 5.87 \\
\hline Ind. s/confec. & 12.80 & 7.60 & 9.60 & 11.10 & 4.80 \\
\hline Confección & 5.70 & 7.20 & 14.90 & 14.30 & 10.30 \\
\hline Comercio & 16.30 & 13.70 & 9.60 & 7.90 & 0.87 \\
\hline Servs./rest. & 13.50 & 9.90 & 11.40 & 12.70 & 12.03 \\
\hline Trab. dom. & 3.90 & 6.10 & 4.40 & 4.80 & 9.47 \\
\hline Restaurantes & 33.10 & 46.40 & 44.00 & 44.40 & 49.93 \\
\hline Construcción & 5.30 & 3.00 & 3.50 & 0.00 & 6.73 \\
\hline Total & 100.00 & 100.00 & 100.00 & 100.00 & 100.00 \\
\hline $\mathbf{N}$ & 448 & 277 & 118 & 68 & 74 \\
\hline
\end{tabular}

R ama de ubicación de la TL en EUA (hombres)\%:

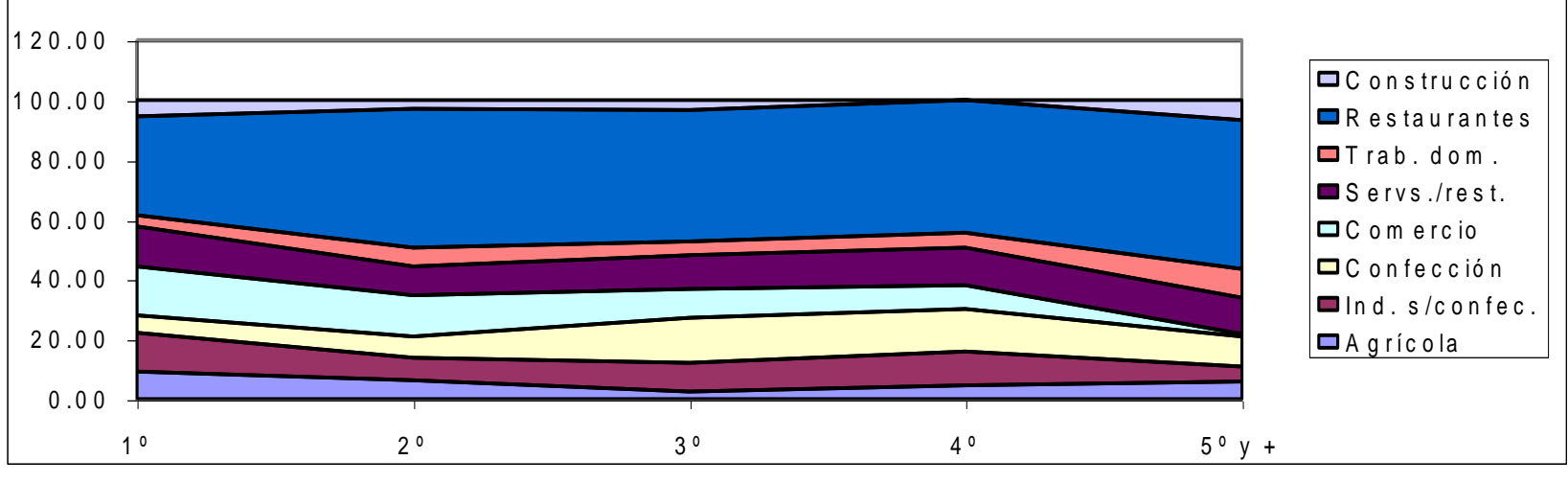


Ramadeubicación de la TLen M éxico (mujeres)\%:

\begin{tabular}{|c|c|c|c|c|}
\hline R a m a / Evento & 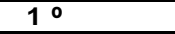 & $2 \circ$ & $3 \circ$ & $4 \stackrel{\circ}{ } y+$ \\
\hline Trabajo dom & 40.80 & 41.50 & 38.20 & 20.60 \\
\hline Agricultura & 23.20 & 3.10 & 11.80 & 5.90 \\
\hline Servicios & 18.40 & 26.20 & 29.40 & 41.20 \\
\hline Comercio & 11.20 & 21.50 & 8.80 & 14.70 \\
\hline Industria gral. & 5.60 & 6.20 & 11.80 & 8.80 \\
\hline Construcción & 0.80 & 1.50 & 0.00 & 8.80 \\
\hline Total & 100.00 & 100.00 & 100.00 & 100.00 \\
\hline $\mathbf{N}$ & 187 & 126 & 47 & 43 \\
\hline
\end{tabular}

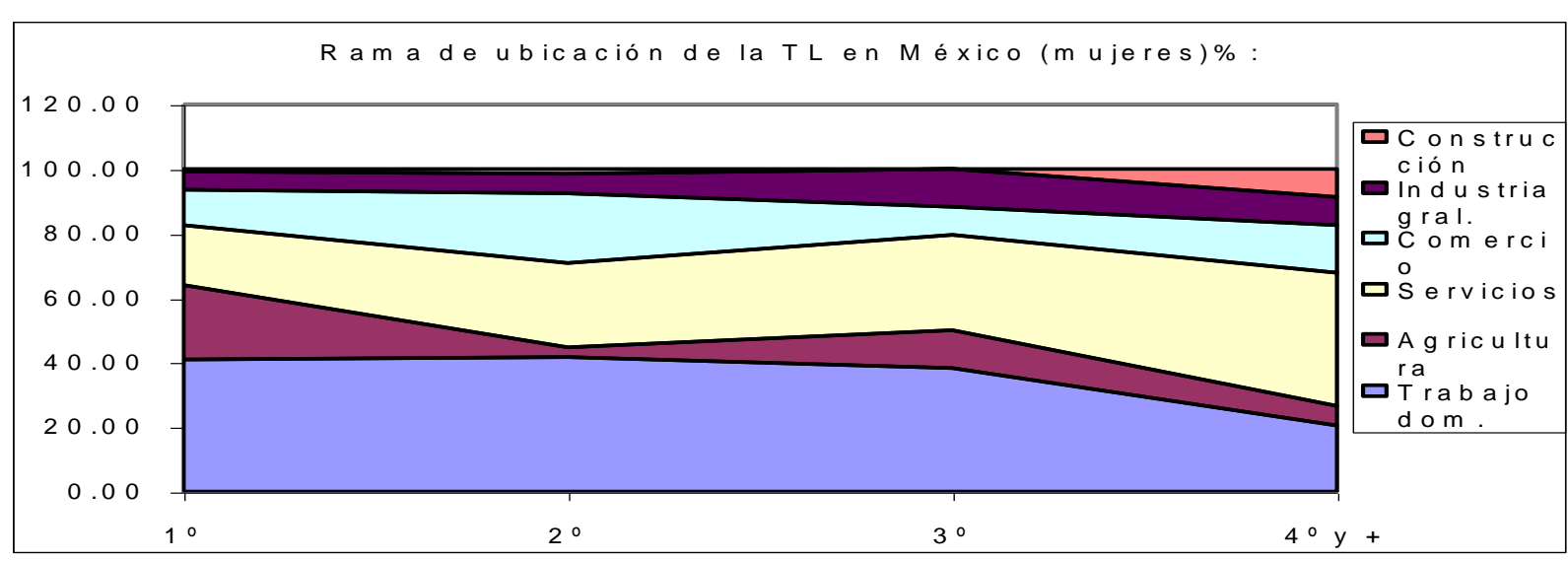

Rama de ubicación de la TL en México (hombres)\%:

\begin{tabular}{|c|c|c|c|c|c|c|}
\hline R a m a /Eventd & $1 \stackrel{0}{0}$ & 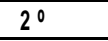 & 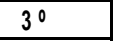 & 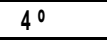 & 50 & $6 \div y+$ \\
\hline A gricultura & 70.40 & 40.70 & 47.60 & 45.70 & 34.40 & 32.10 \\
\hline Industria gra & 6.30 & 15.60 & 9.90 & 11.50 & 14.00 & 16.70 \\
\hline Com ercio & 8.40 & 15.20 & 10.60 & 12.50 & 12.50 & 13.10 \\
\hline Servicios & 6.20 & 13.80 & 18.40 & 18.80 & 25.00 & 21.40 \\
\hline Construcción & 5.20 & 9.20 & 6.40 & 7.30 & 6.30 & 11.90 \\
\hline Trabajo dom & 3.50 & 5.50 & 7.10 & 4.20 & 7.80 & 4.80 \\
\hline Total & 100.00 & 100.00 & 100.00 & 100.00 & 100.00 & 100.00 \\
\hline $\mathrm{N}$ & 425 & 335 & 192 & 115 & 70 & 98 \\
\hline
\end{tabular}

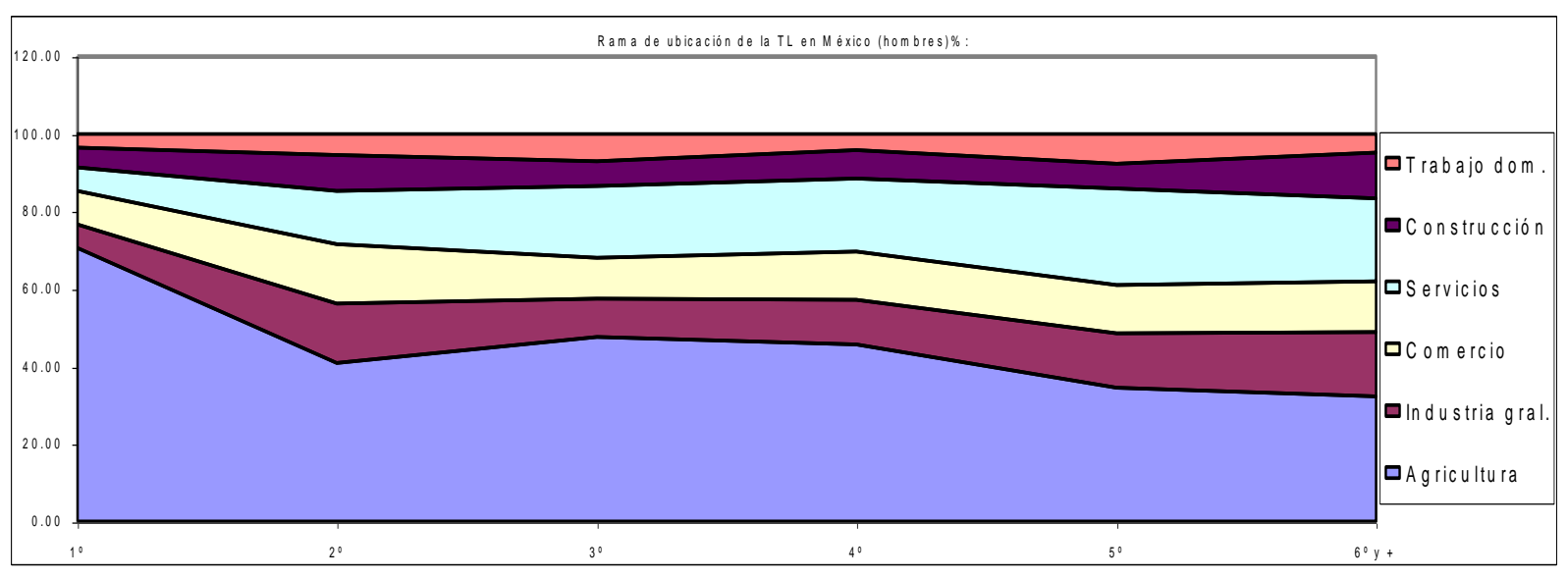


Tamaño de empresa de ubicación de la TL en EUA (mujeres)\%:

\begin{tabular}{|c|c|c|c|c|c|}
\hline Tamaño/Evento & $1^{0}$ & $2^{\circ}$ & 3o & 40 & $50 y+$ \\
\hline Hasta 10 & 40.50 & 30.20 & 42.10 & 62.50 & 53.60 \\
\hline Más de 10 a 20 & 16.20 & 25.30 & 10.50 & 12.50 & 3.60 \\
\hline Más de 20 a 35 & 0.00 & 18.20 & 26.30 & 12.50 & 14.30 \\
\hline Más de 35 a 60 & 19.50 & 17.20 & 15.80 & 0.00 & 7.10 \\
\hline Más de 60 & 23.80 & 9.10 & 5.30 & 12.50 & 21.40 \\
\hline Total & 100.00 & 100.00 & 100.00 & 100.00 & 100.00 \\
\hline $\mathbf{N}$ & 200 & 116 & 45 & 21 & 33 \\
\hline
\end{tabular}

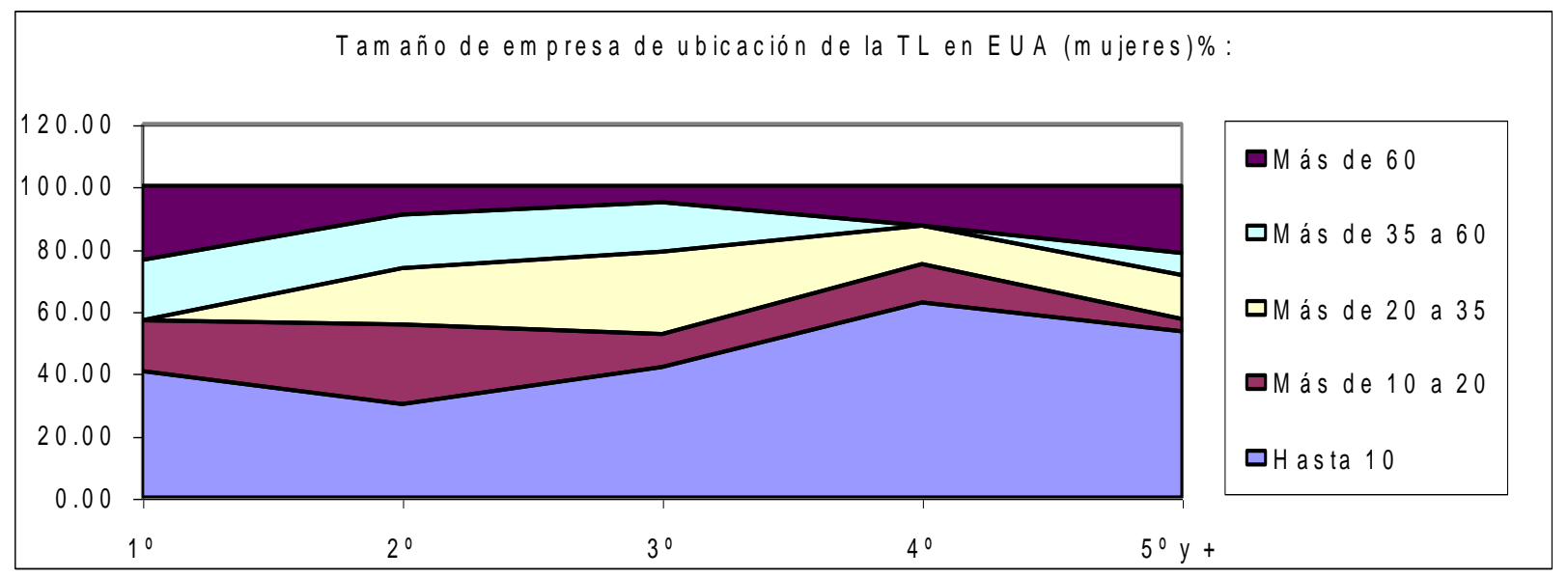

Tamaño de empresa de ubicación de la TL en EUA (hombres)\%:

\begin{tabular}{|c|c|c|c|c|c|}
\hline Tamaño/Evento & 19 & $2^{\circ}$ & $3^{\circ}$ & $4^{\circ}$ & $5^{\circ} y+$ \\
\hline Hasta 10 & 54.00 & 50.50 & 53.60 & 50.90 & 58.27 \\
\hline Más de 10 a 20 & 23.80 & 28.80 & 22.30 & 26.20 & 27.10 \\
\hline Más de 20 a 35 & 0.00 & 9.20 & 9.80 & 4.90 & 2.23 \\
\hline Más de 35 a 60 & 9.70 & 6.90 & 8.90 & 9.80 & 5.10 \\
\hline Más de 60 & 12.50 & 4.60 & $\overline{5.40}$ & 8.20 & 7.30 \\
\hline Total & 100.00 & 100.00 & 100.00 & 100.00 & 100.00 \\
\hline $\mathbf{N}$ & 448 & 277 & 118 & 68 & 74 \\
\hline
\end{tabular}

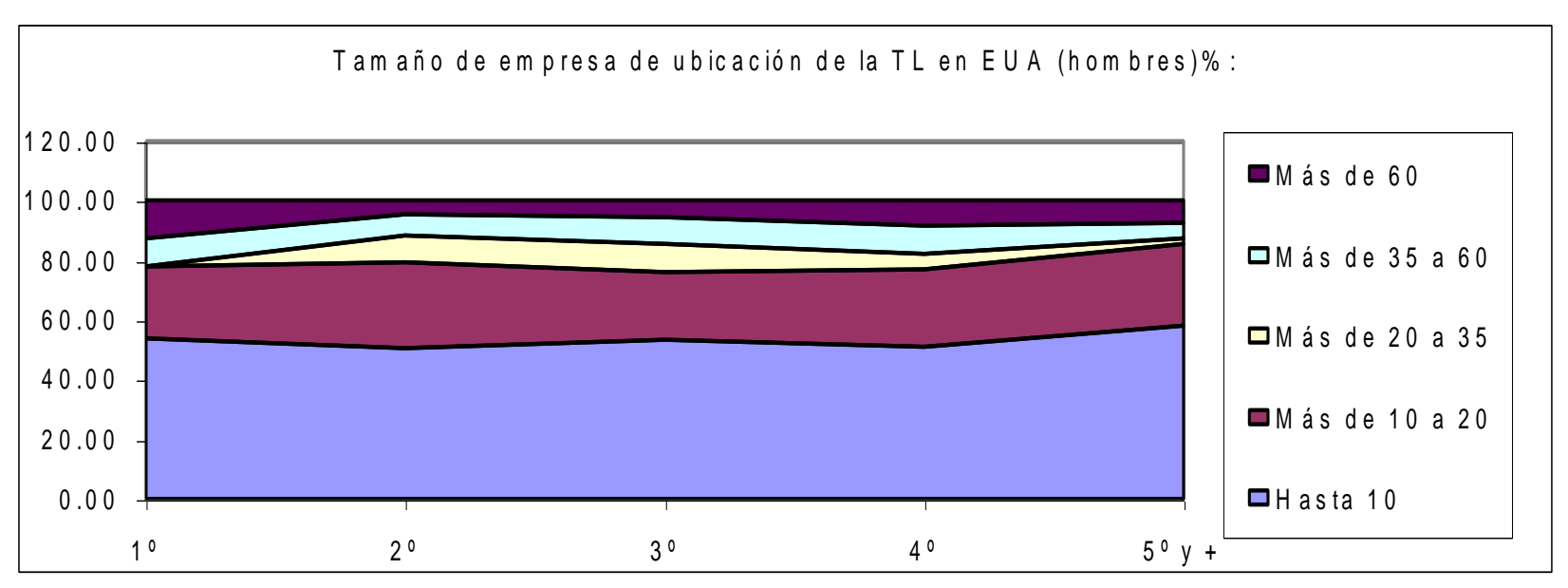


Tiempo de evento de la TL en EUA (mujeres)\%:

\begin{tabular}{|c|r|r|r|r|r|}
\hline Tiempo/Evento & \multicolumn{1}{|c|}{$\mathbf{1}^{\mathbf{o}}$} & \multicolumn{1}{c|}{$\mathbf{2}^{\mathbf{0}}$} & \multicolumn{1}{|c|}{$\mathbf{3}^{\mathbf{0}}$} & \multicolumn{1}{c|}{$\mathbf{4}^{\mathbf{0}}$} & $\mathbf{5}^{\mathbf{0}} \mathbf{+}$ \\
\hline Hasta 0.3 años & 13.50 & 11.20 & 17.80 & 42.80 & 21.20 \\
\hline De más de 0.3 a 1 año & 25.00 & 15.50 & 22.20 & 28.60 & 30.30 \\
\hline De más de 1 a 2 años & 19.00 & 20.70 & 4.40 & 4.80 & 33.40 \\
\hline De más de 2 a 4 años & 25.00 & 38.90 & 44.50 & 9.50 & 9.10 \\
\hline De más de 4 a 10 años & 16.00 & 10.30 & 8.90 & 14.30 & 3.00 \\
\hline Más de 10 años & 1.50 & 3.40 & 2.20 & 0.00 & 3.00 \\
\hline Total & 100.00 & 100.00 & 100.00 & 100.00 & 100.00 \\
\hline $\mathbf{N}$ & 200 & 116 & 45 & 21 & 33 \\
\hline
\end{tabular}

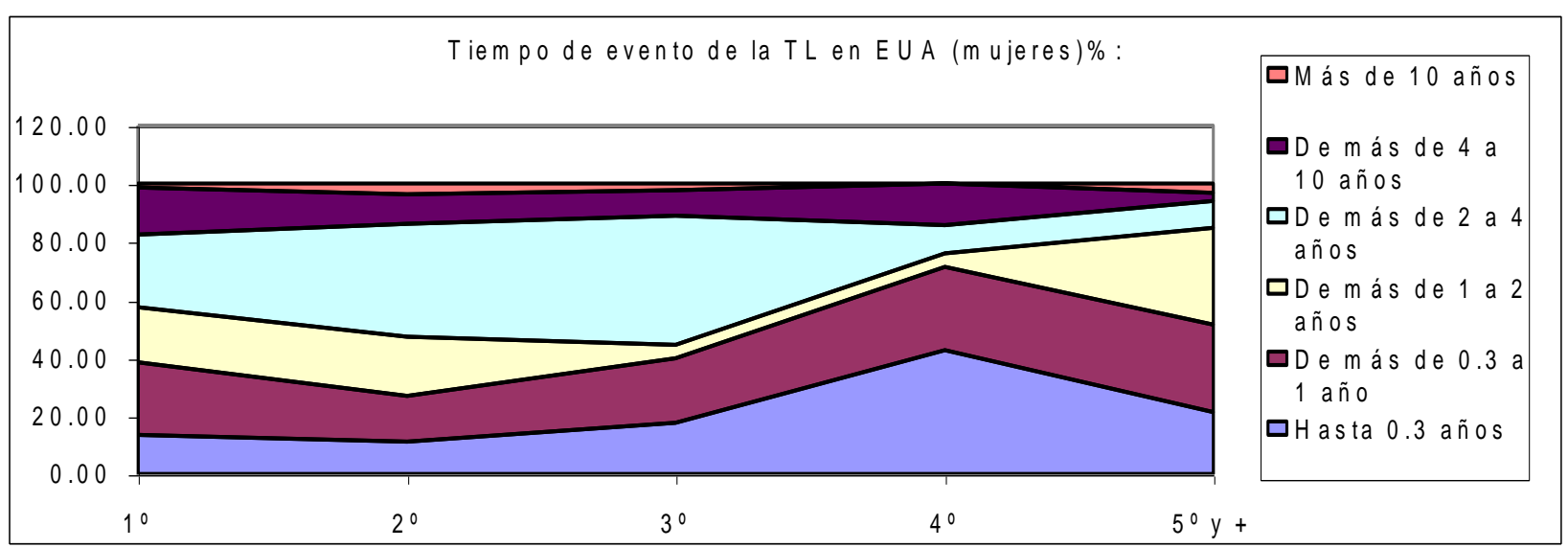

Tiempo de evento de la TL en EUA (hombres)\%:

\begin{tabular}{|c|r|r|r|r|r|}
\hline Tiempo/Evento & \multicolumn{1}{c|}{$\mathbf{1}^{\mathbf{9}}$} & \multicolumn{1}{c|}{$\mathbf{2}^{\mathbf{0}}$} & \multicolumn{1}{c|}{$\mathbf{3}^{\mathbf{0}}$} & \multicolumn{1}{c|}{$\mathbf{4}^{\mathbf{0}}$} & \multicolumn{1}{c|}{$\mathbf{\mathbf { y } +}$} \\
\hline Hasta 0.3 años & 10.70 & 10.50 & 11.90 & 22.10 & 29.47 \\
\hline De más de 0.3 a 1 año & 24.80 & 25.60 & 34.80 & 17.60 & 28.48 \\
\hline De más de 1 a 2 años & 19.00 & 19.50 & 18.60 & 25.00 & 24.05 \\
\hline De más de 2 a 4 años & 26.10 & 27.80 & 23.70 & 25.00 & 15.43 \\
\hline De más de 4 a 10 años & 15.40 & 13.00 & 9.30 & 7.40 & 1.70 \\
\hline Más de 10 años & 4.00 & 3.60 & 1.70 & 2.90 & 0.87 \\
\hline Total & 100.00 & 100.00 & 100.00 & 100.00 & 100.00 \\
\hline $\mathbf{N}$ & 448 & 277 & 118 & 68 & 74 \\
\hline
\end{tabular}

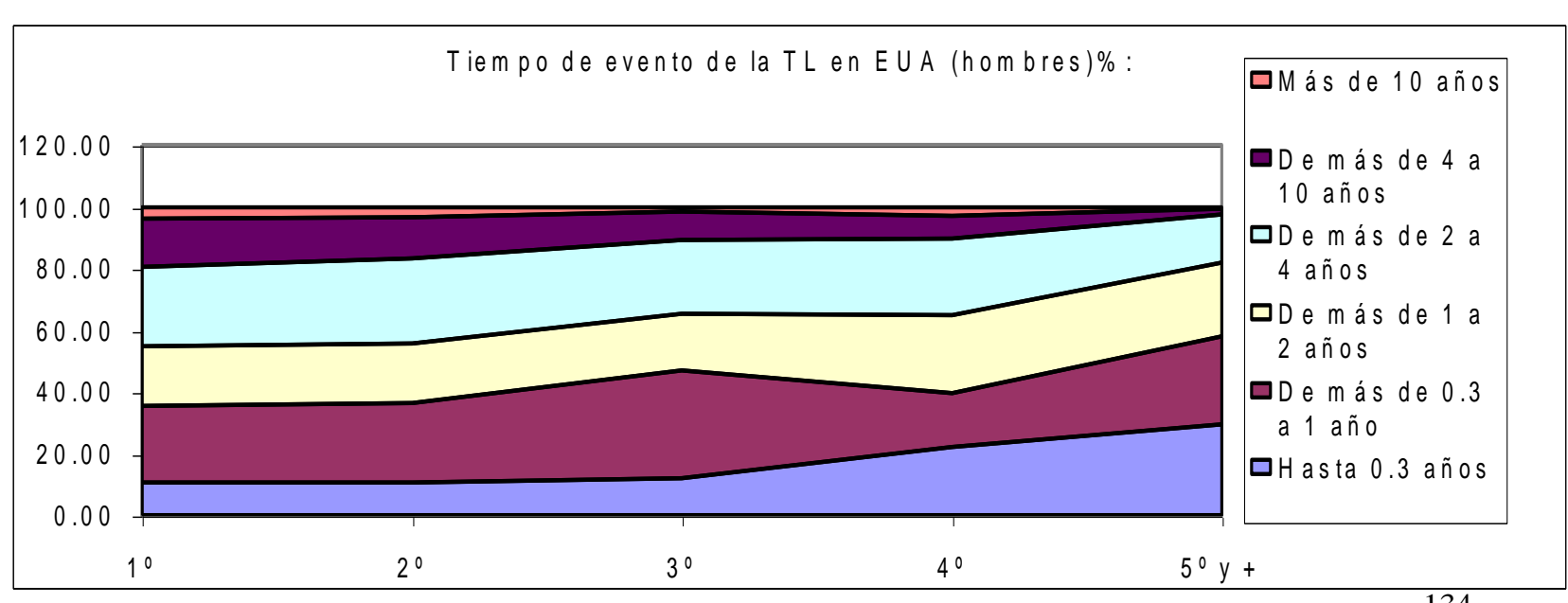


CUADRO Y GRAFICA \# 15

Horas de trabajo semanales de la TL en EUA (mujeres)\%:

\begin{tabular}{|c|r|r|r|r|r|}
\hline Horas/Evento & \multicolumn{1}{c|}{$\mathbf{1}^{\mathbf{0}}$} & \multicolumn{1}{c|}{$\mathbf{2}^{\mathbf{0}}$} & \multicolumn{1}{c|}{$\mathbf{3}^{\mathbf{0}}$} & \multicolumn{1}{c|}{$\mathbf{4}^{\mathbf{0}}$} & $\mathbf{5}^{\mathbf{0}} \mathbf{~ + ~}$ \\
\hline Menos de 40 & 12.40 & 28.90 & 30.80 & 33.30 & 24.00 \\
\hline De 40 a 50 & 29.20 & 29.90 & 25.60 & 53.40 & 32.00 \\
\hline De 50 a 60 & 42.70 & 34.00 & 30.80 & 13.30 & 20.00 \\
\hline Más de 60 & 15.70 & 7.20 & 12.80 & 0.00 & 24.00 \\
\hline Total & 100.00 & 100.00 & 100.00 & 100.00 & 100.00 \\
\hline $\mathbf{N}$ & 200 & 116 & 45 & 21 & 33 \\
\hline
\end{tabular}

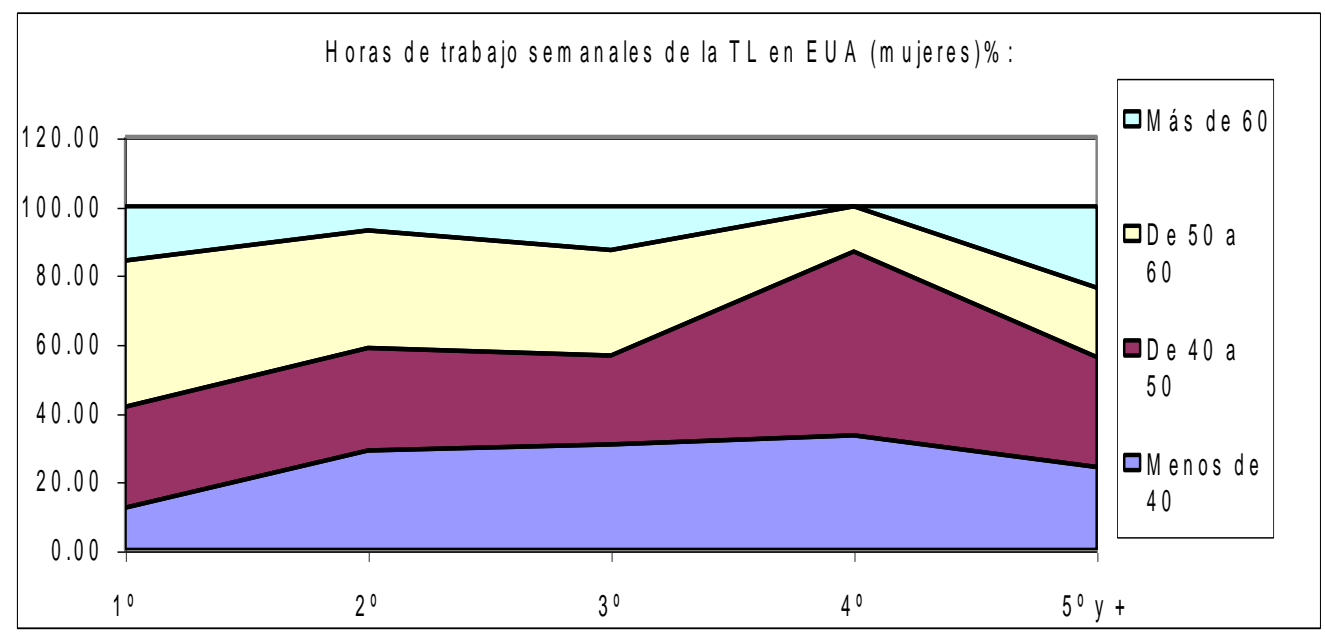

CUADRO Y GRAFICA \# 16

Horas de trabajo semanales de la TL en EUA (hombres)\%:

\begin{tabular}{|c|r|r|r|r|r|}
\hline Horas/Evento & \multicolumn{1}{c|}{$\mathbf{1}^{\mathbf{0}}$} & \multicolumn{1}{c|}{$\mathbf{2}^{\mathbf{0}}$} & \multicolumn{1}{c|}{$\mathbf{3}^{\mathbf{0}}$} & \multicolumn{1}{c|}{$\mathbf{4}^{\mathbf{0}}$} & \multicolumn{1}{c}{$\mathbf{5}^{\mathbf{y}} \mathbf{+}$} \\
\hline Menos de 40 & 12.50 & 24.00 & 30.20 & 34.00 & 13.20 \\
\hline De 40 a 50 & 38.10 & 28.30 & 26.50 & 23.70 & 39.70 \\
\hline De 50 a 60 & 27.00 & 26.30 & 26.50 & 22.00 & 16.20 \\
\hline Más de 60 & 22.40 & 21.40 & 16.80 & 20.30 & 30.90 \\
\hline Total & 100.00 & 100.00 & 100.00 & 100.00 & 100.00 \\
\hline $\mathbf{N}$ & 448 & 277 & 118 & 68 & 74 \\
\hline
\end{tabular}

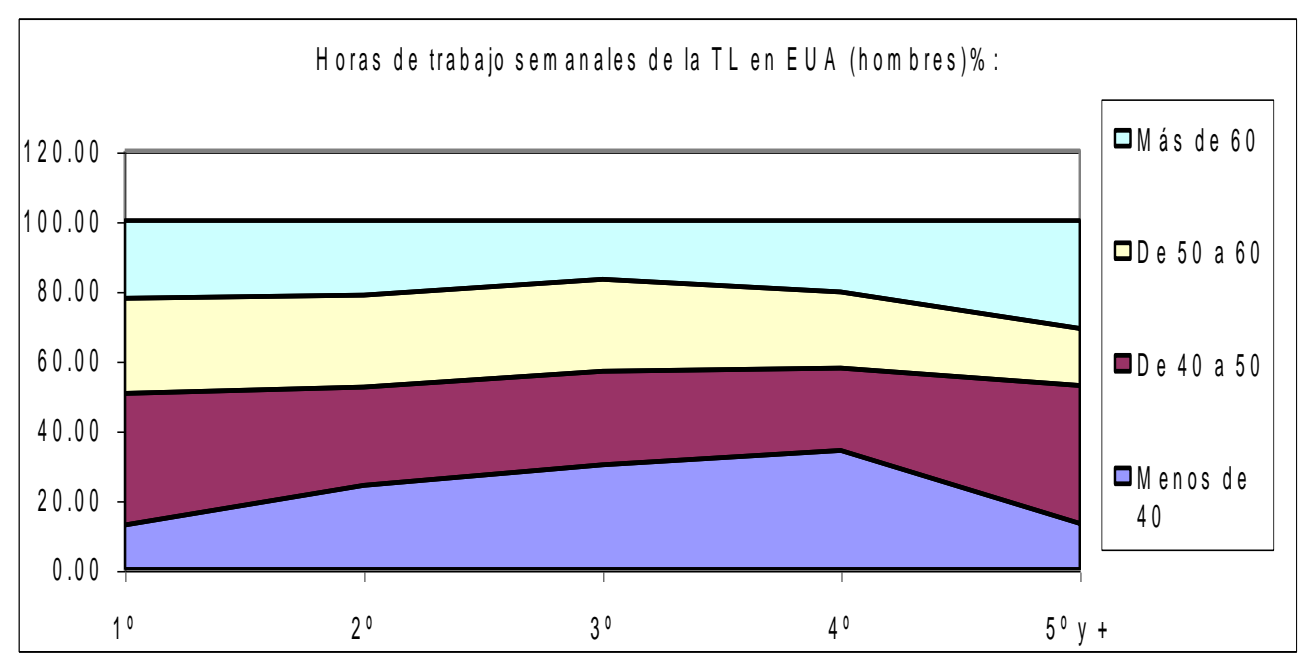


Ramade ubicación de la TL en M éxico (hombres)\%:

\begin{tabular}{|c|r|r|r|r|r|r|}
\hline Rama/Evento & \multicolumn{1}{|c|}{$\mathbf{1}^{\mathbf{0}}$} & \multicolumn{1}{|c|}{$\mathbf{2}^{\mathbf{0}}$} & \multicolumn{1}{|c|}{$\mathbf{3}^{\mathbf{0}}$} & \multicolumn{1}{|c|}{$\mathbf{4}^{\mathbf{0}}$} & $\mathbf{6}^{\mathbf{0}} \mathbf{y +}$ \\
\hline A gricultura & 70.40 & 40.70 & 47.60 & 45.70 & 34.40 & 32.10 \\
\hline Industria gral. & 6.30 & 15.60 & 9.90 & 11.50 & 14.00 & 16.70 \\
\hline Comercio & 8.40 & 15.20 & 10.60 & 12.50 & 12.50 & 13.10 \\
\hline Servicios & 6.20 & 13.80 & 18.40 & 18.80 & 25.00 & 21.40 \\
\hline C onstrucción & 5.20 & 9.20 & 6.40 & 7.30 & 6.30 & 11.90 \\
\hline Trabajo dom & 3.50 & 5.50 & 7.10 & 4.20 & 7.80 & 4.80 \\
\hline Total & 100.00 & 100.00 & 100.00 & 100.00 & 100.00 & 100.00 \\
\hline N & 425 & 335 & 192 & 115 & 70 & 98 \\
\hline
\end{tabular}

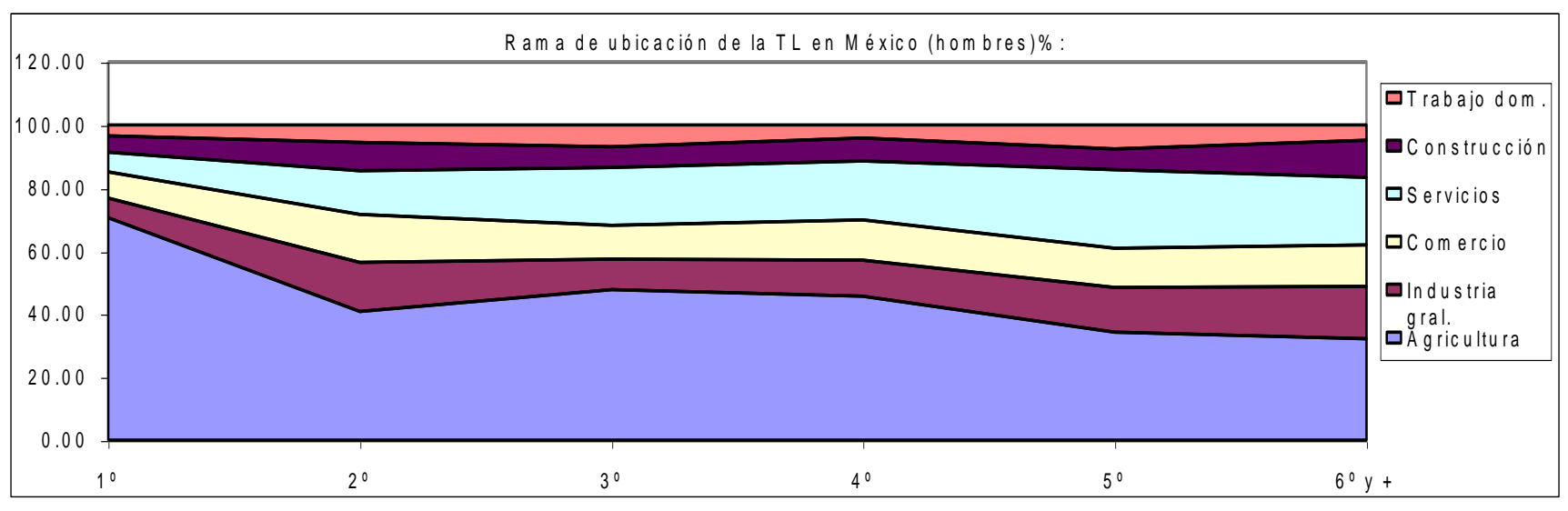

Horas de trabajo semanales de la TL en México (hombres)\%:

\begin{tabular}{|c|c|c|c|c|c|c|}
\hline Horas/Evento & $1^{\circ}$ & 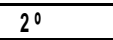 & 30 & 40 & 50 & $6 \div y+$ \\
\hline Menos de 40 & 24.10 & 15.30 & 19.50 & 15.10 & 14.00 & 11.10 \\
\hline Más de 40 y hasta 50 & 40.60 & 45.90 & 42.30 & 47.70 & 49.10 & 42.00 \\
\hline Más de 50 y hasta 60 & 23.70 & 24.10 & 29.70 & 20.90 & 24.60 & 30.90 \\
\hline Más de 60 & 11.60 & 14.70 & 8.50 & 16.30 & 12.30 & 16.00 \\
\hline Total & 100.00 & 100.00 & 100.00 & 100.00 & 100.00 & 100.00 \\
\hline $\mathrm{N}$ & 425 & 335 & 192 & 115 & 70 & 98 \\
\hline
\end{tabular}

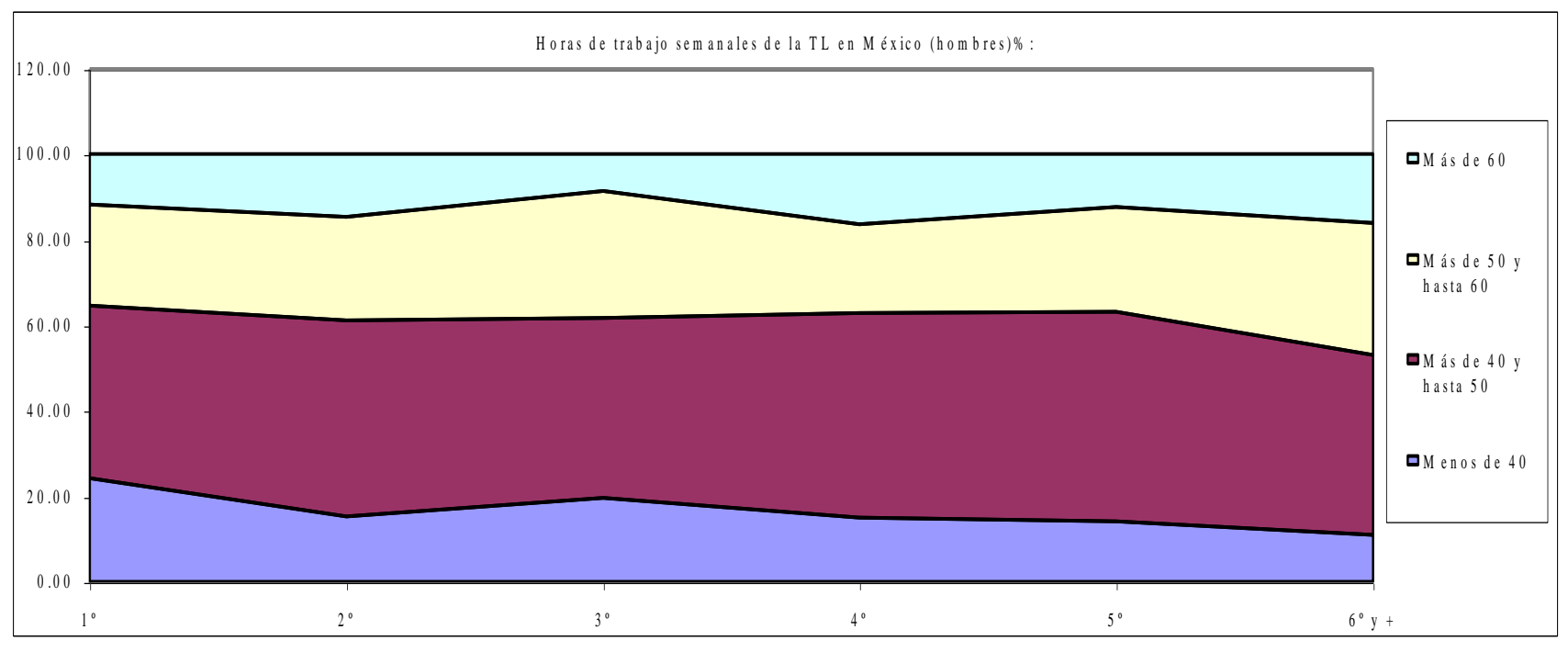


CUADRO Y GRAFICA \# 19

Días laborales semanales de la TL en EUA (mujeres)\%:

\begin{tabular}{|c|c|c|c|c|c|}
\hline Días/Evento & $1^{\circ}$ & 20 & 3응 & $4^{\circ}$ & 5y $y+$ \\
\hline 2 días & 0.00 & 1.00 & 2.60 & 6.70 & 0.00 \\
\hline 3 días & 1.10 & 1.00 & 2.60 & 0.00 & 0.00 \\
\hline 4 días & 1.10 & 1.00 & 0.00 & 6.70 & 4.00 \\
\hline 5 días & 14.10 & 18.20 & 28.20 & 33.30 & 24.00 \\
\hline 6 días & 69.10 & 61.60 & 51.20 & 40.00 & 56.00 \\
\hline 7 días & 14.60 & 17.20 & 15.40 & 13.30 & 16.00 \\
\hline Total & 100.00 & 100.00 & 100.00 & 100.00 & 100.00 \\
\hline $\mathbf{N}$ & 200 & 116 & 45 & 21 & 33 \\
\hline
\end{tabular}

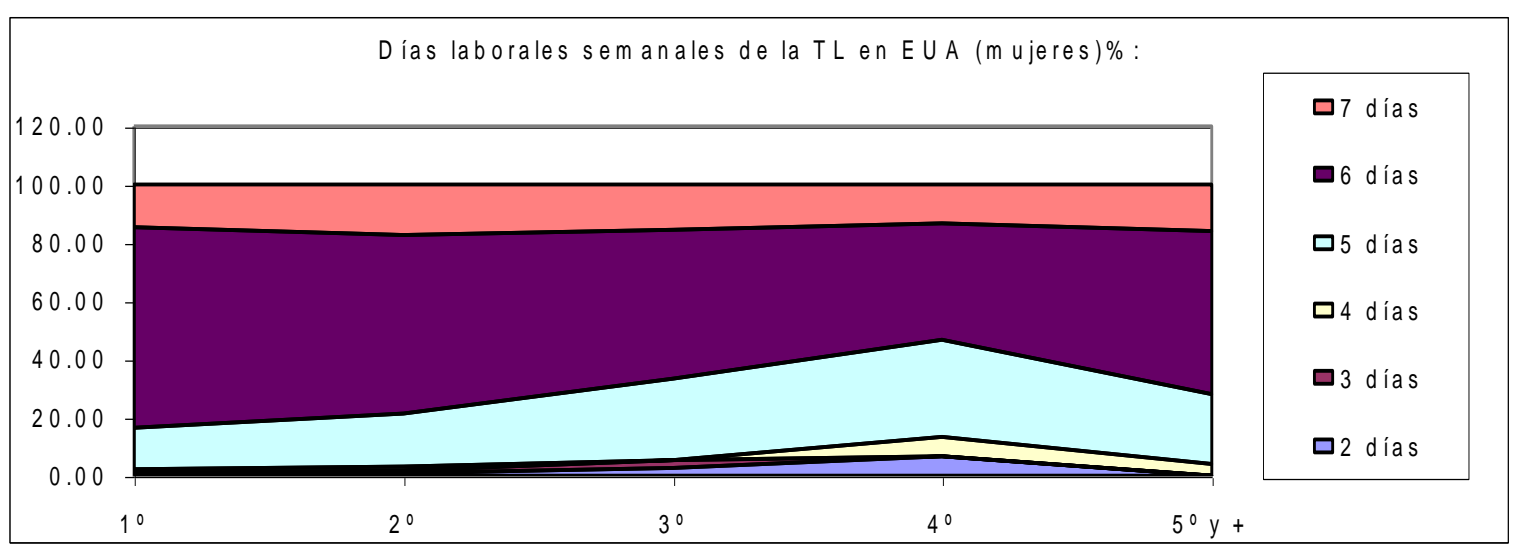

CUADRO Y GRAFICA \# 20

Días laborales semanales de la TL en EUA (hombres)\%:

\begin{tabular}{|c|r|r|r|r|r|}
\hline Días/Evento & \multicolumn{1}{c|}{$\mathbf{1}^{\mathbf{0}}$} & \multicolumn{1}{c|}{$\mathbf{2}^{\mathbf{0}}$} & \multicolumn{1}{c|}{$\mathbf{3}^{\mathbf{0}}$} & \multicolumn{1}{c|}{$\mathbf{4}^{\mathbf{2}}$} & \multicolumn{1}{c|}{$\mathbf{y}+$} \\
\hline 1 día & 0.20 & 0.00 & 0.00 & 0.00 & 0.00 \\
\hline 2 días & 0.20 & 0.00 & 0.00 & 0.00 & 0.00 \\
\hline 3 días & 1.20 & 0.80 & 0.00 & 1.70 & 0.00 \\
\hline 4 días & 1.40 & 0.80 & 0.90 & 0.00 & 0.00 \\
\hline 5 días & 17.10 & 18.30 & 25.70 & 32.20 & 36.37 \\
\hline 6 días & 62.30 & 60.30 & 64.60 & 50.80 & 51.63 \\
\hline 7 días & 17.6 & 19.80 & 8.80 & 15.30 & 12.00 \\
\hline Total & 100.00 & 100.00 & 100.00 & 100.00 & 100.00 \\
\hline $\mathbf{N}$ & 448 & 277 & 118 & 68 & 74 \\
\hline
\end{tabular}

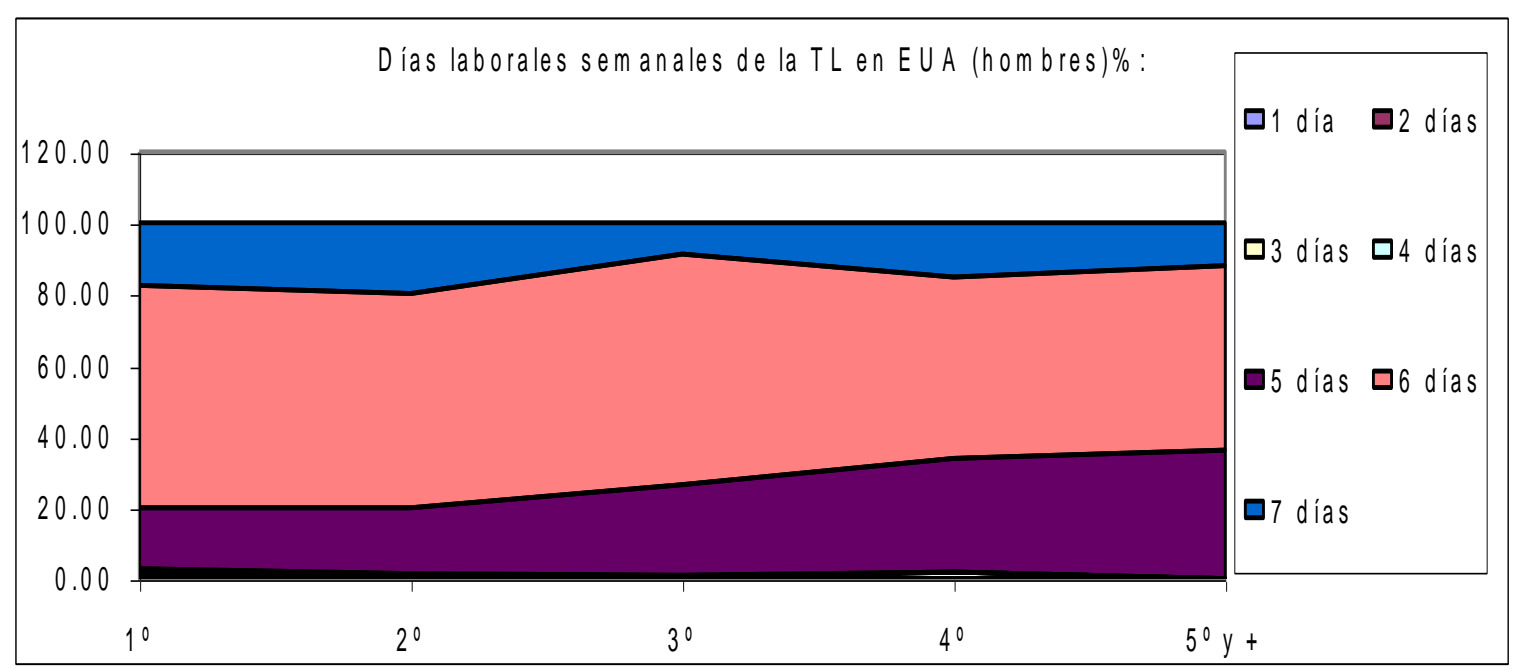


Días laborales semanales de la TL en M éxico (mujeres)\%:

\begin{tabular}{|c|c|c|c|c|}
\hline Días/Evento & 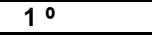 & $2 \circ$ & 3은 & 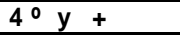 \\
\hline 2 días & 3.90 & 0.00 & 0.00 & 0.00 \\
\hline 3 día s & 0.00 & 6.50 & 5.90 & 12.50 \\
\hline 4 día s & 2.00 & 3.20 & 0.00 & 8.30 \\
\hline 5 día s & 35.20 & 35.50 & 23.50 & 20.80 \\
\hline 6 día s & 31.40 & 29.00 & 29.40 & 41.70 \\
\hline 7 días & 27.50 & 25.80 & 41.20 & 16.70 \\
\hline Total & 100.00 & 100.00 & 100.00 & 100.00 \\
\hline $\mathbf{N}$ & 187 & 126 & 47 & 43 \\
\hline
\end{tabular}

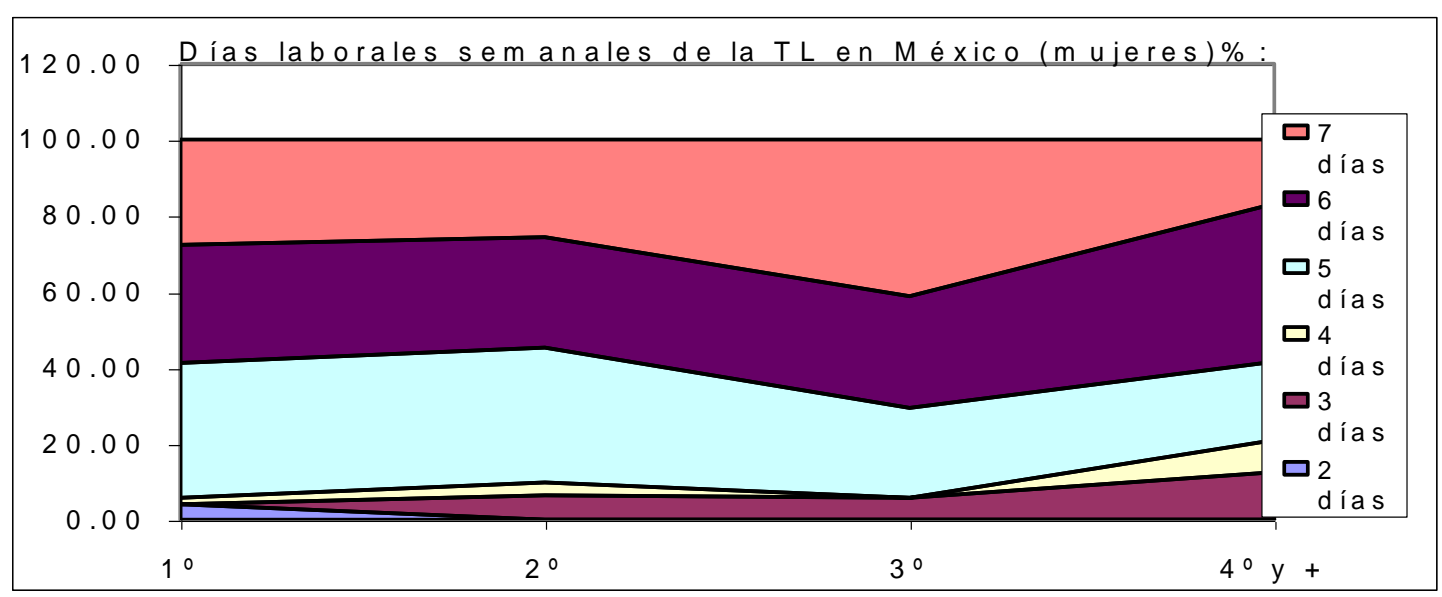

Días laborales semanales de la $T L$ en $M$ éxico (hombres)\%:

\begin{tabular}{|c|c|c|c|c|c|c|}
\hline Días/Evento & $1 \stackrel{0}{9}$ & 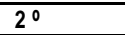 & $3 \div$ & $4 \div$ & 50 & $6 \div y+$ \\
\hline 1 día & 0.00 & 0.60 & 0.00 & 0.00 & 0.00 & 0.00 \\
\hline 2 días & 0.90 & 0.00 & 0.80 & 0.00 & 0.00 & 2.40 \\
\hline 3 días & 1.70 & 1.70 & 0.80 & 2.30 & 3.40 & 2.40 \\
\hline 4 días & 1.70 & 1.20 & 1.70 & 1.10 & 0.00 & 3.60 \\
\hline 5 días & 16.70 & 17.30 & 19.20 & 13.80 & 17.20 & 9.60 \\
\hline 6 días & 56.70 & 61.90 & 60.00 & 61.00 & 69.10 & 65.10 \\
\hline 7 días & 22.30 & 17.30 & 17.50 & 21.80 & 10.30 & 16.90 \\
\hline Total & 100.00 & 100.00 & 100.00 & 100.00 & 100.00 & 100.00 \\
\hline $\mathbf{N}$ & 425 & 335 & 192 & 115 & 70 & 98 \\
\hline
\end{tabular}

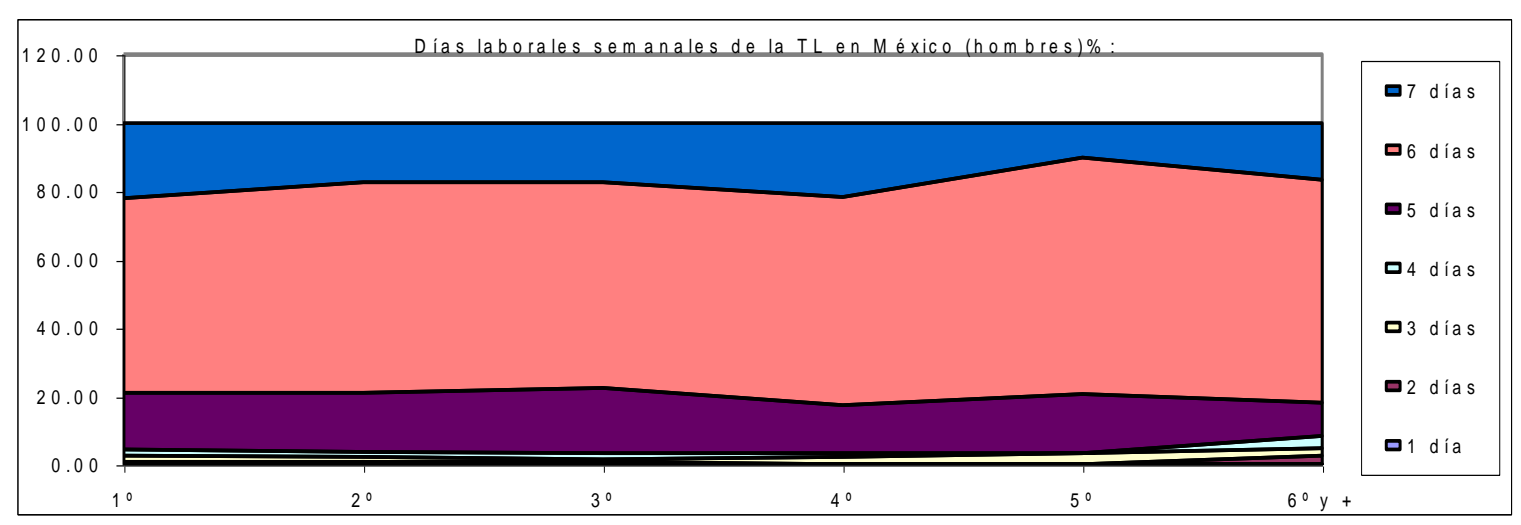


Evento Anterior al Cambio ( $C$ a $m$ bios de $\mathrm{Pa}$ ís $\mathrm{Hacia}$ los EUA)

Total

\begin{tabular}{|c|r|r|r|r|}
\hline Cohorte/Sector & S. Primario & S. Secundario & S. Terciario & \multicolumn{1}{|c|}{ N } \\
\hline Antesde 1987 & 67.20 & 7.40 & 25.40 & 122 \\
\hline De 1987a 1991 & 59.60 & 9.20 & 31.20 & 141 \\
\hline De1991a 1994 & 59.20 & 12.20 & 28.60 & 213 \\
\hline De 1995 en adelante & 50.00 & 10.30 & 39.70 & 69 \\
\hline
\end{tabular}

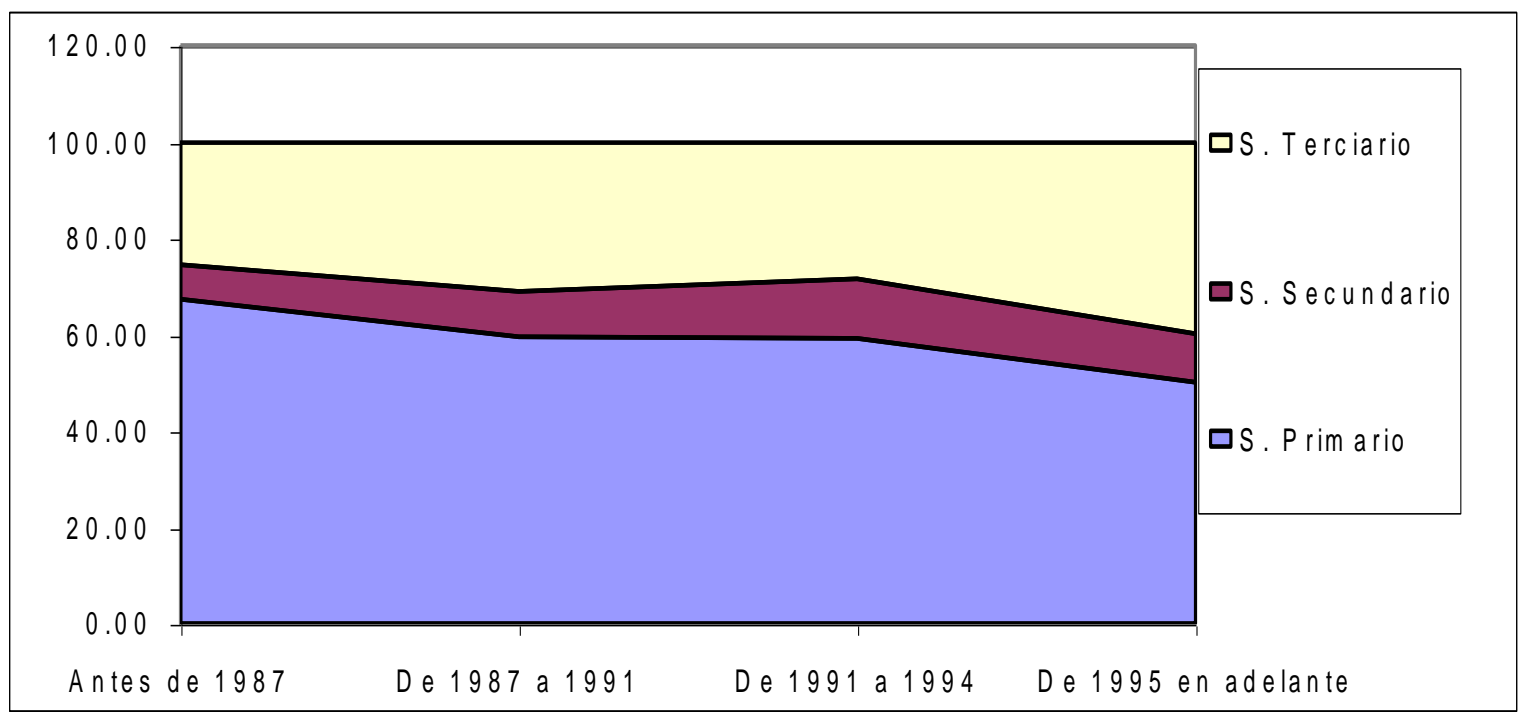

Evento Anterior al Cambio ( $C$ a m bios de $P$ ais $H$ acia $M$ é $x$ ic 0 )

Total

\begin{tabular}{|c|r|r|r|r|}
\hline Cohorte/Sector & S. Primario & S.Secundario & S. Terciario & N \\
\hline Antesde 1987 & 25.30 & 34.20 & 40.50 & 79 \\
\hline De1987a 1991 & 3.80 & 37.70 & 58.50 & 53 \\
\hline De1991 a 1994 & 5.00 & 39.10 & 55.90 & 202 \\
\hline De 1995 en adelante & 7.30 & 34.10 & 58.50 & 369 \\
\hline
\end{tabular}

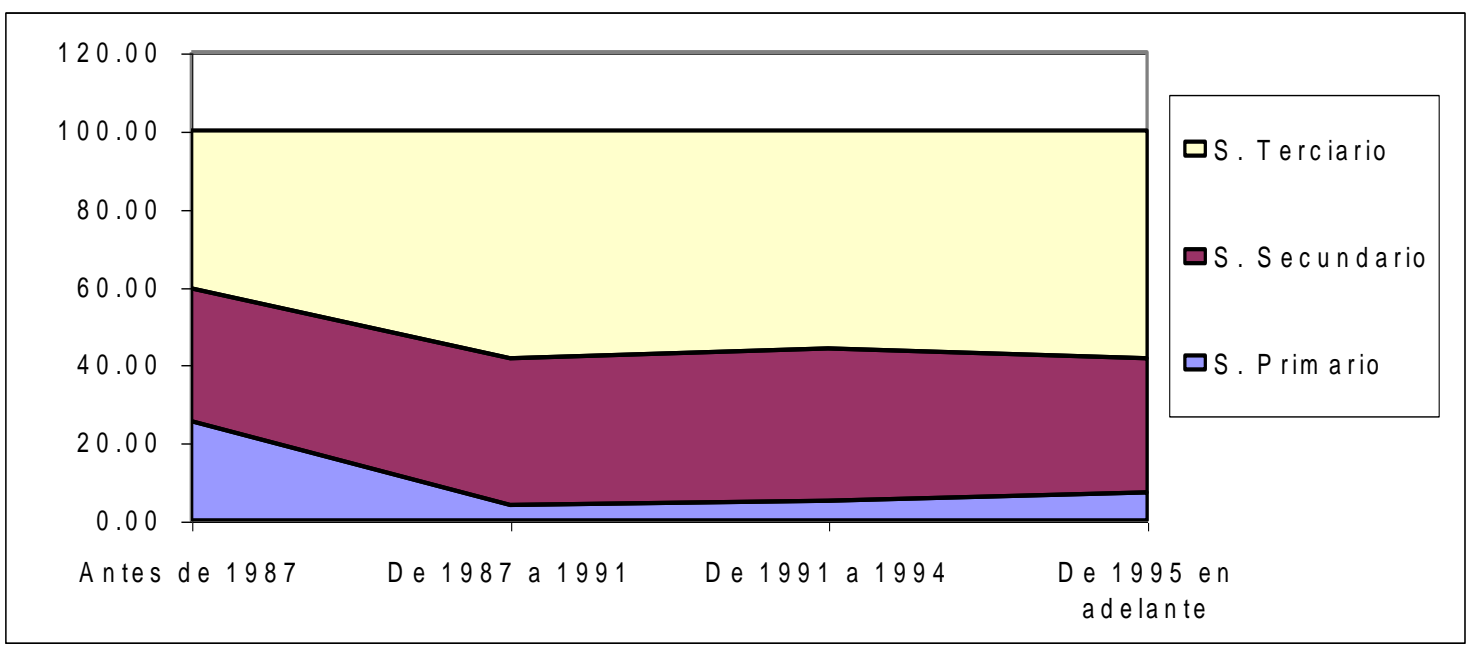


Evento Anterior al Cambio ( $C$ ambios de $\mathrm{Pa}$ is Hacia los EUA)

Mujeres

\begin{tabular}{|c|r|r|r|r|r|r|r|r|r|}
\hline Cohorte/Ram a & A gricult. & Construc. & Ind.s/confec. & Confec. & Serv. s/rest. & Rest. & Serv.domést. & Comercio & N \\
\hline Antes de 1987 & 22.20 & 0.00 & 5.60 & 5.60 & 27.80 & 0.00 & 22.20 & 16.70 & 18 \\
\hline De 1987 a 1991 & 12.90 & 0.00 & 3.20 & 3.20 & 22.60 & 6.50 & 41.90 & 9.70 & 31 \\
\hline De 1991 a 1994 & 33.30 & 1.80 & 3.50 & 0.00 & 8.80 & 1.80 & 36.80 & 14.00 & 57 \\
\hline De 1995 en adelante & 0.00 & 0.00 & 0.00 & 0.00 & 53.80 & 7.70 & 30.80 & 7.70 & 13 \\
\hline
\end{tabular}

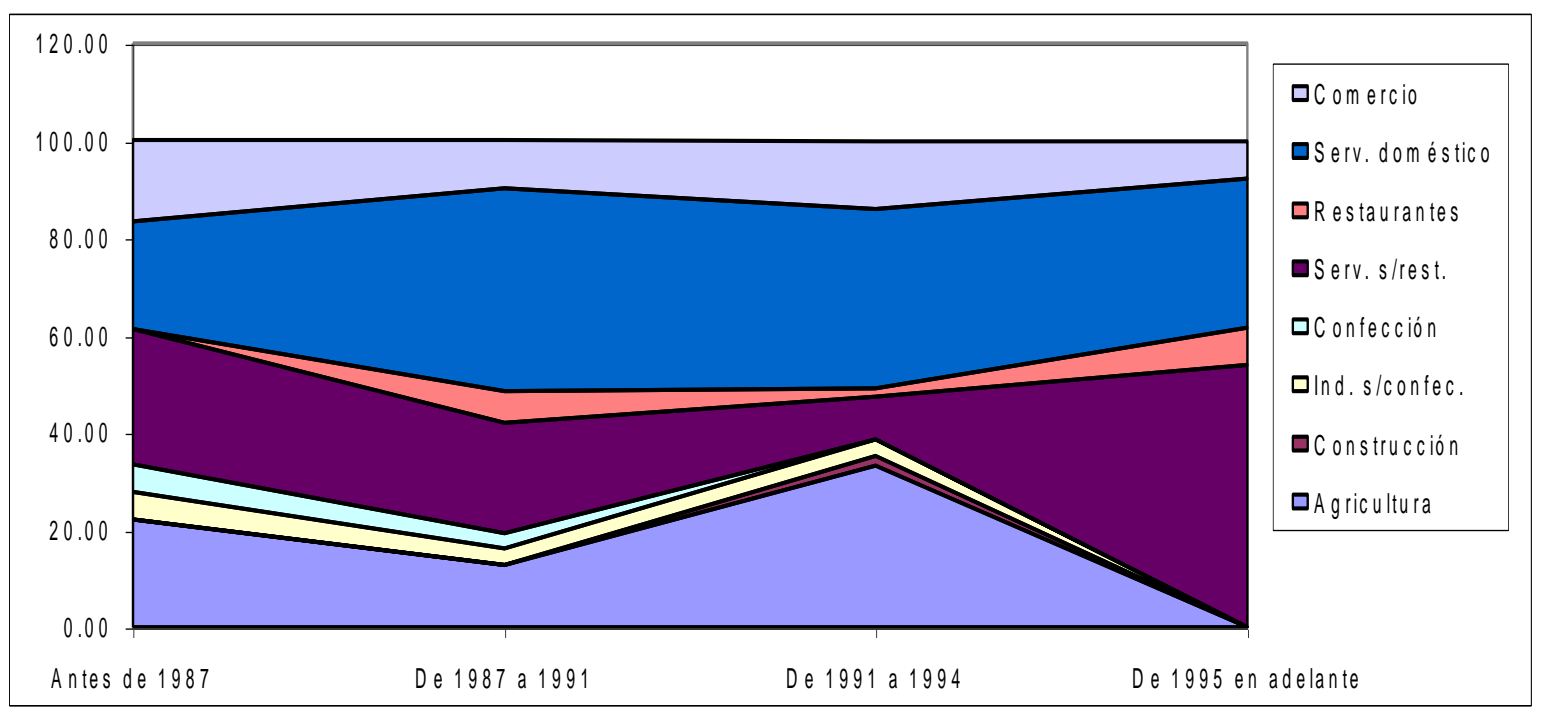

Evento Anterior al $\mathrm{Cambio}$ ( $\mathrm{Cambios}$ de País Hacia los EUA)

Mujeres

\begin{tabular}{|c|c|c|c|c|c|c|c|c|c|}
\hline Cohorte/Rama & A gricult. & Construc. & Ind. s/confec. & Confec. & Serv.s/rest. & Rest. & Serv.domést. & Comercio & $\mathrm{N}$ \\
\hline Antes de 1987 & 22.20 & 0.00 & 5.60 & 5.60 & 27.80 & 0.00 & 22.20 & 16.70 & 18 \\
\hline De 1987 a 1991 & 12.90 & 0.00 & 3.20 & 3.20 & 22.60 & 6.50 & 41.90 & 9.70 & 31 \\
\hline De 1991 a 1994 & 33.30 & 1.80 & 3.50 & 0.00 & 8.80 & 1.80 & 36.80 & 14.00 & 57 \\
\hline De 1995 en adelante & 0.00 & 0.00 & 0.00 & 0.00 & 53.80 & 7.70 & 30.80 & 7.70 & 13 \\
\hline
\end{tabular}

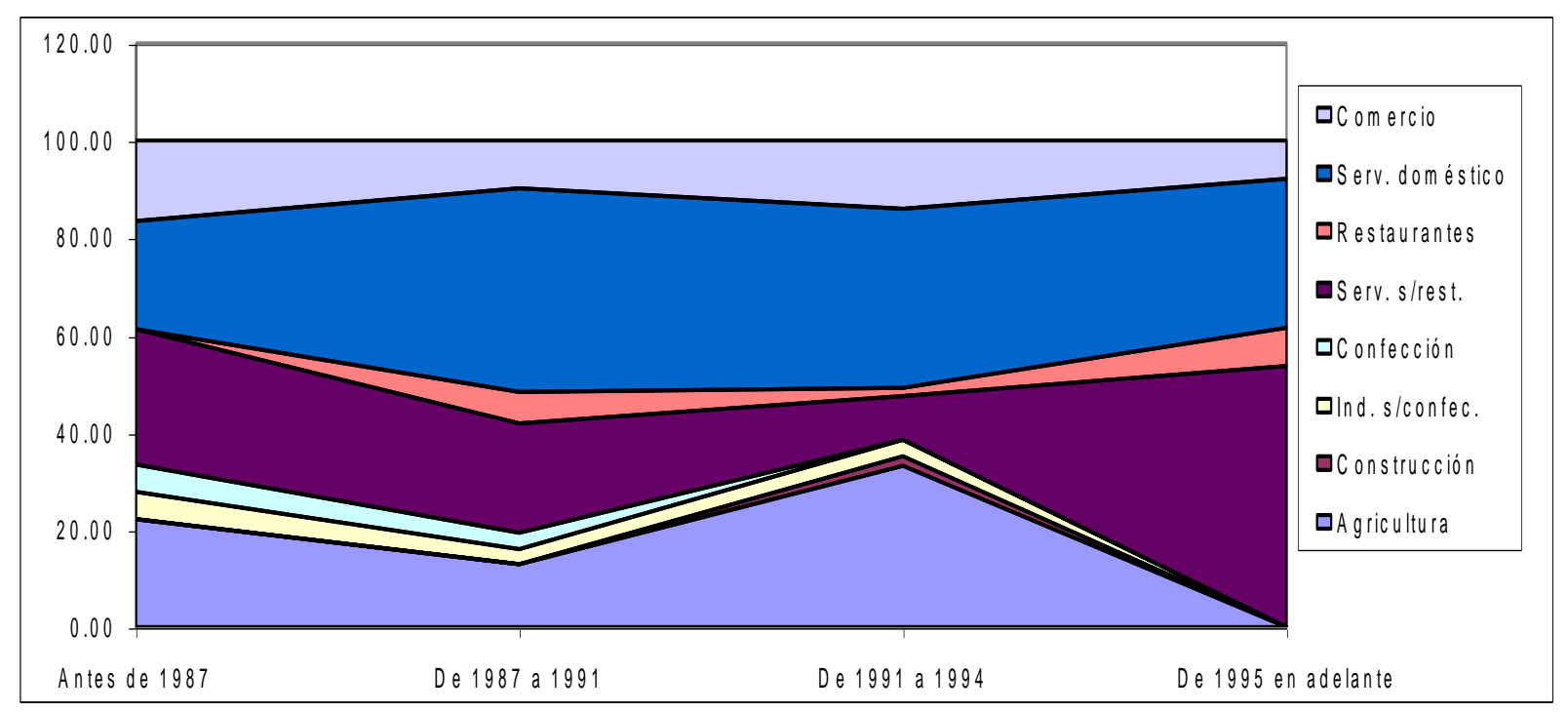


Evento Anterior al $\mathrm{C}$ ambio ( $\mathrm{C}$ a mbios de $\mathrm{Pa}$ is $\mathrm{Hacia} \mathrm{M}$ éxico)

$M$ ujeres

\begin{tabular}{|c|r|r|r|r|r|r|r|r|r|}
\hline Cohorte/Rama & A gricult. & Construc. & Ind.s/confec. & Confec. & Serv. s/rest. & Rest. & Serv.domést. & Comercio & N \\
\hline Antes de 1987 & 0.00 & 0.00 & 18.20 & 36.40 & 0.00 & 27.30 & 9.10 & 9.10 & 11 \\
\hline De 1987 a 1991 & 8.30 & 0.00 & 0.00 & 16.70 & 0.00 & 25.00 & 33.30 & 16.70 & 12 \\
\hline De 1991 a 1994 & 4.50 & 0.00 & 3.00 & 42.40 & 1.50 & 10.60 & 31.80 & 6.10 & 66 \\
\hline De 1995 en adelante & 5.20 & 0.00 & 7.00 & 43.50 & 5.20 & 16.50 & 9.60 & 13.00 & 115 \\
\hline
\end{tabular}

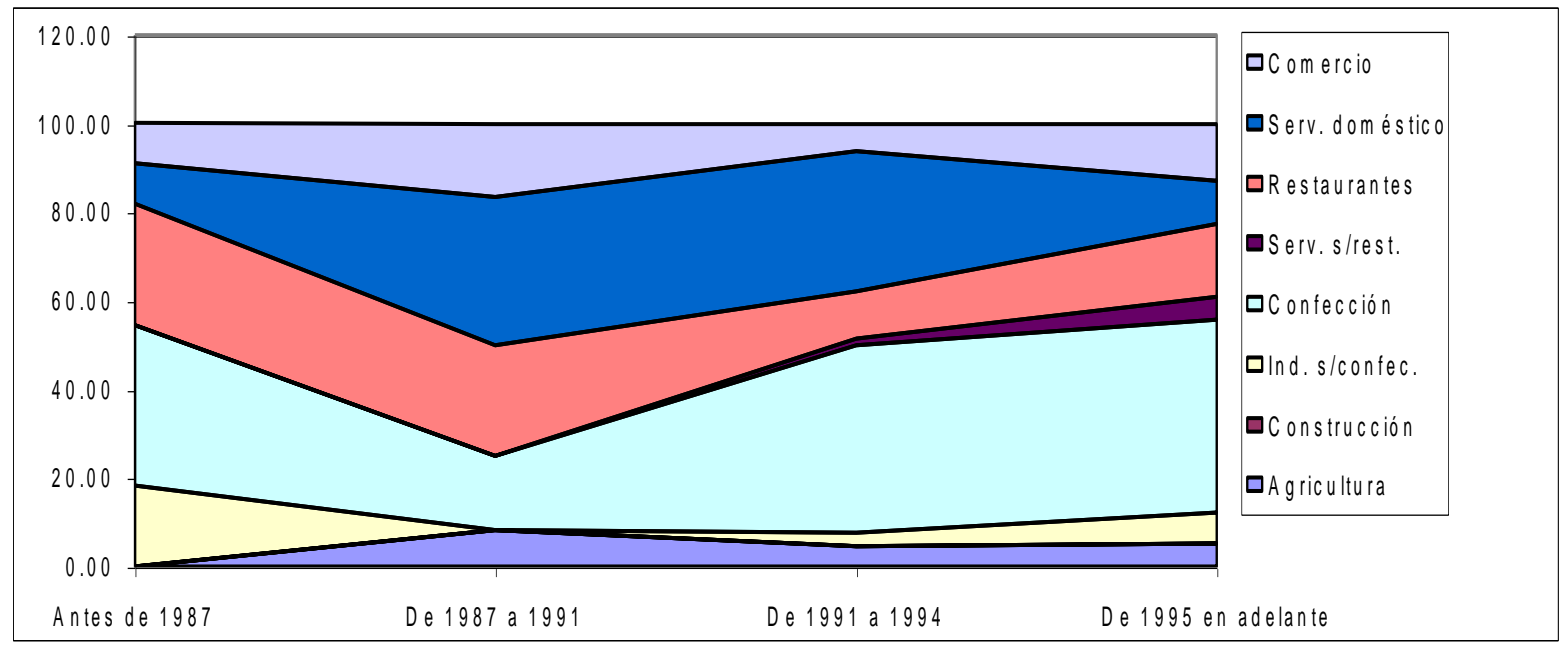

Evento Anterior al Cambio ( $\mathrm{Cambios} \mathrm{de} \mathrm{Pais} \mathrm{Hacia} \mathrm{México)}$

$\mathrm{H}$ om bres

\begin{tabular}{|c|c|c|c|c|c|c|c|c|c|}
\hline Cohorte/Rama & A gricult. & Construc. & Ind. s/confec. & Confec. & Serv.s/rest. & Rest. & Servidomést. & Comercio & $\mathrm{N}$ \\
\hline Antes de 1987 & 29.40 & 26.50 & 0.00 & 4.40 & 1.50 & 35.30 & 1.50 & 1.50 & 68 \\
\hline De 1987 a 1991 & 2.40 & 34.10 & 2.40 & 7.30 & 4.90 & 39.00 & 2.40 & 7.30 & 41 \\
\hline De 1991 a 1994 & 5.10 & 8.10 & 9.60 & 18.40 & 3.70 & 35.30 & 3.70 & 16.20 & 136 \\
\hline D e 1995 en adelante & 8.30 & 4.70 & 11.40 & 10.60 & 7.10 & 41.70 & 3.10 & 13.00 & 254 \\
\hline
\end{tabular}

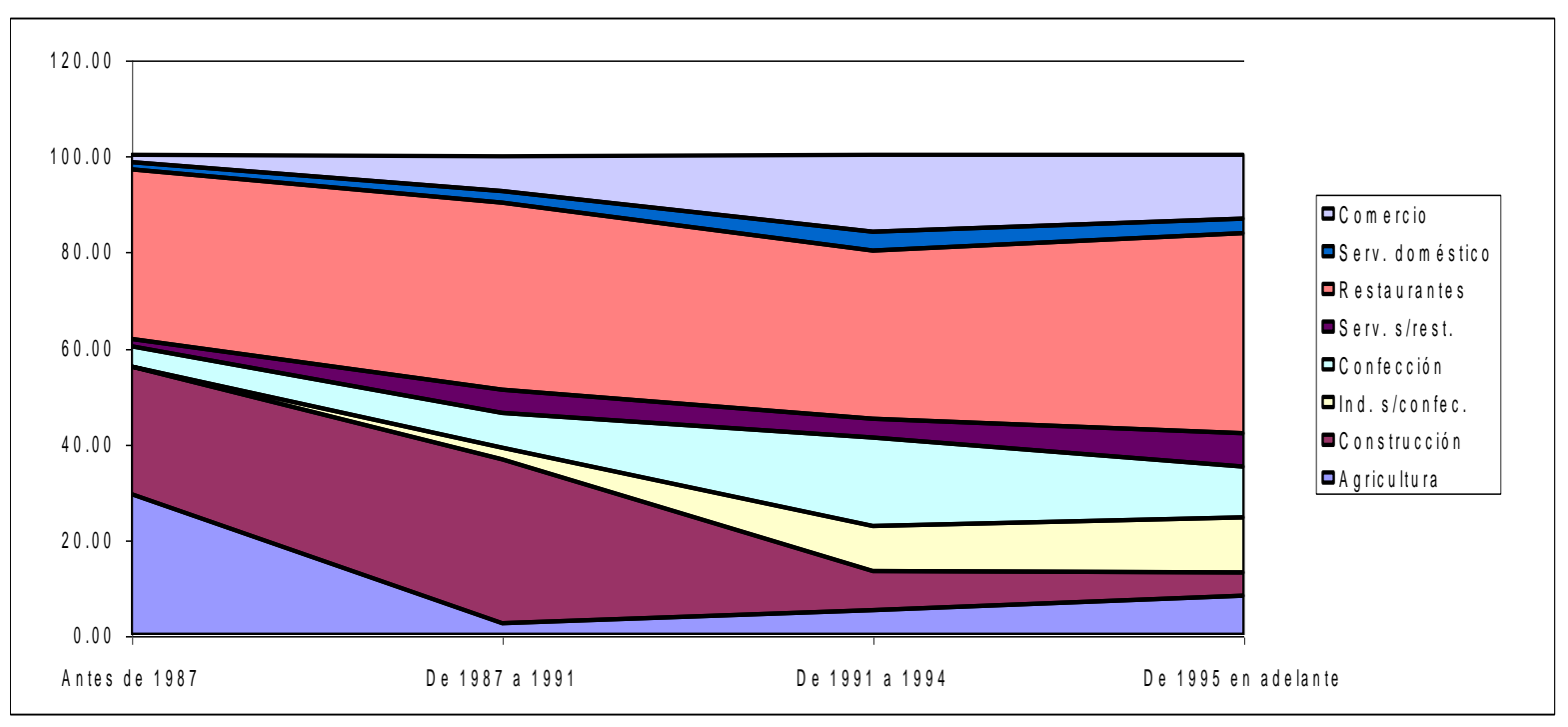




\section{UN MERCADO DE TRABAJO PARA MIGRANTES RECIENTES}

En este capítulo se abordará, primero, el procaso histórico a través del cual se gestaron las condiciones estructurales del mercado de trabajo neoyorquino con las cuales se enfrentó la migración mexicana en el momento de su arribo. Más adelante, se analizarán las características particulares que revisten los nichos de mercado en los que se han insertado, diferenciadamente, las mujeres y los hombres que conforman esta migración.

\section{PRIMERA PARTE: LA CONSTRUCCION HISTORICA DE LA SEGREGACION LABORAL}

\section{INTRODUCCION}

Tal vez parezca innecesario recordar que Nueva York es una ciudad en permanente proceso de transformación, en gran medida por el impacto de las sucesivas olas inmigratorias que han marcado su historia. Sin embargo, hacerlo puede resultar útil para ayudar a comprender la manera relativamente fácil en la que esta ciudad étnicamente tan heterogénea y multicultural, ha acogido a los migrantes mexicanos, quienes pese a su número, aún reducido frente a los otros grupos de migrantes recientes, empiezan ya a dejar huellas bastante perceptibles de su presencia. En sentido estricto, no puede afirmarse que la migración mexicana a Nueva York constituya por sí misma una ola migratoria distinta a las demás. Más bien, podría afirmarse que se incribe como un componente minoritario y tardío de la ola migratoria que, como se verá a continuación, se origina a mediados de los años sesenta y se desarrolla en las dos décadas subsiguientes.

En ese sentido, al menos tres procesos de orden macro social parecen haber sido de gran importancia para crear las condiciones que han permitido el arribo masivo de mexicanos a la zona metropolitana de la ciudad de Nueva York, a partir de la primera mitad de los años ochenta. Uno de ellos, se refiere a un proceso, de largo plazo, de transformación de la economía norteamericana y que en la zona de Nueva York tuvo como efectos, desde al menos los años setenta, una considerable disminución de la actividad industrial manufacturera de tipo formal; así como un regreso de los talleres de manufactura llamados 
sweatshops y del trabajo a domicilio, sobre todo en el sector de la confección; y también un notable crecimiento del peso relativo del sector terciario (Sassen, Bluestone y , Marshall, Altagracia Ortíz, Piore y Sabel, etc).

Otro proceso consiste en lo que Nancy Foner (1987), Kraly (1987) y Marchall (1987) ubicaron, en sus trabajos de mediados de los años ochenta, como la presencia de una nueva ola inmigratoria en Nueva York, cuyas características difieren notablemente de las anteriores olas. En efecto, después de un periodo de disminución de los flujos de inmigración hacia esa zona, a partir de mediados de los años sesenta empieza a llegar una considerable cantidad de inmigrantes que, a diferencia de procesos anteriores, que habían tenido orígenes básicamente centro y norte européos, provenían ahora de diversos rumbos de Latinoamérica (caribeños, centroamericanos y sudamericanos), del Caribe, franco y anglófono, del Asia (de distintos países, sobre todo Coréa y China), de Italia y de la URSS (sobre todo, judíos rusos).

Aunque por otras fuentes se tiene conocimiento de la presencia creciente de mexicanos, éstos aún no eran registrados como una minoría numéricamente importante. Por el contrario, es interesante observar que en el volumen que Foner (1987) dedicó a estudiar a estos nuevos inmigrantes en Nueva York, título de la obra, aparecen sólo seis referencias a los mexicanos (Foner, 1987; y Kraly, 1987), todas ellas orientadas a destacar que el destino de sus migraciones era casi exclusivamente el oeste y el sur de los Estados Unidos, y que en Nueva York solamente se encontraba el 1\% del total de mexicanos radicados en este país.

En realidad, dentro de esta nueva ola inmigratoria, se pueden encontrar subperiodos. El primero de ellos es precisamente el que han estudiado las investigaciones referidas y abarca hasta mediados de los años ochenta; este subperiodo resulta de primordial importancia para la migración mexicana a Nueva York, porque es durante su desarrollo cuando se generan las condiciones a las que se habrán de enfrentar -y aprovechar con mucho éxito quienes empiezan a llegar de México en la dsegunda mitad de los años ochenta. Mientras que el segundo subperiodo se inicia en esos años y se prolonga hasta la acualidad. En este segundo, la presencia de los grupos mexicanos, ecuatorianos, brasileños y paragüayos, resulta notoria (Hernández León, 1998; Smith, 1998). De hecho, la migración mexicana puede decirse que no constituye por sí misma un ola migratoria 
diferenciada, sino que se inscribe como una parte minoritaria y tardía de la nueva ola migratoria que se inició en los años sesenta.

Un tercer proceso de este mismo orden que ha tenido una influencia de gran importancia para el crecimiento de la migración mexicana a Nueva York, se refiere a los cambios que ha habido a partir de 1965 en la legislación norteamericana sobre cuestiones de inmigración, especialmente en los últimos tres lustros.

Aparte de esos grandes procesos de cambio, en la zona metropolitana de Nueva York existen otros procesos de orden más particular o regional, que también han tenido impactos significativos en la definición del tipo de habitat urbano con el que se han enfrentado los migrantes mexicanos, en ese complejo procesos en el que la ciudad transforma a los migrantes, a la vez que éstos transforman a la ciudad (Foner, 1987). Dos de estos cambios pueden ser mencionados. Uno se refiere a los programas de seguridad pública, conocidos como de cero tolerancia, que hicieron de la ciudad de Nueva York una de las más seguras de los Estados Unidos, después de haberse ubicado cerca del extremo contrario, a finales de los años setenta. El otro se refiere a un fenómeno que parece contradecir la afirmación anterior y que consiste en la aparición de un nuevo tipo de bandas juveniles (gangs que devienen gangas), formadas por colombianos, dominicanos y algunos otros latinoamericanos, a las que se han integrado de manera creciente los hijos de los migrantes mexicanos.

\section{La nueva ola inmigratoria en nueva york}

La llegada de la inmigración mexicana a Nueva York se dió en un contexto in migratorio muy específico. Nancy Foner (1987), Ellen Kraly (1987) y Adriana Marshall (1987) ubican hacia 1965 el inicio de una nueva ola inmigratoria en la zona urbana de Nueva York; misma que tiene como efecto el arribo de más de un millón de personas en los veinte años que van desde mediados de los años sesenta hasta mediados de los años ochenta,

precisamente cuando los mexicanos y mexicanas están empezando a llegar masivamente a esa región. Lo anterior es de suma importancia en la definición del contexto específico de recepción de la migración mexicana, sobre todo porque los nuevos habitantes de Nueva York son, en su mayoría, de habla española y se distribuyen a lo largo de todas las zonas urbanas de la ciudad y sus alrededores; lo que va a ser aprovechado por la migración 
mexicana, que va a asentarse preferentemente en barrios con fuertes presencias de puertorriqueños, dominicanos, colombianos, cubanos y, en general, inmigrantes de habla española.

Pero existe, el menos, otro efecto de esa nueva ola que ha tenido consecuencias importantes con relación al trabajo de las y los mexicanos en Nueva York y que consiste en que muchos de los empleadores que se van a encontrar (sobre todo coreanos, pero también colombianos y de otros países asiáticos y latinoamericanos), ya sea en los sweatshops, ya sea en los restaurantes o ya sea en las tiendas o en la venta callejera de frutas y flores, pertenecen a esta nueva ola migratoria.

Cabe señalar que esa nueva ola no afecta sólo a Nueva York, sino que es un fenómeno que caracteriza al mundo de la segunda posguerra y que se agudiza en los últimos 30 años (Castles y Miller, 1993), como efecto de los grandes cambios económicos y políticos producidos como parte de lo que se ha denominado como globalización. Para 1990, según estimaciones de la Organización Internacional para la Migración (OIM), con sede en Suiza, había más de 80 millones de personas migrando en el mundo, independientemente de la causa de su desplazamiento; y aproximadamente el $1.7 \%$ del total de la población mundial se encontraba dentro de alguna de las formas de la migración internacional (Castles y Miller, 1993).

En los Estados Unidos, en particular, la inmigración ha tenido dos grandes ciclos históricos en poco más de un siglo. El primero tuvo como punto culminante la primera década de este siglo y estuvo conformado sobre todo por personas de origen européo. Hubo después un fuerte descenso que llevó a la sima de la inmigración en la década de la depresión. El segundo ciclo, está llegando en los años noventa al punto más elevado de la inmigración en la historia de los Estados Unidos y está constituido mayoritariamente por personas provenientes de América Laina (sobre todo de México) y de Asia: 
TABLA \# 1

\begin{tabular}{|c|c|}
\hline \multicolumn{2}{|c|}{ INMIGRACION A LOS ESTADOS UNIDOS POR DECADA (1881-1930) } \\
\hline $1881-1980$ & $5,246,613$ \\
\hline $1891-1900$ & $3,687,564$ \\
\hline $1901-1910$ & $8,795,386$ \\
\hline $1911-1920$ & $5,735,811$ \\
\hline $1921-1930$ & $4,107,209$ \\
\hline $1931-1940$ & 528,400 \\
\hline $1941-1950$ & $1,035,039$ \\
\hline $1951-1960$ & $2,515,479$ \\
\hline $1961-1970$ & $3,321,677$ \\
\hline $1971-1980$ & $4,493,314$ \\
\hline $1981-1990$ & $7,338,062$ \\
\hline 1991 & $1,827,167$ \\
\hline 1992 & 974,000 \\
\hline 1993 & 880,000 \\
\hline 1994 & 799,190 \\
\hline 1995 & \\
\hline 1996 & \\
\hline & \\
\hline & \\
\hline
\end{tabular}

Fuente: elaboración propia, con datos de Foner (1987) y de Dinnerstein, Nichols y Reumers, 1996, p.123 y 274

Esta nueva ola migratoria a la que se ha venido haciendo referencia, contó con un marco legal cambiante a partir de mediados de los años sesenta. Primero, precisamente en 1965, se presentaron modificaciones que favorecían la inmigración a los EUA de personas originarias de países que previamente habían sido poco bienvenidos. Más adelante, en 1976, se establecieron precisiones legales y administrativas que siguieron con esa tendencia. El crecimiento de la inmigración indocumentada, ligada a cambios desfavorables en el funcionamiento de la economía norteamericana, produjeron en 1987 una nueva legislación (IRCA o Simpson-Rodino) que buscaba regular el flujo migratorio, 
reconociendo la necesidad de legalizar a importantes cantidades de personas indocumentadas, pero aspirando al mismo tiempo a controlar el acceso ulterior de nuevos grupos en esas condiciones. Finalmente, en 1997 se produce un importante giro legislativo, al introducirse modificaciones que buscan sobre todo limitar la inmigración y repatriar a las personas indocumentadas.

Es entonces dentro de este proceso más general en donde se inscribe la nueva aceleración inmigratoria de Nueva York, que tiene como novedades importantes (Foner, 1987) su composición por el origen (mayoritariamente caribeño, latinoamericano y asiático, y ya no européo, excepto en el caso de los judíos rusos y los italianos), por el sexo (ahora las mujeres son un poco más de la mitad), el estatatus legal (a diferencia de las anteriores inmigraciones, ahora es muy elevado el número de indocumentados) y por el nivel educativo (mayor porcentaje de profesionales).

El volumen de esta nueva inmigración es de grandes proporciones. Foner (1987:17) refiere que, de acuerdo al censo, cerca de un millón de personas llegó a Nueva York entre 1965 y 1980; lo que representa más de la mitad de la población inmigrante y aproximadamente el $13 \%$ de la población total de la ciudad. Sin embargo, la cantidad real podría ser de hasta un millón y medio de personas, debido a que el censo sólo registró a 200 mil personas indocumentados y éstas en realidad podrían ser 500 mil más en 1980.

En cuanto a los orígenes nacionales, el censo permite identificar a los dominicanos como el mayor grupo de inmigrantes, seguido de los jamaiquinos, los chinos, los haitianos y los italianos. Con cantidades menores, también se integraron a esta inmigración grupos de Trinidad y Tobago, Colombia, Ecuador, la Unión Soviética y Guyana (Foner, 1987:18). Ellen Kraly (1987:55), por su parte, ofrece un interersante análisis acerca de la composición y las zonas de asentamiento de los principales grupos inmigrantes; que resulta muy útil para entender el patrón de asentamiento de los migrantes mexicanos. Informa que en la región Nueva York SMSA, del total de cada nacionalidad en los EUA, se encuentra más de la mitad de los jamaiquinos, barabadienses, trinitarios, guyanenses y haitianos; más de tres cuartos de los dominicanos; cerca de la mitad de los ecuatorianos y un tercio de los colombianos. Al mismo tiempo, desde los años sesenta, decae el peso de los européos entre el total de los nacidos fuera de los EUA; al tiempo que aumenta el de los asiáticos (Ibid:6162). 
De que Nueva York es una ciudad de inmigrantes, no cabe duda. A principios de siglo, más de una tercera parte de su población había nacido fuera de los EUA. En 1980, los inmigrantes son cerca de una cuarta parte de la población de la ciudad y el $21 \%$ de la NY SMSA; niveles sólo comparables a los del sun belt y el suroeste (Los Angeles: 22\%; Brownsville:19\%; Laredo: 21\%); y sólo superado por Miami:36\%. Un importante resultado de esto, es que la particularidad de Nueva York es su gran diversidad étnica; de hecho, casi todas las nacionalidades européas están representadas, al igual que las asiáticas, las centroamericanas, las del Caribe y las del norte de Sudamérica. Hay que anotar que esto se da en el contexto de un decremento de la población de NY (ciudad y área metropolitana) ${ }^{41}$, entre 1970 y 1980; a diferencia del sur y el oeste de los EUA, que han crecido como consecuencia de inmigraciones de otras zonas del país. Así, de los años treinta al inicio de los setenta, decrece la población de Nueva York nacida fuera de los EUA; pero en el censo de ochenta tiene un repunte, en el que las personas de México empiezan a tener una pequeña participación. Por su antigüedad relativa, la mayoría de los européos inmigró antes de 1960; mientras que los asiáticos, centro y sudamericanos y caribeños, lo hicieron después de 1965 (dos tercios de los japoneses y más de la mitad de los coreanos, después de 1975).

En cuanto a la distribución de los inmigrantes dentro de Nueva York, Kraly (ibid.) refiere que Queens tiene la mayor población nacida en el extranjero y la mayor diversidad étnica (grandes cantidades de italianos, chinos, coreános, caribeños anglo y franco parlantes y sudamericanos). Brooklyn, por su parte, da alojamiento a haitianos, dominicanos, jamaiquinos, caribeños angloparlantes y rusos. El Bronx, a viejos y nuevos migrantes italianos, irlandeses y caribeños. Manhattan, a chinos y dominicanos. Staten Island, contiene las menores cantidades de nacidos fuera de los EUA, pero combina la vieja inmigración (sobre todo de italianos) con la nueva (coreanos y filipinos). Brooklyn, Queens y Manhattan tienen una alta composición (cerca de un cuarto) de nuevos migrantes, mientras que Richmond, Bronx y los distritos suburbanos, tienen pocos inmigrantes

${ }^{41}$ Ciudad de NY: Bronx, Kings (Brooklyn), New York (Manhattan), Queens y Richmond (Staten Island); resto de la zona metropolitana (SMSA): Nassau, Suffolk, Putnam, Rockland, Westchester, Bergen, NY (no incluido en 1970, sino hasta 1980) 
recientes y conservan cantidades importantes de los más antiguos (p.70). Visto de otra forma, de los inmigrantes chinos, cerca de la mitad está en Manhattan y más de un cuarto en Queens; de los inmigrantes asiáticos asiáticos, en general, dos quintas partes habitan en Queens. Más de la mitad de los coreános, de los sudamericanos y de los hidúes lo hacen en ese mismo barrio. Los caribeños angloparlantes y anglófonos; así como quienes llegaron de la entonces URSS, sobre todo judíos, se concentran en Brooklyn. Finalmente, más de la mitad de los dominicanos vive en Manhattan.

Es el anterior el contexto migratorio en el que van a insertarse las personas que empiezan a migrar masivamente de México a la zona metropolitana de Nueva York en los años ochenta, durante lo que aquí se ha considerado como el segundo subperiodo de la nueva ola migratoria. A partir de entonces, este nuevo componente de la nueva ola migratoria, el mexicano, será crecientemente visible y se convertirá en un actor de las nuevas transformaciones. Como puede verse en las gráficas siguientes, la composición de la inmigración a Nueva York por origen nacional se transforma considerablemente, no sólo si se comparan entre sí las distintas grandes olas migratorias, sino que también al interior de la última de éstas, puede apreciarse un gran dinamismo. En efecto, si se comparan los datos de 1970 con los de 1997, puede apreciarse que los grupos de los inmigrantes de mayor antigüedad relativa, como los italianos, los rusos, los polacos, los alemanes y los irlandeses, han acabado por ceder la supremacía numérica frente a inmigrantes mucho más recientes, como lo son los dominicanos, los chinos, los jamaiquinos y, por supuesto, los mexicanos. 


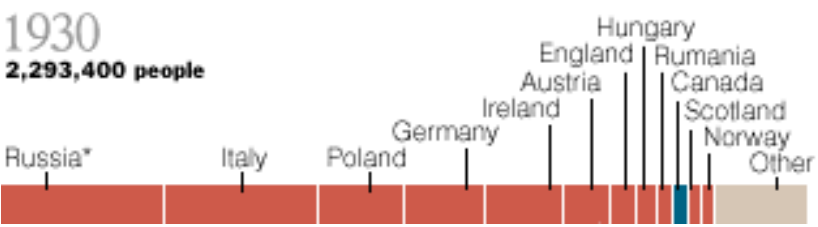

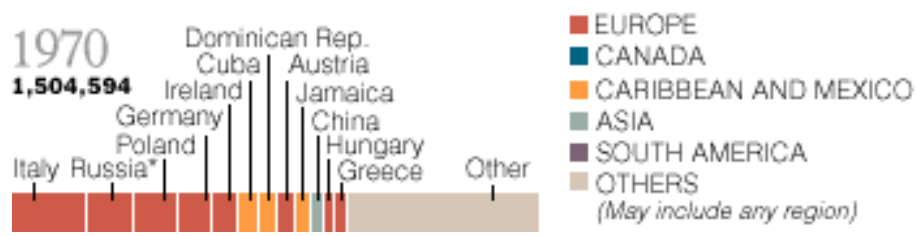

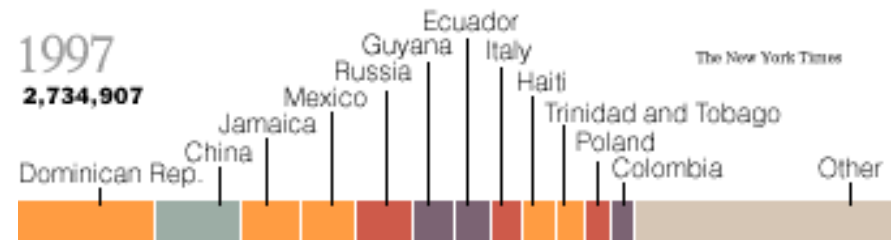




\section{ESQUEMA \# 1}

Población total Porcentaje de personas

en la ciudad de nacidas en el extranjero

Nueva York

(millones de

personas)

6.8

$33.7 \%$

7.9

$19.0 \%$

7.6

$36.1 \%$
Países de origen: los 12 principales (incluida la antigua Unión Soviética)

$\mathrm{x}$

$x$

$x$

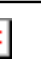

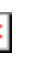

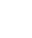

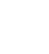
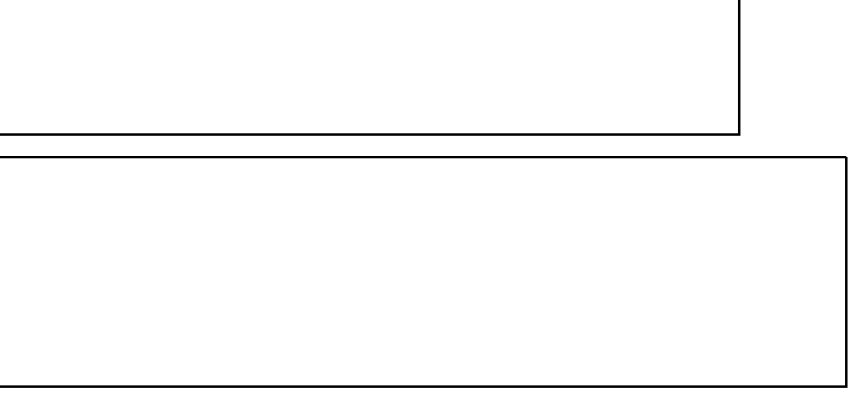

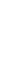




\section{La reestructuración económica en los Estados Unidos y en Nueva York}

Una constante en el mundo occidental, a lo largo de las últimas tres décadas, ha sido el intenso proceso de cambio que se ha operado en las economías y en los sistemas políticos de todos los países, independientemente de su colocación en la división internacional del trabajo; así como en las pautas de relación entre los países y sus economías. Nuevas tecnologías de producción, nuevas formas de organización del trabajo, relaciones laborales flexibles, nuevos materiales y productos, hegemonía de un capital financiero desterritorializado, nuevas formas de comercialización, fin de los pactos corporativos, fin o desmantelamiento de los estados benefactores, replanteamiento de la noción de soberanía y una nueva forma de desplazamiento de la fuerza de trabajo a través de las fronteras nacionales, parecen ser los elementos más importantes de un nuevo orden internacional que algunos deniminan como globalizado; y en el que es posible encontrar fuertes elementos y espacios de transnacionalidad. Muchas han sido las propuestas que se han avanzado para dar cuenta del fenómeno; pero en este lugar no se hará una revisión propiamente de ellas ${ }^{42}$. Aquí la atención se centrará en las consecuencias que esos cambios han tenido particularmente para la economía y la sociedad neoyorquinas; cambios que en mucho explican, a la vez que son explicados por, la presencia de la nueva ola migratoria a la que se ha estado haciendo referencia.

Muy particularmente, cabe adelantar que los nichos del mercado en los que se han insertado sus integrantes son producto tanto de cambios importantes operados en la economía internacional, como por la presencia misma de esa ola migraroria; sin la cual quienes han estudiado de cerca y desde sus inicios el proceso (Marshall, Sabel y Piore, Saasen), consideran que no se hubiera podido presentar ni el renacimiento de un sector manufacturero degradado (Sassen, 1985:302), ni la fuerte expansión de la industria de los servicios (Foner,1987); fenómenos que son característicos de la sociedad neoyorquina actual. Para los fines de este trabajo sobre las y los migrantes de México en Nueva York,

42 nueva división internacional del trabajo, especialización flexible, nuevos modelos productivos, nueva forma de regulacion postmonopólica o flexible, desindustrialización, fin del trabajo, sociedad postindustrial, porstfordismo, postaylorismo, toyotismo, kalmarismo, onnismo, son algunos de los conceptos más importantes invoucrados, en distintos niveles de abstracción, en la discusión internacional generada en el esfuerzo por dar cuenta de los cambios ocurridos. 
cabe adelantar que sin el trabajo previo que realizaron quienes inmigraron antes, a partir de 1965, pero también en las oledas migratorias previas, su asentamiento exitoso hubiera sido seguramente imposible, dado su muy reducido volumen relativo. Cuando llegó el flujo inmigratorio de México a Nuevo York, ya estaban constituidas las bases para su integración a nichos de mercado específicos, de fuerte contenido étnico; pero también estaban conformadas ya las condiciones sociourbanísticas para que les fuera posible a sus integrantes encontrar un ambiente relativamente propicio; en el cual al menos se habla su idioma, se comparten muchas costumbres y se reconoce una identidad común latinoamericana.

Por lo anterior, vale la pena detenerse un poco en la revisión de algunos trabajos pioneros que se realizaron de mediados de los años ochenta en adelante, precisamente cuando el arribo desde Puebla y Tlaxcala a Nueva York empieza a hacerse visible en aquella ciudad, al tiempo que empieza a verse como masivo desde los lugares de origen en México.

Para iniciar esta revisión, se hará referencia a Nancy Green (1997) ${ }^{43}$, quien presenta una espléndida visión histórica de la industria del vestido en NY y de sus relaciones con la geografía urbana y las migraciones; así como de la relación entre los lugares de habitación y los de trabajo de los inmigrantes. En muchas de sus descripciones, parece que está hablando de la muy reciente migración mexicana; en especial de las jóvenes mujeres que trabajan en los talleres de confección. En realidad, dice esta autora, los sweatshops son un vínculo vivo entre el pasado y el presente de la industria norteamericana. Parte insepareble de la vida neoyorkina desde principios de siglo, los sweatshops son, para Green ${ }^{44}$, tal vez la avanzada de lo que serán el modelo económico flexible del siglo XXI . Lo que ha sucedido históricamente es que la industria manufacturera ligera ha aprovechado las sucesivas olas migratorias para mantenerse en acción, de tal forma que aunque los sucesivos grupos

\footnotetext{
43 Nancy Green, Sweatshop Migrations: the Garment Industry Betwen Home and Shop, en Ward y Zunz, The Landscape of Modernity. New York City 1900-1940, The Johns Hopkins University Press, 1997

${ }^{44} \mathrm{La}$ autora recalca su coincidencia en este punto con autores como Waldinger y Lapp (1989; y Piore y Sabel, 1984) (cita a: Roger Waldinger y Michael Lapp, "Back to the sweatshops or ahead to the informal sector", unpublished, 1989; y a Piore y Sabel, 1984).
} 
migratorios se han desplazada hacia afuera del centro de la ciudad, una parte importante de la actividad de la industria de la confección se ha mantenido en él (p.213):.

"Dos fuerzas caracterizan la geografía urbana de la industria del vestido de Nueva York en el siglo veinte: un movimiento centrífugo y una constante redefinición de un núcleo central de producción urbana. Esos dos movimientos son contradictorios sólo a primera vista. El movimiento hacia afuera, para escapar de Manhattan, no es sino una fase en el proceso de redefinición de la industria urbana, de sus necesidades especificas y de las razones de su localización particular” (Green:214).

En una primera fase, que abarca de fines del siglo XIX a los años veinte del pasado, se presenta la concentración. Nueva York fue el centro de la moda en EUA desde fines de el siglo XIX; entonces, la costura migró de los talleres de sastrería y el trabajo rural hacia los talleres y las fábricas; la ropa se mercantilizó, dejó de hacerse en el hogar, para fabricarse con trabajo aslariado para la venta en el mercado. Para 1890, el 44\% de la ropa ordinaria de los EUA se hacía en NY; pero la especialización fue en ropa femenina: Nueva York concentraba hacia 1899 al 53.3\% del empleo nacional en la producción industrial de ropa para mujeres (65\% en 1904 y $57.3 \%$ en 1925; así como el 65\% del valor total de la producción, en 1899 y el $78 \%$ en 1925). A lo anterior ayudó que NY fuera el principal centro financiero y manufacturero y el principal puerto de entrada de los inmigrantes (p.214). Después vino un declive, a partir de la reestructuración que se inicició en los años veinte (p.214-215).

Tuvo lugar entonces la segunda fase, caracterizada por un movimiento centrífugo. Apareció la ropa prefabricada, las grandes fábricas (necesidad de integración y por tanto de mayor espacio), la estandarización y la producción en serie, sobre todo de ropa para hombre, de uniformes de trabajo e interior. Se inició el éxodo de la producción de ropa para hombre y de la de trabajo para mujer. Este proceso se inició en los veintes y sigiuó en la interguerra; aunque no pueda atribirse directamente a la depresión, que afectó mucho más a la industria pesada que a la ligera. El declive se mantuvo después de la II Guerra Mundial: de 1947 a 1954, el empleo en la industria del vestido, a nivel nacional, creció en un 7.8\%, 
pero en NY ese crecimiento fue de sólo un 1.8\% (NY-NJ SMA); mientras que California crecía mucho en importancia.

Localmente, también se presentó un movimiento centrífugo, de Manhattan hacia el resto de los condados. En 1899, Brooklin tenía menos del 6\% de la producción de ropa para mujer de la ciudad de NY, mientras que en 1937 alcanzó el 14.6\% y en 1954 el 17.8\%. Agregadamente, entre 1947 y 1954, Manhattan perdió 14,858 empleos, mientras que Brooklin ganó 4,241, Bronx 2,853 y Queens 1,293 (p.215).

La ruta del éxodo fue, primero, hacia afuera del distrito de Nueva York, hacia los otros condados, hacia los suburbios y hacia Nueva Jersey; después, siguió hacia Pennsilvania y el norte del estado de Nueva York; más adelante, hacia el medio oeste y hacia el suroeste; para finalmente llegar hasta Taiwan.

En este movimiento hacia afuera de Manhattan intervino la necesidad de espacio, pero también hubo razones salariales y sindicales En Nueva York se han enfrentado tradicionalmente dos tendencias: el sector que promueve reformas laborales progresivas y el de los empresarios, que piensa que si estas se llevan a cabo puede desaparecer la industria menufacturera (p.216). En una especie de comportamiento pendular, ninguna de las dos ha logrado la derrota definitiva de la contraria.

La dispersión señalada tuvo, sin embargo, sus límites en ese periodo. Varios factores colaboraron para ese resultado. Por un lado actuaron, dice Green, las necesidad de concentración (de fuerza de trabajo calificada y de administradores y directivos capacitados) y los imperativos de la moda (salones de exibición, modelaje profesional); pero también la disponibilidad de infraestructura de apoyo (de producción de insumos y para el servicio y la reparación de la maquinaria, por ejemplo). Por otro, la capacidad de respuesta rápida y flexible de la industria neoyorquina del vestido frente a los cambios bruscos e imprevistos de la moda, aun dentro de una misma temporada. Ya en la actualidad, por cierto, resulta interesante observar cómo el señor Jaime Lucero, cuya experiencia se relata en otro parte del trabajo, supo aprovechar creativamente estas circunstancias para convertirse en un exitoso empresario en Nueva York-Nueva Jersey; precisamente atendiendo a estas necesidades de intervinculación industrial y de respuesta rápida y flexible frente a los bruscos cambios determinados por las modas. Lo que predominó entonces en Nueva York fue la producción de ropa cara (p.216-217). 
Son entonces dos movimientos complementarios y paralelos, dice Green: hacia fuera de Nueva York, y hacia la concentración dentro de NuevaYork. Parte importante de la historia son, por tanto, los desplazamientos dentro de Nueva York. Primero, fueron del sur hacia el centro de Manhattan, en los años veinte, para situarse en el actual distrito de la confección, en la séptima avenida (gráficas de la p. 218), debido a un desplazamiento general del distrito comercial y a la apertura de la estación Penn del metro; y también a una reestructuración propiamente de la producción. En los años veinte, se da al mismo tiempo un auge de los agiotistas, un crecimiento de los cuellos de botella y exaserbación de la competencia. Los talleres de corte y las salas de exhibición se concentraron en la parte media de la ciudad, mientras que los de costura fueron desplazados fuera del bajo Manhhatan, hacia los demás condados de la zona de Nueva York y hacia Nueva Jersey, Pennsilvania y Connecticut. A inicios de los años cincuenta, del 65 al 80\% de la actividad manufacturera de la industria de la confección se hacía en el perímetro marcado por las calles 30 y 42 y las avenidas décima y quinta. Según Waldinger y Lapp, citados por Green (1997:230), en 1969 se localizaba en esa zona el 63.1\% de la producción de ropa de mujer de Nueva York; y en 1988, el 39.8\% (en Chinatown esas cifras fueron de $12.8 \%$ y 38.2\%, respectivamente).

Visto lo anterior desde una perpectiva nacional, el centro se consolidó en un contexto de descentralización productiva. El desplazamiento hacia el norte de Manhattan se facilitó por la construcción de nuevos edificios en el centro, mejor protegidos contra el fuego y mejor equipados, que podían ser subdivididos en pequeñas unidades de producción (se les llamó Coney Island shops: cabinas o vestidores de playa) (Green:217-219):

La geografía de la producción de ropa ha sido una de migración industrial y de concentración y dispersión, tanto dentro de la ciudad de Nueva York, en relación a los Estados Unidos, como dentro de Manhattan, en relación a la zona metropolitana de Nueva York...Sin embargo, la historia de esa relocalización en Manhattan también corresponde a los movimientos de la fuerza de trabajo inmigrante alrededor de la ciudad. La historia de la migración intraurbana de los trabajadores inmigrante de la confección es la historia del ascenso y la caida de la 
manufactura casera y la separación operada en el siglo XX entre el hogar y el trabajo. (Green:219).

Es por eso importante atender a la geografía de los asentamientos de los inmigrantes. Green (Ibidem.) afirma que la construcción de la séptima avenida obedeció tanto a razones comerciales, industriales y financieras, como a la migración interurbana de los inmigrantes (p.219-220). Los inmigrantes más antiguos se instalaron en el campo, cerca de sus trabajos. Los inmigrantes urbanos de fines del siglo XIX buscaron viviendas urbanas cerca de sus trabajos, muchos de ellos en la industria ligera, en las zonas portuarias más baratas, donde surgieron los primeros barrios de inmigrantes. De tal forma que la industria del vestido guió muchos de sus desplazamientos. Las mujeres que trabajaban en la confección (en fábricas y talleres, caseros y no caseros), ubicados en el bajo Manhattan, buscaban vivir cerca de sus trabajos, a los que podían ir a pié, sin descuidar sus taréas domésticas.

Los talleres étnicos proveían un fácil acceso al empleo y mínimas barreras de lenguaje , y podían ser un primer paso hacia la movilidad social ascendente para los inmigrantes emprendedores (p.220)

Cabría decir: como en los años ochenta y noventa lo son para las migrantes mexicanas; excepto que ahora la distancia frente al trabajo es considerable, como producto de algunos de los procesos que refiere Nancy Green. Todavía en esa época, los empresarios tenían cerca a sus trabajadores y éstos a sus empleo. Pero, pese a la funcionalidad de ese arreglo, tres factores pueden explicar el desplazamiento de industria e inmigrantes: "el movimiento de reforma, las leyes estatales y federales y la transformación interna de los barrios de los inmigrantes" (p.220).

En cuanto a lo primero, los reformadores y los inspectores de salud realizaron fuertes campañas contra los sweatshops y el trabajo domiciliario, simbolizándoles como peligros contra la salud de los trabajadores y los consumidores. Las leyes de 1892, la New York State Factory Act y en 1901 la Tenement House Law, fueron algunos de sus resultados. Hubo sin embargo una fuerte oposición de los empresarios, que argumentaban 
que los salarios subirían y las empresas huirían. Los actuales empresarios coreanos y el sindicato United representan la continuación de esta tensión hasta los años noventa (entrevista con B. Williams, 1997). Green afirma que había también fuertes fallas en la legislación, que unían a trabajadores con empleadores. Se argumentaba que no debía alejarse a las mujeres de su hogar y que las madres podían ser ayudadas por sus hijos. Por otro lado, nunca hubo suficiente presupuesto para garantizar el cumplimiento de esas leyes. Entre los hechos más importantes al respecto de estos intentos regulatorios, en 1933, la National Industrial Recovery Act estableció reglas para el trabajo domiciliario: "las regulaciones anti-sweatshops para proteger al consumidor dieron como respuesta regulaciones anti-trabajo a domicilio para proteger al trabajador" (Green:221). El 94\% de los trabajadores fue empleado por las fábricas cuando entró en vigencia el nuevo código, pero pronto éste fue declarado inconstitucional por la Suprema Corte y el trabajo domiciliario regresó con toda su fuerza: en 1936, 194 empresarios manufactureros de Nueva York envíaban trabajo a 1,661 trabajadores domiciliarios ubicados en 16 estados y en PuertoRico (p.221). Nuevos intentos regulatorios hicieron que en el periodo 1936-1940 se fortalecieran los establecimientos y se debilitara relativamente el trabajo a domicilio. Entre 1935 y 1955, bajó el trabajo domiciliario de 500 mil a menos de 50 mil personas en el estado de NY (p.222).

Finalmente, los barrios de los inmigrantes en donde estaban ubicados los talleres, también se empezaron a transformar y se unieron a la descentralización de la ciudad. Los trabajadores de la industria del vestido, de la primera y la segunda generación, se empezaron a mudar a: Brownsville, East New York, Coney Island, Bensonhurst, Van Cortlant Park y el norte de Nueva Jersey, donde encontraban más espacio y luz e incluso podían adquirir su propia vivienda. Los trabajadores inmigrantes se mudaban entonces tanto por las condiciones de vivienda como por el desplazamiento de los talleres y las fábricas: inicialmente, "los inmigrantes seguían a los trabajos y los trabajos seguían a los trabajadores" (p.222). Pero en los años veinte se inicia un proceso de separación entre el trabajo y el hogar: "La producción fue llevada de la residencia a las fábricas, de la parte baja a la parte media de la ciudad y hacia afuera de ella" (p.222-223). En 1917, 68.6\% de las mujeres que trabajaban en la industria del vestido lo hacían en la parte media de la ciudad, y sólo un 17.5\% en la parte baja. Para 1925, una encuesta arrojó que unas 53 mil 
mujeres trabajadoras de esa industria (40\% de ellas empleadas en Manhattan), vivían en Brooklin y el Bronx, y otras 15 o 16 mil vivían en el alto Manhattan (p.223).

Hay entonces un triple movimiento en los años veinte: "concentración de la producción en el nuevo distrito de la industria del vestido; dispersión de la fuerza de trabajo ocasionada tanto por el desplazamiento de la industria hacia el norte como por el de los inmigrantes hacia afuera de la ciudad; y por el crecimiento cuantitativo y geográfico de la contratación" (p.223). Para inicios de los años cincuenta, tres cuartas partes de la fuerza de trabajo de la industria del vestido seguían empleándose en Manhattan, pero sólo una cuarta parte vivía ahí. Más o menos la mitad de los empleos estaban entre las calles 40 y 42, en donde vivía el $0.5 \%$ de los trabajadores; quienes se transladan al trabajo desde el alto Manhattan, el Lower East Side, Brooklin y el Bronx (ver las figuras de las p.224 y 225).

Desde esa época, se genera una realidad de la que hablan prácticamente todos los migrantes mexicanos actuales: "El transporte subterráneo provee los nuevos vínculos entre el hogar y el trabajo y la concentración de los establecimientos alrededor de la séptima avenida hace que cobre un nuevo sentido para los trabajadores" (p.223). En los años cincuenta, los trabajadores de esta industria respondieron en una encuesta que se oponían a que el distrito fuera cambiado de lugar: "el mercado de trabajo está convenientemente concentrado ahí; los empleadores sólo tienen que colgar un letrero y los buscadores de empleo sólo tienen que cubrir un área relativamente restringida para encontrarlo" (p.223). La facilidad del transporte es una razón fundamental. Pero, para los empresarios, la séptima avenida significa problemas de transporte y una creciente importancia y dependencia del transporte terrestre pesado, para conectarse con sus provedores y sus clientes (p.225). Como ya se comentó, casi tres décadas más adelante, el mexicano Jaime Lucero descubría que resolver estos problemas a los empresarios podía representar el camino hacia el éxito económico. El y su hermano decidieron comprarle un viejo camión a su antiguo patrón del restaurante en el que trabajaban y con él empezaron a hacer funciones de conexión entre los distintos eslabones de la cadena de la industria del vestido. Así, terminaron por convertirse en unos de los primeros empresarios mexicanos en la zona Nueva York-Nueva Jersey (entrevista con el seños Jaime Lucero, 1997). 
Una de las causas importante para que esta situación se sigua reproduciendo con las nuevas oleadas migratoria, es que los nuevos inmigrantes de Asía, Latinoamérica y el Caribe

han recogido lo que dejaron abandonado los primeros migrantes del siglo. En tanto que éstos se desplazan hacia una industria de los servicios en constante expansión, los nuevos inmigrantes continuan manteniendo la tradición neoyorquina en el sector industrial urbano ligero. Se trata, por cierto, de una tradición combinada. Si la proximidad entre el trabajo y el hogar se ha mantenido fuerte en el bajo Manhattan, también recuerda otros aspectos de las condiciones del siglo XIX: elevada rotación, condiciones de trabajo deficientes, bajos márgenes de ganancia para los contratistas y bajos salarios para los trabajadores" (p.228).

El último paso de este proceso de constante transformación, pero a partir del mantenimiento de las mismas pautas centrales, lo explican autores como Piore y Sabel (1984), Nancy Foner (1987), Adriana Marshall(1987) y Ellen Kraly (1987). Una reflexión muy reciente e informada proviene del sindicato United y su Centro de Justicia. Aquí la atención se centrará en analizar las formas en que la presencia de la nueva ola migratoria, modificó de manera importante las condiciones del mercado de trabajo neoyorquino; de tal manera que para la inmigración mexicana fue posible encontrar condiciones que facilitaron su integración masiva y creciente a los nichos más desprotegidos de dicho mercado de trabajo.

Una presencia fundamental es la del grupo inmigrante proveniente de Coréa; aunque las comunidades dominicana, jamaiquina y china juegan también un papel importante. Tanto coreanos, como dominicanos y chinos, han establecido pequeños talleres de confección, en los que emplean tanto a sus compatriotas, como a otros migrantes recientes (Foner, 1987, Pessar, 1987, Wong, 1987).

“Los pequeños negocios establecidos por los inmigrantes coreanos recientes, bien pueden involucrar, ya sea como trabajadores o como propietarios, a cerca de las tres cuartas partes de los coreanos empleados en la zona metropolitana de Nueva York" (p.7) 
En buena medida, se han desarrollado aprovechando el éxodo de judíos e italianos de las zonas habitadas por los coreanos. Por supuesto que no son los únicos empleadores. En una aparente contradicción, pese a que en general han sido elevadas las tasas de desempleo en Nueva York, esta ciudad

...continua siendo una ciudad de oportunidades para los inmigrantes. Dejando a un lado las firmas que son propiedad de inmigrantes, los sectores manufacturero y de servicios de bajos salarios, han provisto de empleo a incontables recién llegados (Foner, 1987:8))

El sector manufacturero es particularmente interesante a este respecto, en tanto ha experimentado dramáticas caidas en el empleo en las últimas décadas, con una pérdida del 35\% de los puestos de trabajo, sólo en 1970 (Sassen-Koob 1985:300). Mientras que muchas plantas han cerrado o se han relocalizado, al mismo tiempo ha habido una expansión de lo que Sasen-Koob (1985:302) llama el sector manufacturero degradado, en donde los sweatsthop y el trabajo a domicilio son formas comunes de producción (Foner, 1987: 8). 


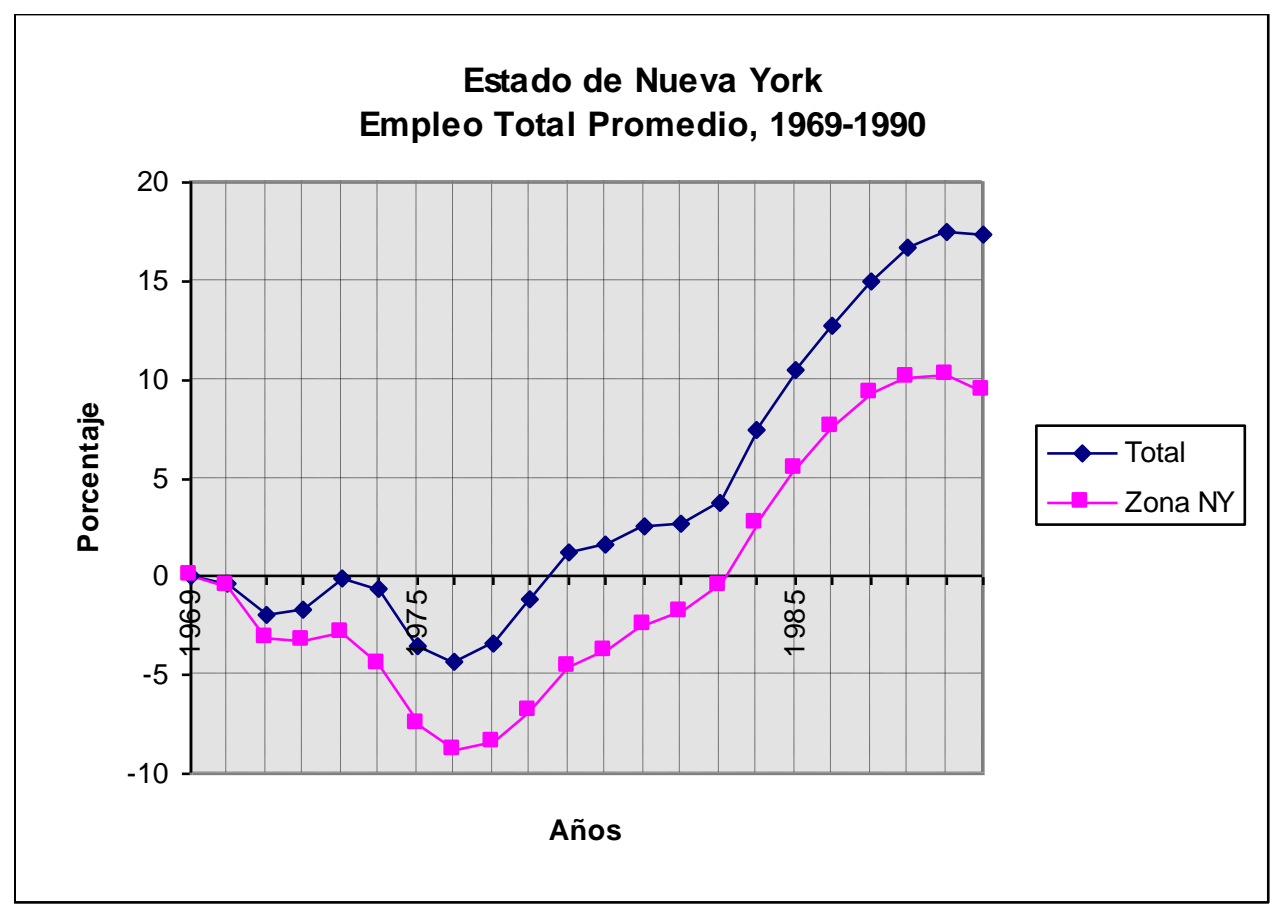

Fuente: Regional Economic Information System, 1969-1990.. U.S. Department of Commerce,

Economics and Statistics Administration Bureau of Economic Analysis, Regional Economic Measurement Division, Mayo de 1992. Elaboración nuestra.

Gráfica 3: Estado de Nueva York. Empleo en la Manufactura. Promedio por Condado, 1969-1990

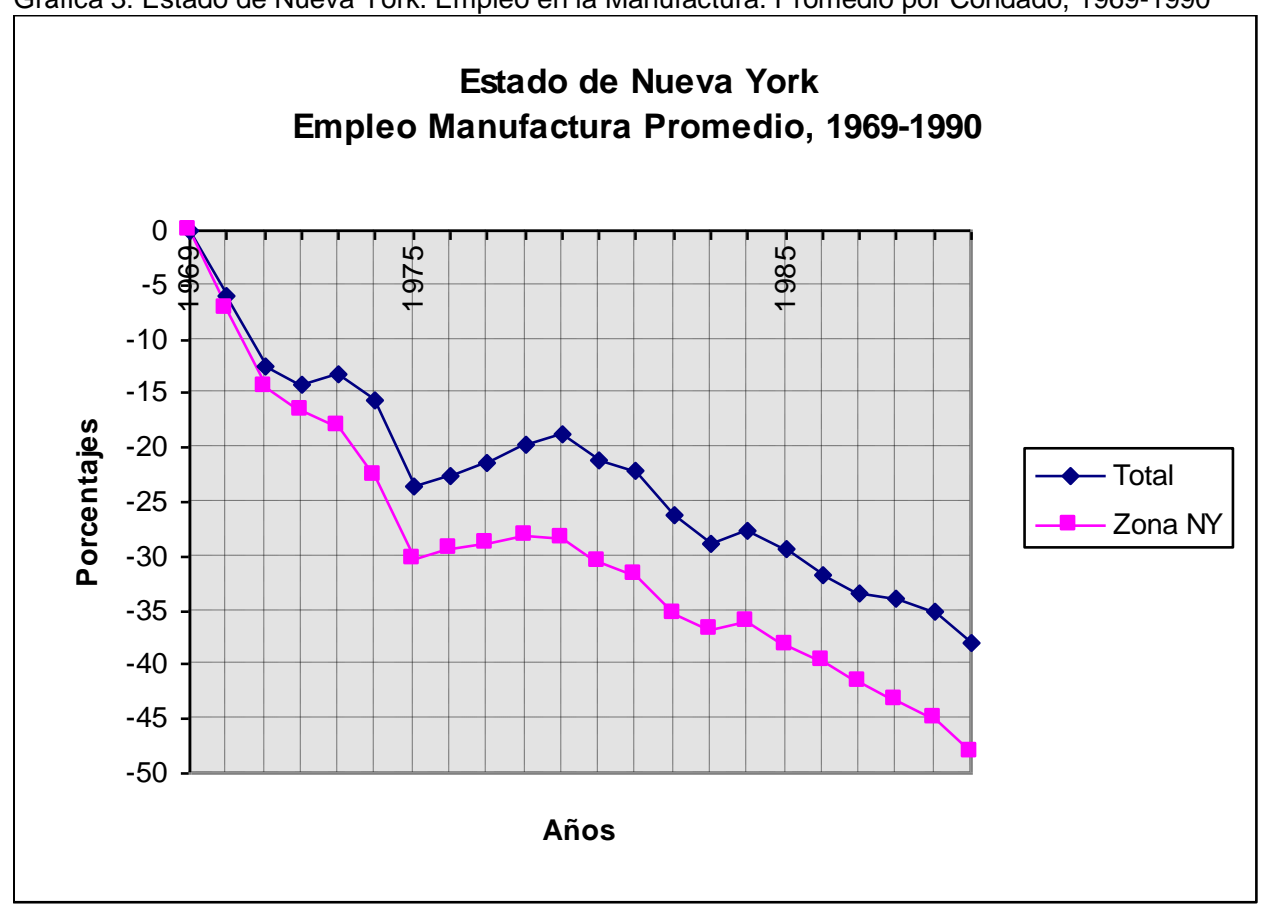

Fuente: Regional Economic Information System, 1969-1990.. U.S. Department of Commerce, Economics and Statistics Administration Bureau of Economic Analysis, Regional Economic Measurement Division, Mayo de 1992. Elaboración nuestra. 
En realidad, se está ante la recreación de nichos étnicos de trabajo. Como señala A. Marshall (1987), los americanos nativos no aceptarían los muy bajos salarios y las condiciones de trabajo en sectores manufactureros como la confección y el cuero. Estas empresas no serían rentables si no hubiera una gran cantidad de inmigrantes recientes dispuestos a aceptar esa situación (Ibid).

Una consecuencia importante de lo anterior, es que el flujo continuo y regular de inmigrantes desalienta la innovación tecnológica (Piore y Sabel, 1984). En su lugar, propicia técnicas intensivas en trabajo y la readopción de de formas de trabajo tales como los sweatshop, el trabajo a domicilio y la subcontratación, así como la reaparición de firmas muy pequeñas, generalmente propiedad de inmigrantes. Este desarrollo, a su vez, incrementa la dependencia frente a los trabajadores inmigrantes para satisfacer la demanda de trabajo (Ibid.):

El resultado final es que la manufactura está crecientemente poblada por trabajadores inmigrantes. Para 1980, conforme al censo, 44 por ciento de los trabajadores de la manufactura había nacido fuera de los Estados Unidos. Cerca de las tres cuartas partes de esos trabajadores extranjeros eran nuevos inmigrantes, con una participación de mujeres asiáticas e hispanas especialmente pronunciada. (Ibid.)

Es sin embargo el sector de los servicios el mayor empleador de nuevos inmigrantes. Eso difícilmente puede sorprender, dado que Nueva York es básicamente una economía de servicios, en la que este sector proporciona más o menos uno de cada tres trabajos en la ciudad (Sassen-Koob, 1985:303) (Foner, 1987:8-9).

Relativamente muy pocos de los nuevos inmigrantes pueden encontrarse en posiciones bien pagadas y de alto estatus profesional, de tipo administrativo, técnico o gerencial, en el sector de servicios; más bien, los nuevos inmigrantes son una significativa fuente de trabajo para los empleos del más bajo nivel de los servicios (Foner, 1987:9). 


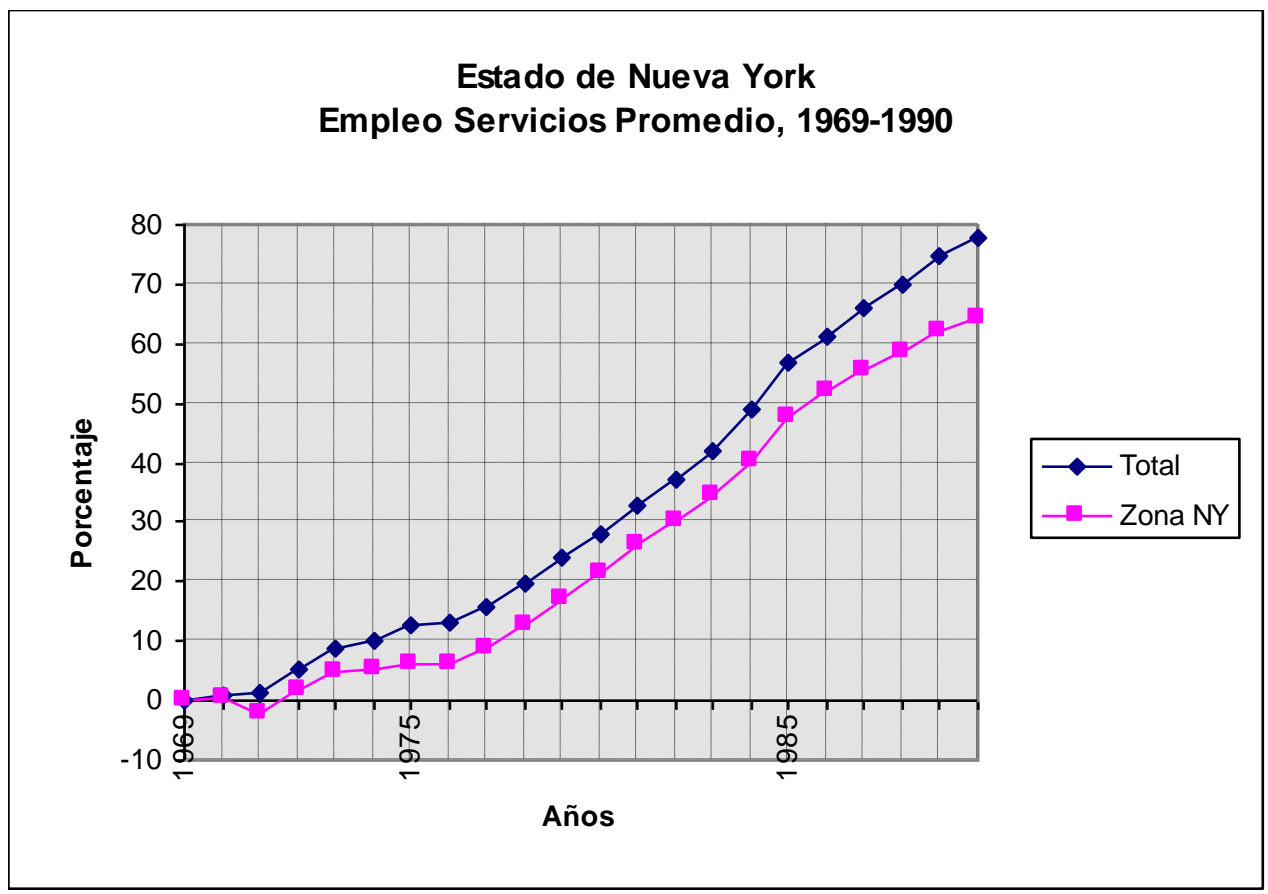

Fuente: Regional Economic Information System, 1969-1990.. U.S. Department of Commerce,

Economics and Statistics Administration Bureau of Economic Analysis, Regional Economic Measurement Division, Mayo de 1992. Elaboración nuestra.

Tal y como sigue sucediendo actualmente con la gente de México en Nueva York, se encuentra trabajo, sobre todo al inicio de las trayectorias laborales, en los rangos más descalificados y de menores salarios de los servicios: como encargados de limpieza, lavaplatos, dependientes de mostrador, mozos de hospital; pero también atendiendo necesidades de los sectores de altos ingresos, trabajando como porteros de edificios o en el servicio doméstico, en donde existe una "expansión casi infinita" de la demanda. Aunque, "debe anotarse también que Nueva York ofrece oportunidades para ciertos servicios profesionales de bajo nivel en los servicios de salud, como lo son los de enfermería". (Foner, 1987:9).

Una importante conclusión a la que llegan los diversos estudios citados es que, de hecho, la creciente absorción de nuevos inmigrantes por el mercado de trabajo de Nueva York, no ha significado "un desplazamiento significativo de trabajadores nativos en la ciudad" (Foner, 1987:24). Adriana Marshall afirma que los nuevos inmigrantes se han posicionado sobre todo en la franja de los trabajos manuales; de tal forma que, para 1980, quienes arribaron en los setenta representaban el 35\% de la ocupación en las áreas de 
trabajo manual. Los puestos que ocuparon son aquellos de los que habían desertado los trabajadores nacidos en los Estados Unidos, al desplazarse hacia trabajos no manuales. Ella propone que "la fuerza de trabajo inmigrante estimula su propia demanda" (Ibid.). Los empleadores tienen que ajustarse a la oferta de trabajo inmigrante y acaban por depender de ella, de tal forma que los inmigrantes se emplean en actividades que no existirían de no estar ellos ahí. (Foner, 1987:24-25).

Entonces, los trabajadores inmigrantes están en empleos que no serían ocupados por los nativos. Si no estuvieran los inmigrantes, las empresas que los emplean se habrían ido o hubieran introducido técnicas ahorradoras de trabajo.(Foner,1987:25). Por ejemplo, más de la mitad de los trabajadores de los restaurantes, en 1980, eran nacidos en el extranjero (Bailey, 1985); pero no competían con los trabajadores nativos en ese sector, sino que había una especialización en diferentes taréas, en la que los inmigrantes trabajaban preferentemente en restaurantes cuyos propietarios eran inmigrantes, así como en labores descalificadas o semicalificadas de las cocinas de los restaurantes caros. (Foner, 1987:25)

Sin embargo, Marshall (op. cit) opina que los trabajadores inmigrantes sí han contribuido, aunque de manera indirecta, a los bajos salarios; especialmente a un lento crecimiento de los salarios en los sectores manufactureros en donde están sobrerepresentados. Aunque no cuenta con suficientes datos, esta autora piensa que lo mismo puede suceder en el sector de los servicios.

En un análisis más detenido, Marshall encuentra que, en los años setenta, en Nueva York había tasas crecientes de desempleo y un crecimiento casi nulo de la demanda de trabajo y, por tanto, había "relativamente demasiados trabajadores nativos en la región, frente al número de trabajosexistente" (p.79). Eso dejaba, para los nuevos inmigrantes , un "rango restringido de opciones de empleo" (p.79); lo que los llevó a concentrarse en sólo ciertas actividades económicas, como la manufactura y los servicios (p.80).

En 1980 y a lo largo de los años setenta, había más de dos millones de inmigrantes en la zona metropolitana de Nueva York (750 mil de ellos, indocumentados). Paralelamente a su arribo, grandes cantidades de blancos y negros abandonaron la ciudad en esos años; y se presentó un declive de la migración puertoriqueña, e incluso un proceso de retorno a Puerto Rico. 
Esos procesos tuvieron efectos significativos en el mercado de trabajo. La mayor parte de los nuevos inmigrantes eran personas adultas jóvenes (16 años o más), con tasas de participación en la fuerza de trabajo mayores que las de los nacidos en los EUA (p.80). Su impacto se presentó sobre todo en las actividades manuales, tanto de "cuello azul", como en los talleres y en los sevicios (p.80-81). En 1980, representaron el 35\% de la furza de trabajo manual de la SMSA de Nueva York, mientras que eran sólo el 16\% de la población de esas misma área. Es probable que los llegados en los años setenta hayan sido la cuarta parte de la fuerza de trabajo manual en 1980 ( 25 de 35 ).

Las condiciones locales de la economía en la que se insertaron, eran de contracción del empleo. El manufacturero decreció en los setenta más que en los sesenta. En 1980, la nómina manufacturera fue 30\% menor que en 1970, que había sido a su vez $16 \%$ inferior a la de 1960. Por su parte, había un crecimiento casi nulo del empleo no manufacturero. En 1975 se presenta un pico en el desempleo, con una tasa del 11.5\% de la fuerza de trabajo en la ciudad de Nueva York. De acuerdo a otro indicador, el total del empleo no agrícola de Nueva York fue en 1980 inferior el de 1960. Para los inmigrantes, la situación era diferente:

"Pese al dramático empeoramiento de la situación del mercado de trabajo en los setentas, la distribución en el empleo de la fuerza de trabajo de la nueva ola de inmigración mostró una notable estabilidad a través del tiempo" (p.81)

Tanto en 1980 como en 1970, el trabajo de los nuevos migrantes se ubicó sobre todo (cuadros 3.1, p. 82, 3.2, p.84, y, p.87, 3.3) en el sector privado, no así en el público, ni en el autoempleo, ni en el familiar no asalariado (p.80-81); en los trabajos manuales menos calificados, tanto en la industria como en los servicios, (en donde descendió considerablemente la participación de los trabajadores nacidos en los EUA (p. 82-84), sobre todo de las mujeres). Sectorialmente, es en la manufactura donde se concentran, en tanto que los nativos se van a otros sectores: 
los trabajadores nativos abandonaban una industria que estaba perdiendo puestos de trabajo; al menos durante los años iniciales de la nueva inmigración, el impacto de esta nueva inmigración en la oferta de trabajo fue relativamente pequeña (p.86).

Con datos del censo de 1970, puede verse que los nuevos inmigrantes representaban apenas un 10\% del empleo manufacturero, pero estaban altamente concentrados en algunas industrias. Los puertoriqueños, que habían llegado masivamente a los EUA después de la II guerra mundial, eran el 12\% de la fuerza de trabajo manufacturera. Para 1980, el 70\% de los nuevos inmigrantes estaban en el sector manufacturero y representaban el $44 \%$ del total del empleo en el sector (mientras que los nacidos fuera de los EUA eran sólo el 21\% de la población del área).

En general, y pese a que el empleo en general decrece en los años setenta, la manufactura incrementa el número de nuevos inmigrantes empleados, en tanto decrece la proporción de nacidos en EUA empleados en ese sector.Particularmente, más de la mitad de las mujeres latinoamericanas y asiáticas estaban empleadas en la manufactura, tanto en 1970 como en 1980. Todo demuestra que el trabajo en las factories es una de las oportunidad realmente al alcance de los nuevos inmigrantes. Aparte, está el trabajo en el sector terciario, que es el mayor empleador en Nueva York, tanto de trabajadores nativos como de inmigrantes, con importantes concentraciones y sobrerepresentaciones (p.88): de latinos y asiáticos, en los negocios de comida y bebida; de asiáticos, en las ventas; de caribeños no hispanoparlantes, en los pequeños negocios y en el reparto; de las asiáticas, en la comida y la bebida; de latinoamericanas y caribeñas hispanoparlantes, en los servicios domésticos y personales; de caribeñas no hispanoparlantes, en los servicios, profesionales o no profesionales, en establecimientos como hospitales.

Los procesos anteriores producen que esas actividades se vuelvan dependientes de los trabajadores extrnajeros y que éstos tengan muy difícilmente acceso a otras actividades, que son ocupadas por los trabajadores nacidos en los EUA. También dan lugar a que se establezcan diferentes patrones laborales para los distintos grupo étnicos. Los nuevos inmigrantes generalmente siguen las rutas laborales abiertas por sus predecesores: son apoyados por amigos y familiares y los empleadores tienden a seleccionarlos étnicamente; 
pero también actua la composición de los grupos de inmigrantes y sus antecedentes sociodemográficos, de trabajo y de formación (p.89-92).

El impacto de la inmigración en la industria manufacturera ha sido considerable. En 1970, excepto los asiáticos, que se distribuían por igual en todos los sectores, los nuevos inmigrantes estaban sobrerepresentados en seis industrias manufactureras (industrias “inmigrantes”): confección, textil, plástico, calzado y otros artículos de piel, artículos no duraderos no especificados y “misceláneos". Ahí se concentraban, del total de trabajadores empleados en actividades manuales, la mitad de los puertoriqueños, latinoamericanos y caribeños no hispanoparlantes, pero sólo una cuarta parte de los hombres nacidos en los EUA. De las mujeres, el $71 \%$ de las puertoriqueñas y latinoamericanas que trabajaban en la manufactura se concentraban en la confección, los artículos de piel y en "misceláneos", mientras que sólo lo hacía la mitad de las mujeres nacidos en los EUA. Precisamente

esas seis industrias tuvieron, en 1970, los más bajos niveles salariales y furon las más intensivas en mano de obra, dentro de la industria manufacturera de Nuev a York (p.93).

Tenían además los más bajos niveles de calificación. En el extremo, el 80\%, más o menos, de la industria de la confección, era trabajo semicalificado (p.93). Los bajos márgenes de ganancia, por otro lado, ocasionaban que: "las firmas en esas industrias enfrentaran obstáculos tanto para invertir en nueva tecnología y equipo, como para elevar los salarios y mejorar las condiciones de trabajo" (p.93). Eso alejaba a las nuevas generaciones de trabajadores nacidos en los EUA. Permitía reclutar a los inmigrantes dispuestos a aceptar los salarios (mejores que en sus lugares de origen) y condiciones de trabajo prevalecientes; que además contaban con una calificación adecuada a esas industrias manufactureras "tradicionales" (p.93).

Para 1980 (cuadro 3.5, p.94), los inmigrantes estaban sobrerepresentados en las mismas industrias manufactureras que en 1970 y todos los grupos lo estaban en la industria de la confección (ahí se empleaba el 90\% del total de mujeres asiáticas que trabajaba en la manufactura) (p.94). Se estaba ya ante el franco regreso de los establecimientos pequeños, de la subcontratación, de los sweatshop, del trabajo domiciliario y del pago a destajo; lo 
que ocasionaba un mayor resago salarial y de la productividad frente a otras industrias y una estrategia de mantenimiento de la competitividad y de las ganancias mediante los bajos salarios

Ese proceso probablemente contribuyó a que se mantiviera la especialización del sector manufacturero de Nueva York en las industrias intensivas en trabajo tradicionales. (p.95)

En términos generales, los salarios manufactureros en Nueva York crecieron más lentamente que en el conjunto de la economía norteamericana. Aunque esta situación no se presentó sólo en esta zona. En general, en todos los centros metropolitanos de EUA con altos índice de inmigración, los salarios crecieron más lentamente que en aquéllos con índices menores. Puede entonces encontrarse una correlación entre mayor presencia de inmigrantes y más bajos salarios o, menor crecimiento salarial.

Como puede verse hasta aquí, en NY se presenta una reconversión industrial que muestra muchos elementos en común con aquella por la que han atravesado los países latinoamericanos, en donde las relaciones laborales son flexibilizadas de manera "salvaje", en donde existe una clara polarización productiva (De la Garza, ) y en donde se aprovecha la sobreoferta de mano de obra (inmigrante, en el caso de Nueva York) para mantener bajos los salarios y para eludir la innovación tecnológica y la introducción de formas participativas y consensuales de organización del trabajo (nada más alejado del silycon valley y más cercano a los detritus industriales de Castillo). Las tesis de "periferialización" del primer mundo parecen tener pertinencia en esta "ciudad global", mientras que las de la "nueva división internacional del trabajo" y las que separan al "primer mundo" del "tercero", parecen inadecuadas para dar cuenta del funcionamiento de la economía neoyorkina. Aquí coexisten las condiciones de trabajo más "posmodernas", por ejemplo en los circuitos financieros y en los sectores dedicados al diseño (con tecnologías de frontera, trabajo autoregulado, altísimos salarios, oficinas virtuales), con las más "premodernas", sobre todo en los sweatshop, péro incluso también en el trabajo de las cocinas de algunos 
restaurantes (con tecnologías obsoletas, relaciones laborales despóticas, salarios inferiores al mínimo legal, jornadas excesivas, ambientes insalubres).

En esas condiciones del mercado de trabajo, con sus nichos étnicos costantemente renovados por las sucesivas olas migratorias y por las recurrentes reestructuraciones económicas, la migración mexicana llega a asentarse en Nueva York, sobre todo en los años ochenta y noventa, durante los cuales las tendencias anteriores se profundizan (Gordon y Sassen, 1992); sobre todo las que tienen que ver con una oferta creciente de empleos en las actividades de servicios u manufactureras de menor calificación y, muy especialmente, con el regreso de los sweatshop y el trabajo domiciliario (Unite, página

Webb, ). A continuación, se revisarán los resultados a los que se llegó en nuestra investigación sobre las trayectorias laborales de los migrantes de Puebla y Tlaxcala.

\section{SEGUNDA PARTE: EL ENCLAUSTRAMIENTO DEL TRABAJO MEXICANO}

\section{Los Nichos de Mercado de los Inmigrantes en Nueva york}

Como se desprende de los análisis presentados en la sección anterior, a lo largo de todo el siglo XX, en Nueva York se han reproducido cíclicamente franjas del mercado de trabajo que sólo se explican por el constante arribo de nueva fuerza de trabajo inmigrante. En especial, la llamada nueva ola migratoria, iniciada hacia 1965, produjo cambios significativos en el mercado de trabajo de la zona de Nueva York; en el cual, destacadamente, se crearon nichos para los nuevos migrantes, en establecimientos de la industria (especialmente de la confección) y los servicios (sobre todo restaurantes y comercios), que en muchos casos eran propiedad de personas pertenecientes a esa misma ola migratoria. Es precisamente en esas condiciones en las que se inserta la migración mexicana de los años ochenta y noventa.

Ahora bien, ¿qué características presentan estos nichos de mercado? ¿están definidos étnicamente; esto es, pertenecen a grupos bien diferenciados de migrantes con una gran unidad étnica?; o bien ¿son nichos multiétnicos, conformados de manera más o menos compleja y cambiante, por personas de diversas procedencias y que llegaron en distintos momentos, de 1965 hacia adelante?. Las evidencias parecen apuntar hacia esto último. Por lo demás, está claro que los nichos en los que se ha insertado la fuerza de 
trabajo mexicano no son nichos exclusivos de los mexicanos. Como se verá a continuación, sólo una muy pequeña minoría de mexicanos es propietaria de los establecimientos que han empleado a la migración mexicana. Por otro lado, la mayoría de los compañeros de trabajo de la gente de México no es mexicana; pero tampoco es nativa de los Estados Unidos.

En realidad, los referidos nichos han sido creados, primero, por las sucesivas olas históricas de migrantes; y, después, por los distintos componentes, o subolas, dentro de ellas. El caso de la migración coréana es elocuente al respecto. Primero, los coreános empezaron a emplearse, hacia los años setenta, en sweatshop que eran propiedad de italianos y de personas identificadas como judías. Más adelante, muchos de los migrantes de Coréa se convirtieron en propietarios de sweatshop y emplearon preferentemente a compatriotas suyos recién llegados. Pero más recientemente, la llegada de nuevos migrantes de distintos orígenes y dispuestos a ganar menores salarios, ha llevado a que en los sweatshop propiedad de coreanos haya habido un desplazamiento creciente de trabajadores coreanos por mexicanos y ecuatorianos, como lo muestran la investigación reciente (p.e., Hernández-León, 1998), los testimonios de activistas sindicales (entrevista a Bertha Williams, 1997) y la observación directa.

Por lo anterior, es interesante preguntarse tanto por el origen de los empleadores de la fuerza de trabajo mexicana en Nueva York, como por la relación previa que pudo haber existido entre éstos y las y los migrantes contratados, así como por la composición étnica y el carácter de inmigrantes o nativos de quienes compartieron con ellas y ellos los lugares de trabajo. Dicho análisis se realizará, primero, considerando los puertos de entrada al mercado de trabajo de Nueva York; para más adelante, tomar en cuenta el desarrollo de las trayectorias laborales. En ambos casos, se diferenciará entre mujeres y hombres y se agruparán los eventos por cohortes; y por eventos sucesivos, en el caso de las trayectorias laborales.

Para el análisis, se parte de supuestos provenientes de lo que se ha desarrollado en la revisión teórica. En relación a las características del mercado de trabajo neoyorquino, se trata de ver si es un mercado abierto, gobernado básicamente por las fuerzas de la oferta y la demanda, y en el que las personas tienen posibilidades de acceso y desarrollo, independientemente de su origen étnico, nacionalidad o condición sexual o migratoria; o bien si se trata de un mercado de trabajo en el que intervienen otras instituciones sociales en 
su estructuración; como pueden serlo esquemas de segregación relacionadas precisamente con la etnia, la nacionalidad, el sexo o el carácter de inmmigrante o nativo de la fuerza de trabajo ${ }^{45}$.

En el primer caso, se esperaría que quienes componen la migración mexicana, se ubicaran en trabajos sin carácterísticas especiales, en cuanto al origen del patrón y los compañeros de trabajo; sino más bien se esperaría que éstos reflejaran de manera aproximada la composición de la población de Nueva York. En el segundo caso, por el contrario, habría que esperar que tanto los patrones como los compañeros de trabajo pertenecieran a grupos específicos de la población. Inmigrantes no muy reciente, en el caso de los patrones; inmigrantes mucho más recientes en el caso de los compañeros de trabajo. Esto es, en este caso se esperaría que existieran nichos diferenciados en el mercado de trabajo; en los cuales la inserción de las personas tendría mucho que ver con el origen étnico o nacional, con el periodo de arribo a los Estados Unidos y con la condición de inmigrante.

Como se podrá apreciar a lo largo de la siguiente exposición, la realidad a la que se ha enfrentado la migración mexicana en Nueva York, se asemeja mucho más a este segundo caso.

\section{No todas las puertas están abiertas para los migrantes: nichos de trabajo etiquetados}

Con porcentajes muy similares, las personas incluidas en la muestra declararon haber trabajado por primera vez en los Estados Unidos para diversos tipos de personas inmigrantes no latinoamericanas: $57 \%$ del total, $59 \%$ de las mujeres y $56.1 \%$ de los hombres. Con patrones de Latinoamérica, se contrató el $9.7 \%$ del total $(12.6 \%$ de las mujeres y $8.5 \%$ de los hombres). En el extremo inferior en los porcentajes, muy pocas personas trabajaron para empleadores originarios de su propia comunidad o región de origen (4.6\%), y del resto de México (5.9\%). Esto permite reafirmar la idea de que esta migración llegó a insertarse en los nichos de mercado que se habían generado a partir de la última nueva ola migratoria abierta a partir de 1965. A reserva de confirmarlo con el análisis de las cohortes de migración y con la visión longitudinal de las trayectorias, todo parece hasta aquí indicar que esta migración mexicana no ha generado sus propios nichos

\footnotetext{
45 En otro capítulo, más adelante, se buscará analizar la influencia de otras instituciones sociales, tales como
} 
en el mercado de trabajo, sino que más bien ha sabido aprovechar la situación ya existente. Cabe hacer resaltar que menos de una cuarta parte del total (menos del 16\% para las mujeres) se empleó inicialmente con patrones identificados como norteamericanos blancos, y sólo una ínfima parte, menos del 2\%, como norteamericanos negros.

Como era de esperarse, la inmensa mayoría no había tenido ningún tipo de relación previa con el patrón (más de las cuatro quintas partes en todos los casos). Una pequeña minoría, por el contrario y consistentemente con los datos inmediatos anteriores, identificó a sus empleadores como familiares $(6.3 \% ; 11 \%$ de las mujeres y $4.2 \%$ de los hombres) o amigos (6.8\%). Una situación un tanto diferente, pero que sin embargo confirma la idea de que esta migración se inserta en el terreno abonado por migraciones que la antecedieron de manera inmediata en el tiempo, la ilustra la composición de los compañeros de trabajo. Si bien entre éstos destaca la presencia de personas identificados en general como latinas no mexicanas (38.8\% para el total), un poco más de una cuarta parte del total son de México (26.3\%) y cerca de otra cuarta parte la conforman diversos tipos de inmigrantes $(23.1 \%)$. Poco es el peso relativo de las personas de la propia comunidad y de la región de origen (3.8\% y $5.8 \%$, respectivamente). Son escasas aquí las diferencias al respecto entre hombres y mujeres.

Como se ha podido ver hasta este punto, un elemento que puede haber intervenido de manera importante, y desde la inserción misma, en la estructuración de las trayectorias laborales de quienes han migrado desde Puebla y Tlaxcala hacia el área de la ciudad de Nueva York y sus alrededores, está en un elemento estructural del mercado de trabajo neoyorquino y que ha sido estudiado ampliamente. Se trata de la existencia de nichos de mercado en actividades económicas que de hecho no podrían existir y renovarse a lo largo del tiempo (todo el siglo XX) si no fuera por la presencia renovada de sucesivas olas de inmigrantes. Como se vio en dicha aproximación general, tanto los patrones como los compañeros de trabajo de los mexicanos en aquella región, son en general personas migrantes de distintos orígenes (en muy pocos casos de su misma comunidad o incluso región o, en el caso de los empleadores, del mismo país), con las que no habían tenido contacto previo. Cabe ahora analizar el desarrollo a través de las cohortes de migración ${ }^{46}$.

46 En este caso, las cohortes son: 1) hasta 1983; 2) de 1984 a 1988; 3) de 1989 a 1993; y 4) de 1994 en adelante. 
Algo que no cambia para ninguno de los dos sexos a lo largo de las cohortes (cuadro y gráfica \# 1) es que los empleadores son mayoritariamente (alrededor del 50\%) personas inmigrantes de diversos orígenes, pero todos distintos al latinoamericano. Para los hombres (cuadro y gráfica \# 2), el segundo grupo empleador importante está formado por personas identificadas como norteamericanas blancas o anglosajonas (oscila alrededor de la cuarta parte del total) y el tercero por gente de Latinoamérica (menos del 10\% en promedio). Para las mujeres, el segundo lugar, con cifras muy similares, excepto en la segunda cohorte, lo comparten los dos últimos grupos mencionados.

Aunque en general son muy pocos los patrones identificados como de la misma comunidad, región o país, resalta que su porcentaje aumenta en la última cohorte, para las mujeres, en el caso de la comunidad, y para ambos sexos, en el caso de México. Como es sabido por otras fuentes (p.e. Vadillo, 2000), es una realidad la aparición y desarrollo de un grupo, pequeño para Nueva York, pero significativo con relación a los lugares de origen, de empresarios mexicanos en aquella región. Tal vez sea demasiado pronto para saber si se está formando o no un mercado de trabajo étnico específico y diferenciado para los migrantes de Puebla y Tlaxcala, pero sí se sabe que algunos de estos empresarios, como es el caso del señor Félix Sánchez, originario de Piaxtla y dueño de una importante cadena de tortillerías en Nueva York, en los últimos años ha estado empleando de manera casi exclusiva a personas originarias de la región de Acajete, en el centro del estado de Puebla, que han migrado precisamente para trabajar con él. ${ }^{47}$

Como podía esperarse, la inmensa mayoría de mujeres y hombres de todas las cohortes (tabla \# 3) no habían tenido ninguna relación previa con el patrón. Sin embargo, cabe observar que las mujeres (cuadro y gráfica \# 3) de las cohortes segunda y cuarta, ubicaron como familiares a quienes las emplearon, en porcentajes del $12.5 \%$ y del $20.6 \%$, respectivamente; mientras que los hombres (cuadro y gráfica \# 4) de la primera identificaron como amigos a un $12.9 \%$.

47 Esta información proviene de la aplicación del mismo cuestionario que aplicamos al resto de las comunidades, a una comunidad que no había sido considerada en el inicio y que, por razones de tiempo, no ha sido incluida en el presente trabajo. La aplicación fue realizada por un estudiante tesista de la escuela de Economía de la UAP, bajo la dirección de Saúl Macías. 
TABLA \# 2

\begin{tabular}{|c|c|c|}
\hline \multicolumn{3}{|c|}{$\begin{array}{r}\text { DISTRIBUCIÓN PORCENTUAL DE HOMBRES Y MUJERES, POR C } \\
\text { PATRÓN (primer trabajo en EUA) }\end{array}$} \\
\hline $\begin{array}{l}\text { Cohorte de ingreso al mercado de } \\
\text { trabajo en EUA }\end{array}$ & $\begin{array}{l}\text { Mujeres } \\
\% \text { del total por cohorte }\end{array}$ & $\begin{array}{c}\text { Hombres } \\
\% \text { del total por cohorte }\end{array}$ \\
\hline \multicolumn{3}{|l|}{ De la misma comunidad } \\
\hline Hasta 1983 & 0 & 4.8 \\
\hline De 1984 a 1988 & 8.0 & 2.9 \\
\hline De 1989 a 1993 & 1.8 & 1.9 \\
\hline Desde 1994 en adelante & 12.1 & 2.4 \\
\hline \multicolumn{3}{|c|}{ De la misma región de origen } \\
\hline Hasta 1983 & 0 & 4.8 \\
\hline De 1984 a 1988 & 0 & 2.9 \\
\hline De 1989 a 1993 & 0 & 1.9 \\
\hline Desde 1994 en adelante & 0 & 0 \\
\hline \multicolumn{3}{|c|}{ De México } \\
\hline Hasta 1983 & 0 & 1.6 \\
\hline De 1984 a 1988 & 16.0 & 7.4 \\
\hline De 1989 a 1993 & 5.5 & 4.2 \\
\hline Desde 1994 en adelante & 9.1 & 9.8 \\
\hline \multicolumn{3}{|c|}{ De América Latina } \\
\hline Hasta 1983 & 20.0 & 3.2 \\
\hline De 1984 a 1988 & 4.0 & 13.2 \\
\hline De 1989 a 1993 & 12.7 & 9.0 \\
\hline Desde 1994 en adelante & 15.2 & 7.3 \\
\hline \multicolumn{3}{|c|}{ Inmigrantes de otros orígenes } \\
\hline Hasta 1983 & 60.0 & 53.2 \\
\hline De 1984 a 1988 & 44.0 & 48.5 \\
\hline De 1989 a 1993 & 65.5 & 63.7 \\
\hline Desde 1994 en adelante & 48.5 & 45.1 \\
\hline \multicolumn{3}{|c|}{ Afroamericanos } \\
\hline Hasta 1983 & 0 & 0 \\
\hline De 1984 a 1988 & 4.0 & 0 \\
\hline De 1989 a 1993 & 0 & 3.3 \\
\hline Desde 1994 en adelante & 3.0 & 1.2 \\
\hline
\end{tabular}




\begin{tabular}{|c|c|c|}
\hline Hasta 1983 & 20.0 & 32.3 \\
\hline De 1984 a 1988 & 24.0 & 25.0 \\
\hline De 1989 a 1993 & 14.5 & 16.0 \\
\hline Desde 1994 en adelante & 12.1 & 34.1 \\
\hline
\end{tabular}


TABLA \# 3

\begin{tabular}{|c|c|c|}
\hline \multicolumn{3}{|c|}{$\begin{array}{r}\text { DISTRIBUCIÓN PORCENTUAL DE HOMBRES Y MUJERES, POR CO } \\
\text { CON EL PATRON (primer trabajo en EUA) }\end{array}$} \\
\hline $\begin{array}{l}\text { Cohorte de ingreso al mercado de } \\
\text { trabajo en EUA }\end{array}$ & $\begin{array}{c}\text { Mujeres } \\
\% \text { del total por cohorte }\end{array}$ & $\begin{array}{c}\text { Hombres } \\
\% \text { del total por cohorte }\end{array}$ \\
\hline \multicolumn{3}{|l|}{ Familia } \\
\hline Hasta 1983 & 7.1 & 8.1 \\
\hline De 1984 a 1988 & 12.5 & 5.8 \\
\hline De 1989 a 1993 & 8.2 & 2.4 \\
\hline Desde 1994 en adelante & 20.6 & 4.9 \\
\hline \multicolumn{3}{|c|}{ Amistades } \\
\hline Hasta 1983 & 7.1 & 12.9 \\
\hline De 1984 a 1988 & 16.7 & 8.7 \\
\hline De 1989 a 1993 & 3.6 & 5.7 \\
\hline Desde 1994 en adelante & 2.9 & 6.1 \\
\hline \multicolumn{3}{|c|}{ Ninguna } \\
\hline Hasta 1983 & 78.6 & 75.8 \\
\hline De 1984 a 1988 & 70.8 & 85.5 \\
\hline De 1989 a 1993 & 87.3 & 90.0 \\
\hline Desde 1994 en adelante & 76.5 & 87.8 \\
\hline \multicolumn{3}{|c|}{ Medios/Mercado } \\
\hline Hasta 1983 & 7.1 & 3.2 \\
\hline De 1984 a 1988 & 0 & 0 \\
\hline De 1989 a 1993 & 0.9 & 1.9 \\
\hline Desde 1994 en adelante & 0 & 1.2 \\
\hline
\end{tabular}


La ubicación dentro de los nichos de mercado de trabajo señalados se refuerza al considerar a los compañeros de trabajo. En este rubro, destaca para hombres y mujeres de todas las cohortes (tabla \# 4), excepto en la primera para los hombres, que éstos son latinamericanos en su mayoría, de manera oscilante para las mujeres y de manera siempre creciente para los hombres. El segundo grupo de compañeros de trabajo, lo constituyen de manera muy equilibrada los inmigrantes de otros orígenes y los mexicanos que no son ni de la misma comunidad ni de la misma región que la persona entrevistada. Aunque cabe señalar que las mujeres de la cohorte más antigua (cuadro y gráfica \# 5) detectaron como de su misma comunidad en un $14.3 \%$ del total. Tal vez como un indicador de la creciente presencia de mexicanos de muy diversos orígenes en Nueva York, pueda mencionarse que el $40 \%$ de los hombres de la cohorte más reciente (cuadro y gráfica \# 6) tuvo como compañeros a mexicanos. Algo que apunta hacia una posible segmentación del mercado de trabajo es el dato de que ni hombre ni mujeres de las distintas cohortes trabajaron con personas identificadas en general como norteamericanas no migrantes (el porcentaje más alto se encuentra entre las mujeres de la última cohorte y es de $8 \%$ ). 
TABLA \# 4

\begin{tabular}{|c|c|c|}
\hline \multicolumn{3}{|c|}{$\begin{array}{l}\text { DISTRIBUCIÓN PORCENTUAL DE HOMBRES Y MUJERES, POR COH } \\
\text { DE TRABAJO (primer trabajo en EUA) }\end{array}$} \\
\hline $\begin{array}{l}\text { Cohorte de ingreso al mercado de } \\
\text { trabajo en EUA }\end{array}$ & $\begin{array}{c}\text { Mujeres } \\
\% \text { del total por cohorte }\end{array}$ & $\begin{array}{l}\text { Hombres } \\
\% \text { del total por cohorte }\end{array}$ \\
\hline \multicolumn{3}{|l|}{ De la misma comunidad de origen } \\
\hline Hasta 1983 & 14.3 & 7.7 \\
\hline De 1984 a 1988 & 4.5 & 6.0 \\
\hline De 1989 a 1993 & 2.0 & 2.4 \\
\hline Desde 1994 en adelante & 8.0 & 1.3 \\
\hline \multicolumn{3}{|c|}{ De la misma región de origen } \\
\hline Hasta 1983 & 7.1 & 12.3 \\
\hline De 1984 a 1988 & 18.2 & 10.4 \\
\hline De 1989 a 1993 & 4.9 & 3.3 \\
\hline Desde 1994 en adelante & 4.0 & 1.3 \\
\hline \multicolumn{3}{|c|}{ De México } \\
\hline Hasta 1983 & 14.3 & 29.2 \\
\hline De 1984 a 1988 & 31.8 & 25.4 \\
\hline De 1989 a 1993 & 22.5 & 22.9 \\
\hline Desde 1994 en adelante & 24.0 & 40.0 \\
\hline \multicolumn{3}{|c|}{ De América Latina } \\
\hline Hasta 1983 & 35.7 & 23.1 \\
\hline De 1984 a 1988 & 22.5 & 38.8 \\
\hline De 1989 a 1993 & 40.2 & 43.3 \\
\hline Desde 1994 en adelante & 32.0 & 45.0 \\
\hline \multicolumn{3}{|c|}{ Inmigrantes de otros orígenes } \\
\hline Hasta 1983 & 28.6 & 23.1 \\
\hline De 1984 a 1988 & 22.7 & 17.9 \\
\hline De 1989 a 1993 & 29.4 & 25.7 \\
\hline Desde 1994 en adelante & 24.0 & 11.3 \\
\hline \multicolumn{3}{|c|}{ De EUA } \\
\hline Hasta 1983 & 0 & 4.6 \\
\hline De 1984 a 1988 & 0 & 1.5 \\
\hline De 1989 a 1993 & 1.0 & 2.4 \\
\hline Desde 1994 en adelante & 8.0 & 1.3 \\
\hline
\end{tabular}




\section{Trayectorias laborales dentro de los nichos etiquetados: movilidad acotada y restringida}

Se busca analizar ahora longitudinalmente algo que ya se ha visto con relación a los puertos de entrada al mercado de trabajo noeyorquino; esto es, si la migración mexicana se ubica laboralmente en un mercado competitivo y abierto; o bien si lo hace en algún tipo de mercado acotado por restricciones, por ejemplo de tipo étnico o nacional. Igualmente, se tratará se ver la presencia de posibles cambios a lo largo del tiempo; ya sea de la sucesión de eventos; ya sea de las distintas cohortes temporales.

Como ya se dijo al inicio de este apartado, un importante indicador para lo anterior está en las características tanto de los empleadores, como de los compañeros de trabajo, en lo que se refiere a su origen étnico o nacional. Como ya se había visto, al inicio de las trayectorias laborales en los Estados Unidos, la gran mayoría de migrantes de México sí se inserta en establecimientos que son propiedad de migrantes de diversos orígenes, distintos a latinaoamérica y México. Por las entrevistas, se sabe que son preferentemente italianos, judíos, coreanos y griegos. Cabe adelantar que, en coincidencia con lo que arrojan otros indicadores, también en este campo las trayectorias de mujeres y hombres muestran diferencias notables.

Una diferencia importante, consiste en que las mujeres (cuadro y gráfica \# 7), a lo largo de los eventos, van teniendo un porcentaje sensiblemente decreciente de patrones inmigrantes, y en compensación tienden a emplearse cada vez más con anglosajones nativos. En efecto, en tanto que los primeros representan casi el $60 \%$ en los primeros eventos, en los últimos su peso desciende a menos del 35\%. Inversamente, los segundos prácticamente duplican su importancia, al pasar de menos de un $16 \%$ a casi un $31 \%$. Si esto mismo es visto a través de las cohortes, la tendencia es la misma: en la segunda cohorte, los empleadores inmigrantes llegan a representar el 68\% y después su peso desciende hasta el $40 \%$. También en la segunda cohorte, los patrones blancos nativos representan sólo un $12 \%$ y en la última ascienden hasta casi un $31 \%$.

En tanto, los hombres (cuadro y gráfica \# 8) se mantienen crecientemente en establecimientos que son propiedad de diversos tipos de innmigrantes. En la sucesión de eventos, el peso de éstos crece desde poco más del $56 \%$ hasta llegar a casi un $66 \%$. En la comparación de las cohortes, sin embargo, se presenta un descenso moderado, al pasar de 
poco menos de un $65 \%$ en la segunda a poco más de un $49 \%$ en la última. El peso de los patrones anglosajones norteamericanos, por su parte, se mantiene bastante estable a lo largo de las trayectorias, oscilando en una banda de entre el $20 \%$ y el $24 \%$. En las cohortes, el comportamiento es más cambiante: decrece inicialmente el peso de este tipo de patrones de manera sensible (de casi un $29 \%$ en la primera, a sólo un $14 \%$ en la segunda), para después crecer hasta representar más de un $36 \%$ en la última.

Aunque la importancia como empleadores de las personas de la misma comunidad, de la misma región de origen, de México o incluso de latinoamérica, es más bien marginal para ambos grupos, cabe hacer resaltar que para las mujeres se presenta un crecimiento apreciable de los patrones mexicanos a lo largo de la trayectoria. Mientras que sólo representan poco más de un $7 \%$ en los primeros eventos, en los últimos llegan a representar más de un 15\%; crecimiento relativo que, no obstante, no se refleja a través de las cohortes. Debe hacerse resaltar también que, pese a su reducido número, es importante destacar la existencia de un núclo de empleadores originarios de los estados de Puebla (sobre todo de la Mixteca) y Tlaxcala.

Otro indicador importante y complementario al anterior, es el que se refiere a los compañeros y compañeras de trabajo. En un mercado libre y abierto a la competencia, se esperaría que la gran diversidad étnica y nacional de Nueva York se reflejara en la composición de las plantillas laborales; sin excluir por supuesto a la fuerza de trabajo nativa. Los datos demuestran que este no es el caso; sino que más bien se está ante un mercado de trabajo con fuertes restricciones étnicas.

Resulta interesante anotar de entrada que los grupos que no aparecían como patrones, aparecen aquí como compañeros de trabajo, y a la inversa; excepto en el caso de los inmigrantes que no son ni mexicanos, ni latinoamericanos. Lo cual refuerza la idea de que en estos nichos de mercado se contrata de manera importante, por parte de los inmigrantes, por ejemplo coreanos, de manera decreciente a los propios coterráneos; y que la gente de México ha aprovechado de manera extensa la existencia de esos nichos. Con algunas particularidades dignas de mención y con cambios a través de la sucesión de eventos y de las cohortes, los tres principales grupos de compañeros de trabajo están constituidos por latinoamericanos, mexicanos y otros inmigrantes. En el extremo contrario, 
la probabilidad de encontrar a personas anglosajonas o afroamericanas como compañeras de mexicanas y mexicanos es prácticamente nula.

Otra anotación inicial que es pertinente hacer, consiste en observar la escaso peso relativo que en general tienen como compañeras de trabajo las personas provenientes de la misma comunidad o región de origen en México. Como sucede con la vivienda, no es que la gente de México no esté con sus familiares y amistades en el trabajo. Por las entrevistas y la observación, se sabe que lo que sucede es que siempre están en minoría relativa en cada lugar (en el cuestionario se preguntó por las características de la mayoría de los compañeros de trabajo). Como se verá más adelante, el peso de las redes a lo largo de las trayectorias es sumamente fuerte; pero dentro del mercado de trabajo de Nueva York, la presencia de la gente de México es aún claramente minoritaria y eso se refleja en la mayor parte de los lugares de trabajo. Más bien, entonces, debe llamar la atención el hecho de que existan algunos establecimientos en los que las personas de la comunidad o la región de origen de la persona entrevistada sean la mayoría.

Las mujeres y los hombres de México se insertan en el trabajo en Nueva York en lugares en donde la mayor parte de la fuerza de trabajo es latinoamericana y, de manera oscilante y decreciente, se mantienen trabajando de manera importante en establecimientos con esas características. Para las mujeres (cuadro y gráfica \# 9), el peso relativo de este tipo de compañía en el trabajo cae de poco más de un $36 \%$ a menos de un $29 \%$. Para los hombres (cuadro y gráfica \# 10), los porcentajes correspondientes descienden de casi un 40\% a menos del 27\%. Para ambos grupos, la presencia de compañeros de trabajo de México, es ligeramente creciente a lo largo de toda la trayectoria y siempre se mantiene con un peso relativo de entre una cuarta parte y un tercio del total de cada evento. Una diferencia entre hombres y mujeres, refiere a que éstas trabajan cada vez menos, en la sucesión de eventos, con otro tipo de inmigrantes (su peso baja de casi un 28\% a un 19\%); mientras que aquéllos lo hacen de manera creciente (el ascenso es desde poco más de un $21 \%$ hasta casi un $32 \%$ ). Como se verá más adelante, esto se liga a una tendencia en los hombres hacia una mayor diversificación de los contactos con otras redes sociales; y a una menor dependencia de las redes familiares y a un aumento del peso de las amistades para desempeñarse en el mercado de trabajo. 
Visto por cohortes, resalta una presencia muy importante y creciente de la gente de México como principal compañía en el trabajo. En el total crece de poco más de un $26 \%$ en la cohorte más antigua, a un $42.4 \%$ en la más reciente (del $24 \%$ al 36\%, para las mujeres; y de casi el $27 \%$ a casi el $45 \%$, para los hombres). En cuanto a la gente de latinoamérica, su presencia es importante, pero decrece considerable en la última cohorte (de $43.5 \%$ a $28.5 \%$, en las dos últimas), sobre todo para las mujeres (de más de $41 \%$ a 18\%). En lo que se refiere a los otros inmigrantes, la diferencia con lo observado a lo largo de la sucesión de eventos es importante. Visto por cohortes, se da una considerable pérdida del peso que representan como compañeros de trabajo. En general, cae de un $23.5 \%$ en la más antigua (casi $28 \%$ en la penúltima) a sólo un poco más del $16 \%$ en la última (22\% entre las mujeres y $14 \%$ entre los hombres).

Como una diferencia importante, cabe señalar que las mujeres tienden a trabajar a lo largo de los eventos sucesivos cada vez más, aunque en proporciones pequeñas, con gente de su propia comunidad (el porcentaje aumenta de poco más del $4 \%$ al 9.5\%) y región de origen, (aquí crece de menos del $7 \%$ a más del 14\%). Los hombres, por su parte, mantienen consistentemente porcentajes sumamente bajos, y decrecientes por cohortes sucesivas, en estos renglones.

Finalmente, tanto hombres como mujeres trabajan sólo ocasionalmente con gente anglosajona o afroamericana nativa de los Estados Unidos; aunque se puede notar un ligero crecimiento si se ve a lo largo de las cohortes (de $2.5 \%$ a más de $6 \%$ de los eventos).

\section{CONCLUSIONES PARCIALES}

Como puede observarse, tanto en el momento del inicio, como en el desarrollo de las trayectorias laborales, y en general a través de todos los tipos de cohortes presentados, se mantienen algunas constantes importantes en el desempeño de la migración mexicana en el mercado de trabajo neoyorkino. Esas constantes, en relación al tipo de patrón y de compañeros de trabajo, refieren claramente a la inserción en nicho de mercado que han sido socialmente etiquetados como nichos de inmigrantes recientes. En ellos, los patrones tienden a ser personas pertenecientes a inmigraciones anteriores, que han podido abandonar los trabajos más descalificados y peor pagados del sector degradado de la manufactura y de la industria de los servicios, para ubicarse como propietarios de negocios pequeños y 
medianos. Quienes trabajan mayoritariamente en esos establecimientos, se identifican por su condición de migrantes recientes y, en general, indocumentados y pertenecientes a muy diversos orígenes; todos ellos típicos de las sub ola migratoria que se presenta de los años ochenta en adelante (originada en China, Ecuador, México, República Dominicana, Brasil).

Las variaciones que se observan en el contexto de esas constantes no son, sin embargo, despreciables. En el caso de la gente de México, destaca el hecho de que existe un crecimiento de la importancia de compatriotas, tanto como patrones como en calidad de compañeros de trabajo; sobre todo a lo largo del desarrollo de los eventos de las trayectorias laborales. Un elemento que diferencia las trayectorias de hombres y mujeres debe ser destacado, sobre todo a la luz de lo que se verá en el siguiente capítulo. Se refiere al hecho de que los hombre tienden a trabajar en mayor medida que las mujeres con personas de orígenes diversos. Como se verá, eso habla de un proceso de diferenciación del capital social de ambos grupos (más lazos débiles en el caso de los hombres).

La inserción y permanencia de la migración mexicana en los nichos de mercado señalados, permite detectar una presencia importante de los esquemas de segregación social como una de las instituciones importantes en la estructuración de las trayectorias laborales de quienes conforman dicha migración. No es que sea imposible encontrar trabajo fuera de esos nichos; sí es muy improbable, sobre todo al inicio de las trayectorias; pero también a lo largo de ellas. Ahora bien, cabe preguntarse como algo fundamental ¿por qué se da la inserción y permanencia en el mercado de trabajo en esos términos?. Por supuesto que no basta con que las condiciones estructurales del mercado laboral lo permitan, debido al proceso histórico de renovación cíclica de esos nichos para migrantes. La acción de otra institución social estructurante, la de las redes de relaciones sociales, juega un papel de primer orden en la explicación.

Esto se podrá observar a través del análisis de los mecanismos específicos que la gente utiliza para informarse acerca de los trabajos y de las posibilidades mismas de migrar, así como de las formas en que la población mexicana migrante se engancha efectivamente en el trabajo en la zona de Nueva York. Ello, junto con el análisis de las razones que llevan a quienes migraron a hacerlo, para después regresar a México y más adelante volver a irse a los Estados Unidos, para nuevamente (y sin saber nunca si es en definitiva) regresar a los 
lugares de origen; con los cuales se ha mantenido una permanente relación simbólica y material (a través de las remesas, por ejemplo, pero no solamente). 
ORIGEN DEL PATRÓN

Hombres (1er. Trabajo en E. U. A.)

\begin{tabular}{|c|r|r|r|r|r|r|r|}
\hline Cohorte & $\begin{array}{c}\text { De la misma } \\
\text { comunidad }\end{array}$ & $\begin{array}{c}\text { De la misma } \\
\text { región de } \\
\text { origen }\end{array}$ & $\begin{array}{c}\text { De } \\
\text { México }\end{array}$ & $\begin{array}{c}\text { De } \\
\text { América } \\
\text { Latina }\end{array}$ & $\begin{array}{c}\text { Inmigrantes } \\
\text { de otros } \\
\text { origenes }\end{array}$ & $\begin{array}{c}\text { Afro- } \\
\text { americanos }\end{array}$ & $\begin{array}{c}\text { Norte- } \\
\text { americanos } \\
\text { anglos }\end{array}$ \\
\hline Hasta 1983 & 4.80 & 4.80 & 1.60 & 3.20 & 53.20 & 0.00 & 32.30 \\
\hline De 1984 a 1988 & 2.90 & 2.90 & 7.40 & 13.20 & 48.50 & 0.00 & 25.00 \\
\hline De 1989 a 1993 & 1.90 & 1.90 & 4.20 & 9.00 & 63.70 & 3.30 & 16.00 \\
\hline $\begin{array}{c}\text { De 1994 en } \\
\text { adelante }\end{array}$ & 2.40 & 0.00 & 9.80 & 7.30 & 45.10 & 1.20 & 34.10 \\
\hline
\end{tabular}

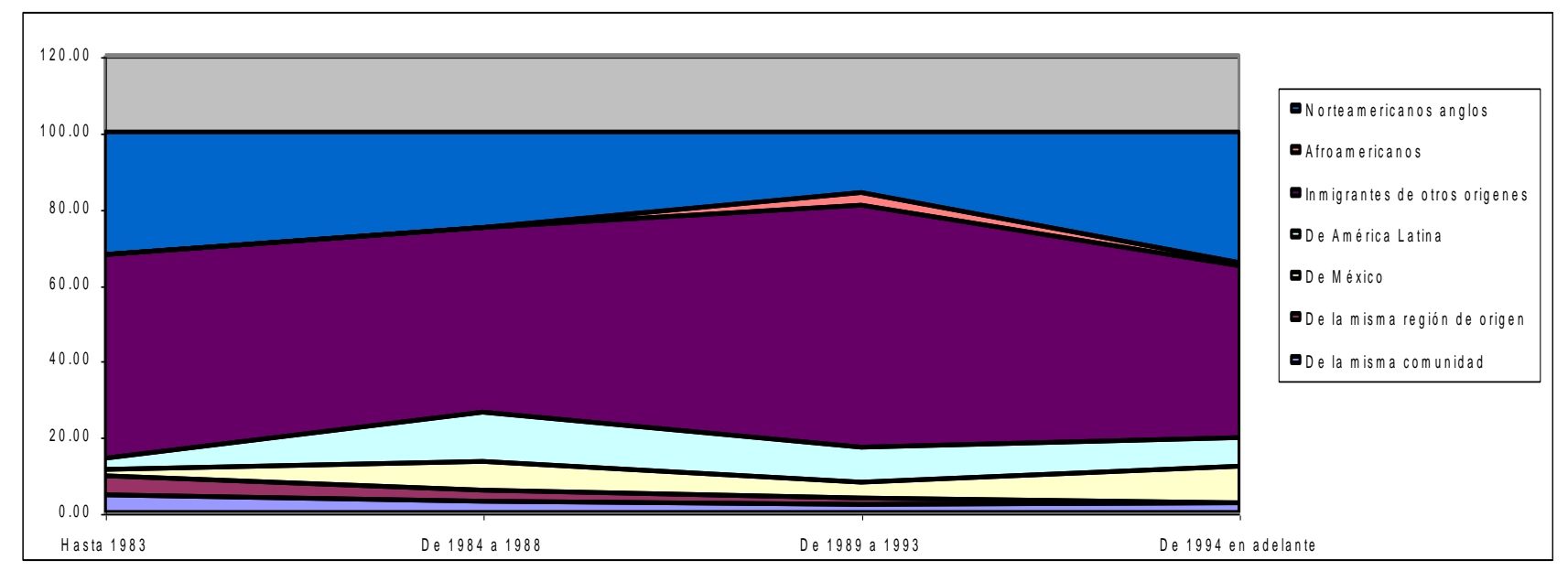

ORIGEN DEL PATRÓN

Mujeres (1er. Trabajo en E. U. A.)

\begin{tabular}{|c|r|r|r|r|r|r|c|}
\hline Cohorte & $\begin{array}{c}\text { De la } \\
\text { misma } \\
\text { comunidad }\end{array}$ & $\begin{array}{c}\text { De la misma } \\
\text { región de } \\
\text { origen }\end{array}$ & $\begin{array}{c}\text { De } \\
\text { México }\end{array}$ & $\begin{array}{c}\text { De } \\
\text { América } \\
\text { Latina }\end{array}$ & $\begin{array}{c}\text { Inmigrantes } \\
\text { de otros } \\
\text { orígenes }\end{array}$ & $\begin{array}{c}\text { Afro- } \\
\text { americanos }\end{array}$ & $\begin{array}{c}\text { Norte- } \\
\text { americanos } \\
\text { anglos }\end{array}$ \\
\hline Hasta 1983 & 0.00 & 0.00 & 0.00 & 20.00 & 60.00 & 0.00 & 20.00 \\
\hline De 1984 a 1988 & 8.00 & 0.00 & 16.00 & 4.00 & 44.00 & 4.00 & 24.00 \\
\hline De 1989 a 1993 & 1.80 & 0.00 & 5.50 & 12.70 & 65.50 & 0.00 & 14.50 \\
\hline $\begin{array}{c}\text { De 1994 en } \\
\text { adelante }\end{array}$ & 12.10 & 0.00 & 9.10 & 15.20 & 48.50 & 3.00 & 12.10 \\
\hline
\end{tabular}

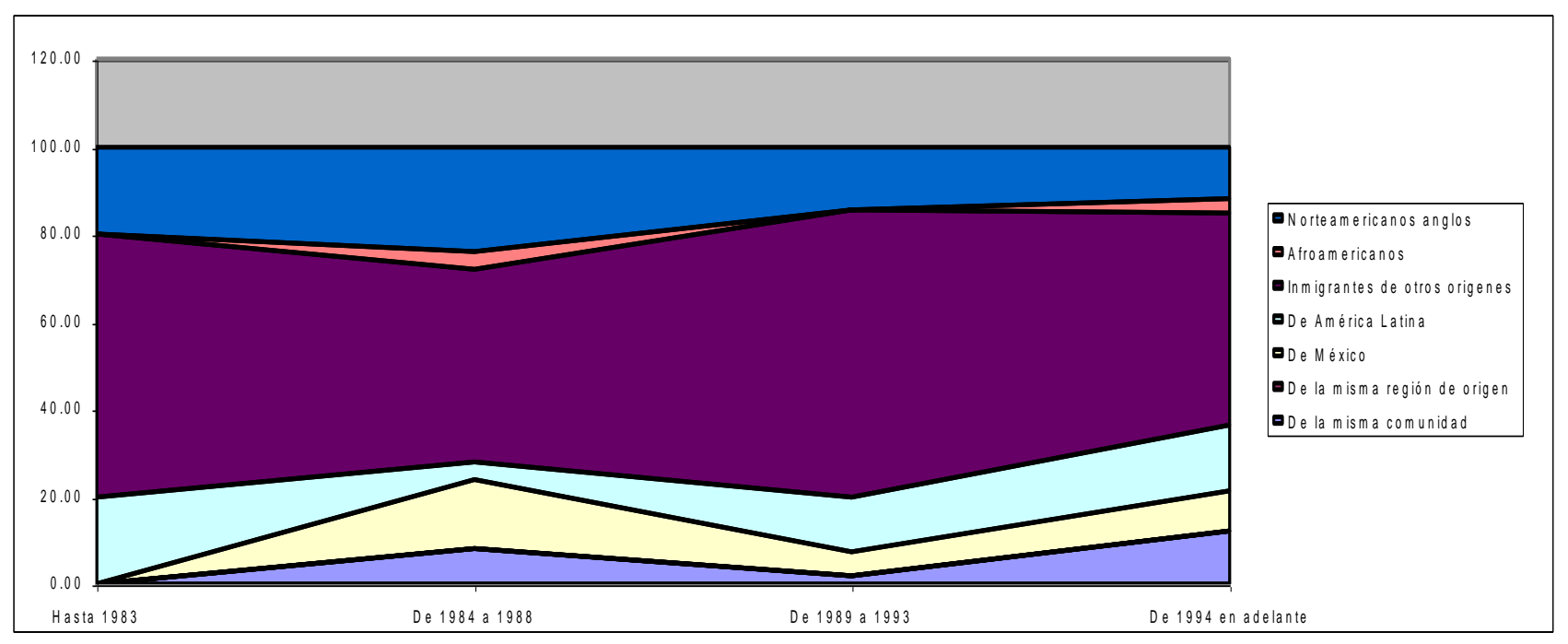


RELACIÓN CON EL PATRÓN

Hombres (1er. Trabajo en E. U. A.)

\begin{tabular}{|c|r|r|r|r|}
\hline Cohorte & Familia & \multicolumn{1}{c|}{ Amistades } & \multicolumn{1}{c|}{ Ninguna } & \multicolumn{1}{c|}{ Medios/mercado } \\
\hline Hasta 1983 & 8.10 & 12.90 & 75.80 & 3.20 \\
\hline De 1984 a 1988 & 5.80 & 8.70 & 85.50 & 0.00 \\
\hline De 1989 a 1993 & 2.40 & 5.70 & 90.00 & 1.90 \\
\hline De 1994 en adelante & 4.90 & 6.10 & 87.80 & 1.20 \\
\hline
\end{tabular}

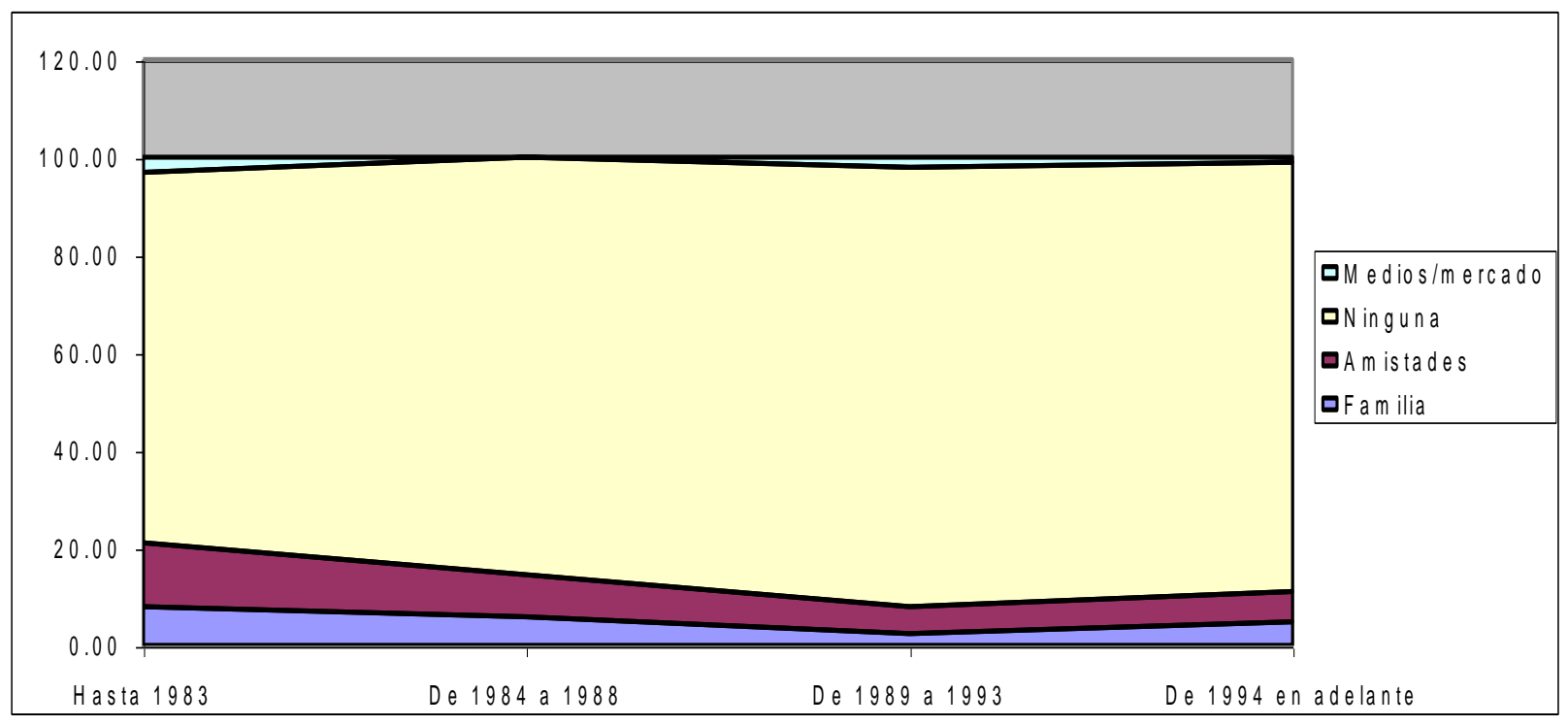

RELACIÓN CON EL PATRÓN

Mujeres (1er. Trabajo en E. U. A.)

\begin{tabular}{|c|r|r|r|r|}
\hline Cohorte & \multicolumn{1}{|c|}{ Familia } & Amistades & Ninguna & Medios/mercado \\
\hline Hasta 1983 & 7.10 & 7.10 & 78.60 & 7.10 \\
\hline De 1984 a 1988 & 12.50 & 16.70 & 70.80 & 0.00 \\
\hline De 1989 a 1993 & 8.20 & 3.60 & 87.30 & 0.90 \\
\hline De 1994 en adelante & 20.60 & 2.90 & 76.50 & 0.00 \\
\hline
\end{tabular}

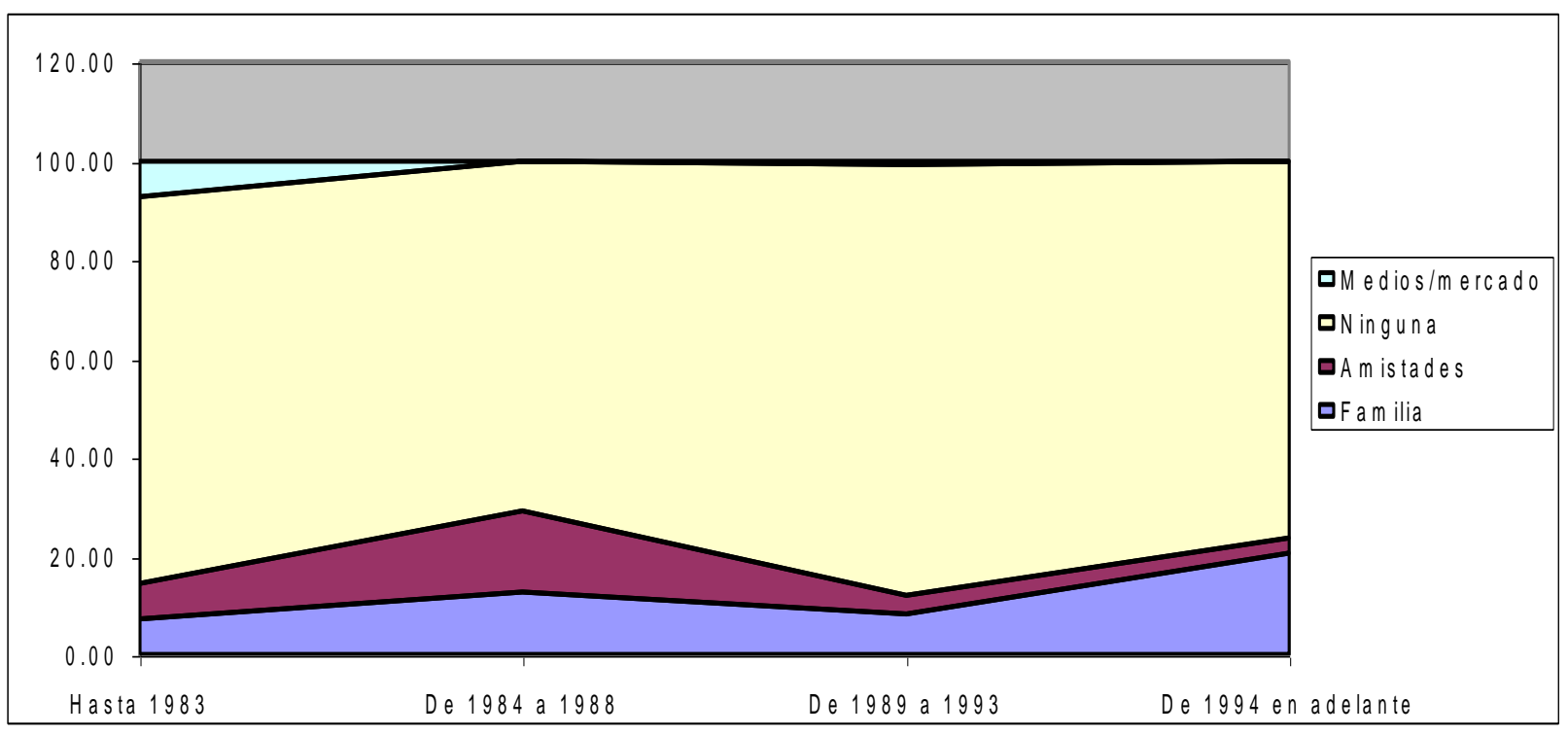


COMPAÑEROS DE TRABAJO

Hombres (1er. Trabajo en E. U. A.)

\begin{tabular}{|c|r|r|r|r|r|r|}
\hline Cohorte & $\begin{array}{c}\text { De la misma } \\
\text { comunidad }\end{array}$ & $\begin{array}{c}\text { De la misma } \\
\text { Región }\end{array}$ & $\begin{array}{c}\text { De } \\
\text { México }\end{array}$ & $\begin{array}{c}\text { De América } \\
\text { Latina }\end{array}$ & $\begin{array}{c}\text { Inmigrantes } \\
\text { de otros origenes }\end{array}$ & De EUA. \\
\hline Hasta 1983 & 7.70 & 12.30 & 29.20 & 23.10 & 23.10 & 4.60 \\
\hline De 1984 a 1988 & 6.00 & 10.40 & 25.40 & 38.80 & 17.90 & 1.50 \\
\hline De 1989 a 1993 & 2.40 & 3.30 & 22.90 & 43.30 & 25.70 & 2.40 \\
\hline $\begin{array}{c}\text { De 1994 en } \\
\text { adelante }\end{array}$ & 1.30 & 1.30 & 40.00 & 45.00 & 11.30 & 1.30 \\
\hline
\end{tabular}

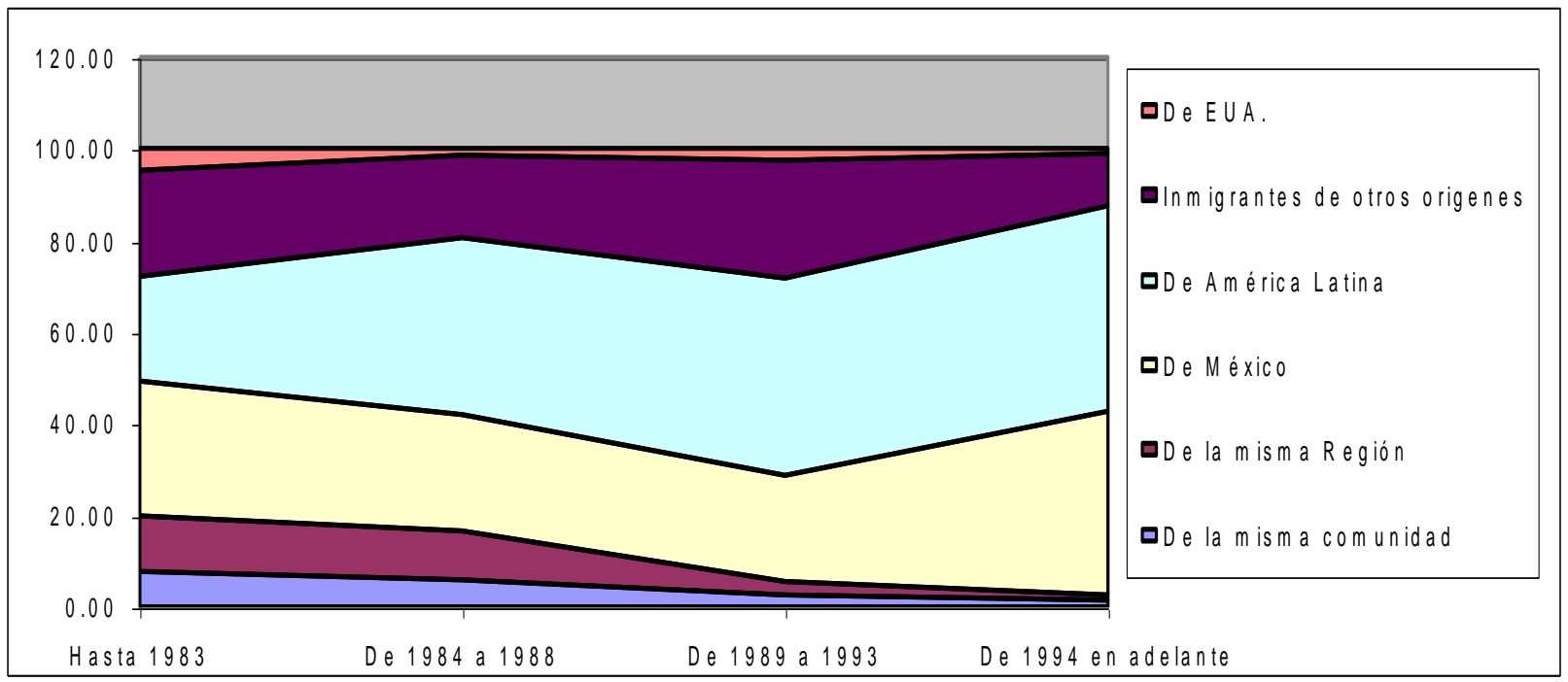

COMPAÑEROS DE TRABAJO

Mujeres (1er. Trabajo en E. U. A.)

\begin{tabular}{|c|r|r|r|r|r|r|}
\hline Cohorte & $\begin{array}{c}\text { De la misma } \\
\text { comunidad }\end{array}$ & $\begin{array}{c}\text { De la misma } \\
\text { Región }\end{array}$ & $\begin{array}{c}\text { De } \\
\text { México }\end{array}$ & $\begin{array}{c}\text { De América } \\
\text { Latina }\end{array}$ & $\begin{array}{c}\text { Inmigrantes } \\
\text { de otros origenes }\end{array}$ & De EUA. \\
\hline Hasta 1983 & 14.30 & 7.10 & 14.30 & 37.50 & 28.60 & 0.00 \\
\hline De 1984 a 1988 & 4.50 & 18.20 & 31.80 & 22.50 & 22.70 & 0.00 \\
\hline De 1989 a 1993 & 2.00 & 4.90 & 22.50 & 40.20 & 29.40 & 1.00 \\
\hline De 1994 en adelante & 8.00 & 4.00 & 24.00 & 32.00 & 24.00 & 8.00 \\
\hline
\end{tabular}

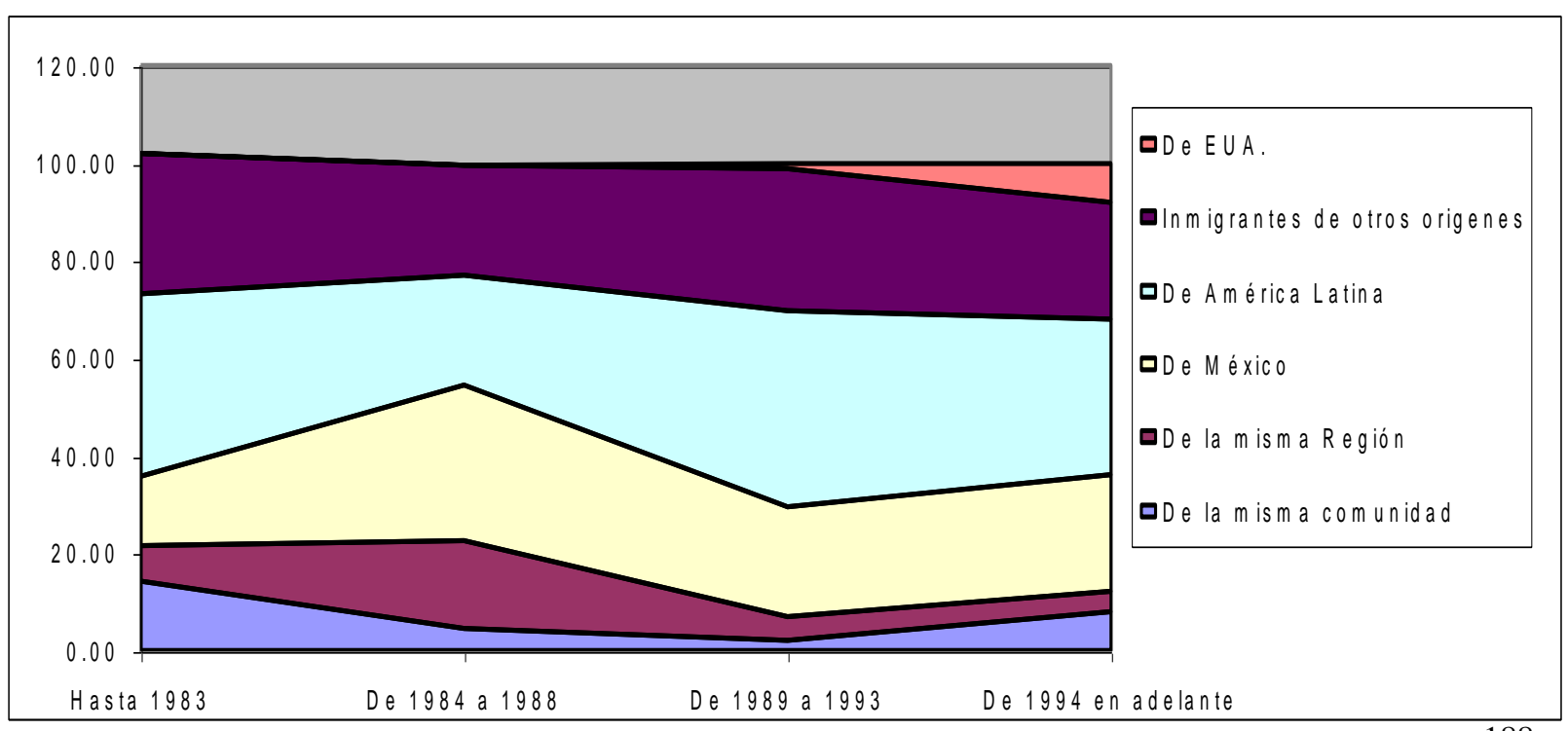


Propietario: origen étnico-nacional para la TL en EUA (mujeres)\%:

\begin{tabular}{|c|c|c|c|c|c|}
\hline Propiet./Evento & 19 & 29 & $3 ?$ & $4 !$ & $5 \div y+$ \\
\hline De la comunidad & 4.40 & 1.00 & 0.00 & 0.00 & 3.80 \\
\hline No de la comun. de la M ixt. & 0.00 & 1.00 & 2.70 & 6.70 & 3.80 \\
\hline No de la M ixt.de Méx. & 7.10 & 5.10 & 2.70 & 0.00 & 15.40 \\
\hline No de Méx.de AL & 12.60 & 4.10 & 8.10 & 13.30 & 3.80 \\
\hline No de AL pero inm igr. & 59.00 & 68.40 & 62.20 & 40.00 & 34.70 \\
\hline De EUA "blanco" & 15.80 & 18.40 & 24.30 & 40.00 & 30.80 \\
\hline De EUA "negro" & 1.10 & 2.00 & 0.00 & 0.00 & 7.70 \\
\hline Total & 100.00 & 100.00 & 100.00 & 100.00 & 100.00 \\
\hline N & 200 & 116 & 45 & 21 & 33 \\
\hline
\end{tabular}

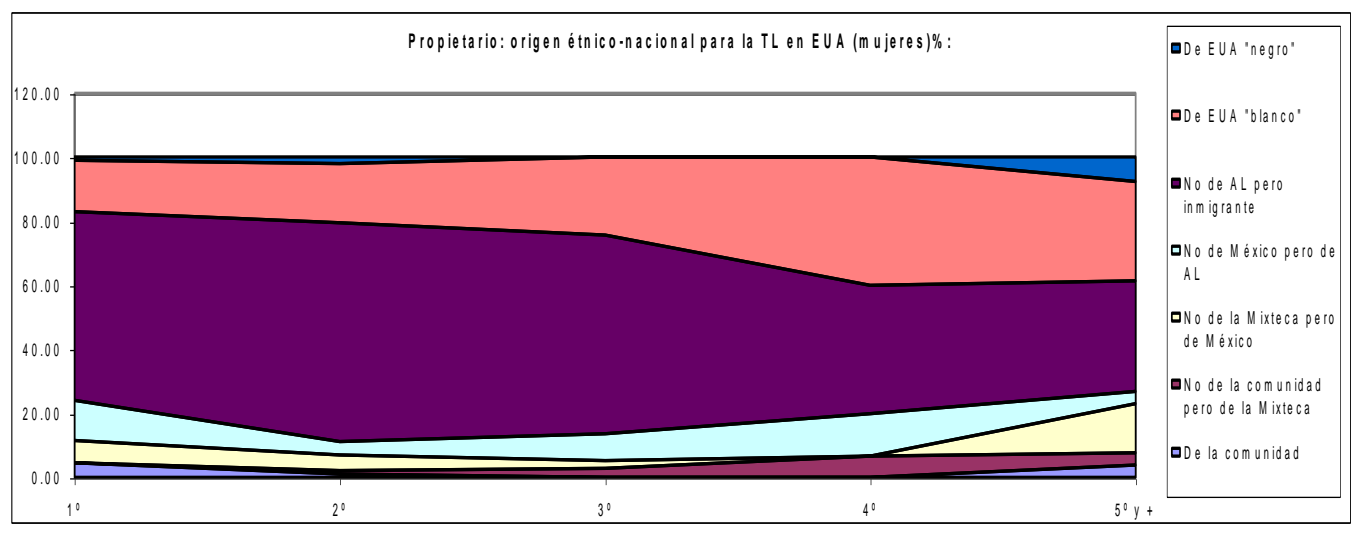

Propietario: origen étnico.nacional para la TL en EUA (hombres $1 \%$ :

\begin{tabular}{|c|c|c|c|c|c|}
\hline Propiet./Evento & $1 !$ & $2 !$ & $3 !$ & $4 !$ & $5 ? y+$ \\
\hline De la comunidad & 2.60 & 2.30 & 0.90 & 1.70 & 0.00 \\
\hline No de la com un. de la M ixt. & 2.10 & 0.80 & 0.00 & 1.70 & 0.00 \\
\hline No de la M ixt. de Méx. & 5.40 & 2.30 & 4.50 & 3.30 & 4.50 \\
\hline No de Méx. de AL & 8.50 & 9.40 & 8.10 & 10.00 & 6.00 \\
\hline No de AL pero inm igr. & 56.20 & 62.20 & 64.00 & 63.30 & 65.60 \\
\hline De EUA "blanco" & 23.30 & 20.70 & 21.60 & 20.00 & 23.90 \\
\hline De EUA "negro" & 1.90 & 2.30 & 0.90 & 0.00 & 0.00 \\
\hline Total & 100.00 & 100.00 & 100.00 & 100.00 & 100.00 \\
\hline$N$ & 448 & 277 & 118 & 68 & 74 \\
\hline
\end{tabular}

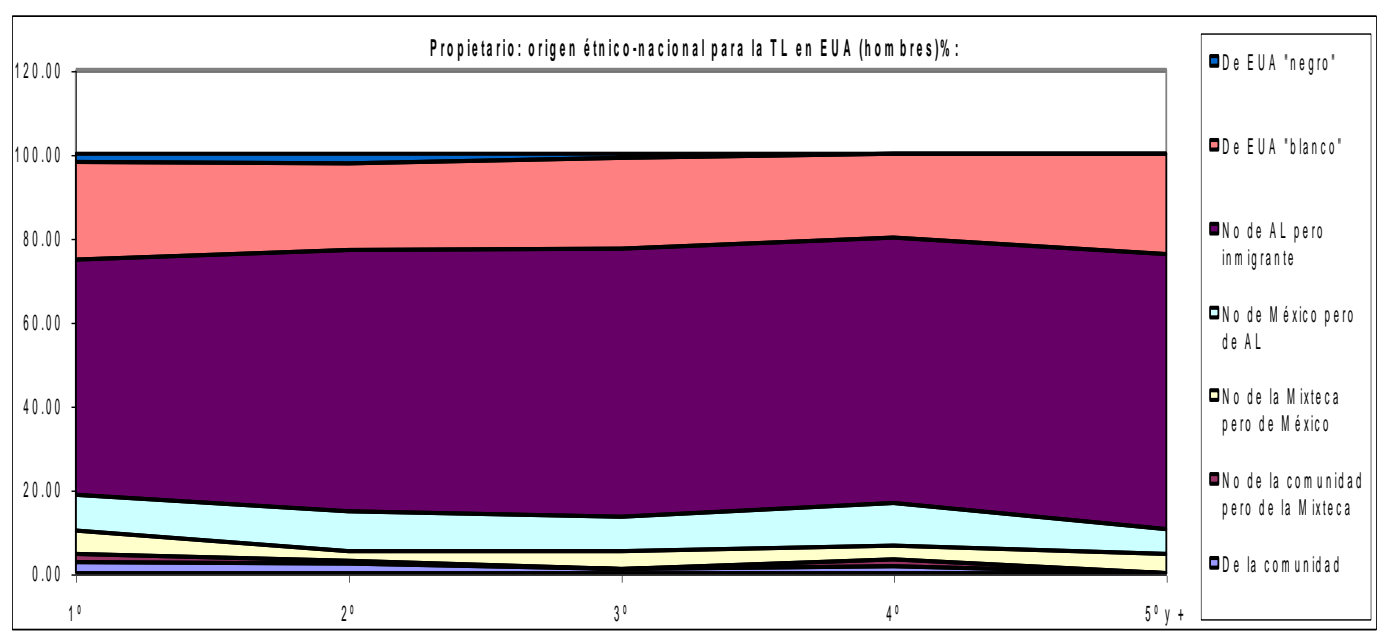


Status migratorio de la TL en EUA (mujeres)\%:

\begin{tabular}{|c|r|r|r|r|r|}
\hline Status/Evento & \multicolumn{1}{|c|}{$1^{?}$} & \multicolumn{1}{c|}{$2^{\circ}$} & \multicolumn{1}{c|}{$3^{?}$} & \multicolumn{1}{c|}{$4^{?}$} & $5^{\circ} \mathrm{y}+$ \\
\hline Indocumentado & 92.2 & 88.90 & 85.30 & 80.00 & 60.80 \\
\hline Turista & 4.2 & 2.80 & 0.00 & 0.00 & 0.00 \\
\hline Perm iso & 2.6 & 4.60 & 4.90 & 15.00 & 7.10 \\
\hline Residente & 0.5 & 3.70 & 9.80 & 5.00 & 32.10 \\
\hline Nacido en E.U. & 0.5 & 0.00 & 0.00 & 0.00 & 0.00 \\
\hline Total & 99.50 & 100.00 & 100.00 & 100.00 & 100.00 \\
\hline N & \multicolumn{1}{|c|}{200} & 116 & 45 & 21 & \multicolumn{1}{c|}{33} \\
\hline
\end{tabular}

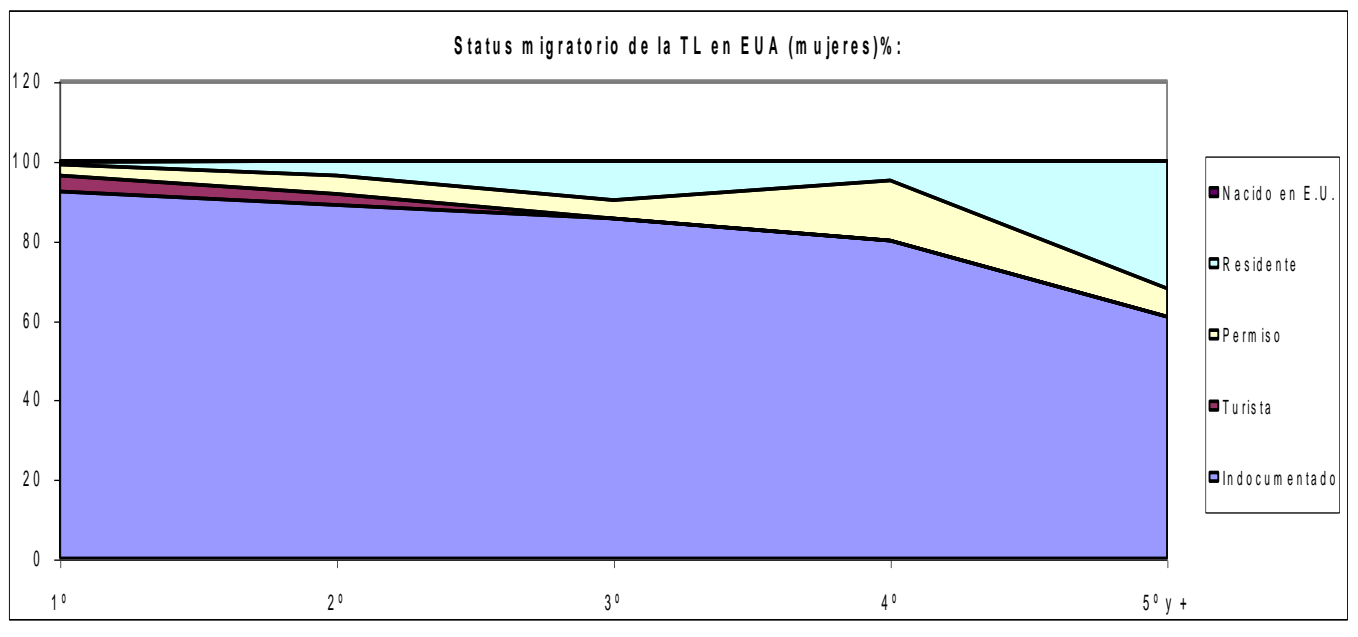


Status migratorio de la TL en EUA (hombres $) \%$ :

\begin{tabular}{|c|c|c|c|c|c|}
\hline Status/Evento & $1 ?$ & $2 !$ & $3 !$ & $4 !$ & $5 \div y+$ \\
\hline Indocumentado & 92.40 & 87.20 & 87.10 & 83.00 & 83.30 \\
\hline Turista & 1.60 & 1.90 & 4.30 & 0.00 & 4.80 \\
\hline Perm iso & 3.20 & 4.50 & 0.00 & 6.20 & 3.93 \\
\hline Residente & 2.10 & 4.90 & 6.90 & 10.80 & 7.10 \\
\hline Nacionalizado & 0.50 & 1.10 & 1.70 & 0.00 & 0.87 \\
\hline Nacido en E.U. & 0.20 & 0.40 & 0.00 & 0.00 & 0.00 \\
\hline Total & 100.00 & 100.00 & 100.00 & 100.00 & 100.00 \\
\hline $\mathrm{N}$ & 448 & 277 & 118 & 68 & 74 \\
\hline
\end{tabular}

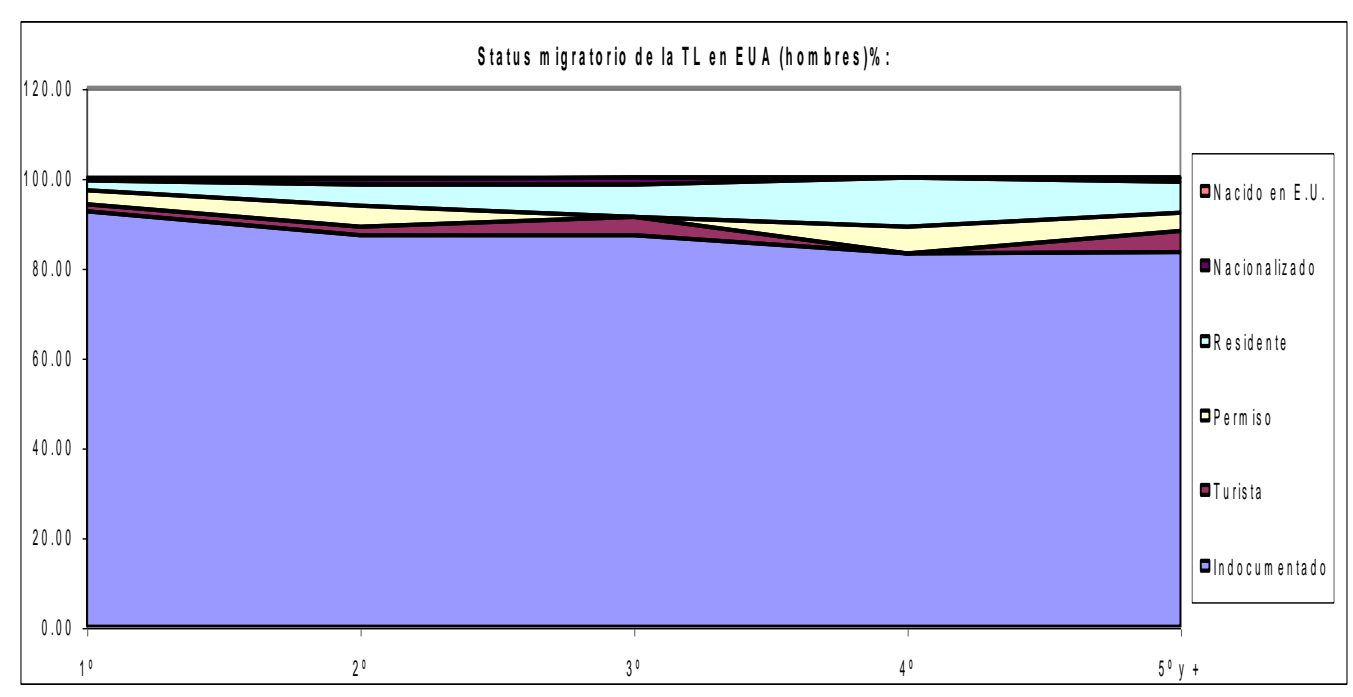


Relación con patrón de la TL en EUA (mujeres)\%:

\begin{tabular}{|c|c|c|c|c|c|}
\hline Relac./Evento & $1 ?$ & $2 ?$ & $3 !$ & $4 \stackrel{2}{4}$ & $5 \div y+$ \\
\hline Fam iliares & 11.00 & 3.20 & 2.60 & 6.70 & 9.10 \\
\hline Am igos & 5.50 & 4.30 & 5.10 & 0.00 & 13.60 \\
\hline Medios/mercado & 1.10 & 0.00 & 2.60 & 6.70 & 4.50 \\
\hline $\mathrm{Nadie}$ & 82.40 & 92.50 & 89.70 & 86.60 & 72.80 \\
\hline Total & 100.00 & 100.00 & 100.00 & 100.00 & 100.00 \\
\hline $\mathrm{N}$ & 200 & 116 & 45 & 21 & 33 \\
\hline
\end{tabular}

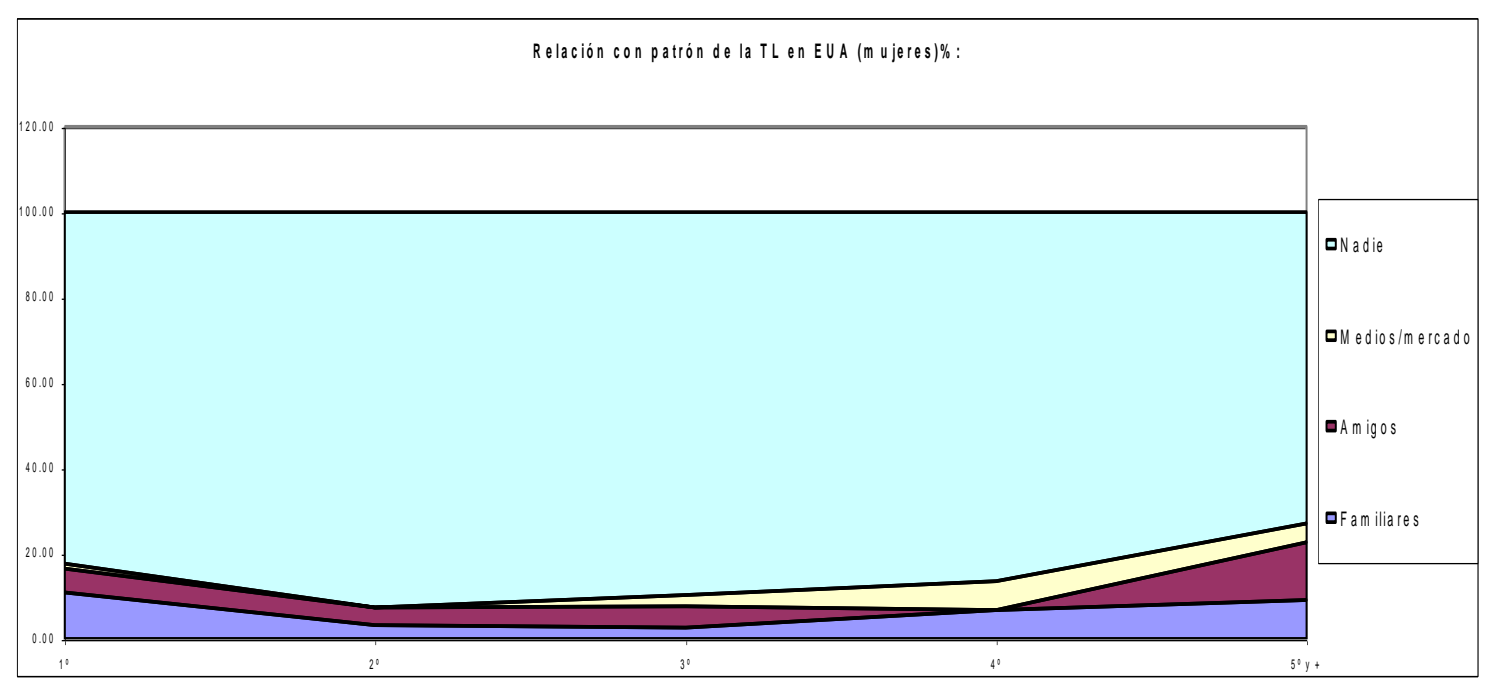

Relación con patrón de la TL en EUA (hombres)\%:

\begin{tabular}{|c|c|c|c|c|c|}
\hline Relac. Evento & $1^{\circ}$ & $2 ?$ & $3 ?$ & $4 ?$ & $5 \div y+$ \\
\hline Fam iliares & 4.20 & 2.80 & 3.70 & 1.80 & 0.97 \\
\hline Am igos & 7.30 & 11.00 & 13.90 & 21.10 & 18.90 \\
\hline Medios/mercado & 1.70 & 2.00 & 0.90 & 3.50 & 0.00 \\
\hline Nadie & 86.80 & 84.20 & 81.50 & 73.60 & 80.13 \\
\hline Total & 100.00 & 100.00 & 100.00 & 100.00 & 100.00 \\
\hline $\mathrm{N}$ & 448 & 277 & 118 & 68 & 74 \\
\hline
\end{tabular}

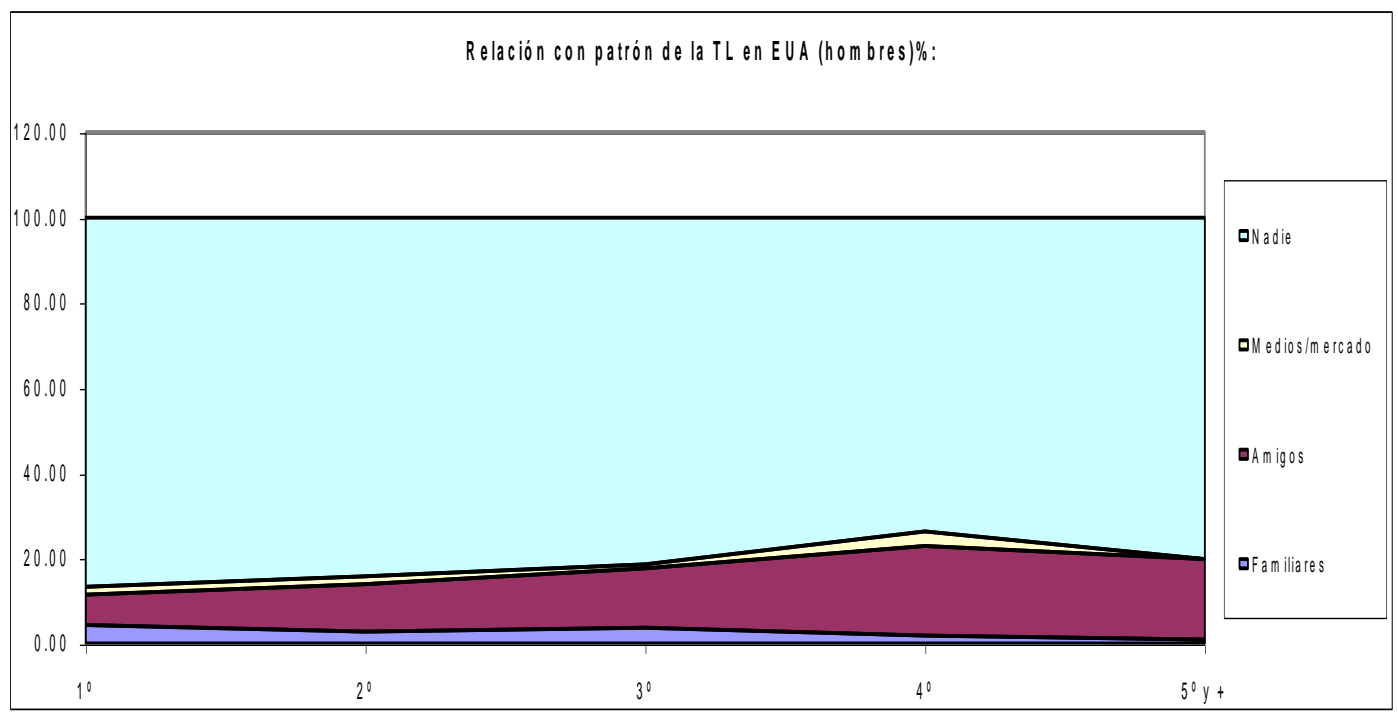


Compañeros de trabajo de la TL en EUA (mujeres)\%:

\begin{tabular}{|c|c|c|c|c|c|}
\hline Compañ./Evento & $1^{9}$ & $2 !$ & $3 \div$ & $4 ?$ & $5 \div y+$ \\
\hline De comunidad & 4.30 & 5.60 & 5.60 & 13.30 & 9.50 \\
\hline De región & 6.70 & 3.40 & 8.30 & 6.70 & 14.30 \\
\hline De México & 23.30 & 25.80 & 19.40 & 26.70 & 28.60 \\
\hline Latinos & 36.30 & 36.00 & 36.10 & 33.30 & 28.60 \\
\hline Otros inm igrant. & 27.60 & 28.10 & 25.00 & 20.00 & 19.00 \\
\hline DeEEUU & 1.80 & 1.10 & 5.60 & 0.00 & 0.00 \\
\hline Total & 100.00 & 100.00 & 100.00 & 100.00 & 100.00 \\
\hline $\mathrm{N}$ & 200 & 116 & 45 & 21 & 33 \\
\hline
\end{tabular}

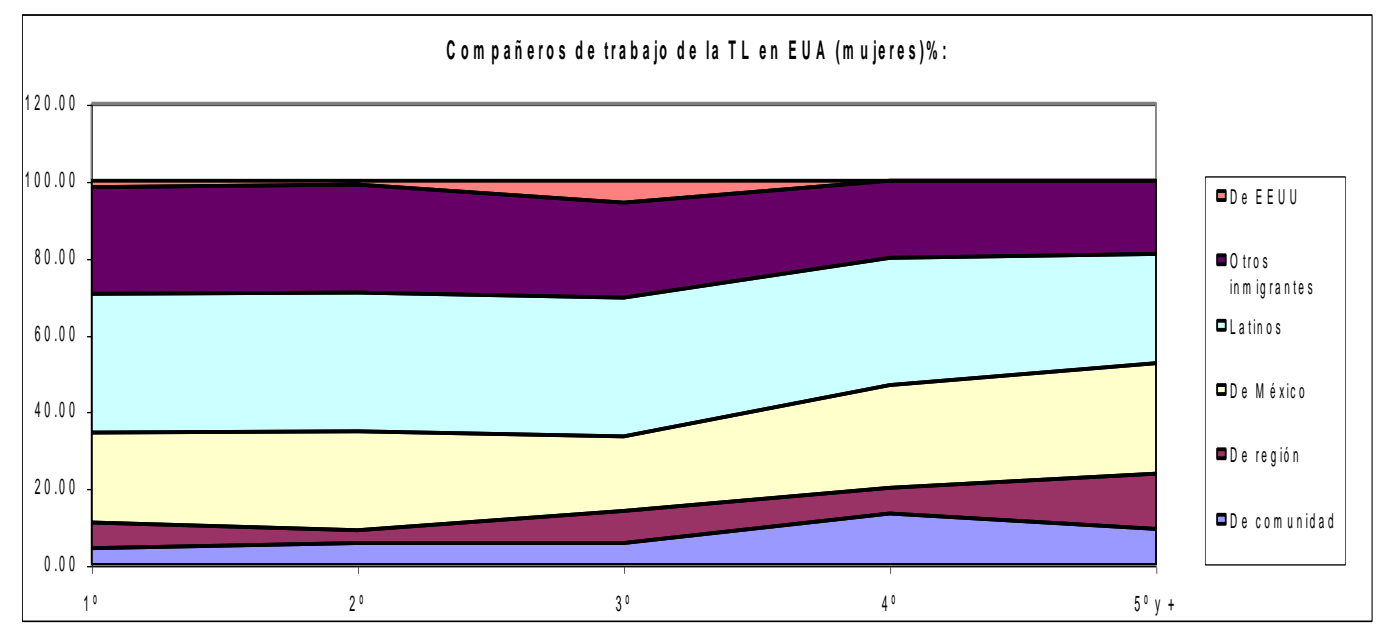

Compañeros de trabajo de la TL en EUA (hombres)\%:

\begin{tabular}{|c|r|r|r|r|r|}
\hline Compañ./Evento & \multicolumn{1}{|c|}{$1^{?}$} & \multicolumn{1}{c|}{$2^{?}$} & \multicolumn{1}{c|}{$3^{?}$} & \multicolumn{1}{c|}{$4^{?}$} & \multicolumn{1}{c|}{$5^{?} \mathrm{y}+$} \\
\hline De comunidad & 3.60 & 5.00 & 2.70 & 3.40 & 4.17 \\
\hline De región & 5.50 & 3.50 & 6.30 & 1.70 & 4.17 \\
\hline De México & 27.50 & 22.80 & 29.50 & 32.80 & 29.93 \\
\hline Latinos & 39.70 & 37.80 & 34.70 & 34.50 & 26.87 \\
\hline Otros inm igrant. & 21.30 & 24.70 & 21.40 & 20.70 & 31.53 \\
\hline De EEUU & 2.40 & 6.20 & 5.40 & 6.90 & 3.33 \\
\hline Total & 100.00 & 100.00 & 100.00 & 100.00 & 100.00 \\
\hline N & \multicolumn{1}{|c|}{448} & 277 & 118 & 68 & 74 \\
\hline
\end{tabular}

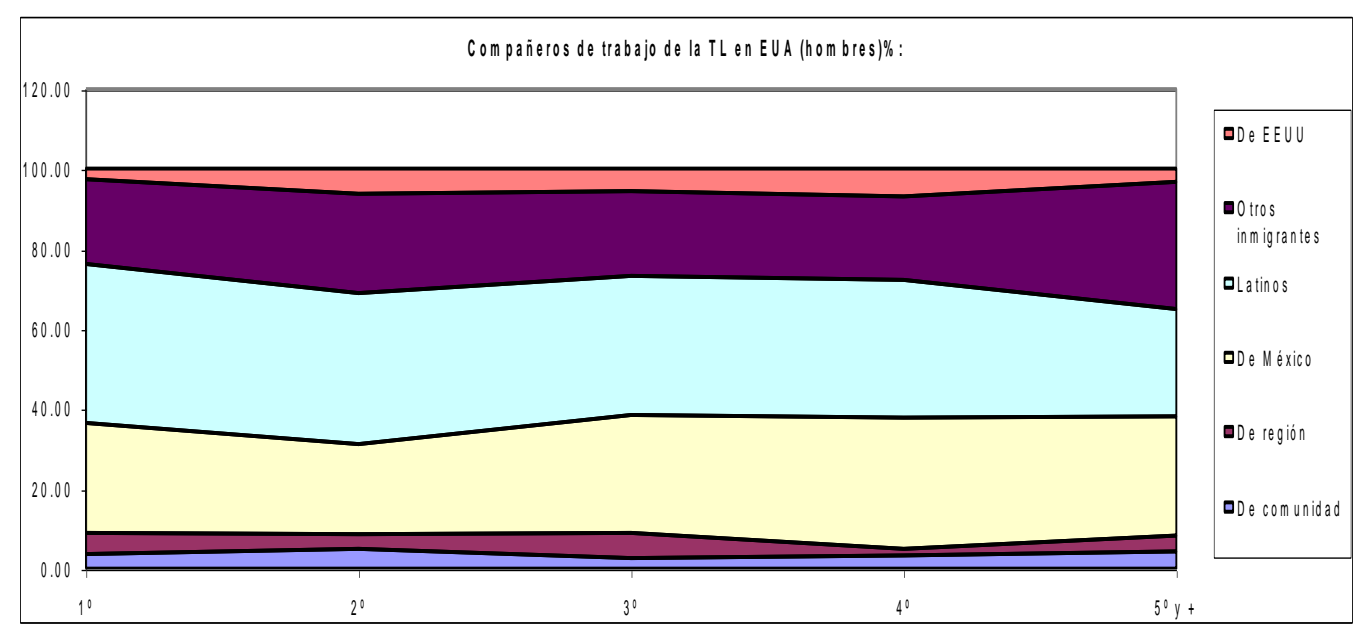




\section{LA ESTRUCTURACION SOCIAL DE LAS TRAYECTORIAS LABORALES}

\section{INTRODUCCION}

En el capítulo anterior se vio la forma en que la migración mexicana a Nueva York y sus alrededores se insertó, desde su llegada, y se desempeñó a lo largo de las trayectorias laborales, en sectores especificos del mercado de trabajo, que pueden ser definidos como nichos de mercado socialmente etiquetados como propios de migrantes recientes. Junto con las fuerzas del mercado, resultó evidente la acción estructuradora de la institución social relacionada con los diversos esquemas de segregación construidos socialmente.

En especial, los formas de discriminación en contra de las personas inmigrantes, que contienen fuertes elementos etnicos y raciales, se mostraron como un elemento muy relevante en la explicación de la inserción de la migración mexicana en nichos de mercado caracterizados por la baja calificación, la precariedad, los bajos salarios y las jornadas prolongadas. Adicionalmente, fue posible observar también una diferenciación, ya presente en el análisis inicial sobre su ubicación sectorial y ramal, entre los agregados femenino y masculino; lo cual habla de la presencia complementaria de otrra manifestación de los mencionados esquemas de segregación, en este caso basada en la diferencia sexual. Tal vez pueda hablarse de que en estos nichos de mercado existe una especie de sobredeterminación de la acción de los mecanismos de segregación sobre el resto de las instituciones actuantes en la estructuración de las trayectorias laborales.

Una vez establecido lo anterior, se trata ahora de ver con qué elementos contaron quienes migraron para desempeñarse en esos nichos específicos del mercado de trabajo de la zona de Nueva York, para trasladarse hasta su nueva ubicación y empleo, para informarse acerca de él, para ingresar a él y para resolver sus necesidades de alojamiento en una nueva ciudad, ajena y distante de la localidad de origen; en trabajos que, en la inmensa mayoría de los casos, poco o nada tenían que ver con sus antiguas ocupaciones. Lo anterior, desde que decidieron por primera vez a ir los Estados Unidos; hasta el momento en que las personas fueron captadas en nuestra encuesta; pasando por todos los cambios de empleo -y, por supuesto, por periodos de desempleo- y de país que se registran en sus trayectorias laborales. 
Se trata, también, de observar el mantenimiento de los vínculos permanentes con los lugares de origen, cuando los eventos se realizan en los Estados Unidos, a través del envío de remesas de dinero; y con la zona de Nueva York, cuando los eventos se realizan en México, pero se conserva allá a parte de la familia y de las amistades cercanas, incluidas aquellas que se hicieron durante la estancia en los Estados Unidos y que pertenecen a otras redes sociales, con las cuales se enriqueció su capital social.

Y se trata, finalmente, de ver cuáles son las razones que llevan a las personas a abandonar los trabajos, especialmente cuando esta decisión implica un cambio de país, así como de analizar si esas decisiones son tomadas sólo por la persona, o bien si en ellas intervienen agentes de las distintas instituciones estructurantes.

El interés que mueve este análisis, se refiere directamente al objetivo central de la tesis, que consiste en ubicar la forma en que las diversas instituciones sociales intervienen en la estructuración de las trayectorias laborales. Aparte de la segregación de quienes conforman las migraciones recientes y del componente de género: ¿qué instituciones sociales intervienen en la estructuración de las trayectorias laborales dentro de esos nichos de mercado, en la zona de Nueva York, incluso para impedir o dificultar la salida de ellos hacia otras zones más favorables del propio mercado de trabajo?. Y en el regreso o los regresos a México: ¿qué instituciones actuan para operar dentro de las trayectorias laborales rupturas ocupacionales tan fuertes como las que pueden detectarse?.

Si fueran solamente las fuerzas del mercado, actuando libremente, no se esperaría que las personas recurrieran a ningún tipo de ayuda para reponder a los retos planteados por el mercado de trabajo. Sus decisiones - migrar o no migrar, cambiar de trabajo o permanecer en el mismo- serían racionalmente maximizadoras; la información estaría disponible de manera homogénea para los actores; los costos de la búsqueda de empleo (translado, alojamiento, alimentación) serían cubiertos por los ahorros de las personas o a través de su endeudamiento en los circuitos financieros; el acceso al empleo estaría dado por mecanismos públicos e impersonales; y, en fin, la posición en el trabajo y el nivel salarial se determinarían por el capital humano de las personas. Cabe adelantar que este escenario aparece como muy lejano a la realidad en la que viven las personas migrantes de México a Nueva York. No obstante, a lo largo de las trayectorias laborales es posible 
detectar cómo, en algunos casos, los mecanismos de mercado son crecientemente utilizados por parte de la migración mexicana.

Si sólo fueran, en otro escenario típico ideal, los mecanismos de las redes de relaciones sociales los que actuaran, las personas obtendrían la información, la recomendación o incluso el reclutamiento, a través de los canales de las propias redes. De la misma manera, los costos de la búsqueda de trabajo serían cubiertos por familiares, amistades y personas conocidas, a través de mecanismos basados en la confianza mútua y la reciprocidad. Las decisiones importantes, a su vez, se tomarían en función de criterios ajenos a la maximización de la ganancia. Esto es, el capital social sería el que explicara el desempeño de las personas en el mercado de trabajo. Al observar el desempeño de las personas de México en la zona de Nueva York, parece evidente que las redes de relaciones sociales tienen un peso determinante en la estructuración de las trayectorias laborales. Sin embargo, debe estarse prevenido para no exagerar o incluso absolutizar su importancia. De hecho, ésta es cambiante a lo largo del tiempo, del espacio (por ejemplo, nacional) y del tipo de decisión o acción que se emprenda en el mercado de trabajo.

En un tercer escenario posible, la organización de la profesión o del oficio estructurarían trayectorias laborales en las que los canales de información y de reclutamiento, estarían directamente relacionados, ya sea con la existencia de organizaciones formales ligadas a los grupos profesionales o gremiales (e, incluso, legislaciones o reglamenteciones $a d$ hoc); o bien a la presencia de redes específicas de ese tipo de actores sociales. En general, se esperaría que las trayectorias laborales de este tipo mantuvieran una clara continuidad en el contenido de los trabajos que las personas desempeñaran, independientemente de los posibles cambios de empleo y de su duración. En los periodos de desmpleo, la existencia de agrupaciones profesionales o gremiales podría ayudar a financiar los costos de la búsqueda de un nuevo empleo. Una forma específica de capital social sería en este caso el recurso fundamental; pero ligado a otro más, cercano éste tanto al capital humano (conocimientos adquiridos, específicos de una profesión u oficio), como al capital cultural (en sus dos vertientes: formalizado, en la forma de credenciales por escolarización; y no formal, cercano al habitus). Aunque en el caso de la migración mexicana a la zona de Nueva York no se presenta de manera importante el caso de profesionales -ni de expertos artesanos- que vayan a los Estados Unidos a desempeñar su 
profesión u ofcio; sí se presenta con frecuencia el caso de personas que en el propio trabajo, sobre todo en las cocinas de los restaurantes, adquieren una formación que les permite mantener una considerable continuidad en una buena parte de su trayectoria laboral en Nueva York; así como adquirir contactos dentro del mundo de los restaurantes (de la gastronomía, muy especialmente). De tal manera que la institución relacionada con la organización de la profesión y, en estos casos, más específicamente del oficio, llega a jugar un papel de gran importancia en la estructuración de largos tramos de las trayectorias laborales de este grupo migrante.

Por último, estaría el escenario en el que la organización de la empresa fuera la institución estructurante de las trayectorias laborales. En este caso, la presencia de mercados internos de trabajo condicionaría que tanto la información sobre acensos (el reclutamiento a los puestos inferiores se haría en el mercado abierto externo), como los mecanismos de reclutamiento hacia los niveles superiores, se hiciera a través de mecanismos administrativos internos. Sería de esperar que las trayectorias laborales mostraran una gran permanencia dentro de la misma empresa o sus establecimientos, al tiempo que se esperaría una notoria movilidad ascendente. Incluso, los posibles periodos de inactividad podrían estar financiados por la propia empresa (por ejemplo, en la forma de pagos parciales por disminuciones temporales de la producción; o bien en la de pagos por liquidación, en el caso de despidos o recortes de personal). Los costos de posible traslados a otros establecimientos de la empresa, seguramente sería financiados por ésta. Una suerte de capital organizacional sería aquí el recurso fundamental para el desempeño en el mercado de trabajo. No parece fácil hacerse a la imagen de que la situación anterior puede estar presente en los nichos de mercado en los que se ha insertado la migración mexicana a Nueva York. Por el contrario, estos parecen ser el resultado más bien de un mercado en general segmentado, en donde el sector primario se ve como totalmente fuera del alcance de los migrantes recientes. En general, esa parece ser la situación. Esta institución estructurante de los mercados de trabajo, actúa en la zona de Nueva York como una especie de restricción estructural para los migrantes. Sin embargo, existen trabajos en los que se presentan situaciones similares a las de los mercados internos de trabajo. Al menos dos casos pueden servir de ejemplo. Uno, es el ya referido de los restaurantes. El otro, es el del servicio doméstico. En ambos, parece posible permanecer durante largos periodos y en 
situaciones que permiten ascensos moderados tanto en la posición en el trabajo, como en el nivel salarial.

Lo que cabe esperar, entonces, es una acción combinada y cambiante, en el tiempo y en el espacio, de las distintas instituciones sociales estructurantes de las trayectorias laborales. Sin embargo, es posible también esperar que alguna combinación de ellas pueda ser la dominente, el menos durante periodos considerables de las trayectorias y sobre grupos importantes de personas. Como ya se ha observado en el trabajo acumulado sobre procesos migratorios, dos instituciones aparecen como las más relevantes: las redes de relaciones sociales (y, sobre todo, las de tipo familiar y amistoso) y los esquemas de segregación. Estos últimos, se adelantaba ya en las conclusiones preliminares del capítulo anterior, parecen tener una gran importancia; al grado de que es posible verlos como la institución que sobredetermina la acción de las restantes instituciones sobre las trayectorias en la zona de Nueva York. En cuanto a las primeras, existen muchos indicios de que son la institución más relevante, para el desempeño de quienes migran en el mercado de trabajo neoyorquino, a partir de las condiciones estructurales dominantes; pero siempre en combinación con las restantes instituciones.

¿Es siempre la motivación de maximizar la ganancia económica la que lleva a abandonar un trabajo y, sobre todo, un país?; o ¿es la disposición de una amplia y completa información acerca de las condiciones coyunturales de los mercados de trabajo de los Estados Unidos y México la que lleva a la toma de decisiones?; o bien ¿será la pura nostalgia o sólo el campo de los afectos lo que lleva de regreso a los migrantes a México?. Por otro lado, y en relación con esas mismas redes sociales, cabe preguntarse si estas actúan siempre de la misma forma para una misma persona, con independencia del país, en el caso de quienes migran. O, más en general, si una misma composición de capital ocasiona que las personas se desempeñen de la misma forma y tomen las mismas decisiones en relación, por ejemplo, a permanecer en un trabajo más o menos seguro en Nueva York, o bien de regresar a México.

Emprender este análisis permitirá observar el papel cambiante que tiene la pertenencia a redes sociales de tipo familiar y amistoso (el capital social) para las decisiones que las personas toman en relación con los mercados de trabajo y la migración. Permitirá, igualmente, observar algo que los análisis sobre redes sociales y capital social 
han enfatizado (De la Rocha, Sassen, Granovetter) y que se refiere a las consecuencias duales e incluso contradictorias que la acción de las redes tiene sobre las personas en el mercado de trabajo. Por un lado, resultan ser una ayuda invaluable para obtener información acerca de posibles trabajos e incluso una vía excelente para obtener recomendaciones que facilitan grandemente el reclutamiento. Más allá de eso, en ocasiones se convierten por sí mismas en verdaderas vías de reclutamiento y en canales que posibilitan el ascenso laboral y la permanencia en el trabajo. Por el otro, sin embargo, pueden llegar a ser la explicación del enclaustramiento de las personas en nichos de trabajo de muy baja calidad, debido a la inexistencia de vínculos (lazos débiles) que conecten a sus redes con otras que puedan tener acceso a otros nichos del mercado de trabajo que cuenten con mejores condiciones. Esta baja calidad del capital social de los grupos sociales puede llevar también, en una variante de la situación anterior y sobre todo en contextos migratorios, a que incluso esos lazos débiles conecten únicamente con grupos sociales también relativamente enclaustrados, por ejemplo, en nichos de mercado etiquetados. Pero este análisis permitirá igualmente matizar y ubicar el peso de esta institución social fundamental, para no correr el riesgo de exagerar su peso relativo en la estructuración de las trayectorias.

\section{¿Cómo me voy y a dónde llego? o: no es lo mismo llegar solo que sólo tener que llegar} Una mano para irme...

Para trasladarse desde sus lugares de origen hasta su nueva ubicación en los Estados Unidos, y para alojarse en aquel lugar, quienes migraron por primera vez contaron sobre todo con la ayuda de sus familiares y amigos, lo que no resulta sorprendente a la luz de los hallazgos acumulados por trabajos de investigación realizados en muy diversos contextos de origen y de destino. Para el traslado, el 75.2\% del total declaró que había sido apoyada por su familia y el $22.7 \%$ por amigos; mientras que sólo el $2.1 \%$ dijo que no había recibido ayuda. Para el alojamiento en los Estados Unidos, el $75.1 \%$ fue ayudado por algún familiar y el $24.1 \%$ por sus amistades, y sólo el $0.8 \%$ no recibió ayuda.

Al comparar los porcentajes de mujeres y hombres, pese a la enorme importancia que en ambos casos tienen las redes familiares y amistosas, se pueden observar algunas diferencias dignas de ser mencionadas. Así, mientras que ninguna mujer dijo haberse 
trasladado sin ayuda, un 3.1\% de los hombres declaró haber iniciado su aventura migratoria sin apoyo. Mayor es la diferencia si se compara el peso relativo de familiares y amistades en cada caso. De esa forma, resulta que las mujeres tuvieron ayuda de la familia en un 87.2\% y los hombres de sólo el 69.7\% (27.2\% de personas amigas). Para el alojamiento, los porcentajes son prácticamente idénticos a los del traslado.

La importancia de lo familiar se mantiene a lo largo de las distintas cohortes ${ }^{48}$ (tabla \# 1). Para todas las personas, hombres y mujeres, la principal ayuda para trasladarse hasta el lugar de su nuevo trabajo en los Estados Unidos fue la familia y en segundo lugar su ubicaron las amistades. Sin embargo, el peso de la ayuda familiar es en todas las cohortes superior para las mujeres (casi en un 20\% superior frente a los hombres); así como la de las amistades lo es para los hombres (cuadros y gráficas \# 1 y 2). Cabe señalar, sin embargo, que en la última cohorte se aproximan considerablemente los porcentajes de ambos grupos, al disminuir para las mujeres el peso relativo de la familia y aumentar el de las amistades y al suceder lo contrario para los hombres; de tal suerte que los perfiles para uno y otro sexo muestran en esta cohorte más reciente una notoria semejanza entre sí.

En uno y otro caso, la importancia de otro tipo de ayudas (endeudamiento, apoyo de asociaciones no gubernamentales) fue siempre de menor relevancia. Salvo en la primera cohorte, que en ambos casos estuvo cerca del 20\%, su valor porcentual se ubicó entre el $5.6 \%$ y el $8 \%$, para las mujeres, y entre el $10.1 \%$ y casi el $13 \%$, para los hombres. Una diferencia importante radica en que mientras ninguna mujer se trasladó sin ayuda, y un porcentaje considerable de hombres sí lo hizo en la primera cohorte, en las siguientes, éstos casi han desaparecido; lo cual bien puede ser reflejo de un mayor capital social acumulado en general por los habitantes de los lugares de origen de la migración; así como de un mayor capital cultural acumulado por las redes sociales de los migrantes, traducido en un creciente conocimiento de las formas y de los recursos necesarios para la migración.

En las narraciones que se tienen grabadas, así como en las pláticas informales, todas las personas hablan de que el viaje se hace generalmente con personas conocidas de la misma localidad. Pero resulta interesante observar que sólo en el primero o en los primeros cruces ilegales a los Estados Unidos se hace necesario el pago a los polleros y coyotes. Más adelante, quienes ya han cruzado en estas condiciones la frontera, son capaces de ayudar al 
traslado de parientes, amistades y coterráneos; algunas veces recibiendo alguna retribución, en otras simplemente acrecentando las obligaciones no escritas ni mensurables en dinero que los familiares de las personas trasladadas adquieren.

48 En este caso, las cohortes consideradas son: 1) hasta 1983; 2) de 1984 a 1988; 3) de 1989 a 1993; y 4) de 1994 en adelante. 


\begin{tabular}{|c|c|c|}
\hline \multicolumn{3}{|c|}{$\begin{array}{c}\text { DISTRIBUCIÓN PORCENTUAL DE HOMBRES Y MUJERES, POR COHORTE Y } \\
\text { POR AYUDA PARA EL TRASLADO (primer trabajo en EUA) }\end{array}$} \\
\hline $\begin{array}{c}\text { Cohorte de ingreso al } \\
\text { mercado de trabajo en EUA }\end{array}$ & $\begin{array}{c}\text { Mujeres } \\
\% \text { del total por cohorte }\end{array}$ & $\begin{array}{c}\text { Hombres } \\
\% \text { del total por cohorte }\end{array}$ \\
\hline \multicolumn{3}{|l|}{ Familia } \\
\hline Hasta 1983 & 75.0 & 51.6 \\
\hline De 1984 a 1988 & 80.0 & 62.3 \\
\hline De 1989 a 1993 & 85.1 & 67.0 \\
\hline Desde 1994 en adelante & 75.0 & 63.5 \\
\hline \multicolumn{3}{|c|}{ Amistades } \\
\hline Hasta 1983 & 6.3 & 20.3 \\
\hline De 1984 a 1988 & 12.0 & 26.1 \\
\hline De 1989 a 1993 & 10.5 & 26.9 \\
\hline Desde 1994 en adelante & 19.4 & 21.2 \\
\hline \multicolumn{3}{|c|}{ Nadie } \\
\hline Hasta 1983 & 0 & 10.9 \\
\hline De 1984 a 1988 & 0 & 1.4 \\
\hline De 1989 a 1993 & 0 & 0.9 \\
\hline Desde 1994 en adelante & 0 & 2.4 \\
\hline \multicolumn{3}{|c|}{ Otros } \\
\hline Hasta 1983 & 18.8 & 17.2 \\
\hline De 1984 a 1988 & 8.0 & 10.1 \\
\hline De 1989 a 1993 & 4.4 & 5.2 \\
\hline Desde 1994 en adelante & 5.6 & 12.9 \\
\hline
\end{tabular}




\section{...y otra para alojarme}

En cuanto a la ayuda para alojarse al llegar a los Estados Unidos, destaca nuevamente en todas las cohortes (tabla \# 3) la importancia de los apoyos familiares y amistosos, si bien ahora éstos son aun mayores que con relación al traslado; y las personas que resolvieron el problema sin ayuda o bien por otros medios, son ahora considerablemente menos que en ese otro rubro. Otra vez cabe hacer resaltar la mayor participación de los lazos familiares en el caso de las mujeres (cuadro y gráfica \# 3) (el porcentaje correspondiente va de más de las tres cuartas partes a cerca de las nueve décimas), frente al de los hombres (cuadro y gráfica \# 4) (en que va de seis a siete décimas partes). A la inversa, para los hombres la ayuda amistosa oscila entre una cuarta parte y un tercio del total; y para las mujeres entre un $7 \%$ y una sexta parte. Los porcentajes de quienes se alojaron sin recibir ayuda son muy poco significativos y, salvo en la primera cohorte para los hombres, el resto de las ayudas también lo es. A diferencia del rubro anterior, en éste los perfiles por sexo no parecen estar tendiendo hacia la convergencia.

La solución del problema del alojamiento a través de familiares y amistades queda plásticamente ilustrado cuando se recorren los hogares de quienes han migrado a Nueva York y su zona aledaña. Resulta prácticamente imposible conocer a alguien que viva sin la compañía de otras personas de México. Más bien, en una enorme dispersión a lo largo de toda la zona metropolitana, generalmente en barrios en donde ya había personas que hablan español, lo más común es encontrar a la gente de México compartiendo los lugares de habitación con familiares, amistades o simples paisanos; muchas veces en condiciones de gran hacinamiento. 


\begin{tabular}{|c|c|c|}
\hline \multicolumn{3}{|c|}{$\begin{array}{c}\text { DISTRIBUCIÓN PORCENTUAL DE HOMBRES Y MUJERES, POR COHORTE Y } \\
\text { POR AYUDA PARA EL ALOJAMIENTO (primer trabajo en EUA) }\end{array}$} \\
\hline $\begin{array}{c}\text { Cohorte de ingreso al } \\
\text { mercado de trabajo en EUA }\end{array}$ & $\begin{array}{c}\text { Mujeres } \\
\% \text { del total por cohorte }\end{array}$ & $\begin{array}{c}\text { Hombres } \\
\% \text { del total por cohorte }\end{array}$ \\
\hline \multicolumn{3}{|l|}{ Familia } \\
\hline Hasta 1983 & 85.7 & 59.4 \\
\hline De 1984 a 1988 & 76.0 & 66.7 \\
\hline De 1989 a 1993 & 88.5 & 69.5 \\
\hline Desde 1994 en adelante & 77.8 & 61.9 \\
\hline \multicolumn{3}{|c|}{ Amistades } \\
\hline Hasta 1983 & 7.1 & 23.4 \\
\hline De 1984 a 1988 & 16.0 & 29.0 \\
\hline De 1989 a 1993 & 10.6 & 26.8 \\
\hline Desde 1994 en adelante & 16.7 & 32.1 \\
\hline \multicolumn{3}{|c|}{ Nadie } \\
\hline Hasta 1983 & 0 & 3.1 \\
\hline De 1984 a 1988 & 0 & 2.9 \\
\hline De 1989 a 1993 & 0.9 & 0 \\
\hline Desde 1994 en adelante & 0 & 0 \\
\hline \multicolumn{3}{|c|}{ Otros } \\
\hline Hasta 1983 & 7.1 & 14.1 \\
\hline De 1984 a 1988 & 8.0 & 1.4 \\
\hline De 1989 a 1993 & 0 & 3.8 \\
\hline Desde 1994 en adelante & 5.6 & 6.0 \\
\hline
\end{tabular}


Cada vez necasito que me ayuden menos, pero cada vez ayudo más: reciprocando, pero siempre recibiendo

Como ya se vió para el caso de los primeros viajes, para el traslado, desde los lugares de origen hasta Nueva York o Nueva Jersey, pasando por Tijuana o por Nogales o por Piedras Negras, y después por San Diego o Tucson, la familia es la principal fuente de apoyo. Esto se mantiene, si bien con cambios, a lo largo de los siguientes translados. Para las mujeres (cuadro y gráfica \# 5), el peso de la ayuda familiar en los primeros eventos empieza siendo de más de un $87 \%$ y después, a lo largo de los eventos de la trayectoria migratoria, desciende hasta un 40\%. Para los hombres (cuadro y gráfica \# 6), es de más del 63\% en los primeros eventos y de más del 64\%, en los últimos. El papel de las amistades es en este terreno de menor y decreciente importancia (empieza siendo de poco más de 12\% para las mujeres y acaba desapareciendo; mientras que para los hombres baja de casi una cuarta parte a casi una décima).

Visto por cohortes el apoyo para el traslado, la importancia de la familia se destaca aún más. En general, en todas se mantiene arriba del 50\% del total de casos; aunque es consistentemente de mayor importancia para las mujeres que para los hombres (la diferencia es siempre superior a los diez puntos). En compensación, los hombres recurren más al apoyo de las amistades (entre $20 \%$ y 25\%), con diferencias que van de 10 a 20 puntos porcentuales sobre las mujeres.

El terreno de la vivienda es en el que la familia juega su papel más destacado; aunque nuevamente sea siempre de mayor importancia para las mujeres que para los hombres; que cuentan más frecuentemente con el apoyo de sus amistades. Para las mujeres (cuadro y gráfica \# 7), la importancia de la familia se mantiene en todos los eventos alrededor de las ocho y las nueve décimas partes del total. Para los hombres (cuadro y gráfica \# 8), desciende a lo largo de los eventos de la trayectoria de casi un $67 \%$ a casi un $55 \%$. Aunque creciente, el papel de las amistades es de poca significación para las mujeres (va de menos del $13 \%$ a poco más del $14 \%$ ). Por el contrario, para los hombres se mantiene siempre alrededor de una cuarta parte del total; si bien con una ligera tendencia al descenso.

Por cohortes, los cambios en el tiempo son menores. Agregadamente, la familia explica siempre entre las seis y las siete décimas partes; pero en los eventos de las mujeres es mayor su peso (constantemente muy cerca o arriba de las ocho décimas partes) que en 
los de los hombres (alrededor de seis décimas partes del total). Nuevamente, en este último grupo, el menor peso de la familia es compensado por uno mayor de las amistades (entre las dos y las tres décimas partes).

Queda claro, pese a las diferencias y a los cambios a lo largo de las trayectorias y las cohortes, que son las redes de relaciones sociales la institución básica para la solución del problema del traslado y el alojamiento, tanto para las mujeres, como para los hombres. Si se completa la información proveniente de la encuesta con los testimonios grabados y las pláticas, se sabe que los fondos necesarios para el viaje migratorio, así como el dinero que en muchos casos se hizo necesario para que la familia se mantuviera en tanto empezaban a llegar las remesas, en la gran mayoría de los casos se obtuvo a través de las propias redes familiares y amistosas.

\section{Dispersos, pero unidos: la vivienda de la gente de México en Nueva York y sus alrededores}

Por las particularidades que reviste, resulta conveniente hacer una descripción detenida de la forma en que viven las y los migrantes en Nueva York y sus alrededores. La vivienda dispersa y concentra a los y las migrantes de México, por todo Nueva York y Nueva Jersey. Dispersa a lo largo y ancho de el Bronx, Brooklin, Queens, Manhattan, Staten Island, Passeic, Paterson, y otros lugares más. Pero en cada una de esas zonas, concentra a las personas en un doble sentido. Por un lado, en los puntos específicos en donde se han encontrado los migrantes mexicanos con asentamientos de gente que habla español; originaria ya sea de El Caribe (Puerto Rico, República Dominicana, Cuba), sobre todo, o bien de Centro América (El Salvador, Guatemala), o Sud América (especialmente de Colombia y Ecuador).

Por otro lado las concentra, literalmente, dentro de las propias viviendas; en donde

grandes números de personas, no necesariamente todas unidas por lazos familiares o amistosos, al menos al inicio, las comparten en condiciones que a veces llegan al franco hacinamiento (¿cuarenta personas en un sótano lo es?); y en un contexto barrial que en ocasiones pasa del simple repudio gestual o verbal y alcanza la agresión física, debido a que, como se los han repetido en innumerables ocasiones, consideran a los mexicanos como 
invasores o colonizadores de sus barrios. Aunque los grupos que así lo hacen, hayan pasado por una situación muy similar en épocas anteriores.

Es el caso, por ejemplo, de la gente de la República Dominicana que se concentra en el ahora llamado Pequeño Santo Domingo, ubicado en el extremo norte de la isla de Manhattan, arriba de Harlem; muy cerca, por cierto, de los campos en donde los domingos celebran sus partidos de futbol los integrantes de la líga mexicana más numerosa de Nueva York y Nueva Jersey. Es también el caso de los puertorriqueños que habitan el legendario Barrio, en el East Harlem (antes de ellos, italiano). O bien de los cubanos, que tradicionalmente se han asentado en la zona de Queens cercana a la línea del subway, a la altura de la estación , en la calle Roosevelt, que ahora empieza a ser conocida como la estación Pantitlán, debido a la gran cantidad de gente de México que vive y trabaja por ahí (sobre todo de Ciudad Neza) y a la proliferación tanto de puestos callejeros de tamales, esquites, garnachas y taquitos, como de restaurantes de comida mexicana y sus derivaciones (sobre todo de tipo tex mex). O también de los puertorriqueños y dominicanos de la calle Amsterdam, en Manhattan, más o menos a la altura de las calles 95 a 120. O de muchos otros ejemplos similares.

Una gran diferencia entre la gente de México y la de el resto de las migraciones de habla española a esa región de los Estados Unidos, está precisamente en que todas éstas han encontrado asentamiento en zonas delimitadas y, aunque no necesariamente hayan formado ghettos, viven en un número reducido de barrios, en los que son la población predominante (Cf. Green, 1997). La gente de México, por el contrario, no es por lo pronto mayoritaria en ninguna de las zonas en las que vive; aunque su presencia en cada una de ellas, que son muy numerosas, sea cada vez más visible.

Otras dos características de la forma de resolver el problema habitacional de los mexicanos en Nueva York y Nueva Jersey, consiste en que la vivienda se encuentra generalmente muy alejada del trabajo y en que la movilidad intraurbana es muy elevada. En cuanto a lo primero, no resulta nada infrecuente que las personas a quienes entrevistamos y con las que convivimos, nos hablen de la enorme cantidad de horas que gastan al día, y sobre todo por las noches, para trasladarse de sus casas al trabajo y a la inversa; tanto ellas mismas como todos sus conocidos. De hecho, para muchos, lo único que importa es que cerca del trabajo y de la vivienda haya una terminal del metro. Lo cual lleva, por cierto, a 
que conozcan la ciudad casi exclusivamente bajo tierra. Entre el tiempo de trabajo, con jornadas siempre muy prolongadas, y la lejanía de la habitación, el tiempo para pasear y conocer la ciudad es casi nulo. Aun en los días de descanso, el traslado por ejemplo a los campos de futbol y el regreso se hacen por el metro y sin escalas en otros lugares, por ejemplo de atracción turística. En general, esas condiciones de vida y de trabajo hacen que las y los migrantes de México prácticamente no conozcan la ciudad en la que viven.

En cuanto a lo segundo, toda la gente nos refiere haber cambiado de dirección muchas veces, a lo largo de uno, dos o tres años. Por abandonar zonas en las que se percibe, o resiente, un mayor riesgo callejero. Por problemas de hostilidad específica en contra de la gente de México o, más en general, de habla española. Para estar más cerca de la estación del metro. Porque los amigos dicen haber encontrado un lugar mejor o más barato. Porque llegaron nuevos parientes o amistades y se requiere de un lugar más amplio. Porque se obtuvo un ingreso superior al anterior y se puede vivir en un mejor sitio... En fin, son múltiples las razones que se escuchan para referirse a una misma situación: la interminable movilidad domiciliaria en la ciudad.

Existen elementos de tipo estructural, propias del desarrollo urbano de Nueva York, que han influido fuertemente para estos desarrollos. El consul José Antonio Lagunas, que tiene alrededor de veinte años en Nueva York y que ha sido testigo directo del crecimiento de la presencia mexicana en esa ciudad, tiene una interesante explicación, que vale la pena citar con amplitud:

...recuerdo cuando llegué, en 1982 no había mexicanos en los metros, ni en el siete, ni en el F, que son las líneas que van a Queens; y ahora (en) Times Square a las siete, ocho de la noche, es puro mexicano...Hubo varios fenómenos que influyeron en esa inmigración interna. Uno de ellos fue (que) tradicionalmente vivían en Bronx, en donde (vive) cantidad todavía. (Ahí) empezó una guerra difícil, con el desarrollo del crack, a mediados de los ochentas, en 85, pues era una guerra un poco difícil entre los grupos que ya existían dentro de las áreas del Bronx y el grupo mexicano incipiente que empezó a llegar, que desarrolló sus familias. Entonces la gente pues no estaba segura, las hijas no se sentían tampoco seguras, empezaron a desplazarse, a principios de los noventas, hacia otras áreas de...Roosevelt, el área de Corona, el área de Jakson High, muchas áreas de Queens; ...(y la misma dispersión se ha presentado) en el Bronx.

En tonces, al creciemiento propiamente del flujo migratorio, se ha sumado una 
creciente reubicación de la población mexicana por todos los rumbos de Nueva York:

Lo malo también es que esa área (el Bornx) está deprimida económicamente, hay mucho contrabando, mucho tráfico de enervantes, nomás que actualmente lo llevan a cabo hispanos; entonces, se siente un poquito menos. (También) son afroamericanos o caribeños. Entonces ese desplazamiento también, es crecimiento incluso, empezó a ser alimentado por gente que nació en México, concretamente en el área de Ciudad Nezahualcóyotl y por eso ha crecido con un comportamiento tan explosivo Entonces ha habido corrientes internas que dan la impresión de que se están llegando mucha gente pues son desplazamientos internos...Son reacomodos.

Aunque no existe aún una área típicamente mexicana, es posible que se llegue a formar en el norte de Queens:

Me imagino que si una zona va a considerarse del área del este de los Angeles o el correspondiente, sería Roosevelt, cómo se va a organizar, se va viendo. Por ejemplo: restaurantes, taquerías, casas de música, tiendas de abarrotes (mexicanos)... Se va concentrando en esa área y hay un desplazamiento, por ejemplo, dentro de las comunidades, como la comunidad cubana. La comunidad cubana casi fue expulsada, no por los mexicanos sino por la presencia de otros grupos de latinoamérica, como uruguayos, argentinos, colombianos, peruanos; que empezaron a llegar al área de Jackson Highs. Ahora los mexicanos también están empezando a desplazar y los que están siendo desplazados, son colombianos, son peruanos. Pero no, son reacomodos, a veces da la impresión de que la población va aumentando desmedidamente, pero lo que se vio en el Bronx hace unos cinco años o diez años, en el 85; se está viendo ahora en El Barrio...y se está viendo en Queens..., en el sur de Bronx y en el norte de Manhattan, esto que se llama Harlem, (que) por cierto es el sitio más pobre de Estados Unidos. En Manhattan están los dos distritos, el más rico y el más pobre: Wall Steet y Harlem, que es al norte de Manhattan y al sur de Bronx. Entonces, pues así está la situación. (Cónsul José Antonio Lagunas, entrevista).

La experiencia de una familia originaria de Xicotzingo puede ilustrar de manera muy plástica esta forma de vivir la ciudad de Nueva York y sus alrededores. Aunque tanto los hermanos como los primos de esta familia son muy cercanos afectivamente entre sí, ha sido imposible para ellos vivir juntos. En 1997, Paco, el primero de los hermanos que migró, allá por los años ochenta, junto con su primo Chava, vivía con su esposa e hijo en un edificio de apartamentos habitado casi exclusivamente por dominicanos, precisamente en el Pequeño Santo Domingo (Washington Heighs). El apartamento lo comparten con otra familia mexicana. Ellos ocupan una de las tres habitaciones y comparten la cocina y el baño con otra familia, también mexicana, que es en realidad la arrendataria oficial de la habitación. Cerca de su casa, pero siempre en ambientes mayoritariamente dominicanos, 
vive una buena cantidad de migrantes de distintos rumbos de los estados de Puebla y Tlaxcala, con los que la familia de Paco tiene una buena relación. En ese barrio, la convivencia con los dominicanos parece haber llegado a un acuerdo de mutua tolerancia, aunque los mexicanos se quejen mucho, en privado, del ambiente ruidoso y muy cercano a la fiesta cotidiana de los merengueros. ${ }^{49}$

Paco vive en ese lugar, por primera vez cerca de su trabajo, en una lavandería cuyo propietario es de origen chino, después de casi diez años de vivir en Nueva York. Antes ha vivido prácticamente por todos los rumbos de la ciudad y le ha tocado enfrentar muy distintas condiciones de habitación y prácticamente todas las formas de rechazo de otros grupos de inmigrantes neoyorquinos. En Brooklin, por ejemplo, vivió en un sótano con aproximadamente cuarenta mexicanos, a los que desconocía en su mayoría al llegar por recomendación de un amigo del pueblo. Sólo el hecho de que algunos trabajaran de día y otros lo hicieran por la noche, hacía posible que el suelo, poblado de colchonetas de extremo a extremo, fuera capaz de contenerlos físicamente a todos.

Lo que resultó imposible, al cabo de algunos meses, fue que ese espacio los contuviera socialmente. Los roces, las fricciones, los malos entendidos, o bien el cansancio acumulado, los problemas en el trabajo y seguramente la lejanía y la nostalgía de muchos, fueron generando tensiones que explotaban con frecuencia en discusiones e incluso algunos golpes. La unión que se había generado entre todos los habitantes del sótano a raíz del enfrentamiento violento y victorioso con los puertorriqueños del barrio, que querían correrlos o al menos amedrentarlos cuando se instalaron, se fue erosionando hasta el desmoronamiento. Al final, dos bandos se enfrentaron en una batalla campal que dio por finalizada la difícil convivencia. De ahí, cada quien por su lado a buscar casa...

Fue con seguridad la peor experiencia de Paco, en cuanto a vivienda se refiere, pero es muy similar a las experiencia que muchos más relatan. No sólo se trata de la dificultad de encontrar dónde alojarse, se trata también, y primordialmente, de gastar lo menos posible y de ahorrar y enviar lo más que se pueda a la casa.

Los hermanos menores de Paco, Rogelio y Gabriel, trabajan en un restaurante texmex, propiedad de un inmigrante griego -casado con una mujer norteamericana-, ubicado cerca del Soho. De hecho, el restaurante queda más o menos a medio camino entre

\footnotetext{
49 Tolerancia no absoluta, como lo pudimos comprobar en nuestro equipo, cuando estuvimos a punto de ser
} 
la casa de Paco y el lugar donde ellos viven, en Brooklin, muy cerca de Coney Island, más o menos a una hora de camino en metro. Para poder verse en la casa del hermano más grande, tienen que disponer de todo el día, porque sólo en el camino de ida y vuelta a su casa pueden ocupar cerca de cuatro horas; lo que es todo un lujo cuando se trabajan alrededor de diez u once horas diarias. Estos dos hermanos obtuvieron esa vivienda, en la que ocupan sólo un cuarto, de un departamento de tres recámaras, por el intermedio del cocinero, también mexicano, del lugar en el que trabajan. En esta vivienda habita éste con su madre, su esposa y su cuñado. La familia es originaria de Atzala, municipio de Izucar de Matamoros, Puebla.

A diferencia del barrio donde vive Paco, en donde viven Gabriel y Rogelio no hay ni mexicanos ni, prácticamente, ningún grupo latinoamericano. La población aquí es casi exclusivamente judía y en la calle puede verse que es una zona en la que viven muchos ministros de culto. Por las referencias de Krally (1987), es muy posible que sus habitantes pertenezcan a la ola migratoria de las últimas décadas, porque nuestros amigos saben que muchos de ellos provienen de Rusia.

Pese a quedar como a una hora del trabajo, para los dos hermanos el lugar resulta prácticamente inmejorable. Es calmado, seguro y tranquilo. Además, aseguran que en ningún momento se han sentido hostilizados y mucho menos agredidos por los vecinos. Para completar las ventajas del lugar, el metro les queda a no más de cinco minutos a pié. Ni por asomo quisieran regresar a vivir al rumbo de la calle Amsterdam, a la altura más o menos de la calle 100, en Manhattan, donde vivieron al llegar a Nueva York. En ese lugar no sólo vivían hacinados, sino que tenían que enfrentar una hostilidad muy abierta tanto de puertorriqueños, como de dominicanos, especialmente en las esquinas en donde el comercio callejero de drogas se concentra.

En ese lugar vivió también con ellos su hermano Osvaldo, quien ha tenido un número considerablemente mayor de cambios de domicilio en los seis o siete años que lleva en Nueva York. Ahora vive en el medio Manhattan, con sus hermanos Beto e Higinio, algunos primos y varios amigos de Xicotzingo, a los que Beto a ayudado a trasladarse (incluyendo el paso por la frontera como indocumentados), instalarse y encontrar trabajo. $\mathrm{Su}$ domicilio inmediato anterior al actual reviste características interesantes, que hablan de 
su enorme capacidad para establecer relaciones en ambientes poco propicios. El trabajaba en Manhattan, en un restaurante mexicano, cuando su patrón, originario de Pixtla, decidió abrir una sucursal en Staten Island y le ofreció irse al nuevo negocio en mejores condiciones. En cuanto empezó a trabajar ahí, un compañero de trabajo mexicano le ofreció que, para no tener que trasladarse desde la parte media de Manhattan hasta Staten Island, podía subarrendarle un cuarto en la mitad de la casa que él arrendaba en este último lugar, con su esposa y sus hijos.

Sataten Island es un lugar de enormes contrastes sociales; aunque las zonas residenciales de lujo ocupan la mayor parte del territorio. No existe, por lo demás, una fuerte presencia de mexicanos; aunque sí es detectable un grupo que trabaja en la industria de la construcción y en los servicios, y que proviene en su mayoría de Michoacán y Oaxaca, no de Puebla ni de Tlaxcala. Cabe observar que existe un lugar en el que los migrantes se reunen en la calle para que los contratistas, sobre todo de la construcción, los recluten para el trabajo. Por cierto, cabe comentar que no parece que la migra acostrumbre acercarse a ese lugar para detener con fines de deportación a los migrantes.

El domicilio de Osvaldo estaba ubicado en un barrio sumamente pobre, habitado sobre todo por afroamericanos y puede decirse que el ambiente es francamente hostil hacia quienes deciden entrar al barrio sin pertenecer a él. Cualquier observador, a simple vista, en alguna tarde de mayo de 1997, podría observar a personas drogándose en la calle o en los patios de casas semiabandonadas; o bien a una mujerer visiblemente drogada que estaba a punto de golpear a otras que discutían con ella a gritos, precisamente junto al teléfono público que se encuentra en la esquina de la casa de Osvaldo; la cual se encuentra en un gran predio cercado en el que hay varias casas, distribuidas entre lo que alguna vez fue un jardín. El mismo observador, tal vez se hubiera sentido intranquilo al pasar junto a los vecinos de Osvaldo, que se hayaban apostados en la entrada, con grandes perros de pelea y vestidos todos con ropa camuflada de tipo militar. De haber querido entrar, el observador seguramente hubiera tenido que ser conducido hacia el interior por algún inquilino o conocido del barrio.

Sin embargo, para Osvaldo en realidad no era un problema el vecindario. Los afroamericanos habían acabado por aceptarlo, convivía con ellos (pese a que él ni toma ni utiliza drogas) e incluso había desarrollado una buena amistad especialmente con los 
aficionados al basquetbol, quienes lo habían adiestrado considerablemente en ese deporte. Tal vez, incluso ahora que vive en un lugar que al menos visualmente es más agradable, al que se cambió sólo porque su hermano Beto decidió regresar a Nueva York, Osvaldo siga extrañando a sus amigos de Staten Island. En la migración parece que alguna gente, y no poca, adquiere algo que tal vez deba considerarse como un componente importante del capital cultural: una notable capacidad para adptarse a medios difíciles y para adoptar de ellos lo que sea más útil para salir adelante.

Muy distinta fue la experiencia reciente de Beto en un barrio afroamericano. El ha vivido ya durante varios periodos en Nueva York, alternados con periodos de regreso a Xicotzingo, en donde viven su esposa y sus hijas. De varias maneras, es el líder del grupo familar, o al menos de una parte de él, que incluye a sus hermanos, a algunos primos y a varios amigos muy cercanos, a quienes él ha iniciado en la experiencia migratoria y a quienes se encarga de adiestrar en la vida neoyorquina. Por sus varios antecedentes en el cruce fronterizo, él ya es capaz de ingresar sin papeles a los Estados Unidos, sin necesidad de contratar coyotes. Otra adquisición para su bagaje cultural, que le permite evitar que los jóvenes cercanos a él pasen por el riesgo que representan las bandas organizadas de traficantes fronterizos, cada vez más profesionales, delincuenciales y vinculados al tráfico de droga conocido como hormiga.

Después del nacimiento de su última hija, en a finales de 1997, decidió terminar con su estancia de aproximadamente dos años en el pueblo y regresar a Nueva York. En octubre de 1998, sin grabadora de por medio, Beto narra la difícil experiencia que había vivido con los primos y amigos que habían ido junto con él - ellos por primera vez- en este viaje. Para ahorrar, tanto dinero como tiempo de traslado entre la vivienda y el trabajo, decidió alquilar un departamento ubicado dentro de Harlem, más o menos a la altura de la calle 132. Aunque el ambiente les pareció hostil desde el principio, creyeron que con no meterse con nadie, las cosas irían aceptablemente bien. Sin embargo, antes de un mes, dos de sus compañeros de vivienda ya habían sido asaltados y golpeados en los alrededores. Todavía entonces creyeron que eso era simplemente parte de los riesgos de la zona y no algo dirigido especialmente contra ellos.

Pronto esa idea cambió radicalmente. Las agresiones siguieron y ellos empezaron a darse cuenta de que no los querían en el barrio. El final se precipitó una noche en la que 
Humberto regresaba ya muy tarde (sale siempre del trabajo como a las 2PM) y vio que siete morenos estaban cerca de la entrada de su casa. Cuando estaba sacando las llaves para entrar, oyó que uno dijo algo y que otro le respondió: “go ahead”. Desde antes, él ya había temido una agresión. De repente, sintió una patada por detrás y cayó al suelo. Intentó correr a gatas, pero lo detuvo una patada en la cara. Despúes, como siempre en esos casos, ya no sintió lo duro sino lo tupido. Cuando le quitaron el dinero que llevaba y lo dejaron tirado, la sangre no dejaba de salirle por la boca. El no quería que sus primos y amigos se enteraran, por temor a la responsabilidad de lo que pudiera desatarse. Sin embargo, cuando entró se enteró de que al mayor de sus primos le había pasado lo mismo un par de horas antes, fue obvio que había que encontrar una respuesta.

Hubo entonces una asamblea deliberativa y sólo parecían presentarse dos opciones: salir en ese mismo momento y enfrentarlos, por cierto sin armas, o bien abandonar al día siguiente el departamento. La discusión no fue fácil, cuenta Beto; el coraje era mucho y ni él ni los demás se consideran dejados, sino más bien lo contrario. En la primera, resultaba claro que, aunque ellos pudiran salir vencedores en el enfrentamiento, lo más probable es que alguien no saliera vivo. Después de mucho eligieron, contra su voluntad, la segunda salida. Ahora comparten con Osvaldo un departamento más caro, pero más seguro, cerca de la zona en la que ya habían vivido con Rogelio y Gabriel, a la altura de la calle 90.

Otras experiencias de vivienda han tenido otros primos de ellos y sus familias, pero ya no se entrará aquí en detalles. Baste decir, para complementar el panorama de dispersión y a las dificultades para convivir al menos semanalmente que, en 1997 Chava, primo de ellos y muy amigo suyo, vivía con su hermano Antonio, su esposa, su cuñado y sus hijos, en Queens Astoria; y que Adrián y Javier, primo y sobrino de todos los anteriores, vivían hasta Patterson, en Nueva Jersey.

No resulta imposible, sin embargo, verlos a todos, o a la inmensa mayoría al menos, juntos y sin limitaciones de tiempo. Sólo que para ello haya que viajar alrededor de cuatro mil kilómetros e instalarse en el patio de la casa que se ha construido Rogelio, en su pueblo, Xocotzingo, junto a la casa de sus padres. Eso sucederá en diciembre de 1999, precisamente durante la celebración de su boda, con una muchacha poblana, estudiante de medicina y avecindada con su familia en esa población tlaxcalteca. Ahí convivirán, larga y cariñosamente, todos los que comparten la experiencia migratoria en Nueva York y una 
vida pendular entre aquella ciudad y su pueblo de origen. Pero no lo harán únicamente entre ellos, sino que también lo harán con sus padres y con una inmensa cantidad de tías, tíos, primas, primos, sobrinas, sobrinos, amigas, amigos, vecinas y vecinos, que a su vez han vivido por su cuenta diversas experiencias migratorias; internas (por ejemplo, hacia la industria textil de la zona metropolitana del DF), en la generación anterior a la de ellos; internacionales (interrumpidas, no necesariamente finalizadas), en la de ellos mismos; o bien que se preparan para irse al norte en el futuro próximo, siguiendo su huella y aprovechando sus conocimiento y relaciones, en la de los más jóvenes.

\section{A la chamba: ¿aquí dónde se pregunta?}

\section{Lo primero es empezar: el primer trabajo}

Pero el papel fundamental de la familia y las amistades no se limita a la ayuda para el traslado y el alojamiento. Con relación al empleo, tienen una importancia central como vehículo de información e incluso como elementos capaces de facilitar el ingreso de las personas al trabajo. En el ámbito del estudio que aquí se reporta, lo anterior se comprueba ampliamente; si bien el peso relativo que tienen los familiares y las amistades como ayuda efectiva para mujeres y para hombres se presenta de manera diferenciada. En general, el acceso al primer trabajo estuvo altamente marcado por la influencia de las redes familiares y amistosas, para hombre y mujeres de todas las cohortes. Pero puede apreciarse con facilidad una menor recurrencia de los hombres a la ayuda familiar y un mayor peso relativo de las amistades, como se observó también en el caso del traslado y el alojamiento. Debe recordarse que una situación similar se presentó en México, en relación a los trabajos previos a la migración a los Estados Unidos.

En el caso de la información sobre el empleo, la familia fue el canal en el 52\% del total y los amigos y amigas lo fueron en el 37.3\%. Sin embargo, para las mujeres el peso de la familia ascendió a un 67.9\% (25\% las amistades) y en el de los hombres a sólo un 45.5\%, mientras que el de las amistades llegó a un $42.7 \%$. Las cantidades son muy similares en lo que se refiere a la recomendación para el ingreso al trabajo.

Visto a través de las distintas cohortes, en tanto que para las mujeres (cuadro y gráfica \# 9)la ayuda familiar, tanto para obtener la información, como para obtener una recomendación para el ingreso, superó siempre el 50\% de los casos y llegó a significar 
hasta un 75\% de ellos; para los hombres (cuadro y gráfica \# 10) únicamente en la segunda cohorte llegó a ocupar la mitad y, en la primera cohorte, fue de sólo un poco más del 30\%. A la inversa, el apoyo de las amistades, aunque decreciente a lo largo de las cohortes, fue para los hombres siempre superior al que obtuvieron las mujeres, con la excepción de la segunda cohorte, cuando alcanzó el 50\% del total entre ellas.

En lo referente a la obtención de la información sobre el, los porcentajes tanto de mujeres como de hombres (tabla \# 3) fueron bastante bajos en lo que toca a no haber recibido ningún tipo de ayuda, o bien haber recibido la información a través de otros medios (anuncios en los medios, mediante hojas impresas o en la puerta de los establecimientos; o bien a través de asociaciones no gubernamentales); si bien en este último caso los hombres de todas las cohortes los utilizaron más que las mujeres (en una proporción que va de dos a una a otra de cinco a uno). 
TABLA \# 3

\begin{tabular}{|c|c|c|}
\hline \multicolumn{3}{|c|}{$\begin{array}{l}\text { DISTRIBUCIÓN PORCENTUAL DE HOMBRES Y MUJERES, POR COHORTE Y } \\
\text { POR INFORMACION SOBRE EL EMPLEO (primer trabajo en EUA) }\end{array}$} \\
\hline $\begin{array}{l}\text { Cohorte de ingreso al } \\
\text { mercado de trabajo en EUA }\end{array}$ & $\begin{array}{c}\text { Mujeres } \\
\% \text { del total por cohorte }\end{array}$ & $\begin{array}{l}\text { Hombres } \\
\% \text { del total por cohorte }\end{array}$ \\
\hline \multicolumn{3}{|c|}{ Familia } \\
\hline Hasta 1983 & 53.3 & 30.2 \\
\hline De 1984 a 1988 & 44.0 & 49.3 \\
\hline De 1989 a 1993 & 74.8 & 49.3 \\
\hline Desde 1994 en adelante & 69.7 & 42.9 \\
\hline \multicolumn{3}{|c|}{ Amistades } \\
\hline Hasta 1983 & 33.3 & 50.8 \\
\hline De 1984 a 1988 & 44.0 & 49.3 \\
\hline De 1989 a 1993 & 19.8 & 40.5 \\
\hline Desde 1994 en adelante & 21.1 & 41.7 \\
\hline \multicolumn{3}{|c|}{ Nadie } \\
\hline Hasta 1983 & 6.7 & 4.8 \\
\hline De 1984 a 1988 & 8.0 & 7.0 \\
\hline De 1989 a 1993 & 3.6 & 5.1 \\
\hline Desde 1994 en adelante & 6.1 & 9.5 \\
\hline \multicolumn{3}{|c|}{ Otros medios } \\
\hline Hasta 1983 & 6.7 & 14.3 \\
\hline De 1984 a 1988 & 0 & 1.4 \\
\hline De 1989 a 1993 & 1.8 & 9.8 \\
\hline Desde 1994 en adelante & 3.0 & 6.0 \\
\hline
\end{tabular}


Para conseguir una recomendación para ingresar a trabajar, mujeres y hombres migrantes (tabla \# 4) tuvieron dificultades en una mayor proporción que en relación a la obtención de la información. Decrecientemente en el caso de las primeras (cuadro y gráfica \# 11), a lo largo de las cohortes (de $14.3 \%$ a 6.1\%), crecientemente desde la segunda cohorte, en el caso de los hombres (hasta llegar a significar la quinta parte del total) (cuadro y gráfica \# 12), el primer trabajo en los Estados Unidos lo obtuvieron sin ayuda alguna. En ambos casos, el recurso a otros medios fue muy poco significativo.

Cabe señalar que los mayores porcentajes de quienes se informaron sobre el trabajo e ingresaron a él a través de medios ni familiares ni amistosos, corresponden en ambos rubros y para ambos sexos a la cohorte migratoria más antigua; como sucede también con quienes ingresaron al trabajo sin recomendación alguna. Nuevamente, los datos parecen hablar de efectos acumulativos de la migración en la conformación y densificación de las redes de relaciones sociales a través del tiempo. 
TABLA \# 4

\begin{tabular}{|c|c|c|}
\hline \multicolumn{3}{|c|}{$\begin{array}{c}\text { DISTRIBUCIÓN PORCENTUAL DE HOMBRES Y MUJERES, POR COHORTEY Y } \\
\text { POR RECOMENDACIÓN PARA EL INGRESO(primer trabajo en EUA) }\end{array}$} \\
\hline $\begin{array}{c}\text { Cohorte de ingreso al } \\
\text { mercado de trabajo en EUA }\end{array}$ & $\begin{array}{c}\text { Mujeres } \\
\% \text { del total por cohorte }\end{array}$ & $\begin{array}{c}\text { Hombres } \\
\% \text { del total por cohorte }\end{array}$ \\
\hline Familia & & \\
\hline Hasta 1983 & 50.0 & 31.7 \\
\hline De 1984 a 1988 & 41.7 & 52.9 \\
\hline De 1989 a 1993 & 75.0 & 48.4 \\
\hline Desde 1994 en adelante & 69.7 & 43.4 \\
\hline \multicolumn{3}{|c|}{ Amistades } \\
\hline Hasta 1983 & 28.6 & 46.0 \\
\hline De 1984 a 1988 & 50.0 & 35.7 \\
\hline De 1989 a 1993 & 18.8 & 36.3 \\
\hline Desde 1994 en adelante & 21.1 & 33.7 \\
\hline \multicolumn{3}{|c|}{ Nadie } \\
\hline Hasta 1983 & 14.3 & 17.5 \\
\hline De 1984 a 1988 & 8.3 & 7.1 \\
\hline De 1989 a 1993 & 4.5 & 13.0 \\
\hline Desde 1994 en adelante & 6.1 & 20.5 \\
\hline \multicolumn{3}{|c|}{ Otros medios } \\
\hline Hasta 1983 & 7.1 & 4.8 \\
\hline De 1984 a 1988 & 0 & 4.3 \\
\hline De 1989 a 1993 & 1.8 & 2.1 \\
\hline Desde 1994 en adelante & 3.0 & \\
\hline
\end{tabular}


Con los datos hasta aquí aportados, no es difícil observar el enorme peso que el capital social disponible tiene para las personas que migran por primera vez a esta zona de los Estados Unidos. Al analizar tanto las cohortes de manera diferenciada, como los eventos que las personas encuestadas fueron acumulando a lo largo de sus trayectorias laborales, será de gran importancia observar los posibles cambios que se presentan en la importancia relativa de este capital social original, con relación a otros tipos de capital, como el cultural, el económico y el organizacional; o bien a los cambios que el propio capital social pueda llegar a presentar, si es que las personas consiguen diversificar sus contactos e involucrarse en redes sociales distintas a las que pertenecían desde el inicio.

\section{En los siguientes trabajos: informo y me informan; recomiendo y me recomiendan}

Como se ha visto, un campo fundamental de acción posible para estas las redes socialers, en especial las familiares y las amistosas, en combinación con otras instituciones, es el de la búsqueda, localización y acceso al trabajo. En Nueva York, para obtener información acerca de posibles empleos y para conseguir recomendaciones para emplearse efectivamente, la familia y las amistades resultan ser de una importancia prioritaria. Sin embargo, pueden establecerse importantes diferencias. Una de gran interés, se refiere a que las familias estructuran de una manera diferenciada las trayectorias de hombres y mujeres. En ambos casos, no obstante, se presenta un perfil cambiante a través del tiempo, en el que la familia tiende a perder importancia en estos renglones, en favor de la acción de las amistades (lo que habla de posibles enriquecimientos y diversificaciones del capital social); pero también de las fuerzas propiamente del mercado, así como de elementos propios de la organización de los establecimientos, que permiten regresar a trabajos que ya se habían tenido y aprovechar así las calificaciones específicas adquiridas y el prestigio personal derivado de un buen desempeño anterior en el mismo establecimiento.

En efecto, mientras más eventos se acumulan, menor es el peso relativo de la familia, mayor el de las amistades y mayor la capacidad de las personas para desempeñarse en el mercado de trabajo sin necesidad de recibir ayuda; ya sea porque se pueden mover conforme a su propio conocimiento de las oportunidades de empleo y de los mecanismos de reclutamiento; ya sea porque se regresa a trabajar a establecimientos en los que ya se ha laborado anteriormente. No es difícil interpretar estos resultados en el sentido de que estas 
personas que acumulan eventos y se pueden desempeñar con una mayor autonomía en el mercado de trabajo, por el otro lado están ya desempeñando el rol que con ellas realizaron quienes migraron antes que ellas: ahora son seguramente el canal a través del cual quienes empiezan su trayectoria migratoria obtienen información y recomendaciones para ingresar al trabajo. Como se podrá ver al analizar las cohortes en las que se agrupa el total de los eventos, a lo largo de los años las redes mantienen en general su importancia, aunque la influencia de la familia tienda a descender ligeramente. Cambian los actores individuales, pero el proceso se mantiene. Llega el momento de corresponder o reciprocar.

En el caso de las mujeres (cuadros y gráficas \# 13 y 14), la familia fue la responsable de informar y de recomendar sobre el trabajo en casi el 70\% del total de los primeros eventos. En ambos renglones, las amistades sólo lo fueron en alrededor de una cuarta parte. Por los medios impersonales propios de las fuerzas del mercado, se explica menos de un $10 \%$ del total. Resulta muy interesante observar que el peso de la familia decrece constantemente durante la sucesión de eventos de la trayectoria, hasta representar apenas poco más del $7 \%$ en los últimos. Las amistades, por el contrario, incrementan su peso relativo y llegan a significar alrededor de la tercera parte del peso total en el final de las trayectorias (35.8\% en el renglón de información y $29.6 \%$ en el de la recomendación).

El aprovechamiento de los propios antecedentes laborales resulta de una importancia creciente: cerca de una quinta parte en promedio de los eventos finales corresponden a mujeres que ya habían trabajado en esos establecimientos. Pero lo que llama poderosamente la atención, es el crecimiento sustancial que tiene el peso de los medios impersonales para el acceso al trabajo; hecho que remite a pensar en que las mujeres adquieren con su experiencia un muy importante conocimiento del mercado de trabajo neoyorquino y una gran capacidad para conocer sus pautas de funcionamiento. Esto es, la adquisición de un importante capital cultural parece ser un producto nada despreciable de las trayectorias laborales en los Estados Unidos. Para los últimos eventos, en más del $35 \%$ de los casos no se requirió de algún familiar o amistad para obtener la información; y en más del 48\%, no existió ningún tipo de recomendación.

En las trayectorias laborales de los hombres (cuadros y gráficas \# 15 y 16), la familia y las amistades son casi igual de importantes al inicio, como fuente de información y recomendación (más del $45 \%$ del total, en promedio, en el primer caso; y $40 \%$ en el 
segundo). La evolución a lo largo de las trayectorias es considerablemente distinta, en lo cuantitativo, a las de las mujeres. En los últimos eventos, las amistades de los hombres se convierten, con mucho, en la primera fuente de información y recomendación (explican alrededor del $50 \%$ de los casos). La familia, sin embargo, decrece en importancia menos que en el caso de las mujeres (representa en los últimos eventos casi el 12\%, en el primer rubro; y más del 17.5\%, en el segundo). Destaca que los hombres parecen regresar menos que las mujeres a trabajos que ya habían ocupado previamente. Aunque la tendencia es creciente, menos del 10\%, en promedio, de los últimos eventos tienen esta característica. Más aún llama la atención el hecho de que los hombres dependen menos de mecanismos impersonales que las mujeres para acceder al trabajo. En el caso de la obtención de información, menos de un $27 \%$ de los casos. En el de la recomendación, menos del 25\%.

Si los eventos son agrupados conforme a cohortes de realización, resalta que las redes familiares y amistosas mantienen su importancia a través del tiempo; si bien la familia es en general más importante para las mujeres, y las amistades lo son para los hombres. Debe destacarse que en las cohortes intermedias crece considerablemente el peso de ambios elementos; pero su importancia decae casi a la mitad en la última cohorte; en la que los medios de tipo impersonal, sobre todo para los hombres, la aumentan considerablemente. Aparentemente, los migrantes de las cohortes más recientes parecen mejor dispuestos para enfrentarse de manera directa al mercado de trabajo; aunque también debe tenerse en cuenta que en esta última cohorte se encuentran muchos eventos de personas que tienen ya largas trayectorias laborales en Nueva York y sus alrdedores.

En este punto es conveniente recordar que la mayor parte de la muestra con la que se trabajó en esta investigación, está compuesta por personas que combinaron eventos laborales en los Estados Unidos con otros en México. Es por ello interesante referirse ahora brevemente a las características que presentan sus trayectorias laborales en la parte correspondiente a este último país, en los renglones que se están abordando. Los perfiles de las trayectorias laborales en México, en estos aspectos muestran pocas diferencias de género. Con porcentajes muy similares en los renglones relativos a la obtención de información y de recomendación para el empleo, los dos grupos muestran una gran dependencia de la familia, que es sin embargo descendente en su peso relativo conforme se suceden los eventos. Para las mujeres (cuadros y gráficas \# 17 y 18), el promedio de estos 
dos renglones arroja casi un 50\%, en los primeros eventos; para descender a casi un 32\%, en los últimos. Para los hombres (cuadros y gráficas \# 19 y 20), esos porcentajes son de más de un $60 \%$ y de casi un 35\%. Las amistades, por su parte, representaron, en promedio, apenas un poco menos de un $22 \%$, en los inicios de las trayectorias de las mujeres, y un poco más del $17 \%$ en las de los hombres. En los eventos finales, para las mujeres representaron casi un 32\%; y para los hombres casi un 33\%. Las mujeres que no requirieron de ayuda para informarse e ingresar al trabajo, representaron en promedio con sus eventos a más del $25 \%$, en los iniciales, y a casi el $27 \%$, en los finales. Los hombres, a poco más del $19 \%$ y al $23 . \%$, respectivamente. El resto de los rubros ocupa un lugar marginal.

Visto por cohortes, este campo muestra pocas variaciones a lo largo del tiempo. Tanto para las mujeres como para los hombres, la familia explica alrededor de la mitad de los casos y las amistades cerca de la cuarta parte; aunque se presenta una ligera tendencia hacia la disminución del peso relativo de lo familiar (de poco más del 50\% a poco más del $40 \%$, en promedio). Un dato que llama la atención es que para las mujeres de la última cohorte, la familia desaparece como fuente de información (no así de recomendación), y es sustituida en el primer lugar por los mecanismos impersonales; mismos que, en general y en promedio, representan para el total un poco menos de la cuarta parte de los casos, con una tendencia ascendente a lo largo de las trayectorias.

En los Estados Unidos, tanto para las trayectorias de los hombres como para las de las mujeres, y a lo largo de las distintas cohortes, la relación que se tenía previamente con los empleadores fue siempre muy baja. Para las mujeres (cuadro y gráfica \# 21), desciende el peso de quienes no tenían relación previa alguna, de poco más del 82\% a poco menos del $73 \%$, entre los primeros y los últimos eventos. Para los hombres(cuadro y gráfica \# 22), de casi el $87 \%$ a poco más del $80 \%$. Aunque muy pocos familiares fungen como patrones, en el caso de los eventos de las mujeres su peso es creciente y llega ser de más del $9 \%$ en los últimos eventos. Más importante para ambos grupos son las amistades que, de manera en general creciente a lo largo de los eventos acumulados, llegan a representar poco menos del $14 \%$, para las mujeres, y casi el 19\%, para los hombres.

Como empleadora, a diferencia de México, la familia no tiene un peso importante en los Estados Unidos. Las amistades, si bien ocupan un lugar pequeño, éste es creciente a 
lo largo de las trayectorias: del 5.5\% a menos del 14\%, para las mujeres; y de poco más del $7 \%$ a casi el 19\%, para los hombres. A lo largo de las cohortes, la situación es muy similar.

En México, por el contrario, la familia sí juega un rol importante como empleadora, especialmente en el caso de los hombres; aunque su peso sea decreciente a lo largo de las trayectorias (va de un más de un $52 \%$ en los primeros eventos de los hombres a poco menos de un $28 \%$ en los últimos; y, en los de las mujeres, gira siempre en alrededor de un tercio del total). Dos diferencias importantes entre ambos grupos se encuentran al analizar los casos en donde no existía ningún tipo de relación previa con el patrón y en los que lo fue la amistad. En el primero, para las mujeres es siempre el renglón de mayor importancia, aunque tienda a decrecer (de más del 51\% al 40\%). Para los hombres, la tendencia es a la inversa, ya que crece desde casi un tercio hasta un $60 \%$ del total. En el segundo renglón, puede verse que las mujeres tienen a emplearse cada vez más con amistades (de poco más del $11 \%$ a una cuarta parte del total de los eventos); en tanto que los hombres lo hacen de manera más bien margianl (decrecen los porcentajes de poco menos del 13\% a poco más del 8\%).

En general, entonces, en la sucesión de eventos que corresponden a México, la tendencia es que las mujeres se empleen crecientemente con familiares y amistades y decrecientemente con patrones desconocidos. Mientras que los hombres siguen un camino inverso, en el que éstos últimos cobran una importancia creciente y acaban por convertirse en los principales empleadores.

La familia, entonces, y las amistades, juegan un papel de primer orden en el proceso migratorio y en la articulación de los distintos territorios en los que se plurilocalizan los espacios sociales transnacionales: ayudan al traslado y al alojamiento; y ayudan también a conseguir trabajo (informando, recomendando e incluso llegando a emplear). Pero quienes han recibido este tipo de ayuda, actuan a su vez de varias formas como continuadores de la articulación mencionada. Continuación se aborda una de las principales: el envío de remesas a los lugares de origen.

\section{Los migradólares, algo más que dinero}

\section{¿Se envía dinero desde que se llega?}


Una clara contraparte para la supervivencia del capital relacional que se pone en juego en las trayectorias migratorio laborales que se están analizando, está en las remesas que quienes migran envían a sus localidades de origen. Remesas que no sólo sirven para la manutención de personas, la construcción de obras y la inversión, sino también para la negociación de la pertenencia y el desarrollo de las expectativas de migración entre quienes permanecen en los pueblos, especialmente las personas jóvenes.

En los primeros eventos en los Estados Unidos, los padres son en todos los casos los principales destinatarios de las remesas. De manera agregada, recibieron el $55.1 \%$ del total; mientras que la persona señalada como conyuge fue destinataria de menos de la mitad (23.5\%) y otro tipo de familiares se hizo acreedor a muy pequeños porcentajes. Para inversiones de diverso tipo (bancarias, en propiedades) se destinó sólo un 9.7\%. Por lo demás, sólo un $1.7 \%$ declaró no haber enviado remesas.

Cabe aquí introducir una aclaración, con relación a las remesas que se destinan a la realización de obras, civiles o religiosas, y a las fiestas patronales de los lugares de origen. Tanto por los testimonios recogidos en las entrevistas a profundidad y en las pláticas de tipo informal, como por los trabajos de investigación previos (sobre todo de Smith, 1994, y de Cortés, ), como por la observación directa, no hay duda de que las personas migrantes de las regiones que se estudian en este trabajo son responsables del financiamiento mayoritario y constante, anualmente, de esa clase de actividades. La razón por la que no aparecen entre los destinos principales de las remesas está en que, para cada persona en lo particular, representan una mínima parte de sus envíos, que es realizada además sólo una, o máximo dos veces al año, y que representa un porcentaje nada significativo dentro del total de sus remesas; pero que cobra una enorme importancia debido a que esas pequeñas aportaciones son realizadas por una gran cantidad de paisanos, de manera organizada.

Es también pertinente hacer otro señalamiento. Nuevamente, se presentan diferencias, no insignificantes, entre los destinos principales de las remesas que envían mujeres y hombres. Si bien en ambos casos la familia es el destinatario central, en el caso de las mujeres los padres recibieron el $68.1 \%$ del total y el conyuge únicamente el 5.5\%. En el caso de los hombres, a los padres correspondió el $50 \%$ y a la conyuge el $30.1 \%$. Cuando se analice el curso de las remesas a lo largo de los distintos eventos laborales en los Estados Unidos, será de gran interés observar hacia qué rumbo de presentan los posibles cambios. 
Este comportamiento puede estar indicando una migración inicial del jefe de familia varón o bien una migración compuesta básicamente por personas solteras. Aunque cabe suponer que buena parte de las remesas enviadas a los padres, sean en realidad para los hijos, cuando los hay, debido a que éstos generalmente quedan en los lugares de origen bajo el cuidado de sus abuelos paternos o maternos.

Resulta interesante observar que en general no se presentan grandes cambios a lo largo de las cohortes en el destino de las remesas, aunque pueden detectarse algunos menores (tabla \# 5). La diferencia que sí se presenta es al comparar entre sí a mujeres y hombres. Aunque en los dos casos son los padres los destinatarios principales de los envíos, las mujeres(cuadro y gráfica \# 23) destinan a ellos un porcentaje siempre arriba del $50 \%$ del total y que llega a alcanzar hasta el $75 \%$ en la tercera cohorte, que resulta mayor que los hombres, en todas las cohortes (entre 15 y 20 puntos, con excepción de la segunda cohorte). Por otro lado, en el caso de los hombres (cuadro y gráfica \# 24) es siempre la conyuge quien ocupa el segundo lugar; mientras que en el de las mujeres, éste es ocupado por distintos rubros: los hijos, en la primera y la tercera cohortes; la inversión, en la segunda; y otros destinatarios en la última. Los porcentajes de la tercera prioridad de las mujeres son cambiantes y poco significativos, en tanto que la de los hombres se dirige en todas las cohortes hacia la inversión. Por último, cabe destacar que prácticamente todos los hombres y las mujeres en este primer evento enviaron remesas a sus lugares de origen. Basta observar en los últimos años la proliferación de casas de cambio (incluso dominicanas, como la casa Delgado) en todas las poblaciones expulsoras de migrantes en los estados de Puebla y Tlaxcala para corroborar la veracidad de esta información. 
TABLA \# 5

\begin{tabular}{|c|c|c|}
\hline \multicolumn{3}{|c|}{$\begin{array}{l}\text { DISTRIBUCIÓN PORCENTUAL DE HOMBRES Y MUJERES, POR COHORTE Y } \\
\text { POR DESTINO DE LAS REMESAS (primer trabajo en EUA) }\end{array}$} \\
\hline $\begin{array}{c}\text { Cohorte de ingreso al } \\
\text { mercado de trabajo en EUA }\end{array}$ & $\begin{array}{c}\text { Mujeres } \\
\% \text { del total por cohorte }\end{array}$ & $\begin{array}{c}\text { Hombres } \\
\% \text { del total por cohorte }\end{array}$ \\
\hline \multicolumn{3}{|l|}{ Conyugue } \\
\hline Hasta 1983 & 0 & 34.4 \\
\hline De 1984 a 1988 & 12.5 & 37.1 \\
\hline De 1989 a 1993 & 5.0 & 25.6 \\
\hline Desde 1994 en adelante & 10.0 & 32.1 \\
\hline \multicolumn{3}{|c|}{ Padres } \\
\hline Hasta 1983 & 66.7 & 43.8 \\
\hline De 1984 a 1988 & 50.0 & 45.7 \\
\hline De 1989 a 1993 & 75.0 & 54.6 \\
\hline Desde 1994 en adelante & 60.0 & 46.9 \\
\hline \multicolumn{3}{|c|}{ Hijos } \\
\hline Hasta 1983 & 16.7 & 4.7 \\
\hline De 1984 a 1988 & 8.3 & 4.3 \\
\hline De 1989 a 1993 & 11.0 & 1.0 \\
\hline Desde 1994 en adelante & 6.7 & 0 \\
\hline \multicolumn{3}{|c|}{ Otros familiares } \\
\hline Hasta 1983 & 0 & 1.6 \\
\hline De 1984 a 1988 & 0 & 1.4 \\
\hline De 1989 a 1993 & 1.0 & 1.9 \\
\hline Desde 1994 en adelante & 3.3 & 0 \\
\hline \multicolumn{3}{|c|}{ Inversión } \\
\hline Hasta 1983 & 8.3 & 9.4 \\
\hline De 1984 a 1988 & 16.7 & 5.7 \\
\hline De 1989 a 1993 & 5.0 & 12.1 \\
\hline Desde 1994 en adelante & 3.3 & 13.6 \\
\hline \multicolumn{3}{|c|}{ Otros } \\
\hline Hasta 1983 & 8.3 & 4.7 \\
\hline De 1984 a 1988 & 12.5 & 5.7 \\
\hline De 1989 a 1993 & 2.0 & 2.4 \\
\hline Desde 1994 en adelante & 16.7 & 3.7 \\
\hline \multicolumn{3}{|c|}{ No envió } \\
\hline Hasta 1983 & 0 & 1.6 \\
\hline De 1984 a 1988 & 0 & 0 \\
\hline De 1989 a 1993 & 1.0 & 2.4 \\
\hline Desde 1994 en adelante & 0 & 3.7 \\
\hline
\end{tabular}




\section{¿Se sigue enviando después?: la permanencia de los envíos de dinero (y del mantenimiento de los vínculos y la pertenencia)}

Aunque todas las personas de la muestra dicen haber enviado remesas constantemente, a lo largo de todas sus trayectorias laborales, al igual que en otros campos, las diferencias que se presentan entre las mujeres y los hombres migrantes son considerables al analizar el destino principal de las remesas enviadas, a lo largo de la sucesión de eventos laborales realizados en los EUA. Aunque en ambos casos son los integrantes de la familia los destinatarios centrales de las remesas, la forma cambiante en que éstas son distribuidas entre sus distintos miembros, habla de formas diferenciadas de relacionarse con la familia, para los hombes y las mujeres.

En el caso de éstas (cuadro y gráfica \# 25), si en los primeros eventos los padres habían sido los receptores más importantes de los envíos (casi siete décimas partes en los dos primeros eventos), el peso relativo de éstos desciende hasta representar apenas un poco más de un $12 \%$ en los últimos. El conyuge, por su parte, incrementa su importancia considerablemente, al pasar de menos del 7\% a más del 37\%. Para los hijos, las mujeres destinaron porcentajes cambiantes, pero en general crecientes, a lo largo de los eventos sucesivos, que fueron de alrededor de una décima parte del total al incicio de la TL, a una cuarta parte en el final. La inversión fue siempre un rubro poco importante (excepto en los cuartos eventos, cuando asciende a una octava parte del total) y desaparece totalmente en los últimos eventos. Llama la atención el hecho de que sea creciente a lo largo de las TL el porcentaje de mujeres que declararon no haber enviado remesas (se acerca a una quinta parte del total en los eventos finales).

Para los hombres (cuadro y gráfica \# 26), son permanentemente los padres los destinatarios más importantes de las remesas; si bien su peso relativo desciende de la mitad del total a la tercera parte, entre el primero y los últimos eventos. El peso de los envíos a la conyuge, por su parte, baja a casi la mitad en esa secuencia, al pasar de poco más del $30 \%$ del total, a poco más del 16\%. Los envíos a los hijos son el renglón que, por el contrario, mayor crecimiento presenta, al pasar de un peso marginal (menos del $2 \%$ del total) a representar casi una cuarta parte del total. La inversión muestra un comportamiento oscilante, pero tiene un ligero crecimiento (de casi $11 \%$ a menos del 13\%). Al igual que en el caso de las mujeres, el porcentaje de hombres que se abstiene de enviar remesas es 
creciente a lo largo de la TL; aunque llegue a tener un peso porcentual menor que en el de aquellas (poco más del 12\% del total en los eventos finales).

\section{¿Dejo el trabajo porque puedo, porque quiero o porque no me queda de otra (o por algo más)?: hacia el norte jala más el dinero, hacia el sur los afectos}

Si el envío de remesas constituye un vínculo más bien material en el que se expresa la vida de las redes de relaciones sociales, en los procesos de toma de decisiones fundamentasles para las personas, las diversas instituciones sociales estructurantes de las trayectorias laborales se manifiestan de manera importantes. ¿Por qué razón las personas deciden dejar su lugar de origen en México y se van a un lugar tan lejano como la zona de Nueva York?; o bien ¿por qué se deciden a abandonar en aquellos lugares un trabajo, que seguramente no ha sido fácil de obtener, para regresar a sus pueblos originales?; pero también ¿que lleva a una persona a estar recurrentemente dejando trabajos y países para trasladarse a miles de kilómetros, a otro país, para buscar un nuevo trabajo?; ¿es siempre la motivación de maximizar la ganancia económica la que lleva a abandonar un trabajo y, sobre todo, un país?; o ¿es la disposición de una amplia y completa información acerca de las condiciones coyunturales de los mercados de trabajo de los Estados Unidos y México la que lleva a la toma de decisiones?; o bien ¿será la pura nostalgia o sólo el campo de los afectos lo que lleva de regreso a los migrantes a México?; ¿no habrá también en México algo de nostalgia por lo que se ha dejado en el norte (familia, amigos, ingresos, formas de vida)?.

El tema es en realidad complejo y una encuesta realizada con preguntas cerradas, sin que exista una previa relación de confianza entre la persona entrevistada y la que entrevista, puede llevar a que muchas causas de gran interés -aunque muy posiblemente no muy significativas estadísticamente- queden ocultas. Es muy difícil que con los instrumentos formales se puedan captar motivos que tienen que ver pleitos familiares, o con hechos delincuenciales, o con alcoholismo, o con drogadicción, o con prostitución o con homosexualidad escondida. Vale la pena referirse a dos ejemplos de razones para regresar a México, o bien para irse a Nueva York, que ejemplifican lo anterior y que señalan campos interesantes para profundizar la investigación cualitativa sobre temas específicas.

El primero de estos ejemplos, se refiere a personas que han tomado la decisión de migrar específicamente a Nueva York, en busca de un estilo de vida que les resulta imposible desarrollar en sus lugares de origen, debido a razones culturales que derivan en 
actitudes y conductas marcadas por la intolerancia hacia preferencias y prácticas que rompen con lo que es localmente considerado como legítimo. Se trata de personas que han elegido la homosexualidad como opción. En la aplicación del custionario sobre trayectorias laborales, la homosexualidad nunca aparece como razón para dejar el trabajo en México y optar por la búsqueda de uno nuevo en los EUA. Sin embargo, al establecer relaciones de confianza con una persona que ayudó de manera importante en nuestra investigación, nos platicó que en Nueva York existe una comunidad homosexual mexicana, de dimensiones no despreciables, y cuyo situación económica en el momento de la migración estaba lejos de ser apremiante. Esas personas se han ido buscando un medio social que les permita desarrollar sus preferencias sexuales sin ser perseguidas ni hostilizadas. Quien nos platicó sobre esta situación, incluso, conminaba al equipo a realizar una investigación específica sobre el tema.

Otro ejemplo, se refiere a personas que han abandonado el trabajo, ya sea en México, ya sea en los Estados Unidos, por razones relacionadas con problemas legales o judiciales. Tampoco esos casos aparecen en las respuestas al cuestionario sobre trayectorias laborales. Aparecen sólo cuando existe un cierto nivel de confianza y, también, cuando la grabadora se ha apagado. Es el caso de un jóven de aproximadamente 25 años, en 1996, nacido en el DF, pero hijo de una mujer migrante interna de una de las regiónes que se incluyeron en el estudio. Este jóven, por influencia de un tío que estaba trabajando en Nueva York decidió migrar haciá allá cuando tenía 17 años. La historia que él cuenta, en confianza y durante varias pláticas, ya sea él solo o bien acompañado de su tío, quien siempre ratificó y complementó la información de Pedro (pseudónimo), habla de una vida extremadamente riesgosa y siempre ubicada en los márgenes de la legalidad. Desde que llegó a Nueva York, se desligó de las personas provenientes de México y se vinculó muy estrechamente con jóvenes de origen puertorriqueño en el Bronx, donde siempre vivió. Con ellos aprendió a moverse y a sobrevivir en la ciudad, a conseguir trabajo, a conocer las costumbres y los hábitos, a hablar algo de inglés mezclado con español y pronunciado con el estilo de ellos; con ellos se hizo parte de la ciudad. También con ellos conoció las drogas y aprendió el difícil y peligroso oficio de desmantelador de automóviles; conocimientos y ocupaciones que lo llevaron a estar cerca de dos años en una cárcel del estado de Nueva Jersey, de donde regresó a México directamente, por primera vez, en 1993. 
Al año siguiente regresó a Nueva York, no sólo sin papeles, sino con un grave antecedente penal y de deportación. Una tragedia lo hizo regresar a finales de ese mismo año a México. En un accidente carretero, cerca de su lugar de origen, murió su madre. A él le aseguraron había tenido la culpa el trailero que chocó contra el vehículo en el que ella viajaba. Después le dijeron que había quedado libre porque la compañía para la que trabaja había metido dinero. Más adelante, le informaron que el trailero seguía cubriendo la ruta y que estaba identificado. Sin comentarlo con nadie, Pedro sólo le avisó a su tío, ya de regreso de su experiencia migratoria y convertido en su informante fidedigno sobre la tragedia y sus secuelas, del día en que pensaba llegar al pueblo. "Vine rápido, hice lo que tenía que hacer y me regresé a Nueva York”. Así me lo platicó él y así lo ratifica el tío, después de varias sesiones acompañadas de cervezas. También dice Pedro que en el pueblo todo mundo lo sabe, pero no lo sabe, porque hizo lo que tenía que hacer.

Pedro regresó en 1995 al pueblo de su madre, a vivir con una tía que tiene una pequeña casita y un terreno en una pequeña comunidad cercana, en donde cultiva con la ayuda de su sobrino. El por supuesto que dice que no trabaja y que sólo vive de lo que ahorró. Lo que hace en el campo, aunque sea cotidiano y él sea el principal responsable, no es trabajo, sino ayuda para la tía que lo aloja. Sus planes desde entonces son casarse (su novia es una guapa jovencita de unos 16 años, con quien asiste a las peregrinaciones en las fiestas patronales y a quien no permitían, todavía en 1998, asistir a los bailes), ir nuevamente a Nueva York, juntar dinero y regresar para montar un bar en el que se alterne con muchachas, como los que conoce en el Bronx.

Otras historias similares aparecieron a lo largo de la investigación. Vale la pena mencionarlo; aunque su existencia pueda no resultar cuantitativamente relevante, cualitativamente hablan de la multiplicidad de razones particulares que pueden mover a tomar la decisión de cambiar de trabajo y de país. Las que aparecen compo resultado de la encuesta aplicada son las siguientes.

En los Estados Unidos, las mujeres (cuadro y gráfica \# 27) abandonan sus trabajos, independientemente de que el siguiente trabajo sea en el mismo país o en México, por razones que varían considerablemente a lo largo de sus distintos eventos laborales. Al incio de sus TL, la familia es la principal causa (56.7\% y 62.8\%, en los dos primeros); pero su importancia relativa desciende después considerablemente, hasta llegar a representar 
únicamente el 15\%, en los últimos. A la inversa, el dinero prácticamente duplica su peso, al pasar de poco más del 15\%, al inicio, al 30\%, en los últimos eventos. El descontento en el trabajo, con oscilaciones importantes, pasa en esa secuencia de poco más del 17\% a una cuarta parte del total. Motivos ajenos a la voluntad de la mujeres trabajadores, como las quiebras y los despidos, duplican su importancia a través de las TL (pasan de poco más del $7 \%$ al 15\%). Problemas relacionados con la discriminación o el estatus legal, ocupan un lugar muy marginal (su valor más elevado es de 5\%, en los últimos eventos.

Por su parte, los hombres (cuadro y gráfica \# 28) en la zona de Nueva York conservan los motivos familiares consistentemente como los más importantes, siempre con valores cercanos al 50\%. Las razones económicas, por el contrario, son de una importancia muy reducida y descendente a lo largo de los eventos laborales (pasan de representar un $17.5 \%$, en el primero, a sólo un $4.3 \%$, en los últimos). También el descontento con el trabajo es considerado como una causa digna de consideración (empieza y termina significando entre el $18 \%$ y el 19\%); al igual que el despido o la quiebra de los establecimientos (pasan de poco más del 9\% al 17\%). No aparece como significativa como razón del abandono del trabajo el hecho de ser mexicanos, indocumentados o no.

Los cambios de trabajo en México tienen una explicación distinta. Las mujeres (cuadro y gráfica \# 29) consistentemente mantienen las razones económicas como la causa principal; aunque su importancia desciende a lo largo de las TL (de cerca de la mitad a poco más de una tercera parte del total, entre los primeros y los últimos eventos). Las cuestiones familiares y el descontento con el trabajo, por el contrario, aumentan su importancia relativa; las primeras pasan de casi un $23 \%$ a casi un $29 \%$; y el segundo, de un $12.5 \%$ a casi un 29\%. La otra razón significativa, la superación personal, ocupa un lugar menor y descendente (pasa de casi un $15 \%$ a un $9.5 \%$ ).

Para los hombres (cuadro y gráfica \# 30) que dejan algún trabajo en México, el dinero empieza siendo la causa principal (casi el 65\%), pero cede su primacía en los últimos eventos a las cuestiones familiares, que suben en peso relativo, de poco más de un $11 \%$ a casi un 28\%; mientras que los asuntos económicos sólo representan al final poco más de un $24 \%$. Tanto la superación personal, como los despidos y las quiebras y el descontento con el trabajo, aumentan su peso relativo a lo largo de las trayectorias, para acabar representando arriba del $22 \%$, cerca del $15 \%$ y poco más del $11 \%$, respectivamente. 
Como puede verse, en general y con diferencias por género y a lo largo de las TL, en los Estados Unidos los trabajos de dejan básicamente por asuntos familiares y en México por cuestiones económicas. Esto aparece más claramente si se aislan los eventos cuya terminación implica un cambio subsecuente de país.

Cuando el cambio es hacia los EUA, la razón principal aducida por las personas es la posibilidad de incrementar los ingresos, de ganar más dinero. Cabe señalar sin embargo que esto ha cambiado a lo largo del tiempo (si se le ve por cohortes ${ }^{50}$ ) y, nuevamente, se presenta una situación diferenciada para mujeres y para hombres.

Efectivamente, de manera agregada (cuadro y gráfica \# 31) se encuentra que el dinero explicaba casi el $82 \%$ de los casos en la cohorte más antigua; pero sólo un poco más del $65 \%$ en la más reciente. En el caso de los hombres (cuadro y gráfica \# 32), con variantes se repite la tendencia general (desciende el peso del dinero de casi un $85 \%$ a casi un $73 \%$ ). Pero en el caso de las mujeres (cuadro y gráfica \# 33) se puede observar una curva con notorias diferencias frente a las anteriores. En la primera cohorte, la importancia del dinero como razón para el cambio de trabajo, representa sólo un $60 \%$ del total, para después ascender en la segunda cohorte hasta casi un $85 \%$, y después descender, primero moderadamente (hasta poco menos de un $78 \%$ ), y más adelante de manera pronunciada (40\% en la última cohorte).

Tanto de manera agregada, como para los hombres, el resto de las razones es considerablemente menor; aunque debe destacarse que las razones familiares incrementan su peso relativo a lo largo de las cohortes, al pasar de un $3.4 \%$ y un $2.6 \%$, respectivamente, a un $14 \%$ y más de un $9 \%$; así como las que tienen que ver con descontentos en el trabajo (pasan de un $6.8 \%$ a un $14 \%$ y de un 3.8 a un $12.1 \%$, respectivamente).

Para las mujeres los cambios anteriores son mucho más significativos, en especial en lo que toca a la familia, que pasa de representar un $10 \%$ de los casos a un $30 \%$ del total. El descontento en el trabajo empieza siendo importante como causa en la primera cohorte (30\% del total de casos), para después dejar de serlo en las cohortes intermedias (valores de $0 \%$ y casi $6 \%$ y representar al final una quinta parte del total. Las demás razones son de una importancia marginal para todos los grupos.

\footnotetext{
${ }^{50}$ En este caso, las cohortes consideradas son: 1) antes de 1987; 2) de 1987 a 1990; 3) de 1991 a 1994; y 4) de 1995 en adelante.
} 
Cuando el cambio de trabajo implica un regreso a México, la situación cambia radicalmente. En este caso, las razones familiares son siempre y en todas las cohortes, las de mayor importancia. Agregadamente (cuadro y gráfica \# 34), representan casi un $61 \%$ en la primera cohorte y más de un $83 \%$ en la última; mientras que para las mujeres (cuadro y gráfica \# 35) pasan de un 50\% a más de un 83\%; y para los hombres (cuadro y gráfica \# 36), de más de un $62 \%$ a casi un $81 \%$. Resulta sin embargo interesante anotar que tanto para las mujeres como para los hombres de la cohorte más antigua, el dinero fue una razón no despreciable para el regreso a México (25\% y $13.6 \%$ del total, respectivamente). Salvo excepciones por género y por cohorte, el resto de las razones ocupa un lugar muy subordinado. Cabe hacer un énfasis en el hecho de que las cuestiones relacionadas con el estatus legal, la discriminación o el racismo, en ningún caso son observables como importantes para dejar un trabajo en los Estados Unidos para regresar a México.

\section{CONCLUSIONES PARCIALES}

Como pudo verse anteriormente, los trabajos que mujeres y hombres desempeñaban en México, inmediatamente antes de los eventos migratorios, tienen muy poca o ninguna relación con aquellos que desempeñaron a continuación en la zona de Nueva York. Y, a la inversa, los trabajos que se tenían en los Estados Unidos, son muy distintos a los que se tuvieron en México, después de una migración en sentido inverso; dentro de este comportamiento pendular en el Espacio Social Transnacional. Pero los trabajos que se tienen en cada uno de los dos países muestran una continuidad considerable.

Como también pudo verse en el presente capítulo, las razones y los contextos en los que se tomaron las decisiones correspondientes, está lejos de ser uniforme. Mientras que para la migración a los Estados Unidos, es fundamental la motivación económica; paro el regreso a México, la familia juega un rol central. Por supuesto que, en ambos casos, en combinación entre sí y con diversos elementos. Porque no se trata de buscar una respuesta bipolar que excluya, por ejemplo, a las fuerzas del mercado a favor de la acción de los mecanismos de acción de las redes de relaciones sociales, ni a la inversa.

Resulta claro, sobre todo de las entrevistas a profundidad y de las pláticas menos formales, que las personas en los pueblos han llegado a acumular, como parte de su capital cultural, una enorme, rica, y bastante confiable información acerca tanto de las condiciones, 
como de los mecanismos de funcionamiento del mercado de trabajo neoyorquino; como patrimonio colectivo y como producto precisamente del carácter pendular de la migración y de los firmes lazos que vinculan internamente las plurilocalizaciones de los Espacios Sociales Transnacionales. En ese sentido, como propone Sassen (1997) para casos ligados a procesos migratorios, existe un mercado local de trabajo plurilocalizado, que funciona como tal tanto para quienes están viviendo en México, como para quienes se encuentran en la zona de Nueva York. La contigüidad territorial, en este caso, es suplida por la facilidad relativa del traslado, pese a la lejanía, por el conocimiento amplio del funcionamiento de los nichos dentro de él en los que resulta posible emplearse y por la riqueza del capital social con la que es posible trasladarse y arribar.

Para recorrer el camino inverso, de regreso -¿temporal? ¿definitivo?, casi nunca se sabe- hacia el lugar de origen, existe también un enorme conocimiento de las posibilidades de acción en el mercado de trabajo y en otros mercados, en los que será posible sacar provecho del capital económico acumulado en los Estados Unidos; pero también de otro tipo de adquisiciones, como el prestigio social que deriva del propio proceso de reinserción en la estratificación social, en un nivel distinto al que se tenía al partir a Nueva York. La fiestas, por ejemplo, serán un espacio de gran importancia para la negociación de esos elementos.

No se trata, entonces, que la familia deje de tener importancia cuando las personas se van a Nueva York y que el mercado deje de ser importante cuando regresan a México. El mercado, sus mecanismos de acción y sus pautas de funcionamiento siempre están presentes en la mente de quienes migran. Eso parece obvio cuando se van a buscar dinero a los Estados Unidos, para cambiar su forma de vida. Pero también está presente cuando, en el regreso a México, se decide sacrificar un ingreso mayor. Esto es, se sabe qué se está sacrificando y se sabe que el mercado de trabajo en México ofrece menores ingresos e, incluso, menores oportunidades de inversión productiva, si se ha logrado ahorrar algún dinero. No es necesariamente una decisión irracional; sino una decisión en la que se valoran como superiores ciertos valores afectivos e identitarios.

La familia, por su parte, por supuesto que está también presente, junto con las amistades, en todas las fases de la trayectoria laboral. Sin embargo, el papel que se le hace jugar es cambiante y multifacético. Para migrar a los Estados Unidos, sirve sobre todo para 
ayudar a trasladarse, a informarse sobre los posibles trabajos e incluso para obtener alguna recomendación para ingresar. Sirve (o puede no servir), incluso para conectarse con otras redes sociales, distintas a las que se llevaban al salir del pueblo de origen; de tal forma que colaboran, ya sea a romper los posibles enclaustramientos en nichos de mercado de pobres posibilidades; ya sea a enclaustrar a las personas en ellos. Aun a la distancia, la parte de la familia que permanece en México, haya o no migrado anteriormente, le sirve a la persona migrante para mantener sus vínculos y el sentido de pertenencia. Enviar remesas no es sólo una obligación moral. Es también un mecanismo de negociación de la pertenencia y, en otro nivel, un importante componente de la afectividad. En el momento del regreso al lugar de origen -¿temporal? ¿definitivo?-, la familia se convierte en el principal imán.

Otras instituciones sociales también actúan. Quien logra permanecer durante un largo periodo y ascender dentro de, por ejemplo, un restaurante, está aprovechando las formas internas de organización del establecimiento. También lo hace quien, excepcionalmente, logra tener un puesto de planta en el ayuntamiento neoyorquino. Aunque cabe preguntarse si no lo hace igualmente quien se mantiene por periodos de hasta diez años, trabajando en el servicio doméstico de alguna casa particular.

El aprendizaje de un oficio, como el de cocinero o cocinera, o el de chofer, o el de electricista, o el de carpintero, o el de panadero, en no pocos casos sirvió en estas trayectorias para obtener condiciones favorables en el mercado de trabajo.

Pero un papel de primer orden, es claro que lo desempeña la institución social de la segregación, tanto étnica como sexual. Las personas migrantes de Puebla y Tlaxcala a Nueva York y sus alrededores no compiten dentro de un mercado homogéneo, abierto a la libre competencia e igualitario. Ellos compiten dentro de sectores que son, sí, muy abiertos a la competencia, pero sólo para los integrantes de las últimas oleadas migratorias; en nichos de mercado en los que los americanos anglosajones y afroamericanos difícilmente se acercan a buscar trabajo.

Por otro lado, la especialización de las mujeres en el trabajo de la confección, al menos en las primeras etapas de sus trayectorias laborales; y de los hombres en los restaurantes, durante la mayor parte de las suyas en los Estados Unidos; son hechos que hablan muy elocuentemente de la existencia de nichos diferenciados de trabajo, dentro del nicho étnico más general, para hombres y mujeres. 
Pero para esa estructuración diferenciada de las trayectorias de mujeres y hombres, las redes sociales parecen jugar un papel fundamental; lo cual puede verse si se atiende a las formas diferenciadas en que cada uno de los grupos obtiene informaciones y recomendaciones para el trabajo; así como la forma igualmente diferenciada del destino de las remesas y a las formas también diferenciadas en que la familia y las amistades, frente a la acción de las demás instituciones, intervienen en el proceso de toma de decisiones, en relación a la migración y el trabajo.

Como ha podido observarse, el peso de las relaciones familiares es, en prácticamente todos los rubros y a lo largo del tiempo, más importante para las mujeres que para los hombres; en tanto que las amistades lo son para estos últimos más que para las primeras. Pero para ambos grupos, el peso conjunto de la familia y las amistades supera considerablemente el efecto estructurador del resto de las instituciones; siempre y cuando se tome en cuenta el efecto sobredeterminante de la segregación étnica en el mercado de trabajo neoyorquino. 
AYUDA PARA EL TRANSLADO

Hombres (1er. Trabajo en E.U.A.)

\begin{tabular}{|c|r|r|r|r|}
\hline Cohorte & \multicolumn{1}{|c|}{ Familia } & \multicolumn{1}{c|}{ Amistades } & \multicolumn{1}{c|}{ Nadie } & \multicolumn{1}{c|}{ Otros } \\
\hline Hasta 1983 & 51.60 & 20.30 & 10.90 & 17.20 \\
\hline De 1984 a 1988 & 62.30 & 26.10 & 1.40 & 10.10 \\
\hline De 1989 a 1993 & 67.00 & 26.90 & 0.90 & 5.20 \\
\hline De 1994 en adelante & 63.50 & 21.20 & 2.40 & 12.90 \\
\hline
\end{tabular}

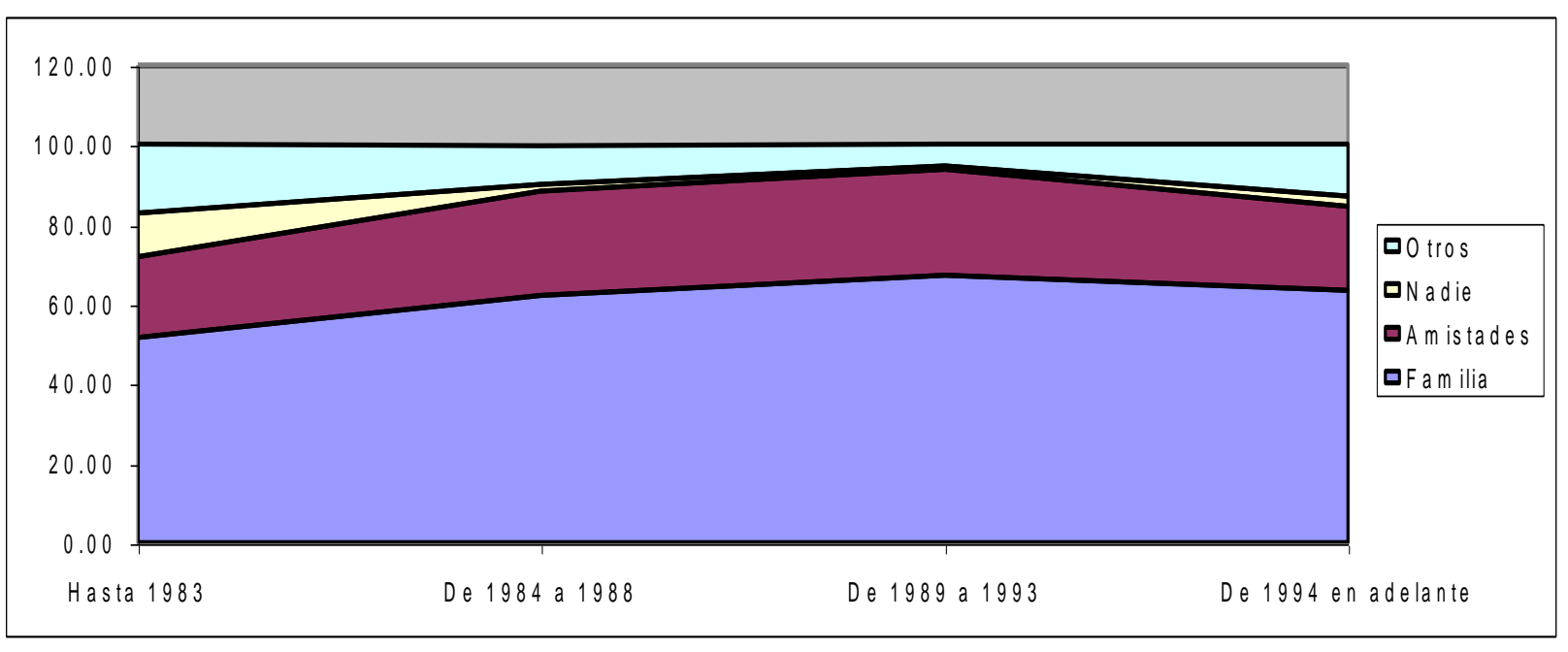

AYUDA PARA EL TRANSLADO

Mujeres (1er. Trabajo en E.U.A.)

\begin{tabular}{|c|r|r|r|r|}
\hline Cohorte & \multicolumn{1}{|c|}{ Familia } & \multicolumn{1}{c|}{ Amistades } & \multicolumn{1}{c|}{ Nadie } & \multicolumn{1}{c|}{ Otros } \\
\hline Hasta 1983 & 75.00 & 6.30 & 0.00 & 18.80 \\
\hline De 1984 a 1988 & 80.00 & 12.00 & 0.00 & 8.00 \\
\hline De 1989 a 1993 & 85.10 & 10.50 & 0.00 & 4.40 \\
\hline De 1994 en adelante & 75.00 & 19.40 & 0.00 & 5.60 \\
\hline
\end{tabular}

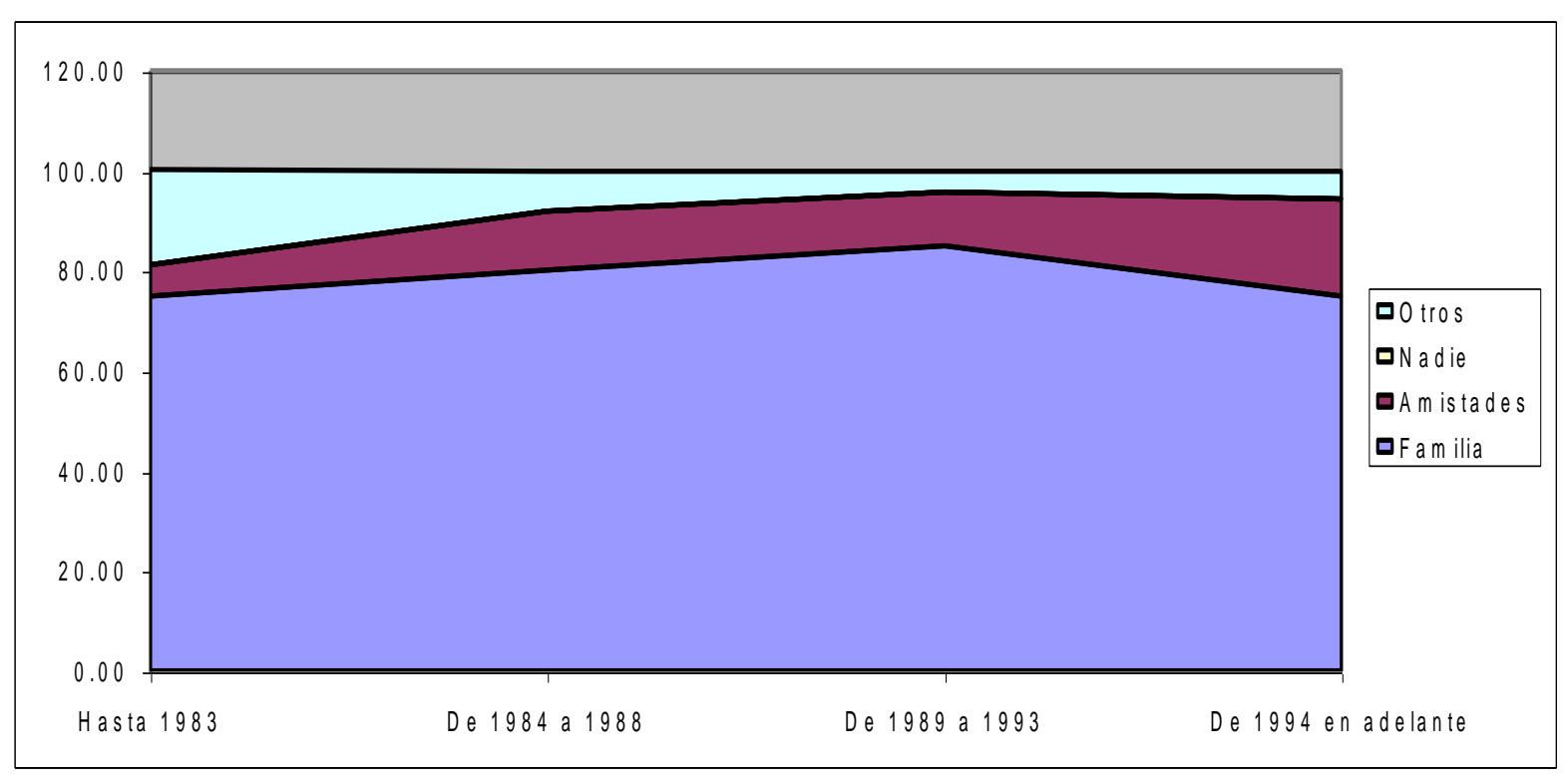


AYUDA PARA ALOJAMIENTO

Hombres (1er. Trabajo en E. U. A.)

\begin{tabular}{|c|r|r|r|r|}
\hline Cohorte & \multicolumn{1}{|c|}{ Familia } & \multicolumn{1}{c|}{ Amistades } & \multicolumn{1}{c|}{ Nadie } & \multicolumn{1}{c|}{ Otros } \\
\hline Hasta 1983 & 59.40 & 23.40 & 3.10 & 14.10 \\
\hline De 1984 a 1988 & 66.70 & 29.00 & 2.90 & 1.40 \\
\hline De 1989 a 1993 & 69.50 & 26.80 & 0.00 & 3.80 \\
\hline De 1994 en adelante & 61.90 & 32.10 & 0.00 & 6.00 \\
\hline
\end{tabular}

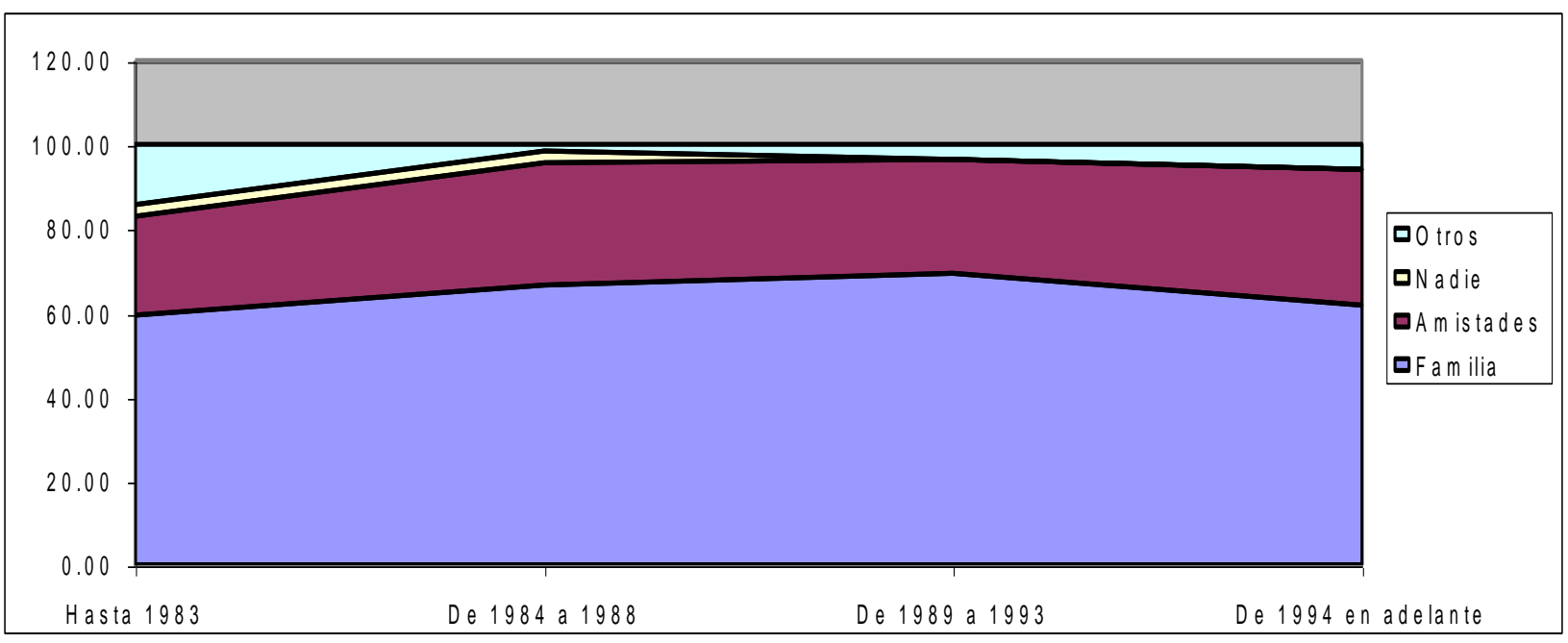

AYUDA PARA ALOJAMIENTO

Mujeres (1er. Trabajo en E. U. A.)

\begin{tabular}{|c|r|r|r|r|}
\hline Cohorte & \multicolumn{1}{|c|}{ Familia } & \multicolumn{1}{c|}{ Amistades } & \multicolumn{1}{c|}{ Nadie } & \multicolumn{1}{c|}{ Otros } \\
\hline Hasta 1983 & 85.70 & 7.10 & 0.00 & 7.10 \\
\hline De 1984 a 1988 & 76.00 & 16.00 & 0.00 & 8.00 \\
\hline De 1989 a 1993 & 88.50 & 10.60 & 0.90 & 0.00 \\
\hline De 1994 en adelante & 77.80 & 16.70 & 0.00 & 5.60 \\
\hline
\end{tabular}

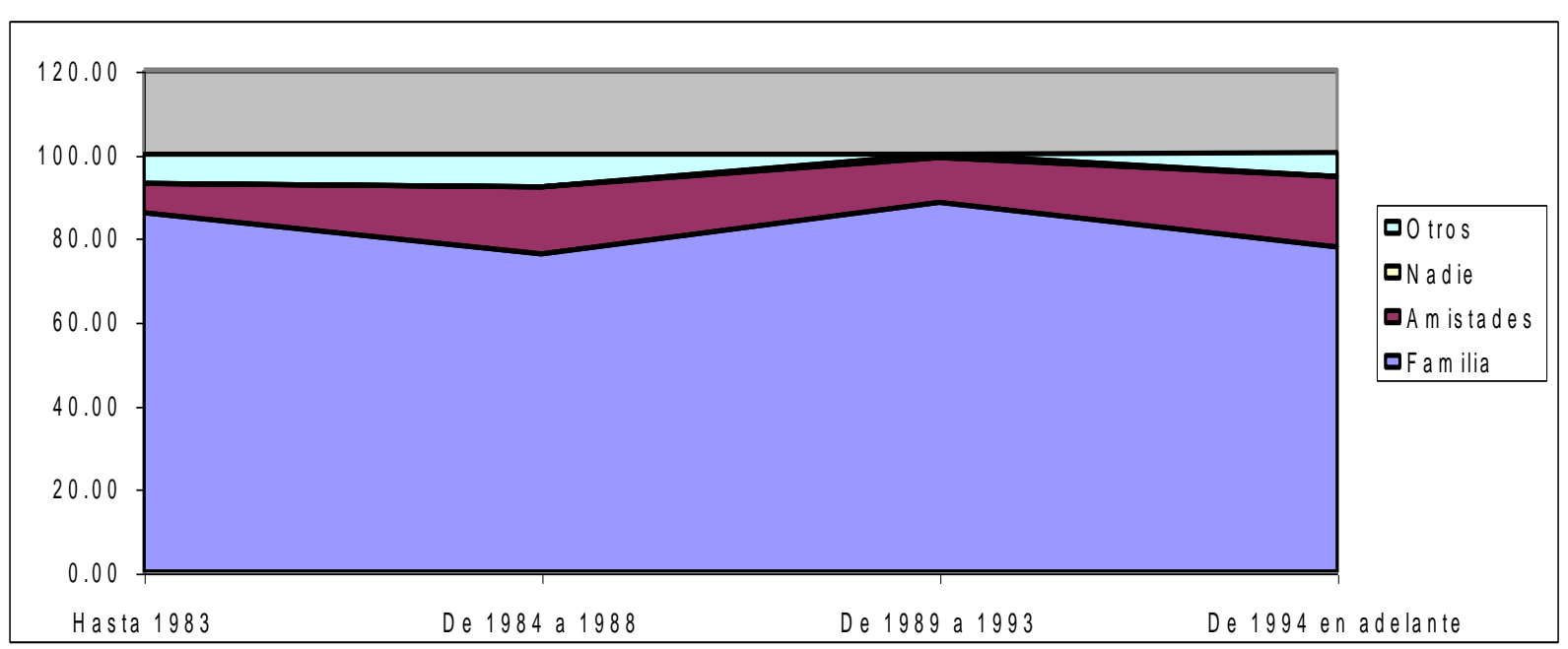


AYUDA PARA ALOJAMIENTO

Hombres (1er. Trabajo en E. U. A.)

\begin{tabular}{|c|r|r|r|r|}
\hline Cohorte & \multicolumn{1}{|c|}{ Familia } & Amistades & \multicolumn{1}{c|}{ Nadie } & \multicolumn{1}{c|}{ Otros } \\
\hline Hasta 1983 & 59.40 & 23.40 & 3.10 & 14.10 \\
\hline De 1984 a 1988 & 66.70 & 29.00 & 2.90 & 1.40 \\
\hline De 1989 a 1993 & 69.50 & 26.80 & 0.00 & 3.80 \\
\hline De 1994 en adelante & 61.90 & 32.10 & 0.00 & 6.00 \\
\hline
\end{tabular}

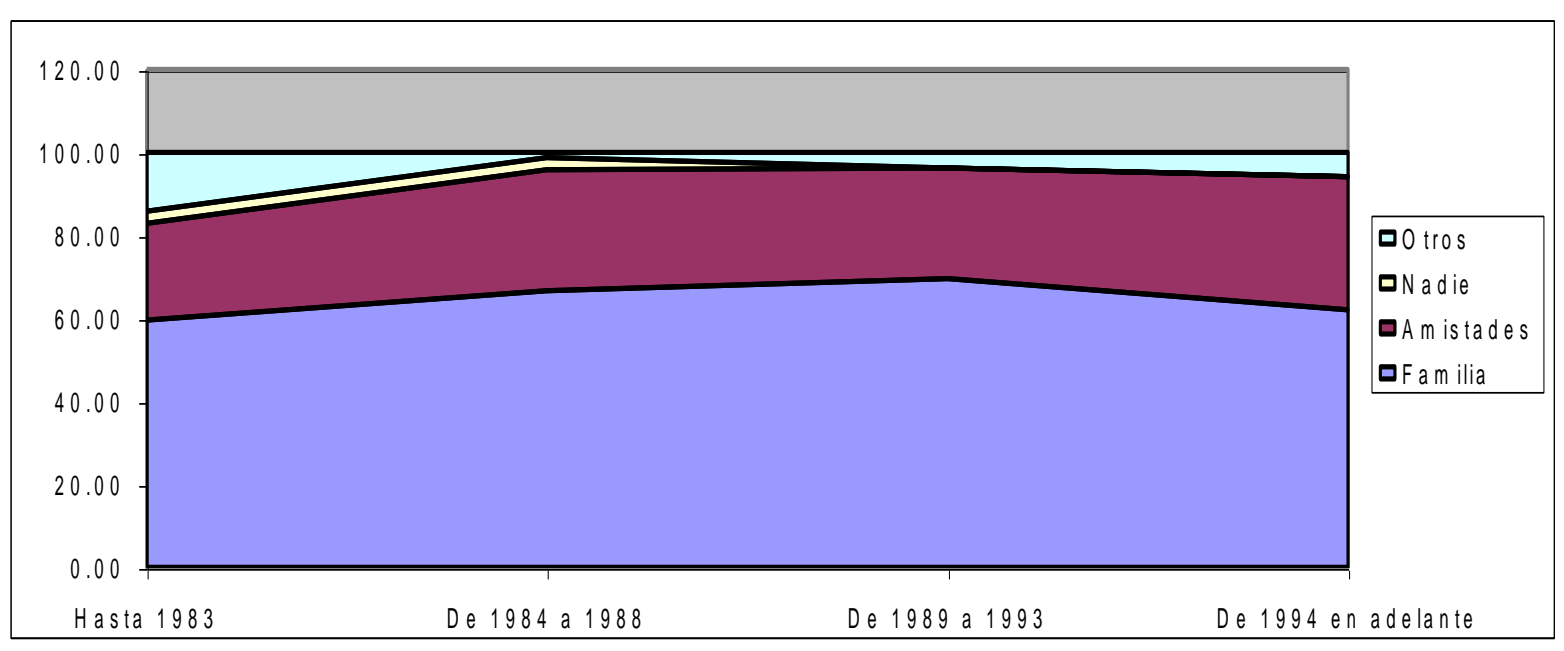

AYUDA PARA ALOJAMIENTO

Mujeres (1er. Trabajo en E. U. A.)

\begin{tabular}{|c|r|r|r|r|}
\hline Cohorte & \multicolumn{1}{|c|}{ Familia } & \multicolumn{1}{c|}{ Amistades } & \multicolumn{1}{c|}{ Nadie } & \multicolumn{1}{c|}{ Otros } \\
\hline Hasta 1983 & 85.70 & 7.10 & 0.00 & 7.10 \\
\hline De 1984 a 1988 & 76.00 & 16.00 & 0.00 & 8.00 \\
\hline De 1989 a 1993 & 88.50 & 10.60 & 0.90 & 0.00 \\
\hline De 1994 en adelante & 77.80 & 16.70 & 0.00 & 5.60 \\
\hline
\end{tabular}

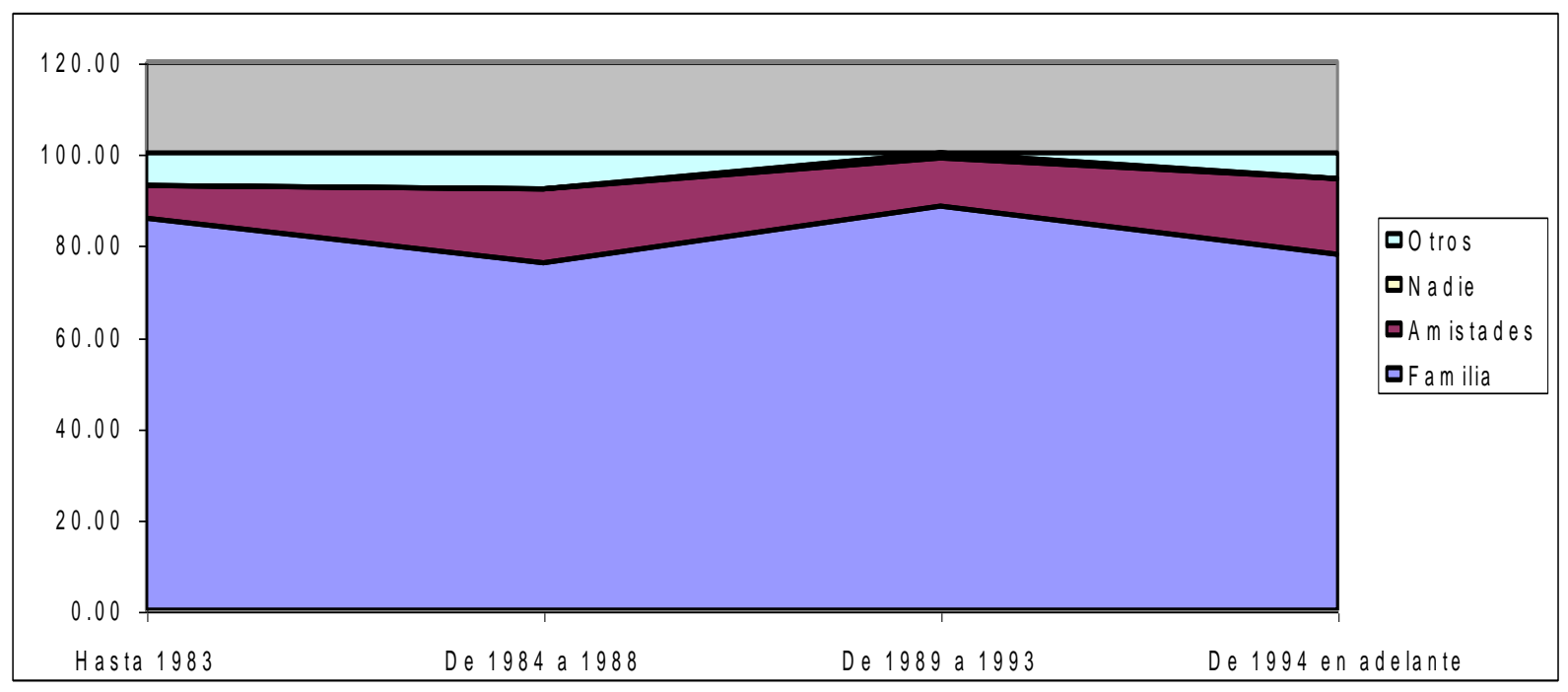


INFORMACIÓN PARA EL TRABAJO

Hombres (1er. Trabajo en E. U. A.)

\begin{tabular}{|c|r|r|r|r|}
\hline Cohorte & \multicolumn{1}{|c|}{ Familia } & Amistades & \multicolumn{1}{c|}{ Nadie } & \multicolumn{1}{c|}{ Otros } \\
\hline Hasta 1983 & 30.20 & 50.80 & 4.80 & 14.30 \\
\hline De 1984 a 1988 & 49.30 & 49.30 & 7.00 & 1.40 \\
\hline De 1989 a 1993 & 49.30 & 40.50 & 5.10 & 9.80 \\
\hline De 1994 en adelante & 42.90 & 41.70 & 9.50 & 6.00 \\
\hline
\end{tabular}

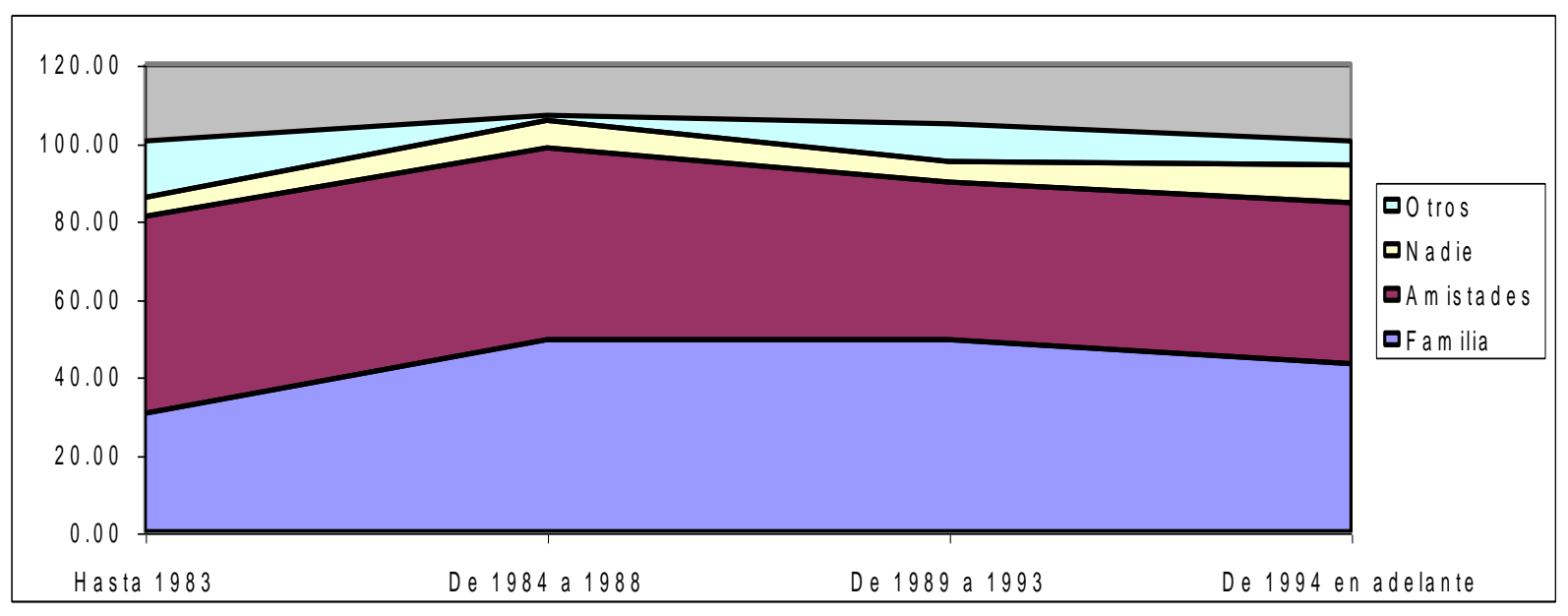

INFORMACIÓN PARA EL TRABAJO

Mujeres (1er. Trabajo en E. U. A.)

\begin{tabular}{|c|r|r|r|r|}
\hline Cohorte & \multicolumn{1}{|c|}{ Familia } & Amistades & \multicolumn{1}{c|}{ Nadie } & \multicolumn{1}{c|}{ Otros } \\
\hline Hasta 1983 & 53.30 & 33.30 & 6.70 & 6.70 \\
\hline De 1984 a 1988 & 44.00 & 44.00 & 8.00 & 0.00 \\
\hline De 1989 a 1993 & 74.80 & 19.80 & 3.60 & 1.80 \\
\hline De 1994 en adelante & 69.70 & 21.10 & 6.10 & 3.00 \\
\hline
\end{tabular}

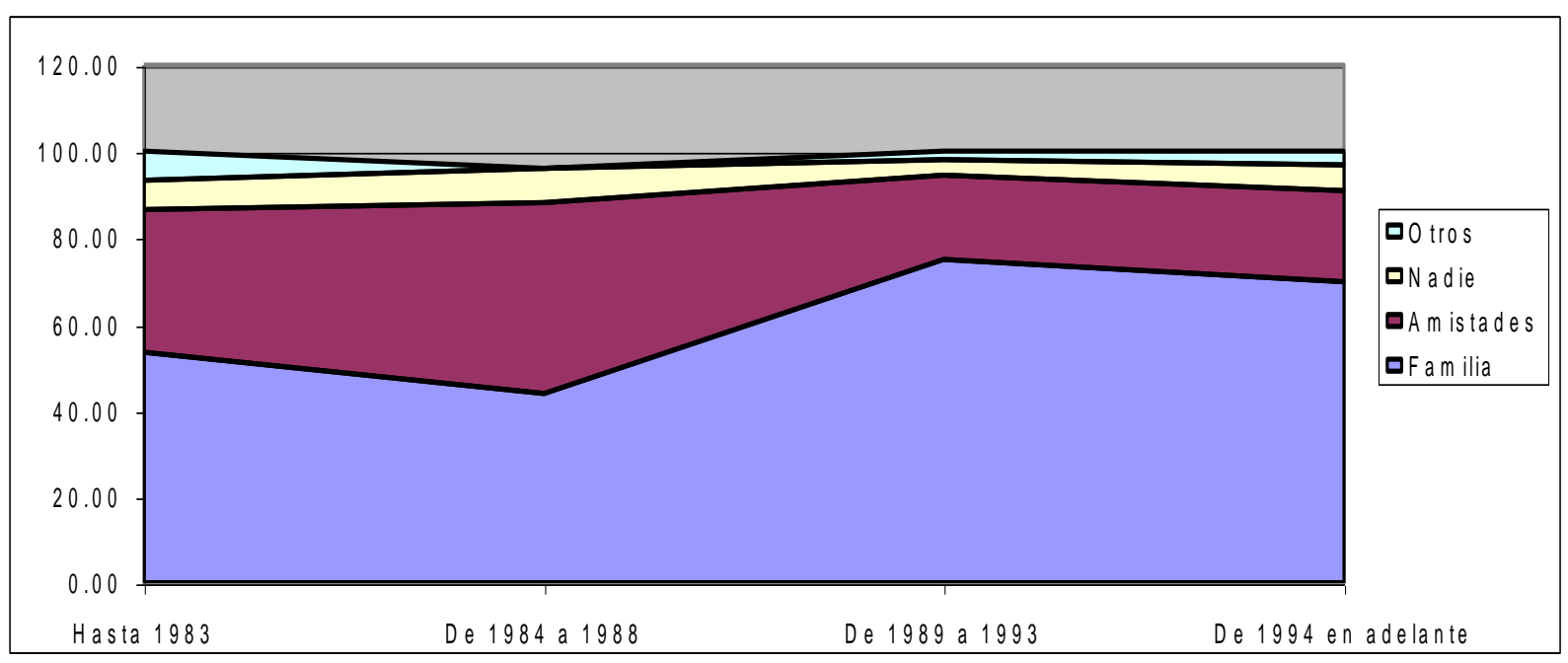


RECOMENDACIÓN PARA EL TRABAJO

Hombres (1er. Trabajo en E. U. A.)

\begin{tabular}{|c|r|r|r|r|}
\hline Cohorte & \multicolumn{1}{|c|}{ Familia } & \multicolumn{1}{c|}{ Amistades } & \multicolumn{1}{c|}{ Nadie } & \multicolumn{1}{c|}{ Otros } \\
\hline Hasta 1983 & 31.70 & 46.00 & 17.50 & 4.80 \\
\hline De 1984 a 1988 & 52.90 & 35.70 & 7.10 & 4.30 \\
\hline De 1989 a 1993 & 48.40 & 36.30 & 13.00 & 2.10 \\
\hline De 1994 en adelante & 43.40 & 33.70 & 20.50 & 2.40 \\
\hline
\end{tabular}

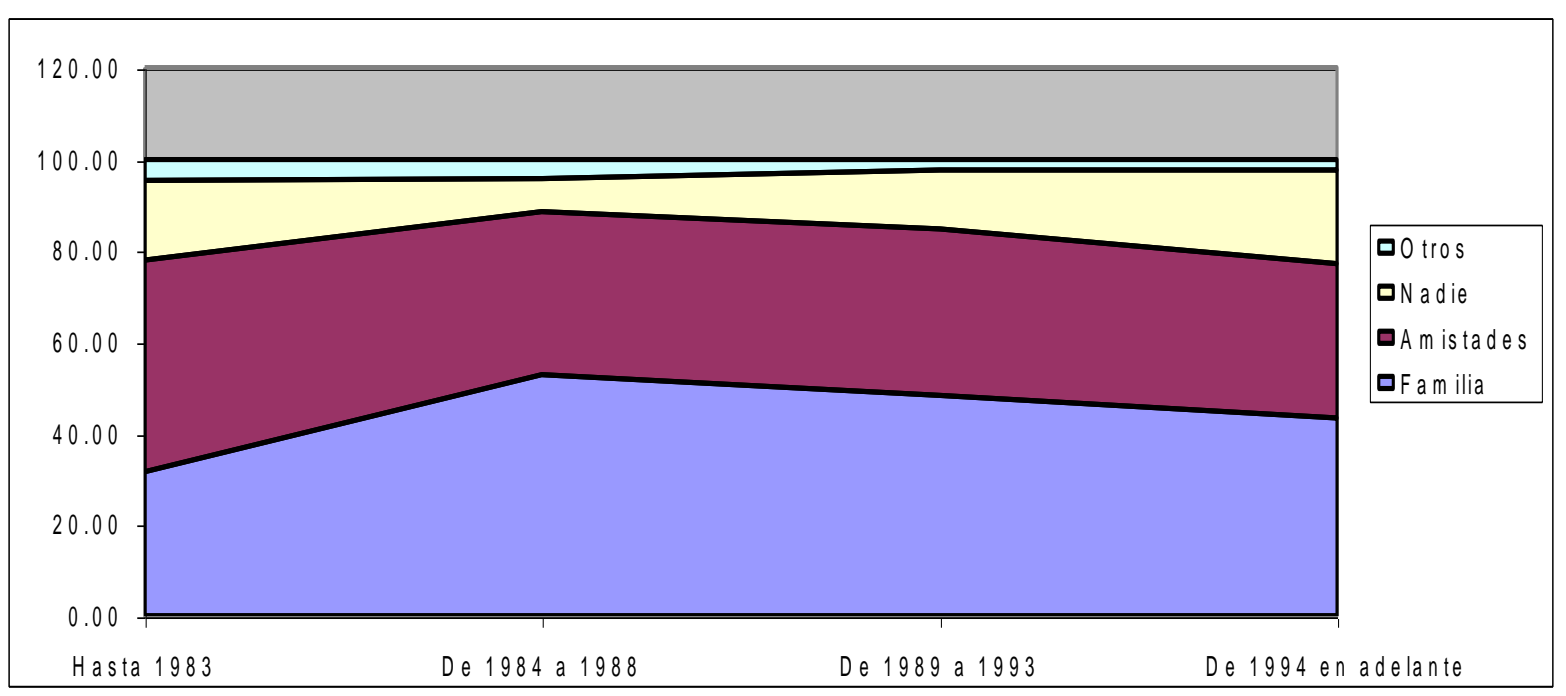

RECOMENDACIÓN PARA EL TRABAJO

Mujeres (1er. Trabajo en E. U. A.)

\begin{tabular}{|c|r|r|r|r|}
\hline Cohorte & \multicolumn{1}{|c|}{ Familia } & \multicolumn{1}{c|}{ Amistades } & \multicolumn{1}{c|}{ Nadie } & \multicolumn{1}{c|}{ Otros } \\
\hline Hasta 1983 & 50.00 & 28.60 & 14.30 & 7.10 \\
\hline De 1984 a 1988 & 41.70 & 50.00 & 8.30 & 0.00 \\
\hline De 1989 a 1993 & 75.00 & 18.80 & 4.50 & 1.80 \\
\hline De 1994 en adelante & 69.70 & 21.10 & 6.10 & 3.00 \\
\hline
\end{tabular}

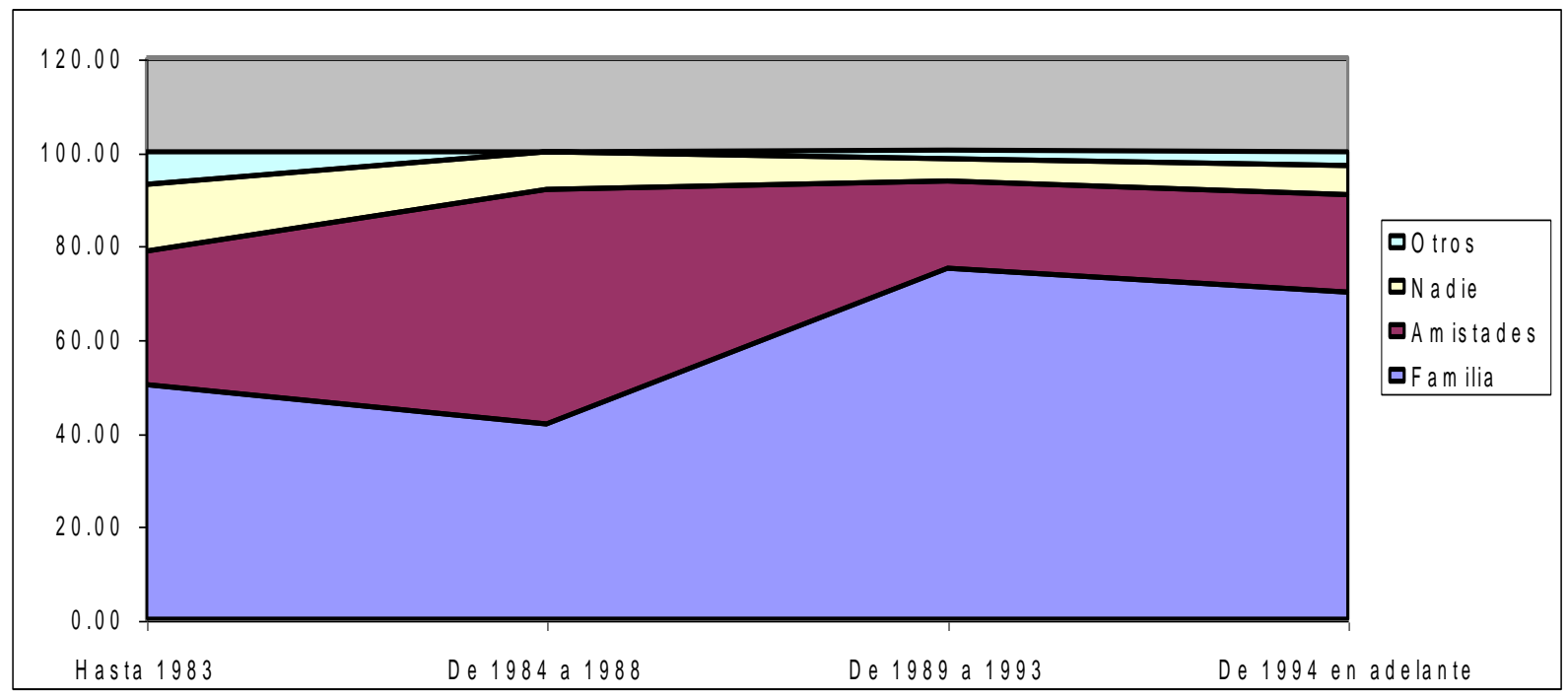


DESTINO DE LAS REMESAS

Hombres (1er. Trabajo en E. U. A.)

\begin{tabular}{|c|r|r|r|r|r|r|r|}
\hline Cohorte & Cónyuge & \multicolumn{1}{c|}{ Padres } & \multicolumn{1}{c|}{ Hijos } & Otros familiares & Inversión & Otros & No envió \\
\hline Hasta 1983 & 34.40 & 43.80 & 4.70 & 1.60 & 9.40 & 4.70 & 1.60 \\
\hline De 1984 a 1988 & 37.10 & 45.70 & 4.30 & 1.40 & 5.70 & 5.70 & 0.00 \\
\hline De 1989 a 1993 & 25.60 & 54.60 & 1.00 & 1.90 & 12.10 & 2.40 & 2.40 \\
\hline De 1994 en adelante & 32.10 & 46.90 & 0.00 & 0.00 & 13.60 & 3.70 & 3.70 \\
\hline
\end{tabular}

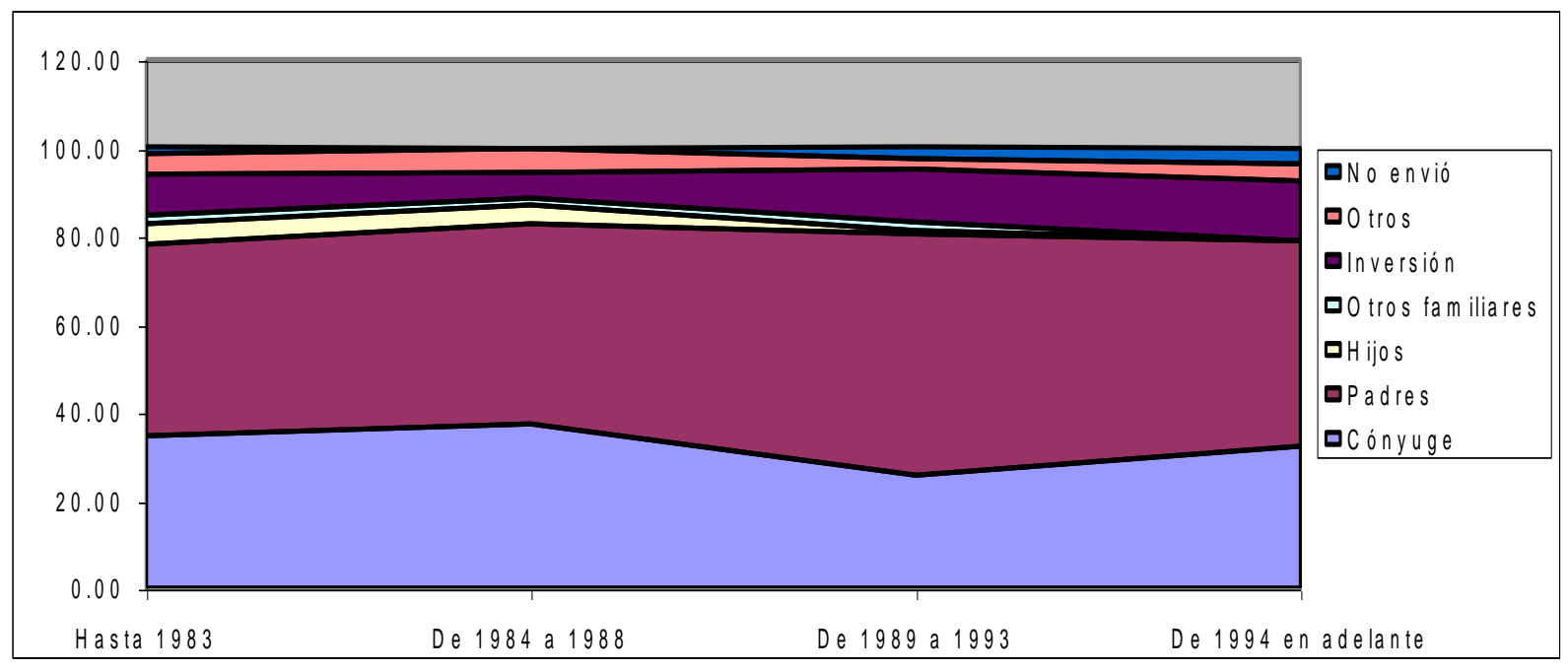

DESTINO DE LAS REMESAS

Mujeres (1er. Trabajo en E. U. A.)

\begin{tabular}{|c|r|r|r|r|r|r|r|}
\hline Cohorte & Cónyuge & Padres & Hijos & Otros familiares & Inversión & Otros & No envió \\
\hline Hasta 1983 & 0.00 & 66.70 & 16.70 & 0.00 & 8.30 & 8.30 & 0.00 \\
\hline De 1984 a 1988 & 12.50 & 50.00 & 8.30 & 0.00 & 16.70 & 12.50 & 0.00 \\
\hline De 1989 a 1993 & 5.00 & 75.00 & 11.00 & 1.00 & 5.00 & 2.00 & 1.00 \\
\hline De 1994 en adelante & 10.00 & 60.00 & 6.70 & 3.30 & 3.30 & 16.70 & 0.00 \\
\hline
\end{tabular}

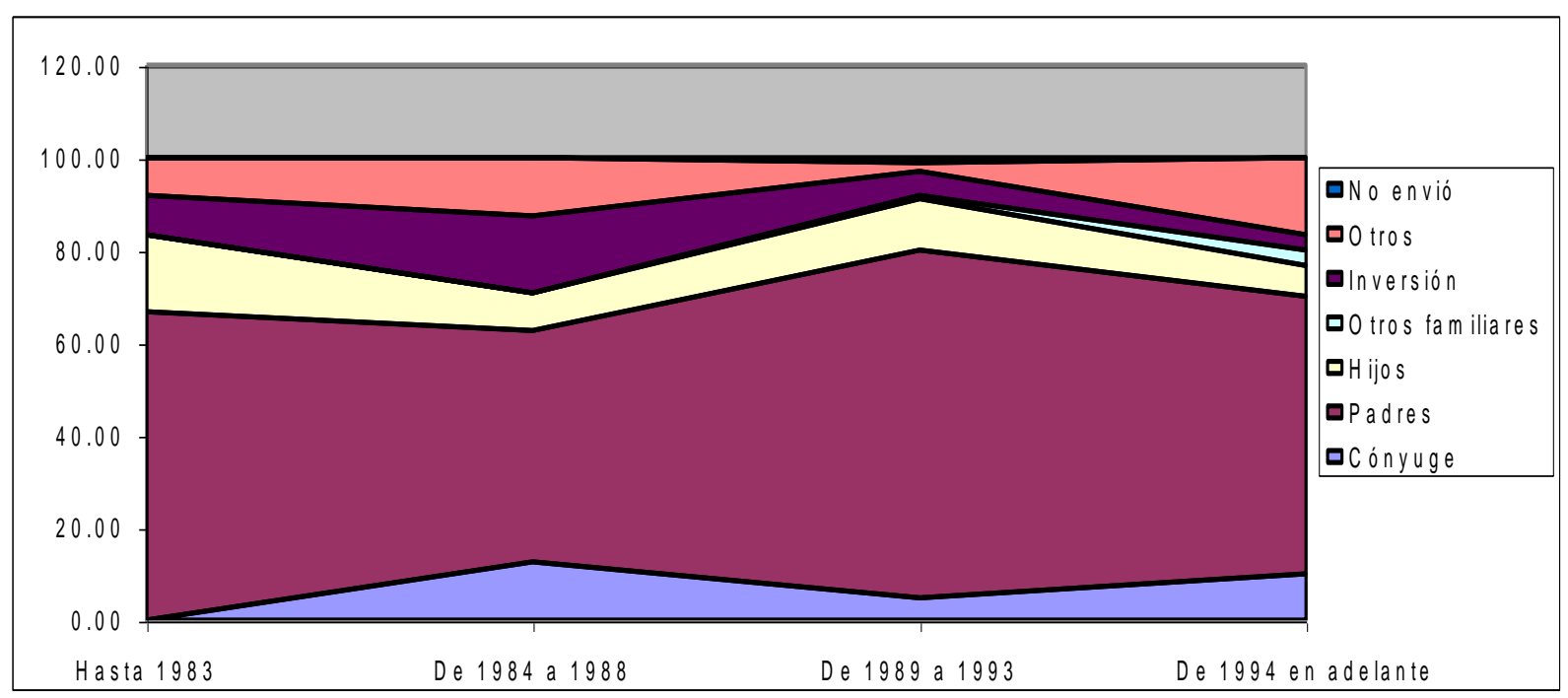


RAZÓN PARA DEJAR EL TRABAJO

Hombres (1er. Trabajo en E.U.A.)

\begin{tabular}{|c|r|r|r|r|r|r|r|r|}
\hline Cohorte & $\begin{array}{c}\text { Econó- } \\
\text { micas }\end{array}$ & $\begin{array}{c}\text { Fami- } \\
\text { liares }\end{array}$ & $\begin{array}{c}\text { Descontento } \\
\text { con trabajo }\end{array}$ & $\begin{array}{c}\text { Despido, } \\
\text { recorte, quiebra }\end{array}$ & $\begin{array}{c}\text { Superación/ } \\
\text { estudios }\end{array}$ & $\begin{array}{c}\text { Status } \\
\text { legal/racismo }\end{array}$ & Embarazo & Otro \\
\hline Hasta 1983 & 17.40 & 27.50 & 10.10 & 13.00 & 8.70 & 1.40 & 0.00 & 21.70 \\
\hline De 1984 a 1988 & 17.60 & 36.50 & 14.90 & 8.20 & 5.40 & 1.40 & 0.00 & 16.20 \\
\hline De 1989 a 1993 & 13.70 & 46.10 & 18.30 & 6.40 & 2.30 & 0.50 & 0.50 & 12.30 \\
\hline De 1994 en adelante & 14.00 & 40.70 & 16.30 & 7.00 & 8.10 & 1.20 & 0.00 & 12.80 \\
\hline
\end{tabular}

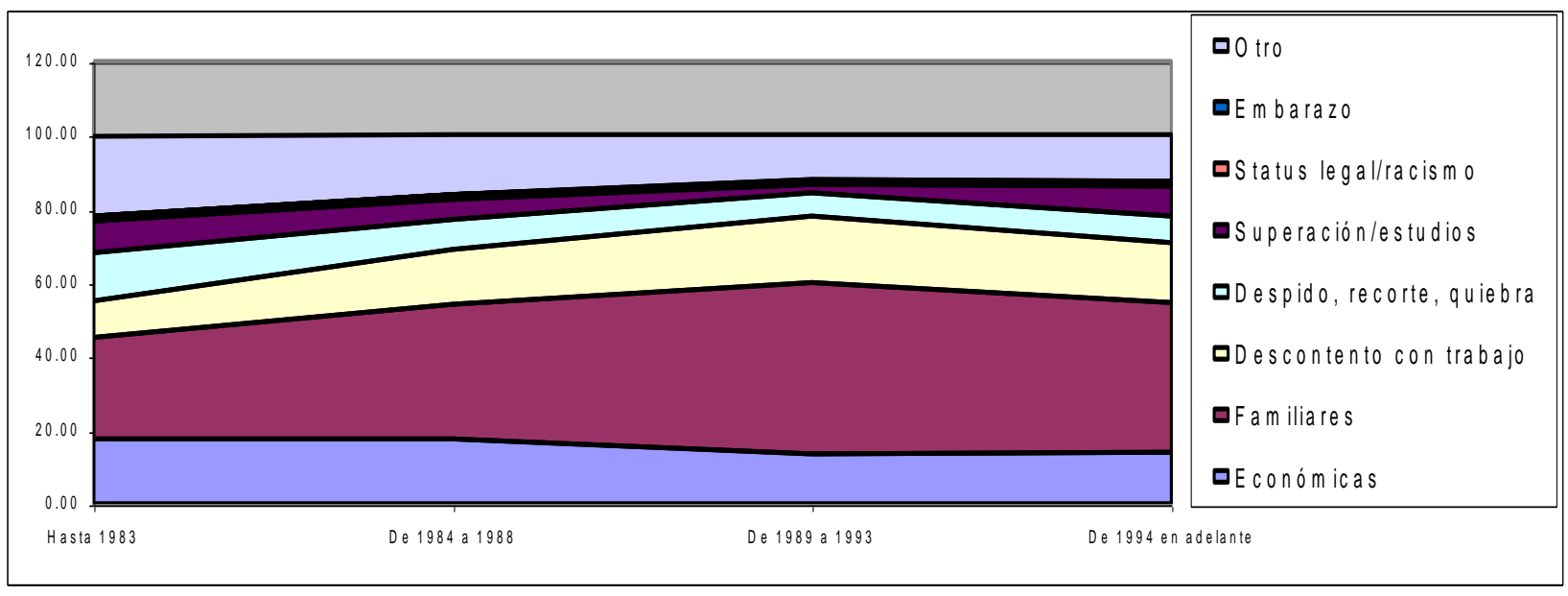

RAZÓN PARA DEJAR EL TRABAJO

Mujeres (1er. Trabajo en E.U.A.)

\begin{tabular}{|c|r|r|r|r|r|r|r|r|}
\hline Cohorte & $\begin{array}{c}\text { Econó- } \\
\text { micas }\end{array}$ & $\begin{array}{c}\text { Fami- } \\
\text { liares }\end{array}$ & $\begin{array}{c}\text { Descontento } \\
\text { con trabajo }\end{array}$ & $\begin{array}{c}\text { Despido, } \\
\text { recorte, quiebra }\end{array}$ & $\begin{array}{c}\text { Superación/ } \\
\text { estudios }\end{array}$ & $\begin{array}{c}\text { Status } \\
\text { legal/racismo }\end{array}$ & Embarazo & Otro \\
\hline Hasta 1983 & 12.50 & 31.30 & 12.50 & 12.60 & 6.30 & 6.30 & 0.00 & 18.80 \\
\hline De 1984 a 1988 & 10.70 & 32.10 & 10.70 & 10.70 & 0.00 & 0.00 & 7.10 & 28.60 \\
\hline De 1989 a 1993 & 13.60 & 50.80 & 15.30 & 4.20 & 0.00 & 0.80 & 2.50 & 12.70 \\
\hline $\begin{array}{c}\text { De 1994 en } \\
\text { adelante }\end{array}$ & 13.20 & 42.10 & 15.80 & 5.20 & 7.90 & 0.00 & 2.60 & 13.20 \\
\hline
\end{tabular}

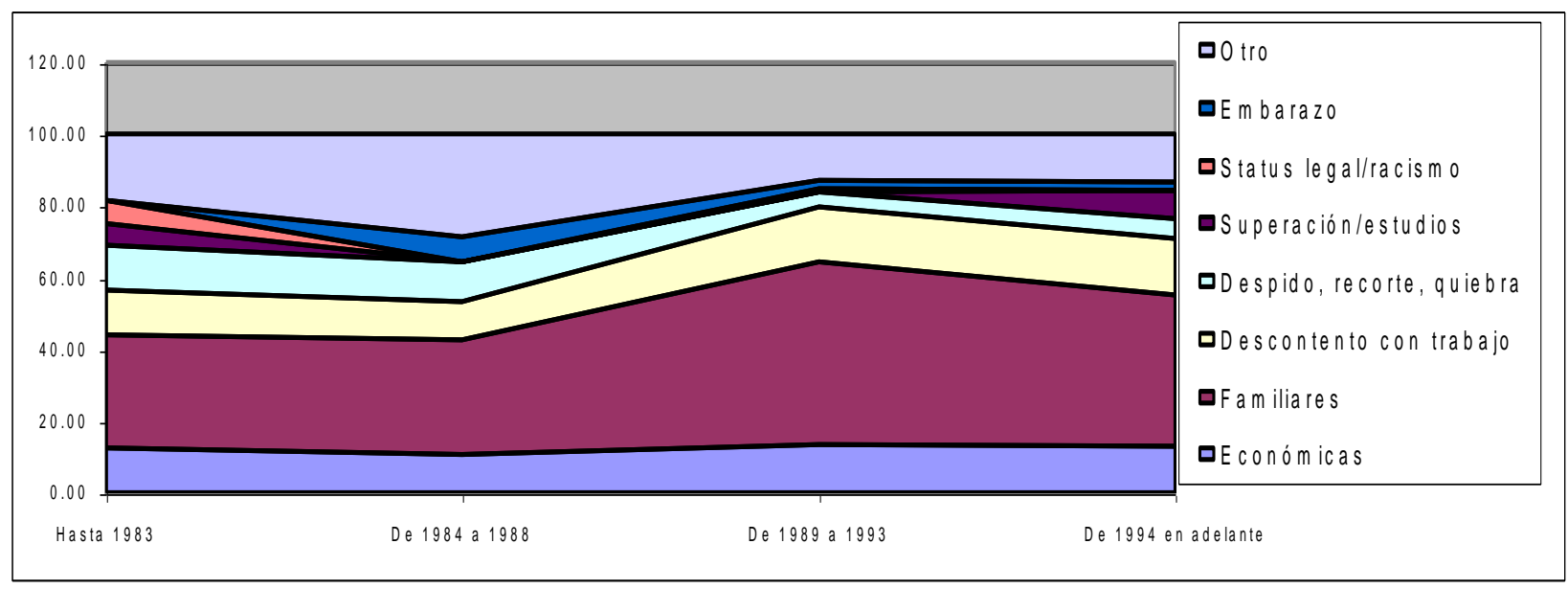


Ayuda para traslado de la TL en EUA (mujeres)\%:

\begin{tabular}{|c|r|r|r|r|r|}
\hline Ayuda trasl./Evento & \multicolumn{1}{|c|}{$1^{\circ}$} & \multicolumn{1}{c|}{$2^{\circ}$} & \multicolumn{1}{c|}{$3^{\circ}$} & \multicolumn{1}{c|}{$4^{\circ}$} & \multicolumn{1}{c|}{$5^{\circ} \mathrm{y}+$} \\
\hline Fam ilia & 87.20 & 76.90 & 68.30 & 50.00 & 40.00 \\
\hline Am igos & 12.80 & 8.50 & 5.30 & 0.00 & 0.00 \\
\hline Ya trabajó alli & 0.00 & 14.60 & 21.10 & 50.00 & 60.00 \\
\hline Nadie & 0.00 & 0.00 & 5.30 & 0.00 & 0.00 \\
\hline Total & 100.00 & 100.00 & 100.00 & 100.00 & 100.00 \\
\hline N & 200 & 116 & 45 & 21 & 33 \\
\hline
\end{tabular}

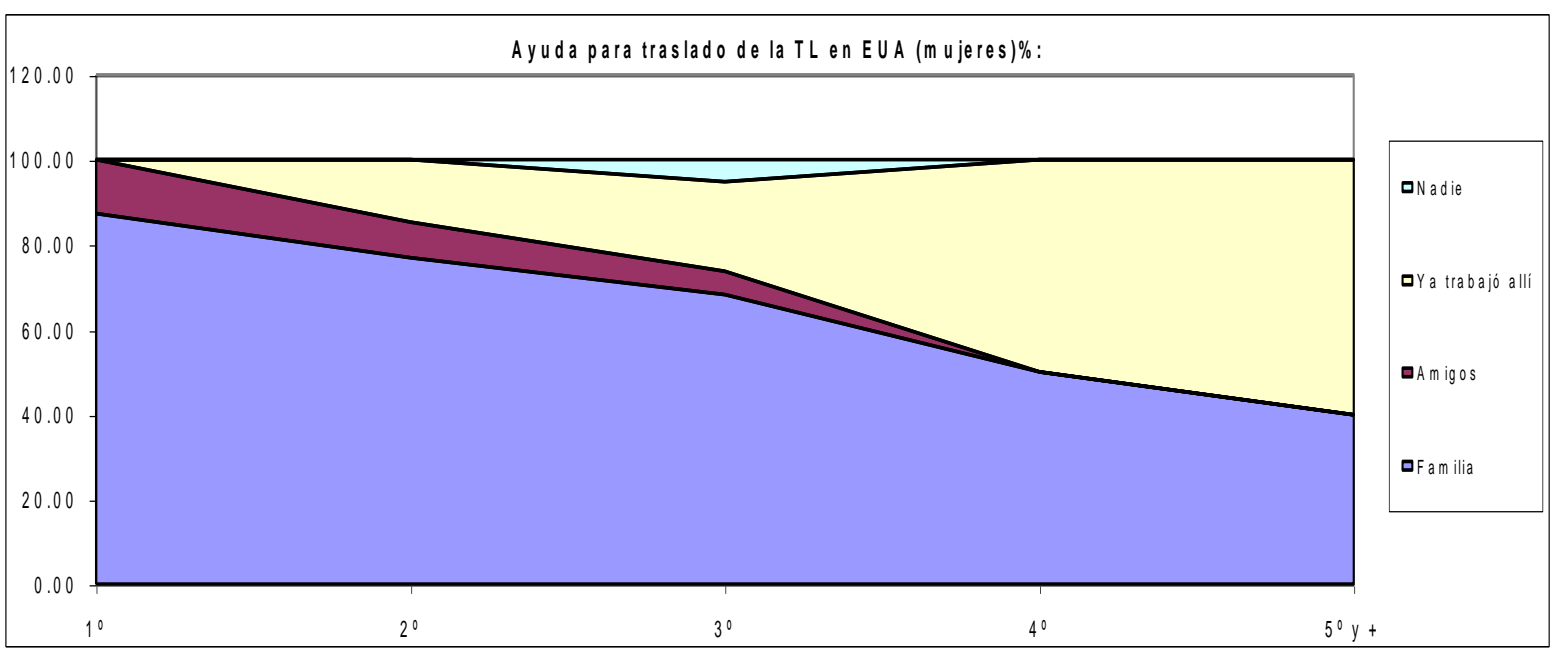

Ayuda para traslado de la TL en EUA (hombres)\%:

\begin{tabular}{|c|c|c|c|c|c|}
\hline Ayuda tras l./Evento & 10 & $2 ?$ & $3 ?$ & $4 !$ & $50 y+$ \\
\hline Fam ilia & 63.20 & 55.00 & 52.20 & 43.90 & 64.28 \\
\hline Amigos & 24.70 & 24.50 & 20.00 & 17.10 & 10.83 \\
\hline Y a trabajó allí & 0.00 & 17.00 & 25.60 & 36.60 & 24.88 \\
\hline Nadie & 12.10 & 3.50 & 2.20 & 2.40 & 0.00 \\
\hline Total & 100.00 & 100.00 & 100.00 & 100.00 & 100.00 \\
\hline $\mathrm{N}$ & 448 & 277 & 118 & 68 & 74 \\
\hline
\end{tabular}

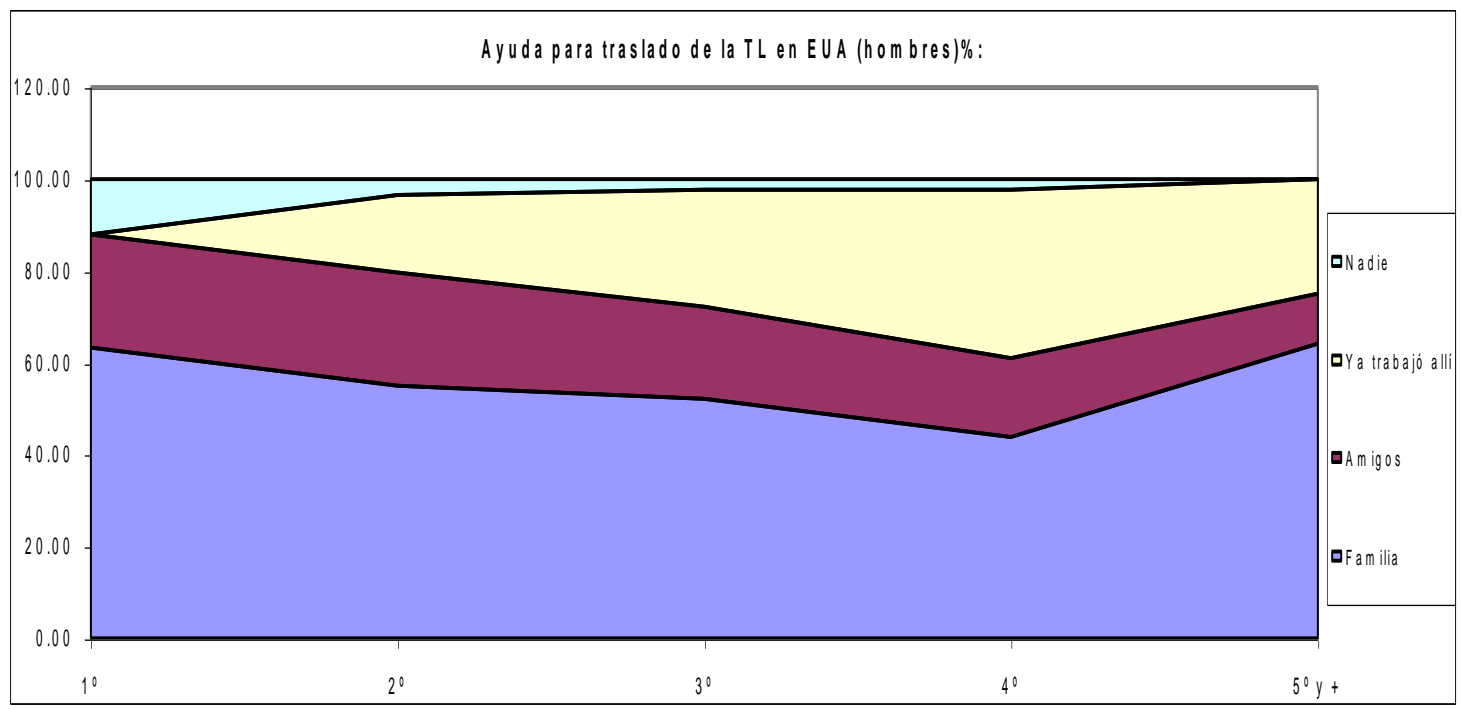


Ayuda para alojam iento de la TL en EUA (mujeres)\%:

\begin{tabular}{|c|r|r|r|r|r|}
\hline Ayuda a loj./Evento & \multicolumn{1}{|c|}{$1^{\circ}$} & \multicolumn{1}{c|}{$2^{\circ}$} & \multicolumn{1}{c|}{$3^{\circ}$} & \multicolumn{1}{c|}{$4^{\circ}$} & \multicolumn{1}{c}{$5^{\circ} \mathrm{y}+$} \\
\hline Fam ilia & 86.90 & 81.30 & 75.00 & 88.90 & 85.70 \\
\hline Am igos & 12.60 & 9.90 & 3.60 & 11.10 & 14.30 \\
\hline Ya trabajó allí & 0.00 & 8.80 & 14.30 & 0.00 & 0.00 \\
\hline Nadie & 0.50 & 0.00 & 7.10 & 0.00 & 0.00 \\
\hline Total & 100.00 & 100.00 & 100.00 & 100.00 & 100.00 \\
\hline N & \multicolumn{1}{|c|}{200} & 116 & 45 & 21 & 33 \\
\hline
\end{tabular}

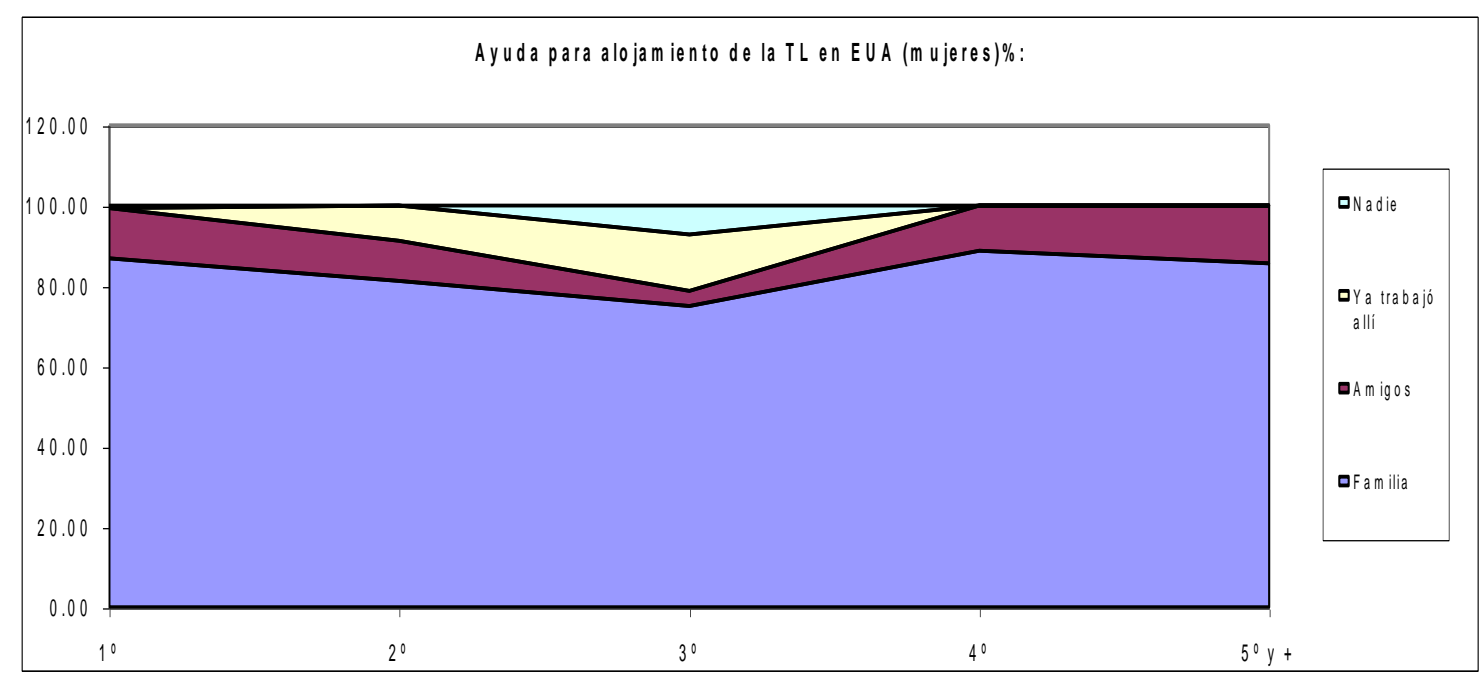


Ayuda para alojam iento de la TL en EUA (hombres)\%:

\begin{tabular}{|c|c|c|c|c|c|}
\hline Ayuda a loj. Evento & $1 ?$ & $2 \stackrel{0}{ }$ & $3 !$ & $4^{0}$ & $5 \div y+$ \\
\hline Familia & 66.00 & 62.80 & 62.10 & 60.40 & 54.85 \\
\hline Amigos & 27.70 & 26.80 & 26.30 & 27.10 & 24.53 \\
\hline Ya trabajó allí & 0.00 & 7.10 & 9.50 & 8.30 & 19.38 \\
\hline Nadie & 6.30 & 3.30 & 2.10 & 4.20 & 1.23 \\
\hline Total & 100.00 & 100.00 & 100.00 & 100.00 & 100.00 \\
\hline $\mathrm{N}$ & 448 & 277 & 118 & 68 & 74 \\
\hline
\end{tabular}

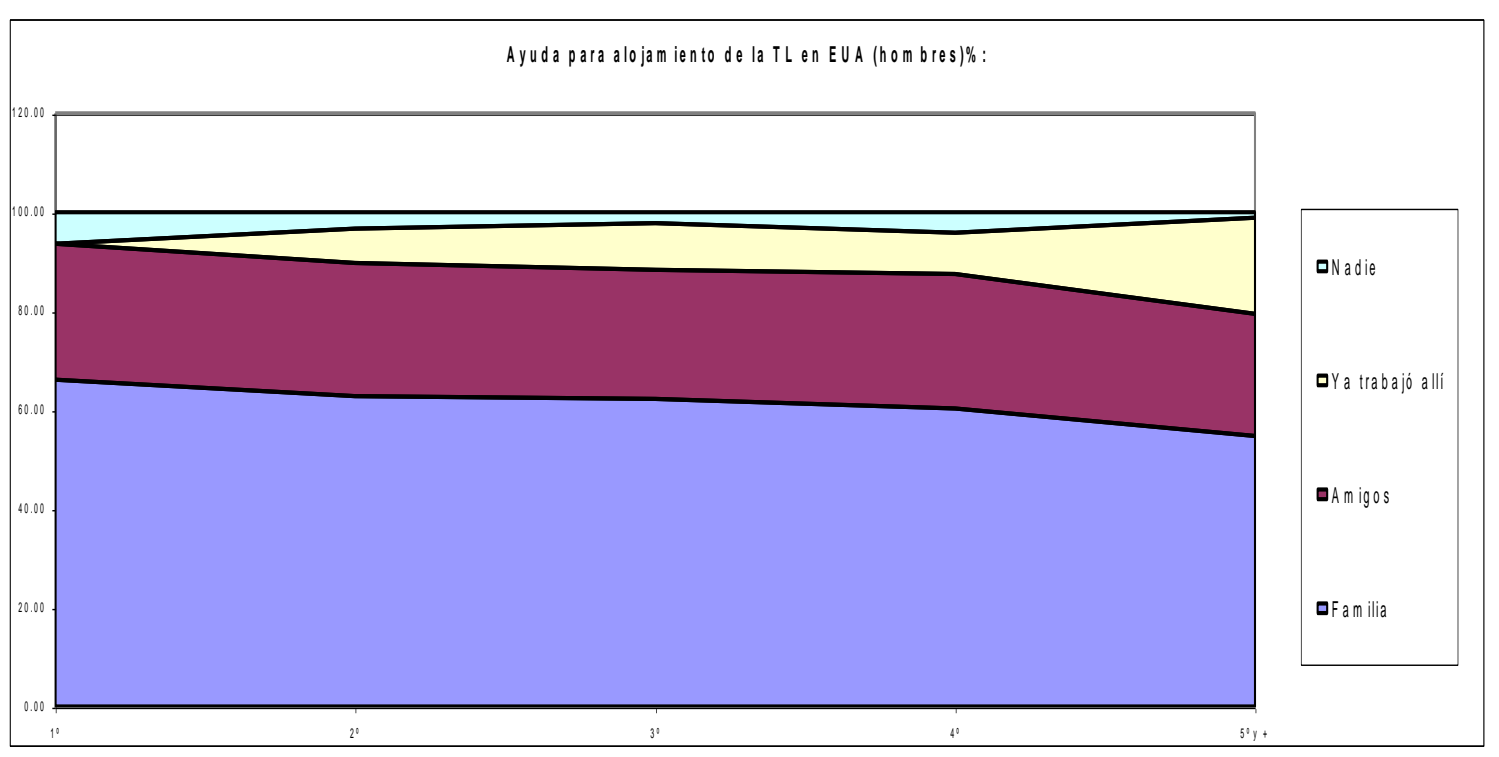


Fuente de información de la TL en EUA (mujeres)\%:

\begin{tabular}{|c|c|c|c|c|c|}
\hline Fuente/Evento & 19 & $2 ?$ & $3 !$ & $4 !$ & $5 \div y+$ \\
\hline Fam ilia & 67.90 & 59.80 & 41.50 & 17.60 & 7.10 \\
\hline Amigos & 25.00 & 23.70 & 26.80 & 35.40 & 35.80 \\
\hline Ya trab.allí & 0.00 & 1.00 & 0.00 & 17.60 & 21.40 \\
\hline Nadie & 4.90 & 13.40 & 29.30 & 11.80 & 25.00 \\
\hline Pren./Rad./T v./Vol./Anun. & 0.00 & 0.00 & 0.00 & 0.00 & 3.60 \\
\hline Otros medios & 2.20 & 2.10 & 2.40 & 17.60 & 7.10 \\
\hline Total & 100.00 & 100.00 & 100.00 & 100.00 & 100.00 \\
\hline $\mathrm{N}$ & 200 & 116 & 45 & 21 & 33 \\
\hline
\end{tabular}

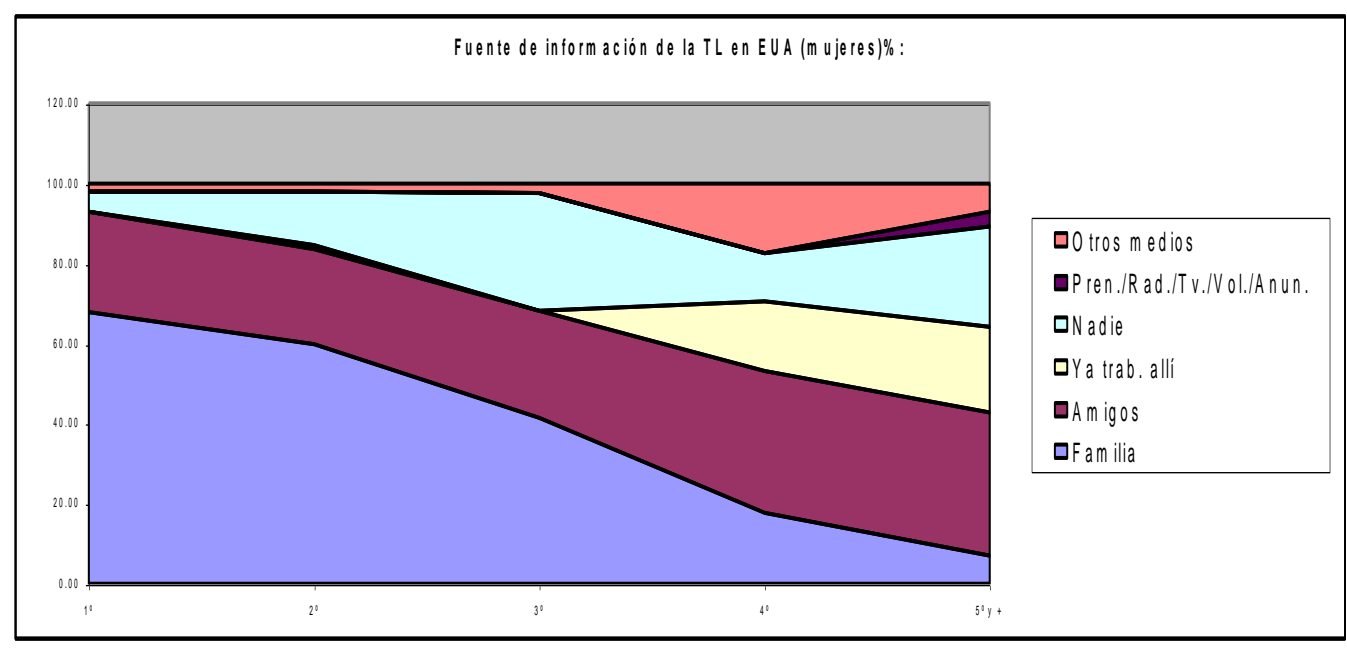

Fuente de información de la TL en EUA (hombres)\%:

\begin{tabular}{|c|r|r|r|r|r|}
\hline Fuente/Evento & \multicolumn{1}{|c|}{$1^{0}$} & \multicolumn{1}{c|}{$2^{0}$} & \multicolumn{1}{c|}{$3^{0}$} & \multicolumn{1}{c|}{$4^{0}$} & \multicolumn{1}{c|}{$5^{\circ}+$} \\
\hline Fam ilia & 45.40 & 36.50 & 26.40 & 23.70 & 11.93 \\
\hline Amigos & 42.70 & 40.50 & 42.70 & 35.60 & 49.17 \\
\hline Ya trab.alli & 0.00 & 4.50 & 7.30 & 11.90 & 13.27 \\
\hline Nadie & 6.30 & 11.70 & 11.80 & 16.90 & 14.60 \\
\hline Otros medios & 5.60 & 6.80 & 11.80 & 11.90 & 11.03 \\
\hline Total & 100.00 & 100.00 & 100.00 & 100.00 & 100.00 \\
\hline N & 448 & 277 & 118 & 68 & 74 \\
\hline
\end{tabular}

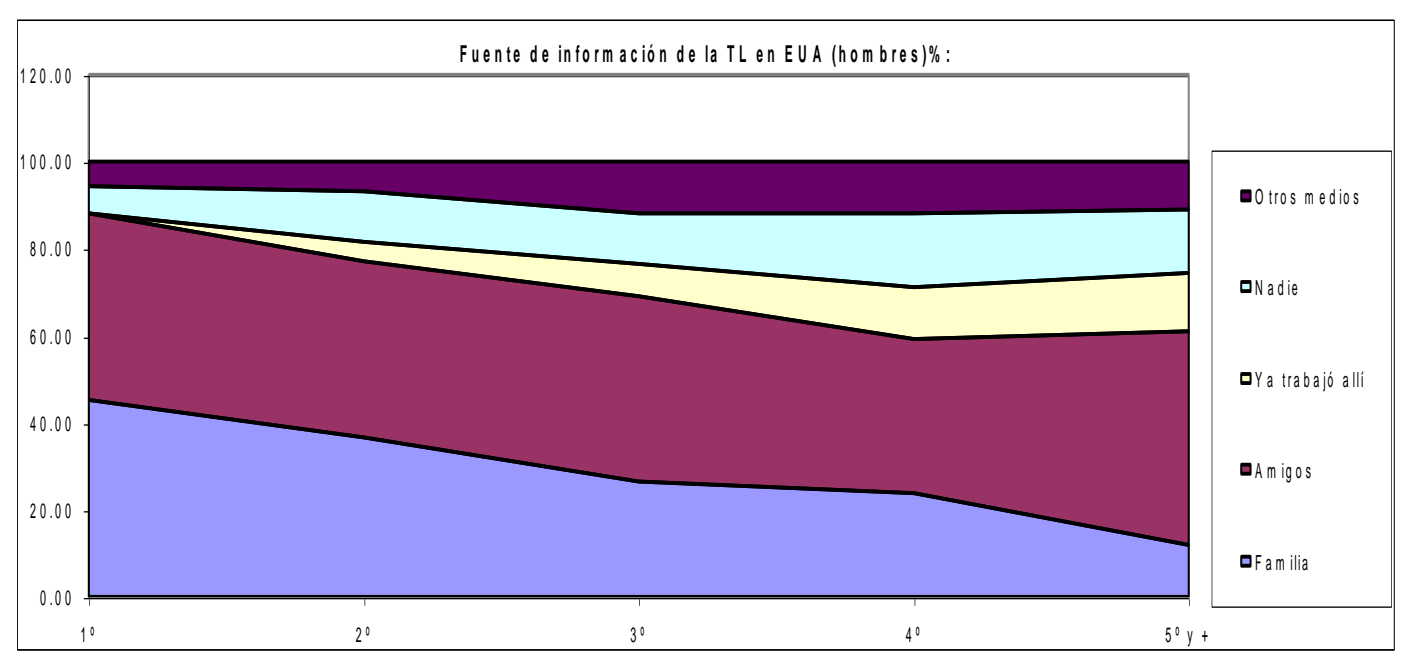


Recomendación para entrar de la TL en EUA (hombres)\%:

\begin{tabular}{|c|c|c|c|c|c|}
\hline Recomend. IEvento & $1 \stackrel{0}{1}$ & $2 \stackrel{0}{ }$ & $3 !$ & 40 & $5 \div y+$ \\
\hline Fam ilia & 45.90 & 38.80 & 27.90 & 16.90 & 17.53 \\
\hline $\mathrm{Amigos}$ & 37.30 & 36.10 & 34.30 & 35.60 & 51.90 \\
\hline Ya trabajó allí & 0.00 & 2.00 & 4.50 & 8.50 & 6.30 \\
\hline Nadie & 14.20 & 18.30 & 24.30 & 30.50 & 21.23 \\
\hline Otros medios & 2.60 & 4.80 & 9.00 & 8.50 & 3.03 \\
\hline Total & 100.00 & 100.00 & 100.00 & 100.00 & 100.00 \\
\hline $\mathrm{N}$ & 448 & 277 & 118 & 68 & 74 \\
\hline
\end{tabular}

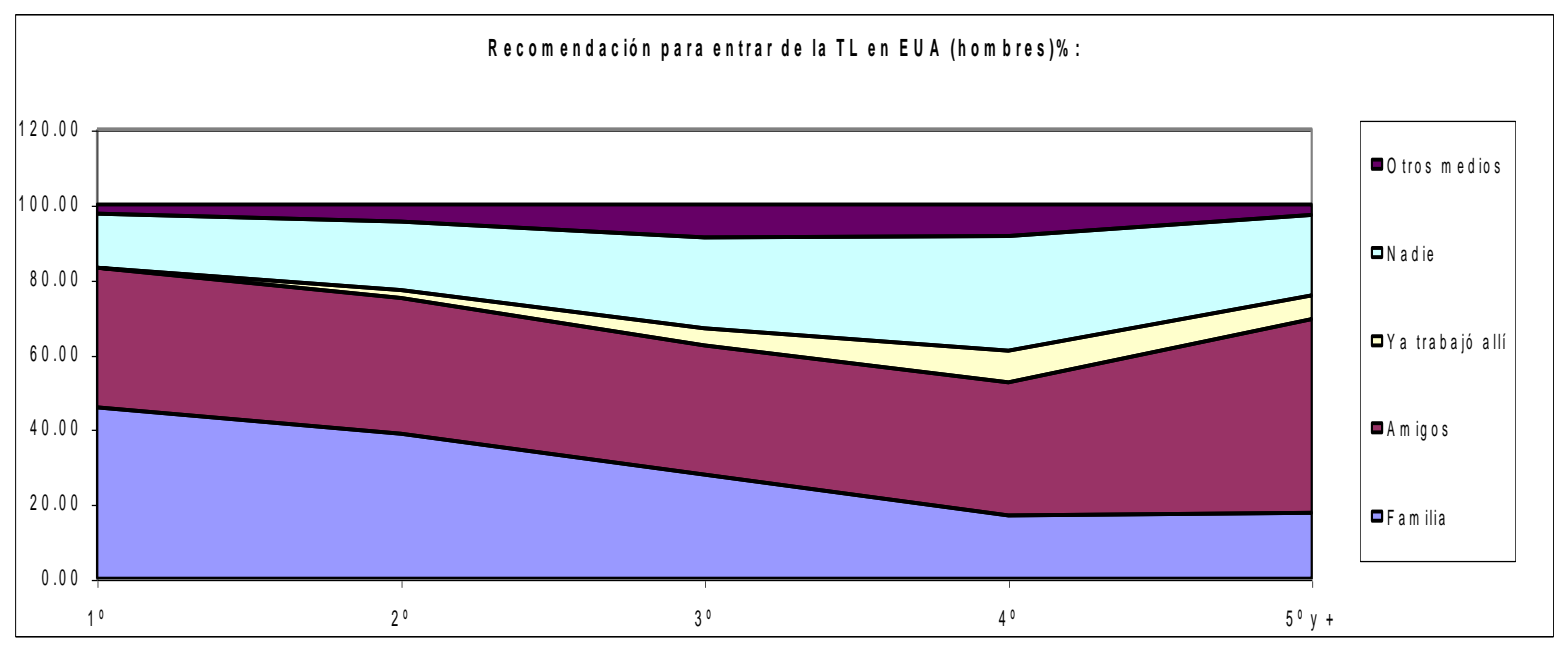

Recomendación para entrar de la TL en EUA (mujeres)\%:

\begin{tabular}{|c|c|c|c|c|c|}
\hline Recomend./Evento & $1 \%$ & $2 \stackrel{0}{2}-10$ & $3 \stackrel{0}{\circ}$ & 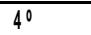 & $5 \div y+$ \\
\hline Fam ilia & 68.20 & 59.80 & 43.50 & 23.50 & 7.40 \\
\hline Amigos & 24.20 & 23.70 & 23.10 & 35.30 & 29.60 \\
\hline Ya trabajó allí & 0.00 & 1.00 & 0.00 & 11.80 & 14.80 \\
\hline Nadie & 6.00 & 13.40 & 30.80 & 17.60 & 40.80 \\
\hline Agencias & 0.00 & 0.00 & 0.00 & 0.00 & 7.40 \\
\hline Otros medios & 1.60 & 2.10 & 2.60 & 11.80 & 0.00 \\
\hline Total & 100.00 & 100.00 & 100.00 & 100.00 & 100.00 \\
\hline $\mathrm{N}$ & 200 & 116 & 45 & 21 & 33 \\
\hline
\end{tabular}

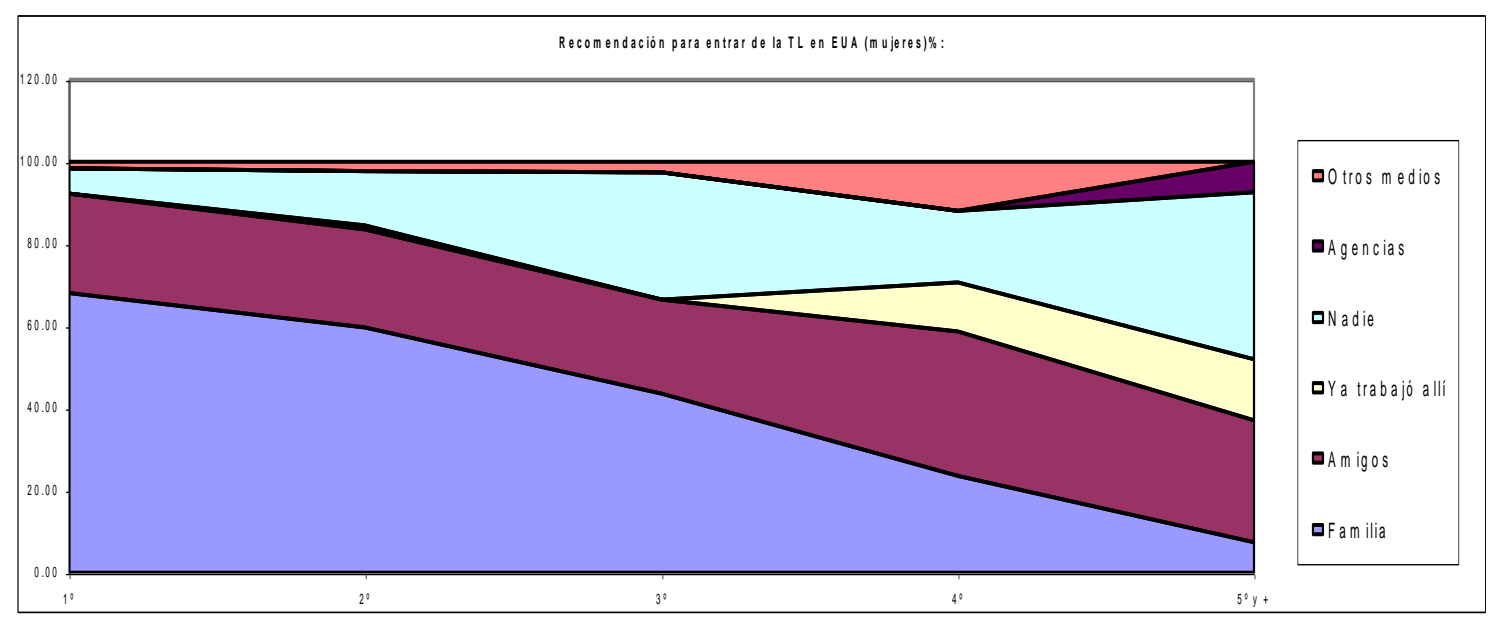


Destino mayor de remesas de la TL en EUA (mujeres)\%:

\begin{tabular}{|c|r|r|r|r|r|}
\hline Destino/Evento & \multicolumn{1}{|c|}{$1^{\circ}$} & \multicolumn{1}{c|}{$2^{\circ}$} & \multicolumn{1}{c|}{3.} & \multicolumn{1}{c|}{$4^{\circ}$} & \multicolumn{1}{c}{$5^{\circ} \mathrm{y}$} \\
\hline Cónyuge & 6.60 & 8.00 & 3.20 & 0.00 & 37.40 \\
\hline Padres & 68.20 & 67.00 & 45.10 & 12.50 & 12.50 \\
\hline Hijos & 10.20 & 8.00 & 16.10 & 12.50 & 25.00 \\
\hline Inversión & 6.60 & 9.10 & 6.50 & 12.50 & 0.00 \\
\hline Otros fam iliares & 1.20 & 3.40 & 19.40 & 25.00 & 6.30 \\
\hline Otro & 6.60 & 0.00 & 3.20 & 12.50 & 0.00 \\
\hline No envió & 0.60 & 4.50 & 6.50 & 25.00 & 18.80 \\
\hline Total & 100.00 & 100.00 & 100.00 & 100.00 & 100.00 \\
\hline N & 200 & 116 & 45 & 21 & 33 \\
\hline
\end{tabular}

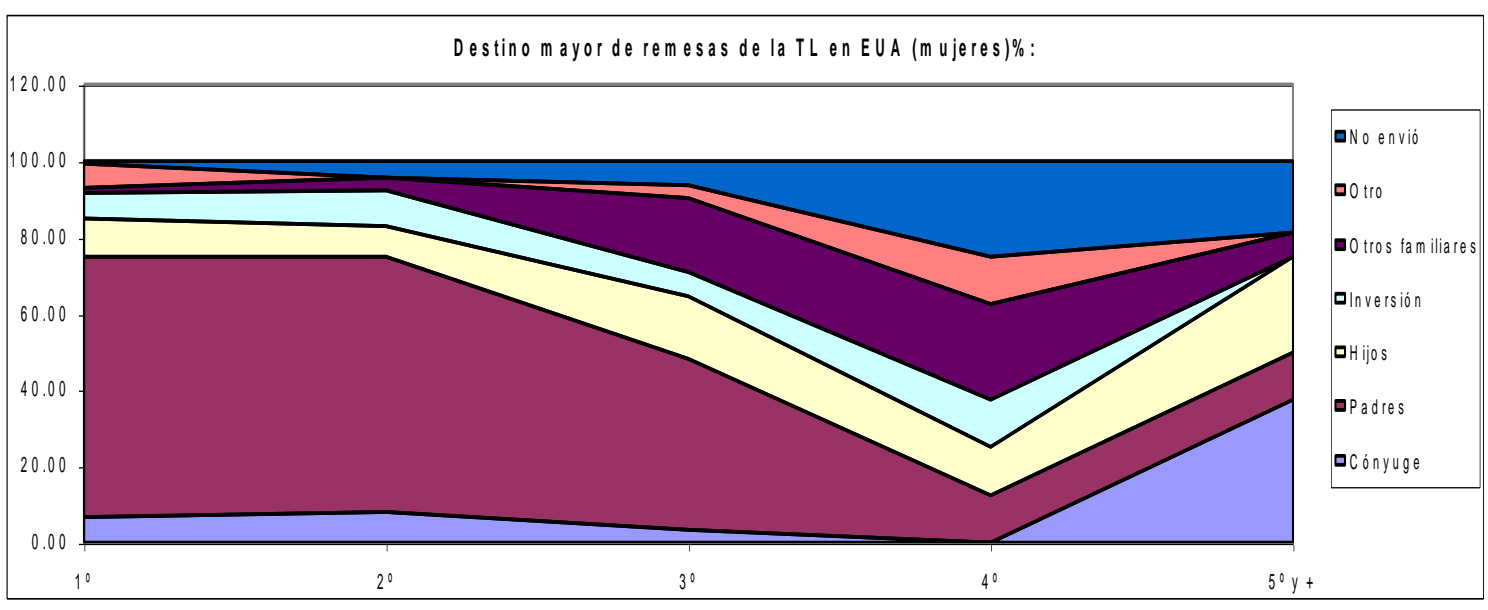

Destino mayor de remesas de la TL en EUA (hombres)\%:

\begin{tabular}{|c|c|c|c|c|c|}
\hline Destino/Evento & $1 \stackrel{0}{ }$ & 29 & $3 ?$ & 4 ? & $5^{0} y+$ \\
\hline Conyuge & 30.10 & 28.20 & 21.90 & 17.50 & 16.17 \\
\hline Padres & 50.00 & 45.50 & 38.00 & 36.80 & 33.35 \\
\hline Hijos & 1.90 & 6.00 & 7.60 & 8.80 & 24.52 \\
\hline Inversión & 10.90 & 14.70 & 22.90 & 22.80 & 12.60 \\
\hline 0 tros fam iliares & 1.40 & 2.80 & 4.80 & 5.30 & 1.00 \\
\hline 0 tro & 3.60 & 0.40 & 0.00 & 0.00 & 0.00 \\
\hline No envió & 2.10 & 2.40 & 4.80 & 8.80 & 12.37 \\
\hline Total & 100.00 & 100.00 & 100.00 & 100.00 & 100.00 \\
\hline $\mathrm{N}$ & 448 & 277 & 118 & 68 & 74 \\
\hline
\end{tabular}

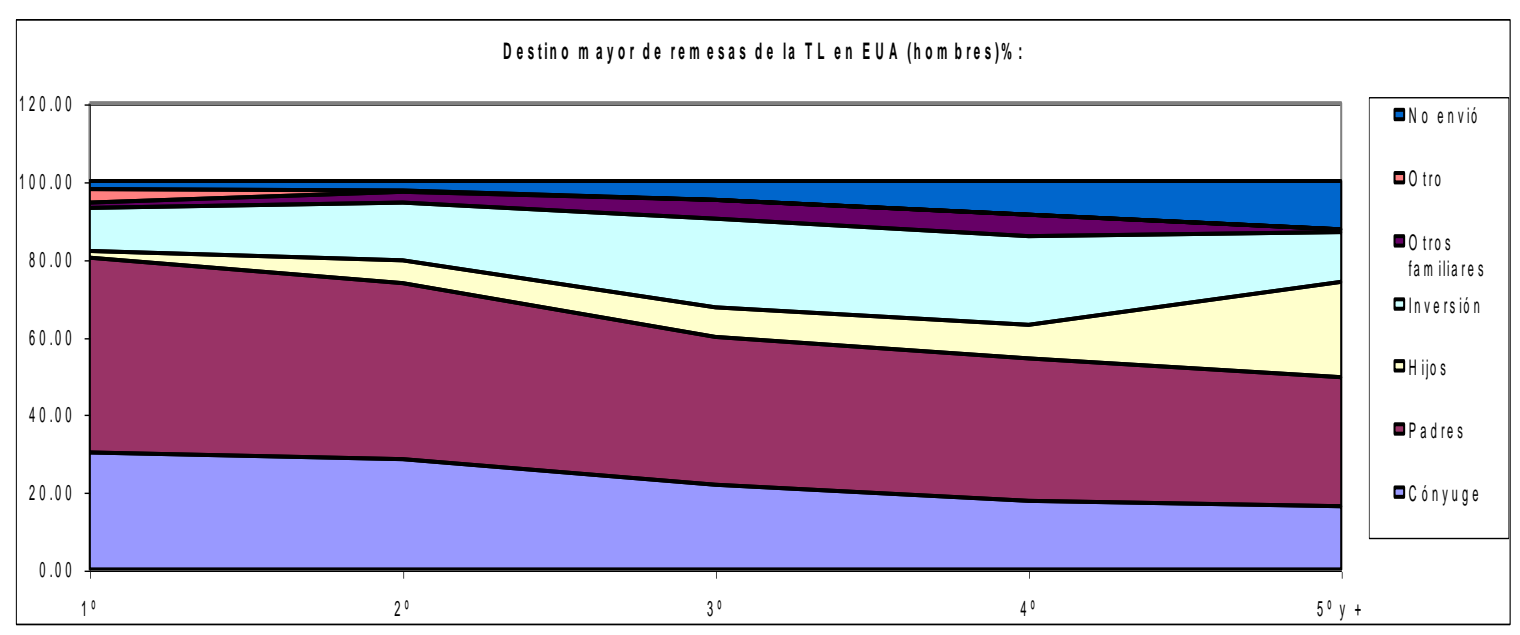


Razón para cambio de la TL en EUA (mujeres)\%:

\begin{tabular}{|c|c|c|c|c|c|}
\hline Destinolevento & $1^{\circ}$ & $2 !$ & $3 !$ & $4^{\circ}$ & $5 \div y+$ \\
\hline Dinero & 15.40 & 15.10 & 23.40 & 27.30 & 30.00 \\
\hline Fam ilia/em barazo & 56.70 & 62.80 & 36.70 & 27.30 & 15.00 \\
\hline Descontento & 17.20 & 8.10 & 20.00 & 0.00 & 25.00 \\
\hline Despido/quiebra & 7.10 & 12.80 & 13.30 & 27.30 & 15.00 \\
\hline Superación & 2.40 & 0.00 & 3.30 & 18.10 & 10.00 \\
\hline Status legal & 1.20 & 1.20 & 3.30 & 0.00 & 5.00 \\
\hline Total & 100.00 & 100.00 & 100.00 & 100.00 & 100.00 \\
\hline $\mathrm{N}$ & & & & & \\
\hline
\end{tabular}

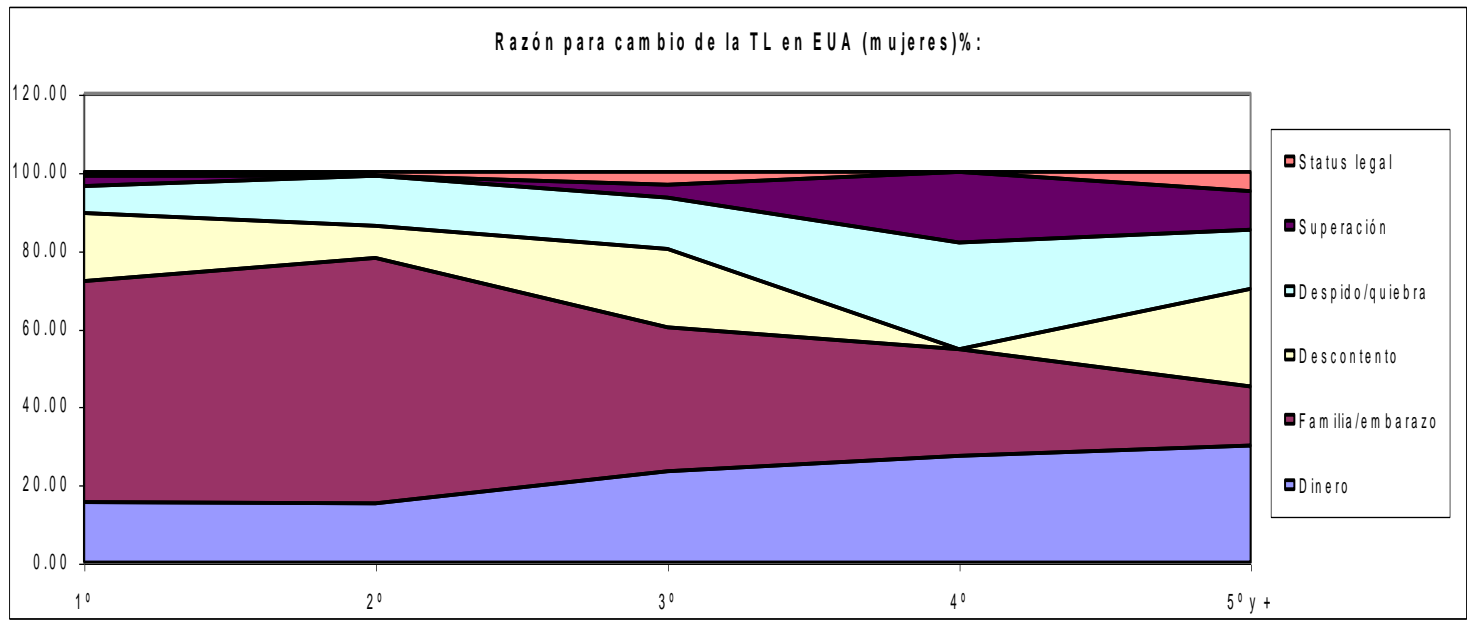

Razón para cambio de la TL en EUA (hombres)\%:

\begin{tabular}{|c|r|r|r|r|r|}
\hline Destino/Evento & \multicolumn{1}{|c|}{$1^{0}$} & \multicolumn{1}{c|}{$2^{0}$} & \multicolumn{1}{c|}{$3^{0}$} & \multicolumn{1}{c|}{$4^{0}$} & \multicolumn{1}{c|}{$5^{0} \mathrm{y}+$} \\
\hline Dinero & 17.50 & 12.20 & 10.90 & 8.50 & 4.30 \\
\hline Fam ilia/embarazo & 47.90 & 60.90 & 44.50 & 53.30 & 52.37 \\
\hline Descontento & 18.80 & 13.00 & 20.80 & 17.00 & 18.33 \\
\hline Despido/quiebra & 9.10 & 8.00 & 16.80 & 10.60 & 17.00 \\
\hline Superación & 5.70 & 3.40 & 5.00 & 10.60 & 6.93 \\
\hline Status legal & 1.00 & 2.50 & 2.00 & 0.00 & 1.07 \\
\hline Total & 100.00 & 100.00 & 100.00 & 100.00 & 100.00 \\
\hline N & 448 & 277 & 118 & 68 & \multicolumn{1}{c}{74} \\
\hline
\end{tabular}

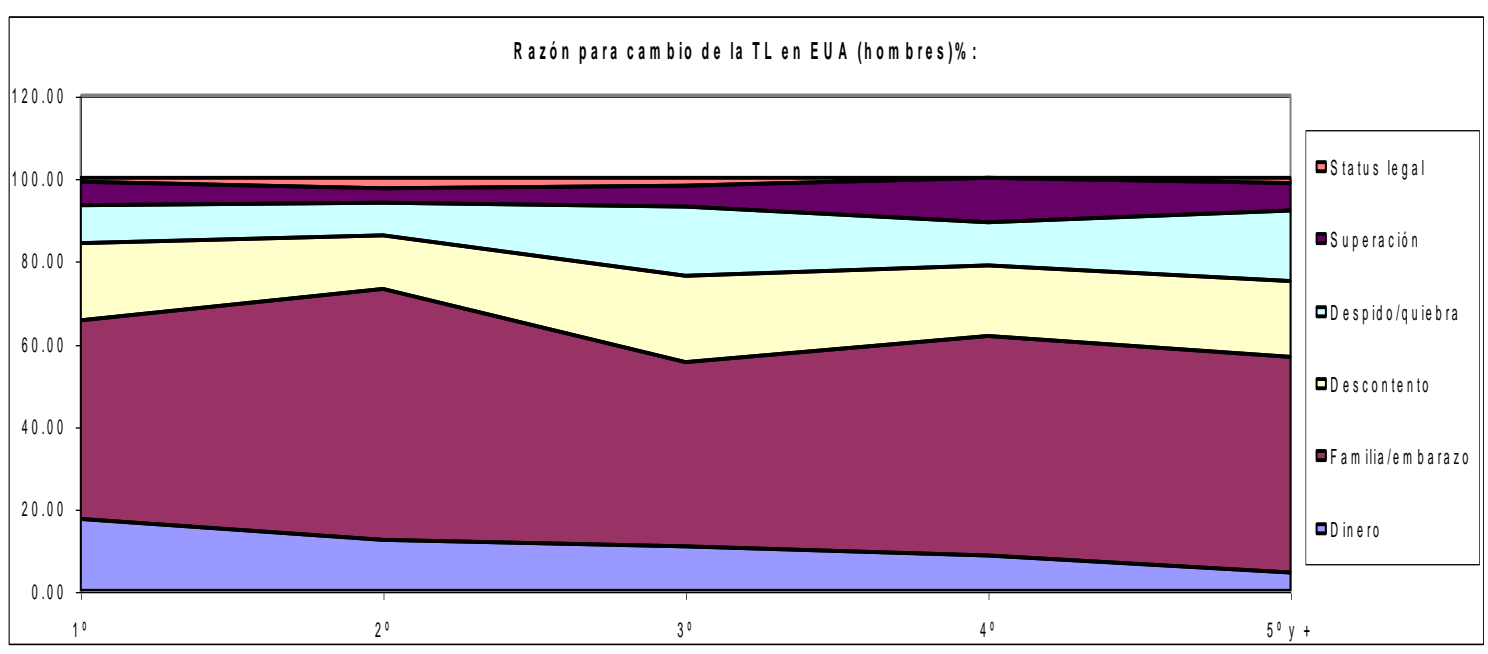


Ingreso en comparación al anterior de la TL en EUA (mujeres)\%:

\begin{tabular}{|c|c|c|c|c|c|}
\hline Ingreso/Evento & $1^{\circ}$ & 20 & 3응 & $4^{\circ}$ & $5^{\circ} y+$ \\
\hline Más & 94.20 & 86.90 & 68.40 & 61.50 & 54.20 \\
\hline Igual & 4.80 & 3.30 & 13.20 & 23.10 & 8.30 \\
\hline Menos & 1.00 & 9.80 & 18.40 & 15.40 & 37.50 \\
\hline Total & 100.00 & 100.00 & 100.00 & 100.00 & 100.00 \\
\hline$\overline{\mathbf{N}}$ & 200 & 116 & 45 & 21 & 33 \\
\hline
\end{tabular}

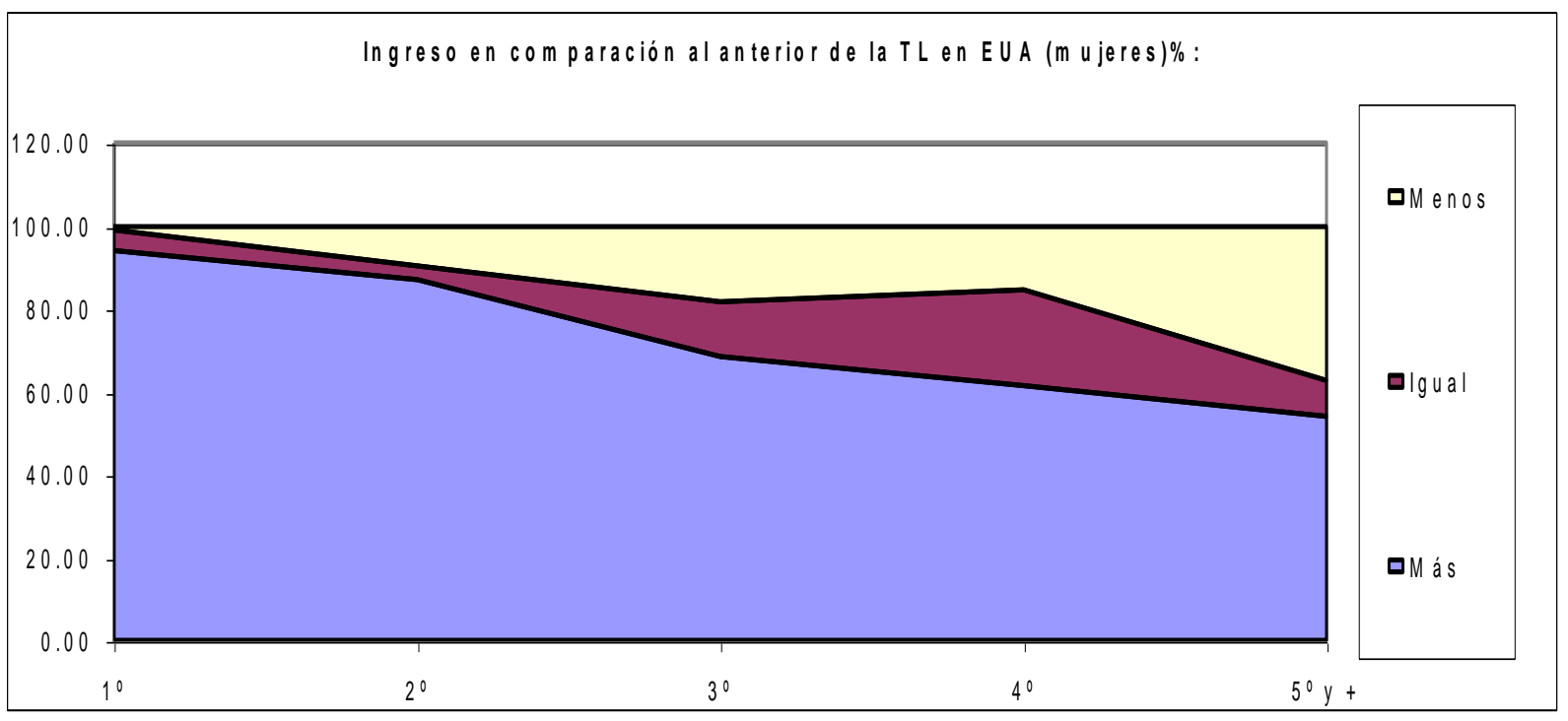

Ingreso en comparación al anterior de la TL en EUA (hombres)\%:

\begin{tabular}{|c|c|c|c|c|c|}
\hline Ingreso/Evento & $1^{0}$ & $2^{\circ}$ & 3응 & $4^{\circ}$ & $5^{\circ} y+$ \\
\hline Más & 91.50 & 84.00 & 72.30 & 67.20 & 59.50 \\
\hline Igual & 5.30 & 7.40 & 16.10 & 21.30 & 21.70 \\
\hline Menos & 3.20 & 8.60 & 11.60 & 11.50 & 18.80 \\
\hline Total & 100.00 & 100.00 & 100.00 & 100.00 & 100.00 \\
\hline $\mathbf{N}$ & 448 & 277 & 118 & 68 & 74 \\
\hline
\end{tabular}

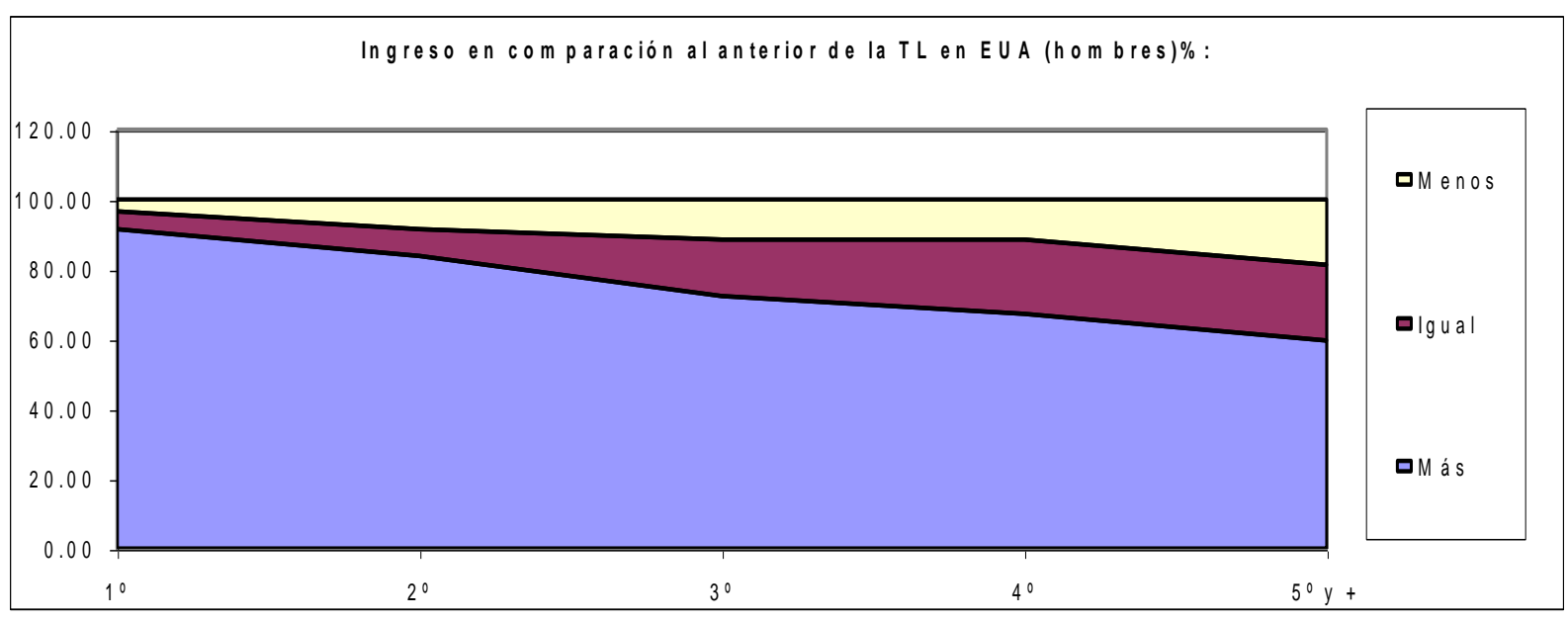


Paticipación en desición de cambio de la TL en EUA (mujeres)\%:

\begin{tabular}{|c|c|c|c|c|c|}
\hline Destino/Evento & $1^{\circ}$ & $2 !$ & $3 \stackrel{0}{\circ}$ & $4 ?$ & $5^{0} y+$ \\
\hline Familia & 47.70 & 54.70 & 31.00 & 30.00 & 33.30 \\
\hline Amigos y medios & 3.50 & 0.00 & 0.00 & 0.00 & 0.00 \\
\hline Nadie & 48.80 & 45.30 & 69.00 & 70.00 & 66.70 \\
\hline Total & 100.00 & 100.00 & 100.00 & 100.00 & 100.00 \\
\hline $\mathrm{N}$ & 200 & 116 & 45 & 21 & 33 \\
\hline
\end{tabular}

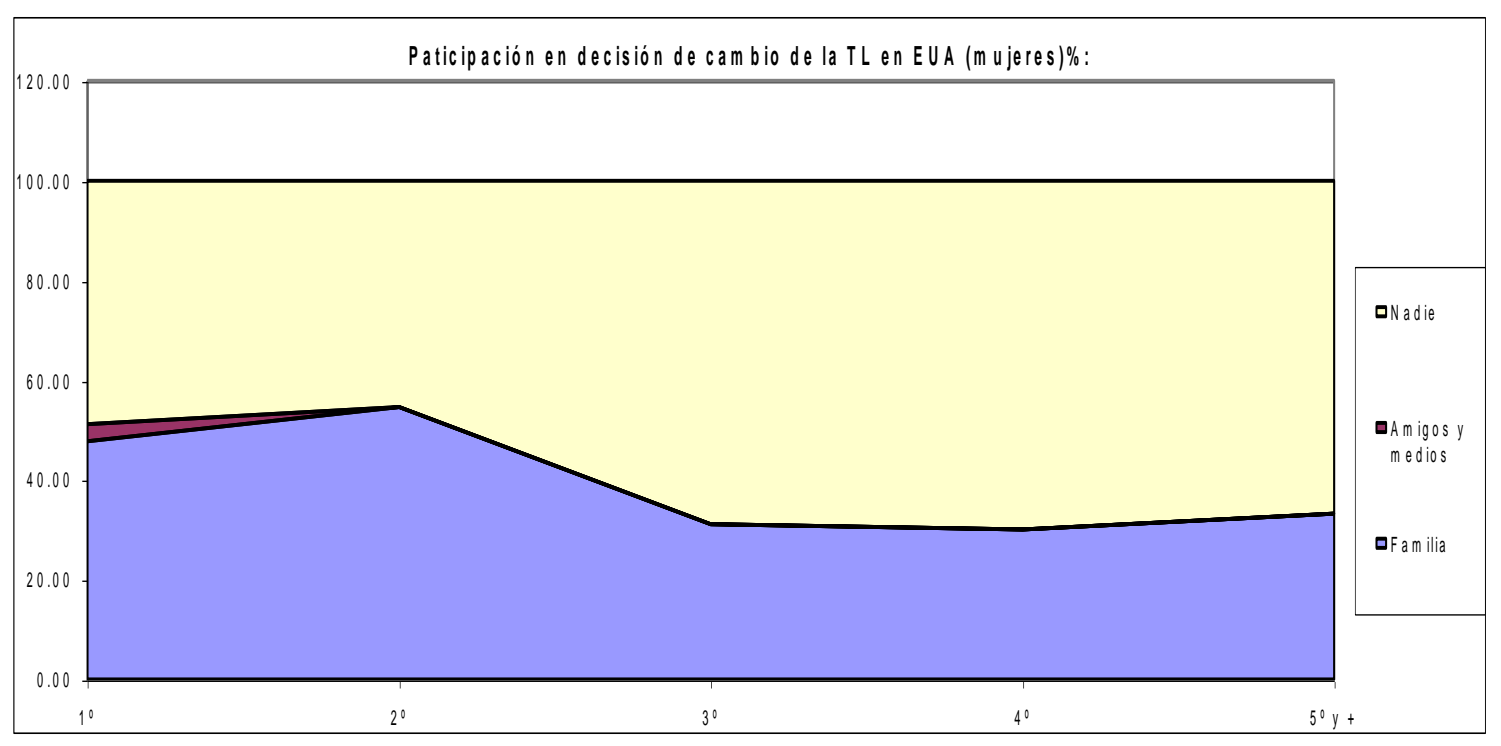

Participación en decisión de cambio de la TL en EUA (hombres)\%:

\begin{tabular}{|c|r|r|r|r|r|}
\hline Destino/Evento & \multicolumn{1}{|c|}{$1^{\circ}$} & \multicolumn{1}{c|}{$2^{\circ}$} & \multicolumn{1}{c|}{$3^{\circ}$} & \multicolumn{1}{c|}{$4^{\circ}$} & \multicolumn{1}{c}{$5^{\circ} \mathrm{y}+$} \\
\hline Fam ilia & 27.10 & 31.20 & 16.80 & 9.80 & 0.00 \\
\hline A m igos y medios & 3.90 & 1.70 & 2.00 & 3.90 & 1.13 \\
\hline Nadie & 69.00 & 67.10 & 81.20 & 86.30 & 98.87 \\
\hline Total & 100.00 & 100.00 & 100.00 & 100.00 & 100.00 \\
\hline N & 448 & 277 & 118 & 68 & 74 \\
\hline
\end{tabular}

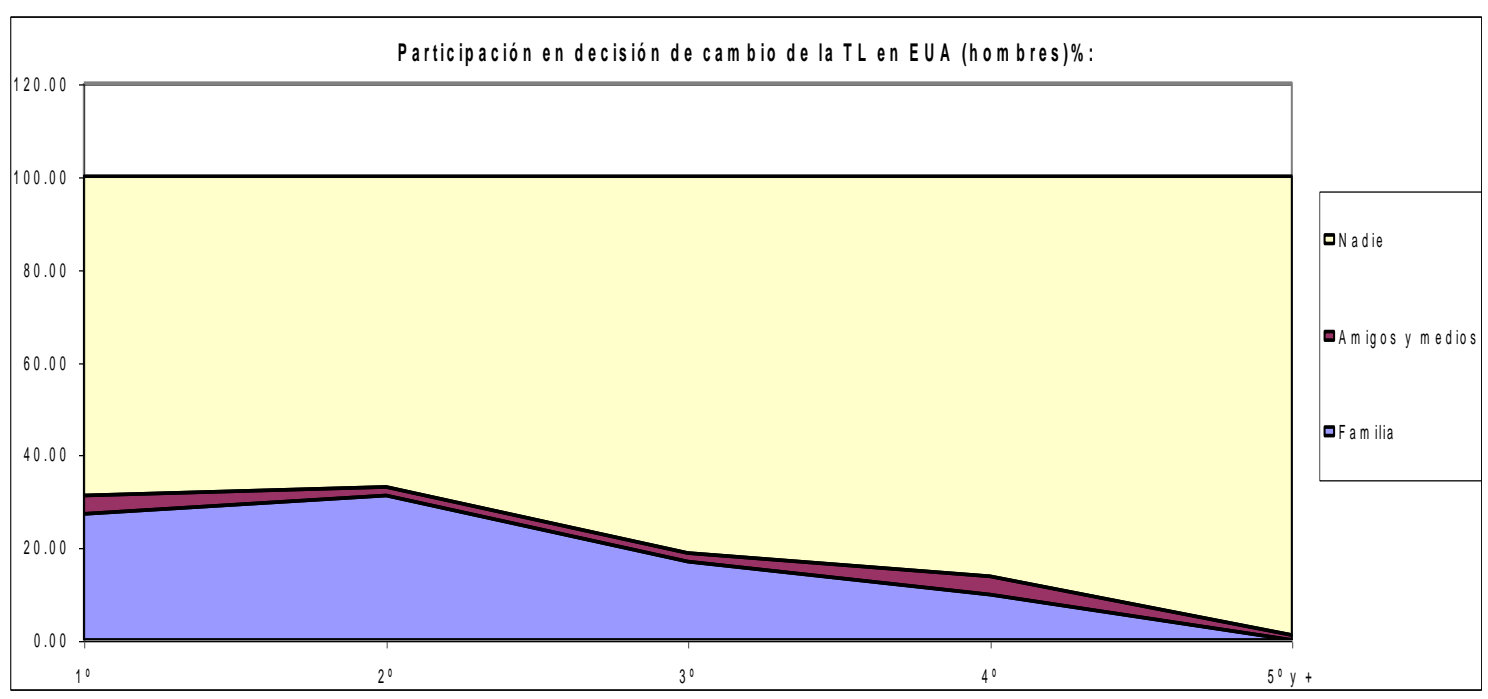


Evento Anterior a I Cambio ( $\mathrm{Cambios} d e \mathrm{~Pa}$ is Hacia los EUA)

Total

\begin{tabular}{|c|c|c|c|c|c|c|c|}
\hline Cohorte/Razón & Dinero & $\mathrm{Fam} \mathrm{il./e} \mathrm{m} \mathrm{bar.}$ & Descont. con trab. & Desp./quiebra & Superac./estud. & Stat. legal/racis mo & $\mathrm{N}$ \\
\hline Antes de 1987 & 81.80 & 3.40 & 6.80 & 0.00 & 8.00 & 0.00 & 88 \\
\hline De 1987 a 1991 & 81.30 & 5.30 & 1.30 & 8.00 & 4.00 & 0.00 & 75 \\
\hline De 1991 a 1994 & 83.70 & 8.70 & 3.80 & 1.00 & 1.00 & 1.90 & 104 \\
\hline De 1995 en adelante & 65.10 & 14.00 & 14.00 & 2.30 & 4.70 & 0.00 & 43 \\
\hline
\end{tabular}

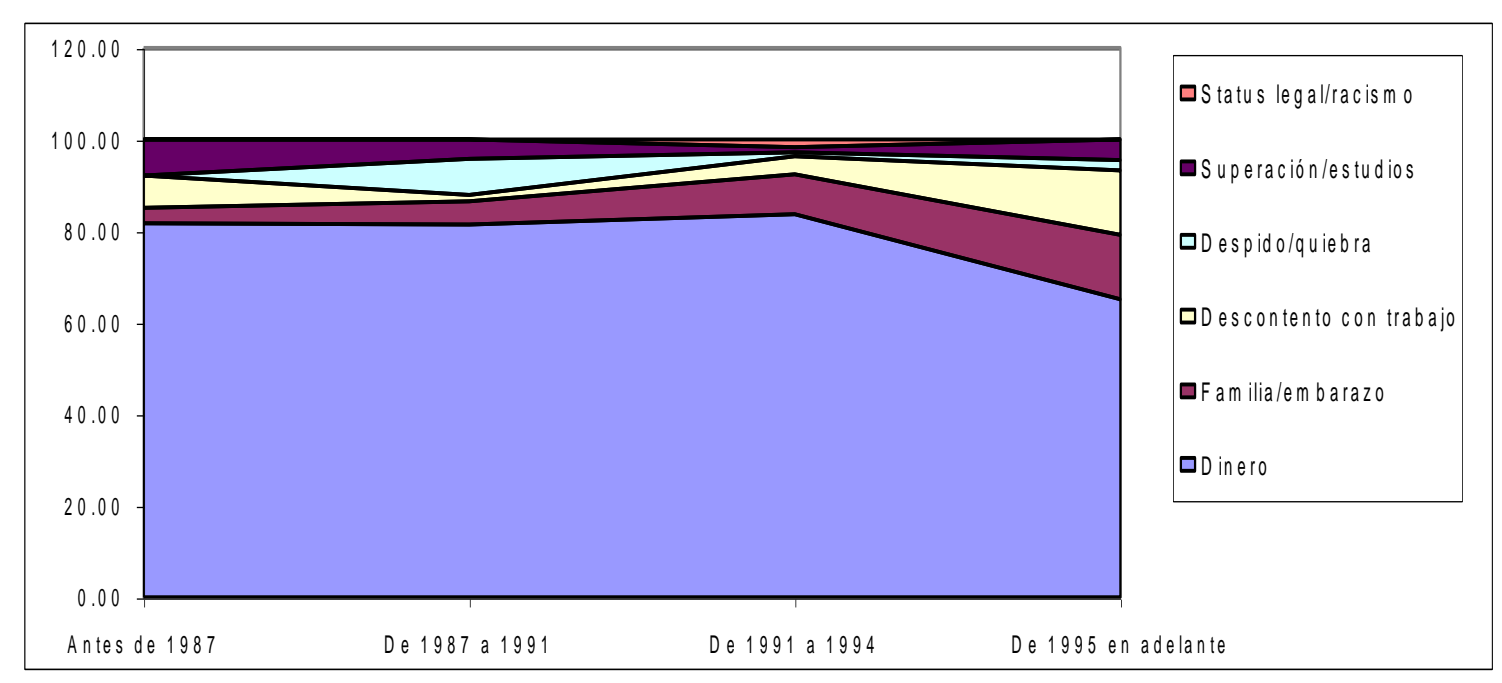

Evento Anterior a I Cambio ( $C$ ambios de $P$ ais Hacia los EUA)

Hom bres

\begin{tabular}{|c|c|c|c|c|c|c|c|}
\hline Cohorte/Razón & Dinero & Fam il./em bar. & Descont.con trab. & Desp./quiebra & Superac.lestud. & Stat. legal/racis m 0 & $\mathrm{~N}$ \\
\hline Antes de 1987 & 84.60 & 2.60 & 3.80 & 0.00 & 9.00 & 0.00 & 78 \\
\hline De 1987 a 1991 & 80.60 & 4.80 & 1.60 & 9.70 & 3.20 & 0.00 & 62 \\
\hline De 1991 a 1994 & 84.90 & 8.10 & 3.50 & 1.20 & 1.20 & 1.20 & 86 \\
\hline De 1995 en adelante & 72.70 & 9.10 & 12.10 & 3.00 & 3.00 & 0.00 & 33 \\
\hline
\end{tabular}

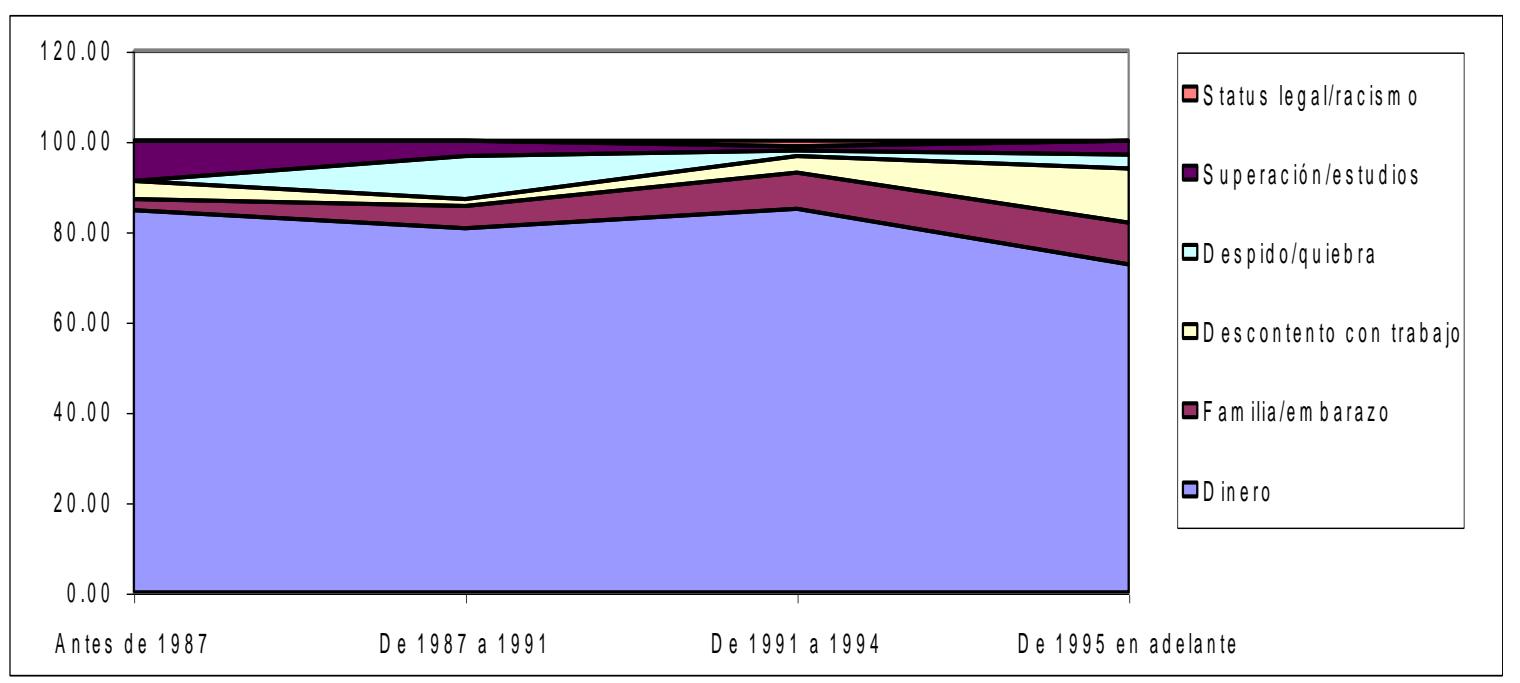


Evento Anterior al Cambio ( $C$ ambios de País Hacia los EUA)

Mujeres

\begin{tabular}{|c|c|c|c|c|c|c|c|}
\hline Cohorte/Razón & Dinero & Fam il./em bar. & Descont.con trab. & Desp.qquiebra & Superac.lestud. & Stat. legal/racis m 0 & $\mathrm{~N}$ \\
\hline Antes de 1987 & 60.00 & 10.00 & 30.00 & 0.00 & 0.00 & 0.00 & 10 \\
\hline De 1987 a 1991 & 84.60 & 7.70 & 0.00 & 0.00 & 7.70 & 0.00 & 13 \\
\hline De 1991 a 1994 & 77.80 & 11.10 & 5.60 & 0.00 & 0.00 & 5.60 & 18 \\
\hline De 1995 en adelante & 40.00 & 30.00 & 20.00 & 0.00 & 10.00 & 0.00 & 10 \\
\hline
\end{tabular}

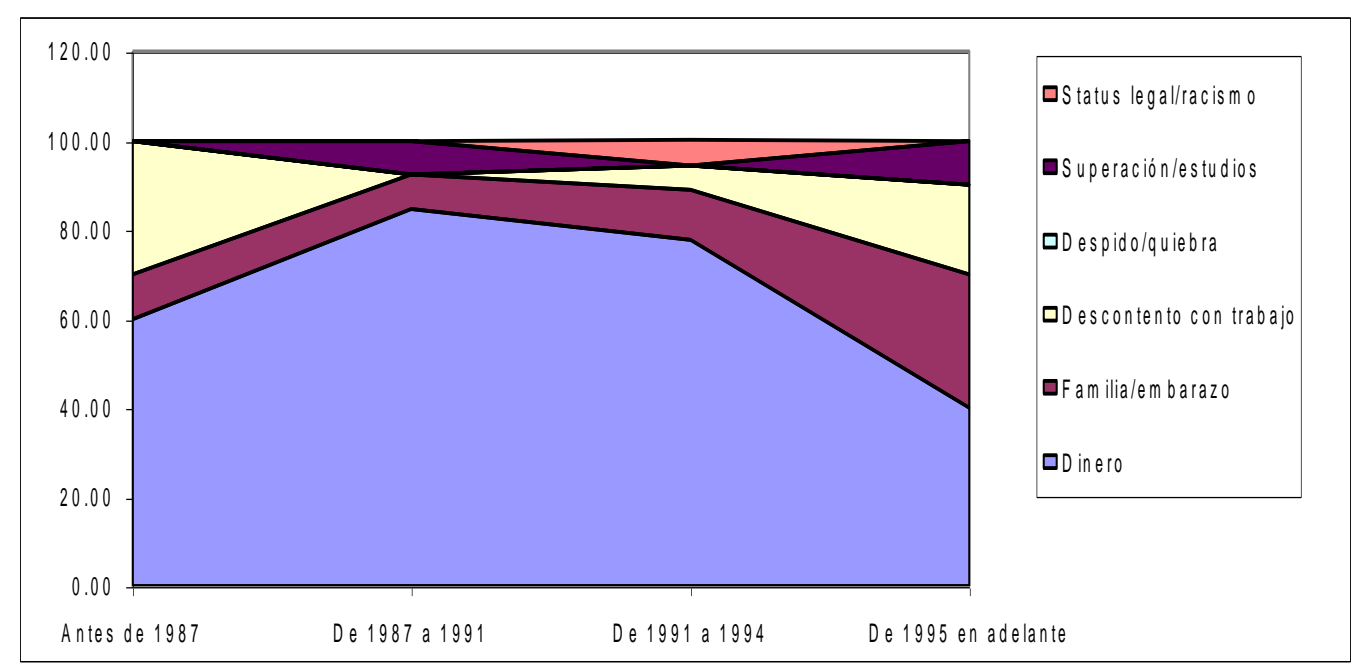

Evento Anterior al Cambio ( $\mathrm{C}$ ambios de Pais Hacia México)

Total

\begin{tabular}{|c|r|r|r|r|r|r|r|}
\hline Cohorte/Razón & Dinero & Fam il./em bar. & Descont.con trab. & Desp./quiebra & Superac./estud. & Stat. legal/racism o & N \\
\hline Antes de 1987 & 14.90 & 60.80 & 6.80 & 13.50 & 1.40 & 2.70 & 74 \\
\hline De 1987 a 1991 & 6.70 & 73.30 & 15.60 & 2.20 & 2.20 & 0.00 & 45 \\
\hline De 1991 a 1994 & 8.70 & 76.10 & 7.10 & 4.90 & 2.20 & & 1.10 \\
\hline De 1995 en adelante & 7.40 & 83.20 & 5.60 & 2.40 & 0.30 & 184 \\
\hline
\end{tabular}

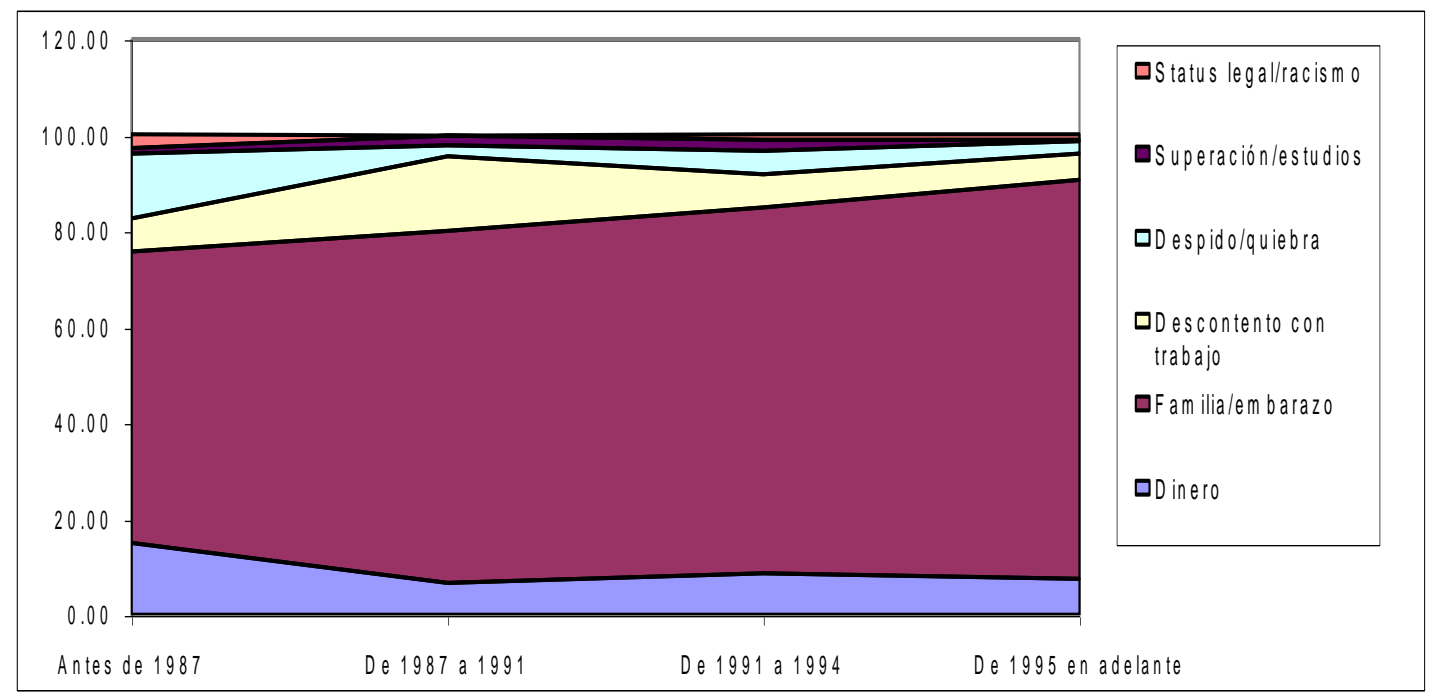


Evento Anterior al Cambio ( $\mathrm{Cambios}$ de Pais Hacia México)

Hombres

\begin{tabular}{|c|r|r|r|r|r|r|r|}
\hline Cohorte/Razón & Dinero & Fam il./em bar. & Descont.con trab. & Desp./quiebra & Superac./estud. & Stat. legal/racism o & N \\
\hline Antes de 1987 & 13.60 & 62.10 & 7.60 & 15.20 & 0.00 & 1.50 & 66 \\
\hline De 1987 a 1991 & 7.70 & 71.80 & 15.40 & 2.60 & 2.60 & & 0.00 \\
\hline De 1991 a 1994 & 7.10 & 75.60 & 8.70 & 4.70 & 3.10 & 39 \\
\hline De 1995 en adelante & 8.90 & 80.90 & 5.90 & 3.00 & 0.00 & 0.80 & 127 \\
\hline
\end{tabular}

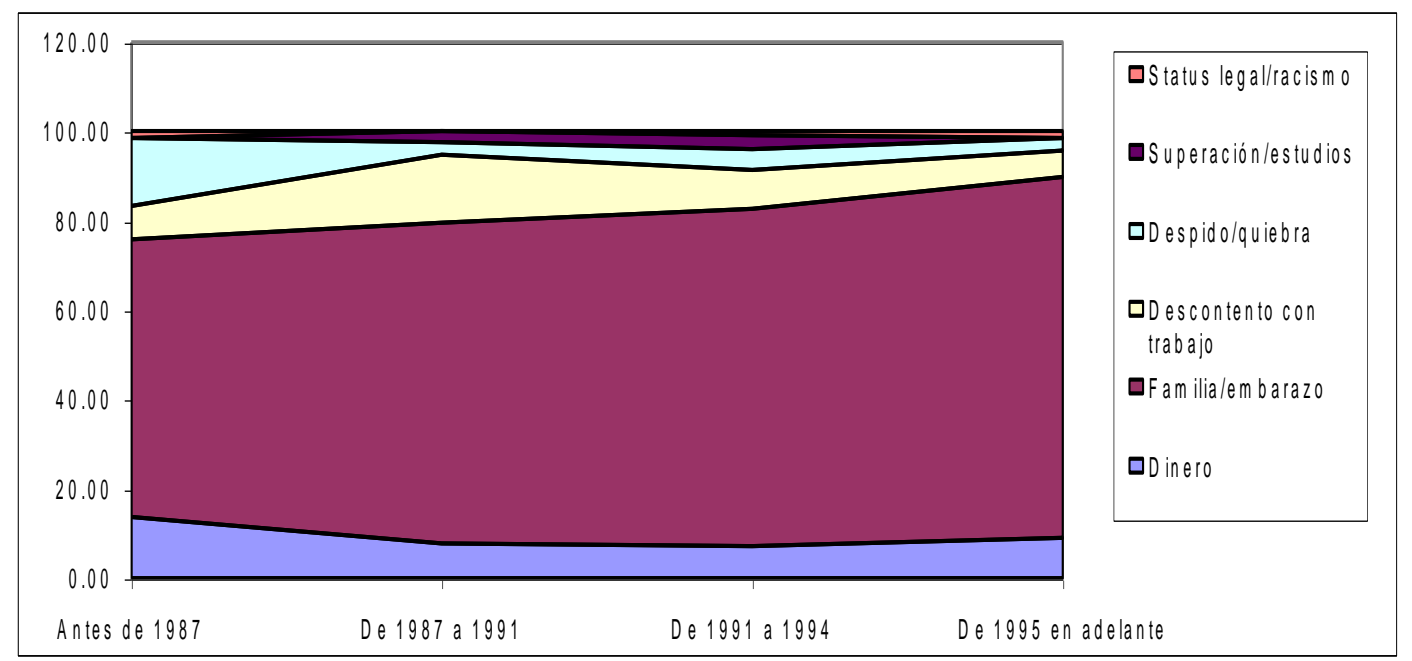

Evento Anterior al Cambio ( $C$ ambios de Pais Hacia México)

$M$ ujeres

\begin{tabular}{|c|r|r|r|r|r|r|r|}
\hline Cohorte/Razón & Dinero & Fam il./em bar. & Descont.con trab. & Desp./quiebra & Superac./estud. & Stat. legal/racism 0 & N \\
\hline Antesde 1987 & 25.00 & 50.00 & 0.00 & 0.00 & 12.50 & 0.00 & 8 \\
\hline De 1987 a 1991 & 0.00 & 83.30 & 16.70 & 0.00 & 0.00 & 0.00 & 6 \\
\hline De 1991 a 1994 & 12.30 & 77.20 & 3.50 & 5.30 & 0.00 & 1.80 & 57 \\
\hline De 1995en adelante & 3.90 & 83.30 & 4.90 & 1.00 & 1.00 & 1.00 & 103 \\
\hline
\end{tabular}

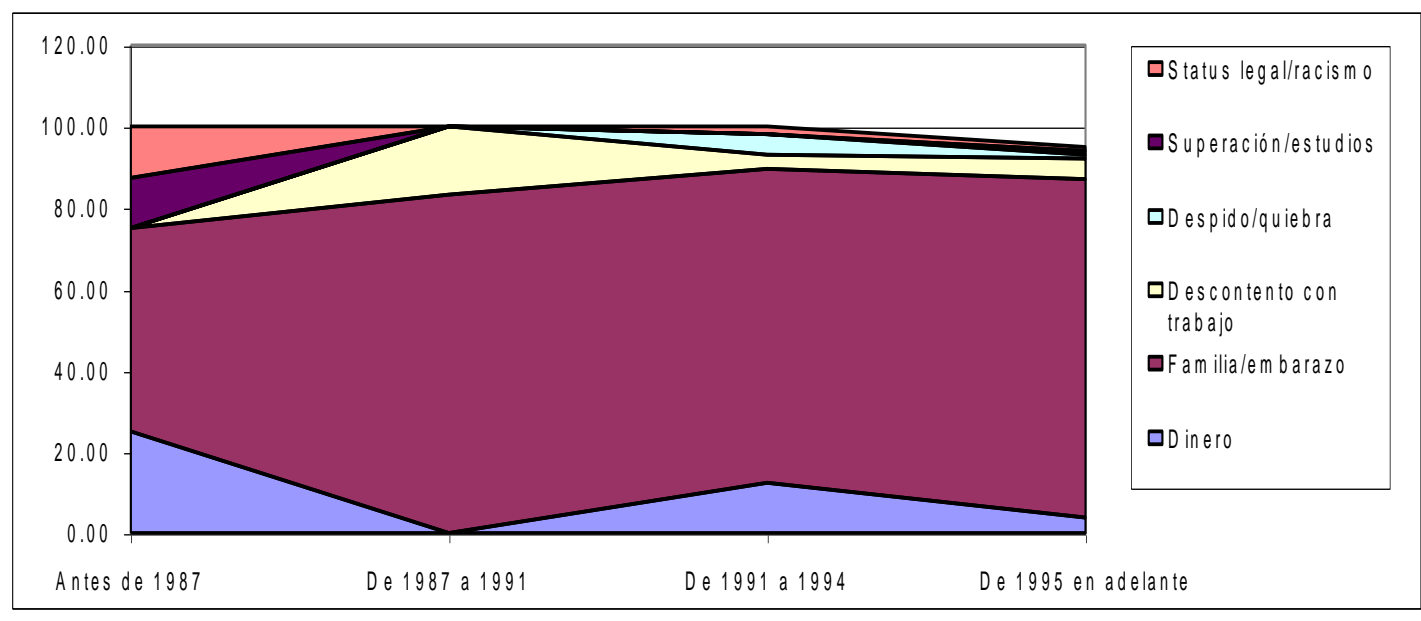




\section{UNA FAMILIA TRANSNACIONAL.}

\section{INTRODUCCION}

Como se ha podido constatar en los capítulos previos, las redes de relaciones sociales son la institución social que aparece globalmente como la más relevante en la estructuración de las trayectorias laborales de quienes han migrado desde Puebla y Tlaxcala a la zona metropolitana de la ciudad de Nueva York; aunque su acción sea cambiante a lo largo del tiempo y el espacio; aunque funcione de manera diferenciada para los agregados de mujeres y de hombres; y aunque, en la zona considerada de los Estados Unidos, su acción de vea sobredeterminada por la segregación hacia los grupos de migrantes recientes. Ahora bien, dentro del universo de contenidos específicos involucrado en las redes, destaca la importancia primordial de los vínculos familiares, unidos a los amistosos y vecinales. Por esa razón, resulta conveniente adentrarse en el análisis del funcionamiento de una familia a la que puede darse la denominación de familia transnacional. Además, con la descripción analítica de esta familia, se busca ilustrar de manera gráfica las conclusiones a las que se ha llegado en los capítulos anteriores.

Definir a las familias transnacionales como una institución propia y esencial de los EST resulta una tarea algo arriesgada. Primero, debe demostrarse que existe en la realidad algún fenómeno social relevante y digno de ese nombre. En seguida, debe comprobarse que efectivamente juega un papel trascendental dentro de los denominados EST. Aquí se busca aproximarse a una caracterización inicial, basada en el conocimiento empírico. Se busca, también, presentar el campo de las trayectorias y las biografías migratorio laborales como uno de los más apropiados, si no es que el más apropiado, para ilustrar la relevancia de estas familias transnacionales como elemento fundamental de los mencionados espacios.

Primero que nada, cabe señalar que estas familias, tanto en el sentido nuclear como en el extenso, se dispersan a lo largo y ancho de los EST y sus miembros tienden a pasar temporadas en un país y temporadas en otro; tienen hijos, padres, hermanos, cuñados, tíos, sobrinos, compadres y comadres, amigos y enemigos, en uno y en otro lado. Pueden ir o venir de vacaciones y quedarse a trabajar por periodos que no están previamente determinados; o bien, a la inversa, decidir que la estancia para trabajar, en uno u otro lado, va a ser por periodos predeterminados de tiempo y actuar después en otro sentido. Pueden 
tener propiedades y negocios en uno y otro lado. Lo que puede ser más importante: desarrollan sus proyectos biográfico-laborales en uno y otro país.

El hecho de estar aquí o allá es siempre una posibilidad abierta, aun sin papeles; pero más aún con ellos. Tener papeles legales en EUA no significa automáticamente que la decisión sea quedarse en definitiva en los EUA. Haber regresado de manera explícitamente definitiva a la comunidad mexicana de origen, tampoco significa haber perdido el interés en el estatus legal norteamericano; de hecho, la residencia en los EUA es un bien muy preciado, que aun las personas que no creen regresar a vivir a los EUA, hacen esfuerzos importantes por conservar y transmitir a los hijos y los cónyuges. La noción de decisiones definitivas, con relación a quedarse para siempre, en México o los EUA, parece tener poco sentido, cuando se mantiene, por ejemplo, la residencia en los EUA y se está viviendo en México; o bien cuando se tienen propiedades o negocios en ambos países, o, lo que es fundamental, cuando parte de la familia está en un lado y la otra en el otro.

El regreso a los EUA es una posibilidad que siempre permanece abierta en las expectativas de quienes han migrado una o más veces; o bien, entre quienes tienen familiares o amigos cercanos que han migrado. No parece implicar una decisión tan fundamental como sucede con quien nunca ha migrado. O, mejor dicho, con quien no pertenece a una población de origen acostumbrada a la actividad migratoria. Migrar se ve como algo que, si bien implica dificultades, estas nunca parecen ser insuperables, aún en momentos en los que las barreras antimigratorias se fortalecen, como sucede actualmente en la frontera de México con los Estados Unidos..

Pero uno de los campos en los que estas familias transnacionales juegan un papel de primera importancia, es en el que se refiere a las historias laborales de los migrantes. A través de aquellas, no sólo corre la información sobre oportunidades de empleo, sobre distintas posibilidades de ingreso y sobre los requisitos para el ingreso al trabajo. En ellas, también, se toman las decisiones cruciales acerca de la migración: ¿cuándo migrar?, ¿a dónde migrar?, ¿quién sí y quién no, dentro de la familia, debe migrar? (esto, por supuesto, a través de diversos mecanismos internos, unos más consensuales, otros más autoritarios; algunos más igualitarios, otros más verticales; algunos más sexistas que otros). Y en estas familias, además, se pueden incluso generar los empleos mismos de los migrantes. Antes de todo esto, en las familias -en su interacción con las redes sociales a las que pertenece y que 
le pertenecen- se ha conformado la configuración cultural que resultará de gran peso, si no determinante, en el conjunto de normas y valores, lealtades y compromisos, que los miembros utilizarán para definir sus proyectos de vida y trabajo.

A partir de la experiencia de estas familias transnacionales parece posible cuestionar una afirmación que frecuentemente se hace con relación a la migración y que hace a ésta culpable de la llamada "desintegración familiar". ¿No será más bien necesario hablar de una suerte de "reconfiguración familiar", con ubicación transnacional?

\section{LA FAMILIA TRANSNACIONAL DE DOÑA ROSA}

Con la historia de la familia de doña Rosa ${ }^{51}$, se quiere ilustrar la enorme importancia que tienen las familias en el proceso de surgimiento y consolidación de los espacios sociales transnacionales. En estas familias, como se ilustrará más adelante, coexisten los diversos tipos de migrantes que en nuestra investigación ha identificado Pries (2000) 52 : los inmigrantes (o, visto a la inversa, emigrantes) definitivos, que se han quedado en definitiva en los Estados Unidos (o bien en México, si nacieron en Nueva York o Nueva Jersey y, por ejemplo, sus padres los llevaron desde pequeños a México); los exmigrantes, que han regresado definitivamente a sus lugares de origen (sea en México o en los Estados Unidos); y, finalmente, los transmigrantes (que pueden haber nacido tanto en México, como en los Estados Unidos); que son los principales agentes responsables de mantener vivos los vínculos, materiales y simbólicos, dentro del tejido social plurilocalizado.

Ahora bien, cabe precisar dos cosas; la primera es que la pertenencia a las dos primeras categorías siempre está en riesgo de modificarse. Esto es, hay muchas personas que en algún momento de su vida han declarado con firmeza que su experiencia migratoria a finalizado, pero que más adelante cambian esa decisión y vuelven a emprender el viaje (o

\footnotetext{
51 Todos los nombres son, por supuesto, ficticios, aunque al menos en dos de los casos fuimos explícitamente autorizados para utilizar los reales y, en uno de ellos, que será objeto de un desarrollo particular en otro lugar, fuimos más bien conminados a referirnos a él con su nombre, apellido y apodo reales.

52 De hecho, este autor identifica tres tipos tradicionales de migrantes: los inmigrantes (o emigrantes), los exmigrantes (los denomina remigrantes y los migrantes de tipo diáspora (que no se presentan en las migraciones de tipo laboral, como la que se analiza en este trabajo). A ellas agrega un nuevo tipo de migrantes: el transmigrantes.
} 
bien que aún no han tenido la oportunidad de opinar ni tomar alguna decisión 53 ). La segunda, es que la mayoría de quienes están en esas categorías viaja con cierta frecuencia entre los diversos territorios de la plurilocalización, ya sea para vacacionar y visitar a los familiares y las amistades, ya sea para asistir a las fiestas patronales de sus lugares de origen 54 .

En la familia que se analizará a continuación, se pueden ubicar cuatro generaciones de migrantes (ver cuadro adjunto): a) la de doña Rosa y sus medios hermanos; b) la de los hijos de doña Rosa (todos ellos medios hermanos entre sí, hijos de doña R., pero de distinto padre): Antonio, el mayor, Aurora, Guadalupe, Ricardo y, Laura, la más pequeña; c) la de los nietos de doña Rosa, los hijos de: Antonio, en sus múltiples uniones), de Aurora (en las dos que ha tenido), de Guadalupe (Guadalupe hija y sus hermanos Rafael y Guillermo); y d) la de los bisnietos de doña Rosa: los hijos reconocidos y no reconocidos del hijo de Antonio y los hijos de sus hijas (que viven en New Jersey); la hija de Guadalupe hija y las hijas de Rafael; y los nietos de Aurora.

La fuente de información para la realización de esta parte del trabajo, está conformada tanto por una gran cantidad de pláticas grabadas con los distintos integrantes de la familia, en su pueblo de origen y en la ciudad de Nueva York, como por múltiples charlas y convivencias más bien informales y amistosas, realizadas sobre todo en el hotel que Ricardo tiene en su pueblo de origen, pero también en su restaurante ubicado en Yonkers. Más que una nota informativa, este comentario quiere también dejar constancia de la enorme, desinteresada y afectuosa ayuda que esta familia ha brindado a nuestro equipo de investigación.

Antes de entrar a una descripción analítica de esta familia, es necesario hacer una precisión. Esta familia ha resultado ser muy exitosa; al cabo de una esfuerzo prolongado a través de varias décadas, y a través de una conjunción de historias vitales que pasaron por múltiples momentos caracterizados por las carencias, las privaciones y diversos tipos de sufrimientos. En esto último resulta ser sumamente representativa de la realidad vivida por la mayoría de los migrantes poblanos y tlaxcaltecas a NY. No así en el primer aspecto: el

\footnotetext{
53 Es el caso del hijo de Aurora, que nació en Nueva York y que vive permanentemente en al lugar de origen de su madre ¿puede asegurarse que al crecer no decidirá trabajar en su lugar de nacimiento y en donde cuenta con documentos que avalan su nacionalidad?
} 
éxito; rubro en el que es más bien excepcional, aunque de ninguna manera un caso único o casi único. Valga esta precisión para evitar cualquier imagen demasiado optimista que pudiera ocasionar este texto.

Con el objetivo de que el desarrollo que se presenta a continuación puede ser seguido sin demasiadas dificultades, se presenta primero un cuadro que incluye las principales características de la mayoría de los miembros identificados de la familia de Doña Rosa; así como un esquema simplificado de su genealogía.

\section{CUADRO: LA FAMILIA TRANSNACIONAL DE DOÑA ROSA}

\begin{tabular}{|c|c|c|c|c|c|c|c|}
\hline Nombre & $\begin{array}{c}\text { Año de } \\
\text { nacimiento }\end{array}$ & Generación & $\begin{array}{c}\text { Posición } \\
\text { frente a la } \\
\text { migración }\end{array}$ & $\begin{array}{c}\text { Actividad } \\
\text { Principal }\end{array}$ & $\begin{array}{c}\text { País de } \\
\text { nacimiento }\end{array}$ & $\begin{array}{c}\text { Relación con } \\
\text { Doña Rosa }\end{array}$ & \begin{tabular}{c} 
No. de hijos \\
\hline
\end{tabular}
\end{tabular}

\begin{tabular}{|c|c|c|c|l|c|c|c|}
\hline \multicolumn{7}{|c|}{ Ascendencia de Doña Rosa } \\
\hline $\begin{array}{c}\text { Padre de } \\
\text { Doña Rosa }\end{array}$ & ND & $1^{\text {a }}$ & No migrante & Campesino & México & Padre & $?$ \\
\hline $\begin{array}{c}\text { Madre de } \\
\text { Doña Rosa }\end{array}$ & ND & $1^{\text {a }}$ & No migrante & Hogar & México & Madre & $?$ \\
\hline $\begin{array}{c}\text { Hermano de } \\
\text { Doña Rosa } \\
(1)\end{array}$ & ND & $2^{\mathrm{a}}$ & $\begin{array}{c}\text { Migrante } \\
\text { definitivo } \\
\text { (programa } \\
\text { bracero) }\end{array}$ & $\begin{array}{l}\text { Jornalero } \\
\text { agrícola }\end{array}$ & México & Hermano & $?$ \\
\hline $\begin{array}{c}\text { Hermano de } \\
\text { Doña Rosa } \\
(2)\end{array}$ & ND & $2^{\text {a }}$ & $\begin{array}{c}\text { Migrante } \\
\text { definitivo } \\
\text { (programa } \\
\text { bracero) }\end{array}$ & Jornalero \\
agrícola & México & Hermano & $?$ \\
\hline
\end{tabular}

\begin{tabular}{|c|c|c|c|l|l|c|}
\hline \multicolumn{7}{|c|}{ Doña Rosa } \\
\hline $\begin{array}{c}\text { Doña Rosa } \\
\text { (ninguno de } \\
\text { sus conyuges } \\
\text { migró) }\end{array}$ & $\begin{array}{c}1923 \\
\text { (aprox) }\end{array}$ & $2^{\mathrm{a}}$ & Transmigr & $\begin{array}{l}\text { En México: } \\
\text { Serv. Dom. } \\
\text { Prep. y venta } \\
\text { de comida } \\
\text { (informal) } \\
\text { Atención a } \\
\text { los negocios } \\
\text { familiares } \\
\text { En EUA: }\end{array}$ & $\begin{array}{c}\text { (en cinco } \\
\text { uniones } \\
\text { maritales) }\end{array}$ \\
\hline
\end{tabular}

${ }^{54}$ Cono estos no costituyen eventos laborales, no fueron registrados en la encuesta sobre trayectorias laborales. 


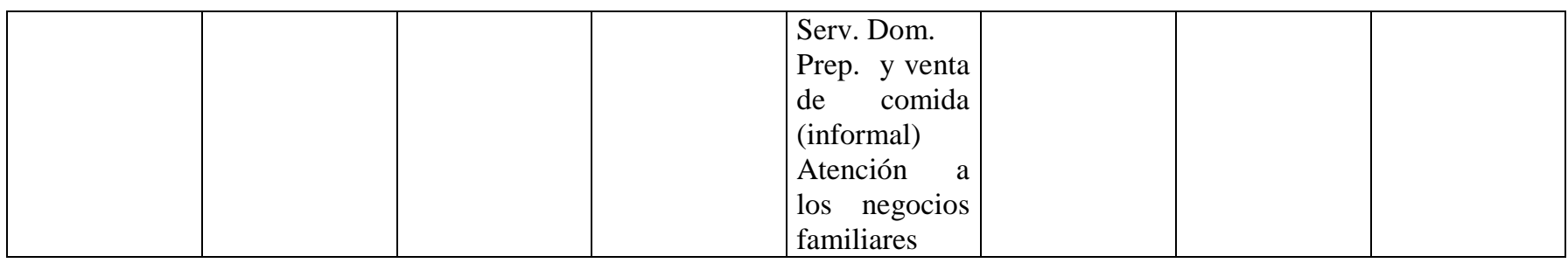

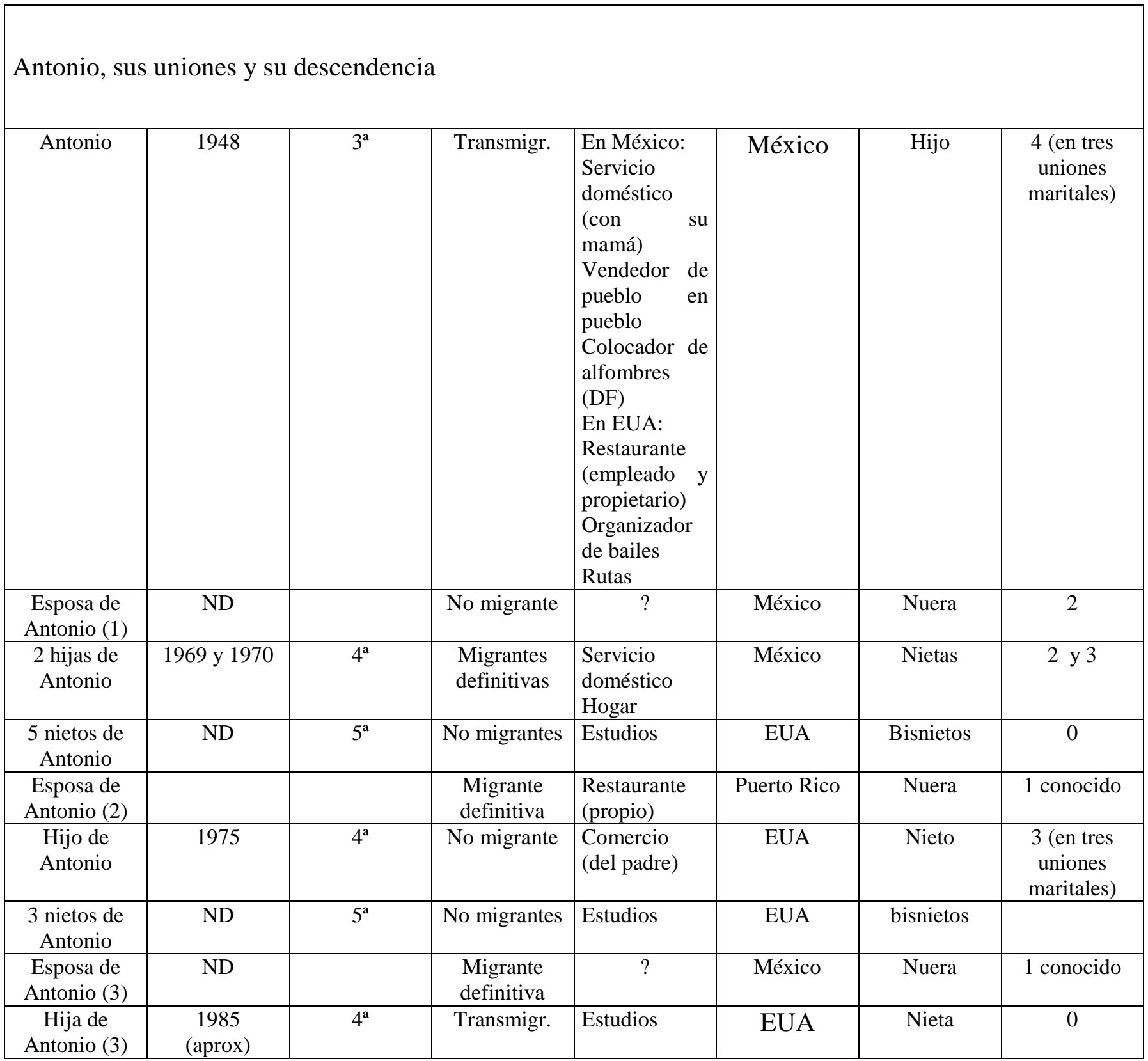

Aurora, sus uniones y su descendencia 


\begin{tabular}{|c|c|c|c|c|c|c|c|}
\hline Aurora & 1946 & $3^{a}$ & Exmigrante & $\begin{array}{l}\text { En México } \\
\text { Servicio } \\
\text { doméstico } \\
\text { (Chiapas, DF) } \\
\text { Admon. De } \\
\text { Hotel- } \\
\text { Restaurante } \\
\text { Restaurante } \\
\text { (propietaria) } \\
\text { En EUA } \\
\text { Sweatshop } \\
\text { Servicio } \\
\text { doméstico }\end{array}$ & México & Hija & $\begin{array}{c}2 \text { (en dos } \\
\text { uniones } \\
\text { maritales) }\end{array}$ \\
\hline $\begin{array}{l}\text { Esposo de } \\
\text { Aurora (1) }\end{array}$ & ND & & No migrante & $?$ & México & Yerno & 1 conocido \\
\hline $\begin{array}{l}\text { Hija de } \\
\text { Aurora }\end{array}$ & $\begin{array}{c}1979 \\
\text { (aprox) }\end{array}$ & $4^{a}$ & No migrante & Hogar & EUA & Nieta & 2 \\
\hline $\begin{array}{c}2 \text { nietos de } \\
\text { Aurora }\end{array}$ & 1995 y 1996 & $5^{a}$ & No migrantes & Estudios & EUA & Bisnietos & 0 \\
\hline $\begin{array}{l}\text { Hijo de } \\
\text { Aurora }\end{array}$ & 1994 & $5^{a}$ & $\begin{array}{c}\text { Migrante } \\
\text { (hasta ahora) } \\
\text { definitivo }\end{array}$ & Estudios & EUA & Bisnieto & 0 \\
\hline
\end{tabular}

\begin{tabular}{|c|c|c|c|c|c|c|c|}
\hline \multicolumn{8}{|c|}{ Gudalupe, sus uniones y su descendencia } \\
\hline Guadalupe & 1957 & $3^{a}$ & Transmigr. & \begin{tabular}{|c}
$\begin{array}{c}\text { En México: } \\
\text { VENTA } \\
\text { DE } \\
\text { CERVEZA } \\
\text { (INFORM } \\
\text { AL) } \\
\text { Atención de } \\
\text { sus negocios } \\
\text { (tienda, venta } \\
\text { de materiales } \\
\text { de construc.) } \\
\text { En EUA } \\
\text { Sweatshops } \\
\text { Atención de } \\
\text { un restaurante } \\
\text { propio) }\end{array}$ \\
\end{tabular} & México & Hija & 3 \\
\hline $\begin{array}{l}\text { Esposo de } \\
\text { Guadalupe }\end{array}$ & 1948 & & Transmigr. & 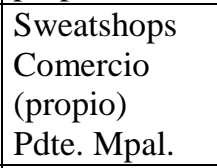 & México & Yerno & 3 \\
\hline $\begin{array}{c}\text { Rafael (hijo } \\
\text { de Gpe.) }\end{array}$ & 1972 & $\mathrm{a}$ & $\begin{array}{l}\text { Exmigrante } \\
\text { (EUA-Mex) }\end{array}$ & $\begin{array}{l}\text { Comercio } \\
\text { (familiar) }\end{array}$ & EUA & Nieto & 2 \\
\hline 2 hijos de & & $5^{\mathrm{a}}$ & Exmigrs. & Estudios & EUA & bisnietos & 0 \\
\hline
\end{tabular}




\begin{tabular}{|c|c|c|c|c|c|c|c|}
\hline Rafael & & & (EUA-Mex) & & & & \\
\hline $\begin{array}{l}\text { Guadalupe } \\
\text { chica }\end{array}$ & 1973 & $4^{a}$ & Transmigr. & $\begin{array}{l}\text { Hotel- } \\
\text { restaurante } \\
\text { (familiar) } \\
\text { Hogar } \\
\end{array}$ & $\overline{E U A}$ & nieta & 2 \\
\hline $\begin{array}{l}\text { Esposo de } \\
\text { Guadalupe } \\
\text { chica }\end{array}$ & $\begin{array}{c}1971 \\
\text { (aprox) }\end{array}$ & & $\begin{array}{l}\text { Migrante } \\
\text { reciente }\end{array}$ & Restaurante & México & & 2 \\
\hline $\begin{array}{l}2 \text { hijos de } \\
\text { guadalupe } \\
\text { Chica }\end{array}$ & 1998 y 1999 & & Transmigr. & Ninguna & EUA & Bisnietos & o \\
\hline
\end{tabular}

\begin{tabular}{|c|c|c|c|c|c|c|c|}
\hline \multicolumn{8}{|c|}{ Ricardo, sus uniones y su descendencia } \\
\hline Ricardo & 1965 & $3^{a}$ & Tramsmigr. & \begin{tabular}{|l} 
En México: \\
Prep. Y venta \\
de comida \\
(informal, \\
con su mamá) \\
Propietario de \\
un hotel- \\
restaurante) \\
En EUA: \\
Prep. Y venta \\
de comida \\
(informal, \\
con su mamá) \\
Oraganizador \\
de bailes \\
Atención de \\
una tienda de \\
su propiedad
\end{tabular} & México & Hijo & 2 \\
\hline $\begin{array}{c}\text { Esposa de } \\
\text { Ricardo }\end{array}$ & ND & & Transmigr. & $\begin{array}{c}\text { Restaurante } \\
\text { (propio) } \\
\text { Hogar }\end{array}$ & México & Nuera & 2 \\
\hline $\begin{array}{c}2 \text { hijos de } \\
\text { Ricardo }\end{array}$ & ND & $4^{a}$ & Transmigr. & Estudios & EUA & nietos & 0 \\
\hline
\end{tabular}

Laura, sus uniones y su descendencia

\begin{tabular}{|c|c|c|c|l|c|c|c|}
\hline Laura & 1967 & $3^{\mathrm{a}}$ & $\begin{array}{l}\text { Migrante } \\
\text { definitiva }\end{array}$ & Hogar & México & Hija & 2 \\
\hline $\begin{array}{c}\text { Esposo de } \\
\text { Laura }\end{array}$ & ND & $\begin{array}{c}\text { Migrante } \\
\text { definitivo }\end{array}$ & $\begin{array}{l}\text { Restaurante } \\
\text { Totillería } \\
\text { (propia) }\end{array}$ & México & Yerno & 2 \\
\hline $\begin{array}{c}2 \text { hijos de } \\
\text { Laura }\end{array}$ & ND & $4^{\mathrm{a}}$ & No migrantes & Estudios & EUA & Nietos & 0 \\
\hline
\end{tabular}




\section{PRIMERA IMAGEN EN MOVIMIENTO: LA PLURILOCALIZACION DE LOS MIEMBROS DE LA FAMILIA}

\section{Las múltiples actividades}

Si obviando las dificultades técnicas que representa la plurilocalización de los espacios sociales transnacionales, en cualquier día de mayo de 1997 se hiciera una toma en video de esta familia, es probable que ubicara a doña Rosa (media hermana, madre, abuela y bisabuela de migrantes; migrante ella misma) transitando entre su casa en El Bronx y los negocios (restaurantes, carnicería, almacén, tortillería) que sus hijos y nietos tienen en Yonkers.

El mayor de ellos, Antonio, es muy posible que se encontrara precisamente ahí, en el restaurante de comida mexicana que posee en copropiedad con su hermana Guadalupe, y que está situado enfrente de su propia carnicería, que atienden su hijo mayor y su nuera, y muy cerca de su nuevo restaurante de mariscos. No sería improbable que estuviera platicando animadamente con algunos amigos, que seguramente estarían riendo constantemente con los chistes que su anfitrión nunca deja de contar, mientras les refiere con gran sentido del humor las fases más difíciles e incluso tristes de su experiencia como migrante permanente, primero dentro de México (en el estado de Puebla, en el Distrito Federal, en el norte de la república mexicana), después en la zona de NY, a lo largo de la cual pasó de lavaplatos a empresario, pasando por actividades como la de pelapollos, la de ayudante de músicos, la de vendedor de imágenes de santos, músico y la de organizador de bailes para mexicanos en NY.

No sería extraño que el objeto de la visita de sus amigos, fuera el de recoger alguna de las múltiples contribuciones que los miembros de los comités de paisanos recaudan entre los transmigrantes, para la realización de obras civiles y religiosas en el pueblo, o bien para las actividades de la fiesta patronal, que se celebra en el mes de enero de cada año. Contribuciones que los familiares de Antonio en NY y NJ nunca han dejado de entregar. En particular, Antonio se enorgullece de participar anualmente en el financiamiento del rodeo de la fiesta. Tampoco sería de extrañar que entre esos amigos se encontrara un oficial de la policía, alto y muy rubio, que año tras año es invitado por su amigo Antonio a la celebración patronal en el pueblo de origen, en el sur del estado de Puebla. 
La menor de las hijas de doña Rosa, casi seguramente se encontrará atendiendo a sus hijos y su casa, ubicada en una muy agradable zona boscosa situada en el norte del estado de NY, pero no demasiado lejos de Yonkers, en donde su esposo es copropietario de una de las tantas tortillerías mexicanas de NY.

El otro de los hijos menores de doña Rosa, Ricardo, con toda seguridad estará al frente del comercio que abrió en Yonkers apenas en 1996 y que le permitió abandonar el negocio, rentable pero agotador, de manejar una ruta de venta a domicilio de productos mexicanos, a lo largo de toda la zona metropolitana de NY. Actividad que, por cierto y acompañada de otras más, como la de ayudar a su hermano en el restaurante y en la organización de bailes para mexicanos, le permitió ahorrar lo suficiente como para construir un hotel en el pueblo de origen de toda la familia, en la mixteca poblana.

Si es sábado, muy probablemente estará también preparando todo lo necesario para poder instalar, como todos los domingos de la temporada de futbol de los mexicanos en el norte de Manhattan, el puesto de venta de antojitos mexicanos (tostadas, gorditas, fruta y verduras con chile), cervezas y cubas, que desde hace muchos años atiende junto con doña Rosa en los campos de futbol que las organizaciones de mixtecos poblanos han conseguido que les sean prestados a los cerca de 70 equipos que domingo a domingo disputan su campeonato anual.

Por la importancia que tienen estos campos en la vida de la gente de México, como espacios de socialización y de gestación de la pertenencia al espacio social transnacional, en los que es posible convivir ampliamente con el resto de los paisanos, se justifica hacer una especie de acercamiento de la toma al lugar donde doña Rosa y su hijo realizan su trabajo de fin de semana.

\section{Acercamiento a los campos de futbol de Nueva York}

Al recorrer la Mixteca poblana es fácil constatar que el futbol no es una práctica deportiva habitual en esa región. O, más bien, no lo era, hasta hace algunos pocos años. Tradicionalmente, la zona de la ciudad de Atlixco siempre fue más bien beisbolera, como la mayoría de las zonas textileras del centro del país. Es cierto que las cosas han cambiado en los últimos lustros, en gran medida como efecto de la televisión y de los elevados salarios que se pagan en la primera división de futbol de México, pero aun así es posible observar 
que no hay una gran proliferación de canchas futboleras en estas regiones. Por otro lado, los aficionados al deporte y los empresarios deportivos, saben bien que sólo a raiz del camponato mundial de futbol de 1994, que se realizó en los Estados Unidos, en este país ha conseguido este deporte empezar a hacerse popular fuera de las zonas de mayor migración mexicana del centro de la república, como Los Angeles.

Por ello, no deja de resultar un tanto sorprendente que en Nueva York y Nueva Jersey, una de las actividades colectivas de mayor importancia para quienes migran desde México, y uno de los espacios privilegiados de convivencia e interacción social, se haya conformado precisamente en torno de este deporte; y desde mucho antes de 1994. Para ello, seguramente influyó el trabajo de promoción realizado tanto por algunos líderes comunitarios (el señor Julio Sierra, por ejemplo), como por el consulado mexicano. El campeonato mundial debe también haber influido en el crecimiento del interés. La existencia de ligas mexicanos en otros lugares de la Unión Americana y la realización de camponatos interligas, promovidos por el Programa de Comunidades Mexicanas en el Extranjero, de la Secretaría de Relaciones Exteriores de México, puede también haber influido. La constante trasmisión de los juegos de la selección mexicana de futbol por los canales que trasmiten en español, puede igualmente haber jugado un papel importante. Pero lo que puede constatarse, independientemente de las causas que originaron el fenómeno, es que el crecimiento de las ligas de futbol mexicanas en la zona de Nueva York y Nueva Jersey es enorme 55 .

Para 1997, había ligas mexicanas de futbol en Manhattan (la mayor, con alrededor de 60 equipos), Brooklin, Bronx y Passeic. Si se toma en cuenta que cada equipo consta de al menos once jugadores, más los suplentes y el entrenador, además del árbitro central y los dos asistentes, se puede tener una idea aproximada de la cantidad de gente que está directamente involucrada propiamente en el desarrollo de los juegos.

Pero lo más importante es que no sólo asisten a los partidos los actores directos. Por el contrario, los domingos de futbol se convierten en el lugar de encuentro de un sector muy

55 Fue una gran suerte para nuestro equipo de investigación el que nuestras visitas hayan coincidido con periodos en los que las ligas están activas (de mayo a septiembre). Primero Marcia y Ludger, después María Luisa, Saúl y yo, pudimos vivir directamente la experiencia de estos espacios. Particularmente, en mayo de 1997 las condiciones fueron muy propicias porque es el mes en el que se inaguran las ligas y, a los asistentes habituales, se suma un verdadero ejército de madrinas, provistas de enormes arreglos florales, y de gente que no necesariamente asiste todos los domingos. 
amplio de la migración, a donde asisten grandes cantidades de familiares y amistades de los futbolistas. No se trata solamente de ir a jugar un partido de futbol, sino que se trata de pasar el día completo con la familia -si no la propia, la de las amistades- y con los paisanos. Algo fundamental para que esto suceda consiste en que los campos de futbol, como sucede en México, en los llanos, por ejemplo de ciudad Nezahualcoyotl o de Guadalajara, se convierten en una verdadera romería, en la que es posible comer y tomar cuanto antojito mexicano se pueda pensar y cuanta bebida nacional se ocurra ${ }^{56}$. Tacos de barbacoa y de carnitas; gorditas, sopes, memelas y garnachas; algún caldo picosito o molito y hasta guasmole; fruta con limón y chile piquín; cerveza corona y tecate, cubas y aguas frescas; dulces típicos, en fin..., todo un agasajo de sabores y aromas para calmar la nostalgia y alimentar la convivencia y el encuentro que las distancias y los horarios hacen $\tan$ difícil.

También han resultado los campos de futbol un buen espacio para la ampliación y diversificación de las redes de relaciones sociales mexicanas en esas zonas. Resulta que el ambiente festuvo y alegre de los domingos futboleros mexicanos, ha empezado a atraer a cantidades crecientes de inmigrantes de diversos origenes latinoamericanos. No es extraño ver dentro de los propios equipos de futbol a caribeños y a centro y sudamericanos. Más de una persona de México nos ha dicho que ahí ha conocido y trabado amistad con quienes después pueden ayudar a conseguir trabajo o vivienda.

Las canchas de futbol de la liga de Manhattan se encuentran ubicadas en el norte de la isla Manhattan, junto el río Hudson, cerca del puente George Washington y del Pequeño Santo Domingo, en unos terrenos de gran extensión cedidos por las autoridades de la ciudad a las organizaciones de migrantes de México. Si la hipotética toma que se está pidiendo imaginar se acercara lo suficiente, en la inaguración de esta liga, el día 11 de mayo, registraría a Doña Rosa y a su hijo Rosendo, precisamente en su puesto de antojitos y bebidas de México. No sería del todo fácil, porque especialmente ese día se encontraría con verdaderos ríos de gente circulando a lo largo de los campos y entre los múltiples puestos.

Antes de localizarlos, seguramente había registrado la una ceremonia inagural, presidida por el Consul General de México, Sr. Jorge Pinto, por el Consul para la atención de las comunidades mexicanas en el extranjero, Sr. José Antonio Lagunas y por el dirigente 
de la liga, el señor Julio Sierra. Como invitado de honor, habría tomado al exjugador y excapitán de la selección mexicana, Manuel Negrete ${ }^{57}$. Entre los mariachis y las bandas la toma constataría que para los asistentes se haría difícil atender a los discursos inagurales; pero también que a la hora de interpretar los himnos nacionales, de México y de los Estados Unidos, la gente mostraría respeto por el segundo y una verdadera emoción por el primero. Permitiría ver, igualmente, que en esos ambientes la convivencia y el trato se hacen fáciles y la gente muestra poca reserva para hablar con personas desconocidas. Ser de México es el pasaporte que permite entablar fácilmente pláticas en las que se habla del lugar de origen, del trabajo, de la familia. Es un lugar ideal para adquirir, si se anda cargando categorías teóricas, capital social; si no es el caso, se consiguen ahí amistades o, al menos, personas conocidas dispuestas a brindar su apoyo, sobre todo a los recién llegados.

En la fotografía en movimiento, se apreciaría que, una vez que empezaran los primeros partidos de la liga, el flujo de gente disminuiría y sería más fácil caminar hasta el extremo norte de los campos; en donde se locliza el puesto de doña Rosa ${ }^{58}$. Todo el menú que quedó referido más arriba estaba presente en su puesto. Cualquier observador puede constatar que los encuentros de los clientes en los puestos que no son casuales en su mayoría. La gente conoce a doña Rosa y a su hijo y se conoce entre sí. Se busca en ese puesto, como seguramente sucede en cada uno de los demás. Son lugares de encuentro y reencuentro. En muchos sentidos, recuerda, aunque sus dimensiones sean mucho mayores, a la estación de Las Palomas en la Mixteca poblana. Ahí se platica de lo que se ha hecho desde el fin de la liga, el año pasado, de si se fue o no al pueblo, de si se cambió o no de trabajo o domicilio, se pregunta por conocidos, se informa por la salud de las amistades, se intercambia información sobre empleos. Se está muy lejos de la actitud del espectador de deportes profesionales que acude al estadio exclusivamente a observar un partido y se dirije a los puestos de comida sólo a satisfacer su apetito. Aquí los puestos son mucho más que lugares de consumo y las canchas mucho más que lugares de deporte: son espacios de convivencia e interacción, que quienes han migrado han construido para satisfacer

\footnotetext{
56 Perdón, pulque no llegamos a ver, pero tal vez de lata...

57 Famoso, entre otras cosas, por un formidable gol de media tijera, en el mundial de 1986.

$58 \mathrm{Si}$ algún temor abrigábamos acerca de que las promesas de apoyo para nuestro trabajo no fueran del todo ciertas, la recepción de Doña Rosa y su hijo acabó totalmente con él. Aunque la relación era de hecho muy reciente -sobre todo a partir de las fiestas de enero en su pueblo, en México-, nos recibieron como si fuéramos viejos amigos o, incluso, hasta parientes.
} 
necesidades que tienen que ver con la distracción, por supuesto, pero también con los afectos y las identidades.

Ese contenido produce, por cierto, ambientes en los que no todo es armonía. Se pueden escuchar testimonios, de pleitos ocurridos tanto en la cancha, como entre los espectadores; por cierto como ocurre en cualquier llano futbolero de México. Si el equipo de filmación se dirigiera una semana después de la inaguración anterior, a la inaguración de la liga de futbol de Passeic, Nueva Jersey, pordría dar cuenta de un hecho conflictivo que vale la pena referir.

En este pueblo, la gente de México vive mucho más concentrada que en otros lugares. Aunque no existe propiamente un barrio mexicano, sí existe cerca del centro una zona en la que se agrupa la mayor parte de las familias mexicanas y a sus huéspedes, y en la que viven muchas personas del Caribe. Como muchas poblaciones de Nueva Jersey, Passeic muestra fácilmente a la vista los estragos de la desindustrialización regional. Muchos edificios recuerdan la narración de Paul Auster (A salto de mata, 1998), cuando refiere el avance de la decadencia de la zona, reflejada en el deterioro creciente de los edificios de su padre. Naves industriales abandonadas, espuelas de ferrocarril en desuso, edificios despintados y semiabandonados, marcan la tónica del centro de esta y otras poblaciones cercanas; que contrasta marcadamente con el aparentemente interminable suburbio, poblado de casas bien cuidadas y rodeadas de amplios jardines, que se extiende desde los puentes que comunican con Nueva York hasta muy adentro del estado de Nueva Jersey. Casas en las que, por cierto, se emplea una buena cantidad de gente de México, en los servicios domésticos de limpieza y jardinería:

...hay mucha gente, por ejemplo... paisanos que están haciendo, digamos, su... sí se le puede llamar, su industria ¿no?, este... perdón, cortar pasto, arreglar jardines, todo eso. Ya casi, pues ¿qué puedo decir?, quizás un $10 \%$ este... de la gente que está aquí, de los mexicanos, tienen su camioncito para llevar su herramienta, para cortar pasto y de ahí, se llevan dos o tres que no tienen papeles, son familiares o... pues este... les ayuda bastante ¿no?(Sr.Herminio García).

Los campos de futbol se encuentran muy cerca de donde se concentra la gente de México; aunque la liga local atrae a muchos que viven dispersos en un buen número de poblaciones cercanas; lo que permite que se integren alrededor de cuarenta equipos. En 
general, aunque sus dimensiones sean más pequeñas, en los campos de Passeic se encuentra una casi total correspondencia con lo que sucede en los de Manhattan. El formato de la inaguración también es muy similar. La diferencia estuvo en que, enmedio del acto, cuando al Sr. Herminio García, presidente de la liga, anunció que se tocarían los himnos nacionales, un grupo de jóvenes intentó sabotear el acto.

Esos jóvenes, muy jóvenes, se distinguían fácilmente del resto de la concurrencia por su atuendo y sus peinados. Vestidos casi completamente de negro, con ropa muy holgada, con grandes y vistosos tenis, con cachucha y con peinados punk, habían estado rondando los campos desde hacía algún tiempo, pero sin ingresar al área cercada. Algún observador desprevenido, le podría haber parecido incluso que no eran mexicanos, sino posiblemente caribeños, precisamente porque se veía que habitaban en el barrio, pero no convivían con el resto de los asistentes. Su conato de sabotaje fue fácilmente controlado, pero fue evidente la tensión que se ocasionó.

Ese mismo día, brevemente, pero con más calma en una entrevista que concedió él días más tarde, el Sr. Herminio explica que esos muchachos son, en su gran mayoría, hijos de migrantes, que ya han nacido en los Estados Unidos, pero que muestran una creciente resistencia a adoptar las costumbres de sus padres y se niegan a ser considerados como mexicanos. Son una pequeña parte de los nacidos por aquellos rumbos, afirma el Sr. Herminio, pero constituyen una problema para la comunidad, porque tienden a integrarse a los pandillas (gangas) de otros grupos inmigrantes.

Problemas de la segunda generación, diría Robert Smith, estas gangas de jóvenes mexicanos representan un tema al que se refieren invariablemente las personas a quienes entrevistamos y al que la prensa en español de Nueva York concede cada vez mayor importancia (¿exagerada por un ánimo antimexicano de los puertorriqueños que la controlan?)

\section{Corte al pueblo de origen}

Después de este acercamiento a los campos de futbol en Nueva York y Nueva Jersey, la toma puede abrirse nuevamente para seguir dando cuenta de la plurilocalización de esta familia en el espacio transnacional. Por cierto, cabe señalar que así como Ricardo ha ayudado siempre a su madre en el trabajo, ella también ha hecho lo propio; por ejemplo, 
cuando Aurora decidió abrir su propio negocio, el hotel y restaurante de Ricardo en el pueblo, fue dado en administración a unas personas que no satisficieron las expectativas. Entonces, doña Rosa se fue a México para hacerse cargo de la administración durante casi un año.

Aurora, la más grande de las mujeres hijas de doña Rosa, aparecerá muy lejos de ellos en la hipotética fotografía, en el pueblo de origen de la familia. Con su hijo más pequeño, de dos años y nacido en NY, estará en la cocina de la fonda de comida que echó a andar en 1996, cuando decidió que podía independizarse con los ahorros que obtuvo en los cinco que trabajó en el hotel de su hermano Ricardo, situado también en el en el pueblo, administrando, cocinando y atendiendo a los huéspedes.

Porque los otros ahorros, los que provienen de sus diez años de trabajo como sirvienta en NY, en su segunda experiencia migratoria, orgullosamente refiere que ha podido mantenerlos a salvo en el banco. Los de su primera y mucho menos exitosa primera experiencia como migrante a NY, le sirvieron, sin embargo, para comprar el terreno en el que ahora, con el producto de su propio negocio, está terminando de construir su casa. Obra a la que este año dedicará buena parte del dinero que el año pasado no pudo invertirle, debido a que se fue un par de meses a NY -sin problemas migratorios, por cierto, porque desde 1984 es residente de los EUA- para conocer a su nueva nieta, hija de su hija mayor, quien está casada y vive en NY con un paisano originario de un pueblo cercano a esta parte de la mixteca poblana, y quien se dedica a la venta de cerveza, como comisionista a cargo de una gran unidad de transporte comercial.

La segunda hija de doña Rosa, Guadalupe, sería muy improbable que no estuviera atendiendo clientes en su negocio, situado en el mero centro del pueblo, ubicado a unos cuantos metros de la fonda de su hermana Aurora, y a tres cuadras del hotel de su hermano Ricardo. Este negocio es por cierto múltiple, porque es al mismo tiempo mueblería, supermercado y tienda de materiales para la construcción. El origen de estos negocios está en lo que la señora Guadalupe y su marido ahorraron cuando ambos fueron los migrantes pioneros de esta familia en NY, a finales de los años sesenta. Experiencia que dieron por terminada cuando fueron padres por segunda ocasión y decidieron que no querían que ni el hijo mayor ni su pequeña hermana crecieran y se educaran en NY, donde habían nacido. 
No por ello rompió la señora Guadalupe sus lazos con los EUA; por el contrario, hasta la fecha sigue siendo copropietaria y coadministradora en Yonkers, junto con su hermano Antonio, del restaurante de comida mixteca poblana en el que más arriba se ubicaba a éste en la fotografía que se está imaginando. Cada año, ella pasa algunos meses en Yonkers, atendiendo directamente el negocio. Su marido, que por cierto fue el primer exmigrante que llegó a ser Presidente Municipal de este pueblo, generalmente se queda en la mixteca para atender los negocios mexicanos.

Aunque la toma fotográfica pudiera incluir a muchos más personajes, aquí sólo se va a dar cuanta de uno más: una joven y atractiva señora que está, con su hijita de meses en los brazos, al frente del hotel de su tío Ricardo, en el pueblo de origen de su abuela y su madre. Se trata de una ciudadana norteamericana, nacida a principios de los años setenta en NY y después emigrada a México, en donde estudió hasta casi terminar sus estudios de nivel profesional, hasta que no se casó con un migrante a NY, originario de la misma región de la mixteca poblana y con quien acaba de procrear a una pequeña hija, que nació, como ella misma, en la ciudad de NY; lugar en el que aún trabaja el marido de ella, como cocinero de un restaurante y al que ella puede en cualquier momento retornar ien forma definitiva? ${ }^{59}$.

\section{SEGUNDA IMAGEN EN MOVIMIENTO: LA FAMILIA EN LA FIESTA PATRONAL DEL PUEBLO DE ORIGEN}

Pero una imagen estática resulta engañosa con relación a la compleja y activa vida de esta familia. Una segunda imagen, aún igualmente estática, ayuda a aproximarse al movimiento real de los integrantes de esta red familiar. Puede pensarse que esta segunda fotografía imaginaria se toma en el mes de enero de 1997, con motivo de la fiesta del pueblo de origen de la familia.

Sin tener demasiado en mente los datos que hasta aquí se han aportado, pudiéramos tener la imagen de una familia que, si bien pudo haber estado fuera de su lugar de origen durante distintos periodos, se ha reencontrado con sus raíces y se ha reinsertado sin demasiados problemas en sus antiguas redes locales. Pero esa sería una falsa imagen

\footnotetext{
${ }^{59}$ La respuesta no tardó en llegar. si la toma se hubiera hecho en 1999, ya encontraría a guadalupe hija, con su hija y su marido, nuevamente en Nueva York ¿en definitiva?
} 
producida por el hecho de que en realidad nunca se han desligado de sus orígenes, aunque puedan haber transformado en gran medida muchas de sus costumbres, así como sus hábitos de consumo y sus formas de vida.

En efecto, la fiesta patronal del pueblo sería un muy buen momento para captar la movilidad y la pertenencia transnacional de los integrantes de esta familia. En principio, tanto doña Rosa, como toda su familia, si es cerca del mediodía, podrían ser captados en la cocina del restaurante del hotel de Ricardo; algunos estarían preparando los ingredientes de la comida o bien cocinando; otros más estarían jugando con los sobrinos, nietos o bisnietos. Con ellos, seguramente, estarían departiendo viejos amigos, originarios del pueblo y la región. Muy posiblemente, se encontrarían reunidas al menos cuatro generaciones de transmigrantes.

Durante las dos semanas que duran regularmente los festejos (la primera, los de tipo religioso; la segunda, los civiles o, como les denomina el sacerdote del pueblo, los profanos), los miembros de esta familia, como los de muchas otras, aprovechan para reencontrarse tanto con sus familiares y amigos -tanto con los que viven en el pueblo como con los que viven en NY-, como con muchas de sus costumbres y tradiciones; pero también es un momento en el que las propias costumbres y tradiciones se ven afectadas por las nuevas prácticas que se introducen por la interrelación constante con quienes viven y trabajan en NJ y NY.

Un buen ejemplo de ello es la forma misma en que se celebran las festividades 60 . Un punto culminante de ellas lo constituye la carrera que se realiza desde la Villa de Guadalupe, en la ciudad de México, hasta la iglesia del pueblo. Hace muchos años, nos comentan, esta carrera no se realizaba, sino que se hacía una procesión local. Ahora, esta actividad no podría explicarse sin el concurso de tres tipos de participantes (aunque, debe destacarse, una misma persona pueda pertenecer a distintos tipos, en distintos momentos de su vida).

Un primer tipo es el de los organizadores locales de los festejos; básicamente, el sacerdote, las autoridades municipales y los encargados de la mayordomía. El segundo, es el de los representantes de las organizaciones de los paisanos en NY y NY, quienes se encargan de organizar la recaudación de fondos entre quienes se encuentran trabajando en

60.- De estos aspectos ya ha dado cuenta Robert Smith (1994 y 1995) 
aquellas zonas, y de canalizarlos tanto para la realización de obras civiles y religiosas, como para la compra, por ejemplo, de las bicicletas y los uniformes de los participantes. El tercer tipo, es precisamente el que conforman estos últimos, y que está constituido por jóvenes, tanto mujeres como hombres, que residen tanto en NY y NJ, como en el pueblo en México. Aunque muchísimos paisanos acuden año tras año a estas festividades -aun quienes carecen de papeles legales en los EUA-, para los que no pueden hacerlo existen dos formas de participación: una, digamos más tradicional, es a través de las filmaciones que realizan tanto los responsables del comité organizador (formado por personas de los dos primeros tipos), como por los propios transmigrantes; otra, más reciente, es a través de la transmisión radial directa de las ceremonias y las fiestas.

Cabe aquí hacer una reflexión más particular sobre las festividades patronales en general, dado que este tipo de celebraciones en las comunidades de origen de los migrantes, constituyen una excelente oportunidad para observar algunos cambios importantes relacionados con la migración y con la transnacionalización de los espacios sociales originados por los procesos migratorios. Lo anterior, por supuesto, no es una particularidad de la migración de Puebla y Tlaxcala a la zona metropolitana de la ciudad de Nueva York. Como se ha observado en otras regiones, por ejemplo en un trabajo reciente de Víctor Espinoza (199 ), este tipo de fiestas tiende a convertirse de manera generalizada en el espacio social de interacción más importante para los procesos de negociación de la ciudadanía y de la pertenencia de los migrantes; así como para los de transformación cultural de las comunidades productoras de migrantes y para la consolidación de los elementos de transnacionalidad que las caracterizan.

Ahora bien, debe señalarse que en este campo se presentan contrastes muy importantes entre las poblaciones pertenecientes a las comunidades con flujos migratorios más antiguos y las que sólo recientemente se han integrado a la migración a la zona de Nueva York. En las comunidades rurales de la zona de Atlixco, que pertenecen a este último grupo, por ejemplo, si bien las festividades han resentido el efecto de la migración, éste se ha manifestado sobre todo en la cantidad de dinero (migradólares) que se gasta en las celebraciones religiosas y civiles de los meses de diciembre y enero de cada año; pero se presenta una clara tendencia al uso privado del dinero, si bien compartido porque en las fiestas se invita prácticamente a todo el pueblo y aun a las amistades de los pueblos 
vecinos. No hay signos ni testimonios de la utilización de esos recursos para la construcción o reparación de obras religiosas o civiles. Un buen ejemplo de lo anterior, puede encontrarse en la forma en que las comunidades rurales del municipio de Atlixco celebran la fiesta de cumpleaños del sacerdote que se encarga itinerantemente de su atención.

En cambio, en las zonas de migración más antigua, existen formas de utilización comunitaria de los recursos provenientes de la migración. Primero que nada, debe destacarse que estas festividades se han convertido a lo largo de las últimas décadas en el principal momento de encuentro entre quienes permanecen en el pueblo -ya sea porque nunca lo han dejado, ya sea porque migraron y regresaron para quedarse en definitiva o bien están a la espera de una nueva oportunidad para regresar al norte o, incluso, porque aún no han decidido qué hacer con su futuro-, y los paisanos, aquéllos que siguen con la aventura de los dólares y los dolores de la lejanía, la nostalgia, los trabajos precarios, pero redituables en relación a México, los malos tratos, y los fríos y los calores extremos de Nueva York.

Paisanos y paisanas que pueden ser esposos y esposas, padres y madres, hijos e hijas, amigos y amigas, y aun rivales, y a quienes sólo es posible ver en esas fechas y, dirían algunos, en esas fachas. Porque si algo es notorio a primera vista para quien llega desde afuera como observador, es el contraste entre la vestimenta de los del pueblo y la de los paisanos. En las generaciones más jóvenes, los pantalones bombachos, los aretes y las arracadas, el peinado de hongo, las chamarras que parecen saldos del ejército americano, las camisetas de basquetbol, las cachuchas beisboleras con la visera colocada hacia atrás, los tenis de enormes suelas y colores chillantes y los enormes aparatos de sonido colgando del hombro; o, en las personas adultas, la ropas arregladas o de ciudad, los peinados y las omnipresentes cámaras de video, contrastan tanto con vestimentas típicamente campesinas, como con esa extraña y más o menos reciente moda con la que los vendedores ambulantes de ropa empiezan a uniformar a los habitantes de poblaciones rurales mexicanas, separadas entre sí incluso por miles de kilómetros.

Pero no todo es cambio, en todas las comunidades, en este terreno. En particular, una institución social tan importante como la mayordomía mantiene en algunos pueblos básicamente su forma tradicional. Aunque cuenta ahora para su financiamiento con 
aportaciones en dólares, ésta no es la mayoritaria, pues la mayordomía se financia con, al menos, cuatro tipos de donaciones: en pesos, en dólares, en especie (chivos, guajolotes, leña, ceras, etc.) y en trabajo (tortilleras, molenderas, para adorno y aseo del lugar, etc.). En el caso de Chinantla, la encargada de la mayordomía en 1999 cuenta que su familia ha tenido este cargo durante 20 años y que ella, que es profesora de la carrera de psicología en la Universidad Autónoma de Puebla, quiere continuar con esa tradición familiar y enfatiza la importancia de la fiesta patronal como una forma de mantener la unión entre los habitantes del pueblo y conservar las costumbres de la región.

Los cambios son detectables en varios niveles. Uno muy importante se refiere a los esfuerzos que se han realizado para facilitar dichos encuentros. Por un lado, en algunas localidades se han modificado las fechas mismas de las festividades de los santos patrones, para hacerlas coincidir con las celebraciones de la navidad y el fin de año, que es cuando por diversos motivos, resulta más fácil el regreso para los paisanos.

En las comunidades rurales del poniente del municipio de Atlixco, por ejemplo, se comparte como santa patrona a la Virgen de Guadalupe; pero sus festividades no se limitan al día 12 de diciembre, sino que los distintos pueblos han acordado prolongar su celebración desde ese día hasta la primera semana de enero; de tal forma que a cada colonia le pueda corresponder un día para organizar los festejos, religiosos y civiles, a los cuales está invitado obviamente la población del resto de las colonias.

En Tulcingo, para citar otro ejemplo que refiere Cortés (1999), tradicionalmente se celebraban las fiestas del pueblo los días 23 y 24 de marzo, fecha de celebración de su santo patrono. Ahora, para permitir la participación de los paisanos, se ha instituido una segunda fiesta, que se ha convertido en la principal, entre el 25 y el 30 de diciembre.

Por otro lado, las celebraciones familiares, tales como los bautisos, las primeras comuniones, los quince años (aun de manera desplazada) y los matrimonios, se concentran visiblemente en ese mismo periodo, para contar con la presencia de los migrantes. Esto, junto con las festividades religiosas, convierte a las comunidades de origen de los migrantes, de hecho en una fiesta permanente durante los meses de diciembre y enero. Reporta Cortés (1999) que, en lugares como

...Chinantla, Albino Zartuche, Tulcingo, Guadalupe Santana y Axutla, que registraron tasas de emigración superior al 2 por ciento entre los años de 1990 y 
1997..., los matrimonios celebrados entre diciembre y enero ... equivalen a un tercio o más del total de matrimonios de todo el año.

Situaciones similares, aunque no cuantificadas, saltan a la vista de cualquier visitante que llegue en esos meses al sur de Puebla, pero también a su parte central y al sur de Tlaxcala. Precisamente en el mes de diciembre pasado (1999), dos integrantes del equipo de investigación asistieron en Xicotizingo, Tlaxcala, a la boda de Rogelio, quien fue una de las personas que, junto con sus hermanos y sus primos, mayor apoyo brindaron a nuestro equipo de investigación en Nueva York, primero, y en su propio pueblo, más adelante.

Los esfuerzos por mantener, a partir de las fiestas, los vínculos entre los de allá y los de acá, incluyen la utilización sumamente creativa de varias de las tecnologías modernas disponibles en el mercado, desde aquéllas ligadas al transporte de personas y bienes materiales, como aquéllas que se relacionan con las comunicaciones a distancia y con el envío de bienes inmateriales. Así, como ya lo refería Robert Smith (199 ) para el caso de Ticuani, a principios de los años noventa, las celebraciones que se realizan en el pueblo son videograbadas para que los paisanos las puedan disfrutar allá, en el norte, en reuniones y celebraciones que sirven para reunir a los migrantes que, como ya se ha descrito, generalmente viven sumamente dispersos en todas las zonas de la ciudad de Nueva York y sus alrededores. Más recientemente, en 1998, tanto la llegada de la carrera ciclista anual para celebrar al Padre Jesús, santo patrono de Chinantla, como la misa principal de las celebraciones y el baile de gala, fueron transmitidos directamente por vía radiofónica hasta una estación de Nueva Jersey que es fácilmente captada en toda la región de la ciudad de Nueva York.

Una razón muy importante para lo anterior consiste en que una gran parte (mayoritaria) de los gastos de estas festividades es sufragada por los paisanos, quienes a través de sus comités en Nueva York, aportan diversas cantidades de dólares en las colectas anuales que sirven no sólo para propósitos celebratorios, sino también para el financiamiento de obras públicas, como la introducción de agua potable que refiere Robert Smith en Chinantla, a finales de los ochenta, o la reconstrucción de la plaza central de El Rosario Micaltepec; pero también de obras religiosas, como el remosamiento de atrios, portadas, retablos y altares de los templos de las comunidades. En estos casos, las placas 
conmemorativas indican el hecho con claridad e incluso con el detalle de los nombres y las cantidades aportadas individualmente.

Para la carrera ciclista mencionada, por cierto, que anualmente se celebra entre La Villa de Guadalupe, en la ciudad de México, y la población de Chinantla, el comité chinantleco de Nueva York financia, como producto de las aportaciones que recoge, tanto las bicicletas, como las camisetas de los participantes. En las videograbaciones, los migrantes que han aportado parte de su patrimonio pueden atestiguar, ya sea la inaguración de las obras, ya sea su resultado objetivo y sumamente visible en la transformación de sus lugares de origen.

Ahora bien, los esfuerzos de los migrantes para mantener sus vínculos y su presencia en sus comunidades no se limitan al envío de dinero para fines colectivos. Por ejemplo, no es extraño que existan grupos de hermanos que están trabajando en Nueva York y que anualmente reunan fondos para mandar a uno de ellos, de manera rotativa, a su lugar de origen. En Acatlán de Osorio, por ejemplo, tres hermanos tienen esa costumbre para visitar a su madre, quien tiene un puesto de comida en el mercado y con quien es posible ir a saborear chilates y tortas de romeros con tempesquistles, desde los días de muertos hasta finales de enero. Mucho más frecuente es el caso de una gran cantidad de gente que viaja desde Nueva York a Puebla o Tlaxcala, a veces anualmente, con o sin los documentos que le permitan el regreso a los EUA.

Un ámbito en el que se muestra de manera muy plástica y dramática el efecto de la migración en las festividades religiosas, está en las ofrendas que se depositan en honor de los santos patrones. En enero de 1999, en Chinantla, fue posible que los asistentes observaran que una gran cantidad de ellas consitía en billetes de dólar de distintas deniminaciones, que eran adheridos mediante broches a la capa de la imagen del Padre Jesús. Otras ofrendas consisten en juguetes y otros artefactos de origen norteamericano.

\section{NOTA: INSERTAR AQUI LA FOTO DEL PADRE JESUS CON LAS OFRENDAS}

Otro campo importante es el de la reina de las fiestas. En más de una ocasión, la elección a recaído en jóvenes nacidas en Nueva York o Nueva Jersey, hijas de migrantes antiguos, que vienen a conocer la tierra de sus padres. Robert Smith refiere uno de los primeros casos a fines de los años ochenta. En las fiestas de enero de 1998 se sucitó una situación bastante especial que ocasionó cierto disgusto entre los habitantes de Chinantla, si 
bien éste no se hizo totalmente público ni tuvo aparentemente mayores repercusiones. Resulta que fue electa una bella joven, nacida en los EUA, hija de una pareja de mexicanos y conocida en el medio de los migrantes. Pero, por intermedio de ella misma, resultó electa como princesa una gran amiga suya que tenía el inconveniente de ser hija de puertoriqueños; relación que difícilmente puede extrañar en Nueva York, ya que los mexicanos se han asentado allá sobre todo en zonas en donde se habla español, especialmente de puertoriqueños y de dominicanos.

Cabe introducir aquí una precisión. No todos los cambios recientes que se han operado en las fiestas patronales de las comunidades caracterizadas por la presencia de fuertes flujos migratorios de este tipo (pendulares, recurrentes, transnacionalizantes), pueden ser atribuidos de manera directa al fenómeno migratorio mismo. De hecho, es posible observar, aun sin haber realizado un estudio especial sobre el tema, que en el país existen fuertes tendencias hacias la homogeneización de las fiestas locales. De tal manera que éstas empiezan a parecerse considerablemente entre sí, aunque se celebren en muy distintas fechas y en lugares sumamente distantes unos de otros. En buena medida esto puede explicarse tanto por la extensión del control que ejercen fuertes redes comerciales sobre algunas de las principales actividades que se realizan en este tipo de festividades, como por la acción de los medios masivos de comunicación. Efecto este último muy visible en la forma, claramente influida por la empresa Televisa, en que se organizan tanto los concursos de belleza en donde se elige a las reinas de las fiestas, como los espectáculos musicales que acompañan a las festividades.

Un ejemplo de lo primero, puede encontrarse en la transformación reciente de las fiestas patronales de Acatlán de Osorio, que coinciden con la semana santa, en donde los últimos años han sido testigos de la introducción de elementos sumamente televisivos, como los desfiles de modas, los concursos de belleza y los espectáculos musicales, en los que muy fácilmente puede encontrarse el formato popularizado por televisa para ese tipo de eventos que, no obstante el atractivo que representan para la población, se presentan paralelamente a las clebraciones más tradicionales, como las danzas de los ticuanes. En este lugar, incluso las celebraciones propiamente religiosas han mostrado fuertes transformaciones. Un claro ejemplo de ello se encuentra en la transformación de la conmemoración de la pasión de Cristo, que se realiza ahora con un formato muy similiar al 
de Iztapalapa, en una iglesia -El Calvario- que fue especialmente acondicionada durante la década pasada, precisamente para ese fin.

En cuanto a los grupos musicales, es fácil observar que los que participan en los bailes de los pueblos, no son propiamente elegidos por los organizadores locales, sino en una mínima medida. En realidad, existen grandes promotores de espectáculos que arreglan las giras de los grupos por todo el país, siguiendo la ruta de los festejos locales y ofreciendo a los organizadores en las comunidades paquetes que combinan grupos de distintos niveles de prestigio, popularidad y, por supuesto, costo. Fenómeno que puede hacerse extensivo a la organización de jaripeos, peleas de gallos y corridas de toros; espectáculos que se han ido agregando a los festejos incluso de comunidades que no tenían como costumbre incluirlos en sus celebraciones. De hecho, los jaripéos no constituyen una tradición mixteca, pero ahora resultan indispensables en los festejos patronales. En una tienda mexicana de el barrio, en el alto Manhattan, puede constatarse lo anterior, porque tiene a la venta los videos de los jaripéos de todas las poblaciones mixtecas.

De la misma manera, es posible detectar con cierta facilidad, al asistir a varias de estas festividades en distintos lugares, que el tipo de mercaderías que se venden en los puestos callejeros temporales que se instalan durante las fiestas, no expenden básicamente productos locales, por ejemplo de tipo artesanal. Aun en poblaciones que cuentan con una gran riqueza artesanal tradicional, como es el caso de la producción de cerámica de barro en Acatlán de Osorio, en esos puestos de venden sobre todo artículos de plástico, hule o metal, de procedencia muchas veces extranjera, y cuya calidad tiende a ser asimilada en el lenguaje popular con el término de chatarra. Otro tanto sucede con la ropa e, incluso, con la comida. ¿Tendrán su origen algunos de estos productos en los sweatshop neoyorquinos en donde se emplean los migrantes mexicanos?.

Un campo especial en estos procesos, aunque ligado al de los bailes, tiene que ver con el fuerte dominio que ejercen las grandes compañías productoras y distribuidoras de cerveza. De hecho, difícilmente puede encontrarse una festividad de este tipo en la que no se encuentren instaladas grandes lonas que cubren mesas y sillas de metal con los logotipos de estas compañías y en donde la venta de cerveza se prolonga día y noche, a lo largo de todos los días que dura el festejo. Ligado directamente a lo anterior, está la presencia de redes de prostitución que igualmente son controladas en la mayoría de los casos por 
personas ajenas a las comunidades que, en todo caso, cuentan con sus agentes locales, dueños de cabarets o prostíbulos, que dependen de las redes externas de traficantes para su funcionamiento. (nota: aquí pueden meterse los apuntes que tengo de Don Rafa, en Acatlán y en su local en las fiestas Chinantla, de 1998)

Los dueños de juegos mecánicos son, para acabar este recuento no exahustivo, representantes de otro tipo de intereses comerciales que se caracterizan por su itinerancia y por ser una fuerza poderosa que tiende a diluir las particularidades locales y a crear una especie de proptotipo de fiesta patronal que empieza a extenderse por todas las regiones del país.

No obstante lo anterior, es posible tratar de establecer los vínculos entre los procesos anteriores y la presencia regional de migradólares y, en general, de los procesos de constitución de espacios sociales transnacionales. No en todas las regiones del país, o incluso de los estados, el auge de las fiestas se presenta de igual manera. En el estado de Puebla, en particular, resulta muy clara la relación que se presenta entre la realización de festejos que pueden incluir a los grupos musicales de mayor popularidad en el momento, y la presencia de fuertes procesos migratorios hacia la zona de la ciudad de NY.

Cabe hacer mención de que la exepción frente a los grupos musicales fuereños la constituye la inclusión permanente, aunque nunca como la atracción principal, en el programa de los bailes de lugares como Acatlán, Chinantla, Piaxtla, Tecomatlán o Tulcingo, del transnacional grupo Mandato, conformado por músicos de la región, algunos de ellos exmigrantes, que es apadrinado por un empresario transnacional de la región y que viaja frecuentemente a Nueva York para tocar en los bailes de los paisanos. Y algo similar sucede con Jorge Domínguez y su Super Class, del estado de Tlaxcala.

En todos los casos, cabe hacer notar que los empresarios locales tienen que limitarse a optar por alguna combinación, encabezada siempre por grupos ajenos a la región y conocidos en estas localidades sobre todo a través de la televisión, que los empresarios ajenos a la región tienen ya preparada para realizar una gira por la Mixteca, por Atlixco o por el sur de Tlaxcala. Muchas veces, el éxito relativo de las fiestas depende de si los empresarios locales se arriesgan o no a contratar una cambinación de alto costo. Sin embargo, lo que quiere hacerse resaltar es que, por un lado, aunque los empresarios sean ajenos a las localidades, los responsables directos, quienes dan la cara ante la población, 
resultan ser personas originarias de la región, pero con la particularidad de que el dinero que les permite fungir como empresarios -subordinados, pero empresarios- es el dinero obtenido por la migración. Pero, también, que la capacidad de consumo que permite a los habitantes de una de las regiones de mayores índices de marginalidad del país pagar por los boletos, caros, para asistir a ese tipo de bailes, proviene no de los ingresos que es posible obtener en los pocos empleos que se generan regionalmente, sino de alguna vinculación directa con los migradólares.

Puede verse, entonces, que las fuertes transformaciones que se han presentado en las festividades patronales de las regiones que presentan flujos migratorios significativos en el sur y el centro del estado de Puebla, así como en el sur del estado de Tlaxcala, obedecen tanto a causas ligadas directamente con la migración y los fenómenos de transmigración (remesas, visitas periódicas, cambios en las formas de vestir y en el consumo en general, modos de hablar, tipos de ofrenda, capacidad de consumo), como a otras que afectan de manera más generalizada al conjunto de comunidades rurales expuestas a la acción de redes comerciales de diverso tipo y a la influencia de los medios masivos de comunicación. Pero tal vez lo más interesante sea tratar de observar cómo en cada caso particular se resignifican

y especifican de manera diferenciada esas múltiples influencias, para convertirse en elementos constitutivos de los diversos espacios sociales transnacionales generados por la migración.

Cabe señalar que algunos de los integrantes de la familia de Doña Rosa, incluida ella misma, han jugado un papel de gran importancia en las festividades de 1999, cuando se han convertido precisamente en los exitosos organizadores del baile central. Pero no debe olvidarse que para llegar a esta posición, la historia fue larga y difícil. Una última imagen en movimiento sobre sus orígenes permite establecer el contraste necesario.

\section{TERCERA IMAGEN EN MOVIMIENTO: LOS ORIGENES}

Por último, y para tener una idea de los orígenes, si la fotografía hipotética que se ha venido proponiendo como herramienta se hubiera tomado en los últimos años de la década de los sesenta, nos hubiera ofrecido una imagen de doña Rosa aún joven, pero cargada de la gran responsabilidad de sacar ella sola adelante a sus hijos, sin la ayuda de los respectivos padres de cada uno de ellos. Con toda seguridad, en el caso de ser miércoles, ella estaría desde la 
madrugada preparando y vendiendo comida en un puesto del mercado de la población vecina -separada de su propio pueblo por sólo una calle-, aprovechando la gran afluencia de gente ocasionada por la plaza ganadera semanal.

Como su principal ayudante estaría su hijo Antonio, niño encargado de llevar los utensilios y las materias primas desde su casa hasta el mercado y de acarrear agua y otras cosas necesarias. También en el puesto estaría la niña Guadalupe -estudiante de primaria, siempre descalza-, quien además de ayudar a su madre en el negocio de alimentos, se estaría encargando de su propio negocio de venta de cerveza, que inició por su propia inciativa cuando se dio cuenta de que eso le arrojaría una ganancia creciente, en lo que fue el incio de su destacada carrera empresarial.

No estarían en el mismo cuadro los dos hijos más pequeños de doña Rosa; por su corta edad, ellos estarían tal vez dormidos, bajo el cuidado de su abuela materna. Tampoco estaría en este cuadro la hija mayor de doña Rosa; debido a su dificultad para tratar con la gente, ella estaría en la casa familiar, lavando ropa, limpiando, cuidando a los animales y preparando parte de los alimentos que vendería doña Rosa.

\section{LA HISTORIA QUE UNE ESAS IMAGENES}

Entre esas dos imágenes extremas que se han presentado, se encuentra una rica y compleja historia familiar, de la cual se presenta a continuación una breve síntesis. Aunque los medios hermanos de doña Rosa habían migrado a distintos puntos de los EUA a lo largo de los años sesenta, el escaso contacto entre ellos no posibilitó que su experiencia se transmitiera directamente a doña Rosa y sus hijos. Fue a principios de los años setenta cuando un migrante originario del pueblo, vecino al de ellos, regresó de Nueva York a buscar a alguna joven que quisiera casarse con él y acompañarlo en la aventura del regreso al norte, en donde el joven llevaba trabajando unos dos años. Conoció ahí a una pequeña de trece años, recién salida de la escuela primaria, que vendía cervezas y ayudaba a su madre en la venta de alimentos, en el mercado ganadero de los miércoles. No con facilidad, por razones que en otro lugar será pertinente referir, pudo convencer a Guadalupe de la seriedad de sus propuestas. Para ello ayudaron dos cosas. La primera fue la oferta cumplida de matrimonio. La segunda, la extensión de la invitación a migrar al resto de la familia. 
Cuando la pareja se fue a NY, con ella migró también el hijo mayor de doña Rosa. Para él, quedaba atrás una niñez, una adolescencia y una temprana juventud ricas en experiencias, en retos y en carencias; pero también en la adquisición de sus principales recursos: el gusto por la aventura y el disfrute de la vida, por un lado, y la disposición, por el otro, para aprender y realizar correctamente cualquier tipo de trabajo, y en cualquier lugar, que se le presentara en el camino. Así, después de ayudar a su madre en la preparación y la venta de alimentos, en la limpieza de casas y en el lavado de ropa ajena, empezó una vida itinerante que habría de continuar hasta la actualidad. Trabajó, en una población cercana a su lugar de origen, pelando y destazando pollos; después ayudó a un vendedor de artículos varios, que recorría en una camioneta todas las poblaciones que van de la estación de las Palomas, situada entre Tehuitzingo y Acatlán, hasta el extremo sur del estado de Puebla, camino a Tlapa, Guerrero. Más adelante, en la ciudad de México desempeñó varios oficios y procreó a sus primeras hijas (quienes, por cierto, ahora viven en NJ y fueron las primeras en hacerlo abuelo). De ahí se fue al norte del país a recorrer pueblos vendiendo imágenes de santos (era judas, dice él: porque andaba vendiendo a Cristo).

Al principio, los tres encontraron trabajo en el tipo talleres de confección que en NY son conocidos como sweatshop. Más adelante, Antonio empezó lo que sería una exitosa carrera en restaurantes. De hecho, pese a haber realizado múltiples actividades, la ocupación que articuló la vida laboral de Antonio es la del trabajo en restaurantes.

Mientras tanto, la familia de doña Rosa empezó a hacerse grande en NY. La joven pareja formada por Guadalupe y su marido procreó de inmediato un hijo, que al año siguiente sería seguido de una hermanita. Además, el resto de la familia empezó a seguir los pasos de los primeros migrantes. Doña Rosa se fue acompañada de su hija mayor, que había estado alejada de la familia, trabajando como sirvienta, primero en Chiapas y despúes en la ciudad de México, en donde una tía le había conseguido trabajo. Doña Rosa encontró rápidamente trabajo como sirvienta. Para su hija fue más difícil; la carencia del idioma inglés y una marcada timidez la hicieron dejar un trabajo doméstico inicial y la ubicaron laboralmente en distintos sweatshop, experiencia que fue para ella sumamente dura y que la llevó a tomar la decisión de regresarse a su pueblo de origen, dos años después. Tanto en el caso de Alejandra, como en de Guadalupe y su marido, el trabajo que realizaron como 
migrantes en NY fue básicamente en los llamados sweatshop, establecimientos que, como ya se ha visto, representan una de las principales fuentes de empleo para los mexicanos en NY.

Finalmente, los dos hijos más pequeños de doña Rosa, que se habían quedado a cargo de la abuela materna, se unieron a la expedición migratoria, porque ya no pudo cuidarlos la mamá de doña Rosa, que se vio seriamente afectada en su salud, como consecuencia del violento temblor de tierra que sacudió a México en septiembre de 1973. El caso del menor de los hijos de doña Rosa, Ricardo, resulta sumamente interesante porque permite observar una de las formas en que la existencia y acción de las familias transnacionales se convierte en un importante agente en la creación de los EST. Ricardo fue, junto con su hermana más pequeña, el último en migrar a los EUA. De hecho, su mamá había pensado inicialmente en que estos dos pequeños permanecieran en México mucho más tiempo; sin embargo, el fuerte temblor de tierra de 1973 hizo que se agravara el estado de salud de la madre de doña Rosa, quien había quedado a cargo de los niños. Entonces, casi al mismo tiempo en que Guadalupe, su esposo y sus dos hijos se instalaban de regreso en el pueblo, los dos hermanos menores se trasladaron a los EUA. Al igual que el resto de la familia, Ricardo empezó a trabajar desde muy pequeño, auxiliando a su madre, quien se dedicó siempre a realizar trabajos domésticos en casas particulares. Eso, además de colaborar, como ya se ha dicho, en la actividad que doña Rosa empezó a realizar todos los fines de semana y que acabó convirtiéndose en un trabajo permanente y muy lucrativo, que se mantiene hasta la fecha: la preparación y venta de antojitos y bebidas mexicanas, en los campos de futbol de las ligas mexicanas, ubicados en el norte de la isla de Manhattan, en la zona conocida como Washington Heighs 61.

Cuando Ricardo creció, sus ocupaciones fueron en gran medida siguiendo la huella de las actividades de su hermano mayor, de quien se convirtió en el brazo derecho, en la organización de los bailes y en el manejo del restaurante. Más adelante, Antonio y Ricardo detectaron la existencia de un posible negocio. Por un lado, observóaron que muchos mexicanos empezaban a instalar pequeñas empresas productoras de tortillas. Por otro, notaron algo que sus contactos, propios y familiares, hacían resaltar siempre: la gran

\footnotetext{
61 .- Aunque, más recientemente, a esta zona se le empieza a denominar como el pequeño Santo Domingo, por la gran cantidad de personas dominicanas que habitan ahí.
} 
dispersión en la que viven los mexicanos en el área de la ciudad de NY y las áreas vecinas (sobre todo en NJ). En efecto, lejos de haberse ubicado, como lo han hecho otros grupos de migrantes en el pasado, en una zona delimitada y única, los mexicanos se han asentado en muy diversas zonas del Bronx, Brooklin, Queens, Staten Island, Manhattan y Yonkers, en NY, y de la parte de NJ más cercana a NY, como Passeic. Muchos de estos migrantes dicen que la razón de esta dispersión obedece a que han buscado para vivir aquellas zonas en donde ya estaban previamente asentados grupos de hispanoparlantes, sobre todo puertoriqueños y dominicanos.

Complementariamente, los hermanos observaron que los horarios de trabajo, y las grandes distancias entre los lugares de habitación y los de trabajo de los mexicanos en NY, dificultaban enormemente la tarea de aprovisionamiento de víveres. Lo anterior, agravado por el hecho de que, hasta muy recientemente, la llegada de productos mexicanos a NY era muy tortuosa. Según nos han referido, estos productos llegaban primero desde California, y más adelante desde Chicago. Ha sido sólo muy recientemente, cuando algunos mexicanos y otros puertoriqueños y colombianos, han empezado a desempeñarse en el muy lucrativo negocio de la introducción y venta de productos mexicanos en NY.

Decidieron entonces que su negocio consistiría en vender de puerta en puerta sobre todo tortillas, pero también otros productos, como chiles, pasta para hacer mole o pipián, harina para hacer tamales y otros productos del mismo estilo, de los que permiten a los migrantes sentirse de alguna manera menos lejos de su tierra. La red de contactos, inicialmente sólo conformada por los de su propia familia y los amigos más cercanos, fue creciendo casi por sí misma, a través de la recomendación de los propios clientes. Cuando Ricardo la vendió (Antonio se la había dejado en exclusiva años atrás), en 1996, había adquirido proporciones considerables y adquirido un precio que le permitió completar lo necesario para instalar su propio negocio estable, en la zona de Yonkers, muy cerca de los demás negocios de la familia.

Debido a que estas rutas representan un campo fundamental para la integración de los espacios de vida y trabajo de la gente de México en Nueva York, vale la pena detenerse un poco y profundizar en la historia de esta ruta construida a lo largo del tiempo por Antonio y Ricardo. Como se ha dicho y repetido en este trabajo, la dispersión habitacional de la población mexicana en Nueva York y Nueva Jersey, ha sido creativamente 
aprovechada por quienes han desarrollado y mantenido las llamadas rutas de distribución domiciliaria de productos mexicanos. Los ruteros son personas que juegan un papel de primera importancia en la vida de quienes han migrado. A través de estas rutas, es posible contar cotidianamente con una extensa variedad de productos mexicanos, que son entregados directamente en las viviendas, una, dos o incluso más veces a la semana.

Las rutas consituyen un importante campo de actividad ocupacional para los migrantes mexicanos en NY. Aunque, en términos generales, constituyen una actividad complementaria frente a otro tipo de trabajo, como pueden serlo el de los restaurantes o los sweatshop, por ejemplo, el manejo de una ruta brinda amplias posibilidades para obtener ingresos relativamente elevados, a cambio de realizar esfuerzos considerables.

...tenía una venta de 1300, 1400 dólares (en los fines de semana), pero rapidísimo sí, porque era de casita en casita........así es que le digo que, yo el dinero que me pagaban, directo de mi... de mi sueldo iba directo al banco, ese ni lo tocaba yo siquiera, por ese tiempo se ganaba poco, se ganaban 600 dólares me parece...600 dólares, de cocinero, se ganaba poco entonces. Ahora un cocinero, cocinero.... buen, buen cocinero, así... le estoy hablando de un buen cocinero, en un buen sitio se lleva sus 1200, 1300 dólares, por semana. Un buen cocinero... (Antonio, originario de Piaxtla).

Redituable, el negocio de las rutas es, sin embargo, difícil y riesgoso:

...entonces, ya para subir dos cajas de tortillas hasta el sexto piso, y eso que no es todos los días, pues... Ora, en tiempo de hielo, en tiempo de invierno, vas caminando con tu caja de tortillas y que ya un resbalón, ya te caíste con todo y la caja de tortillas, con toda la mercancía y arriesgando... arriesgando el... porque es peligrosísimo andar manejando en el hielo ¿no? los carros este... derrapan, se chorrean, subidas, no puedes subir, un montón de hielo, es malísimo eso.

Uno de los elementos más interesantes que surgen al analizar el trabajo en las rutas es que éstas no existen, por así decirlo, ni por sí mismas, ni al margen de la o las personas que realizan el trabajo. De hecho, las rutas son la combinación de la capacidad emprendedora y de trabajo del rutero con sus contactos personales y los de su familia; así como con la información que la persona que la opera tenga sobre los lugares precisos de habitación de los paisanos, el conocimiento sobre sus preferencias y necesidades de consumo y sobre sus horarios de trabajo, pero también sobre los productores locales y los introductores de los productos mexicanos más demandados en NY por los paisanos: 
... yo empecé vendiendo tortilla para un italiano pero ese italiano la traía de... de California. La traían por avión la tortilla, por avión llegaba... la hacían hoy y al otro día ya estaba la tortilla aquí en Nueva York. Y entonces yo iba... iba a comprarla, la compraba yo y me tiraba yo a repartir. Me tiraba yo a repartir...Por toda la ciudad, le digo, empezaba yo aquí (en Yonkers). La tortilla la iba yo a traer hasta un pueblo por allá arriba, por... se llama... de Newark adelante, por ahí, cómo se llama, por ahí donde está... por ahí por la Orange... Hasta allá iba yo a traer las tortillas, como una hora y media me iba yo, me iba yo los viernes, saliendo de mi trabajo (como cocinero)...A esa hora me iba yo, todos los viernes yo iba a traer mi tortilla, ya entraba yo aquí a Yonkers como a las 8 de la noche y entre 8 de la noche a... entre 7 y 8 hasta las 11 que me iba yo de aquí...Todo venía de California, sí... de California, sí... Sí, de ahí empecé, tuve la ruta como... como unos 8 años (Antonio, originario de Piaxtla).

Ahora bien, una vez establecidas y después de un tiempo de operación, las rutas cobran de hecho una cierta existencia autónoma, pero que no depende de ningún tipo de reglamentación formal o incluso legal; sino de la posibilidad que tienen los contactos personales y la información de ser transladados de una persona a otra; lo cual permite, por ejemplo, que estas rutas puedan llegar a ser vendidas. Como sucede en general con las redes de relaciones sociales, esta actividad que depende centralmente de ellas, tiene una existencia más bien virtual. La forma de operación de una ruta es relativamente sencilla, y aunque el trabajo pueda ser agotador, no requiere de una gran inversión inicial, ni de credenciales, ni de largos y especializados periodos y procesos de capacitación y adiestramiento; aunque sí se requieran habilidades y conocimientos específicos, como saber conducir un auto, conocer la propia ciudad, así como su tránsito y sus reglas. Por otro lado, resulta un trabajo altamente autoregulado, dentro de los límites que le imponen los hábitos y costumbre de los clientes. De hecho, una ruta bien puede iniciarse con algún medio de transporte - propio o alquilado-y con el contacto, y posible crédito, con algunos productores locales de productos mexicanos -el central: la tortillla-, o bien con algún introductor que los haga llegar desde Chicago, desde Los Angeles o incluso desde México; pero, sobre todo, debe contarse con una lista de mexicanos, sus direcciones, y sus horarios y días de 
trabajo. Lo demás sólo es trabajo, contando con que los paisanos sigan estando dispersos por toda la zona metropolitana, sigan consumiendo tortillas y sigan teniendo dificultades, por sus extensos horarios de trabajo, para ir a surtirse directamente a los negocios, por lo que les resulta más cómodo recibir una o más veces a la semana la visita del rutero. Antonio, originario de Piaxtla, recuerda:

....andaba yo vendiendo productos mexicanos, empecé vendiendo en el 80, en... 79, me dio por..., vendía yo productos mexicanos, vendía..., empezaba del... viernes, sábado.... viernes, sábado nada más vendía yo, dos días. Pues para ese tiempo sí se ganaba buen dinero... a la semana yo me ganaba un promedio de... en dos días me ganaba un promedio de 1400, 1500 dólares...Yo empecé a vender en... aquí en Yonkers precisamente, a vender en..., empecé a vender aquí en Yonkers. De aquí me iba para el Bronx, del Bronk me iba para Manhattan, de Manhattan para Brooklyn, de Brooklyn a Queens. En primera había poco vendedor, había poco vendedor y había mucho cliente.

Cabe señalar, sin embargo, que en este campo parecen estarse introduciendo cambios que bien pueden llegar a afectar el funcionamiento de las rutas, hasta llegar, en el extremo, a hacerlas innecesarias. Esto tiene que ver con la creciente presencia de los mexicanos en NY, con el éxito de algunos de sus empresarios (por ejemplo, en el ramo del comercio y los restaurantes) y, cabe destacarlo, incluso con la extensión de los hábitos y gustos alimenticios mexicanos hacia otros sectores de la población neoyorquina. Esto es, tiene que ver en general con una cierta institucionalización de la presencia de los mexicanos en Nueva York y Nueva Jersey. Específicamente, la proliferación de tortillerías y tiendas de productos mexicanos por toda la zona parece ser una realidad creciente, como incluso se ha documentado en programas de televisión de Neva York62. Como puede comprobarse en algunas filmaciones que realizamos, también puede detectarse en las calles de NY una presencia creciente de transportes comerciales de las propias empresas productoras, sobre todo de tortillas.

En este sentido, tal vez se esté iniciando el tránsito de una actividad independiente a una de tipo dependiente y asalariada, pero que puede llegar a convertirse en una importante

\footnotetext{
62.- Tenemos la grabación en video de un par de ellos, que nos fueron dados a conocer por un orgulloso empresario comercial de origen mexicano -ahora nacionalizado americano- que fue entrevistado para esos programas.
} 
fuente de empleo estable para los mexicanos en NY. Como lo refiere el señor Herminio García, propietario de una tortillería:

...(los ruteros) trabajan por su cuenta. Ellos van y me compran la tortilla y la van a vender, ahí me la pagan y ellos la venden como pueden ¿no? y ya tienen sus clientes también. Pero aparte yo tengo mis choferes, mis camiones, que llegan, cargan y se van; traen el dinero, lo distribuyen y cobran y, me entregan el dinero y yo les pago semanal (Sr. Herminio García).

NOTA: AQUI VA LA FOTOGRAFIA DE LA CAMIONETA DE REPARTO DE LA TORTILLERIA PIAXTLA

\section{CONCLUSIONES PARCIALES}

Aunque son múltiples los comentarios que parece necesario hacer después de haber descrito en imágenes algunos aspectos importantes de esta familia transnacional, a continuación se hacen sólo algunos pocos. A partir de lo que se ha visto hasta aquí, es posible afirmar que para esta familia parece ser más fuerte lo que une entre sí a los dos espacios principales en los que desarrollan su existencia (el pueblo de la mixteca poblana y la región NY-NY), que lo que separa a México de los EUA. A los dos espacios los une la presencia en ambos de familares muy cercanos, en el sentido afectivo, pero también incluso empresarial. Los une la posibilidad permanente, y regularmente muy utilizada, de mantener comunicaciones (telefónicas, para envíos de dinero, etc) entre uno y otro espacio. Los une también su propio transcurrir constante entre uno y otro polo, ya sea con fines laborales, con fines rituales o de esparcimiento, como asistir a la fiesta patronal, en México, o a conocer la región de NY; o bien de negocios, como en el caso de doña Rosa, para atender el hotel-restaurante de su hijo en el pueblo, cuando éste se ha quedado sin administración, como sucedió entre 1996 y 1997; o bien como Guadalupe, para atender durante una amplia temporada anual el restaurante que posee con su hermano en Yonkers.

A ambos espacios los une, en otro nivel, la seguridad de que las costumbres, hábitos y preferencias que ha desarrollado la familia a lo largo de los años y la convivencia, pueden ser desplegados en cualquiera de ellos sin mayores problemas. No se trata aquí de la mera reproducción en los EUA de la vida del pueblo en México, ni tampoco de la reproducción en éste de la vida norteamericana. Se trata de una mezcla creativa de elementos que, si bien 
pueden mostrar con cierta claridad sus orígenes en alguna de las dos culturas, reflejan sobre todo la forma en que estos migrantes han vivido la parte de la sociedad norteamericana con la que han tenido contacto (marcada por un carácter fuertemente multiétnico y multicultural); y la forma en que, con esa experiencia asimilada, han vivido el regreso itinerante a un pueblo que, además, se ha visto seriamente modificado por al constante ir y venir de sus habitantes a los EUA.

Por ejemplo, Aurora, que pareciera la más asentada como exmigrante en su pueblo de la Mixteca, conserva en NY a una hija, un yerno, también migrante, y a dos nietos, nacidos en los EUA, además de su madre, sus medios hermanos y sus sobrinos. Conserva también los papeles que acreditan su residencia legal en los EUA, lo que le permite ir, al menos cada dos años, a visitar a sus descendientes. Pero, adicionalmente, dentro de su proyecto de vida, NY sigue siendo el lugar en el que piensa invertir en favor de su hija los ahorros que conserva de su estancia como trabajadora migrante. Esto es, aunque en sentido estricto no puede ser considerada como transmigrante, por su prolongada y estable permanencia en México, dispone de los recursos que le brinda la transnacionalización del espacio social y los integra a sus prácticas y expectativas; pera lo cual cuenta destacafdamente con la acción de los miembros de la familia que propiamente pueden ser considerados como transmigrantes.

En la generación más joven (si se deja fuera a los niños pequeños, que a su corta edad ya han acumulado una importante experiencia transmigratoria), la hija de Guadalupe se mantiene igualmente en el espacio transnacional. Si bien ha pasado la mayor parte de su vida, como muchas de las jóvenes del pueblo de origen de sus padres, en calidad de estudiante -ahí mismo hasta que salió de la secundaria y como migrante interna a la ciudad de Puebla para la realización de sus casi culminados estudios universitarios-, se diferencia de muchas de ellas (y se asemeja a otros tantas) por el hecho de haber nacido en NY y poseer la nacionalidad norteamericana, y por estar casada con un joven migrante. Y se asemeja a la mayoría porque sabe que entre los recursos con los que cuenta para desarrollar su proyecto vital se encuentra la presencia en NY de las casas, los negocios y la protección de sus familiares y las redes sociales en las que ellos se desenvuelven y que ella ha podido conocer en los largos periodos vacacionales que ha pasado allá con su familia (vacaciones, 
por cierto, que siempre incluyen alguna forma de colaboración, ya sea en la tienda o en el restaurante de su mamá y su tío).

El caso de esta familia permite observar varios elementos que fortalecen la propuesta de la existencia transgeneracional de los espacios sociales transnacionales. Para sus miembros, la pertenencia a dos sociedades nacionales diferentes no parece representar un problema mayor. Aunque muchos han adquirido ya sea la residencia, ya sea la nacionalidad, en los EUA, siempre siguen afirmando su nacionalidad mexicana y, muy particularmente, su pertenencia a su pueblo de origen. En particular, es de hacerse resaltar la importancia que la red familiar ha tenido para la estructuración de las historias laborales y los proyectos biográfico-laborales de sus integrantes. Aunque cabe hacer notar que todos ellos han sido capaces de combinar de manera muy creativa los recursos que ofrecen las distintas instituciones estructurantes del mercado de trabajo.

Antonio, por ejemplo, inicia su trabajo completamente dentro de la red familiar, en México, pero muy pronto empieza a aventurarse en trabajos en los que no cuenta sino con sus fuerzas y habilidades (entre éstas, por supuesto que debe contarse la de ampliar constantemente sus contactos sociales). Sin embargo, la decisión de migrar está claramente determinada por la oportunidad que le abren su hermana y su cuñado y su experiencia migratoria se inicia junto con ellos y su madre. Nuevamente, no obstante, en el desarrollo mismo de su trabajo será capaz de adquirir el dominio de un oficio y de hacer carrera en el medio de los restaurantes, lo que le permitirá a la larga independizarse y convertirse en pequeño empresario (dejando por lo pronto a un lado su frustrada carrera como empresario de los espectáculos), totalmente abierto a las fuerzas del mercado; aunque aprovechando, para la conformación de su clientela, su partenencia a redes sociales sumamente diferenciadas (capital social rico en lazos débiles) en las que tiene prestigio como cocinero y en las que es popular como persona. Sin por ello desligarse de la red familiar, ya sea ayudando a su hermano menor, quien funge en muchos momentos como su ayudante; ya sea asociándose con su hermana en el restaurante; ya sea empleando en sus negocios a sus familiares; ya sea vacacionando en México junto con su mamá y otros miembros de la familia..

Así, tanto la familia vista como una extensa red de relaciones sociales muy estrechas, como cada uno de sus integrantes, no viven esta experiencia como una ruptura 
que parta su vida entre dos mundos escindidos entre sí, sino como un continuo que, si bien está separado por la distancia y por las disposiciones administrativo-legales de dos estados formalmente soberanos e independientes, brinda la posibilidad de estar físicamente tanto en uno de sus lados como en el otro; pero permite también estar, tanto en el terreno afectivo como en el más pragmático de los negocios y el trabajo, en ambos lados a la vez. Esto es, posibilita mantener una noción de pertenencia múltiple y multilocalizada.

Pero debe anotarse también que la existencia de este tipo de familias no agota su importancia en sí misma. Por el contrario, para la existencia y pervivencia de los EST, juega en varios sentidos un papel que la trasciende. En un sentido muy general, su mera presencia sirve como ejemplo de lo que puede obtenerse con la migración, aunque su imagen exitosa pudiera considerarse como engañosa, en tanto no representa la generalidad de los casos, sino más bien a unos pocos de ellos. También, en muchas formas pragmáticas, este tipo de familias juega un importante papel como generador de empleo y, sobre todo, como vehículo confiable que favorece el tránsito de personas y de mercancías; así como la circulación de informaciones muy útiles sobre posibilidades de empleo, vivienda, costumbres locales, peligros, posibilidades, formas de transporte y reglas sociales. Pero, en un nivel más simbólico, es igualmente vehículo para la circulación y fusión de costumbres, prácticas, hábitos, formas de consumo y expectativas. Esto es, las familias transnacionales parecen ser un vehículo -más bien: un agente- tanto para los intercambios materiales, como para la creación, recreación y transformación cultural; elementos ambos fundamentales en la creación y pervivencia de los EST. 


\section{CONCLUSIONES}

1. El proceso migratorio desarrollado entre Puebla y Tlaxcala y la zona metropolitana de la ciudad de Nueva York, ha generado nuevas realidades sociales que pueden ser denominadas como espacios sociales transnacionales;

2. estos espacios sociales transnacionales cuentan con elementos de diversos órdenes, que les permiten desarrollarse y sobrevivir, en una relación crítica con los estados nacionales, sus legislaciones y sus mecanismos punitivos; en tanto la acción social que se desarrolla hacia su interior, es capaz de traspasar y trasvasar fronteras y territorios;

3. entre los elementos mencionados, destacan: una infraestructura para el traslado e intercambio de personas y de bienes, materiales y simbólicos; un conjunto de instituciones sociales, propias o apropiadas, que juegan un papel central en la estructuración de los diversos subespacios (como el correspondiente a los mercados de trabajo) de los espacios sociales transnacionales; y el surgimiento y desarrollo de formas culturales e identitarias transnacionalizadas, que combinan creativamente elementos de las sociedaes de origen y de las de destino;

4. el campo o subespacio de los mercados de trabajo es uno de los principales para la generación y continuidad de los espacios sociales transnacionales. Aunque de ninguna manera sea el único, en él puede observarse la presencia y el funcionamiento de los diversos elementos mencionados arriba como propios de estos espacios sociales transnacionales;

5. muchas de las principales prácticas transnacionales de los migrantes, tienen lugar precisamente en el campo de los mercados de trabajo: la combinación de trabajos en uno y otro país, a lo largo de las trayectorias laborales; el traslado de la información sobre el funcionamiento de los mercados locales de trabajo, entre uno y otro país; el traslado de personas, con fines laborales, de México a los Estados Unidos; el reclutamiento para el trabajo, propiamente dicho, en localidades mexicanas para ocupar empleos en Nueva York; el financiamiento para que los nuevos migrantes

puedan sufragar los costos de la migración (viaje, mantenimiento de la familia, alojamiento); los envíos de remesas (partición del salario obtenido); la trasmisión, 
voluntaria o involuntaria (como consecuencia no necesariamente prevista de la acción), de la expectativa de migrar, hacia las personas más jóvenes de las localidades de origen; son todas ellas algunas de las más importantes;

6. el estudios de las trayectorias y de las biografías laborales de los migrantes, permite observar el proce espacios sociales transnacionales so de transnacionalización, tanto de las referidas trayectorias y biografías laborales, como de las instituciones sociales que intervienen en su estructuración y que, a su vez, son estructuradas por aquéllas;

7. las personas reconocen los distintos anclajes territoriales y culturales de la plurilocalización de los espacios sociales transnacionales -con relación a los mercados de trabajo; pero también a otros mundos de vida-, como subespacios diferenciados, pero unificados entre sí, precisamente por su propia experiencia de vida translocal, por sus propias prácticas transnacionales y por su contacto permanente con instituciones, actores, formas de vida y elmentos infraestructurales transnacionalizados;

8. las personas que migran hacia Nueva York, encuentran trabajo en aquella zona en segmentos o nichos de mercado (o bien: en mercados locales de trabajo, tal y como éstos son reconceptualizados por Sassen (1997)) etiquetados no solemente como para migrantes, sino como para migrantes recientes. Esto es, que son sectores en los que no únicamente se segrega a las personas migrantes con relación a las nativas; sino que se segrega antre sí a los migrantes más recientes de los de mayos antigüedad relativa, conforme a las sucesivas olas migratorias que han poblado Nueva York;

9. estos sectores o nichos del mercado de trabajo, constituyen realidades muy cercanas a verdaderos segmentos de mercado, en tanto resulta sumamente difícil -aunque no imposible- salir de ellos para ubicarse, como asalariados, en otro sectores con mejores condiciones relativas;

10. lo anterior tiene que ver tanto con la historia de las migraciones y de los mercados de trabajo de Nueva York, como con la forma de funcionamiento de las redes de los migrantes; 
11. además, esos segmentos muestran evidencias de que, hacia su interior, segregan a los personas con base en el sexo;

12. en consecuencia, la segregación aparece como la institución sobredeterminante $-\mathrm{O}$ determinante estructural más general- de las trayectorias laborales de los migrantes en Nueva York,

13. a partir de esa sobredeterminación - o detrminación estructural general-, las redes de relaciones sociales, y especialmente las que tienen que ver con las familias, resultan ser la institución social fundamental en la estructuración de esos segmentos de mercado; tanto en el sentido favorable de fecilitar la información y el acceso, como en el desfavorable de enclaustrar a las pesonas dentro de esos segmentos;

14. cabe observar que las trayectorias y las biografías laborales de los migrantes presentan fuertes discontinuidades si se les observa separando la parte de ellas que sucede en México de la que tiene lugar en los EUA;

15. esas discontinuidades se presentan tanto en el tipo de trabajo que se desempeña, como en la forma y la intensidad con las que intervienen en su estructuración las diversas instituciones sociales relacionadas con el funcionamiento de los mercados de trabajo;

16. la forma $y$ el funcionamiento de las instituciones que intervienen en la estructuración de las trayectorias laborales de los migrantes se ha transnacionalizado, o bien reconfigurado a lo largo de los espacios sociales transnacionales que ha generado el proceso migratorio;

17. las familias transnacionales, que precisamente son una institución reconfigurada en este proceso, son un actor de gran importancia dentro de esas redes de relaciones sociales, al actuar como elementos articuladores de actores y espacios, particularmente en el funcionamiento de los mercados de trabajo;

18. estas familias transnacionales, así como las redes en las que se articulan, actuan en todos los territorios en los que se asienta la plurilocalización de los espacios sociales transnacionales que surgen con el proceso migratorio;

19. al actuer como canales privilegiados para transmitir la información hacia los ligares de origen, en México, acerca del funcionamiento de esos segmentos del mercado de trabajo, en Nueva York, las redes de relaciones sociales juegan un papel 
fundamental en la transnacionalización de los mercados locales neoyorquinos; llegando a actuar con frecuencia incluso como agentes reclutadores y facilitadores del traslado, y no sólo como transmisores de la información;

20. por supuesto que la acción de este tipo de familia no se agota en el funcionamiento de los mercados de trabajo, sino que también juega un papel fundamental en la generación y continuidad de los espacios sociales transnacionales; ya sea en terrenos simbólicos como el de la creación cultural y el de las identidades colectivas; o bien en los campos propios de otros mercados igualmente transnacionalizados, como los de bienes y servicios;

21. es importantes señalar que, pese a su papel central, no son solamente la segregación y las redes de relaciones sociales las únicas instituciones sociales que intervienen en la estructuración de las trayectorias laborales de los migrantes en Nueva York, sino que en ésta intervienen también $-\mathrm{y}$, en algunos casos lugares y momentos, de manera determinante- el mercado, la organización de la empresa y la organización de la profesión o el oficio;

22. estos mercados locales de trabajo transnacionalizados se convierten en espacios de acción social específicos, que trabajan a favor del surgimiento, la consolidación y la continuidad de los espacios sociales transnacionales más generales (que abarcan mundos de vida que no están directamente ligados al trabajo);

23. por lo anterior, las redes de relaciones sociales y, especialmente las familias transnacionales, son un elemento central, producto-productor, de los espacios sociales transnacionales. 


\section{BIBLIOGRAFÍA}

Agnew, John. 1999. "Mapping Political Power Beyond State Boundaries: Territory, Identity, and Movement in World Politics." Milennium: Journal of International Studies, Vol. 28, No. 3:499-521.

Alba, Richard and Victor Nee. 1997. "Rethinking Assimilation Theory for a New Era of Immigration.” International Migration Review 31: 826-874.

Alvarez, Robert (1990), "Mexican entrepreneurs and markets in the City of Los Angeles: A case of an immigrant enclave", en UrbanAnthropology, Vol. 19,Núms. 1-2, Primavera-Verano de 1990, págs. 99-124.

Amigoni, David (1991) "Life histories and the cultural politics of historical knowing: the Dictionary of National Biography and the late nineteenth-century political field", en Shirley Dex (Ed.), Life and Work HistoryAnalyses. Qualitative and Quantitative Developments, Londres, Routledge, 1991, págs. 144-186.

Anderson, Benedict. 1998. "Long-Distance Nationalism," Pp. 58-74 in Benedict Anderson, The Spectre of Comparisons. Nationalism, Southeast Asia and the World, London: Verso.

Anderson, Benedict, 1983: Imagined Communities: Reflections on the Origins and Spread of Nationalism. New York: Verso.

Arizpe, Lourdes (1978) "Mujeres migrantes y economía campesina: análisis de una cohorte migratoria a la ciudad de México”, en América Indígena, Vol. xxxviii, Núm. 2, abriljunio de 1978, págs. 303-326.

-------. (1991) Audiencia Informativa sobre Derechos Humanos de los Trabajadores Migratorios Mexicanos, México, Comisión Editorial del Senado de la República, 1991, 246 págs.

Augé, Marc (1993) Los "no lugares” espacios del anonimato. Una antropología de la sobremodernidad. Barcelona, Editorial Gedisa, 1993, 125 págs.

Balan, Jorge, Harley Browning y Elizabeth Jelin (1973) Migración, estructura ocupacional y movilidad social (El caso de Monterrey), México, UNAM, 1973, 289 págs.

------- y otros (1974) Las historias de vida en ciencias sociales. Teoría y técnica. Buenos Aires, Eds. Nueva Visión, 1974, 217 págs. 
--------, Harley Browning y Elizabeth Jelin (1977), El Hombre en una Sociedad en Desarrollo. Movilidad geográfica y social en Monterrey. México, FCE, 1977 (1973), 444 págs.

-------, y Elizabeth Jelin (1979) La estructura social en la biografía personal, Buenos Aires, Estudios CEDES, Vol. 2, Núm. 9, 1979.

Barrow, Anita (1988) “Generations of persistence: Kinship amidst urban poverty in São Paulo and New York”, en Urban Anthropology, Vol. 17, Núms. 2-3, 1988, págs. 193228.

Basch, Linda G., Nina Glick Schiller and Cristina Szanton Blanc. 1994. Nations Unbound: Transnational Projects, Post-colonial Predicaments, and De-territorialized NationStates. Langhorne, PA: Gordon and Breach.

Basch, Linda/Glick Schiller, Nina/Szanton Blanc, Cristina, 1997: Nations Unbound. Transnational Projetcs, Postcolonial Predicaments, and Deterritorialized NationStates. Amsterdam: Gordon and Breach (4 ${ }^{\text {th }}$ edition, $1^{\text {st }}$ edition 1994).

Behrens, Johann y Ursula Rabe-Kleberg (1991) "Gatekeeping in the life course: A pragmatic typology", en Walter R. Heinz (Ed.), Theoretical Advances in Life Course Research, Weinheim, Deutscher Studien Verlag, Volumen III, 1991, págs. 237-260.

Benson, Janet E. (1990) "Households, Migration, and Community Context", en Urban Anthropology, Vol. 19, Núms. 1-2, Primavera-Verano de 1990, págs. 9-30.

Berger, John, Jean Mohr et al (1975) A seventh man: the story of a migrant worker in Europe, United Kingdom, Penguin Books, 1975, págs. 238.

Bertaux, Daniel (1991) "From methodoligical monopoly to pluralism in the sociology of social mobility", en Shirley Dex (Ed.), Life and Work History Analyses. Qualitative and Quantitative Developments, Londres, Routledge, 1991, págs. 73-92.

------ y Martin KOHLI (1984) “The life story approach: a continental view”, en Ann. Rev. Sociol., Núm. 10, 1984, págs. 215-237.

Bertone, Santina (1995) “Inmigrant female workers and Australia”.

Blossfeld, Hans-Peter (1986) "Career opportunities in the Federal Republic of Germany: a dynamic approach to the study of life-course, cohort, and period effects", en European Sociological Review, Vol. 2, Núm. 3, Diciembre de 1986, págs. 208-225.

------. (s.f.) "Entry into the Labor Market and Occupational Career in the Federal Republic. A Comparison with American Sutdies", Reprint... 
-------. (1987) "Labor-Market Entry and the Sexual Segregation of Careers in the Federal Republic of Germany", en American Journal of Sociology, Vol. 93, Núm. 1, Julio de 1987, págs. 89-118.

Böhning, W. R. (1992) “La integración y las corrientes migratorias en Europa occidental”, en Revista Internacional del Trabajo, Vol. 111, Núm. 1, 1992, págs. 23-40.

Bourdieu, Pierre (1991), "El capital simbólico", en El sentido práctico, Madrid, Taurus Ediciones, 1991, págs. 189-204.

------. (1990), “Espacio social y génesis de las “clases””, en Pierre Bourdieu, Sociología y cultura, México, Ed. Grijalbo y CONACULTA, 1990 (1984), págs. 281-309.

Boyd, Monica (1989), "Family and personal networks in international migration: recent developments and new agendas", en International Migration Review, Vol. xxiii, Núm. 3, otoño de 1989, págs. 638-670.

Brock, Lothar. 1999. “Observing Change, 'Rewriting' History: A Critical Overview;" Milennium: Journal of International Studies, Vol. 28, No. 3:483-497.

Brown, Richard P. C. (1994) "Las remesas de los emigrantes, el ahorro y la inversión en el Pacífico meridional”, en Revista Internacional del Trabajo, Vol. 113, Núm. 3, 1994, págs. 399-419.

Brubaker, Rogers, 1994: Citizenship and Nationhood in France and Germany. Cambridge/London: Harvard University Press ( $2^{\text {nd }}$ edition, $1^{\text {st }}$ edition 1992 ).

Brysk, Alison. 1996. "Turning Weakness into Strength: the Internationalization of Indian Rights;" Latin American Perspectives, vol. 23, no. 2.

Burchell, Brendan (1993) "A new way of analyzing labour market flows using work history data", en Work, Employmen \& Society, Vol. 7, Núm. 2, Junio de 1993, págs. 237258.

Bustamante, Jorge A./Martínez, G.G., 1979: Undocumented Migration from Mexico: Beyond Borders but with Systems. In: Journal of International Affairs (New York), Vol. 33, No. 2, pp. 265-284.

Cadwallader, Martin (1992), Migration and Residential Mobility. Macro and Micro Approaches. Madison (Wisconsin), The University of Wisconsin Press, 1992, 269 págs.

Calderon Chelius, Leticia. 1999. "Ciudadanos Inconformes. Nuevas formas de representacion política en el marco de la experiencia migratoria: El caso de los migrantes mexicanos;" Frontera Norte, vol. 11, no. 21:117-146. 
----. 1998. "El ABC del voto en el exterior;" L'Ordinaire Latino-Americain, no. 173174:144-152.

Campillo, Marcia, Garcia, Patricia, Herrera, Fernando y Macias, Saúl (1996), Ponencia presentada en el Primer Congreso Latinoamericano de Sociología del Trabajo, Guadalajara, mes de marzo.

Castillo G., Manuel Ángel (1993) "La economía centroamericana y la inmigración a México", en Comercio Exterior, agosto de 1993, págs. 763-773.

Castles, Stephen/Miller, Mark J., 1993: The Age of Migration. International Population Movements in the Modern World. Hampshire London:Macmillan.

Cattan, Peter (1993) "The diversity of hispanics in the U.S. work force", en Monthly Labor Review, Agosto de 1993, págs. 3-15.

Cederström, Thoric Nils (s.f.) The impacts of migrant remittances on the peasant economy of four communities of the Mixteca Baja region of Puebla, [s.1.], [s.f.], Preliminary Examination for the Doctoral Dissetation, University of Arizona.

Cederström, Thoric Nils (s.f.), The impacts of migrant remittances on the peasant economy of four communities of the Mixteca Baja region of Puebla, [s.l.], [s.f.], Preliminary Examination for the Doctoral Dissetation, University of Arizona.

Centro de Estudios Internacionales (1979) Indocumentados: mitos y realidades, México, El Colegio de México, 1979, 238 págs.

Chavez, Leo R. (1990) "Coresidence and Resistance: Strategies of survival among undocumented Mexicans and Central Americans in the United States", en Urban Anthropology, Vol. 19, Núms. 1-2, Primavera-Verano de 1990, págs. 31-62.

. (1989) "Migrants and settlers: A comparison of undocumented Mexicans and Central Americans in the United States", en Frontera Norte, Vol. 1, Núm. 1, enerojunio de 1989, págs. 49-75.

------. "The power of the imagined community: The settlement of undocumented Mexicans and Central Americans in the United States", en American Anthropology, Vol. 96, Núm. 1, págs. 52-73.

Chimal, Carlos (1990) "Movimiento perpetuo. Mixtecos en California", en México Indígena, Núm. 4, enero de 1990.

Cicekli, Bulent. 1999. "The Rights of Turkish Migrants in Europe Under International Law and EU Law;" International Migration Review, vol. 33, Number 2:300-353. 
Cohen, Robin, 1996: The Sociology of Migration. (The International Library of Studies on Migration 3) Cheltenham/Brookfield: Elgar.

Comité Cívico Popular Mixteco (1990) "Entrevista con Arturo Pimentel Salas. 'Estaciones de un Largo Retorno"”, en México Indígena, Núm 15, Diciembre de 1990.

Corona Vázquez, Rodolfo (1993), "Migración permanente interestatal e internacional, 1950-1990”, en Comercio Exterior, agosto de 1993, págs. 750-762.

--------, et al (1982) Migrantes internacionales con y sin antecedentes de migración interna: algunas características socioeconómicas, México, CENIET, 1982, 190 págs.

Cortés Sánchez, Sergio (1996), "El retorno de los chinantlecos", en La Jornada de Oriente, 31 de enero de 1996, pág. 11.

-------, 1995a: La Mixteca, tierra de emigrados. In: Perfil de La Jornada de Oriente, 08.03.1995.

--------, 1995b: Los migrantes de la Mixteca poblana. In: La Jornada de Oriente, 29.11.1995, pp. 14-15.

Coutin, Susan Bibler. 1998. "From Refugees to Immigrants: The Legalization Strategies of Salvadoran Immigrants and Activists," International Migration Review, vol. 32, Number 4:901-925.

Cruz Piñeiro, Rodolfo (1992) La fuerza de trabajo en los mercados urbanos de la frontera norte. Tijuana, El Colegio de la Frontera Norte, 1992, 75 págs. Castles, Stephen y Mark J. Miller (1993), The Age of Migration. International Population Movements in the Modern World. Hong Kong, The MacMillan Press Ltd., 1993, 307 págs.

Dex, Shirley (1991) “Life and work history analyses”, en Shirley Dex (Ed.), Life and Work History Analyses. Qualitative and Quantitative Developments, Londres, Routledge, 1991, págs. 1-19.

Díez-Canedo Ruíz, Juan (1984) La migración indocumentada de México a los Estados Unidos. Un nuevo enfoque. México, FCE, 1984, 206 págs.

Durand, Jorge/Massey, Douglas S., 1992: "Mexican Migration to the USA", in: Latin American Research Review (University of New Mexico), Vol. 27, No. 2, pp. 3-42. (1993) "Las remesas en dólares: usos y alternativas de financiamiento", en Marie Nöelle Chamoux et. al., (Coordinadores), Prestar y pedir prestado. Relaciones sociales y crédito en el México del siglo xvi al xx. México, CIESAS/Ediciones de la Casa Chata, [1993], págs. 169-179. 
-------. (1994) Más allá de la línea. Patrones migratorios entre México y Estados Unidos. México, Consejo Nacional para la Cultura y las Artes, 1994, 334 págs., Bibliografía.

Einstein, Albert, 1960: "Vorwort", in: Max Jammer, Das Problem des Raumes. Die Entwicklung der Raumtheorien. Darmstadt, pp.. XI-XV.

Elder, Glen H. (1991) “Lives and social change”, en Walter R. Heinz, Ed., Theoretical advances in life course research, Weinheim, Deutscher Studien Verlag, 1991, págs. 58-86.

Escobar Latapí, Agustín (1986), Con el sudor de tu frente. Mercado y clase obrera en Guadalajara, El Colegio de Jalisco, 312 p.

(1993), "Reestructuración económica y desigualdad social en México: el caso de Guadalajara”. Ponencia preparada para el Primer Congreso Latinoamericano de Sociología del Trabajo. México, D. F., 22-26 Noviembre 1993, 31 págs.

México: el caso de Guadalajara”, Estudios Sociológicos, vol. XIII, n.38, mayoagosto, México, El Colegio de México, p. 231-259.

- (1997), “¿Qué hacemos cuando estudiamos el Mercado de trabajo?", mimeo.

Espinosa, Kristin/Massey, Douglas, 1997: "Undocumented Migration and the Quantity and Quality of Social Capital", in: L. Pries (Ed.), Transnationale Migration. Special Issue No. 12 SOZIALE WELT. Baden-Baden: Nomos, pp. 141-162.

Evans, Peter. 2000. "Fighting Marginalization with Transnational Networks: CounterHegemonic Globalization;” Contemporary Sociology, Vol 29, No. 1:230-241.

Faist, Thomas (1995a), A preliminary analysis of political-intitutional aspects of international migration: internationalization, transnationalization, and internal globalization, Mimeo, Paper presented at the meeting of the working group “Theories of Migration and Development”, Biskops Arnö, abril 20-23, 1995, 28 págs.

- (1995b), Sociological theories of international migration: the missing meso-link, Mimeo, Paper prepared for presentation at the meeting of the theory group of the 
Migration and Development (MAD) project, Hamburgo, Octubre 13-15, 1995, 52 págs.

-------. 2000. The Volume and Dynamics of International Migration and Transnational Spaces. New York: Oxford University Press.

Fawcett, James T. "Networks, linkages, and migration systems", en International Migration Review, Vol. xxiii, Núm. 3, [ ], págs. 671- 680.

Featherstone, Mike (Ed.) (1990) Global culture. Nationalism, globalization and modernity. Londres, Sage Publications, 1991 (1990), 397 págs.

Fingrutd, Meryl, Michele Ethier "Social movements and network analysis: A Roberta Karant y David McDonald (1985) case study of Nineteenth-Century women's reform in New York state”, en American Journal of Sociology, Vol. 90, Núm. 5, 1985, págs. 1022-1054.

Foner Nancy. 1997. "What's New about Transnationalism? New York Immigrants Today and at the Turn of the Century;" Diaspora 6: 355-375.

Foner, Nancy (1987), "Inmtroduction: New Immigrants and Changing Patterns in New York City", en: Nancy Foner (1987), New Immigrantes in New York, Columbia University Press, New York, p.1-33.

Frente Indígena Oaxaqueño Binacional (1995) Frente Indígena Oaxaqueño Binacional, Oaxaca, [s.e.], [1995], 15 págs.

Gans, Herbert. 1992. "Second Generation Decline: Scenarios for the Economic and Ethnic Futures of the Post-1965 American Immigrants." Ethnic and Racial Studies 15: 173192.

-----. 1997. "Toward a Reconciliation of "Assimilation" and "Pluralism: The Interplay of Acculturation and Ethnic Retention.” International Migration Review 31: 875-892.

García Canclini, Néstor (1990) Culturas Híbridas. Estrategias para entrar y salir de la modernidad. México, Ed. Grijalbo/Consejo Nacional para la Cultura y las Artes, 1990 (1989), 363 págs.

------- y otros (1994) De lo Local a lo Global. Perspectivas desde la Antropología. México, UAM, Departamento de Antropología, 1994, 191 págs.

García Hernández, Gerardo (1995) "Un corredor industrial, licor de pitaya y apoyo a las comunidades. Los proyectos de la Universidad Tecnológica de la Mixteca”, en 
Yucunitzá (Testimonios de la Vida Cultural de la Mixteca), Núm. 19, DiciembreEnero de 1995, págs. 21-24.

Garrido Medina, Luis y Enrique Gil Calvo (Eds.) (1993) Estrategias familiares. Madrid, Alianza Editorial, 1993, 356 págs.

Geertz, Clifford (1995), La interpretación de las culturas, Barcelona, Editorial Gedisa, 1995 (1973), 372 págs.

Gendreau, Mónica y Gilberto JIMENEZ (1999), Entre Popocatepetl y Brooklin..., ponencia presentada en el Encuentro de Investigadores sobre Migración Internacional de la Región Golfo Centro, Puebla, Puebla, 8 y 9 de julio de 1999.

Gerard Griffin trade unions”, en Relations Industrielles/Industrial Relations, Vol. 50, Núm. 1, 1995, págs. 117-146.

Giddens, Anthony (1984), The Constitution of Society, Polity Press, Cambridge, 1984.

Glick Schiller, Nina, Linda Basch, And Christina Blanc-Szanton. 1992. "Transnationalism: A New Analytic Framework for Understanding Migration," Annals of the New York Academy of Sciences, no. 645, pp. 1-24.

Glick Schiller, Nina. 2000. "Transmigrants and Nation-States: Something Old and Something New in the U.S. Immigrant Experience." Pp. 94-119 The Handbook of International Migration: The American Experience, edited by Charles Hirschman, Philip Kasinitz, and Josh DeWind. New York, NY: Russell Sage Foundation.

Glick Schiller, Nina and Georges Fouron. 1998. "Transnational Lives and National Identities: The Identity Politics of Haitian Immigrants." Comparative Urban and Community Research 6: 130-161.

Glick Schiller, Nina and Georges Fouron. 1999. "Transnational Lives and National Identities" and "Terrains of Blood and Nation: Haitian Transnational Social Fields," Ethnic and Racial Studies 6: 340-366.

Glick Schiller, Lina Bach y Cristina Blanc-Szanton (1992), "Transnacionalism: a New Analytic Framework for Undestnding Migration", reprinted from "Towards A Transnational Perspectives on Migration", vol. 645 of the Annals of the New York Academy of Science, mes de julio.

Glick Schiller, Lina Bach y Cristina Blanc-Szanton (1992), "Transnacionalism: a New Analytic Framework for Undestnding Migration", reprinted from "Towards A 
Transnational Perspectives on Migration", vol. 645 of the Annals of the New York Academy of Science, mes de julio.

Glick Schiller, Lina Bach y Cristina Blanc-Szanton (1992) "Transnacionalism: a New Analytic Framework for Undestnding Migration", reprinted from "Towards A Transnational Perspectives on Migration", vol. 645 of the Annals of the New York Academy of Science, mes de julio.

Glick Schiller, Nina and Georges Fouron. 1998. "Transnational Lives and National Identities: The Identity Politics of Haitian Immigrants," Comparative Urban and Community Research 6 (1998): 130-161.

Glick Schiller, Nina and Georges Fouron. 1999. "Transnational Lives and National Identities" and "Terrains of Blood and Nation: Haitian Transnational Social Fields," Ethnic and Racial Studies 6: 340-366.

Glick Schiller, Lina Bach y Cristina Blanc-Szanton (1992). "Transnacionalism: a New Analytic Framework for Undestnding Migration", reprinted from "Towards A Transnational Perspectives on Migration", vol. 645 of the Annals of the New York Academy of Science, mes de julio.

Goldring, Luin (1992) "La migración México-EUA y la transnacionalización del espacio político y social: perspectivas desde el México rural”, en Estudios Sociológicos, Vol. X, Núm. 29, 1992, págs. 315-340.

------. (1992a), Blurring the border: transnational community and social transformation in Mexico-U.S. migration. Mimeo, University of Illinois at Chicago. Sociology and Latin American Studies, 1992, 23 págs.

------. (1996b), "Blurring borders: constructing transnational community in the process of Mexico-U.S. Migration”, en Research in Community Sociology, JAI Press, Vol. VI, 1996, págs. 
(1996c), "Gendered memory: Constructions of rurality among mexican transnational migrants", en E. Melanie DuPuis y Peter Vandergeest (eds.), Creating the countryside: The politics of rural and enviromental discourse. Filadelfia, Temple University Press, 1996, págs. 303-329.

-------, 1997: "Power and Status in Transnational Social Spaces, in: L. Pries (Ed.), Transnationale Migration. Special Issue No. 12 SOZIALE WELT. Baden-Baden: Nomos, pp. 179-196.

. (1997), "Difuminando fronteras: Construcción de la comunidad transnacional en el proceso migratorio México-Estados Unidos”, en Saúl Macías Gamboa y Fernando Herrera Lima, Migración y Espacio Social Transnacional, México, BUAP, En Prensa.

-------. 1998. "The Power of Status in Transnational Social Fields," Comparative Urban and Community Research 6: 165-195.

, 2001: Dissagregating Transnational Social Spaces: Gender, Place and Citizenship in Mexico-U.S. Transnational Spaces. In: Pries, L. (Hg.), New Transnational Social Spaces. International Migration and Transnational Companies. London: Routledge.

-------. (s.f.). Power and status in transnational social spaces. Mimeo, s.f. págs.

Goode, Judith (1990) "A wary welcome to the neighborhood: Community responses to immigrants", en Urban Anthropology, Vol. 19, Núms. 1-2, Primavera-Verano de 1990, págs. 125-154.

González de la Rocha, Mercedes (1995), "Reestructuración social en dos ciudades metropolitanas: un análisis de grupos domésticos en Guadalajara y Monterrey", Estudios Sociológicos, vol. XIII, n.38, mayo-agosto, México, El Colegio de México, p. 261-281.

(1999), "La reciprocidad amenazada: un costo más de

la pobreza urbana, Revista Latinoamericana de Estudios del Trabajo, Brasil, ALAST, p.33-50. 
González, Soledad/Ruiz, Olivia/Velasco, Laura/Woo, Ofelia (comp.) 1995: Mujeres. Migración y maquila en la frontera norte. México/Tijuana: El Colegio de la Frontera Norte/El Colegio de México.

Goodson-Lawes, Julie (1993) "Feminine authority and migration: The case of one family from Mexico", en Urban Anthropology, Vol. 22, Núms. 3-4, 1993, págs. 277-297.

Gordon, Milton. 1964. Assimilation in American Life. New York: Oxford University Press.

Graham, Pamela. 1997. "Reimagining the Nation and Defining the District: Dominican Migration and Transnational Politics," in Patricia Pessar (ed.), Caribbean Circuits: New Directions in the Study of Caribbean Migration. Staten Island, New York: Center for Migration Studies, pp. 91-126.

Granovetter, Mark S. (1973) “The strengh of weak ties”, en American Journal of Sociology, Vol. 78, Núm. 6, [ ], págs. 1360-1380.

Grasmuck, Sherri and Patricia Pessar. 1991. Between Two Islands: Dominican International Migration. Berkeley: University of California Press.

-----. 1996. "First and second generation settlement of dominicans in the United States:1960-1990.” In Silvia Pedraza and Ruben Rumbaut (eds.), Origins and Destinies: Immigration, Race and Ethnicity in America. Belmont: Watsworth Press.

Green, Nancy L. (1997), Sweatshop migrations: the garment industry between home and shop", en David Ward y Olivier Zunz (Editores), The landscape of modernity: New York City, 1900-1940, Baltimore, The Johns Hopkins University Press, 1997, págs. 213-232.

Griffith, David (1990) "Consequences of immigration reform for low-wage workers in the Southeastern U.S.: The case of the Poultry Industry", en Urban Anthropology, Vol. 19, Núms. 1-2, Primavera-Verano de 1990.

Guarnizo, Luis E. 1994."Los Dominicanyorks: The making of a binational society.”Annals of the American Academy of Political and Social Sciences 533:70-86.

-------. 1997. "The Emergence of a Transnational Social Formation and the Mirage of Return Migration among Dominican Transmigrants,” Identities, vol. 4, no. 2, pp.281232. 
1998. "The Rise of Transnational Social Formations: Mexican and Dominican State

Responses to Transnational Migration," Political Power and Social Theory, vol. 12, pp. 45-94.

and Michael Peter Smith. 1998. "The Locations of Transnationalism," Comparative Urban and Community Research 6: 3-34.

, Arturo Ignacio Sanchez, and Elizabeth M. Roach. 1999. "Mistrust, Fragmented

Solidarity and Transnational Migration: Colombians in New York City and Los Angeles," Ethnic and Racial Studies 22: 367-396.

and Díaz, Luz Marina. 1999. "Transnational Migration: A View from Colombia.”,"

Ethnic and Racial Studies 22: 397-421.

Hagestad, Gunhild (1991) "Trends and dilemmas in life course research: an international perspective", en Walter R. Heinz, (Ed)., Theoretical advances in Life Course Research, Weinheim, Deutscher Studien Verlag, 1991, págs. 23-57.

Hall, John A./Ikenberry, G. John, 1989: The State. Milton Keynes: Open University Press. Hartlyn, Jonathan. 1998. The Struggle for Democratic Politics in the Dominican Republic, Chapel Hill: The University of North Carolina Press.

Heer, David M. (1993) Los mexicanos indocumentados en los Estados Unidos. México, FCE, 1993 (1990), 289 págs.

Heinz, Walter (1991a) "Status passages, social risks and the life course: A conceptual framework", en Walter R. Heinz (Ed.), Theoretical Advances in Life Course Research, Weinheim, Deutscher Studien Verlag, Volumen I, 1991, págs. 9-22.

-------. (1991b) "Introduction: Institutional gatekeeping and biographical agency", en Walter R. Heinz (Ed.), Theoretical Advances in Life Course Research, Weinheim, Deutscher Studien Verlag, Volumen III, 1991, págs. 9-27.

------. (1991c) "Introduction: The life course and social change in comparative perspective", en Walter R. Heinz (Ed.), Theoretical Advances in Life Course Research, Weinheim, Deutscher Studien Verlag, Volumen II, 1991, págs. 9-19.

Hernández, Alberto (1990) “Mixtecos en Baja California. Destino San Quintín”, en México Indígena, Núm. 11, agosto de 1990.

Herrera, Fernando (1996), La Regulación Social de la Ocupación en el Espacio Social Transnacional, Tesis para obtener el grado de Maestro en Ciencias Antropológicas, UAM-I. 
-/Macías Gamboa, Saúl, 1998: Migración de la Mixteca Poblana a Nueva York: Espacio social transnacional", in: Macías Gamboa, Saúl/Herrera Lima, Fernando (eds.), Migración laboral internacional. Puebla: Benemérita Universidad de Puebla, pp. 107-163.

, 2001: "Transnational Families: Institutions of Transnational Social Space", in:

Pries, L. (Ed.), New Transnational Social Spaces. International Migration and Transnational Companies. London: Routledge.

Hirabayashi, Lane R. (1985) "Formación de asociaciones de pueblos migrantes a México: Mixtecos y Zapotecos”, en América Indígena, Vol. xlv, Núm. 3, julio-septiembre, 1985, págs. 579-598.

Hirschman, Albert. 1970. Exit, Voice, and Loyalty. Cambridge, MA: Harvard University Press.

Ianni, Octavio (1994), “Globalização: Novo paradigma das ciências sociais”, en Estudos Avançados, Vol. 8, Núm. 21, 1994, págs. 147-163.

Immigration and Naturalization Service (INS). 1999. The Triennial Comprehensive Report on Immigration. U.S Department of Justice Immigration and Naturalization Service and U.S. Department of Labor bureau of International Labor Affairs.

----. 1998. Statistical Yearbook. Www.ins.usdol.gov/graphics/aboutins/statistics/ 1998yb.pdf.

Inegi (1993), Migración. Tabulados temáticos. XI Censo General de Población y Vivienda, 1990, México, 1993, 2 tomos.

Itzigsohn, Jose. 1995. "Migrant Remittances, Labor Markets, and Household Strategies: A Comparative Analysis of Low-Income Household Strategies in the Caribbean Basin," Social Forces, vol. 74, no. 2, pp. 633-657.

--------, Carlos Dore Cabral, Esther Hernández Medina, and Obed Vazquez. 1999. "Mapping Dominican Transnationalism: Narrow and Broad Transnational Practices." Ethnic and Racial Studies 22: 316-339.

-------. 2000. "Immigration and the Boundaries of Citizenship: the Institutions of Immigrants' Political Transnationalism.” International Migration Review,Vol, 34, no. 4:1126-1154.

Jacobson, David. 1996. Rights Across Borders: Immigration and the Decline of Citizenship. Baltimore: Johns Hopkins University Press. 
Karpathakis, Anna. 1999. "Home Society Politics and Immigrant Political Incorporation: The Case of Greek Immigrants in New York City," International Migration Review, vol. 33, Number 1:055-078.

Kearney, Michael/Nagengast, Carole, 1989: Anthropological Perspectives on Transnational Communities in Rural California. Davis/CA: California Institute for rural Studies, Working Group on Farm Labor and Rural Poverty (Working Paper No. 3).

Keck, Margaret, and Kathryn Sikkink. 1998. Activists Beyond Borders: Advocacy Networks in International Politics. Ithaca, NY: Cornell University Press.

Kraly, Ellen P. (1987), "U.S. Immigration Policy and the Immigrant Populations of New York, en: Nancy Foner (1987), New Immigrantes in New York, Columbia University Press, New York, p.35-78.

Krotz, Esteban (Compilador) (1993) La Cultura Adjetivada. El concepto "cultura" en la Antropología Mexicana actual a través de sus adjetivaciones. México, UAM, Departamento de Antropología, 1993, 173 págs.

Kyle, David. 1999. "The Otavalo Trade Diaspora: Social Capital and Transnational Entrepreneurship," Ethnic and Racial Studies 22 (1999): 422-446.

Laguerre, Michel S. 1999. "State, Diaspora, and Transnational Politics: Haiti Reconceptualised," Milennium: Journal of International Studies, Vol. 28, No. 3:633651.

-----. 1998. Diasporic Citizenship: Haitian Americans in Transnational America.” New York: St. Martin's Press.

Landolt, Patricia. 2000. "Exploring the Spaces of Political Transnationalism: Insights from Salvadoran Transnational Migration;" paper presented at the Latin American Studies Association conference, Miami, March 2000.

Landolt Patricia, Lilian Autler and Sonia Baires. 1999. "From Hermano Lejano to Hermano Mayor: the Dialectics of Salvadoran Transnationalism," Ethnic and Racial Studies 22: $290-315$.

Lee, Everett S. (1966), “A Theory of Migration”, en Demography, Núm. 3, 1966, págs. 6496.

Leichter, State Senator ranz, Glenn F. von Nostiz y Maria Gonzalez (1981), "The Return of the Sweatshop". 
Levitt, Peggy J. 1997 “Transnationalizing Community Development: The Case of Migration Between Boston and the Dominican Republic," Nonprofit and Voluntary Sector Quarterly, vol. 26, no. 4, pp. 509-526.

-----. 1998 "Social Remittances: Migration-Driven, Local-Level Forms of Cultural Diffusion," International Migration Review, forthcoming.

Lewis, Óscar (1987), Antropología de la pobreza. Cinco familias. México, FCE, 1987 (1959), 302 págs.

-------. (1982), Los hijos de Sánchez, México, Editorial Grijalbo, 1982 (1961), 521 págs.

Linton, Ralph (1936), “Status y rol”, en Estudio del Hombre, México, FCE.

Lomnitz, Larissa Adler Redes Sociales, Cultura y Poder: Ensayos de Antropología Latinoamericana. México, Miguel Ángel Porrúa/Flacso, 1994.

López Castro, Gustavo, 1986: La casa dividida. Un estudio de caso sobre la migración a Estados Unidos en un pueblo michoacano. Zamora: El Colegio de Michoacán/Asociación Mexicana de Población.

------ (Ed.), 1988: Migración en el Occidente de México. Zamora: El Colegio de Michoacán.

López Angel, Gustavo y Thoric Nils Cederström (1990), “Moradores en el Purgatorio: el regreso periódico de los migrantes como una forma de peregrinación", en INAH/CNCA, Memoria del Simposio Internacional de Investigaciones Regionales. Izúcar de Matamoros, México, 1990.

Macías Gamboa, Saúl (1996a), “Trayectoria migratoria laboral: Transnacionalización de la movilidad social", en Economía Internacional, Núm. 51, julio septiembre de 1996, págs. 4-16.

------. (1996b), Trayectoria migratoria laboral: Transnacionalización de la movilidad social. Tesis de Maestría en Ciencias Antropológicas, Departamento de Antropología, UAM-I, 71 págs.

--------. y Fernando Herrera L. (coordinadores) (1997), Migración laboral internacional: transnacionalidad del espacio social, México, BUAP. 
- y Fernando Herrera Lima (1997), "Migración poblana y Nueva York: Espacio social transnacional”, en Saúl Macías Gamboa y Fernando Herrera Lima, Migración y Espacio Social Transnacional, México, BUAP, En Prensa..

-, 1998: "Migración laboral y movilidad social: método y complementariedad" in: Macías Gamboa, Saúl/Herrera Lima, Fernando (eds.), Migración laboral internacional. Puebla: Benemérita Universidad de Puebla, pp. 165-225.

Mahler, Sara J. 1995. American Dreamin: Immigrant Life on the Margin, Princeton, NJ: Princeton University Press.

-------. 1998. "Theoretical and Empirical Contributions Toward a Research Agenda for Transnationalism," Comparative Urban and Community Research, vol. 6, pp. 64102.

Mandaville, Peter G. 1999. "Territory and Translocality: Discrepant Idioms of Political Identity;” Milennium: Journal of International Studies, Vol. 28, No. 3:653-673.

Margolis, Maxine L. (1990) "From mistress to servant: Downward mobility among Brazilian immigrants in New York City”, en Urban Anthropology, Vol. 19, Núm. 3, 1990, págs. 215-231.

Mark J. Miller Population Movements in the Modern World. Hong Kong, The MacMillan Press Ltd., 1993, 307 págs.

Marsh, Catherine y Jonathan Gershuny (1991) "Handling work history data in standard statistical packages", en Shirley Dex (Ed.), Life and Work History Analyses. Qualitative and Quantitative Developments, Londres, Routledge, 1991, págs. 93-143. Marshall, Adriana (1987), "New Immigrants in New York's Economy”, en: Nancy Foner (1987), New Immigrantes in New York, Columbia University Press, New York, p.79101.

Massey, Douglas S., Rafael ALARCÓN, Jorge Durand y Humberto González (1991), Los Ausentes. El proceso social de la migación laboral en el Occidente deMéxico. México, CNCA/Alianza Editorial, 1991. (En particular el capítulo 6, "La organización social de la migación laboral”, págs. 170-201).

./Arango, Joaquín/Hugo, Graeme/Kouaouci, Ali/Pellegrino, Adela/Taylor, Edward P., 1998: Worlds in Motion. Understanding International Migration at the End of the Millennium. Oxford: Clarendon Press.

et al (1993). 
--------, et al (1993), “Theories of international migration: a review and appraisal”, en Population and Developmemt Review, Vol. 19, Núm. 3, septiembre de 1993, págs. 431-466.

--------, et al (1994), "An Evaluation of International Migration Theory:The North American Case", Population and Development Review, 20 no. 4, december 1994.

--------, Joaquín Arango, Hugo Graeme, Ali Kouaouci, Adela Peregrino y J. Edward Taylor (1993), "Theories of International Migration: A Review and Appraisal", Population and Development Review, 19, no 3, september 1993.

--------, Luin Goldring and Jorge Durand (1994), "Continuities in Transnational Migration: An Analysis of Nineteen Mexican Comunities", en American Journal of Sociology, vol. 99 , no. 6 , may 1994).

Méndez Irene Y Leticia Mercado, (1985) Migración: decisión involuntaria, México, INI, 1985, 269 págs.

“Mitos y Realidades del Valle de San Quintín”, en Yucunitzá (Testimonios de la Vida Cultural de la Mixteca), Núm. 19, Diciembre-Enero de 1995, págs. 15-16 y 19.

Mora Vázquez, Teresa (1982), La Mixteca Baja, su migración: Nieves Ixpantepec y San Nicolás Hidalgo, Oax., Mimeo, DEAS-INAH, Cuadernos Núm. 30, 1982, 129 págs., Apéndice.

Morales, Patricia (1989) Indocumentados Mexicanos. Causas y razones de la migración laboral. México, Ed. Grijalbo, 2a. Ed., 1989 (1981), 396 págs.

------. (1988) Regreso a Aztlán, Mimeo, 1988, 251 págs.

Motta Sánchez, J.A., 1990: "'De Piaxtla, Pue. to New York' noticias sobre algunas consecuencias del trabajo migratorio internacional en una localidad )rural? de la mixteca poblana", in INAH/CNCA (ed.), Memoria del Simposio Internacional de Investigaciones Regionales. Izucar de Matamoros/México, pp. 119-124. 
Mummert, Gail (Ed.), 1990: Población y Trabajo en Contextos regionales. Zamora: El Colegio de Michoacán.

O'connor, Mary (1990) "Women's networks and the social needs of Mexican immigrants", en Urban Anthropology, Vol. 19, Núms. 1-2, Primavera-Verano de 1990, págs. 8198.

Oliveira, Orlandina de (1977) Migración y absorción de mano de obra en la ciudad de México: 1930-1970, México, El Colegio de México, 2a. Ed., 1977, 30 págs.

Ong, Aihwa/Nonini, Donald (Hg.), 1997: Ungrounded Empires. The Cultural Politics of Modern Chinese Transnationalism. London/New York: Routledge.

O'rand, Angela M. y Margaret L. Krecker (1990), “Concepts of the life cycle: Their history, meaning, and uses in the social sciences", en Annu. Rev. Sociol, Núm. 16, págs. 241-262.

Orozco, Juan Luis S.J. (1992) El negocio de los ilegales ganancias para quién. México, Editorial Ágata, Instituto Tecnológico y de Estudios Superiores de Occidente (ITESO), 1992, 601 págs.

Perlmann, Joel and Roger Waldinger. 1997. "Second Generation Decline? Children of Immigrants, Past and Present - A Reconsideration." International Migration Review 31: 893-922.

Pessar, Patricia R. 1995. A Visa for a Dream: Dominicans in the United States, Needham Heights, MA: Allyn and Bacon.

Pessar, Patricia R. (1991) Fronteras permeables: migración laboral y movimientos de refugiados en América, Buenos Aires, Editorial Planeta, 1991, 235 págs.

-----. 2000. "The Role of Gender, Households, and Social Networks in the Migration Process: A Review and Appraisal." Pp 53-70 in The Handbook of International Migration: The American Experience, edited by Charles Hirschman, Philip Kasinitz, and Josh DeWind. New York, NY: Russell Sage Foundation. 
Popkin, Erik. 1999. "Guatemalan Mayan Migration to Los Angeles: Constructing Transnational Linkages in the Context of the Settlement Process," Ethnic and Racial Studies 22: 267-289.

Portes Alejandro, Carlos. Dore Cabral and Patricia Landolt (eds.). 1997. The Urban Caribbean: Transition to the New Global Economy, Baltimore: The Johns Hopkins University, 1997.

------. (Editor) The Economic Sociology of Immigration. Essays on Networks, Ethnicity, and Entrepreneurship. New York, Russel Sage Foundation, 1995, págs.

y Rubén Rumbaut (1990), Immigrant America. A portrait. Berkeley (California), University of California Press, 1990, 300 págs.

------. (1995) "Economic Sociology and the Sociology of Immigration", en Alejandro Portes (Editor), The Economic Sociology of Immigration. Essays on Networks, Ethnicity, and Entrepreneurship. New York, Russel Sage Foundation, 1995, págs. 141.

-----. 1999. "Conclusions: Toward a new world - the origins and effects of transnational activities." Ethnic and Racial Studies, vo. 22(2): 464-477.

-----. 2000. "Immigration Theory for a New Century: Some Problems and Opportunities." Pp 21-33 in The Handbook of International Migration: The American Experience, edited by Charles Hirschman, Philip Kasinitz, and Josh DeWind. New York, NY: Russell Sage Foundation.

--------. 1996. "Transnational Communities: Their Emergence and Significance in the Contemporary World System," in Roberto Patricio Korzeniewicz and William C. Smith (eds), Latin America in the World Economy, Westport, CT: Greenwood Press, pp.151-68. 
------ (Hg.), 1995: The Economic Sociology of Immigration. Essays on Netowrks, Ethnicity, and Entrepreneurship. New York: Russell Sage Foundation.

and Luis E. Guarnizo. 1991. "Tropical capitalists: U.S. bound immigration and small enterprise development in the Dominican Republic." Pp. 101-31 in S. Diaz-Briquets and S. Weintraub (eds.) Migration, Remittances, and Small Business Development: Mexico and Caribbean Basin Countries. Boulder, CO: Westview Press.

and Rubén Rumbaut. 1996. Immigrant America: A portrait (second edition). Berkeley, CA: University of California Press.

y József Böröcz (1989) "Contemporary immigation: Theoretical perspectives on its determinants and modes of incorporation", en International Migration Review, Vol. xxiii, Núm. 3, otoño de 1989, págs. 606-630.

-, Luis E. Guarnizo and Patricia Landolt. 1999. "Introduction: Pitfalls and Promise of an Emergent Research Field," Ethnic and Racial Studies Vol. 22, No2: 217-237.

------- and Julia Sensenbrenner (1993), "Embeddedness and immigration: notes on the social determinants of economic action", American Journal of Sociology, v.98, n.6, may, p.1320-1350.

Preibisch, Kerry Lynne (1996), "Neoliberalismo y migración en el campo mexicano: bosquejo de dos comunidades poblanas", en Economía Internacional, Núm. 52, octubre-diciembre de 1996, págs. 73-79.

Pries, Ludger (1993), Hacia una sociología del empleo (tres ensayos), Puebla, El Colegio de Puebla, A. C., Avances de Investigación, Año 8 (Nueva Época), Núm. s-1, noviembre de 1993. 
(1994), The structuration of labor and employment mobility in the life course. Paper

presented to the International Workshop Sociological Perspectives of the Labor Market: Mexican and US-American Approaches, México, febrero de 1994.

--------, 1996: "Transnationale Soziale Räume. Theoretisch-empirische Skizze am Beispiel der Arbeitswanderungen Mexiko-USA", in Zeitschrift für Soziologie, Vol. 25, pp. 437-453.

-, 1998: "'Transmigranten' als ein Typ von Arbeitswanderern in pluri-lokalen sozialen Räumen. Das Beispiel der Arbeitswanderungen zwischen Puebla/Mexiko und New York", in Soziale Welt, Vol. 49, pp. 135-150.

-/Herrera Lima, Fernando/Saúl Macías Gamboa, 1998: Las migraciones laborales internacionales y el surgimiento de Espacios Sociales Transnacionales. El ejemplo de la migración del Estado de Puebla hacia la región metropolitana de Nueva York. Informe de investigación proyecto "Migración laboral de la Mixteca Poblana hacia Nueva York" (Convenio No. 400200-5-0234PS, clave 0234P-59506, CONACYT).

-------, 1999: "New Migration in Transnational Space", in: L. Pries (Ed.), Migration and Transnational Social Spaces. Aldershot: Ashgate, pp. 1-35.

-------. (s.f.,a) Conceptos de trabajo, mercados de trabajo y "proyectos biográficos laborales”, Mimeo, [s.f.,a], 46 págs.

(2000), Una nueva cara de la migración globalizada: el surgimiento de nuevos espacios sociales transnacionales y plurilocales, en: Trabajo, n.3, nueva época, (en prensa).

------ (s.f.), Biografía y sociedad. Un enfoque integrativo e interdisciplinario. Mimeo, [s.f.].

, 2000a: The disruption of social and geographic space. US-Mexican migration and the emergence of transnational social spaces. (forthcoming in: International Sociology).

2001: Transnational Social Spaces: Do We Need a New Approach In Response to New Phenomena!? In: Pries, L. (Ed.), New Transnational Social Spaces. International Migration and Transnational Companies. London: Routledge. 
-------. (1997), “Migración Laboral Internacional y Espacios Sociales Transnacionales: Bosquejo Teórico-Empírico", en Saúl Macías Gamboa y Fernando Herrera Lima, Migración y Espacio Social Transnacional, México, BUAP, En Prensa.

Pujadas, Juan José (s.f.) El método biográfico: el uso de las historias de vida en ciencias sociales, Madrid, Centro de Investigaciones Sociológicas, [s.f.].

Ravenstein, Ernst Georg (1885), “The laws of migration”, en Journal of the Statistical Society, Vol. 46, págs. 167-235.

------. (1889), “The laws of migration: Second paper”, en Journal of the Royal Statistical Society, Vol. 52, págs. 241-305.

Reichert, Joshua S. (1981) "The migrant syndrome: Seasonal U.S. wage labor and rural development in Central Mexico", en Human Organization, Vol. 40, Núm. 1, 1981, págs.56-66.

Repak, Terry. 1995. Waiting on Washington: Central American Workers in the Nation's Capital, Philadelphia, PA: Temple University Press.

Requena, Félix (1991) "Redes sociales y mecanismos de acceso al mercado de trabajo", en Sociología del Trabajo, Madrid, Siglo XXI, Núm. 11, invierno 90/91.

Ritzer, George Teoría Sociológica Contemporánea, Madrid, McGraw Hill, 199 , págs. 447450 y $562-564$.

Roberts, Bryan, Reanne Frank, and Fernando Lozano-Ascencio. 1999. "Transnational Migrant Communities and Mexican Migration," Ethnic and Racial Studies 22: 238266.

Robinson, William I. 1998. "Beyond Nation-State Paradigms: Globalization, Sociology, and the Challenge of Transnational Studies.” Sociological Forum, Vol. 13, No. 
4:561-594.

Romer, Marta (s.f.) Comunidad, Migración y Desarrollo. El caso de los Mixes de Totontepec. México, Instituto Nacional Indigenista, [s.f.], 165 págs.

Rosenbleuth, Ingrid (1984) Roles conyugales y redes de relaciones sociales, México, UAM-I, Cuadernos Universitarios Núm. 15, 1984.

Ross, Robert y Kent Trachte (1982), Global Cities and Global Classes, Mimeo.

Rossi, Ino y Edward O’Higgins (1981) Teorías de la cultura y métodos antropológicos. Barcelona, Editorial Anagrama, 1981, 155 págs.

Rouse, Roger (1987), "Migration and the politics of family life: divergent projects and rhetorical estrategies in a mexican transnational migrant community, manuscrito, La Jolla, UC-San Diego.

Ruíz, Olivia (1992) "Visitando la Matria: Los cruces trasfronterizos de la población estadunidense de origen mexicano", en Frontera Norte, Vol. 4, Núm. 7, Enero- Junio de 1992, págs. 103-130.

Saltalamacchia, Homero (1992) Historia de Vida. Puerto Rico, Ediciones CIJUP, 1992.

Saraceno, Chiara (1991) “Changing women's course patterns in Italy: Gender, cohort and social class differences", en Walter R. Heinz (Ed.), Theoretical Advances in Life Course Research, Weinheim, Deutscher Studien Verlag, Volumen II, 1991, págs. $185-200$.

Sassen, Saskia, The Global City, Princeton University Press, 1991.

Scott, John (1991) Social Network Analysis. A Handbook. Londres, Sage Publication Ltd., 1991, 210 págs. 
PISPAL/CIUDAD/CENEP.Se fue a volver. Seminario sobre migraciones temporales en América Latina. México, El Colegio de México (PISPAL/CIUDAD/CENEP), 1986, 588 págs.

Segal, Aaron (1994) International migration in the Americas. Will stay at home work? El Paso, Texas, University of Texas, 1994.

Signorelli, Amalia (1994) "La construcción de lo local como valor y como ideología. La experiencia de los emigrantes italianos", en Néstor García Canclino, et. al., De lo local a lo global. Perspectivas desde la Antropología. México, UAM-I, 1994, págs. 39-66.

Simmel, Georg, 1903: "Soziologie des Raumes", reimpression in: Dahme, H.J/Rammstedt, O. (Eds.) 1983, Simmel. Schriften zur Soziologie. Frankfurt/M: Suhrkamp, pp. 221242.

Simmons, Alan B. (1991) "Explicando la migración: la teoría en la encrucijada", en Estudios Demográficos y Urbanos, Vol. 6, Núm. 1, Enero-Abril de 1991, págs. 5-31.

Smith, Robert C. 1998. "Transnational Localities: Community, Technology, and the Politics of Membership within the Context of Mexico and U.S. Migration," Contemporary Urban and Community Research 6: 196-238.

(1994), "Los ausentes siempre presentes": The imagining, making and politics of a transnational community between Ticuani, Puebla, Mexico, and New York City. Mimeo, (Submitted in Partial Fulfillment of the Requirements of the Degree of Doctor of Philosophy in the Graduate School of Arts and Sciences), Columbia University, 1994, 325 págs.

------ 1997: "Reflections on Migration, the State and the Construction, Durability and Newness of Transnational Life", in: Pries, Ludger (Ed.), Transnationale Migration. Special Issue 12 SOZIALE WELT. Baden-Baden: Nomos, pp. 197-220.

(1993a) “Mexicanos en Nueva York", en Nexos, 1993. 
------. (1993b) “Una región transnacional”, en Ojarazca, 1993.

------. (1993b), “Una región transnacional”, en Ojarazca (1993), Transnational localities: Community, technology and the politics of membership within the context of Mexico-US migration. Mimeo, Paper prepared for the American Sociological Association Meetings, Washington, D. C., Agosto de 1995 [In preparation for submission to American Sociological Review], 44 págs.

Soysal Yasemin N. 1994. Limits of Citizenship: Migrants and Postnational Membership in Europe. Chicago, IL: The University of Chicago Press.

Speck, Ross y Carolyn Attneave Redes Familiares, Buenos Aires, Amorrortu, 1974.

Stoddard, Ellwyn R. "Frontiers, Borders and Border Segmentation: Toward a conceptual clarification”, en Journal of Borderlands Studies, Vol. VI, Núm. 1, págs. 1-22.

Suárez López, Leticia (1992) "Trayectorias laborales y reproductivas: una comparación entre México y España”, en Estudios Demográficos y Urbanos, Vol. 7, Núms. 2 y 3 , Mayo-Diciembre de 1992, págs. 359-375.

Tambiah, Stanley. 2000. “Transnational Movements, Diaspora, and Multiple Modernities.” Daedalus, vol 129(1): 163-194.

Tavera F., Ligia (1993) La teoría de las redes sociales. Tesis de Licenciatura en Ciencias Sociales. México, ITAM, 1993.

Thompson, Grahame (1991) Markets, Hierarchies and Networks. The coordination of social life. London, Sage Publications, 1991.

Tilly, Charles, 1975: The Formation of National States in Western Europe. Princeton: Princeton University Press. 
Torres-Saillant, Silvio and Ramona Hernandez. 1998. The Dominican Americans.

Tuirán, Rodolfo (1990) Theoretical approaches to the study of life course, Mimeo, University of Texas at Austin, Population Research Center, 1990.

--------, coord. (2000), Migración México-Esttados Unidos. Presente y futuro, CONAPO, $181 \mathrm{p}$.

Ulrich, Karl (1990a) "Age period, and cohort in the study of the y Johannes Huinink life course: A comparison of classical A-P-C-analysis with event history analysis or Farewell to Lexis", en David Magnusson y Lars R. Bergman (Eds.), Data Quality in Longitudinal Research, Cambridge, Cambridge University Press, 1990, págs. 211232.

--------y Glenn R. Carroll (1987) “Jobs and classes: Structural constrains on career mobility”, en European Sociological Review, Vol. 3, Núm. 1, Mayo de 1987, págs. 14-38.

--------y Nancy Brandon Tuma (1990b) "Life course research and event history analysis: An overview", en Karl Ulrich y Nancy Brandon Tuma (Eds.), Event History Analysis in Life Course Research, Madison, Wi., University of Wisconsin Press, 1990, págs. $3-20$.

Valdéz, Luz María (1994), "Migración laboral de mexicanos a Nueva York”, en Instituto Matías Romero de Estudios Diplomáticos, La migración laboral mexicana a Estados Unidos: una perspectiva desde México, México, SRE, 1994, págs. 207-213.

-------. (1996), "La Gran Mannhatitlán", en Nexos, julio de 1996.

Van Cott, Donna Lee (ed.). 1994. Indigenous Peoples and Democracy in Latin America. New York: St. Martin Press.

Velasco Ortiz, Laura, 1990: "Los mixtecos. Una cultura migrante", in México Indígena 4, pp. 46-49.

------ (1995) "Entre el jornal y el terruño: los migrantes mixtecos en la frontera noroeste de México”, en Nueva Antropología, Núm. 47, Marzo de 1995, págs. 113-129.

Vélez-Ibañez, Carlos G. (1993) Lazos de Confianza. México, FCE, 1993, 174 págs.

Vertovec Steven. 1999. "Conceiving and Researching Transnationalism," Ethnic and Racial Studies 22: 347-462. 
Villar, María de Lourdes (1990) "Rethinking settlement processes: The experience of Mexican undocumented migrants in Chicago", en Urban Anthropology, Vol. 19, Núms. 1-2, Primavera-Verano de 1990, págs. 63-80.

Watson, Ian (1993) "Life history meets economic theory: The experiences of three working-class women in a local labour market", en Work, Employment \& Society, Vol. 7, Núm. 3, Septiembre de 1993, págs. 411-435.

Weber, Max 1972: Wirtschaft und Gesellschaft. Tübingen: Mohr ( $5^{\text {th }}$ edition, $\left.1^{\text {st }} 1922\right)$. Westport, CT: Greenwood Press.

World Bank. 1998. World Development Indicators. Washington D.C.: CD-ROM.

Yashar, Deborah J. 1998. "Democracy, Indigenous Movements, and the Postliberal Challenge in Latin America.” Comparative Politics, Vol. 31 (October): 23-42.

Zolberg, Aristide R./ Smith, Robert C., 1996: Migration Systems in Comparative Perspective. An Analysis of the InterAmerican Migration System with Comparative Reference to the Mediterranean-European System. New York: The New School for Social Research.

Zúñiga, Víctor (1992) “Tradiciones migratorias internacionales y socialización familiar: expectativas migratorias de los alumnos de secundaria de cuatro municipios de Nuevo León”, en Frontera Norte, Vol. 4, Enero-Junio de 1992, Núm. 7, págs. 45-74 